Ulrike Schneider / Helga Völkening /
Daniel Vorpahl (Hrsg.)

\title{
Zwischen Ideal \\ und Ambivalenz
}

Geschwisterbeziehungen in ihren soziokulturellen Kontexten

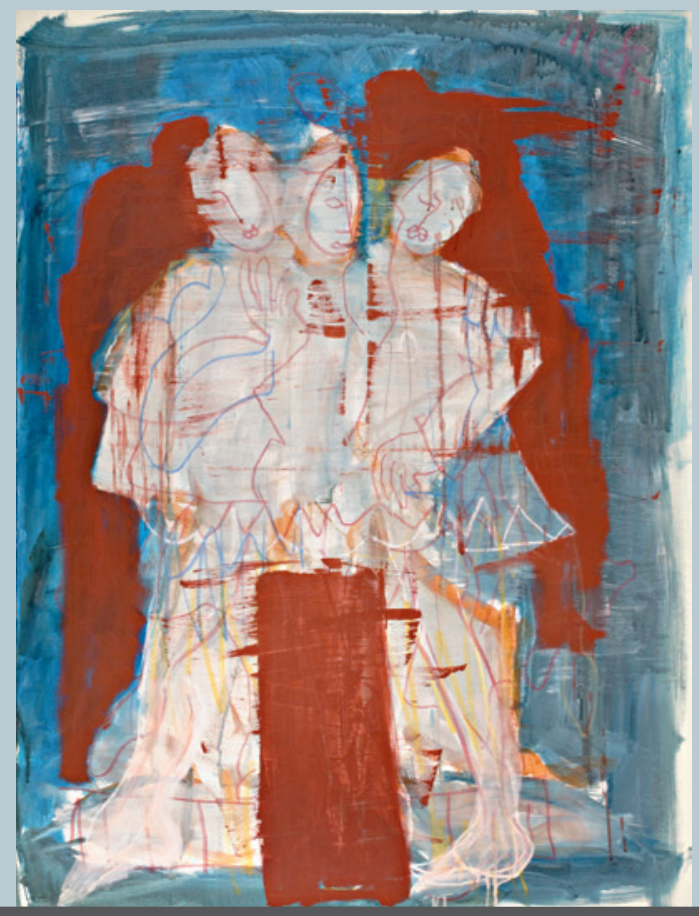

Ulrike Schneider, Helga Völkening and Daniel Vorpahl - 978-3-65.3-98812-3 Downloaded from PubFactory at 01/11/2019 10P4:37AGA D E M IC 


\section{Ulrike Schneider / Helga Völkening/Daniel Vorpahl (Hrsg.)}

\section{Zwischen Ideal und Ambivalenz}

Der Sammelband bietet einen interdisziplinären Überblick über die Darstellung von Geschwisterbeziehungen und die Verwendung geschwisterbezogener Termini innerhalb abendländischer sowie antiker nahöstlicher Kulturtraditionen. Zum einen erörtern die Autoren spezifische Darstellungsformen, Prämissen und Funktionen exemplarischer Geschwisterpaare in Literatur, Bildender Kunst, Musik, Philosophie und historischer, gesellschaftspolitischer sowie religiöser Tradition. Zum anderen befassen sie sich mit den jeweiligen metaphorischen Rezeptionen und Adaptionen geschwisterlicher Termini, Motive und Zuschreibungen.

\section{Die Herausgeber}

Ulrike Schneider ist wissenschaftliche Mitarbeiterin am Institut für Germanistik/ Jüdische Studien und Religionswissenschaft sowie Koordinatorin des Studiengangs Jüdische Studien an der Universität Potsdam.

Helga Völkening ist wissenschaftliche Mitarbeiterin am Institut für Jüdische Studien und Religionswissenschaft (Schwerpunkt Christentum) an der Universität Potsdam. Daniel Vorpahl ist wissenschaftlicher Mitarbeiter für Hebräische Bibel und Exegese an der School of Jewish Theology am Abraham Geiger Kolleg an der Universität Potsdam. 
Zwischen Ideal und Ambivalenz 
Ulrike Schneider, Helga Völkening and Daniel Vorpahl - 978-3-653-98812-3

Downloaded from PubFactory at 01/11/2019 10:54:37AM 


\section{Ulrike Schneider / Helga Völkening / \\ Daniel Vorpahl (Hrsg.)}

\section{Zwischen Ideal und Ambivalenz}

Geschwisterbeziehungen in ihren soziokulturellen Kontexten 


\section{Bibliografische Information der Deutschen Nationalbibliothek}

Die Deutsche Nationalbibliothek verzeichnet diese Publikation

in der Deutschen Nationalbibliografie; detaillierte bibliografische

Daten sind im Internet über http://dnb.d-nb.de abrufbar.

Umschlagabbildung:

Armin Mueller-Stahl "Die drei Schwestern (Tschechow)",

Acryl auf Leinwand 2007, Format $140 \times 100$

Copyright Kunsthaus Lübeck

This book is an open access book and available on www.oapen.org and www.peterlang.com. This work is licensed under the Creative Commons Attribution-NonCommercial-NoDerivs 4.0 which means that the text may be used for non-commercial purposes, provided credit is given to the author. For details go to http://creativecommons.org/licenses/by-nc-nd/4.0/

\section{(cc) BY-NC-ND}

ISBN 978-3-631-65057-8 (Print)

E-ISBN 978-3-653-04175-0 (E-PDF)

E-ISBN 978-3-653-98812-3 (EPUB)

E-ISBN 978-3-653-98811-6 (MOBI)

DOI 10.3726/978-3-653-04175-0

(c) Peter Lang $\mathrm{GmbH}$

Internationaler Verlag der Wissenschaften

Frankfurt am Main 2015

Alle Rechte vorbehalten.

PL Academic Research ist ein Imprint der Peter Lang GmbH.

Peter Lang - Frankfurt am Main - Bern - Bruxelles - New York · Oxford - Warszawa $\cdot$ Wien

Das Werk einschließlich aller seiner Teile ist urheberrechtlich geschützt. Jede Verwertung außerhalb der engen Grenzen des

Urheberrechtsgesetzes ist ohne Zustimmung des Verlages unzulässig und strafbar.

Diese Publikation wurde begutachtet. 


\section{Vorwort}

Im kulturellen Gedächtnis sind zahlreiche Geschwisterpaare durch mediale Überlieferungen ebenso verankert wie metaphorische Begrifflichkeiten aus dem Bereich der Geschwisterbeziehung. Beide Elemente bilden bis in die Gegenwart hinein einen unerlässlichen Bestandteil nicht allein der europäischen Tradition. Während biblischen Geschwistern, insbesondere im Buch Genesis, eine wichtige Funktion für die Etablierung eines sozial-rechtlichen und ethischen Rahmens zukommt, stellen Geschwister in weiteren antiken Texten ein wesentliches Element der Dramatisierung dar, über die auch gesellschaftliche Konflikte erörtert werden, die weit über familial begrenzte Prozesse hinausreichen. Erinnert sei nur an Sophokles' Tragödie Antigone.

Eines der berühmtesten Brüderpaare, neben den in der römischen Mythologie beschriebenen Brüdern Romulus und Remus, ist zweifellos Kain und Abel aus dem Buch Genesis. Der damit verbundene Brudermord, der auch bei Romulus und Remus das wesentliche Motiv darstellt und durch den die Topoi Rivalität, Eifersucht und Schuld verhandelt werden, hat unzählige Adaptionen in der Literatur und der Bildenden Kunst erfahren, beispielsweise in Else LaskerSchülers Poem Abel (1913) oder in Hermann Hesses Gedicht Das Lied von Abels Tod (1929). Zudem lässt sich für die westdeutsche Literatur eine erweiterte Verwendung des Kain-und-Abel-Stoffes feststellen, die über Gattungsgrenzen hinweg verläuft und unterschiedliche Standortbestimmungen von Schriftsteller_innen nach 1945 aufzeigt. So unternimmt die Lyrikerin und Remigrantin Hilde Domin 1969 über das Brüderpaar eine Befragung des deutsch-jüdischen Verhältnisses der Nachkriegszeit. In ihrem Appell zur Umkehrung des Brudermordes, impliziert durch den Imperativ Abel steh auf, der zugleich den Titel des Gedichtes bildet, wird Kain eine Wandlungsfähigkeit zugestanden, die - übertragen auf die gesellschaftliche Gegenwartssituation - Bruderliebe anstelle von Bruderhass, Verantwortlichkeit und Solidarität anstelle von Gewalt und Verfolgung setzt. Abel, dessen Name für die Unterdrückten und Verfolgten fungiert, würde nach Domins Deutung einen Schutzraum erhalten, der durch die Verantwortlichkeit Kains ermöglicht wird. Der Dichter Günter Kunert dagegen greift 1984 anlässlich seiner Rede Kain und Abels Brüderlichkeit zur Woche der Brüderlichkeit der Gesellschaft für christlich-jüdische Zusammenarbeit auf das Motiv zurück, um die Diffizilität und Problematiken des deutsch-jüdischen Verhältnisses zu betonen, welches er - im Unterschied zu Domin - keineswegs als brüderlich versteht, sondern aufgrund des vernichteten jüdischen Gesprächspartners als monologisch benennt. Über den Terminus Brüderlichkeit formuliert er 
seine Kritik an einer „Formalisierung“" des Erinnerns, über das eine „Scheinharmonie “2 in der westdeutschen Nachkriegsgesellschaft hergestellt werde.

Bildet der Kain-und-Abel-Stoff eine der prominentesten Vorlagen für künstlerische Bearbeitungen und gesellschaftspolitische Aktualisierungen, wird bei der intensiveren Beschäftigung mit der Thematik der Geschwisterbeziehungen evident, dass eine facettenreiche Bandbreite und Relevanz von Geschwisterkonstellationen innerhalb der einzelnen geistes- bzw. kulturwissenschaftlichen Disziplinen zwar festgestellt werden kann, bis dato aber eine adäquate Erforschung vor allem in der Individual- und Sozialpsychologie unternommen wurde. Ausgewiesene induktive und deduktive, exemplarische und diachrone, fachbezogene sowie interdisziplinäre Forschungen, in denen die Relevanz von Geschwisterdarstellungen eingehend untersucht wird, stellen nach wie vor ein Desiderat dar.

Dieser Befund war der Ausgangspunkt für den vorliegenden Sammelband, der aus der im September 2013 an der Universität Potsdam veranstalteten interdisziplinären Tagung Biographie - Allegorie - Ideologie. Die Darstellung der Geschwisterbeziehung als soziokulturelles Ideal- und Spiegelbild hervorgegangen ist. In Anknüpfung an das Tagungsthema wird mit dem Band ein erweiterter Überblick zu der Thematik gegeben, der neben einer fächerübergreifenden Bestandsaufnahme geschwisterlicher Beziehungen von der Antike bis zur Gegenwart eine Zusammenstellung der Prämissen, Implikationen und Funktionen geschwisterbezogener Terminologie enthält. Neben der Erörterung spezifischer Darstellungsweisen und Bedeutungszuschreibungen am Beispiel exemplarischer Geschwisterpaare in Literatur, Kunst, Geschichte und religiöser Tradition stehen Untersuchungen der metaphorischen Verwendung von Termini und Konnotationen aus dem Geschwisterbereich im Zentrum. Darüber hinaus verdeutlichen vertiefende Analysen die komplexen Wirkungsweisen von Geschwisterbeziehungen, die durch diese fixierten gesellschaftlichen Wertzuschreibungen sowie aktuelle Ideologisierungen und Funktionalisierungsprozesse hinsichtlich des Begriffes.

Mittels einer erstmaligen eingehenden disziplinübergreifenden Systematisierung rekonstruiert und reflektiert Helga Völkening die Verwendungen und Bedeutungszuschreibungen des Geschwisterterminus. Vertiefend zeichnet sie zudem die zentralen Themen und Kontexte der verschiedenen Fachbereiche der Psychologie und Sozialwissenschaft zur Geschwisterforschung nach, in denen zugleich wesentliche und wegweisende Forschungen zu der Thematik durchgeführt wurden, die bis heute auf Disziplinen der Geistes- bzw. Kulturwissenschaft

1 Kunert, Günter: Kain und Abels Brüderlichkeit. Eine Rede. Hauzenberg 1984, S. 1. 2 Ebd. 
zurückwirken. Anhand der Hebräischen Bibel, des Neuen Testaments und des Korans entfalten Daniel Vorpahl, Rainer Kessler und Hans-Michael Haußig die Grundlagen traditioneller Geschwisterdarstellungen und verweisen unter Hinzuziehung unterschiedlicher Auslegungen auf die Funktionen, die diesen in den verschiedenen religiösen Traditionen zugeschrieben werden. Darüber hinaus wird die Verwendung geschwisterlicher Metaphorik innerhalb der religiösen Schriften von ihnen befragt. Während Sandra Kaden einen vertiefenden genderorientierten historischen Einblick in die Einbindung von Schwestern in das öffentlich vermittelte Herrschaftskonzept der römischen Kaiser unternimmt, erörtert Denise von Weymarn-Goldschmidt die familialen, gesellschaftlichen und juristischen Bedeutungen von Geschwisterschaft in adligen Familien des 18. und 19. Jahrhunderts. Beide Autorinnen verdeutlichen in ihren geschichtswissenschaftlichen Darstellungen, welche Funktionen Schwestern bzw. Geschwistern für die Stabilisierung von Familiendynastien resp. aristokratischen Häusern zukamen. Die in dem Band vertretenen literatur-, kunst- und musikwissenschaftlichen Analysen spiegeln das in der geisteswissenschaftlichen Forschungslandschaft $\mathrm{zu}$ konstatierende spezifische Interesse an der Geschwisterthematik. Während bisher vor allem motiv- und rezeptionsgeschichtliche Untersuchungen $\mathrm{zu}$ herausgehobenen Geschwisterpaaren der Bibel, der Mythologie oder in Märchen vorliegen, konzentrieren sich die Beiträgerinnen dieses Bandes auf bislang nur marginal erforschte literarische Geschwisterpaare bzw. künstlerische Darstellungen oder erstellen neue Klassifikationsmodelle. So entwickelt Jenny Vorpahl auf der Grundlage der Kinder- und Hausmärchen der Gebrüder Grimm ein Analysemodell, anhand dessen die Signifikanz der leiblichen Verwandtschaftsbeziehungen für die Handlungsschemata herausgearbeitet wird, die eine wesentliche Funktion für die Konstituierung bürgerlicher Ideale im 19. Jahrhundert hatten. Am Beispiel ausgewählter Romane und Erzählungen der Restaurationszeit geht Anna Głowacka den Darstellungsweisen und Deutungsmustern von Schwesternbeziehungen nach, deren solidarische, aber auch konfliktbeladene Beziehungen sie als Spiegelbild der konträren Epoche interpretiert. Dagmar Bruss analysiert anhand ausgewählter Erzählungen Robert Walsers die metaphorische Übertragung des ambivalent gedeuteten Geschwisterbegriffes auf den Bereich der Freundschaft, womit eine Serie von Beziehungen eröffnet werde. Im Zentrum des Beitrags von Yael Kupferberg steht eine Untersuchung der musikalischen Adaption des biblischen Geschwisterpaares Moses und Aron in der gleichnamigen Oper von Arnold Schönberg, deren Antagonismus von ihr als innerfamiliärer Diskurs, vor allem aber als innerjüdischer Konflikt zwischen Geist und Körper, Idee und Leben gedeutet wird. Constanze Musterer schließt mit ihrem Beitrag eine bestehende Forschungslücke, indem sie erstmals einen systematischen Überblick über Darstellungen von Geschwisterbeziehungen und 
ihrer Kontextualisierungen in der Bildenden Kunst vorlegt. Den Band beschlieBen drei Artikel, in denen unterschiedliche soziokulturelle und kulturwissenschaftliche Implikationen in den Blick genommen werden. Uta Lohmann arbeitet mittels der Zwillingsmetaphorik die Rezeption des jüdischen Aufklärers Moses Mendelssohn durch den Gründer der Jüdischen Freischule David Friedländer heraus, der Mendelssohn in sokratischer Tradition als Sittenlehrer darstellte und darüber pädagogische Grundgedanken der jüdischen Aufklärung postulierte. Die Verwendung und Konstituierung des Brüderlichkeitsgedankens im Dominikanerorden demonstriert Ulrich Engel, wobei neben der demokratischen Organisationsstruktur des Ordens als einem Element des Brüderlichkeitsbegriffes auch dessen Übertragung auf pastorale bzw. wissenschaftliche Ebenen exemplifiziert wird. Mittels des in der US-amerikanischen SisterhoodJugendbuchreihe von Ann Brashares glorifizierten Ideals der Mädchenfreundschaft verweist Katharina Gerund auf die die Texte bestimmenden gesellschaftlichen Rezeptionsmuster familialer Strukturen sowie auf einen damit verbundenen entfremdeten Postfeminismus. Die dadurch evozierte ideologische Bestimmung von Freundschaft als ,Schwesternschaft ' dient laut der Autorin der Fortschreibung und Festigung überlieferter Geschlechterrollen.

Die interdisziplinäre Ausrichtung des Bandes verdeutlicht das große Potenzial für Synergieeffekte, da die eigenen begrenzten, fachspezifischen Perspektiven auf die Thematik erweitert und Ansätze interdisziplinärer Zusammenarbeit im Bereich der Geschwisterforschung initiiert werden konnten. Allerdings kann der Band angesichts des großen Umfangs des Themas nur eine erste Bestandsaufnahme mit einzelnen vertiefenden Interpretationsansätzen zur Betrachtung der Geschwisterthematik als kulturelles Phänomen bieten. Weitere phänomenologische, systematische und diskursanalytische Untersuchungen, die Aspekte der Geschwisterbeziehung fokussieren, stehen noch aus. Das große Interesse an der Thematik, welches in diesem Tagungsband durch die Aufsätze von Nachwuchswissenschaftlerinnen, die zu dem Schwerpunkt forschen, evident wird, verweist zugleich auf die Aktualität einer geisteswissenschaftlichen Geschwisterforschung.

Den Referent_innen der vorangegangenen Tagung danken wir herzlich für ihre Bereitschaft, sich auf das Thema eingelassen und in inspirierender Weise einen ersten Zugang zu diesem ermöglicht zu haben. Unser Dank gilt zudem allen, die zum Gelingen der Tagung beigetragen haben, insbesondere dem Institut für Jüdische Studien und Religionswissenschaft, dem Institut für Germanistik und der School of Jewish Theology an der Universität Potsdam, ohne deren institutionelle Unterstützung die Tagung nicht hätte umgesetzt werden können. Der Fritz Thyssen Stiftung danken wir für die großzügige Förderung der Tagung, der Postdocförderung der Universität Potsdam für die weitere Unter- 
stützung. Der Professur für Religionswissenschaft mit dem Schwerpunkt Christentum und Prof. Dr. Johann Ev. Hafner sei herzlich für die Übernahme der Druckkosten gedankt. Des Weiteren danken wir Armin Mueller-Stahl und dem Kunsthaus Lübeck für die freundliche Genehmigung zum Abdruck des Titelbildes Die drei Schwestern (Tschechow). Ein besonderer Dank gebührt den Autorinnen und Autoren dieses Bandes, die mit ihren Artikeln neue Zugänge zur Thematik eröffnen und sich mit uns an das Abenteuer der Geschwisterbeziehungen gewagt haben. Ohne die gemeinsame, gewinnbringende Arbeit an diesem Projekt hätte der Band nicht realisiert werden können.

Im Namen der Herausgeber_innen

Ulrike Schneider

Potsdam, im Mai 2015 
Ulrike Schneider, Helga Völkening and Daniel Vorpahl - 978-3-653-98812-3

Downloaded from PubFactory at 01/11/2019 10:54:37AM

via free access 


\section{Inhalt}

\section{Semantische Einleitung und Stand der Geschwisterforschung}

\section{Helga Völkening}

„Dann sei dir darüber im Klaren, daß du auch ein Bruder bist“. Prämissen, Implikationen und Funktionen geschwisterbezogener Terminologie, Rezeption

und Metaphorik - Versuch einer disziplinübergreifenden Systematisierung

\section{Helga Völkening}

Themen, Kontexte und Perspektiven sozial- und individualpsychologischer

Geschwisterforschung - Ein Überblick 65

\section{Exegetische Studien zur Präsenz von Geschwisterbeziehungen in religiösen Traditionen}

\section{Daniel Vorpahl}

Geschwisterlichkeit als sozialethische Matrix des Volkes Israel in der Tora 85

Rainer Kessler

Kinder Israels und Gottes Kinder - Geschwisterlichkeit

in der Hebräischen Bibel und im Neuen Testament 105

Hans-Michael Haußig

Isaak und Ismael in der islamischen Überlieferung - Ein widersprüchliches Bild.

III. Historische Untersuchungen zur gesellschaftlichen Relevanz von Geschwisterbeziehungen

\section{Sandra Kaden}

Zwischen Macht und Ohnmacht - Zur Bedeutung der Kaiserschwestern im Principat von Augustus bis Commodus (27 v. Chr. - 192 n. Chr.)

Denise von Weymarn-Goldschmidt

Adlige Geschwisterbeziehungen im 18. und 19. Jahrhundert Ideale und gelebte Praxis 
IV. Motivgeschichtliche Analysen zur Darstellung von Geschwisterbeziehungen in Literatur, Musik und Bildender Kunst

\section{Jenny Vorpahl}

„Hiermit Gott befohlen und seyd hübsch alle, ihr viere brüderlich, ihr zwei schwesterlich, getreu“ - Die Darstellung von Geschwisterbeziehungen in den Kinder- und Hausmärchen in ihrem soziokulturellen Kontext

\section{Anna Gtowacka}

Schwestern am Scheideweg - Zur Schwesternbeziehung

in der Literatur der Restaurationszeit.

Dagmar Bruss

Geschwister, Geschwisterlichkeit und Serien bei Robert Walser

\section{Yael Kupferberg}

Moses und Aron in der musikalischen Rezeption Arnold Schönbergs 239

\section{Constanze Musterer}

Der schöne Schein - Untersuchungen zu Geschwisterdarstellungen in der Kunst des 20./21. Jahrhunderts

V. Kulturwissenschaftliche und soziokulturelle Untersuchungen zu Rezeptionen und Funktionen von Geschwistermetaphern

\section{Uta Lohmann}

Sokrates und Mendelssohn - Zur Bedeutung der Zwillings-Metapher im Bildungskonzept von David Friedländer und Jeremias Heinemann

\section{Ulrich Engel}

„Unsere Demokratie soll Ausdruck unserer Brüderlichkeit sein“-

Eine theologische Rekonstruktion von Geschwisterlichkeitskonzeptionen in katholischen Ordensgemeinschaften am Beispiel des Ordo Praedicatorum

\section{Katharina Gerund}

Wie Schwestern? Freundschaft in Ann Brashares' Sisterhood-Reihe 


\section{Semantische Einleitung und Stand der Geschwisterforschung}


Ulrike Schneider, Helga Völkening and Daniel Vorpahl - 978-3-653-98812-3

Downloaded from PubFactory at 01/11/2019 10:54:37AM

via free access 


\title{
„Dann sei dir darüber im Klaren, daß du auch ein Bruder bist $^{\text {‘1 }}$. Prämissen, Implikationen und Funktionen geschwisterbezogener Terminologie, Rezeption und Metaphorik - Versuch einer disziplinübergreifenden Systematisierung
}

\author{
Helga Völkening
}

\begin{abstract}
The present article provides a systematic overview on the diverse aspects of sibling relationships as seen from the perspective of different disciplines. Thereby it expounds the variety of definitions, etymological derivations and sociocultural influences, as well as historical and cultural receptions of sibling relations and of sibling metaphors.
\end{abstract}

In einem Interview für den Berliner Tagesspiegel konstatiert die Autorin Charlotte Link anlässlich ihrer 2014 erschienenen Publikation Sechs Jahre - Der Abschied von meiner Schwester ${ }^{2}$ :

Dabei ist mir aufgefallen, dass man über Schwestern gar nicht so viel redet. Nicht, weil man sie schamhaft verschweigt. Aber wenn es eine gute Beziehung ist, ist das etwas Selbstverständliches im Leben. Man redet über Probleme mit Partnern, Eltern, Kindern. Schwestern kommen nicht vor. Vermutlich, weil sie so stabile Größen sind. ${ }^{3}$

Diese persönliche Einschätzung korrespondiert mit einer anhaltend marginalen Thematisierung von Geschwisterbeziehungen auf wissenschaftlicher Ebene. Erst seit kurzer Zeit wird diese mangelnde Reflexion vereinzelt problematisiert und angesichts der außergewöhnlichen Relevanz der Geschwisterrelationen für persönliche Biographien wie für die gesamte Kultur- bzw. Geistesgeschichte als Defizit bewertet. In der Kritik stehen nicht nur die lediglich sporadischen Fokussierungen der Geschwisterbeziehung innerhalb der Psychologie ${ }^{4}$ und Soziolo-

1 Epiktet, Dissertationes 2,10. Zit. nach: Epiktet - Teles - Musonius. Wege zum Glück. Auf der Grundlage der Übertragung v. Wilhelm Capelle neu übersetzt u. mit Einführungen u. Erläuterungen versehen von Rainer Nickel. Zürich, München 1991, S. 102.

2 In diesem Buch beschreibt Charlotte Link die letzten gemeinsamen Jahre mit ihrer Schwester Franziska, die 2012 infolge einer Krebserkrankung gestorben ist.

3 Charlotte Link. Interview mit Deike Diening und Julia Prosinger, in: Der Tagesspiegel. Sonntagsteil: Schwestern. Man sucht sie sich nicht aus - und liebt sie dann doch!? Ein Spezial. Sonntag, 14.09.2014, 22/165, S. 1.

4 Vgl. Onnen-Isemann, Corinna: Geschwisterbeziehungen aus soziologischer Perspektive, in: dies.; Rösch, Gertrud Maria (Hrsg.): Schwestern. Zur Dynamik einer lebenslangen Beziehung. Frankfurt/Main, New York 2005, S. 23-36, hier S. 23. 
gie $^{5}$, sondern vor allem ihre ausbleibende oder seltene Behandlung respektive inadäquate Gewichtung in den Fachbereichen der Anthropologie ${ }^{6}$, Ethnologie und Pädagogik ${ }^{7}$ sowie in der Kunst-, Musik-, Medien-, Literatur- und Geschichtswissenschaft ${ }^{8}$. Letztlich beziehen sich die Vorwürfe somit auf nahezu alle human-, kultur- bzw. geisteswissenschaftlichen Disziplinen ${ }^{9}$, einschließlich der Theologie, Religions- und Rechtswissenschaft ${ }^{10}$. Bestenfalls wird einzelnen Fachvertreter_innen in diesem Zusammenhang zugestanden, dieses Desiderat ansatzweise erörtert und Schritte zur Kompensation präsentiert bzw. eingeleitet zu haben.

Konkret liegen bisher lediglich in der Individual- und Sozialpsychologie ${ }^{11}$ sowie bezüglich der Begriffsgeschichte ${ }^{12}$ umfangreichere, richtungsweisende Untersuchungen vor. Zugleich lässt sich eine zunehmende Präsenz der Thematik in den Medien feststellen: Neben einer Vielzahl aktueller Reportagen innerhalb der Tages- und Wochenpresse ${ }^{13}$ behandeln auch zahlreiche literarische Publika-

5 Vgl. z.B. Onnen-Isemann: Geschwisterbeziehungen, S. 23f.; Onnen-Isemann, Corinna; Rösch, Gertrud Maria: Einleitung, in: dies. (Hrsg.): Schwestern, S. 7-19, hier S. 8; Labouvie, Eva: Zur Einstimmung und zum Band, in: dies. (Hrsg.): Schwestern und Freundinnen. Zur Kulturgeschichte weiblicher Kommunikation. Köln u.a. 2009, S. 1131, hier: S. 16.

6 Vgl. Thelen, Tatjana; Coe, Cati; Alber, Erdmute: The Anthropology of Sibling Relations. Explorations in Shared Parentage, Experience, and Exchange, in: dies. (Hrsg.): The Anthropology of Sibling Relations. Shared Parentage, Experience, and Exchange. New York 2013, S. 1-26, hier S. 4.

7 Vgl. Onnen-Isemann: Geschwisterbeziehungen, S. 23 u. Labouvie: Einstimmung, S. 16.

8 Vgl. Onnen-Isemann, Corinna; Rösch, Gertrud Maria: Schwesterherz - Schwesterschmerz. Schwestern zwischen Solidarität und Rivalität. Heidelberg 2006, S. 9.

9 Vgl. Labouvie: Einstimmung, S. 16.

10 Vgl. Hartmut Kasten: Die Geschwisterbeziehung. Bd. 1. Göttingen 1993, S. 9.

11 Zum gegenwärtigen Forschungsstand der Geschwisterpsychologie vgl. meinen Artikel „Themen, Kontexte und Perspektiven sozial- und individualpsychologischer Geschwisterforschung - Ein Überblick“ in diesem Band.

12 Diesbezügliche Verdienste und wegweisende Relevanz insbesondere im Hinblick auf die Wortfelder ,Bruder' oder ,brüderlich' kommen vor allem Wolfgang Schieder (Brüderlichkeit. Bruderschaft, Verbrüderung, Bruderliebe, in: Geschichtliche Grundbegriffe. Historisches Lexikon zur politisch-sozialen Sprache in Deutschland. Bd. 1. Stuttgart 1992, S. 552-581) und hinsichtlich der antiken und religiösen Verwendung Karl Hermann Schelkle (Bruder, in: Reallexikon für Antike und Christentum. Bd. 2. Stuttgart 1954, Sp. 631-640) zu.

13 So z.B. Schwestern. Man sucht sie sich nicht aus - und liebt sie dann doch!? Ein Spezial, in: Der Tagesspiegel. Sonntag, 14.09.2014, 22/165, S. 1-8; Braun, Maria: Geschwisterbeziehungen - das reinste Schicksal, in: Die Welt, 30.01.2011, http://www.welt.de/ wissenschaft/article12372691/Geschwisterbeziehungen-das-reinste-Schicksal.html; 
tionen $^{14}$ oder Kino- und Fernsehfilme ${ }^{15}$ in den letzten Jahren vermehrt Geschwisterbeziehungen.

Vor allem hinsichtlich der zuvor besonders vernachlässigten Schwesternbeziehung werden gegenwärtig seitens Kultur-, Literatur- und Sozialwissenschaftler_innen sowohl das Potenzial als auch die fächerübergreifende Prädisposition der Thematik betont ${ }^{16}$ und erste Ansätze eines interdisziplinären Dialogs initiiert $^{17}$. Um diese nicht nur zusammenzuführen, sondern in jeweils möglichem Rahmen auch einen tatsächlichen, beflügelnden Austausch und nachhaltige Synergismen zu befördern, bedarf es jedoch der Ausweitung zu einem breiteren, fächerübergreifenden Diskurs sowie einer Systematisierung der Gegenstandsbereiche. Hierbei müssen nicht nur die unterschiedlichen methodischen Zugangsweisen, Erkenntnisinteressen und -grenzen der jeweiligen Wissenschaftsdisziplinen stets reflektiert und berücksichtigt werden. Auch unterschiedliche terminologische Prämissen und Definitionen - auf fachspezifischer Ebene oder infolge lokaler und kultureller Spezifika - bedürfen der expliziten Darlegung und Erörterung. Birgt doch die strukturelle Einbindung in fachinterne Konventionen ebenso wie der Sachverhalt, dass die Begriffe ,Geschwister', ,Bruder oder ,Schwester" aus dem allgemeinen Sprachgebrauch vertraut sind und ihre inhaltliche Bedeutung selbstverständlich erscheint, die Gefahr, vorschnell eine

Röbke, Thomas: Geschwister. Wie sie uns lebenslang prägen, in: Seniorenratgeber. Juni 2011, S. 62-69; Baier, T.: Die längste Liebe des Lebens, in: Süddeutsche Zeitung, 03.03.2010, online: http://www.sueddeutsche.de/wissen/ geschwisterforschung-dielaengste-liebe-des-lebens-1.6717; der Titelartikel im Spiegel 2/2006: „Geschwister. Die ewigen Rivalen“, darin: Thimm, Katja: Rivalen fürs Leben, 09.01.2006, online: http://www.spiegel.de/spiegel/print/d-45280085.html (jeweiliger letzter Zugriff: 24.03.2015).

14 Vgl. Maria Rösch, Gertrud: Auf der Suche nach der anderen: Schwesternbeziehungen in der deutschen Gegenwartsliteratur, in: Onnen-Isemann; dies.: Schwestern, S. 184.

15 Exemplarisch seien hier genannt: „Die geliebten Schwestern“, ein Historiendrama von Dominik Graf (Deutschland/Österreich 2014); das Drama „Meine Schwestern“ von Lars Kraume (Deutschland 2014); das Familiendrama „My Sister’s Keeper“ (dt. „Beim Leben meiner Schwester") von Nick Cassavetes (USA 2009); das Remake des dänischen Originals „Brothers - Zwischen Brüdern“ von Susanne Bier: „Brothers“ von Jim Sheridan (USA 2009); der Historienfilm „,The Other Boleyn Girl“ (dt. „Die Schwester der Königin“) von Justin Chadwick (GB/USA 2008); die Filmtrilogie „Brüder“ von Wolfgang Murnberger (Österreich 2002.2003.2006) sowie das südkoreanische Kriegsdrama „Brotherhood“ von Je-gyu Kang (Südkorea 2004).

16 Vgl. Labouvie: Einstimmung, S. 20f. u. Onnen-Isemann; Rösch: Einleitung, S. 7.

17 So z.B. 2003 in einem interdisziplinären Symposium, das an der Universität Regensburg unter Beteiligung der Fachgebiete der Sozial-, Kultur- und Literaturwissenschaft stattfand (vgl. Onnen-Isemann; Rösch: Einleitung, S. 19). Vgl. auch den Sammelband von Labouvie (Hrsg.): Schwestern und Freundinnen. 
allgemeine semantische Übereinstimmung bzw. Übereinkunft vorauszusetzen, die keiner näheren Erläuterung oder Reflexion bedarf. ${ }^{18}$ Bei detaillierterem Blick auf die (Fach-)Literatur unterschiedlicher Provenienz und Betrachtung der jeweils tatsächlichen Anwendung bzw. Nichtverwendung der Termini in verschiedenen Ethnien und Kulturen ${ }^{19}$, zeitgeschichtlichen oder sozialen Kontexten lässt sich jedoch schnell eine durchaus heterogene Verwendung der Begriffe feststellen. Die folgende Zusammenführung der Geschwisterdefinitionen innerhalb verschiedener Sachgebiete soll daher einen ersten Überblick über disparate terminologische Prämissen und inhaltliche Implikationen ermöglichen.

\section{Definitionen}

\section{Biologische Definition}

Die genetische Abstammung von gemeinsamen Eltern gilt historisch und kulturübergreifend als das nächstliegende Kriterium, Geschwister zu bestimmen. ${ }^{20}$

Gemäß (des Grades) ihrer übereinstimmenden biologischen Herkunft wird im deutschsprachigen Sprachgebrauch zwischen „vollbürtigen“ bzw. „leiblichen“ Geschwistern, die gemeinsame Eltern haben, und „halbbürtigen“ Geschwistern mit nur einem übereinstimmenden Elternteil (Halbgeschwister) unterschieden. ${ }^{21}$ Eine Sonderstellung nehmen in diesem Zusammenhang eineiige

18 So bietet selbst der Duden keine Begriffserklärungen für die Stichwörter ,Geschwister', ,Bruder' oder ,Schwester'. Vgl. Duden. Bd. 1: Rechtschreibung. Mannheim u.a. 2004.

19 Vgl. hierzu Kasten: Geschwisterbeziehung, S. 8; Kaiser, Peter: Schwestern im familialen Systemkontext, in: Onnen-Isemann; Rösch (Hrsg.): Schwestern, S. 65-88, S. 65 u. Bollmann, Vera: Schwestern. Interaktion und Ambivalenz in lebenslangen Beziehungen. Wiesbaden 2012, S. 44.

20 Vgl. Kasten: Geschwisterbeziehung, S. 8.

21 Vgl. Brockhaus. Enzyklopädie in 30 Bänden. Stichwort: Geschwister. Bd. 10. Leipzig, Mannheim 2006 u. Kaiser: Schwestern, S. 65.

Der seit dem 16. Jahrhundert oft verwendete Terminus der Blutsverwandtschaft, hier konkret der Blutsgeschwister, dem die Vorstellung gleichen Bluts bei leiblichen Verwandten zugrunde liegt, wird angesichts moderner wissenschaftlicher Erkenntnisse, wonach ausschließlich die DNA das Erbgut enthält, in den Bereich der Halbwahrheit oder Metaphorik verwiesen. Vgl. Schmidt-Denter, Ulrich: Soziale Beziehungen im Lebenslauf. Lehrbuch der sozialen Entwicklung. Weinheim, Basel 2005, S. 53 u. Dilcher, Gerhard: An den Ursprüngen der Normbildung - Verwandtschaft und Bruderschaft als Modelle gewillkürter Rechtsformen, in: Krieger, Gerhard (Hrsg.): Verwandtschaft, Freundschaft, Bruderschaft. Soziale Lebens- und Kommunikationsformen im Mittelalter. Berlin 2009, S. 37-55, hier S. 37. 
Zwillinge ein, da sie nicht nur dieselben Eltern aufweisen, sondern auch genetisch identisch sind. ${ }^{22}$

Dieser genetisch-genealogischen Grundlegung zufolge wird die geschwisterliche Relation somit vorgefunden bzw. vorgegeben und impliziert keine Wahlfreiheit oder Entscheidungsoption hinsichtlich des Beginns oder auch der Aufhebung der Geschwisterbeziehung bzw. der eigenen geschwisterlichen Identität.

\section{Juristische Definition}

Auch im Bürgerlichen Gesetzbuch wird zwischen vollbürtigen und halbbürtigen Geschwistern differenziert ( $\$ 1307$ BGB). Generell gelten Geschwister als in der Seitenlinie verwandt, da sie von (mindestens) einer gemeinsamen dritten Person abstammen. ${ }^{23}$ Der juristische Geschwisterbegriff ist somit ebenfalls primär biologisch-genetisch bzw. genealogisch determiniert.

Darüber hinaus lässt sich eine rechtliche Ausweitung des Geschwisterbegriffs feststellen, da adoptierten Kindern die gleiche rechtliche Stellung, mit entsprechenden Rechten und Pflichten, zugesprochen wird wie leiblichen Abkömmlingen der/s annehmenden Eltern/-teils. ${ }^{24}$ Folglich fällt beispielsweise eine Heirat oder eine eheähnliche bzw. sexuelle Verbindung zwischen angenommenen oder adoptierten und leiblichen Abkömmlingen mindestens eines Elternteils unter das Inzestverbot, sofern die Annahme in der Kindheit erfolgt ist. Während allerdings in diesem Fall die Möglichkeit besteht, das Eheverbot durch Auflösung des Annahmeverhältnisses zu umgehen ( $\$ 1308$ BGB), sieht die Gesetzgebung keine vergleichbare Option bei Personen gemeinsamer genetischer Abstammung vor - selbst wenn diese aufgrund einer Adoption oder einer anderwärtigen Annahme während der Kindheit nicht im selben Umfeld aufgewachsen sind und ihr Verwandtschaftsverhältnis folglich im rechtlichen Sinne erloschen ist. ${ }^{25}$ Die genetische Geschwisterbestimmung bleibt somit irreversibel konstitutiv und rechtsbindend.

22 Zwillinge können in diesem Band leider nicht ausführlich berücksichtigt werden. Vgl. zur metaphorischen Anwendung des Zwillingmotivs den Artikel von Uta Lohmann „Sokrates und Mendelssohn - Zur Bedeutung der Zwillings-Metapher im Bildungskonzept von David Friedländer und Jeremias Heinemann“ in diesem Band.

Angesichts der modernen Reproduktionsforschung wäre in diesem Zusammenhang darüber hinaus zu fragen, inwieweit künstlich reproduzierte Klone als Geschwister bzw. Zwillinge gelten können, wären diese doch bei der hier angeführten Definition zunächst durchaus impliziert.

23 Verwandte in ,gerader“ Linie stammen demgegenüber direkt von einer Person ab (Eltern-Kind-Verhältnis), vgl. § 1589 BGB.

24 Vgl. § 1754 BGB. Dies gilt lediglich für Kinder, nicht für Erwachsene (§ 1770 BGB).

25 Vgl. § 1307 BGB.

Ulrike Schneider, Helga Völkening and Daniel Vorpahl - 978-3-653-98812-3 
Grundsätzlich wird folglich in deutschen Gesetzestexten terminologisch zwischen Halb-, Stief-, Adoptiv- und Pflegegeschwistern unterschieden, rechtlich gelten sie jedoch als (nahezu) gleichgestellt.

\section{Soziokulturelle bzw. ethnologische Definition}

Die juristische Geschwisterdefinition berücksichtigt neben der genetischen Disposition bereits zugleich die soziale Komponente des gemeinsamen Aufwachsens, der parallelen Erfahrung, Sozialisation und Prägung innerhalb des primären familialen Umfelds (oder weiterer übereinstimmender Kontexte). Dies korrespondiert mit der sozialwissenschaftlichen Akzentuierung der gesellschaftlichen Determinierung der Geschwisterdefinition, ${ }^{26}$ wonach Geschwister in erster Linie ,als soziale Gruppe und als gesellschaftliches Produkt sozialhistorischer Prozesse ${ }^{627}$ verstanden und analysiert werden. Hierbei wird vor allem betont, dass es sich bei dem Geschwisterverhältnis um ein Konstrukt bzw. um eine kulturelle Kategorie handelt, das/die durch soziokulturelle Festlegung, Beeinflussung sowie Ausgestaltung konstituiert und bestimmt wird. Die Feststellung, wer als Geschwister gilt bzw. wie sich die Geschwisterbeziehung definiert und charakterisiert, erweist sich demzufolge als Resultat einer innergesellschaftlichen Zuschreibung, Übereinkunft oder Erwartung. ${ }^{28}$ Sie ist somit in erster Linie sozial- und kulturgeschichtlich oder ethnisch geprägt und variabel, da die Begrenzungen oder Ausweitungen des Geschwisterbegriffs an die jeweiligen historischen, gesellschaftlichen oder kulturellen Umstände, Kontexte, Erfahrungen und Werte gebunden sind. ${ }^{29}$ Demgemäß gehen Ethnologen gegenwärtig insbesondere der Frage nach, wie bzw. wann Verwandtschaft und hier konkret Geschwisterschaft konstruiert wird, welche sozialen Praktiken und Normen realiter dazu führen, dass sich Individuen als Geschwister wahrnehmen bzw. gesellschaftlich als solche definiert werden. In diesem Kontext werden neben der biologischen Herkunft insbesondere gemeinsame Erfahrungen ${ }^{30}$ (vor allem innerhalb der Kindheit bzw. Sozialisation, aber auch aufgrund spezifischer, Nä-

26 Vgl. z.B. Dilcher: An den Ursprüngen, S. 37.

27 Bollmann: Schwestern, S. 12. Vgl. auch Bodarwé, Katrinette: Befreundete Schwestern. Beziehungs- und Kommunikationskulturen klösterlicher Frauen im Frühmittelalter, in: Labouvie (Hrsg.): Schwestern und Freundinnen, S. 377-393, hier S. 381 u. OnnenIsemann; Rösch: Schwesterherz, S. 15.

28 Vgl. Thelen u.a.: The Anthropology, S. 6 u. Bollmann: Schwestern, S. 32.

29 Vgl. z.B. Bodarwés Explikation hinsichtlich der mittelalterlichen Verwandtschaftspraxis (Befreundete Schwestern, S. 381).

30 Vgl. Thelen u.a.: The Anthropology, S. 10. 
he schaffender, prägender Momente) ${ }^{31}$ als potenziell übergreifende, transkulturelle bzw. transethnische Übereinstimmung mit ihren jeweiligen kulturellen oder lokalen Spezifika und Ausprägungen in den Blick genommen.

Gerade das Moment der (nicht-)geteilten Erfahrung und Sozialisation stellt sich jedoch in den (gegenwärtig) verbreiteten Patchworkfamilien ${ }^{32}$ respektive Stieffamilien als Problem dar: Da die neuen Familienmitglieder zumeist „keine gemeinsame Historie ${ }^{\text {33 }}$ haben, fehlen ihnen Gemeinschaftserfahrungen. Zumindest in der Anfangszeit des Zusammenlebens ist somit von einer gewissen Distanz unter den neu konstituierten Stief- oder Halbgeschwistern auszugehen, welche den gesellschaftlichen Zuschreibungen und Erwartungen an eine familiale Vertraut- und Verbundenheit (noch) nicht entspricht. ${ }^{34}$ Grundsätzlich bedarf es somit auch hier einer Differenzierung zwischen leiblichen Geschwistern und Halb-, Stief- oder Pflegegeschwistern sowie anderer sozialer Geschwisterbindungen. ${ }^{35}$

\section{Individualpsychologische und -soziologische Definition}

Auf individueller Ebene werden Geschwister bzw. Geschwisterbeziehungen in der Psychologie, Pädagogik und Sozialforschung insbesondere als persönlichkeitsprägende Faktoren verstanden. Entwicklungs- und Individualpsycholog_innen analysieren in erster Linie, inwieweit und auf welche Weise die Geschwisterkonstellation die emotionale, intellektuelle und soziale Entwicklung sowie Charakterbildung des Einzelnen beeinflusst und durch welche Momente

31 Thelen, Coe und Alber nennen generell drei Möglichkeiten der Konstituierung von Geschwisterschaft: „Shared Parentage: Highlighting Intergenerational Significance“, „Shared Experience: Creating Feelings of Similarity“ sowie „Siblings through Exchange and Care: Living Difference and Mutuality“, dies.: The Anthropology, S. 7, 10 u. 12. Vor allem das in den verschiedensten Kulturen verbreitete Moment des gemeinsamen Nährens bzw. Essens, der Essensvergabe oder des Teilens der Mahlzeit als Verwandtschaft bzw. Geschwisterschaft begründender Akt wird hierbei des Öfteren betont. Vgl. ebd., S. 6f. Ähnliche Prämissen liegen der sogenannten Milchgeschwisterschaft (collactaneus) zugrunde. Unter Milchbrüdern bzw. Milchschwestern werden herkömmlich Personen verstanden, die nicht biologisch verwandt sind, aber von derselben Frau bzw. Amme genährt worden sind und folglich auch zumeist gemeinsam aufwachsen.

32 Hartmut Kasten betont in diesem Rahmen die steigende Zahl der Patchworkfamilien seit dem Ende des 20. Jahrhunderts: „Heute erleben weniger als die Hälfte der Kinder das 18. Lebensjahr in derselben Familie“. Zit. nach: Sitzler, Susann: Geschwister. Die längste Beziehung des Lebens. Stuttgart 2014, S. 168.

33 So der Soziologe Christian Alt, zit. nach: Sitzler: Geschwister, S. 177.

34 Vgl. ebd., S. 68.

35 Die verschiedenen Konstellationen werden in den letzten Jahren zunehmend berücksichtigt. Vgl. Onnen-Isemann; Rösch: Schwesterherz, S. 16. 
sie konkret geprägt wird (Rivalität, Verbundenheit etc.). ${ }^{36}$ Betont wird dabei in jüngeren Untersuchungen neben der Ambivalenz vor allem die Konstanz und Dynamik der Geschwisterbeziehung im Lebenszyklus.

Ulrich Schmidt-Denter definiert Geschwisterbeziehungen entsprechend als horizontale Beziehungen, die nicht freiwillig gewählt, sondern schicksalhaft sind. Sie gehörten zu den ,verfügbarsten, intensivsten und dauerhaftesten sozialen Erfahrungen ${ }^{637}$.

\section{Konkretion}

\section{Etymologische Annäherung}

\section{Geschwister, Bruder und Schwester}

Der Begriff ,Geschwister ${ }^{38}$ geht auf westeuropäische Ursprünge zurück und wird bis zum Spätmittelalter ausschließlich als Plural zum Substantiv ,Schwester' verwendet. ${ }^{39} \mathrm{Ab}$ dem 16 . Jahrhundert ist er zudem im heute gebräuchlichen Sinne belegt, welcher ebenfalls Brüder einbezieht. ${ }^{40}$

Die Bezeichnung ,Schwester' wird gemeinhin auf die indoeuropäische Wurzel suēsor zurückgeführt. ${ }^{41}$ Die primäre Bedeutung lässt sich nicht mehr exakt bestimmen. ${ }^{42}$ Allerdings erwägt der Philologe Richard Kannicht einen sozialen Grundgehalt, insofern er annimmt, der Begriff habe sich ursprünglich auf ein ,weibliches Mitglied einer Gruppe' bezogen und somit zunächst kein biologisches Verwandtschaftsverhältnis vorausgesetzt. ${ }^{43}$

36 Vgl. hierzu die näheren Ausführungen in meinem Artikel ,,Themen, Kontexte und Perspektiven sozial- und individualpsychologischer Geschwisterforschung. Ein Überblick“ in diesem Band.

37 Schmidt-Denter: Soziale Beziehungen, S. 53.

38 Althochdeutsch: ,giswestar“; mittelhochdeutsch: ,geswister“.

39 Vgl. unter dem jeweiligen Stichwort „Geschwister“: Duden. Bd. 7: Etymologie. Herkunftswörterbuch der deutschen Sprache. Mannheim u.a. 1989 u. Brockhaus. Bd. 10.

40 Vgl. Bollmann: Schwestern, S. 43.

41 Von dieser Wurzel sind u.a. das Alt- und Mittelhochdeutsche Pendant „swester“ sowie die Begriffe „sister“ (englisch) oder ,,soror“ (lateinisch) abgeleitet. Vgl. Duden. Bd. 7: Etymologie, Stichwort: Schwester.

42 Vgl. Harders, Ann-Cathrin: Zwischen Kooperation und Repräsentation: BruderSchwester-Beziehungen in der römischen Republik und im frühen Prinzipat (2. Jh. v. Chr. - 1. Jh. n. Chr.), in: Historical Social Research, Vol. 30 (2005), S. 61-79, S. 65.

43 Vgl. Kannicht, Richard: Geschwisterbeziehungen in der griechischen Dichtung, in: Klosinski, Gunther (Hrsg.): Verschwistert mit Leib und Seele. Geschwisterbeziehungen gestern - heute - morgen. Tübingen 2000, S. 59-70, S. 59f. 
Der äquivalente männliche Terminus leitet sich ebenfalls begriffsgeschichtlich von einer indoeuropäischen Wurzel her: bhrâter oder bhrātor. ${ }^{44}$ Während im Etymologie-Lexikon des Duden als Grundbedeutung „Bruder und Blutsverwandter “45 angeführt ist, mutmaßt Richard Kannicht auch hier, der Begriff habe sich im ersten Jahrtausend v.d.Z. ursprünglich auf ein „Mitglied einer clanartig organisierten sozialen Gruppe: eben eine ,Bruderschaft "“46 in Griechenland bezogen. Ähnlich geht auch Schieder von einer Bezeichnung für einen ,ursprünglich wohl religiöse[n] Verband mehrerer Familien“47 aus.

Eine genuin biologische Geschwisterschaft implizieren demgegenüber die

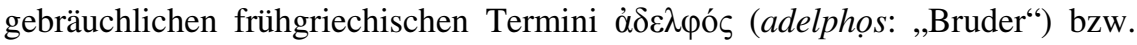

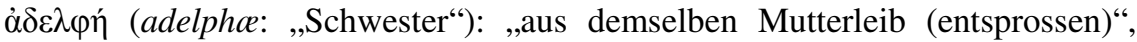
„denselben Uterus geteilt““. ${ }^{48}$ Sie verweisen folglich auf die gemeinsame leibliche Abkunft von einer Mutter, wobei die maskuline Pluralform $\alpha \dot{\alpha} \varepsilon \varepsilon \varphi$ oí (adelphoi) Schwestern mit einbezieht. ${ }^{49}$

\section{Bruderschaft und Brüderlichkeit, Schwesternschaft sowie Schwesterlichkeit}

Im Rahmen der emanzipatorischen Bemühungen des Philanthropen Joachim Heinrich Campe, fremdsprachige Ausdrücke durch deutsche Synonyme zu ersetzen, erhielt auch die Übersetzung der französischen Revolutionsmaxime ,fraternité ' mit dem Terminus ,Brüderlichkeit' Einzug in den deutschen Sprachgebrauch. ${ }^{50}$ Bereits Johann Kaspar Lavater (1776) hatte den Begriff der ,Brüder-

44 Auf diese gehen sowohl die Bezeichnungen „,bruoder“ (alt- und mittelhochdeutsch) als

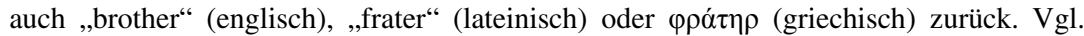
Duden. Bd. 7: Etymologie, Stichwort: Bruder; Kannicht: Geschwisterbeziehungen, S. 59 oder Dilcher: An den Ursprüngen, S. 38.

45 Vgl. Duden. Bd. 7. Etymologie, Stichwort: Bruder.

46 Vgl. Kannicht: Geschwisterbeziehungen, S. 59.

47 Schieder: Brüderlichkeit, S. 553.

48 Es handelt sich hierbei um ein Kompositum (alpha-copulativum mit dem Substantiv

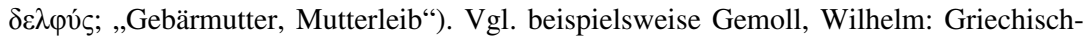

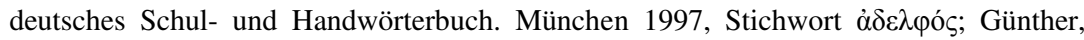
Walther: $\alpha \dot{\delta} \varepsilon \lambda \varphi o ́ \varsigma$ Bruder, Nächster, in: Theologisches Begriffslexikon zum Neuen Testament. Hrsg. v. Lothar Coenen u.a. Wuppertal 1967, S. 146-149, hier S. 146; Kannicht: Geschwisterbeziehungen, S. 60; Frey, Jörg: Brother, Brotherhood, I. New Testament, in: Encyclopedia of the Bible and Its Reception, Bd. 4. Hrsg. v. Hans-Josef Klauck u.a. Berlin, Boston 2012, Sp. 550-557, hier Sp. 551. Vgl. zur griechischen Begriffsbedeutung auch den Artikel von Rainer Kessler „Kinder Israels und Gottes Kinder - Geschwisterlichkeit in der Hebräischen Bibel und im Neuen Testament" in diesem Band.

49 Vgl. Günther: ả $\delta \varepsilon \lambda \varphi o ́ \varsigma$ Bruder, S. 146.

50 Die alternativ von Immanuel Kant vorgeschlagene Übersetzung „Selbstständigkeit“ konnte sich demgegenüber nicht langfristig durchsetzen. Vgl. Stupperich, Robert: Bru- 
lichkeit' in Abgrenzung zum gebräuchlichen Terminus ,Brüderschaft' (,Bruderschaft ${ }^{*}$ oder ,Verbrüderung $\left.{ }^{*}\right)$ verwendet. ${ }^{51}$ Während letzterer traditionell und fortan speziell eine institutionelle gesellschaftliche Organisationsform, konkret einen Personenverbund, ${ }^{52}$ bezeichnete, impliziert(e) der Neologismus ,Brüderlichkeit" nun in erster Linie eine konkrete Gesinnung in politischer, sozialer oder religiöser Hinsicht: eine als brüderlich identifizierte Grundhaltung, Programmatik bzw. Verhaltensweise. ${ }^{53}$

Campe führte in diesem Zusammenhang jedoch mit dem Terminus ,Schwesterlichkeit" auch den im französischen (und englischen) Sprachgebrauch fehlenden, äquivalenten weiblichen Begriff in den deutschen Sprachraum ein. ${ }^{54}$ Das zugehörige Adjektiv ,schwesterlich“ wird sodann im Deutschen Wörterbuch der Gebrüder Grimm ebenfalls auf die positiv konnotierte „Gesinnung und Eigenart“ „Empathie, Nähe und Hilfe“"55 bezogen, ohne jedoch den politischideologischen Bezugsrahmen, der dem männlichen Pendantbegriff ,Brüderlichkeit' zugeordnet ist, einzuschließen. Er wird meist in Abgrenzung zum Terminus ,Schwesternschaft' verwendet, welcher die biologische Abstammung von gemeinsamen Eltern ${ }^{56}$ oder soziale Institutionen bezeichnet.

derschaften/Schwesternschaften/Kommunitäten, in: Theologische Realenzyklopädie. Bd. VII. Berlin, New York 1981, S. 195-206, S. 204.

51 Vgl. Stupperich: Bruderschaften/Schwesternschaften, S. 204 sowie Stammler, Wolfgang: Politische Schlagworte in der Zeit der Aufklärung, in: ders.: Kleine Schriften zur Sprachgeschichte. Berlin u.a. 1954, S. 48-100, hier S. 98.

52 Konkret werden diesbezüglich ,[...] Freundschafts-, Amts- und Zunftverbindungen, oder auch die $\mathrm{zu}$ einer solchen Verbindung gehörigen Personen [...]“ genannt. Heinric, Joachim: Wörterbuch zu Erklärung und Verdeutlichung der unserer Sprache aufgedrungenen fremden Ausdrücke. Ein Ergänzungsband zu Adelungs Wörterbuche. In zwei Bänden. Braunschweig 1801, S. 375; zitiert nach: Harders, Ann Cathrin: ,Sororitas“? Überlegungen zu einem Konzept der Schwesterlichkeit im antiken Rom, in: Labouvie (Hrsg.): Schwestern und Freundinnen, S. 243-261, hier S. 244.

53 Vgl. Stupperich: Bruderschaften/Schwesternschaften, S. 204.

Das Verb ,verbrüdern' war dagegen schon zuvor in Deutschland verbreitet, wurde es doch bereits „1711 als Übersetzung für: ,faire alliance de frère, faire fraternité, fraterniser““ (Stammler: Politische Schlagworte, S. 99) seitens des Lexikographen Rädlein erwähnt.

54 Vgl. Harders: Sororitas, S. 244.

55 Onnen-Isemann; Rösch: Einleitung, S. 12 unter Bezugnahme auf das Deutsche Wörterbuch, Bd. 9, Sp. 2594, 2599 u. 2605.

56 Vgl. Onnen-Isemann; Rösch: Einleitung, S. 12.

Ulrike Schneider, Helga Völkening and Daniel Vorpahl - 978-3-653-98812-3 


\section{Sozial- und kulturgeschichtliche Rahmenbedingungen}

\section{Sprachgeschichtliche Kontexte}

Bereits in frühgriechischen Quellen finden sich Belege für die Anwendung ge-

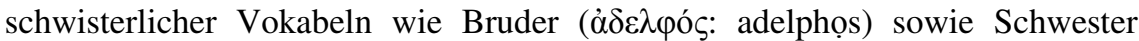
( $\dot{\delta} \delta \varepsilon \varphi \eta \dot{\eta}:$ adelphæ) hinsichtlich weiterer Verwandter (Cousins, Cousinen, Schwägerinnen, Schwäger). ${ }^{57}$ Auch im mittelalterlichen europäischen Sprachgebrauch wurden Schwägerinnen oder Schwäger zuweilen als Schwester bzw. Bruder bezeichnet. ${ }^{58}$ Hier liegt insbesondere bezüglich der Frau die Prämisse zugrunde, dass diese mit der Eheschließung in einen anderen Hausstand übergeht, d.h. von ihrer Herkunftsfamilie zu einer neuen Kernfamilie wechselt, in welche sie vollständig integriert wird. ${ }^{59}$

Vor allem seit dem Mittelalter lässt sich eine erweiterte Verwendung geschwisterlicher Metaphern in vielfältigen gesellschaftlichen Kontexten feststellen. ${ }^{60}$ Gabriela Signori konkludiert sogar, keine andere Metapher sei „im Mittelalter wirkungsmächtiger" gewesen, ,der Nähe zwischen zwei Personen Ausdruck zu verleihen, als die Begriffe Bruder oder Schwester ${ }^{\text {‘61 }}$. So seien insbesondere im Spätmittelalter enge Freunde als Schwestern oder Brüder bezeichnet worden. ${ }^{62}$ Signifikant sind auch die vielzähligen religiös-spirituellen und berufsstandbezogenen Schwestern- und Bruderschaften im mittelalterlichen Europa, deren Angehörige sich selbst als Schwester und Brüder angeredet haben bzw. von außen entsprechend bezeichnet worden sind.

\section{Sozialhistorische und soziokulturelle Konstellationen sowie Konsequenzen}

Die oft als Novum und Charakteristikum der Postmoderne betrachtete Patchworkfamilie war in vorindustrieller Zeit und in späteren Jahrhunderten noch vor

57 Vgl. Günther: $\alpha \dot{\delta} \varepsilon \lambda \varphi$ ó $\varsigma$ Bruder, S. 147.

58 Vgl. Signori, Gabriela: Geschwister: Metapher und Wirklichkeit in der spätmittelalterlichen Denk- und Lebenswelt, in: Historical Social Research. Vol. 30 (2005), S. 15-30, hier S. 17. Diesbezügliche Spuren finden sich noch im gegenwärtigen französischen Sprachgebrauch, wenn Schwägerinnen und Schwäger als ,belle-sœuir' bzw. beau-frère“ bezeichnet werden (vgl. Bollmann: Schwestern, S. 44) oder im Rahmen des englischen Ausdrucks , sister in law' für die Schwägerin (vgl. Onnen-Isemann; Rösch: Schwesterherz, S. 23).

59 Den durch den Wechsel veränderten sozialen und rechtlichen Status der Frau betont bereits der römische Jurist M. Antistius Labeo (gest. 10/11 n.d.Z.); vgl. Harders: Zwischen Kooperation, S. 65.

60 Vgl. Bodarwé: Befreundete Schwestern, S. 381.

61 Signori: Geschwister, S. 17.

62 Vgl. ebd. u. Bollmann: Schwestern, S. 43. 
allem in Adelsfamilien ${ }^{63}$ weit verbreitete Lebenswirklichkeit. Aufgrund der hohen Sterblichkeit der (Ehe-)Partner sind die Kinder, so Vera Bollmann, seltener als zumeist angenommen in stabilen Großfamilien, sondern zu einem großen Teil in neu gebildeten Stieffamilien aufgewachsen. ${ }^{64}$ Als weitere Folge der hohen Geburts- und Mortalitätsrate müsse der zu dieser Zeit nicht ungewöhnliche große Altersabstand zwischen den (Stief-)Geschwistern Berücksichtigung finden. Dieser habe des Öfteren einer egalitären Geschwisterbeziehung entgegengestanden und hierarchische Verhältnisse der Fürsorge und Belehrung protegiert. ${ }^{65}$ Zudem sei aufgrund des zeitlich durchschnittlich früheren Auszugs älterer Geschwister bei Beginn einer beruflichen Ausbildung, zwecks standesgemäßer Erziehung ${ }^{66}$ oder infolge der Gründung eines eigenen Hausstands der Auf- oder Ausbau einer nahen geschwisterlichen Beziehung zusätzlich erschwert gewesen. ${ }^{67}$ Insgesamt bestanden somit ,schlechte Voraussetzungen für die Herausbildung einer als einheitlich wahrnehmbaren sozialen Gruppe und einer engen sozialen Beziehung zwischen Geschwistern“68. Bollmann folgert daraus, „dass Geschwister als soziale Beziehungen ein eher neuzeitliches Phänomen darstellen. ${ }^{609}$ Erst im 17. Jahrhundert habe sich das Familienleben in gehobenen Schichten ,,mit der Verbreitung von schulischen und universitären

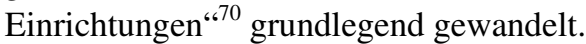

Ab dem 18. Jahrhundert entstanden im Rahmen des nun in den Mittelpunkt gerückten Gesellschaftsmodells der bürgerlichen Familie, welche der öffentlichen Außenwelt als privater, intimer Gegenpol entgegengestellt wurde, ${ }^{71}$ sowie infolge der ,Entdeckung der Kindheit' im 17. Jahrhundert als eigenständige, zu

$63 \mathrm{Zu}$ den Familienkonstellationen im späteren Adel siehe den Artikel von Denise von Weymarn-Goldschmidt „Adlige Geschwisterbeziehungen im 18. und 19. Jahrhundert Ideale und gelebte Praxis“ in diesem Band.

64 Bollmann bezeichnet in diesem Kontext die Vorstellung vorherrschender Großfamilien in der Zeit vor der Industrialisierung mit vielen Kindern als Mythos, da die hohe Zahl der Fehlgeburten sowie der Sterblichkeitsrate bei Säuglingen und kleinen Kindern infolge von Epidemien, Kriege und Hunger nicht berücksichtigt worden seien. Vgl. Bollmann: Schwestern, S. 21.

65 Vgl. ebd., S. 22.

66 Vgl. hierzu den den Artikel von Denise von Weymarn-Goldschmidt ,Adlige Geschwisterbeziehungen im 18. und 19. Jahrhundert - Ideale und gelebte Praxis“ in diesem Band.

67 Vgl. Thelen u.a.: The Anthropology, S. 10 u. Bollmann: Schwestern, S. 22.

68 Ebd., S. 23.

69 Ebd.

70 Ebd. Insgesamt müssen bei der Analyse von Geschwisterbeziehungen auf historischer Basis die verschiedenen innergesellschaftlichen Verhältnisse und individuellen Ausgangslagen stärker berücksichtigt werden.

71 Vgl. Bollmann: Schwestern, S. 23f.

Ulrike Schneider, Helga Völkening and Daniel Vorpahl - 978-3-653-98812-3 
berücksichtigende Lebensphase auch neue Konditionen für die Konstituierung einer (engeren) Geschwisterbeziehung in bürgerlichen bzw. gehobenen Kreisen. Exemplarisch nennt Bollmann in diesem Zusammenhang die Trennung der Arbeits- und Familienbereiche im 18. und 19. Jahrhundert als Folge der Industrialisierung sowie die damit verbundene Einführung von Kinderzimmern, in denen Kinder „,mit ihren Geschwistern, fern und unabhängig von der Erwachsenenwelt, viel Zeit zusammen verbrachten und eine eigenständige Beziehung zueinander aufbauen konnten.“72

Bildete die bürgerliche Kernfamilie ${ }^{73}$ vor allem im 19. Jahrhundert bis Mitte oder Ende des 20. Jahrhunderts (1950er und 1960er Jahre) ein Ideal und die meist als selbstverständlich vorausgesetzte sowie praktizierte Lebensform in den westlichen Industrienationen, so charakterisieren und prägen Individualisierung der Lebensentwürfe und Pluralität der Lebenswelten die Postmoderne. Neben nicht selten temporären und variablen Konstellationen innerhalb des Familienlebens $^{74}$ ist die Haushaltsgröße insgesamt gesunken. Hatte sich die Kinderzahl ab Ende des 19. Jahrhunderts bereits auf zumeist drei bis vier reduziert und betrug in der ersten Hälfte des 20. Jahrhunderts durchschnittlich zwei bis drei, ${ }^{75}$ so ist bis zum Ausgang des 20. Jahrhunderts ein weiterer Rückgang festzustellen: Seit Ende der 1990er Jahre beträgt die jährliche Geburtenrate in Deutschland relativ konstant 1,4 Kinder pro Frau. ${ }^{76}$ Laut Erhebung des Statistischen Bundesamts wuchs 2012 in 42 Prozent der Familien in Deutschland ein Kind allein auf (EinKind-Familien). In 43 Prozent der Familien lebten zwei und in 15 Prozent drei oder mehr minderjährige Kinder. ${ }^{77}$ Trotz Zunahme von Ein-Kind-Familien ${ }^{78}$

72 Ebd., S. 25.

73 „Spricht man im soziologischen Kontext von Familie, so ist in der Regel die Kernfamilie gemeint, die aus den Eltern und einem oder mehreren nicht mündigen und unverheirateten Kindern, die im gemeinsamen Haushalt leben, besteht und die sich in modernen Gesellschaften als Kleinfamilie relativ unabhängig vom übrigen Verwandtschaftssystem organisiert (Neidhardt 1974).“ Ebd., S. 15 [Hervorhebung im Original].

74 In der jährlichen Stichprobenerhebung des vom Statistischen Bundesamt erhobenen Mikrozensus wird dieser Pluralität Rechnung getragen, indem unter dem Begriff ,Familie' nun sowohl Ehepaare als auch Lebensgemeinschaften sowie alleinerziehende Mütter und Väter gefasst werden. Vgl. Ebd., S. 30.

75 Vgl. Bollmann, Schwestern, S. 25f. Ab der zweiten Hälfte des 20. Jahrhundert stellt die Zwei-Kind-Familie die verbreitetste Familienform dar. Ebd., S. 30.

76 Da die Zahl der potenziellen Mütter im Alter zwischen 26 und 35 Jahren aber real zurückgegangen ist, ist die Zahl der Geburten faktisch gesunken. Vgl. die Angaben des Statistischen Bundesamts unter: https://www.destatis.de/DE/ZahlenFakten/Gesellschaft Staat/Bevoelkerung/Geburten/Geburten.html (letzter Zugriff: 24.03.2015).

77 Vgl. die Angaben des Statistischen Bundesamts unter: https://www.destatis.de/DE/ ZahlenFakten/GesellschaftStaat/Bevoelkerung/HaushalteFamilien/HaushalteFamilien. 
überwiegt somit noch immer die Sozialisation mit einem oder mehreren Geschwister(n), so dass auf demographischer Basis zwar ein Rückgang, aber noch keine ,geschwisterlose Gesellschaft ${ }^{\star}$ konstatiert werden kann. ${ }^{79}$ Zudem verbringen Geschwister gegenwärtig durchschnittlich mehr Zeit gemeinsam, ${ }^{80}$ da sich der Auszug aus dem Elternhaus vor allem aufgrund verlängerter Ausbildungszeiten $^{81}$ (vielleicht auch wegen des größeren, zur Verfügung stehenden privaten Wohnraums und zumeist liberalerer Erziehungsmethoden) zeitlich nach hinten verschiebt. Infolge der statistisch höheren Lebenserwartung dehnt sich der Zeitraum der Geschwisterbeziehung zudem bezüglich der gesamten Lebensspanne weiter aus. $^{82}$

Auf persönlichkeitsbezogener Ebene wird derzeit vermehrt der Einfluss der Geschwistererfahrung und -beziehung auf die soziale Entwicklung des Einzelnen bzw. auf die individuelle Sozialisation (beispielsweise hinsichtlich des Erlernens und Eingehens sozialer Beziehungen und der Übernahme spezifischer Rollen ${ }^{83}$ ) untersucht. Fokussiert werden dabei neben den insgesamt heterogenen familialen Ausgangssituationen ${ }^{84}$ und dem zumeist längeren Verbleib innerhalb der Kernfamilie auch veränderte demographische Entwicklungen in Industrieländern wie Deutschland oder innerhalb von Ländern mit restriktiver politischer Reglementierung der Bevölkerungszahl (z.B. die Ein-Kind-Politik in China). Hier stehen neben der Reflexion über die Auswirkungen einer verminderten Geschwisteranzahl oder gänzlich fehlender Geschwister auf gesamtgesellschaftliche Verhältnisse vor allem die Konsequenzen für die individuelle persönliche bzw. soziale Entwicklung im Vordergrund: So wird beispielsweise der Frage

html (letzter Zugriff: 24.03.2015). Allerdings wird über den jährlichen Mikrozensus nicht die exakte Geschwisterzahl ermittelt, da z.B. bereits ausgezogene (erwachsene) Geschwister ebenso wie (Halb-)Geschwister, die in anderen Haushalten leben, statistisch nicht erfasst werden.

78 Laut Corinna Onnen-Isemann wuchs demgegenüber 2004 erst jedes dritte Kind (31\%) in Deutschland ohne Geschwister auf, fast die Hälfte der minderjährigen Kinder (47\%) hatte eine Schwester oder einen Bruder und 22\% der Kinder mehrere Geschwister. Vgl. Onnen-Isemann: Geschwisterbeziehungen, S. 29.

79 Vgl. Bollmann: Schwestern, S. 29.

80 Dies gilt unter der Voraussetzung, dass die Familienkonstellation stabil bleibt oder Geschwister auch nach einer elterlichen Trennung weiterhin zusammen wohnen.

81 Vgl. Onnen-Isemann; Rösch: Schwesterherz, S. 104 u. Bollmann: Schwestern, S. 31f.

82 Aufgrund der durchschnittlich höheren Lebenserwartung von Frauen wirkt sich diese temporäre Verlängerung insbesondere auf die Schwesternbeziehung aus. Vgl. OnnenIsemann; Rösch: Schwesterherz, S. 104 u. Bollmann: Schwestern, S. 17.

83 Vgl. Onnen-Isemann; Rösch: Einleitung, S. 8.

84 Z.B. Sozialisation in Patchworkfamilien oder in nichtehelichen, alleinerziehenden oder gleichgeschlechtlichen Haushalten.

Ulrike Schneider, Helga Völkening and Daniel Vorpahl - 978-3-653-98812-3 
nachgegangen, welche Konsequenzen sich aus dem Sachverhalt ergeben, dass Kindern bzw. Jugendlichen ohne Geschwister das soziale ,Übungsfeld ' auf horizontaler Ebene fehlt, sie somit unter Umständen Kompetenzen, sich gegenüber anderen zu behaupten, Konflikte auszutragen bzw. zu bewältigen sowie Rollenidentitäten auszubilden, nicht entwickeln können. ${ }^{85}$

\section{Kulturgeschichtliche Rezeption}

\section{Geschwisterliche Ideal- und Leitbilder}

Stereotype und Idealvorstellungen hinsichtlich der Geschwisterbeziehung scheinen einerseits kultur- und zeitübergreifende Kontinuität zu besitzen, andererseits werden diese jeweils lokal oder zu unterschiedlichen Zeiten betont bzw. einzelne Momente erhalten eine verstärkte Relevanz, Priorität oder Modifikation. Letztlich kommt ihnen eine zweifache Funktion zu: Sie sind Ausdruck der sozio- bzw. kulturgeschichtlichen Situation und prägen diese zugleich. ${ }^{86}$ So spiegelte der ab 1800 in vielen deutschsprachigen literarischen bzw. künstlerischen Werken enthaltene Topos der Geschwisterliebe einerseits das Aufklärungsideal oder konkret das neue bürgerliche Familienbild, andererseits beeinflusste es als zeitgenössisches Leitbild selbst die kulturellen Werte sowie die Lebensorientierungen der Zeitgenossen. ${ }^{87}$

\section{Die Bruder-Schwester-Beziehung}

Der lateinische Grammatiker Verrius Flaccus erörtert in seinem einflussreichen Glossar De verborum significatu ${ }^{88}$ die Geschwisterbeziehung anhand des Begriffs der amita, der Tante väterlicherseits. Dabei fokussiert er die besondere affektive Nähe und Harmonie zwischen Bruder und Schwester (zwischen Vater und Tante aus Sicht der Nachkommen). Diese sieht er bereits terminologisch

85 Vgl. Onnen-Isemann: Geschwisterbeziehungen, S. 32.

86 S. Onnen-Isemann; Rösch: Einleitung, S. 10.

87 Vgl. hierzu Bausinger, Hermann: Geschwister gehen bis zum Rhein... Perspektiven der Volkstradition, in: Klosinski, Gunther (Hrsg.): Verschwistert mit Leib und Seele. Geschwisterbeziehungen gestern - heute - morgen. Tübingen 2000, S. 21-30, hier S. 24. Vgl. hierzu auch den Artikel von Anna Głowacka „Schwestern am Scheideweg - Zur Schwesternbeziehung in der Literatur der Restaurationszeit" in diesem Band.

88 In diesem Werk erklärt er seltene Begriffe anhand grammatikalischer, tradierter oder etymologischer Bezüge, vgl. Der Kleine Pauly. Lexikon der Antike. Bd. 5. München 1979, Stichwort: Verrius Flaccus, Sp. 1209f. 
verankert, da er amita - linguistisch zweifelhaft - von amata, Geliebte/Freundin (des Bruders), herleitet. ${ }^{89}$ Ann-Cathrin Harders resümiert:

Ausgehend von diesen Überlegungen kann also festgestellt werden, dass ein römischer Diskurs zu fassen ist, der der Bruder-Schwester-Beziehung eine zentrale Rolle in der Familienordnung zuweist. Dabei ist erstens zu konstatieren, dass dem geschwisterlichen Verhältnis eine besondere affektive Nähe zugesprochen wird. Affektivität darf dabei nicht mit Emotionalität gleichgesetzt werden; sie ist vielmehr als Rollenverhalten zu begreifen. Die enge Beziehung, wie sie in der römischen Gesellschaft zwischen Bruder und Schwester erwartet wird, mag demnach konstruiert sein, um spezielle Funktionen zu erfüllen, wie sie sich auch in anderen, die agnatischen Grenzen überspringenden Verwandtschaftsbeziehungen in Rom feststellen lassen: In diesem Fall interfamiliale Verantwortung und Kooperation. ${ }^{90}$

Schon die altgriechische Literatur (Herodot), aber auch frühe buddhistische Schriften enthalten darüber hinaus das Motiv der Schwester, die ihren Bruder bevorzugt, wenn sie gezwungen wird, lediglich eine Person auszuwählen, die gerettet werden kann. Sie entscheidet sich - so die übereinstimmende Quintessenz - weder für ihren Ehemann noch für ihre Kinder, weil nur der Bruder für sie nicht ersetzbar ist. Einen Ehemann könne sie demgegenüber ebenso erneut finden wie Kinder bekommen. ${ }^{91}$ Besondere Relevanz und Verbreitung erhielt dieser Topos sodann in seiner Antigone-Ausgestaltung innerhalb der Tragödie des Sophokles, der in der Literatur- und Kunstgeschichte vielfältig adaptiert worden ist: Antigone widersetzt sich dem Verbot, ihren Bruder Polyneikes zu bestatten und wird zur Strafe lebendig begraben.

89 „Oder sie wird amita genannt, weil sie von meinem Vater geliebt wird. Denn Schwestern werden von ihren Brüdern mehr geliebt als Brüder von ihren Brüdern, sicherlich wegen der Unähnlichkeit der Personen, so dass weniger Uneinigkeit und umso weniger Rivalität zwischen ihnen sind. ' [Fest. 13L].“ Zit. nach: Harders: Zwischen Kooperation, S. 67.

90 Harders: Zwischen Kooperation, S. 67. Auch nach der Eheschließung der Schwester blieben die sozialen Bindungen zur Herkunftsfamilie und hier besonders zum ältesten Bruder in römischer Zeit grundsätzlich bestehen. Harders betont in diesem Kontext die anhaltende Fürsorge des Bruders gegenüber der Schwester: „Aufgrund der hohen Mortalitätsraten rückte der Bruder nach dem Tod des Vaters als wichtige männliche Bezugsperson einer Frau auf und trat mit dem Ehemann in Konkurrenz. Es war die Aufgabe des Bruders, sich um die Schwester wie um ihre Nachkommen zu kümmern und diese auch vor dem Ehemann zu schützen.“ Harders: Sororitas, S. 248. Vgl. hierzu konkreter den Artikel von Sandra Kaden „Zwischen Macht und Ohnmacht - Zur Bedeutung der Kaiserschwestern im Principat von Augustus bis Commodus (27 v. Chr. - 192 n. Chr.)“ in diesem Band.

91 Vgl. Bausinger: Geschwister, S. 27.

Ulrike Schneider, Helga Völkening and Daniel Vorpahl - 978-3-653-98812-3 
In Märchen wie Brüderchen und Schwesterchen oder Hänsel und Gretel wird dann entsprechend des Öfteren der besondere Zusammenhalt, die Fürsorge, Verbundenheit und Ergänzung aufgrund komplementärer Fähigkeiten und Lösungsansätze - jenseits von entzweiender Polarität und Rivalität - betont. ${ }^{92}$

\section{Die Brüderbeziehung}

In seinem Handbuch historischer Exempla, den Facta et dicta memorabilia, ${ }^{93}$ behandelt der römische Schriftsteller Valerius Maximus das ethisch gebotene Verhältnis zwischen Brüdern innerhalb der Abschnitte zu den virtutes (Tugenden) konkret unter dem „Aspekt der ,pietas“, des pflichtgemäßen Verhaltens“. So führt er in Kapitel 5,5 solidarische Brüderpaare ${ }^{94}$ an, welche exemplarisch für die Verwirklichung dieser römischen Haupttugend stehen. In der Zeit der römischen Republik zählten zur pietas gegenüber Brüdern vor allem das „,gemeinsame[n] Management des Familienvermögens“, der „Umgang und [die] Sorge für die Familienmitglieder“ sowie die „brüderliche[n] Kooperation in rechtlichen wie politischen Belangen“" ${ }^{\text {"95. }}$.

Plutarch thematisiert die Geschwisterbeziehung, speziell die Bruderliebe, sodann im Rahmen seiner moralphilosophischen Diskurse zur allgemeinen Menschen- oder Freundesliebe. So hebt er mittels der (Statuen der) Dioskuren, Castor (Kastor) und Pollux (Polydeukes) ${ }^{96}$, in De fraterno amore insbesondere die Freundschaft bzw. Liebe ( $\varphi \imath \lambda i ́ \alpha)$ als signifikantes Charakteristikum des idealen Verhältnisses zwischen Brüdern mahnend hervor. Genau genommen schreibt er der Liebe unter Brüdern als erster Liebe neben der Eltern-Kind-Verbindung

92 Vgl. hierzu den Artikel von Jenny Vorpahl „,Hiermit Gott befohlen und seyd hübsch alle, ihr viere brüderlich, ihr zwei schwesterlich, getreu' - Die Darstellung von Geschwisterbeziehungen in den Kinder und Hausmärchen in ihrem soziokulturellen Kontext" in diesem Band.

Auf den in der Kulturgeschichte ebenfalls verbreiteten Topos des geschwisterlichen Inzests als Potenzierung der harmonischen Beziehung oder Tabubruch zwischen Geschwistern kann an dieser Stelle nicht eingegangen werden.

93 Das Kaiser Tiberius gewidmete Werk entstand nach 27 n.d.Z. Vgl. Der Kleine Pauly. Bd. 5, Stichwort: Valerius Maximus, Sp. $1117 \mathrm{f}$.

94 Vgl. Harders: Sororitas, S. 247.

95 Harders: Sororitas, S. 248.

96 Die Söhne Ledas, der Ehefrau Tyndareos', des Königs von Sparta, stehen in der Antike für die selbstlose, opferbereite geschwisterlicher Liebe. Habe doch Polydeukes, nach dem Tode seines Bruders, seine eigene Unsterblichkeit zur Disposition gestellt, um nicht von diesem getrennt zu sein und bei (seinem Vater) Zeus erreicht, dass beide ihre Tage gemeinsam - abwechselnd auf dem Olymp und im Hades - verbringen. Vgl. Tripp, Edward: Reclams Lexikon der antiken Mythologie. Stuttgart 2001, Stichwort Dioskuren/Dioskuroi, S. 164-165. 
eine archetypische bzw. paradigmatische Relevanz für alle weiteren Liebesbzw. freundschaftlichen Beziehungen zu, welche er letztlich als Abbilder jener Urbeziehungen versteht. ${ }^{97}$ Diese Ähnlichkeit plausibilisiere zudem die Verwendung geschwisterlicher Metaphern für enge freundschaftliche Bindungen (innerhalb sozialer Gruppen), implizieren jene doch seiner Auffassung zufolge Solidarität, Wohlwollen, Liebe, Verbundenheit, Fürsorge, Schutz und Respekt. ${ }^{98}$ Allerdings sei der familialen (Bruder-)Beziehung stets höhere Priorität beizumessen als der Freundschaft $(491 \mathrm{~B}),{ }^{99}$ wie bereits Hesiod in seinen Hauslehren betont hat. ${ }^{100}$ Konfliktpotenzial sieht Plutarch in der Ungleichheit der Brüder aufgrund verschiedener Anlagen und gegensätzlicher Entwicklungen. Demgegenüber würden ,,[...] Brüder, die gegen einander Liebe und Zuneigung haben, und die, so sehr auch die Natur sie dem Körper nach getrennt hat, in allen Affecten und Handlungen sich zu vereinigen suchen, die gemeinsam mit einander ihre Zeit in die Wissenschaft und in die Erholung theilen, [...] die Bruderliebe zu etwas Süßem und Beseeligendem “"101 machen.

\section{Die Schwesternbeziehung}

Beziehungen zwischen Schwestern standen aufgrund der historisch zumeist eingeschränkten Teilhabe und weniger exponierten Rolle der Frauen im öffentlichen Leben ${ }^{102}$ seltener im Fokus kulturwissenschaftlicher oder gesellschaftspo-

97 Vgl. Plutarch's Werke. Ein und dreißigstes Bändchen. Moralische Schriften. Übersetzt von Joh. Christian Felix Bähr. 12. Bd. Stuttgart 1857; Ueber die Bruderliebe, S. 1489.

98 Vgl. Harland, Philip A.: Familial Dimensions of Group Identity: „Brothers“ (A $\Delta \mathrm{E} \Lambda$ ФOI) in Associations of the Greek East, in: Journal of Biblical Literature 124/3 (2005), S. 491513, hier S. 513.

99 „Davor müssen wir uns allerdings hüten, und selbst wenn wir einem Freunde eben so zugethan sind, doch dem Bruder immer die erste Stelle bei Aemtern, Staatswürden, bei Einladungen und Bekanntschaften mit Fürsten erhalten, so wie überhaupt bei Allem, was in den Augen der Menge Glanz und Ruhm verleiht, und auf diese Weise der Natur die gebührende Achtung und Würde einräumen.“ Plutarch's Werke: Ueber die Bruderliebe, S. $1521 f$.

100 „Nicht gleich werde der Freund wie der leibliche Bruder geachtet.“ (Hauslehren 707, in: Hesiods Werke. Übersetzt von Johann Heinrich Voß. Tübingen 1911, S. 21-90).

101 Plutarch's Werke: Ueber die Bruderliebe, S. 1491.

102 Die seltene Präsenz von Frauen im öffentlichen gesellschaftlichen bzw. politischen Leben bis zum letzten Drittel des 19. Jahrhunderts erörtert bereits Simone de Beauvoir anhand der Termini Transzendenz und Immanenz: Während Männer Öffentlichkeit und Status vertreten hätten, seien Frauen auf den privaten Ort festgelegt worden, womit tendenziell eine „Abwertung von Freundschaften unter Frauen und eine[r] Aufwertung von Beziehungen zu Männern einher[gegangen sei].“ Liebold, Renate; Hack, Birgit M.: 
litischer Diskurse. Bis in die jüngste Zeit wurden Schwestern somit unter anderem in der Geschichts- oder Literaturwissenschaft allenfalls vereinzelt behandelt bzw. motiv- oder zeitgeschichtlich analysiert. ${ }^{103}$

Dennoch konstatieren Onnen-Isemann und Rösch traditionell verfestigte gesellschaftliche Vorstellungen und Ideale, die gemeinhin mit Schwesternbeziehungen verbunden waren und sich darüber hinaus am jeweils historisch-kulturell vermittelten Frauenbild orientierten. ${ }^{104}$ Als charakteristische Zuschreibungen nennen sie u.a. „Harmonie und gegenseitige[s] Verständnis“" ${ }^{\text {105 }}$, ähnliche Verhaltensweisen, ${ }^{106}$ enge emotionale Verbundenheit, Zusammengehörigkeit, Sanftheit und Fürsorge sowie Mitgefühl, d.h. kooperative und kommunikative Fähigkeiten, die stereotyp speziell mit Frauen assoziiert worden seien. ${ }^{107}$

Zudem habe die literarische, musikalische bzw. weitere künstlerische Darstellung von Schwesternbeziehungen im zeit- und geistesgeschichtlichen Kontext der Aufklärung ihrer Auffassung zufolge zumeist gesamtgesellschaftlichen pädagogischen Zwecken gedient: Mittels des harmonischen Schwesternverhältnisses sollte nicht selten Programm und Möglichkeit des aufklärerischen Ideals der Humanisierung der Gesellschaft aufgezeigt und $\mathrm{zu}$ einer entsprechenden Nachahmung auf sozialer Ebene angeregt werden. ${ }^{108}$

Zwischen Verbundenheit und Differenz: Zum Mythos Schwesternschaft in weiblichen Zusammenschlüssen, in: Onnen-Isemann; Rösch (Hrsg.): Schwestern. S. 89.

103 Margaret Lanzinger führt dies konkret auf die vornehmliche historische Erörterung von Geschwistern ,,unter dem Aspekt von Macht und Erbe“ zurück, welche in erster Linie eine Domäne von Männern bzw. Brüdern darstellte. Vgl. Lanzinger, Margareth: Schwestern-Beziehungen und Schwager-Ehen. Formen familialer Krisenbewältigung im 19. Jahrhundert, in: Labouvie (Hrsg.): Schwestern und Freundinnen, S. 263-282, hier S. 263 sowie Harders: Sororitas, S. 249. Auch Harders betont, Schwestern seien in historischen Untersuchungen, wenn sie denn erwähnt worden seien, zumeist mit ihren Brüdern assoziiert worden. Vgl. Harders: Sororitas, S. 248. Vgl. zu diesem Phänomen zudem den Artikel von Sandra Kaden „Zwischen Macht und Ohnmacht - Zur Bedeutung der Kaiserschwestern im Principat von Augustus bis Commodus (27 v. Chr. - 192 n. Chr.)“ in diesem Band.

104 Vgl. Onnen-Isemann; Rösch: Einleitung, S. 13f.

105 Onnen-Isemann; Rösch: Schwesterherz, S. 16.

106 Vgl. ebd., S. 18.

107 Vgl. ebd., S. 19 u. 23.

108 Vgl. Onnen-Isemann; Rösch: Einleitung, S. 14; Onnen-Isemann; Rösch: Schwesterherz, S. 22 u. Bartl, Andrea: Ungleiche Zwillinge: Adalbert Stifters ,Zwei Schwestern “ - mit einem anthropologischen Seitenblick auf Ernst von Feuchtersleben, in: Onnen-Isemann; Rösch (Hrsg.): Schwestern, S. 153-169, S. 153. Siehe hierzu die entsprechenden Beispiele im Artikel von Anna Głowacka „Schwestern am Scheideweg - Zur Schwesternbeziehung in der Literatur der Restaurationszeit“ in diesem Band. 


\section{Polarität - Geschwister als Antagonisten}

Während innerhalb gemischtgeschlechtlicher Geschwisterkonstellationen konträre Eigenschaften und Fähigkeiten meist als komplementäre Ergänzung positiv bewertet werden, führen diese bei Geschwistern gleichen Geschlechts im Drama oder innerhalb der Opernhandlung oft zu einer verhängnisvollen Eskalation bzw. werden in ihrer Polarität besonders akzentuiert. ${ }^{109}$

Bereits die Gegensätzlichkeit von Schwestern stellt ein durchgehendes (kulturgeschichtliches) Motiv dar. Ihr wurde allerdings gewöhnlich nicht das gleiche Ausmaß folgenschwerer dramatischer Zuspitzung zugeschrieben wie dem gleichgeschlechtlichen brüderlichen Pendant. In der Hebräischen Bibel findet sie sich bereits in Gestalt der Ahnfrauen Lea und Rahel (Gen 29.30.35), im Neuen Testament mittels der Schwestern Maria und Martha umgesetzt - letztere als Repräsentantinnen verschiedener Glaubens- und Lebensweisen, der Vita activa und Vita contemplativa (Lk 10,38-42). Diese sind ebenso wie weitere konträre Schwesterngestalten leitmotivisch in diversen kunst- und kulturgeschichtlichen Werken $^{110}$ abgebildet. Besonders augenscheinlich ist die Polarität innerhalb der Volksmärchen ausgestaltet, da hier die äußerliche Kontrastierung zumeist mit einer antithetischen Verschiedenheit in charakterlich-ethischer Hinsicht einhergeht (vgl. z.B. Goldmarie und Pechmarie in Frau Holle). ${ }^{111}$ Eine signifikante Verfestigung dichotomischer Ausgestaltungen von Schwesterpaaren konstatiert Andrea Bartl konkret für die deutschsprachige Literatur im Laufe des 19. Jahrhunderts, im Anschluss an ihre überwiegend harmonische Aufnahme in den Epochen der Aufklärung und Empfindsamkeit. ${ }^{12}$

109 Dies korrespondiert mit den Ergebnissen der individualpsychologischen Geschwisterforschung, wonach Rivalität und Konflikte in erster Linie und in verstärktem Maße unter gleichgeschlechtlichen Geschwistern anzutreffen sind. Zur musikalisch-dramatischen Umsetzung brüderlicher Polarität vgl. u.a. den Artikel von Yael Kupferberg „Moses und Aron in der musikalischen Rezeption Arnold Schönbergs“" in diesem Band.

110 Siehe die diesbezüglichen Beispiele im Artikel von Constanze Musterer „Der schöne Schein - Untersuchungen zu Geschwisterdarstellungen in der Kunst des 20./21. Jahrhunderts" in diesem Band.

111 Vgl. hierzu den Artikel von Jenny Vorpahl „,Hiermit Gott befohlen und seyd hübsch alle, ihr viere brüderlich, ihr zwei schwesterlich, getreu' - Die Darstellung von Geschwisterbeziehungen in den Kinder und Hausmärchen in ihrem soziokulturellen Kontext" in diesem Band.

112 Diese stehen aber im Kontext einer ohnehin häufigeren Erwähnung von Schwestern, wie sie Gertrud Maria Rösch für den Beginn des 19. Jahrhunderts bis zur Jahrhundertwende feststellt. Vgl. Rösch: Auf der Suche, S. 171. Vgl. hierzu ebenfalls den Artikel von Anna Głowacka „Schwestern am Scheideweg - Zur Schwesternbeziehung in der Literatur der Restaurationszeit" in diesem Band. 
Die gegensätzliche Darstellung von Brüdern führt in der Literatur- und Kulturgeschichte des Öfteren zu einem Konflikt, zu offen ausgetragener Konkurrenz sowie Aggression, die bis zum Brudermord eskalieren kann. Letzterer stellt vor allem innerhalb des antiken Mythos meist das Resultat einer Rivalität um Herrschaft und Thron dar (Romulus und Remus, Polyneikes und Eteokles, Osiris und Seth), um eine Frau (vgl. z.B. die biblischen Söhne Davids, Absalom und Amnon, in 2 Sam 13) oder um die elterliche oder göttliche Anerkennung, die Segen und Erbe impliziert (Kain und Abel sowie letztlich ohne Eskalation im Brudermord: Isaak und Ismael ${ }^{113}$, Jakob und Esau oder Josef und seine Brü$\operatorname{der}^{114}$ ). So betrifft der Konflikt meist nicht allein die individuelle, emotionale Befindlichkeit, sondern tangiert zugleich übergeordnete patriarchale sowie gesellschaftliche Momente von Erbe, Macht und Herrschaft. ${ }^{115}$ Magda Motté sieht im Brudermord als „Urmuster zwischenmenschlicher Konflikte“ eine „abendländische Tradition" und betont, kaum ein anderes biblisches Motiv sei so häufig rezipiert worden wie die Brudermorderzählung von Kain und Abel. ${ }^{116}$

Insgesamt wird nicht nur die Geschwisterliebe um 1800 in der Literatur auffällig häufig propagiert, auch das Gegenmotiv der feindlichen Brüder ist signifikant verstärkt aufgenommen. Speziell das Kain-und-Abel-Motiv erhält sodann in der Literatur des 20. Jahrhunderts besondere Aufmerksamkeit und Rezeption. ${ }^{117}$

\section{Metaphorische Verwendung}

Die übertragene Verwendung von Geschwistertermini ${ }^{118}$ erweist sich als äußerst umfangreich, vielfältig und tief im kulturellen Gedächtnis verankert. Bereits in der griechischen Antike und dann besonders im Mittelalter finden sich zahlrei-

113 Zur Ausgestaltung und Bedeutung dieser im Islam vgl. den Artikel von Hans-Michael Haußig „Isaak und Ismael in der islamischen Überlieferung - Ein widersprüchliches Bild" in diesem Band.

114 Vgl. die Darlegungen im Artikel von Daniel Vorpahl „Geschwisterlichkeit als sozialethische Matrix des Volkes Israel in der Tora“ in diesem Band.

115 So ebenfalls der Freiburger Germanist Gerhard Kaiser. Vgl. Sitzler: Geschwister, S. 98f.

116 Vgl. Gen 4. und dazu Motté, Magda: „Brudermord als abendländische Tradition“. Kain und Abel - Urmuster zwischenmenschlicher Konflikte, in: Schmidinger, Heinrich M. (Hrsg.): Die Bibel in der deutschsprachigen Literatur des 20. Jahrhunderts. Mainz 2000, S. 64-79, hier S. 64. Vgl. hierzu auch die exemplarischen Verweise von Ulrike Schneider im Vorwort dieses Bandes.

117 Vgl. Motté: Brudermord, S. 67ff.

118 Die metaphorische Rezeption von Geschwisterbezeichnungen könnte auf die mit dem verwandten Adjektiv implizierten übertragenen Wortbedeutungen , verwandt', ,ähnlich', ,übereinstimmend‘ zurückgehen. Vgl. Günther: $\alpha \delta \varepsilon \lambda \varphi$ ó Bruder, S. 147. 
che Belege für die Anwendung geschwisterlicher Begriffe im weiteren oder übertragenen Sinne. Allerdings bezieht sich der metaphorische Transfer nicht stets auf ein betontes Moment oder appliziertes Charakteristikum der Geschwisterbeziehung. Vielmehr scheinen jeweils verschiedene Aspekte des Verhältnisses konstituierend und prägend gewesen zu sein und bedürfen somit der näheren, systematischen Differenzierung. Eine solche soll im Folgenden unter dem Vorbehalt, nicht jegliche Nuance lokaler, historischer und kultureller Provenienz

anführen zu können oder Vollständigkeit zu beanspruchen, dargelegt werden. ${ }^{119}$ Auch sind angesichts der Komplexität der semantischen Konnotationen bildimmanente Überschneidungen nicht auszuschließen.

\section{Geschwisterschaft als Status und Prädisposition}

\section{Universal-menschliche Geschwisterschaft als conditio humana}

Der Stoiker Epiktet thematisiert Geschwisterschaft im Kontext seiner Reflexionen innerhalb der Diatriben (Dissertationen), auf welche Weise der Mensch Eudämonie, d.h. Glückseligkeit bzw. seelisches Wohlbefinden, erlangen kann. Er setzt hierbei eine genuine bzw. natürlich vorgegebene Geschwisterschaft aller Menschen voraus, welche sich im gemeinsamen Ursprung in Gott begründe und konstituiere (Diatr 1,13). ${ }^{120}$ Diese impliziere die Gleichheit und Freiheit aller Menschen und verpflichte zu einem , geschwisterlich'-solidarischen, sittlichem Verhalten gegenüber Mitmenschen - jenseits realgesellschaftlicher Herrschaftsstrukturen oder Verfügungsgewalt über Sklaven. ${ }^{121}$

Ein universal-menschlicher Geschwistergedanke lässt sich ebenfalls aus monotheistischen Traditionen ableiten. So kann auch im Judentum, Christentum und Islam aus der apriorischen Glaubensprämisse, dass ein Gott jeden Menschen und alles andere geschaffen hat, gefolgert werden, dass alle Menschen oder auch jegliche Geschöpfe Geschwister sind. In der Hebräischen Bibel erscheint dies mittels der beschriebenen Abstammung aller Menschen von einem, von Gott erschaffenen Urmenschenpaar narrativ umgesetzt. Auf eben diese biblische Schöpfungstradition rekurriert auch der christliche Aufklärer Theodor Gottlieb

$119 \mathrm{Im}$ Folgenden wird in erster Linie die abendländische Tradition im Vordergrund stehen.

120 In dem Abschnitt „Wie man bei jedem Tun den Göttern gefallen kann“ heißt es entsprechend: „Du Sklave, kannst du deinen eigenen Bruder nicht ertragen, der Zeus zum Vorfahren hat und wie ein Sohn aus demselben Samen und demselben Ursprung im Himmel hervorgegangen ist wie du? Und da willst du, wenn du in eine ähnliche Stellung über andere gesetzt bist, dich gleich als Tyrann aufspielen? Vergißt du denn ganz, was du bist und über wen du herrschst? Daß es Verwandte, von Natur aus Brüder und Kinder Gottes sind?“ (Diatr. 1,13). Zit. nach: Epiktet - Teles - Musonius, S. 170.

121 Epiktet (50-120 n.d.Z.) steht hiermit im Kontext des umfassenden stoischen Humanitätsund Gerechtigkeitsgedankens. Vgl. Günther: $\grave{\alpha} \delta \varepsilon \lambda \varphi$ ó $\varsigma$ Bruder, S. 147. 
von Hippel, wenn er feststellt: „Die Menschheit ist wahrlich eine große Brüderschaft, unter die Gott die Erde getheilt hat!“122 Zuvor hat bereits Franz von Assisi in seinem Sonnengesang die Geschwisterschaft auf die gesamte Schöpfung ausgedehnt, indem er auch die Elemente (Wind, Wasser, Feuer, Erde) und Gestirne (Sonne, Mond), selbst den Tod, als Schöpfungswerke als „Bruder“ oder „Schwester“ anredete. ${ }^{123}$ Diese universale Geschwisterschaft gründet ihm zufolge somit konkret in der göttlichen Schöpfungstat resp. in Christus und aktualisiert sich in der jeweils gelebten Bruder- bzw. Schwesternschaft. ${ }^{124}$

Letzteres erhält schließlich vor allem zur Zeit der Reformation eine exponierte Akzentuierung. ${ }^{125}$ So führt beispielsweise Christian Fürchtegott Gellert in einem Kirchenlied die aus der gemeinsamen Herleitung von einem Schöpfergott gefolgerte gegenseitige Verantwortung und grundsätzliche Egalität (vor Gott) als ethisches Postulat an: „Wir haben einen Gott und Herrn, / Sind eines Leibes Glieder; / drum diene deinem Nächsten gern, / Denn wir sind alle Brüder.“'126 Wird die universell-menschliche Geschwisterschaft ernst genommen, so müsse dies zwangsläufig Konsequenzen im sozialen Umgang und im realpolitischen Bereich nach sich ziehen, insofern ungerechte gesellschaftliche Verhältnisse nicht mehr akzeptiert bzw. hingenommen werden. Letzteres setzt beispielsweise der Philanthrop Christian Gotthilf Salzmann implizit voraus:

Da singen sie: Wir sind Bürger einer Welt, Kinder eines Vaters - Brüder!... Ach Gott! statt dessen kommen die Elenden, die von nichts als Bruderliebe reden, predigen, singen, und brauchen ihre Waffen um die schwachen Brüder zu schrecken... behalten ihren Reichthum für sich und reißen dem Dürftigen seinen Bissen Fleisch aus dem Munde. ${ }^{127}$

122 Zit. nach: Stammler: Politische Schlagworte, S. 99.

123 So heißt es beispielsweise: „Sei gepriesen, mein Herr, durch alle deine Geschöpfe, besonders Herrin Schwester Sonne [...]. Herr, sei gelobt durch Bruder Mond und die Sterne [...].“ Zit. nach Doyle, Eric: Von der Brüderlichkeit der Schöpfung. Der Sonnengesang des Franziskus. Zürich 1987, S. 53 (vgl. auch S. 81f.). Vgl. zudem Atwood, Craig D.: Brother, Brotherhood, V. Christianity, in: Encyclopedia of the Bible and Its Reception. Bd. 4, Sp. 557-564, hier Sp. 559.

124 Vgl. Doyle: Von der Brüderlichkeit, S. 9. Eine transhumane Ausweitung des Geschwisterbezugs ist bereits im neuplatonischen und neupythagoreischen Denken angelegt. So stellt beispielsweise Plotin fest, ,alle Dinge der Welt“ seien Brüder bzw. Geschwister. Vgl. Günther: $\dot{\alpha} \delta \varepsilon \lambda \varphi o ́ \varsigma$ Bruder, S. 147. Des Weiteren vertreten neupythagoreische Repräsentanten eine „Bruderschaft“ oder ein Einssein von Mensch und Tier. Vgl. Krause, Gerhard: Antike Collegia, Stichwort: Bruderschaften/ Schwesternschaften/ Kommunitäten, in: Theologische Realenzyklopädie. Bd. VII. Berlin, New York 1981, S. 195.

125 Vgl. hierzu z.B. die angeführten Beispiele bei Stammler: Politische Schlagworte, S. 97.

126 Zit. nach: ebd.

127 Carl von Carlsberg V 1787, S. 123. Zit. nach: Stammler: Politische Schlagworte, S. 98. 
Notwendige sozialpolitische Auswirkungen spricht auch Chr. G. Otto in seinen verbreiteten, in das Kommersbuch eingegangenen Liedversen an:

Wir Menschen sind ja alle Brüder, / Und jeder ist mit uns verwandt, / Die Schwester mit dem Leinwandmieder, / Der Bruder mit dem Ordensband... / Der Mann auf seinem Throne lebe, / Mit allem, was ihm angehört, / Und unser Vaterland umschwebe / Der Friedensengel ungestört. / Der Fürst sei Mensch, der Sklave frei, / Dann eilt die goldne Zeit herbei. ${ }^{128}$

Johann Gottfried Herder leitet die Bruderschaft aller Menschen schließlich nicht mehr von einem personalen, monotheistischen Schöpfergott ab, sondern setzt die gemeinsame Teilhabe an einer Weltseele bzw. Weltvernunft voraus. ${ }^{129}$

\section{Geschwisterschaft qua sozio-politischer bzw. nationaler Zugehörigkeit}

Ebenfalls auf eine Prädetermination - hier in Folge nationalpolitischer Konstellationen - geht die Definition einer übertragenen Geschwisterschaft aufgrund der Zugehörigkeit zu einem Volk, einer Nation, einem Land o. Ä. zurück. So setzt beispielsweise Plato in seinem Frühdialog Menexenos eine nationale Brüderschaft voraus, welche alle Griechen (Volksgenossen) umfasst. ${ }^{130}$ Seinen Ausführungen zufolge begründet sich das Bruderverhältnis der Griechen in der Isogonia (Isogonie), der gleichen, d.h. gemeinsamen Abstammung (von einer Mutter; konkret: von der Erde/dem Land). Hieraus leitet er den Grundsatz bzw. das Postulat der Gleichheit aller Griechen vor dem Gesetz (Isonomia, Isonomie) ab, welche sich laut Plato jedoch lediglich auf die genuine Ausgangslage jedes Einzelnen bezieht. Eine Nivellierung und Teilhabe an der politischen Macht aller, im Sinne einer Demokratie, lehnt er ab und befürwortet stattdessen eine Differenzierung und Auslese nach Weisheit, Fähigkeit und Leistung (d.h. konkret eine Aristokratie im Sinne der Auswahl der Tüchtigsten bei der Verteilung staatstragender Ämter). ${ }^{131}$

Ähnliche Gedanken äußert er in seinem Entwurf eines idealen Staats (Politeia). Um potenzielle künftige Regenten zu überzeugen, Regierungsver-

128 Zit. nach: ebd.

129 Vgl. ebd., S. 99.

$130 \mathrm{Vgl}$. Menexenos 239a. Die übertragene Verwendung des Begriffs, frater ' für Volks- und Stammesgenossen ist zudem in klassischen lateinischen Quellen bei Vergil oder Horaz belegt. Vgl. Schelkle: Bruder, Sp. 632.

131 „Wir aber und die Unseren, als Brüder von einer Mutter stammend, wollen einander weder Sklaven noch Herren sein, sondern die Gleichheit unserer Abstammung nötigt uns, auch nach der Gleichheit vor dem Gesetz zu trachten und uns einer dem andern nur dann unterzuordnen, wenn dieser im Ruf steht, ein tüchtiger und kluger Mann zu sein.“ (Menexenos 239a). Zit. nach: Platon: Frühdialoge. Eingeleitet von Olof Gigon, übertragen von Rudolf Rufener. Zürich, München 1974, S. 358.

Ulrike Schneider, Helga Völkening and Daniel Vorpahl - 978-3-653-98812-3 
antwortung zu übernehmen, solle diesen, so Plato in seiner Staatsutopie, eine phönikische Sage erzählt werden. Dieser zufolge ist die Stellung jedes Einzelnen in der Polis bereits von göttlicher Seite vorherbestimmt, indem künftigen Herrschern bei der Bildung seitens der Gottheit Gold beigemischt worden ist, den Wächtern, als Vertretern der künftigen exekutiven Gewalt, Silber und den Bauern, Handwerkern bzw. übrigen Arbeitern Eisen und Erz oder Kupfer (Politeia 415a). Auch hier werden alle Bürger - konkret die Einwohner der Polis als Brüder bezeichnet, da sie sich von einem Schöpfer ableiten. Dennoch kommen laut Plato jedem unterschiedliche Fähigkeiten und somit verschiedene soziale Entwicklungsmöglichkeiten resp. Zukunftsperspektiven innerhalb der Polis zu. Die individuelle Anlage solle dabei laut dieser platonischen Konzeption die Stellung im Staatswesen bestimmen, nicht die soziale oder familiale Herkunft. ${ }^{132}$ Demzufolge verlieren die tatsächlichen genetisch-genealogischen Bindungen in seinem idealen Staat letztlich ihre Relevanz zugunsten der Staatsräson. Dies zeigt sich auch in der platonischen Befürwortung einer staatlich organisierten gemeinschaftlichen Erziehung der Anwärter der jeweiligen Herrscher- bzw. Wächterstände. Abgesondert von ihren Familien bzw. Eltern, die ihnen nicht bekannt sind, müssen sie prinzipiell jeden in der unmittelbaren Umgebung als potenziellen Verwandten bzw. als Bruder oder Schwester ansehen. In der Konsequenz sollen sich somit innerhalb eines Standes alle als Geschwister oder weitere Verwandte anreden und behandeln.

3. Geschwisterschaft als Ausdruck entstehender oder bestehender Differenz bzw. Hierarchie

Nicht Egalität und Nivellierung, sondern Divergenz stehen vorrangig im Mittelpunkt, wenn disparate Entwicklungen, Altersunterschiede oder unterschiedliche Geschwisterrangpositionen betont werden. Hier liegt einerseits die Vorstellung der Trennung, der Entscheidung für verschiedene (Lebens-)Wege von einer gemeinsamen Ausgangsbasis zugrunde. In diesem Sinne werden somit beispielsweise Religionen eines Ursprungs, wie das Juden- und Christentum, als Bruderreligionen bezeichnet oder Völker mit gemeinsamen Wurzeln Brudervölker genannt.

132 Im Kontext der Sage heißt es diesbezüglich: „Wenn ihr Sproß Erz oder Eisen mitgemischt erhalten hat, dann dürfen sie [die Herrscher] sich in keiner Weise erbarmen, sondern müssen ihm die seiner Natur zukommende Stellung geben und ihn zu Handwerkern und Bauern verstoßen. Wenn aber von diesen Ständen ein Kind Gold oder Silber in sich trägt, dann müssen sie es ehren und emporführen zum Stand der Wächter die einen, zum Stand der Gehilfen die andern [...].“ (Politeia 415b-c) Zit. nach: Platon. Der Staat (Politeia). Übersetzt u. hrsg. v. Karl Vretska. Stuttgart 2012, S. 202. 
Demgegenüber impliziert die Akzentuierung unterschiedlicher Ausgangssituationen innerhalb der Geschwisterposition (z.B. großer und kleiner Bruder, ältere und jüngere Schwester) zumeist ein Moment des Ungleichgewichts, der Hierarchie bzw. der einseitigen Überlegenheit und Dominanz. Dies findet im positiven Sinne in der Unterweisung, Fürsorge und Hilfe, in seiner negativen Ausformung in der Kontrolle bzw. Disziplinierung seitens der älteren Geschwister seinen konkreten Ausdruck. ${ }^{133}$

Ein vertikal helfender resp. fürsorgender oder altruistischer Aspekt kommt darüber hinaus bei der Anwendung geschwisterlicher Termini im karitativen Bereich bzw. in der Pflege zum Tragen. So nannten sich die bereits in der Spätantike in Großstädten verbreiteten (christlichen) Fürsorgevereinigungen zumeist „Bruderschaften“. Sie wirkten vor allem auf karitativ-seelsorgerlichem Gebiet der Krankenpflege und des Bestattungswesens ${ }^{134}$ und erhielten spätestens im hohen und späten Mittelalter maßgebende, multifunktionale Bedeutung. ${ }^{135}$ Bis dato ist der unterstützende, fürsorgliche, manchmal selbstlos-altruistische Aspekt in den Anreden und Selbst- bzw. Organisationsbezeichnungen enthalten bzw. ersichtlich: (Kranken-)Schwestern sowie „Schwestern mit Herz“, „Die mobilen Schwestern“ etc. ${ }^{136}$

Des Weiteren verweist der Titel und die Agenda des 1904 in New York gegründeten und von 2007 bis 2013 auch in Deutschland realisierten Programms Big Brother Big Sister auf den nachhaltig positiven Aspekt der Unterstützung älterer Geschwister im Sinne der Fürsorge, der Lebenshilfe und des Beistands. Zunächst als Hilfsaktion zur Wiedereingliederung entlassener Straftäter seitens Mentoren gegründet, stellt es gegenwärtig ehrenamtliche Personen, die sozial benachteiligte Kindern bei der Bewältigung alltäglicher Lebensaufgaben unterstützen. ${ }^{137}$

Eine negativ konnotierte hierarchische Rolle kommt demgegenüber dem in einer Zuschauerposition befindlichen Kollektiv, Big Brother, in George Orwells

133 Beide Momente sind auch immanent, wenn ein politisch, sozial oder wirtschaftlich dominierender Staat mit Blick auf einen, von jenem abhängigen, meist protegierten Staat als ,Großer Bruder' bezeichnet wird.

134 Vgl. Stupperich: Bruderschaften/Schwesternschaften, S. 196.

135 Vgl. Escher-Apsner, Monika: Mittelalterliche Bruderschaften in europäischen Städten. Funktionen, Formen, Akteure / Medieval confraternities in European towns. Functions, forms, protagonists. Eine Einleitung (An introduction), in: dies. (Hrsg.): Mittelalterliche Bruderschaften in europäischen Städten. Funktionen, Formen, Akteure. Frankfurt/Main 2009, S. 9-27, hier S. 9 u. 15.

136 Vgl. zu den Beispielen: Sitzler: Geschwister, S. 86.

137 Vgl. ebd., S. 210. Vgl. zur Big-Sister-Ghetto-Organisation auch Fishel, Elizabeth: Schwestern. Liebe und Rivalität innerhalb und außerhalb der Familie. Berlin u.a. 1979, S. 280. 
Werk 1984 oder im gleichnamigen privaten Fernsehformat zu. Bei Orwell noch eine literarisch-futuristische Fiktion einer alle Bereiche des menschlichen Lebens umfassenden Überwachungs-, Kontroll- und Reglementierungsinstanz, bietet die ,Reality“-Fernsehsendung Big Brother den Zuschauern eine distanzierte, bequem-überlegene Beobachtungsposition, die Voyeurismus ebenso wie Parteinahme, überhebliche Kritik oder Schadenfreude, Spott sowie Hohn bedient und protegiert.

Geschwisterschaft als Status und Auftrag, zwischen Prädisposition und dynamischer Verschwisterung

Da bei Israeliten bzw. Juden zumeist Abstammung, Volks- und Religionszugehörigkeit zusammenfällt, bezeichnet auch der hebräische Begriff ,Bruder' (אָ: $a h$, griech. $\left.\alpha \delta \varepsilon \lambda \varphi{ }^{\prime} \varsigma\right)$ schon in der Bibel im weiteren, übertragenen Sinne sowohl ein Mitglied der Volksgemeinschaft als auch einen Vertreter derselben Religion (Glaubensbruder). ${ }^{138}$ Des Öfteren wird jedoch die primäre Bedeutung in der $\mathrm{Zu}$ gehörigkeit zur selben Religionsgemeinschaft eruiert. ${ }^{139}$ Joseph Ratzinger hebt in diesem Zusammenhang das Selbstverständnis Israels als Bundesgemeinde Gottes hervor, von dem sich die „Idee der Brüderlichkeit“ ableite und stellt jenes Moment der göttlichen Zuneigung und Erwählung des Volks als „erstgeborener Sohn ${ }^{\text {(140 }}$ der platonischen Herleitung von einem gemeinsamen Ursprung aus einer Mutter Erde gegenüber. ${ }^{141}$ Eine außergewöhnliche, Israel geltende liebende Zuwendung Gottes wird auch insbesondere im biblischen Prophetenbuch Hosea in poetischer Metaphorik dargelegt, indem im Anschluss an Unheilankündigungen die Verheißung angeführt wird, die Söhne Israels würden wieder „Söhne des lebendigen Gottes" genannt werden bzw. sein. Hierauf folgt die Aufforderung, die (Bundes-)Brüder „Ammi“ („Mein Volk“) und die (Bundes-)Schwestern „Ruchama“ (,Erbarmen“) zu nennen (Hos 2,3). Das Verhältnis Gottes zu seinem

138 Als Beispiele für die beidseitige Ausrichtung des Begriffs führt Schelkle exemplarisch die Verse Ex 2,11; Lev 10,4; Dtn 15,3.12; 17,15; 18,15; Jud 14,3; Ps 49,20; Jer 22,18; Neh 3,2 sowie 2 Chron 31,15 an. Vgl. Schelkle: Bruder, Sp. 635.

139 Zur Bezeichnung des Volksgenossen wird eher רע (,ra“, griech. $\pi \lambda \eta \sigma i ́ o v)$ verwendet.

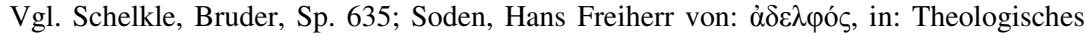
Wörterbuch zum Neuen Testament. Erster Band. Hrsg. v. Gerhard Kittel. Stuttgart 1949, S. 144-146, S. 145; sowie Ratzinger, Joseph: Erwägungen über die christliche Brüderlichkeit, in: Aufderbeck, Hugo; Fritz, Martin (Hrsg.): Bruderschaft und Brüderlichkeit. Pastoral-Katechetische Hefte. Heft 22. Leipzig 1964, S. 9-35, hier S. 9. In rabbinischen Schriften wird dann terminologisch präzise zwischen Volks- sowie Religionsgenossen unterschieden. Vgl. Günther: ả $\delta \varepsilon \lambda \varphi$ ó $\varsigma$ Bruder, S. 147.

140 Ratzinger: Erwägungen, S. 10.

141 Vgl. ebd., S. 9f.

Ulrike Schneider, Helga Völkening and Daniel Vorpahl - 978-3-653-98812-3 
Volk konstituiert somit auch die metaphorische Identifikation und Anrede der anderen Mitglieder des Gottesvolkes als Geschwister. Laut Günther verweist die Verwendung der Geschwisterbegrifflichkeiten an dieser Stelle auf einen Übergang hinsichtlich des Sprachgebrauchs: von der leiblichen zur geistlichen Bruderschaft. ${ }^{142}$

In sozialrechtlichen biblischen Texten werden sodann von den Religionsund Volksgenossen ethische bzw. soziale Verhaltensweisen gefordert, welche gemeinhin vorrangig innerhalb familialer Relationen zwischen Geschwistern vorausgesetzt bzw. postuliert werden: Solidarität, Fürsorge und tätige Hilfe. ${ }^{143}$ Vorrangig gilt dieser Aufruf zu einem entsprechend mitmenschlichen Umgang allerdings hinsichtlich denjenigen gesellschaftlichen Gruppen, die besonderer Unterstützung bedürfen: Arme, sozial Benachteiligte sowie Schwache und Wehrlose. In Ex 23,4f. umfasst der tätige Unterstützungsappell dann sogar Mitglieder feindlicher Völker. Nicht zuletzt erhält das in Lev 19,17f. vorgetragene Verbot des Hasses gegen den brüderlichen Mitisraeliten und der Anordnung, den Nächsten wie sich selbst zu lieben ${ }^{144}$, in dem Gebot, den Fremden, der im Lande lebt, so zu lieben wie sich selbst (Lev 19,34), einen erweiterten Bezugsrahmen ${ }^{145}$ bzw. Anwendungsbereich.

\section{Geschwisterwerdung als Postulat und Prozess}

\section{Universale Verschwisterung und rechtspolitische Egalisierung}

Friedrich Schillers Ode An die Freude ${ }^{146}$ enthält einen universalen Verbrüderungsgedanken. Obwohl in dieser durchaus noch ein „,lieber Vater“, der „,überm

142 Vgl. Günther: ả $\delta \varepsilon \lambda \varphi o ́ \varsigma$ Bruder, S. 147.

143 Vgl. z.B. Dtn 22,1-4, siehe auch Seow, Choon-Leong: Brother, Brotherhood, I. Hebrew Bible/Old Testament, in: Encyclopedia of the Bible and Its Reception. Bd. 4. Hrsg. v. Hans-Josef Klauck u.a. Berlin, Boston 2012, Sp. 540-546, hier Sp. 541. Vgl. hierzu den Artikel von Daniel Vorpahl „Geschwisterlichkeit als sozialethische Matrix des Volkes Israel in der Tora" in diesem Band.

144 Hier erscheinen folglich ,Bruder ' und ,Nächster' als Synonyme.

145 Diese Erweiterung spricht gegen den von Doyle unter Berufung auf Joseph Ratzinger konstatierten eingrenzenden Bedeutungsgehalt: „Im Alten Testament wird es [das Wort ,Bruder'] für die Mitglieder des jüdischen Volks gebraucht, das heißt für die, die die gleiche Volkszugehörigkeit und den gleichen Glauben hatten. In all diesen Fällen hat das Wort eine eingrenzende Bedeutung; es ist in seinem Gebrauch durch eine Grenze, ja ein Hindernis bestimmt, sei es die Grenze der Stadt, der Nation, der Religion oder die der Klasse. Alle andern sind Ausländer, Feinde, Tölpel, Heiden oder Barbaren und werden nicht durch den Namen Bruder geehrt. [Josef Ratzinger, Die christliche Brüderlichkeit, München 1960, S. 11-25].“ Doyle: Von der Brüderlichkeit, S. 81.

146 Die erste Fassung entstand 1786, die zweite 1803. 
Sternenzelt ${ }^{\star 147}$ wohnt, vorausgesetzt ist, erscheint die Bruderschaft nicht mehr primär oder explizit von der gemeinsamen Herkunft von einem Schöpfergott abgeleitet. Statt einer vorgefundenen, feststehenden Prädisposition werden Bruderschaft bzw. Verbrüderung in der Ode vielmehr als dynamische, säkularhistorisierte Prozesse definiert und begrüßt: „Bettler werden Fürstenbrüder, wo dein sanfter Flügel weilt“ (1786) bzw. „Alle Menschen werden Brüder, Wo dein sanfter Flügel weilt" (1803). Menschen sind folglich nicht zwangsläufig bzw. von vornherein Brüder, sie werden erst zu solchen, ${ }^{148}$ konkret durch die sie vereinigende bzw. verbindende Freude, ${ }^{149}$ Freundschaft, Liebe und Sympathie. ${ }^{150}$ Die Ode kann daher in erster Linie als ein Appell zu einem geschwisterlichen Zusammenschluss aller Menschen verstanden werden. ${ }^{151}$

Im Kontext der Französischen Revolution bezog sich die geforderte Brüderlichkeit auf die rechtspolitische Nivellierung oder explizite Abschaffung von Klassen- bzw. Standesunterschieden. Konkret beinhaltete die ,Fraternité das bürgerlich-jakobinische Programm des gleichberechtigten (brüderlichen) $\mathrm{Zu}$ sammenwirkens über Stände- und Nationengrenzen hinweg. Sie war somit auf die praktische Realisierung der revolutionären bürgerlichen Ziele der selbstbestimmten Freiheit und sozialrechtlicher Gleichheit - liberté und égalité - ausgerichtet. $^{152}$

Generell lässt sich im Zuge der Französischen Revolution und Aufklärung eine Säkularisierung und Entinstitutionalisierung des Geschwister-, konkret des Bruderbegriffs feststellen. Mit „der aufgeklärt freisinnigen Abwertung von Insti-

147 „Brüder - überm Sternenzelt muß ein lieber Vater wohnen.“ (in beiden Fassungen). Zit. nach: Schillers Werke. Nationalausgabe. Zweiter Band, Teil I. Hrsg. v. Julius Petersen u. Friedrich Beißner. Weimar 1983, S. 169, S. 185.

148 Vgl. Dilcher: An den Ursprüngen, S. 38.

149 „Freude, schöner Götterfunken, / Tochter aus Elisium, / Wir betreten feuertrunken / Himmlische, dein Heiligtum. / Deine Zauber binden wieder, / Was die Mode streng getheilt, / Alle Menschen werden Brüder, / Wo dein sanfter Flügel weilt.“ (1803). Zit. nach: Schillers Werke: Petersen; Beißner, S. 185.

150 „Wem der große Wurf gelungen, / Eines Freundes Freund zu seyn, / Wer ein holdes Weib errungen, / Mische seinen Jubel ein! / Ja - wer auch nur Eine Seele SEIN nennt auf dem Erdenrund! / Und wer's nie gekonnt, der stehle / Weinend sich aus diesem Bund! / Was den großen Ring bewohnet / Huldige der Simpathie!“ (1803). Zit. nach: Schillers Werke, Petersen; Beißner, S. 185.

151 Der mit dem Freimaurer und Herausgeber seiner Werkausgabe, Christian Gottfried Körner, befreundete Friedrich Schiller verfasste diese Ode ursprünglich für die Tafel der Freimaurerloge „Zu den drei Schwertern“ in Dresden. Der Gedanke einer universalmenschlichen Verbindung entsprach dem freimaurerischen Ideal.

152 Vgl. Dilcher: An den Ursprüngen, S. 39; Onnen-Isemann; Rösch: Schwesterherz, S. 20 u. Stupperich: Bruderschaften/Schwesternschaften, S. 204. 
tutionen“ ging auch eine ,institutionelle Lockerung des modernen Bruderdenkens “ ${ }^{\text {153 }}$ einher. Fortan, so Schieder, „,bürgerte sich ein, die gesinnungsmäßige ,Brüderlichkeit' (oder auch ,Bruderliebe') von ,Verbrüderung' als Institution begrifflich und sachlich zu trennen“"154.

\section{Verschwisterung aufgrund homogener sozialer Konstellationen}

Zuvor bezeichneten sich vorwiegend Personen auf gleicher oder ähnlicher gesellschaftlicher Ebene, von gleichem Status oder Beruf im übertragenen Sinn als Geschwister. So belegen schon akkadische, altägyptische, hellenistische sowie biblische Quellen die wechselseitige Anrede der Herrscher als Brüder. ${ }^{155}$ Auch im griechischen oder lateinischen Abendland galt die Bezeichnung ,Bruder" als hierarchisch streng genormter höfischer Würdetitel, dem der Gedanke der ,Brüderlichkeit" bzw. der brüderlichen Verbundenheit der Monarchen zugrunde lag. ${ }^{156}$

Auch die Übertragung geschwisterlicher Termini auf Amts- oder Berufskolleg_innen ist früh belegt: Bereits in der Hebräischen Bibel werden Priester bzw. Leviten oder Personen weiterer übereinstimmender Berufsgruppen Brüder genannt. ${ }^{157}$

Ferner wurden insbesondere innerhalb beruflicher Genossenschaften in Südeuropa (collegia) nicht nur geschwisterliche Anredeformen und Titel für unmittelbare Berufskollegen oder Personen des gleichen Berufsstands angewandt, sondern auch die Bezeichnungen der übergeordneten institutionalisierten Organisationsformen der Zusammenschlüsse stammten oft aus dem Bereich der Geschwisterbeziehung. In erster Linie ist hier der Begriff fraternitas ${ }^{158}$ bzw. Bruderschaft zu nennen. Angelehnt an familiale sozial- und rechtsbezogene

153 Ebd.

154 Schieder: Brüderlichkeit, S. 569.

155 Vgl. zu den akkadischen und ägyptischen Texten: Seow: Brother, Brotherhood, S. 545. Exemplarisch für die Bibel: 1 Kön 20,32.

156 Vgl. Schelkle: Bruder, Sp. 640 bzw. ders.: Brüderlichkeit der Fürsten, in: Reallexikon für Antike und Christentum. Bd. 2. Stuttgart 1954, Sp. 641-646.

157 Vgl. zu den Priestern (Kohanim: Lev 21,10; 2 Kön 23,9; Neh 3,1, konkret zu den Leviten: Num 16,10 oder zwischen Kohanim und Leviten: Num 18,6; 2 Chron 29,34). Vgl. Seow: Brother, Brotherhood, Sp. 545.

158 Diese Begriffsverwendung belegen unter anderem römische Inschriften, welche Berufsgenossenschaften erwähnen, die sich durch fraternitas verbunden fühlen. Vgl. Schieder: Brüderlichkeit, S. 553; vgl. auch Krause: Antike Collegia, S. 195. 
Strukturen organisiert, stand bei diesen vor allem die solidarische, gemeinsame Haftung, die gegenseitige Unterstützung und Fürsorge im Vordergrund. ${ }^{159}$

Max Weber führt konkret die Konzeption und Ausgestaltung der Handelsgesellschaft auf die langobardisch-germanische Rechtstradition der erbenden Söhne zurück. Jener zufolge sei das ungeteilte Vermögen des verstorbenen Vaters ebenso wie seine Haftungsverpflichtungen im Gegensatz zur römischen Praxis gemeinschaftlich auf die Söhne als brüderliche Solidargemeinschaft übergegangen. ${ }^{160}$ Ähnlich hätten auch die Handelsgesellschaften in erster Linie das „unmittelbare wirtschaftliche Ziel“ gehabt, „Kapital und Handelstätigkeit zur Kooperation zusammenzuführen“"161 und somit letztlich die Unabhängigkeit, Emanzipation bzw. Ablösung von verwandtschaftlichen oder familialen Bindungen bewirkt. ${ }^{162}$

(Städtische) Gilden und Zünfte bildeten im Mittelalter, der Blütezeit institutioneller Bruderschaften, darüber hinaus wirtschafts- und berufsbezogene Zusammenschlüsse, die unter anderem als fraternitas, confraternitas oder confratria bezeichnet wurden. ${ }^{163}$ Ebenfalls an brüderlichen Rechtsprinzipien orientiert, bestand die Funktion der Gilden und Zünfte zusammenfassend darin, außerhalb der Familie im gemeinsamen Berufsstand „Schutz nach außen und Hilfe nach innen zu gewähren“. ${ }^{164}$ Für die Zünfte konkretisiert Monika EscherApsner diese Hilfestellung als „Regelungen und Maßnahmen zur gegenseitigen Absicherung von Unterstützung und Pflegeleistungen“ bis hin zur „Teilnahme

159 Gerhard Krause expliziert hinsichtlich der Funktion und Organisation dieser Genossenschaften: „Bei wirtschaftlich Schwachen (collegia tenuiorum) handelte es sich vor allem um Beerdigungskasten. [...]. Sie dienten sozialen und wirtschaftlichen, teils auch geselligen Aufgaben (Plinius, Ep. 10, 93ff). [...] Arme versammelten sich zum collegium in einer Taverne, Reiche oft in eigenen Häusern (scholae) mit Versammlungs-, Speise- und Kultraum mit Altar. Die Mitglieder [...] nannten sich Brüder und Schwestern.“ Krause: Antike Collegia, S. 195.

160 Vgl. Dilcher: An den Ursprüngen, S. 40f.

161 Ebd., S. 53.

162 Vgl. ebd., S. 42.

163 Vgl. ebd., S. 43. Dilcher betont allerdings ebenfalls, dass der Terminus Bruderschaft (fraternitas) lediglich „,bei Verbänden mit religiöser Zweckrichtung“ die hauptsächliche Bezeichnungsweise gewesen sei, während er sonst zumeist nur ein Synonym für weitere Benennungen darstellte, wie „Gilde und Zunft, Kommune, auch collegium, societas, universitas [im Original collegium, societas und universitas: kursiv]“. Ebd., S. 53.

164 Dilcher verweist in Hinblick auf die Unterstützungsmaßnahmen in den Gilden auf die „,kollektive Unterstützung bei der Austragung von sozialen Konflikten“ im Rahmen gewaltsamer Fehden oder vor Gericht sowie auf die „Hilfe bei Bedürfnis und Not“. Ebd., S. 44 . 
an Begräbnissen verstorbener Mitglieder“, ${ }^{165}$ Unterstützung beim Totengedächtnis, in Form von moralischer Integrität und religiöser sowie gemeinschaftsbildender Zusammenkünfte und Rituale. ${ }^{166}$

Gilden und Zünfte stellten somit nach paritätischen Prinzipien organisierte rechtliche Institutionen dar. Sie setzten sich aus einer sozial weitgehend homogenen Mitgliedschaft zusammen, deren Interaktion den Normen eines Verhältnisses unter Geschwistern zugrunde lag. ${ }^{167}$ Gerhard Dilcher sieht in diesen Zusammenschlüssen explizit ,zwei verschiedene Formen des bruderschaftlichen Prinzips" enthalten bzw. realisiert:

[...] das Prinzip der im Friedensgedanken und in Gleichheit charismatisch geeinten christlichen Gemeinschaft von Menschen unterschiedlicher Herkunft und das Prinzip eines sozial homogenen, rechtlich institutionalisierten bruderschaftlichen Verbandes. ${ }^{168}$

Zusammengehörigkeit, Freundschaft und Frieden wurden innerhalb der Verbände schließlich durch regelmäßige gemeinsame Feste, Mahle, gemeinschaftliches Geld für gemeinsame Zwecke und in Gedenkveranstaltungen für verstorbene Mitglieder rituell gefestigt. ${ }^{169}$

\section{Geschwisterschaft innerhalb religiöser und kultischer Gemeinschaften}

Gemeinschaftstiftende, -konsolidierende, aber auch abgrenzende Momente lassen sich zudem hinsichtlich spiritueller, kultischer sowie religiöser Gruppen feststellen. Bereits in altorientalischen Religionsgemeinschaften (vor allem unter Anhängern syrischer Baalskulte), innerhalb Mysterienkulten in römischer Zeit (z.B. im Mithraskult) sowie in gnostischen Sekten war der Bruder- oder Geschwisterbegriff für die Religions- bzw. Kultmitglieder verbreitet. Konstituiert wurde die religiös-kultische Geschwisterschaft zumeist durch Initiationsriten und Einweihungszeremonien, mittels derer die neuen Mitglieder bzw. Mysten in

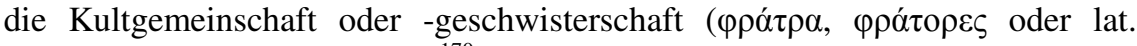
fratres) aufgenommen wurden. ${ }^{170}$

Angelehnt an den Sprachgebrauch der Hebräischen Bibel werden auch die Anhänger Jesu, Mitchristen und Glaubensgenossen (sowie Juden) innerhalb des Neuen Testaments im übertragenen Sinn als Brüder oder Schwestern bezeich-

165 Escher-Apsner: Mittelalterliche Bruderschaften, S. 15.

166 Vgl. ebd., S. 16.

167 Vgl. Dilcher: An den Ursprüngen, S. 45.

168 Ebd., S. 50.

169 Vgl. ebd., S. 54.

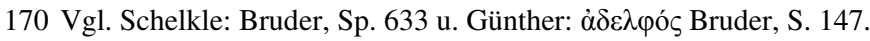

Ulrike Schneider, Helga Völkening and Daniel Vorpahl - 978-3-653-98812-3 
net. ${ }^{171}$ Die Kirchenväter Justin und Tertullian knüpfen schließlich die Zugehörigkeit zur Geschwistergemeinschaft an die Taufe. ${ }^{172}$ So konstatiert Tertullian, nur bzw. „erst der Getaufte ist vollbürtiges Mitglied der christl. Familie. “173 Mit dem Glauben an Gott bzw. durch die Nachfolge Jesu, konstituiert in der Taufe, werden demnach neue, verbindliche, geschwisterliche“ Bande geknüpft.

Die durch Neugeburt erlangte Geschwisterschaft zieht jedoch nicht nur Konsequenzen im rechtlichen, gesellschaftlichen und ethischen Bereich nach sich, indem beispielsweise Unterschiede hinsichtlich der sozialen, genealogischen, ethnischen und kulturgeschichtlichen Herkunftsverhältnisse irrelevant bzw. aufgehoben werden (Gal 3,28). Für den Einzelnen ergeben sich des Weiteren ethisch-moralische Verpflichtungen, die im urchristlichen Postulat und Ideal der geschwisterlichen Liebe ( $\varphi \imath \lambda \alpha \delta \varepsilon \lambda \varphi$ ía [Philadelphia], „Bruderliebe") zusammengefasst sind. Im Sinne der Eintracht, der gegenseitigen Verbundenheit, Achtung, Zuneigung, Fürsorge, der tätigen Hilfe, Barmherzigkeit und Demut unter den Glaubensgenossen verstanden (vgl. z.B. Röm 12,9-21; 1 Petr 3,8), findet sie schließlich in der Anrede Brüder und Schwestern (in Christus) ihren direkten Ausdruck (u.a. Röm 12,1.19). Darüber hinaus wird aber ebenfalls der bedürftige Mitmensch bzw. der Nächste, in Anlehnung an die Anordnungen hinsichtlich der geforderten Solidarität und Fürsorge bezüglich der mittellosen Religionsund Volksgenossen und Mitbewohner des Landes im Buch Deuteronomium (Dtn 15,1-12), als (geringster) „Bruder“ bezeichnet (vgl. Mt 25,31-40).

Eine Anrede der Glaubensgenossen als Brüder bzw. Glaubensschwestern ist zugleich unter Muslimen verbreitet. ${ }^{174}$ Sie wird unter Berufung auf die Abschiedspredigt Mohammeds in Mekka (632) religionsethisch fundiert und auch

$171 \mathrm{Vgl}$. Soden, $\alpha \delta \varepsilon \lambda \varphi o ́ \varsigma$, S. 145. Während $\alpha \delta \varepsilon \lambda \varphi o ́ \varsigma$, Bruder, laut Jörg Frey insgesamt an 343 Stellen im Neuen Testament im biologischen oder metaphorischen Sinne vertreten ist, findet sich das weibliche Pendant lediglich an 26 Stellen. Der männliche Plural bezieht allerdings - vor allem in übertragener Verwendung - auch Schwestern mit ein. Vgl. Frey: Brother, Brotherhood, Sp. 550f. Vgl. hierzu den Artikel von Rainer Kessler „Kinder Israel und Gottes Kinder - Geschwisterlichkeit in der Hebräischen Bibel und im Neune Testament“ sowie den Artikel von Ulrich Engel „,Unsere Demokratie soll Ausdruck unserer Brüderlichkeit sein " - Eine theologische Rekonstruktion von Geschwisterlichkeitskonzeptionen in katholischen Ordensgemeinschaften am Beispiel des Ordo Praedicatorum" in diesem Band.

172 Vgl. Stupperich, Bruderschaften/Schwesternschaften, S. 196.

173 Schelkle: Bruder, Sp. 639.

174 So ist auch im Koran (Sure 49, V. 10) formuliert: „Die Gläubigen sind Brüder; so stiftet Frieden unter euern Brüdern und fürchtet Allah; vielleicht findet ihr Barmherzigkeit.“ Zit. nach: Der Koran. Aus dem Arabischen übersetzt von Max Henning. Einleitung und Anmerkungen von Annemarie Schimmel. Stuttgart 2010, S. 498. 
hier werden entsprechende Konsequenzen für die Praxis des mitmenschlichen Umgangs abgeleitet:

$\mathrm{O}$ ihr Menschen, höret, was ich sage, und begreift es: ihr solltet wissen, daß der Muslim dem anderen Muslim ein Bruder ist und daß alle Muslime untereinander Brüder sind. Keiner ist berechtigt, etwas von seinem Bruder wegzunehmen, es sei denn, dass er dies völlig freiwillig gegeben hat. Unterdrückt euch nicht gegenseitig! $!^{175}$

Im Christentum beziehen sich geschwisterliche Bezeichnungen bis in das 3. Jahrhundert vorwiegend auf die Gesamtheit der (getauften) Christen. ${ }^{176} \mathrm{Ab}$ dem 4. Jahrhundert scheint sodann eine begriffliche Differenzierung oder Aufspaltung stattgefunden zu haben, indem die Bezeichnung ,Bruder' nun vermehrt zur gegenseitigen Anrede seitens der Bischöfe und Priester auf gleicher hierarchischer Ebene angewendet worden ist. Während jene von den anderen Gläubigen als ,Vater' tituliert wurden, beschränkte sich der Brudertitel offensichtlich auf den (gleichrangigen) geistlichen Amtsgenossen. ${ }^{177}$ Eine weitere Differenzierung bzw. Aufgliederung des Begriffs war mit der Anwendung desselben auf Personengruppen mit weiteren besonderen Diensten innerhalb der Gemeinde ${ }^{178}$ und als Fremd- sowie Selbstbezeichnung der Angehörigen der sich allmählich bildenden monastischen Gemeinschaften verbunden. ${ }^{179}$

\section{Geschwister qua gemeinsamer (geistlicher) Lebensführung}

Mit der Entstehung monastischer Gemeinschaften als Intensivform eines christlichen Lebens mit und in der Nachfolge Christi avancierten die zuvor auf Christen oder Menschen allgemein bezogenen Begriffe ,Bruder' und ,Schwester'zu formellen Titeln, Termini technici und Anredeformen für diejenigen Personen, die sich zwecks eines Gott geweihten, spirituellen Lebens klösterlichen Institutionen anschlossen. ${ }^{180}$ Jene wurden nicht nur als Brüder und Schwestern

175 Zit. nach: Rassoul, Muhammad Ahmad: Die Brüderlichkeit im Islam. Köln 1983, S. 66.

176 Vgl. Schelkle: Bruder, Sp. 639.

177 Vgl. Atwood: Brother, Brotherhood, Sp. 639.

178 Vgl. Stupperich: Bruderschaften/Schwesternschaften, S. 196.

179 Vgl. Atwood: Brother, Brotherhood, Sp. 558 u. Schelkle: Bruder, Sp. 639f.

180 Vgl. Atwood: Brother, Brotherhood, Sp. 558 u. Bodarwé: Befreundete Schwestern, S. 382. „Ordensfrauen sprachen sich untereinander als Schwestern oder lateinisch mit soror oder consoror (Mitschwester) an. Weibliche Angehörige geistlicher Orden wurden Kloster-, Konvents-, Ordens-, Chor-, Profess-, Laien-, Nonnen und Mitschwestern genannt. Der mittelalterliche Ausdruck Schwesternschaft stand für die Gesamtheit dieser Schwestern, der weiblichen Personen, der Nonnen eines Klosters.“ Knackmuß, Susanne: Leibhaftige Klosterschwestern. Schwesternbeziehungen von Nonnen um 1500, in: OnnenIsemann, Corinna; Rösch, Gertrud Maria (Hrsg.): Schwestern. Zur Dynamik einer le- 
bzw. Bruder- sowie Schwesternschaften bezeichnet, das gemeinschaftliche Zusammenleben der jeweiligen Mönche oder Nonnen sollte auch nach geschwisterlichem Vorbild, Ideal und Lebensmodell gestaltet sein (z.B. geschwisterliche Liebe, gemeinsamer Besitz, Fürsorge, Asexualität). ${ }^{181}$ Als prägend erwiesen sich dabei insbesondere die Ordensregeln des Basilius, ${ }^{182}$ in denen das monastische Leben bereits insgesamt als brüderliches Leben definiert wurde, der Orden explizit ,Brüderschaft' genannt und die Mönche zudem als Brüder bezeichnet wurden. ${ }^{183}$ Benedikt von Nursia rezipierte diese 540 für seine Ordensregel, welche sodann als Benediktinische Regel normative Bedeutung für die nachfolgenden Statuten in westlichen Klöstern erlangte. ${ }^{184}$

Auch in der Benediktinischen Regel werden im Rahmen der monastischen Familienmetaphorik die Mönche als Brüder angeredet. ${ }^{185}$ Damit ist allerdings keine vollständige Aufhebung der sozialen Unterschiede bzw. hierarchischer Strukturen verbunden. Vielmehr erweist sich die Klostergemeinschaft in Form einer Rangordnung organisiert, die sich laut Ordensregel aus der Länge des Zeitraums der Zugehörigkeit, der persönlichen Verdienste oder des Ermessens- und Verfügungsrahmens des Abtes bzw. der Äbtissin ergibt und von allen Mönchen oder Schwestern akzeptiert werden muss. ${ }^{186}$ Zudem wird ein geschwisterlicher Umgang unter den Mönchen in ,brüderlicher Liebe“ gefordert, welche ,sie einander in reiner Gesinnung erweisen“187 sollen.

benslangen Beziehung. Frankfurt/Main, New York 2005, S. 131-152, hier S. 131. [Hervorhebungen im Original].

181 Diese doppelte Bezugnahme akzentuiert auch Ulrich Engel in seinem Artikel „,Unsere Demokratie soll Ausdruck unserer Brüderlichkeit sein ‘ - Eine theologische Rekonstruktion von Geschwisterlichkeitskonzeptionen in katholischen Ordensgemeinschaften am Beispiel des Ordo Praedicatorum“ in diesem Band.

182 Sie wurden 358 bis 359 als Entwurf verfasst und nach seiner Bischofsernennung veröffentlicht (nach 370). Vgl. Die großen Ordensregeln. Hrsg. v. Hans-Urs von Balthasar. Einsiedeln u.a. 1948, S. 29-31.

183 Vgl. z.B. den Abschnitt „Vom gemeinsamen Leben“, in: Die großen Ordensregeln, S. $50 \mathrm{ff}$.

184 Vgl. diesbezüglich den Artikel von Ulrich Engel „,Unsere Demokratie soll Ausdruck unserer Brüderlichkeit sein' - Eine theologische Rekonstruktion von Geschwisterlichkeitskonzeptionen in katholischen Ordensgemeinschaften am Beispiel des Ordo Praedicatorum“ in diesem Band.

185 Vgl. Die großen Ordensregeln, S. 137-145 sowie S. 150f.157.

186 Vgl. hierzu das dreiundsechzigste Kapitel: Von der Rangordnung in der Klostergemeinschaft, in: Die großen Ordensregeln, S. $207 \mathrm{f}$.

187 Die großen Ordensregeln, S. 215. Diese wird zuvor wie folgt expliziert: „Sie sollen einander mit Ehrerbietung zuvorkommen. Körperliche oder geistige Gebrechen anderer sollen sie in aller Geduld ertragen; in heiligem Wettstreit sollen sie einander gehorchen. 
Insbesondere ab dem 12. Jahrhundert orientierten sich schließlich viele der neu entstandenen, spirituellen und monastischen Reformbewegungen konkret an dem benediktinischen Brüderlichkeitsprinzip, das in seinem wahren Kern revitalisiert und realisiert werden sollte. ${ }^{188}$ Die Ordensregel der Klarissen, welche ihrer Ordensgründerin, Klara von Assisi, zufolge als sorores pauperum (,arme Schwestern") bezeichnet werden sollten, forderte schließlich sogar auf ordensrechtlicher Ebene die Schwesterlichkeit ein, indem von den Ordensfrauen verlangt wurde, sich wie Schwestern zu fühlen. ${ }^{189}$ Die Verantwortung und Verbundenheit gegenüber allen Mitschwestern des Konvents sollte sogar über derjenigen stehen, die hinsichtlich der tatsächlichen biologischen Verwandten vorausgesetzt wurde, denn die Kommunität bildete ,quasi eine neue Kernfamilie, die die im Kloster zusammengekommenen Frauen besonders eng miteinander verband.“" 190

\section{Verschwisterung als Ausdruck friedlichen Einvernehmens}

Bereits verbündete antike Herrscher redeten sich als Brüder an. ${ }^{191}$ Einer Verbrüderung im übertragenen Sinne entsprach auch die Heilige Allianz der Monarchen Russlands, Österreichs und Preußens, welche 1815 nach der Niederlage Napoleons in Abwehr der Freiheits-, Egalitäts- und Brüderlichkeitsbestrebungen der Aufklärer gegründet wurde. Die verbündeten christlichen Regenten versicherten sich in diesem Rahmen ihrer gegenseitigen Hilfe und des Schutzes gegen revolutionäre Kräfte. Sie rekurrierten hierbei explizit auf christliche Grundsätze und nahmen auch entsprechende Anleihen an christliche Geschwisterlichkeitsbezüge, -motive und -termini. Brüderlichkeit avancierte nun zu einem antirevolutionären, reaktionären Terminus bzw. Programm. ${ }^{192}$

Keiner strebe nach dem, was er für sich selbst, sondern für den andren von Vorteil hält.“ Ebd.

$188 \mathrm{Zu}$ diesen gehörten beispielsweise die Zisterzienser, aber auch die Beginen und Begharden bzw. Lollarden (als Schwestern und Brüder des freien Geistes) sowie die Franziskaner. Vgl. Atwood: Brother, Brotherhood, Sp. 559.

189 Vgl. Knackmuß: Leibhaftige Klosterschwestern, S. 132. Vgl. auch Onnen-Isemann; Rösch: Schwestern, S. 13.

190 Bodarwé: Befreundete Schwestern, S. 382. Vgl. hierzu auch Signori: Geschwister, S. 17.

191 Vgl. zu den akkadischen und ägyptischen Texten: Seow: Brother, Brotherhood, S. 545.

192 Dies gilt umso mehr, da sich die Brüderlichkeit nach Korrektur des ursprünglichen Vertragsentwurfs seitens des österreichischen Kanzlers Klemens Wenzel Fürst von Metternich nur noch auf die jeweiligen Monarchen der Länder bezog Vgl. Schieder: Brüderlichkeit, S. 571. 
Demgegenüber beinhaltet die sogenannte Blutsgeschwister- bzw. Blutsbruderschaft ${ }^{193}$ ursprünglich einen archaischen, rituell-symbolischen Akt. Auf (magische) Rituale zurückgehend, wonach symbolisch oder real das Blut zweier Clans bzw. exemplarischer Kontrahenten vermischt und symbolisch oder tatsächlich durch „,wechselseitiges Trinken vom Blut des anderen oder gemeinsames Eintauchen der Hand in Tierblut ${ }^{\star 194}$ ausgetauscht und mit einem gegenseitigen Treuegelöbnis verbunden worden ist, steht es für einen Friedensschluss bzw. eine Befriedungsmaßnahme sowie für eine anhaltend enge Verbindung. ${ }^{195}$ Das Austauschen des Bluts soll dabei sicherlich die nachträglich vollzogene, nicht aufhebbare „Blutsverwandtschaft“ symbolisieren sowie Frieden initiieren. Später entwickelte sich hieraus eine metaphorische bzw. pathetische Bezeichnung für eine ausnehmend intensive, bleibend verbindlich angelegte Wahlgeschwisterschaft. ${ }^{196}$

\section{Geschwister qua Gesinnung}

Auch wenn Schillers Ode An die Freude sowie weitere, im freimaurerischen Umfeld entstandene Werke das Ideal einer universalen Verbrüderung postulieren und folglich alle Menschen als Geschwister angesehen werden, ${ }^{197}$ lässt sich unter den Freimaurern noch eine interne Verwendung des Geschwisterbegriffs feststellen, die sich lediglich auf die Mitglieder (und deren Familien) ${ }^{198}$ der ei-

193 Ein weiblicher Pendantbegriff ist nicht übergreifend gebräuchlich.

194 Brockhaus. Enzyklopädie. Bd. 4, Stichwort: Bruder; vgl. auch den Artikel zum Stichwort Blutsbrüderschaft.

195 Vgl. Fishel, Schwestern, S. 281 u. Sitzler: Geschwister, S. 207.

196 Als eine „,enge freundschaftl. Verbindung zweier nicht miteinander verwandter Männer in Form eines ,Bundes' mit den Rechten und Pflichten von leibl. Brüdern“, wird die Blutsbrüderschaft entsprechend im Brockhaus. Enzyklopädie (Bd. 4, Stichwort: Blutsbrüderschaft) definiert. Vgl. hierzu auch Sitzler: Geschwister, S. 207.

197 Entsprechend heißt es in einer freimaurerischen Informationsschrift: „Wer aber seines eigenen Ursprungs aus Gott gewiß ist, dem ist die ganze Welt göttlichen Ursprungs, und er sieht in jedem Menschen seinen Bruder, der mit ihm innerlich wesenseins und nur in der Erscheinung von ihm getrennt ist." Was sind die Freimaurer und was wollen sie? Ein Wort zur Wehr und Lehr über Ursprung, Wesen, Bedeutung und Ziele der Freimaurerei. Von einem Br. Freimaurer. Lissa i. P. 1906, S. 63f.

198 In ihrer traditionellen Form bleibt die Zugehörigkeit zu den Freimaurern Männern vorbehalten. Erst ab 1945 entstanden vermehrt Logen für Frauen. Vgl. Sitzler: Geschwister, S. 342. Familienangehörige (v.a. Ehefrauen) der Freimaurer werden zwar in Statuten und Liedern gelegentlich als Schwestern bezeichnet, gelten aber nicht als vollständig eingeweihte, reguläre Mitglieder und werden allenfalls einer Schwesternloge zugeordnet. Vgl. Gesetz=buch der gerechten und vollkommenen St. Johannes=Loge Friedrich August zu den drei Zirkeln im Orient Zittau. Reichenau 1921, § 91, S. 24. 
genen Loge oder mit dieser verbundenen Logen bezieht. ${ }^{199}$ Es handelt sich somit um eine exklusive Verbrüderung einer besonderen Gemeinschaft innerhalb der übergreifenden gesamtmenschlichen Geschwisterschaft, welche in der gemeinsamen Gesinnung und somit in einem Gefühl der tieferen Verbundenheit und jeweiligen Vervollkommnung gründet. So stellt die streng genormte und geheime Mitgliedschaft zu einer Loge die notwendige Vorbedingung dar, innerhalb dieser Gesellschaft als Bruder im engeren Sinne angeredet und behandelt zu werden. Laut dem Handbuch für die Brüder der Großen Landes-Loge der Freimauer von Deutschland soll die maurische „Verbrüderung [...] ,zur Ehre Gottes, zur eigenen Veredlung und zur Veredlung der Brüder, zur Förderung der allgemeinen Liebe und Erhöhung der Würde und des Wohles der Menschheit““200 dienen. Sie ist somit zunächst auf die Logenbrüder als einsichtige Vordenker unter den Menschen ${ }^{201}$ und erst mittel- bzw. langfristig auf die gesamte Menschheit ausgerichtet. ${ }^{202}$ Hinsichtlich des Verhältnisses und des gegenseitigen Umgangs wird in Paragraph 18 eine Egalisierung postuliert: ,[...] alle Unterschiede des Standes, Ranges und Besitzes [fallen demnach] weg ${ }^{\star 203}$. Konkret enthält das Handbuch darüber hinaus die Forderung, die grundsätzlichen Pflichten, welche „der Freimaurer allen Menschen gegenüber hat“, auf seine maurischen Mitbrüder in erhöhtem Maße anzuwenden. ${ }^{204}$ Entsprechend eindringlich ermahnen die maurischen Lieder zur Bruderliebe. ${ }^{205}$ Im Freimaurerlied $Z u$ Eh-

199 So z.B. im Handbuch für die Brüder der Großen Landes-Loge der Freimaurer von Deutschland. Eine Übersicht ihrer Einrichtungen. Berlin 1898.

200 Handbuch für die Brüder, S. 1.

201 „Daher sucht die Freimaurerei ,die Einsichtsvollen aller Bestandteile der menschlichen Gesellschaft zu einer Gemeinschaft zu vereinigen, innerhalb welcher sie sich als Glieder einer Familie betrachten lernen, und in welcher sie, ohne einander in der freien Ausübung ihrer persönlichen Anschauungen in sozialen, politischen und religiösen Fragen zu beschränken, sich dazu verpflichten, vor allem das Sittengesetz zur Grundlage gegenseitiger Achtung zu machen und so von kleinen Kreisen aus eine Versöhnung der Gegensätze anzubahnen $[\ldots]^{\prime}$." Was sind die Freimaurer, S. 60.

202 Vgl. Stammler: Politische Schlagworte, S. 98.

203 Handbuch für die Brüder, S. 7. Organisatorisch-strukturell werden die einzelnen Logenmitglieder jedoch hinsichtlich des Grades der Einweihung und ihrer Befugnisse unterschieden. Vgl. ebd., S. 745-748.

204 Vgl. das Handbuch für die Brüder, S. 7.

205 So heißt es entsprechend einer Eröffnung-Hymne zum hundertjährigen Stiftungsfest:

„Wenn Gottesfurcht im Herzen thront / Und Bruderliebe in uns wohnt,

Wird unser Werk auch nie vergehn, - / Und felsenfest der Tempel stehn. [...]

Ist uns're Bruderliebe echt / Und unser Wandel winkelrecht,

Dann wird auch Segen und Gedeih'n / Der Loge bleibend Erbtheil sein." Schweitzer, Ludwig: Gesänge und Sprüche für Brüder Freimaurer. Leipzig 1877, S. 11. 
ren der besuchenden Brüder wird diese Harmonie und einende Liebe zudem mit der Nivellierung bzw. Aufhebung sozialer Rangunterschiede unter den Mitgliedern verbunden und die verbindende Mentalität betont:

Wie ist es im Kreise der Brüder so schön!

Weil hier keine Kasten und Kästchen bestehn;

Uns trennet nicht Meinung, nicht Rang und nicht Stand,

Wir sind uns ja innig als Brüder verwandt;

Uns einet der Liebe verklärender Schein;

Drum ist es so herrlich ein Bruder zu sein. ${ }^{206}$

Geschwisterschaft bzw. Geschwisterlichkeit wird somit in freimaurerischen Logen wie auch in anderen kollektiven Zusammenschlüssen oder Zuordnungen, die sich aufgrund gemeinsamer Anschauungen, Interessen und Werte verbunden fühlen, ${ }^{207}$ als Gesinnungsgemeinschaft verstanden, wodurch letztlich auch eine gewisse Abgrenzung von ,Andersdenkenden“ impliziert, in Kauf genommen oder beabsichtigt wird. ${ }^{208}$

\section{Verschwisterung aufgrund emotionaler Verbundenheit und Nähe}

Freundschaft und Verwandtschaft werden nicht selten als konträre Momente gegenübergestellt. Während Freundschaft gemeinhin als intensive Verbindung definiert wird, die optional, hinsichtlich Person, Art sowie Zeitraum frei wählbar (und entsprechend wieder aufhebbar) ist, stellt sich die Geschwisterbeziehung als nicht selten lebenslange, herkunftsbedingte, ambivalente Vorfindlichkeit des Menschen dar. Dennoch wurden und werden aber immer wieder beide Beziehungsformen gedanklich und begrifflich zusammengeführt, um eine besonders intensive und harmonische emotionale Beziehung bzw. Verbundenheit auszu-

206 Schweitzer: Gesänge und Sprüche, S. 81.

207 Ähnlich erklärt sich auch die Anwendung der Zwillingsmotivik auf Sokrates und Mendelssohn. Vgl. den Artikel von Uta Lohmann „Sokrates und Mendelssohn - Zur Bedeutung der Zwillings-Metapher im Bildungskonzept von David Friedländer und Jeremias Heinemann" in diesem Band.

208 Dies gilt zudem in besonderem Maße für die gegenwärtige Hip-Hop-Kultur, in der in besonders signifikanter Weise auf geschwisterliche Termini und Bezüge rekurriert wird. So ergeben beispielsweise Internetanfragen anhand der Stichwörter ,Bruder' und ,HipHop“ ca. 490.000; , bruda“ und ,Hip-Hop“ ca. 488.000 und die interne Abkürzung für ,brother', ,bro“ und ,Hip-Hop“ 19.200.000 Ergebnisse (letzter Zugriff: 24.03.2015). Die zwecks exklusiver Zuordnung zu einer Gemeinschaft mit gemeinsamen Anschauungen und Lebensweisen verwendeten, übertragenen geschwisterlichen Begriffe und Motive finden sich exemplarisch im Liedtext „Wie ein Bruder“ (2013) von Kayef \& Liont angewendet: „Du denkst das Gleiche wie ich, hast den gleichen Instinkt, gleiche Sprache, gleiche Art, nur nicht das gleiche Gesicht. Wahre Liebe gibt es nur unter Brüdern [...]“. 
drücken. Bereits in der Hebräischen Bibel werden die Bezeichnungen ,Freund“ und ,Bruder' an einigen Stellen (fast) synonym verwendet (Ps 35,14; 122,8) bzw. kombiniert. ${ }^{209}$

In der römischen Antike ähnelt der Bedeutungsrahmen der Freundschaft, amicitia, sogar in weitem Umfang dem der geistigen oder symbolischen Verwandtschaft. ${ }^{210}$ Für das Mittelalter konstatiert Katrinette Bodarwé dann eine „Ausdifferenzierung“ des Freundschaftskonzepts ,,in eine persönliche, eine politische und [als Novum] eine geistliche Dimension“211. Auch hier komme der Freundschaft Bodarwé zufolge eine ähnlich relevante Funktion zu wie leiblichen sowie geistig oder symbolisch konstruierten Verwandtschaftsbeziehungen: „Gewährung von Hilfe und Unterstützung in allen Lebenslagen und mit allen Kräften“212. Demzufolge könne die Freundschaft mit den Worten Gerd Althoffs zu „,den ,gemachten“ oder , künstlichen“ Verwandtschaften “ ${ }^{\text {‘213 }}$ gezählt werden. ${ }^{214}$

Ähnlich betont Sjaak van der Geest die inhärente Diskrepanz sowie Gemeinsamkeiten zwischen Geschwisterschaft und Freundschaft mit Blick auf die moderne Begriffsverwendung: „They are in one respect each other's antipode, but they also share common sentiments of belonging and affection. ${ }^{6215}$ Auf dieser Basis wurden und werden die Bezeichnungen ,Bruder " und ,Schwester" in vielen Kulturen zur Akzentuierung besonders enger emotionaler Beziehungen sowie für Gefühle tiefer Solidarität, der Ähnlichkeit oder Gleichheit, auch außerhalb der biologisch konstituierten Verwandtschaft, verwendet. ${ }^{216}$ Hieraus ergibt sich allerdings ein Paradoxon:

„[...] Created sibling relationships are not only as good as natural ones, they are potentially better. They are an improvement on nature in the sense that they allow for the purest expression of 'brotherly love' [...]" (Marshall 1977: 649). The paradox is that people choose kinship terms to express love and affection, apparently assuming that the truest love is found in kinship, such as between siblings. But, at the same

209 Letzteres bezieht sich vor allem auf die in der Bibel als besonders nahe Freundschaft geschilderte Beziehung zwischen David und Jonathan. Dessen Liebe sei David - dem Klagelied nach dem Tod Jonathans zufolge - lieber gewesen als die Liebe der Frauen. Gleichzeitig wird jener von ihm als ,mein Bruder Jonathan“ bezeichnet (2 Sam 1,26).

210 Vgl. Der Kleine Pauly. Bd. 1, Stichwort: Amicitia, Sp. 299f.

211 Bodarwé: Befreundete Schwestern, S. 379.

212 Ebd.

213 Ebd.

214 Vgl. in diesem Kontext auch den Artikel von Dagmar Bruss „Geschwister, Geschwisterlichkeit und Serien bei Robert Walser“ im vorliegenden Band.

215 Geest, Sjaak van der: Kinship as Friendship. Brothers and Sisters in Kwahu, Ghana, in: Alber, Erdmute u.a. (Hrsg.): The Anthropology of Sibling Relations. Shared Parentage, Experience, and Exchange. New York 2013, S. 51-70, hier S. 51.

216 Vgl. hierzu Geest: Kinship as Friendship, S. 52 u. Thelen u.a.: The Anthropology, S. 4. 
time, they recognize that a voluntarily chosen relationship is more precious and carries deeper emotional satisfaction than one that has been thrown on them. ${ }^{217}$

Insbesondere die Repräsentanten des 18. Jahrhunderts entwickelten - auch oder vor allem unter freimaurerischem Einfluss bzw. im Kontext aufklärerischer Ideale - einen Freundschaftskult, in dem „das Ideal ,echter“, auf Tugend, Verstand und Ebenbürtigkeit gebauter Freundschaft ${ }^{\star 218}$ konstruiert wurde. Das transkulturell verbreitete Konzept der „Wahlverwandtschaft“ (Johann Wolfgang von Goethe) oder der „Seelenverwandtschaft“ (Geschwister im Geiste oder Herzen) entfaltete sich vor allem in der europäischen Klassik und Romantik. ${ }^{219}$ Als bürgerlicher Leitwert diente es in seinem Bedeutungsrahmen bzw. seiner moralischen Essenz insbesondere zur Abgrenzung von rational-berechnenden Zweckbündnissen, welche gemeinhin dem Adel zugeschrieben wurden. ${ }^{20}$

\section{Problematisierung und Kritik}

Die Hauptkritik an der Verwendung übertragener Geschwisterbegrifflichkeiten und -motive bezieht sich letztlich auf ihren inhärenten exklusiven bzw. exkludierenden Charakter. Wie bei tatsächlichen Geschwistern ist dieser - von der universalen Anwendung abgesehen - zumeist auf bestimmte Menschen begrenzt, schließt somit parallel andere aus und grenzt eine spezielle Gruppe von anderen ab.

Aus kommunistisch-sozialistischer Perspektive wurde insbesondere die realpolitische Bezogenheit und Beschränkung des aufklärerischen Programms der fraternité auf den bürgerlichen Stand kritisiert, attackiert und mit der ständeund nationenübergreifenden Ausrichtung des Sozialismus kontrastiert: Erst der Sozialismus werde die Ideale der französischen Revolution für die gesamte Menschheit realisieren bzw. die Nationen fraternisieren. ${ }^{221}$ Vor allem in der An-

217 Geest: Kinship as Friendship, S. 69.

218 Baumgärtel, Bettina: Angelika Kaufmann und der Freundschaftskult der Künstlerinnen. Bildtypologien der Freundschaft um 1800, in: Labouvie, Eva (Hrsg.): Schwestern und Freundinnen. Zur Kulturgeschichte weiblicher Kommunikation. Köln u.a. 2009, S. 221240, hier S. 221.

219 Allerdings war hiermit in der Regel wohl keine ,geschlechtsübergreifende Kategorie der Menschenliebe" verbunden. Vielmehr wurde es wie in Michel de Montaignes Essay „Über die Freundschaft“ aus dem 16. Jahrhundert zumeist ,als Leitwert für den Umgang unter Männern definiert“. Baumgärtel: Angelika Kaufmann, S. 221f.

220 Vgl. Sitzler: Geschwister, S. 133.

221 So konstatiert beispielsweise August Bebel: „Die menschliche Gesellschaft hat in Jahrtausenden alle Entwicklungsphasen durchlaufen, um schließlich dahin zu gelangen, von wo sie ausgegangen ist, zum kommunistischen Eigentum und zur vollen Gleichheit und Brüderlichkeit, aber nicht mehr bloß der Gentilgenossen, sondern aller Menschen. Das 
fangszeit übernahmen die Repräsentanten der deutschen Arbeiterbewegung somit noch die Brüderlichkeitstermini und -bezüge der französischen Revolution, indem sie die Arbeiterinnen und Arbeiter beispielsweise zur Verbrüderung resp. Fraternisierung, zum Zusammenschluss und zur gegenseitigen Unterstützung aufriefen. ${ }^{222}$ Allerdings lässt sich bald eine fortschreitende Distanzierung, Ablehnung und Vermeidung des Brüderlichkeitsbegriffs und seiner bürgerlichen Konnotationen in den öffentlichen Verlautbarungen, konkret seitens Friedrich Engels und Karl Marx, feststellen. An seine Stelle trat der weniger bürgerlichchristlich ,vorbelastete“ Terminus ,Solidarität‘. ${ }^{223}$

Fehlende Solidarität auf internationaler Ebene wirft letztlich auch Clara Zetkin der überwiegenden Zahl der „,bürgerlichen Frauenorganisationen aller Länder“ vor. Hätten sich diese doch trotz ,ihrer feierlichen Festgesänge internationaler Schwesterschaft und brennender Friedensliebe“ „im Namen der ,Vaterlandsverteidigung' als fanatische nationalistische, mordspatriotische Durchhalterinnen des mehr als vierjährigen imperialistischen Völkergemetzels، ${ }^{624}$ erwiesen. Zwar gesteht Zetkin einigen bürgerlichen Vorkämpferinnen in Frankreich und Deutschland durchaus zu, im Rahmen ihrer Gleichberechtigungs- bzw. Emanzipationsbestrebungen ${ }^{225}$ auch für die „Verbesserung der Lebensbedingungen der Arbeiterinnen“ eingetreten zu sein. Dies sei aber nicht

ist der große Fortschritt, den sie macht. Was die bürgerliche Gesellschaft vergeblich erstrebte und woran sie scheitert und scheitern muss, die Freiheit, Gleichheit und Brüderlichkeit aller Menschen herzustellen, wird der Sozialismus verwirklichen." Bebel, August: Die Frau und der Sozialismus. Berlin 1990, S. 520, vgl. auch S. 522. [Hervorhebungen im Original kursiv]; siehe zudem Zetkin, Clara: Zur Geschichte der proletarischen Frauenbewegung Deutschlands. Frankfurt/Main 1978, S. 150f.

Für die Literaturhinweise zum sozialistischen Diskurs danke ich Ulrike Schneider.

222 Vgl. z.B. das Grundstatut der Allgemeinen deutschen Arbeiter-Verbrüderung von 1850: „Die Arbeiterverbrüderung hat den Zweck, unter den Arbeitern aller Berufsarten eine starke Vereinigung zu begründen, welche, auf Gegenseitigkeit und Brüderlichkeit gestützt [...] [sein] soll.“ Schieder: Brüderlichkeit, S. 575 [dort kursiv].

223 Vgl. Stupperich: Bruderschaften/Schwesternschaften, S. 204 u. die ersten beiden Kapitel in Danzer, Doris: Zwischen Vertrauen und Verrat. Deutschsprachige kommunistische Intellektuelle und ihre sozialen Beziehungen (1918-1960). Göttingen 2012.

224 Zetkin: Zur Geschichte, S. 151. Zetkin akzentuiert in diesem Zusammenhang generell die gewalttätige, schuldbelastete Vergangenheit als potenzielle Implikation des Brüderlichkeits-Programms. Vgl. ebd. sowie Heinz, Rudolf: „Alle Menschen werden Brüder...“. Mytho-philosophische Anmerkungen zum Geschwisterproblem, in: Sohni, Hans (Hrsg.): Geschwisterlichkeit. Horizontale Beziehungen in Psychotherapie und Gesellschaft. Psychoanalytische Blätter, Bd. 12. Göttingen 1999, S. 55-66, insb. S. 58-60.

225 Die rechtliche Gleichstellung der Frau als Konsequenz der Egalität und Brüderlichkeit aller Menschen postuliert auch August Bebel aus sozialistischer Perspektive. Vgl. hierzu: Bebel: Frau und Sozialismus. 
aus einem ,proletarischen Klassenstandpunkt“ motiviert gewesen, sondern auf der Grundlage bzw. „im Namen einer gefühlsseligen Humanität, die den , armen Schwestern' von oben helfen, sie aber nicht zum selbsthelfenden Kampfe rufen wollte ${ }^{626}$, geschehen. Hier ist somit eine hierarchische, soziale Unterschiede akzeptierende bzw. konsolidierende Konnotation der übertragenen Geschwistermotivik und -termini angesprochen ${ }^{227}$ - ein Charakteristikum, das bereits in christlichen, mittelalterlichen Fürsorgebruderschaften inhärent war und in der Begriffsverwendung des „Großen Bruders“ noch expliziter ausgedrückt ist.

In verstärktem Maße akzentuiert schließlich Hannah Arendt eben jene hierarchische Implikation in ihrer Gegenüberstellung der Bedeutungsinhalte des Brüderlichkeits- und Freundschaftsbegriffs. Ersteren expliziert sie als affektiven Terminus, der sich im Moment des Mitleids und somit in „finsteren Zeiten“ realisiere, da er ein Ungleich- bzw. Ausbeutungsverhältnis, ein Paria-Dasein voraussetze:

Die Brüderlichkeit, welche die Französische Revolution der Freiheit und Gleichheit, die seit eh und je die politische Sphäre des Menschen charakterisierten, hinzufügte, hat ihren natürlichen Ort in der Lebenssphäre der Unterdrückten und Verfolgten, der Ausgebeuteten und Erniedrigten [...]. ${ }^{228}$

Demzufolge stehe „die Menschlichkeit der Brüderlichkeit“ all denen nicht zu, welche ,nicht zu den Erniedrigten und Beleidigten gehören und nur durch das Mitleid an ihr Anteil haben können“222. Dagegen impliziere die freigewählte Freundschaft eine horizontale, ranggleiche Beziehung „ohne falsche Überheblichkeit oder Minderwertigkeitskomplexe auf der anderen Seite“, mit der sich

226 Zetkin: Zur Geschichte, S. 150.

227 Vgl. in diesem Zusammenhang auch die Ausführungen zur Kritik am feministischen Sisterhoodbegriff in dem Artikel von Katharina Gerund „Wie Schwestern? Freundschaft in Ann Brashares' Sisterhood-Reihe“ in diesem Band.

228 Arendt, Hannah: Von der Menschlichkeit in finsteren Zeiten. Rede am 28. September 1959 bei der Entgegennahme des Lessing-Preises der Freien und Hansestadt Hamburg. Hamburg 1999, S. 25.

229 Arendt: Von der Menschlichkeit, S. 28. „Durch das Mitleid versuchte die revolutionär gesinnte Humanität des achtzehnten Jahrhunderts, sich mit dem Unglück und dem Elend zu solidarisieren, gleichsam in die Sphäre zu dringen, in der die Brüderlichkeit beheimatet ist. Dabei stellte sich sehr bald heraus, daß diese Art der Menschlichkeit, wie sie in ihrer reinsten Ausprägung ein Vorrecht der Parias ist, nicht übertragbar ist und von denen, die nicht dazugehören, nicht ohne weiteres, auch nicht durch den Affekt des Mitleids oder selbst des Mitleidens, angeeignet werden kann. Auf das Unheil, das das Mitleid in die modernen Revolutionen getragen hat, weil es versuchte, die Unglücklichen glücklicher zu machen, anstatt für alle Gerechtigkeit zu etablieren, können wir hier nicht eingehen." Ebd., S. 26. 
somit tatsächlich „ein Stück Menschlichkeit in einer unmenschlich gewordenen Welt ${ }^{‘ 230}$ verwirkliche.

Renate Liebold und Birgit M. Hack konstatieren ferner hinsichtlich moderner Frauenbewegungen die Tendenz, sich aus einer unterdrückten Position heraus gegen die erfahrene, geschlechtsbezogene Diskriminierung zu Schwesternbünden zusammenzuschließen und euphorisch die Gemeinsamkeit und Verbundenheit innerhalb dieser zu proklamieren. ${ }^{231}$ Gegenwärtig würden die geschwisterlichen Begrifflichkeiten und Bezüge jedoch postmodern dekonstruiert, indem beispielsweise der ausschließlich positive Bedeutungsrahmen des Begriffs ,Schwesterlichkeit' entmythisiert bzw. in Frage gestellt würde und somit auch Differenzen, Hierarchien, Konkurrenz zwischen Frauen oder in weiblichen Zusammenschlüssen nicht mehr tabuisiert, sondern vermehrt thematisiert würden. ${ }^{232}$

Darüber hinaus schließt der aufklärerische Terminus der Brüderlichkeit zumindest nicht explizit den weiblichen Teil der Menschheit ein. Auf die exkludierende männliche Ausrichtung verweisen jedoch erst gegenwärtige Stimmen in verstärktem Maße. ${ }^{233}$ Bemerkenswert erscheint allerdings dabei, dass sich auch in heutiger Zeit, in der genderbedingte (sprachliche) Diskriminierungen in weitem Maße reflektiert werden, der alternative geschlechtsneutrale Begriff „Geschwisterlichkeit“ oder die weibliche Form ,Schwesterlichkeit' noch nicht umfassend durchgesetzt haben. ${ }^{234}$

\section{Resümee:}

\section{Inklusion und Exklusion, Nivellierung und Differenzierung}

In Korrespondenz zu den vielfältigen Modalitäten und Erscheinungsweisen real erfahrener Geschwisterbeziehungen stellt sich auch die sozio-kulturelle Aufnahme geschwisterlicher Topoi und Begrifflichkeiten ambivalent dar. Dies gilt zunächst für künstlerische und ethische Rezeptionen von Geschwistern und geschwisterlicher Beziehungen, welche einerseits gesellschaftliche Erwartungen

230 Arendt: Von der Menschlichkeit, S. 41.

231 Vgl. Liebold; Hack: Zwischen Verbundenheit, S. 91. Vgl. hierzu auch die Vorstellung der politischen Utopie der Schwesterlichkeit in den modernen Frauenbewegungen in: Rösch: Auf der Suche, S. 171.

232 Vgl. Liebold; Hack: Zwischen Verbundenheit, S. 91f.

233 So z.B. Heinz (Alle Menschen, S. 59f.), der auch einen tatsächliche Ausschlussintention hinsichtlich Frauen erörtert.

234 So führt beispielsweise der Duden die Begriffe „brüderlich“ und „Brüderlichkeit“ an, während die Adjektive ,schwesterlich“ und ,geschwisterlich“ zwar bereits Eingang gefunden haben, nicht aber die jeweils substantivierten Formen „Schwesterlichkeit“ und „Geschwisterlichkeit“. Vgl. Duden. Bd. 1: Rechtschreibung. Mannheim u.a. 2004. 
an ein Harmonieideal innerhalb der Geschwisterbeziehungen spiegeln, andererseits aber auch eine Folie für die Darstellung antagonistischer Stereotypen bieten. Beide bilden somit die Realität tatsächlicher geschwisterlicher Relationen zumeist allenfalls partiell - mit jeweils besonderem Akzent auf die Rivalität oder Nähe unter Geschwistern - ab.

Die übertragene Verwendung geschwisterlicher Termini und Bezüge suggeriert demgegenüber zunächst eine ausschließlich positive Konnotation: Mit Begriffen wie ,geschwisterlich', ,brüderlich“ und ,schwesterlich“ werden gemeinhin Momente der Gleichheit, Zusammengehörigkeit, Solidarität, Unterstützung und Zuneigung verbunden. ${ }^{235}$ Allerdings gelten diese Werte idealiter, in erster Linie oder im ausschließlichen Sinne dem als Mitbruder bzw. Mitschwester definierten Gegenüber. Nach außen wirken dagegen, implizit oder intendiert, Abgrenzungsprozesse gegenüber denjenigen, die dem inneren (geistigen) Geschwisterkreis nicht zugerechnet werden, da sie einer anderen Nation, einem anderen Berufsstand, einer anderen Glaubensrichtung angehören, andere Interessen, eine alternative Gesinnung vertreten oder ein divergentes Leben führen. Die Distanzierungsmechanismen manifestieren sich konkret in der Betonung der Zusammengehörigkeit, der Ritualisierung gemeinschaftsstiftender oder -konsolidierender Praktiken, Regeln und Versicherungen oder Bekenntnissen, in gemeinschaftlicher Arbeit an der Durchsetzung kollektiver Interessen und Ziele. In erster Linie stehen somit die Gemeinsamkeiten, Homogenität und Einheitlichkeit - gegebenenfalls verbunden mit einer Nivellierung individueller Unterschiede - im Vordergrund. Dies gilt im Besonderen, wenn der geistigen Geschwisterschaft ein dynamischer, optionaler Prozess der Verbrüderung bzw. Verschwesterung zugrunde liegt, der eine Darlegung der Zugehörigkeit in Form von Initiation, Bestätigung und Bekräftigung impliziert - mit integrierender Funktion nach innen und abgrenzendem Moment nach außen.

Definiert sich die Gemeinschaft jedoch nicht primär auf der Grundlage gemeinsamer Anliegen, Interessen, Anschauungen und Werte, die Geschwisterlichkeit zum Resultat haben, sondern gilt das Geschwistersein vielmehr als vorgegeben bzw. ist es als statisch gesetztes Moment aufgrund eines gemeinsamen Ursprungs, der gleichen Herkunft beispielsweise von einem Schöpfer oder der Zugehörigkeit zu einem Staat konstituiert, so bedarf es nicht in gleicher Weise der besonderen Betonung gemeinschaftskonsolidierender Momente und außergewöhnlicher Homogenität oder Konformität. Gleichheit wird in diesem $\mathrm{Zu}$ sammenhang in erster Linie auf die gemeinsame Abkunft und somit auf eine

235 Sitzler (Geschwister, S. 86-88) nennt darüber hinaus: „Verlässlichkeit, Reinheit, Integrität und Beständigkeit“" sowie „Altruismus und Friedfertigkeit“, „Rücksicht und Selbstlosigkeit". 
grundsätzlich übereinstimmende, aber nicht frei gewählte Ausgangsposition bezogen, so wie sich auch die tatsächliche Geschwisterkonstellation in der Familie letztlich als fixiert und vorgefunden darstellt. Dies schließt folglich eine innere Differenzierung im Sinne einer heterogenen Entwicklung im Rahmen der Gemeinschaft nicht aus oder gilt sogar als selbstverständlich, ${ }^{236}$ wodurch die genuine geistige wie auch tatsächliche Geschwisterschaft nicht tangiert wird.

Grundsätzlich besteht offensichtlich eine Korrelation zwischen Säkularisierungstendenzen, in deren Folge die Prämisse einer übergeordneten universalen Gottheit bzw. eines höchsten, transzendenten Prinzips ausgeklammert wird, abnehmenden Bedeutungen nationaler Zugehörigkeiten und vermehrter Rückgriffe auf geschwisterliche Termini und Topoi im hier erörterten dynamischen, homogenisierenden Sinne. Die Versicherung und Festigung gemeinsamer Werte, Interessen und Implikationen, wie sie gemeinhin der Geschwisterbeziehung in ihrer Idealform zugeschrieben werden, scheinen letztlich vielleicht besonders geeignet, alternative säkulare und überstaatliche Gemeinschaft zu stiften.

\section{Quellen}

Arendt, Hannah: Von der Menschlichkeit in finsteren Zeiten. Rede am 28. September 1959 bei der Entgegennahme des Lessing-Preises der Freien und Hansestadt Hamburg. Hamburg 1999.

Bebel, August: Die Frau und der Sozialismus. Berlin 1990.

Charlotte Link. Interview mit Deike Diening und Julia Prosinger, in: Der Tagesspiegel. Sonntagsteil: Schwestern. Man sucht sie sich nicht aus - und liebt sie dann doch!? Ein Spezial. Sonntag, 14. September 2014, 22/165, S. 1.

Epiktet - Teles - Musonius. Wege zum Glück. Auf der Grundlage der Übertragung von Wilhelm Capelle neu übersetzt und mit Einführungen und Erläuterungen versehen von Rainer Nickel. Zürich, München 1991.

Gesetz=buch der gerechten und vollkommenen St. Johannes=Loge Friedrich August zu den drei Zirkeln im Orient Zittau. Reichenau 1921.

Die großen Ordensregeln. Hrsg. v. Hans-Urs von Balthasar. Einsiedeln u.a. 1948.

Handbuch für die Brüder der Großen Landes-Loge der Freimaurer von Deutschland. Eine Übersicht ihrer Einrichtungen. 2. Aufl., Berlin 1898.

Hesiods Werke. Übersetzt von Johann Heinrich Voß. Tübingen 1911.

Der Koran. Aus dem Arabischen übersetzt von Max Henning. Einleitung und Anmerkungen von Annemarie Schimmel. Stuttgart 2010.

Platon. Frühdialoge. Eingeleitet von Olof Gigon, übertragen von Rudolf Rufener. Zürich, München 1974.

Platon. Der Staat (Politeia). Übersetzt u. hrsg. von Karl Vretska. Stuttgart 2012.

236 Dies gilt ebenso für die Schwesterngesellschaft in der Wirtschaft wie für den von Platon entworfenen idealen Staat. 
Plutarch's Werke. Ein und dreißigstes Bändchen. Moralische Schriften. Übersetzt von Joh. Christian Felix Bähr. 12. Bd. Stuttgart 1857.

Schillers Werke. Nationalausgabe. Zweiter Band, Teil I. Hrsg. v. Julius Petersen u. Friedrich Beißner. Weimar 1983.

Schweitzer, Ludwig: Gesänge und Sprüche für Brüder Freimaurer. 2. Aufl., Leipzig 1877.

Was sind die Freimaurer und was wollen sie? Ein Wort zur Wehr und Lehr über Ursprung, Wesen, Bedeutung und Ziele der Freimaurerei. Von einem Br. Freimaurer. 10. Aufl., Lissa i. P. 1906.

Zetkin, Clara: Zur Geschichte der proletarischen Frauenbewegung Deutschlands. Frankfurt/Main 1978.

\section{Lexika}

Brockhaus. Enzyklopädie in 30 Bänden. 21. Aufl., Leipzig, Mannheim 2006.

Duden. Bd. 7: Etymologie. Herkunftswörterbuch der deutschen Sprache. 2. Aufl., Mannheim u.a. 1989.

Encyclopedia of the Bible and Its Reception. Bd. 4. Hrsg. v. Hans-Josef Klauck u.a. Berlin, Boston 2012, Sp. 550-557.

Gemoll, Wilhelm: Griechisch-deutsches Schul- und Handwörterbuch. 9. Aufl., München 1997.

Heinric, Joachim: Wörterbuch zu Erklärung und Verdeutlichung der unserer Sprache aufgedrungenen fremden Ausdrücke. Ein Ergänzungsband zu Adelungs Wörterbuche. In zwei Bänden. Braunschweig 1801.

Der Kleine Pauly. Lexikon der Antike. München 1979.

Reallexikon für Antike und Christentum. Stuttgart 1954.

Reclams Lexikon der antiken Mythologie. 7. Aufl., Stuttgart 2001.

Theologisches Begriffslexikon zum Neuen Testament. Hrsg. v. Lothar Coenen u.a. Wuppertal 1967.

Theologisches Wörterbuch zum Neuen Testament. Hrsg. v. Gerhard Kittel. Stuttgart 1949.

Tripp, Edward: Reclams Lexikon der antiken Mythologie. 7. Aufl., Stuttgart 2001

\section{Literatur}

Alber, Erdmute; Coe, Cati; Thelen, Tatjana (Hrsg.): The Anthropology of Sibling Relations. Shared Parentage, Experience, and Exchange. New York 2013.

Atwood, Craig D.: Brother, Brotherhood, V. Christianity, in: Encyclopedia of the Bible and Its Reception. Bd. 4. Hrsg. v. Hans-Josef Klauck u.a. Berlin, Boston 2012, Sp. 557-564.

Baier, T.: Die längste Liebe des Lebens, in: Süddeutsche Zeitung, 3. März 2010, online: http://www.sueddeutsche.de/wissen/geschwisterforschung-die-laengste-liebe-des-lebens1.6717 (letzter Zugriff: 24.03.2015).

Bartl, Andrea: Ungleiche Zwillinge: Adalbert Stifters Zwei Schwestern - mit einem anthropologischen Seitenblick auf Ernst von Feuchtersleben, in: Onnen-Isemann, Corinna; Rösch, Gertrud Maria (Hrsg.): Schwestern. Zur Dynamik einer lebenslangen Beziehung. Frankfurt/Main, New York 2005, S. 153-169. 
Baumgärtel, Bettina: Angelika Kaufmann und der Freundschaftskult der Künstlerinnen. Bildtypologien der Freundschaft um 1800, in: Labouvie, Eva (Hrsg.): Schwestern und Freundinnen. Zur Kulturgeschichte weiblicher Kommunikation. Köln u.a. 2009, S. 221-240.

Bausinger, Hermann: Geschwister gehen bis zum Rhein... Perspektiven der Volkstradition, in: Klosinski, Gunther (Hrsg.): Verschwistert mit Leib und Seele. Geschwisterbeziehungen gestern - heute - morgen. Tübingen 2000, S. 21-30.

Bodarwé, Katrinette: Befreundete Schwestern. Beziehungs- und Kommunikationskulturen klösterlicher Frauen im Frühmittelalter, in: Labouvie, Eva (Hrsg.): Schwestern und Freundinnen. Zur Kulturgeschichte weiblicher Kommunikation. Köln u.a. 2009, S. 377393.

Bollmann, Vera: Schwestern. Interaktion und Ambivalenz in lebenslangen Beziehungen. Wiesbaden 2012.

Braun, Maria: Geschwisterbeziehungen - das reinste Schicksal, in: Die Welt, 30.01.2011, http://www.welt.de/wissenschaft/article12372691/Geschwisterbeziehungen-das-reinsteSchicksal.html (letzter Zugriff: 24.03.2015).

Danzer, Doris: Zwischen Vertrauen und Verrat. Deutschsprachige kommunistische Intellektuelle und ihre sozialen Beziehungen (1918-1960). Göttingen 2012.

Dilcher, Gerhard: An den Ursprüngen der Normbildung - Verwandtschaft und Bruderschaft als Modelle gewillkürter Rechtsformen, in: Krieger, Gerhard (Hrsg.): Verwandtschaft, Freundschaft, Bruderschaft. Soziale Lebens- und Kommunikationsformen im Mittelalter. Berlin 2009, S. 37-55.

Doyle, Eric: Von der Brüderlichkeit der Schöpfung. Der Sonnengesang des Franziskus. Zürich 1987.

Escher-Apsner, Monika: Mittelalterliche Bruderschaften in europäischen Städten. Funktionen, Formen, Akteure / Medieval confraternities in European towns. Functions, forms, protagonists. Eine Einleitung (An introduction), in: dies. (Hrsg.): Mittelalterliche Bruderschaften in europäischen Städten. Funktionen, Formen, Akteure. Frankfurt/Main 2009, S. 927.

Fishel, Elizabeth: Schwestern. Liebe und Rivalität innerhalb und außerhalb der Familie. Berlin u.a. 1979.

Frey, Jörg: Brother, Brotherhood, I. New Testament, in: Encyclopedia of the Bible and Its Reception, Bd. 4. Hrsg. v. Hans-Josef Klauck u.a. Berlin, Boston 2012, Sp. 550-557.

Geest, Sjaak van der: Kinship as Friendship. Brothers and Sisters in Kwahu, Ghana, in: Alber, Erdmute; Coe, Cati; Thelen, Tatjana (Hrsg.): The Anthropology of Sibling Relations. Shared Parentage, Experience, and Exchange. New York 2013, S. 51-70.

Günther, Walther: á $\delta \varepsilon \lambda \varphi o ́ \varsigma$ Bruder, Nächster, in: Theologisches Begriffslexikon zum Neuen Testament. Hrsg. v. Lothar Coenen, Erich Beyreuther und Hand Bietenhard. Wuppertal 1967, S. 146-149.

Harders, Ann-Cathrin: ,Sororitas“? - Überlegungen zu einem Konzept der Schwesterlichkeit im antiken Rom, in: Labouvie, Eva (Hrsg.): Schwestern und Freundinnen. Zur Kulturgeschichte weiblicher Kommunikation. Köln u.a. 2009, S. 243-261.

Harders, Ann-Cathrin: Zwischen Kooperation und Repräsentation: Bruder-SchwesterBeziehungen in der römischen Republik und im frühen Prinzipat (2. Jh. v. Chr. - 1. Jh. n. Chr.), in: Historical Social Research, Vol. 30 (2005), S. 61-79. 
Harland, Philip A.: Familial Dimensions of Group Identity: „Brothers“ (A $\Delta \mathrm{E} \Lambda \Phi O I)$ in Associations of the Greek East, in: Journal of Biblical Literature, 124/3 (2005), S. 491-513.

Heinz, Rudolf: „Alle Menschen werden Brüder...“. Mytho-philosophische Anmerkungen zum Geschwisterproblem, in: Sohni, Hans (Hrsg.): Geschwisterlichkeit. Horizontale Beziehungen in Psychotherapie und Gesellschaft. Psychoanalytische Blätter, Bd. 12. Göttingen 1999, S. 55-66.

Kaiser, Peter: Schwestern im familialen Systemkontext, in: Onnen-Isemann, Corinna; Rösch, Gertrud Maria (Hrsg.): Schwestern. Zur Dynamik einer lebenslangen Beziehung. Frankfurt/Main, New York 2005, S. 65-88.

Kannicht, Richard: Geschwisterbeziehungen in der griechischen Dichtung, in: Klosinski, Gunther (Hrsg.): Verschwistert mit Leib und Seele. Geschwisterbeziehungen gestern heute - morgen. Tübingen 2000, S. 59-70.

Kasten, Hartmut: Die Geschwisterbeziehung. Bd. I. Göttingen 1993.

Knackmuß, Susanne: Leibhaftige Klosterschwestern. Schwesternbeziehungen von Nonnen um 1500, in: Onnen-Isemann, Corinna; Rösch, Gertrud Maria (Hrsg.): Schwestern. Zur Dynamik einer lebenslangen Beziehung. Frankfurt/Main, New York 2005, S. 131-152.

Krause, Gerhard: Antike Collegia, Stichwort: Bruderschaften/Schwesternschaften/ Kommunitäten, in: Theologische Realenzyklopädie. Bd. VII. Berlin, New York 1981, S. 195.

Labouvie, Eva (Hrsg.): Schwestern und Freundinnen. Zur Kulturgeschichte weiblicher Kommunikation. Köln u.a. 2009.

Labouvie, Eva: Zur Einstimmung und zum Band, in: dies. (Hrsg.): Schwestern und Freundinnen. Zur Kulturgeschichte weiblicher Kommunikation. Köln u.a. 2009, S. 11-31.

Lanzinger, Margareth: Schwestern-Beziehungen und Schwager-Ehen. Formen familialer Krisenbewältigung im 19. Jahrhundert, in: Labouvie, Eva (Hrsg.): Schwestern und Freundinnen. Zur Kulturgeschichte weiblicher Kommunikation. Köln u.a. 2009, S. 263-282.

Liebold, Renate; Hack, Birgit M.: Zwischen Verbundenheit und Differenz: Zum Mythos Schwesternschaft in weiblichen Zusammenschlüssen, in: Onnen-Isemann, Corinna; Rösch, Gertrud Maria (Hrsg.): Schwestern. Zur Dynamik einer lebenslangen Beziehung. Frankfurt/Main, New York 2005, S. 89-105.

Motté, Magda: „Brudermord als abendländische Tradition“. Kain und Abel - Urmuster zwischenmenschlicher Konflikte, in: Schmidinger, Heinrich M. (Hrsg.): Die Bibel in der deutschsprachigen Literatur des 20. Jahrhunderts. 2. Aufl., Mainz 2000, S. 64-79.

Onnen-Isemann, Corinna: Geschwisterbeziehungen aus soziologischer Perspektive, in: dies.; Rösch, Gertrud Maria (Hrsg.): Schwestern. Zur Dynamik einer lebenslangen Beziehung. Frankfurt/Main, New York 2005, S. 23-36.

Onnen-Isemann, Corinna; Rösch, Gertrud Maria: Einleitung, in: dies. (Hrsg.): Schwestern. Zur Dynamik einer lebenslangen Beziehung. Frankfurt/Main, New York 2005, S. 7-19.

Onnen-Isemann, Corinna; Rösch, Gertrud Maria: Schwesterherz - Schwesterschmerz. Schwestern zwischen Solidarität und Rivalität. Heidelberg 2006.

Rassoul, Muhammad Ahmad: Die Brüderlichkeit im Islam. 2. Aufl., Köln 1983.

Ratzinger, Joseph: Die christliche Brüderlichkeit. München 1960.

Ratzinger, Joseph: Erwägungen über die christliche Brüderlichkeit, in: Aufderbeck, Hugo; Fritz, Martin (Hrsg.): Bruderschaft und Brüderlichkeit. Pastoral-Katechetische Hefte. Heft 22, Leipzig 1964, S. 9-35. 
Röbke, Thomas: Geschwister. Wie sie uns lebenslang prägen, in: Seniorenratgeber, Juni 2011, S. 62-69.

Rösch, Gertrud Maria: Auf der Suche nach der anderen: Schwesternbeziehungen in der deutschen Gegenwartsliteratur, in: Onnen-Isemann, Corinna; Rösch, Gertrud Maria (Hrsg.): Schwestern. Zur Dynamik einer lebenslangen Beziehung. Frankfurt/Main, New York 2005, S. 171-185.

Schelkle, Karl Hermann: Bruder, in: Reallexikon für Antike und Christentum. Bd. 2. Stuttgart 1954, Sp. 631-640.

Schelkle, Karl Hermann: Brüderlichkeit der Fürsten, in: Reallexikon für Antike und Christentum. Bd. II. Stuttgart 1954, Sp. 641-646.

Schieder, Wolfgang: Brüderlichkeit. Bruderschaft, Verbrüderung, Bruderliebe, in: Geschichtliche Grundbegriffe. Historisches Lexikon zur politisch-sozialen Sprache in Deutschland. Bd. 1. 4. Aufl., Stuttgart 1992, S. 552-581.

Schmidt-Denter, Ulrich: Soziale Beziehungen im Lebenslauf. Lehrbuch der sozialen Entwicklung. Weinheim, Basel 2005.

Schwestern. Man sucht sie sich nicht aus - und liebt sie dann doch!? Ein Spezial, in: Der Tagesspiegel. Sonntag, 14. September 2014, 22/165, S. 1-8.

Seow, Choon-Leong: Brother, Brotherhood, I. Hebrew Bible/Old Testament, in: Encyclopedia of the Bible and Its Reception. Bd. 4. Hrsg. v. Hans-Josef Klauck u.a. Berlin, Boston 2012, Sp. 540-546.

Signori, Gabriela: Geschwister: Metapher und Wirklichkeit in der spätmittelalterlichen Denkund Lebenswelt, in: Historical Social Research, Vol. 30 (2005), S. 15-30.

Sitzler, Susann: Geschwister. Die längste Beziehung des Lebens. Stuttgart 2014.

Soden, Hans Freiherr von: å $\delta \varepsilon \lambda \varphi o ́ \varsigma$, in: Theologisches Wörterbuch zum Neuen Testament. Erster Band. Hrsg. v. Gerhard Kittel. Stuttgart 1949, S. 144-146.

Stammler, Wolfgang: Politische Schlagworte in der Zeit der Aufklärung, in: ders.: Kleine Schriften zur Sprachgeschichte. Berlin u.a. 1954, S. 48-100.

Stupperich, Robert: Bruderschaften/Schwesternschaften/Kommunitäten, in: Theologische Realenzyklopädie. Bd. VII. Berlin, New York 1981, S. 195-206.

Thelen, Tatjana; Coe, Cati; Alber, Erdmute: The Anthropology of Sibling Relations. Explorations in Shared Parentage, Experience, and Exchange, in: Alber, Erdmute; Coe, Cati; Thelen, Tatjana (Hrsg.): The Anthropology of Sibling Relations. Shared Parentage, Experience, and Exchange. New York 2013, S. 1-26.

Thimm, Katja: Rivalen fürs Leben, in: Der Spiegel, 2/2006:, 09.01.2006, Online: http://www.spiegel.de/spiegel/print/d-45280085.html (letzter Zugriff: 24.03.2015). 


\title{
Themen, Kontexte und Perspektiven sozial- und individualpsychologischer Geschwisterforschung - Ein Überblick
}

\author{
Helga Völkening
}

\begin{abstract}
In his psychological and psychoanalytic treatises Alfred Adler mainly analyzed how the birth order shapes the personality of siblings. Since the second half of the 20th century further factors of the personal development and especially of the nature and quality of sibling relations were taken into account. Sibling relations in general proved to be ambivalent: in addition to closeness, bond and solidarity they are characterized by rivalry and segregation mechanisms.
\end{abstract}

\section{Geschwister und Geschwisterbeziehungen als Gegenstand der Forschung}

Die gegenwärtige Geschwisterforschung ist in verschiedenen Teildisziplinen der Sozial- bzw. Humanwissenschaft verortet. Zu den beteiligten Fachbereichen zählen neben der Individual- bzw. Entwicklungspsychologie ferner die Soziologie und Ethnologie sowie die Pädagogik resp. Verhaltensgenetik. ${ }^{1}$

Disziplinübergreifend lässt sich seit den 1980er Jahren eine signifikante Intensivierung, Systematisierung und Differenzierung der Geschwisterforschung feststellen, ${ }^{2}$ welche mit einem generellen psychologischen Perspektivwechsel einhergeht: In Ergänzung zu den bisher vorrangig fokussierten vertikalen Bezie-

1 Vgl. Bollmann, Vera: Schwestern. Interaktion und Ambivalenz in lebenslangen Beziehungen. Wiesbaden 2012, S. 34 u. Labouvie, Eva: Zur Einstimmung und zum Band, in: dies. (Hrsg.): Schwestern und Freundinnen. Zur Kulturgeschichte weiblicher Kommunikation. Köln u.a. 2009, S. 11-31, hier S. 17.

2 Vgl. hierzu Kasten, Hartmut: Die Geschwisterbeziehung, Bd. 1. Göttingen 1993, S. 13 u. 15; Sohni, Hans: Einführung, in: ders. (Hrsg.): Geschwisterlichkeit. Horizontale Beziehungen in Psychotherapie und Gesellschaft. Göttingen 1999, S. 5-9, hier S. 6f.; Cierpka, Manfred: Unterschiede und Gemeinsamkeiten bei Geschwistern, in: ebd., S. 1031, hier S. 1; Ley, Katharina: Geschwisterliche Räume. Stimmen der Horizontale im Geschwisterlichen und in der Psychotherapie, in: ebd., S. 67-81; Reberg, Sonja: Die Entwicklung der Geschwisterbeziehung unter handlungstheoretischer Perspektive. Eine Längsschnittstudie an Geschwisterpaaren mit zweijährigem Altersabstand. Frankfurt/ Main 2001, S. 43; Onnen-Isemann, Corinna: Geschwisterbeziehungen aus soziologischer Perspektive, in: dies.; Rösch, Gertrud Maria (Hrsg.): Schwestern. Zur Dynamik einer lebenslangen Beziehung. Frankfurt/Main, New York 2005, S. 23-36, hier S. 23 u. OnnenIsemann, Corinna; Rösch, Gertrud Maria: Einleitung, in: ebd., S. 7-20, hier S. 8. 
hungen (z.B. Eltern-Kind-Triade ${ }^{3}$ ) erhalten nun auch horizontale Bezüge - zu Geschwistern, zu Freundinnen und Freunden (Peer Group) oder dem Partner bzw. der Partnerin - besondere Aufmerksamkeit. Zusätzlich zur zentralen Relevanz, die speziell Geschwistern in diesem Rahmen gemeinhin für die individuelle (soziale) Persönlichkeitsentwicklung zugesprochen wird, akzentuieren die Autoren in ihren psychologischen und sozialwissenschaftlichen Beiträgen nun vor allem die charakteristische Besonderheit der geschwisterlichen Bindung als eine der „verfügbarsten, intensivsten und dauerhaftesten“4 ${ }^{\text {zwischenmensch- }}$ lichen Beziehungen, die ein Mensch im Laufe seines Lebens eingeht.

\section{Konstellationen und Determinanten der Geschwisterbeziehung}

\section{Genealogische Geschwisterposition}

Der Beginn der wissenschaftlichen (psychologischen) Geschwister-Erforschung wird zumeist mit der 1927 publizierten Abhandlung Menschenkenntnis von Alfred Adler verbunden, ${ }^{5}$ der folglich auch als „Pionier“6 ${ }^{\text {"6 }}$ oder „Vater der Geschwisterforschung “7 bezeichnet wird. Als Individual- bzw. Entwicklungspsychologe galt Adlers Forschungsinteresse insbesondere der Interferenz zwischen Geschwisterposition sowie psychosozialer Entwicklung ${ }^{8}$ und somit der Frage, inwiefern die genealogische Stellung innerhalb der geschwisterlichen Geburtenfolge (jüngstes, ältestes, mittleres Kind) die individuelle Persönlichkeit bestimmt. Seine unter den Bezeichnungen „Familienkonstellation“ oder „Geschwisterposition“ bzw. „Geschwisterrang“ in die Forschung eingegangenen Thesen, Schlussfolgerungen und Begrifflichkeiten prägten nicht nur über Jahrzehnte die anschließende wissenschaftliche Beschäftigung, sondern fanden zugleich in popularisierter Form Eingang in den allgemeinen Sprachgebrauch (z.B. ,Nesthäkchen', ,Sandwichkind', ,Entthronung des Erstgeborenen').

Adlers Hauptthese besteht in der Annahme bzw. Überzeugung, dass die „Persönlichkeit von Menschen“ „,aufgrund ihrer Position in der Geschwister-

3 Exemplarisch seien hier die tiefenpsychologischen Analysen Sigmund Freuds genannt.

4 Schmidt-Denter, Ulrich: Soziale Beziehungen im Lebenslauf. Lehrbuch der sozialen Entwicklung. Weinheim, Basel 2005, S. 53.

5 Im Folgenden zitiert nach: Adler, Alfred: Menschenkenntnis. Köln 2008.

6 Schmidt-Denter: Soziale Beziehungen, S. 53. Vgl. auch Onnen-Isemann, Corinna; Rösch, Gertrud Maria: Schwesterherz - Schwesterschmerz. Schwestern zwischen Solidarität und Rivalität. Heidelberg 2006, S. 69.

7 Lüscher, Berit: Die Rolle der Geschwister. Chancen und Risiken ihrer Beziehung. Berlin 1997, S. 2. Vgl. Fishel, Elizabeth: Schwestern. Liebe und Rivalität innerhalb und außerhalb der Familie. Berlin u.a. 1979, S. 50.

8 Vgl. hierzu beispielsweise Bollmann: Schwestern, S. 33

Ulrike Schneider, Helga Völkening and Daniel Vorpahl - 978-3-653-98812-3 
reihe typologisiert werden“9 kann. Konkret unterschied er fünf „Geschwistertypen" mit zwar idealtypischen, aber durchaus kombinierbaren Positionen innerhalb der Geschwisterfolge: der/die Einzige, Älteste, Zweite, Jüngste und Mittlere. ${ }^{10}$ So erhalte beispielsweise das einzige Kind die ,ungeteilte Anerkennung und Zuwendung" seitens der Eltern, erfahre sich somit als etwas Einmaliges, „Besonderes“. Bekommt es allerdings einen Bruder oder eine Schwester, werde bzw. fühle es sich ,gleichsam ,entthront ““11 , da es nun (nicht nur, aber vor allem) die Aufmerksamkeit der Eltern, mit seinem jüngeren Geschwister teilen muss. Infolgedessen und zur Kompensation dieser Entthronungserfahrung - so Adlers Schlussfolgerung - sei Erstgeborenen in erster Linie an Macht, Machtdurchsetzung und -erhalt gelegen. ${ }^{12}$

Das zweite Kind hat dagegen nie die einzigartige Stellung und ungeteilte Aufmerksamkeit erfahren, die einem ersten Kind entgegengebracht wird. Es ist stattdessen von Vornherein mit seinem älteren Geschwister konfrontiert und wird folglich bereits in eine (sekundäre) Geschwisterposition bzw. -hierarchie hineingeboren. Wenn es sich allerdings zugleich um das jüngste Kind handelt, besäße es zumindest wiederum eine einmalige, wenn auch andersartige Position als letztes Glied innerhalb der Geschwisterfolge und erhielte als solches gemeinhin ebenfalls eine besondere Behandlung resp. spezielle Zuwendung. ${ }^{13}$ Obwohl bzw. auch wenn Geschwister somit gemeinsam in einer Familie aufwachsen, gestalten sich ihre Sozialisationserfahrungen - diesen Prämissen zufolge - als durchaus divergent. Denn die persönlichen Erfahrungen, Erlebnisse und Kontexte werden durch die jeweilige Stellung in der Geschwisterfolge unterschiedlich determiniert. ${ }^{14}$

Im Anschluss an Adlers Thesen entstanden zahlreiche empirische Untersuchungen und theoretische Abhandlungen, in denen Korrelationen zwischen der geschwisterlichen Geburtenfolge und der Persönlichkeitsentwicklung (Charaktereigenschaften, Lebensstil) vorausgesetzt bzw. eruiert wurden (sog. birth-

9 Onnen-Isemann; Rösch: Schwesterherz, S. 69. „Eine Situation besonderer Art ist nun in der Stellung gelegen, die ein Kind in der Reihe seiner Geschwister einnimmt. Auch nach diesem Gesichtspunkt können wir die Menschen einteilen und sind, wenn wir über genügend Erfahrung verfügen, imstande zu erkennen, ob jemand ein Erstgeborener, der Einzige, der Jüngste usw. ist.“ Adler: Menschenkenntnis, S. 134.

10 Vgl. ebd., S 134-140 u. Klosinski, Gunther: Verschwistert mit Leib und Seele - beglückt oder bestraft, in: ders. (Hrsg.): Verschwistert mit Leib und Seele. Geschwisterbeziehungen gestern - heute - morgen. Tübingen 2000, S. 9-18, hier S. 10.

11 Ebd., S. 10f. Der sog. Entthronung wird traumatisches Potenzial zugeschrieben. Vgl. Schmidt-Denter: Soziale Beziehungen, S. 53.

12 Vgl. Adler: Menschenkenntnis, S. 137.

13 Vgl. ebd., S. 134-137 u. Klosinski: Verschwistert, S. 11.

14 Vgl. auch Bollmann: Schwestern, S. 34.

Ulrike Schneider, Helga Völkening and Daniel Vorpahl - 978-3-653-98812-3 
order-effects). ${ }^{15}$ Exemplarisch sei an dieser Stelle Walter Toman genannt, der den Einfluss der Familienkonstellation auf die menschliche Entwicklung ,aus sozialpsychologischer und persönlichkeitstheoretischer Sicht" untersuchte und ,für jede Position innerhalb der Familie bestimmte Persönlichkeits- und Charaktermerkmale ${ }^{\text {“16 }}$ ermittelte. In seinen empirischen Studien kam er zu dem Ergebnis, dass die ältesten Geschwister und Einzelkinder ihren jüngeren Geschwistern in der Regel intellektuell überlegen seien, während letzteren zumeist eine größere Kompetenz im sozialen Bereich zugesprochen werden könne. ${ }^{17}$

Ebenfalls an den Prämissen der Geschwisterkonstellationsforschung orientiert, führt der Wissenschaftshistoriker Frank Sulloway schließlich den biologischen Begriff der "Nische“ ein, ${ }^{18}$ indem er die Verschiedenheit der Geschwister primär mit einer unterschiedlichen Nischenbesetzung innerhalb des familialen Systems begründet ${ }^{19}$ : Jüngere Geschwister fänden bereits belegte Nischen vor und müssten demnach alternative Positionen bzw. Rollen innerhalb der Familie finden. Nahezu zwangsläufig oder zumindest des Öfteren stellten sie in diesem Zusammenhang ,den Status quo in Frage“ ${ }^{20}$ bzw. seien gezwungen, „größere Offenheit für Erfahrungen“ ${ }^{\star 21}$ auf alternativem Gebiet zu entwickeln. Demgegenüber orientierten sich die ältesten Geschwister häufiger an den Eltern. Sie seien somit grundsätzlich angepasster und konservativer und wiesen gemeinhin ein dominanteres, machtorientierteres Sozialverhalten auf als ihre jüngeren Geschwister. ${ }^{22}$

15 Vgl. Schmidt-Denter: Soziale Beziehungen, S. 53 (unter Berufung auf Brian SuttonSmith und Benjamin George Rosenberg).

16 Bollmann: Schwestern, S. 33 zu: Toman, Walter: Familienkonstellationen. Ihr Einfluss auf den Menschen. München 2002. Vgl. demgegenüber die Studie von Karl König (Brothers and Sisters. A Study in Child Psychology. New York 1963), die ,keine signifikanten Zusammenhänge zwischen der Position in der Geschwisterreihe und spezifischen Charaktereigenschaften, Intelligenz oder Habitus bei seinen Probanden und Probandinnen“ ergab, allerdings deutliche Unterschiede ,in Bezug auf soziale Kontaktfähigkeit“ „,Zwischen Erst- und Zweitgeborenen“ bilanzierte. (Bollmann: Schwestern, S. 33f.).

17 Vgl. Schmidt-Denter: Soziale Beziehungen, S. 53f.

18 Vgl. hierzu Sulloway, Frank: Der Rebell der Familie. Geschwisterrivalität, kreatives Denken und Geschichte. Aus dem Amerikanischen von Klaus Binder und Bernd Leineweber. Berlin 1997.

19 Die Geschwisterposition bestimmt laut Sulloway ,unser Verhalten mehr als unsere Gene, unser Geschlecht, unser Temperament und unsere soziale Schicht.“ Klosinski: Verschwistert, S. 9.

20 Schmidt-Denter: Soziale Beziehungen, S. 54.

21 Ebd.

22 Er untermauert dies mit einem Verweis auf die überdurchschnittlich hohe Zahl bekannter (Führungs-)Persönlichkeiten, die sich aus den Reihen Erstgeborener rekrutieren, während Ulrike Schneider, Helga Völkening and Daniel Vorpahl - 978-3-653-98812-3 


\section{Neuausrichtung der Geschwisterforschung: Multiperspektivität}

Seit den 1970er ${ }^{23}$ und vor allem in den 1980ern Jahren wird zunehmend die Engführung auf die Geburtsfolge und somit konkret die Eindimensionalität der traditionellen Geschwisterpositionsforschung kritisiert ${ }^{24}$ sowie auf zusätzliche, relevante Determinanten und die Bedeutung bisher vernachlässigter interaktiver Prozesse hingewiesen. ${ }^{25}$ Als weitere signifikante Faktoren bzw. Variablen, welche die Geschwisterbeziehung zusätzlich zur Geburtsfolge maßgeblich beeinflussen bzw. bedingen, nehmen die Untersuchungen neben der Gesamtzahl der Geschwister, dem Altersabstand und Geschlecht der jeweiligen Geschwister ${ }^{26}$ auch individuelle Anlagen (Persönlichkeitsmerkmale, Fähigkeiten und Eigenschaften) resp. biographische Erfahrungen verstärkt in den Blick. ${ }^{27}$

Darüber hinaus wird gegenwärtig u.a. die methodische Vorgehensweise sowie das Fehlen eines ,integrative[n] theoretische[n] Ansatzes“"28 innerhalb der Geschwisterpositionsforschung bemängelt und ,normative Abweichungen ' resp. alternative Familienkonstellationen in größerem Maße berücksichtigt. Folglich erhalten nun auch Geschwister mit Beeinträchtigungen ${ }^{29}$ oder in Trennungs-, Patchwork-, Stief- und Adoptionsfamilien sowie aus anderen Kulturkreisen ${ }^{30}$

unter den Rebellen, Erneuerern und Entdeckern signifikant mehr Zweit-, Nach- oder Spätgeborene als Erstgeborene oder Einzelkinder vertreten seien. Vgl. Klosinksi: Verschwistert, S. 11 u. mit konkretem Blick auf eine Familienkonstellation mit Schwestern: Onnen-Isemann; Rösch: Schwesterherz, S. 70-76. „Streben nach Macht und Überlegenheit“" sowie einen „konservativen Zug“" hatte bereits Alfred Adler dem ältesten Geschwister zugeordnet. Vgl. Adler: Menschenkenntnis, S. 137.

23 Bereits in den 1970er Jahren beschäftigten sich vor allem angloamerikanische Frühpädagog_innen, Verhaltensgenetiker_innen und Entwicklungspsycholog_innen im Rahmen diverser Studien mit der Geschwisterbeziehung. Sie fanden jedoch in der deutschsprachigen Familienforschung wenig Resonanz. Vgl. hierzu auch Bollmann: Schwestern, S. 34.

24 In diesem Rahmen sind vor allem die Studien und Abhandlungen von Brian SuttonSmith und Benjamin George Rosenberg sowie Sutton-Smith und Michael Lamb (1970 resp. 1982) zu nennen, in denen weitere Einflussfaktoren auf die Geschwisterbeziehung und die Entwicklung der Persönlichkeit eines Geschwisters einbezogen werden. Vgl. Reberg: Entwicklung, S. 43.

25 Vgl. Schmidt-Denter: Soziale Beziehungen, S. 53.

26 Vgl. Reberg: Entwicklung, S. 43 u. Onnen-Isemann; Rösch: Schwestern, S. 16.

27 Vgl. Schmidt-Denter: Soziale Beziehungen, S. 55 u. Klosinski: Verschwistert, S. 12f.

28 Schmidt-Denter: Soziale Beziehungen, S. 55.

29 Vgl. z.B. Kasten, Hartmut: Die Geschwisterbeziehung, Bd. 2: Spezielle Geschwisterbeziehungen. Göttingen u.a. 1993 u. Schmidt-Denter: Soziale Beziehungen, S. 55-59.

30 Interkulturelle Vergleiche hinsichtlich Geschwisterbeziehungen bieten z.B. Zukow, Patricia Goldring (Hrsg.): Sibling Interaction across Cultures. Theoretical and Methodo- 
erhöhte und differenziertere Aufmerksamkeit. Zugleich wird der Fokus auf die gesamte menschliche Lebensdauer ausgeweitet. ${ }^{31}$ Der Pädagoge, Familienforscher und Entwicklungspsychologe Hartmut Kasten fasst den hiermit verbundenen Paradigmenwechsel komprimiert zusammen, wenn er feststellt:

Im Mittelpunkt der Aufmerksamkeit stehen nicht mehr vordergründige Effekte strukturell einfacher Variablen (wie Geburtsrangplatz), sondern die dahinterliegenden, verursachenden Prozesse und Wechselwirkungen. Intra- und interindividuelle Ähnlichkeiten und Unterschiede und auch kulturelle Variabilität werden stärker berücksichtigt. Der Blick richtet sich nicht mehr nur auf die frühen Entwicklungsstufen, sondern auch auf spätere Abschnitte und die gesamte Lebensspanne [...]. ${ }^{32}$

In Abgrenzung zur Geschwisterrang- oder Geschwisterpositionsforschung wird diese multiperspektivische wissenschaftliche Annäherung explizit als „Geschwisterforschung " bezeichnet. ${ }^{33}$

\section{Lebenszyklische Dynamik der Geschwisterbeziehung}

Verstärkt wird in Geschwisterstudien und theoretischen Abhandlungen neueren Datums die besondere Konstellation akzentuiert, dass die Geschwisterbeziehung eine ,intragenerationale ${ }^{\text {‘34 }}$ und somit eine dauerhafte, zumeist sogar die zeitlich längste Bindung im Lebenslauf eines Menschen darstellt. ${ }^{35}$ Andere Beziehungen weisen demgegenüber zumeist eine engere zeitliche Limitierung auf: Der Kontakt zu den Eltern bricht in der Regel durch deren Tod im mittleren oder späteren Erwachsenenalter unwiderruflich ab und Beziehungen zu Freund_innen, Lebensgefährt_innen sowie Kolleg_innen können jeweils flexibel zu verschiedenen Zeiten im Laufe des Lebens beginnen bzw. enden oder sogar nur für einen (sehr) kurzen Zeitraum Bestand haben. Neben dieser grundsätzlichen Konstante betonen und analysieren Geschwisterforscher_innen zudem die Prozesshaftigkeit, Dynamik und Modifikation von Geschwisterbeziehungen sowie ihre variable, individuelle Bedeutung innerhalb verschiedener Stadien der Persönlichkeitsentwicklung und -entfaltung. Vermehrt werden in Langzeitstudien ${ }^{36}$,

logical Issues. New York 1989 oder Kasten, Hartmut: Geschwister. Vorbilder, Rivalen, Vertraute. München 2003.

31 Vgl. Schmidt-Denter: Soziale Beziehungen, S. 53 u. 58.

32 Kasten: Geschwisterbeziehung. Bd. 1, S. 11.

33 Vgl. z.B. Bollman: Schwestern, S. 33-41.

34 Ebd., S. 46.

35 So z.B. Schmidt-Denter: Soziale Beziehungen, S. 65, unter Bezug auf Cicirelli, Victor G.: Sibling Relationships across the Life Span. New York, London 1995.

36 Vgl. z.B. die Langzeitanalysen von Vanessa Burholt und G. Clare Wenger (Differences over Time, in: Ageing and Society, Nr. 18 [1998], S. 537-562), welche die Qualität der Geschwisterbeziehung im Lebensverlauf untersuchen u. Bollmann: Schwestern, S. 52. 
Querschnitts- bzw. retrospektiven Erhebungen ${ }^{37}$ sowie in empirischen und biographischen Untersuchungen folglich Personen bzw. Geschwister im reiferen Lebensalter in den Blick genommen. Sie verweisen auf eine prinzipielle lebensgeschichtliche Varianz hinsichtlich der Beurteilung, Intensität und Qualität der Geschwisterbeziehung. Stehen doch beispielsweise Phasen der unmittelbaren und oft auch konfliktreichen (räumlichen) Nähe während der gemeinsamen kindlichen Sozialisation nicht selten Zeiten des geringeren Kontakts nach Gründung eines eigenständigen Hausstands bzw. einer eigenen Familie in den mittleren Erwachsenenjahren gegenüber. Auch ist im Alter eine häufige Wiederannäherung sowie Affirmation der Beziehung mit Blick auf die Kontakthäufigkeit und -intensität unter Geschwistern festzustellen. ${ }^{38}$

Dennoch bildet die Periode der (frühen) Kindheit als traditioneller Zeitraum des gemeinsamen Aufwachsens in (räumlicher) Nähe, mit geteilten Erfahrungen und (größtenteils) kongruenter Sozialisation im Rahmen der Primärfamilie ${ }^{39}$ weiterhin den vorrangigen inhaltlichen Schwerpunkt, Fokus und Bezugsrahmen der Geschwisterforschung. ${ }^{40}$ Dies ist nicht zuletzt dem Sachverhalt geschuldet, dass die in ihren Primärfamilien aufwachsenden Kinder und Jugendlichen empirisch (leichter) zu erfassen sind und die Komponenten sowie Modalitäten der Beziehung aufgrund der räumlichen und emotionalen Nähe besser erschlossen und analysiert werden können. Demgemäß sind Geschwisterstudien noch immer in der Majorität auf den Zeitraum der Kindheit bis zur Adoleszenz bezogen und bieten gerade für diese Lebensphase differenzierte Erkenntnisse. Verstärkt kommen in diesem Rahmen sodann nicht nur Momente der Qualität und Art der Geschwisterbeziehung, sondern auch ihre Bedeutung und Funktion für die Persönlichkeitsentfaltung, für die kognitive, emotionale und soziale Entwicklung,

37 Vgl. Schmidt-Denter: Soziale Beziehungen, S. 65.

38 Schmidt-Denter expliziert diesbezüglich: „In der postparentalen Phase sowie verstärkt zum höheren Lebensalter hin gibt es jedoch einen Trend zur Reintensivierung der Geschwisterbeziehungen (Neyer, 2002). Hierbei spielen kritische Lebensereignisse sowie bestimmte Entwicklungsaufgaben, die im Alter zu bewältigen sind, eine große Rolle. So können der Tod eines Ehepartners, die Pflegebedürftigkeit der Eltern oder das Bedürfnis nach bewährten sozialen Kontakten, die auch eine Brücke zur Vergangenheit bilden, die Geschwister wieder enger aneinander binden (Bedford, 1995).“ Ebd., S. 65. Vgl. hierzu auch Fishel (Schwestern, S. 93f.), Bollmann (Schwestern, S. 52f.), mit besonderem Fokus auf ältere Frauen sowie Onnen-Isemann: Geschwisterbeziehungen, S. 24.

39 Vgl. Bollmann: Schwestern, S. 46.

40 Folglich stehen hier dann auch persönlichkeits- bzw. entwicklungspsychologische und Momente und Fragen, wie z.B. der Einfluss von Geschwisterbeziehungen auf die kognitive Entwicklung oder im Rahmen der Sozialisation, in besonderem Maße im Mittelpunkt. Vgl. z.B. Schmidt-Denter: Soziale Beziehungen, S. 53 u. 64 u. Reberg: Entwicklung, S. 42f. 
Prägung und Sozialisation sowie die von außen Einfluss nehmenden Faktoren aus entwicklungspsychologischer und soziologischer Perspektive zur Sprache.

\section{Lebensalter und Altersabstand}

Neben der Geburtenfolge und dem Wandel der geschwisterlichen Beziehung im Laufe des Lebens wird in der gegenwärtigen Geschwisterforschung dem jeweiligen Alter bzw. dem Altersunterschied der Geschwister ein besonderer Stellenwert in Bezug auf die Intensität und Qualität der geschwisterlichen Interaktion und der Persönlichkeitsprägung zugeschrieben. Bisher allenfalls implizit innerhalb der Zwillingsforschung in seiner Relevanz erfasst, wendet sich eine Vielzahl jüngerer Studien dieser Determinante der Geschwisterbeziehung nun explizit zu. So betont bereits Fishel den Einfluss des zeitlichen Abstands auf „die Auswirkungen der Geschwisterstellung und die Beziehungen innerhalb der Geschwisterhierarchie“, konstatiert allerdings zudem relativierend:

Geschwister, die im Abstand von fünf oder mehr Jahren geboren wurden, zeigen beispielsweise häufig einige der Merkmale von Einzelkindern, und ein in der Mitte geborenes Kind mag ebenso auch das Älteste von einer zweiten Geschwistergruppe sein. $^{41}$

Gemeinhin korreliert - so die Mehrzahl der Studien - ein geringerer Altersabstand mit größerer Intimität, zahlreicheren Interaktionen und intensiveren Kontakten (Spiel etc.), mit nivellierten Statusdifferenzen, ${ }^{42}$ konvergenten Lebenswelterfahrungen sowie einer weitgehend synchronen Wahrnehmung und Behandlung seitens der Eltern bzw. des weiteren Umfelds. Andererseits beinhalte die geringe Altersdistanz gerade aufgrund dieser weitreichenden Nähe zumeist größeres Konfliktpotential und befördere Abgrenzungstendenzen. ${ }^{43}$ So trete Rivalität zwischen Geschwistern grundsätzlich umso ausgeprägter auf, je geringer der Altersunterschied ist. ${ }^{44}$ Diese Korrelation wird vor allem für den Zeitraum der primären Sozialisation und Adoleszenz festgestellt. ${ }^{45}$ Als Demar-

41 Fishel: Schwestern, S. 57.

42 Vgl. Kaiser, Peter: Schwestern im familialen Systemkontext, in: Onnen-Isemann; Rösch (Hrsg.): Schwestern, S. 65-88, hier S. 77f.

43 Vgl. Schmidt-Denter: Soziale Beziehungen, S. 65 u. Reberg: Entwicklung, S. 185.

44 Vgl. hierzu beispielsweise Corinna Onnen-Isemann (Geschwisterbeziehungen aus soziologischer Perspektive, S. 24) und konkret in Bezug auf Schwestern: Onnen-Isemann; Rösch: Einleitung, S. 17.

45 Vgl. Bollmann: Schwestern, S. 51; Schütze, Yvonne: Geschwisterbeziehungen, in: NaveHerz, Rosemarie; Markefka, Manfred (Hrsg.): Handbuch der Familien- und Jugendforschung. Neuwied, Frankfurt/Main 1989, S. 311-324; Bank, Stephen P.; Kahn, Michael D.: The Sibling Bond. New York 1997 (deutsche Übersetzung: Geschwister-Bindung. Paderborn 1989). 
kationslinie gelten hierbei zumeist drei bis vier bzw. fünf Jahre. Einen Rückgang der „Rivalität- und Konfliktneigung“ stellt Peter Kaiser „,bei einem Altersabstand von mehr als vier Jahren“46 fest. Zudem eruiert er bei einer Distanz von ca. vier Jahren „einen positiven Synergieeffekt ${ }^{4}{ }^{47}$ : Ältere Geschwister nähmen in dieser Konstellation verstärkt eine Mentoren-, Beschützer- sowie Lehrerrolle ein bzw. fungierten des Öfteren als Vorbild für ihre jüngeren Geschwister. ${ }^{48}$

Im Erwachsenenalter determiniert der Altersabstand jedoch nicht mehr in gleichem Maße die Modalität und Qualität der Geschwisterbeziehung: So nivelliert sich beispielsweise ein in der Kindheit ungleiches, seitens des älteren Geschwister dominiertes Verhältnis laut Vera Bollmann in der Regel nach dem gemeinsamen Eintritt in den Erwachsenenstatus. Die Qualität bzw. Nähe der Beziehung erwachsener Geschwister werde dann hauptsächlich oder zusätzlich seitens weiterer Faktoren beeinflusst. ${ }^{49}$

\section{Elterliche Einflussnahme}

Ein entscheidender Einfluss auf die Qualität des geschwisterlichen Verhältnisses und hinsichtlich der Übernahme altersadäquater Rollen seitens der Geschwister wird in der gegenwärtigen Forschung den Eltern (oder weiteren sozialen Bezugspersonen wie z.B. Erzieher_innen oder Lehrer_innen) zugeschrieben. Diese würden beispielsweise durch Einbezug und Vorbereitung des/der älteren Geschwisterkindes/r hinsichtlich der Geburt eines (neuen) Geschwisters auf die (entstehende) Geschwisterbeziehung einwirken bzw. jene prädeterminieren und könnten somit ein nahes, fürsorgliches innergeschwisterliches Verhältnis initialisieren. Positive Wechselwirkungen auf das Geschwisterverhältnis würden sich des Weiteren in der Regel ergeben, wenn die Eltern ihre Kinder altersgerechtindividuell behandeln, fördern bzw. fordern. Hinsichtlich des Anbahnens der geschwisterlichen Beziehung hieße dies, dass die Eltern das ältere Geschwister-

46 Kaiser: Schwestern, S. 73.

47 Ebd., S. 77.

48 In optimaler Weise förderten speziell ältere Schwestern bei einem Altersabstand von vier bis fünf Jahren laut einer Studie von Christine Schmid und Monika Keller ,die kognitive und soziomoralische Entwicklung ihrer Geschwister“ (Kaiser: Schwestern, S. 77). Vgl. hierzu auch die folgenden Ausführungen unter „Geschlechtszugehörigkeit“" sowie „Nähe und Verbundenheit".

49 Vgl. Bollmann: Schwestern, S. 51. Vgl. zudem die Schlussfolgerungen aus ihrer Fallanalyse: „Mit Beginn des Individualisierungsprozesses wirken andere Mechanismen (Partnerschaft, Bildung, Beruf) differenzierend oder auch verbindend auf die Schwesternbeziehung ein. Für die Qualität und Innigkeit der Beziehung spielt der Altersabstand, nachdem beide Schwestern den Erwachsenenstatus erreicht haben, keine Rolle mehr." Ebd., S. 232.

Ulrike Schneider, Helga Völkening and Daniel Vorpahl - 978-3-653-98812-3 
kind in angemessenem, nicht überforderndem Maße in eine fürsorgende und vorbildhafte oder unterweisende Rolle einführen und es bei entsprechender Übernahme bzw. Ausfüllung seiner Rolle positiv bestärken. ${ }^{50}$ Andererseits könnten Eltern aber auch bestehende Rivalitäten, Eifersucht und Neid durch wertende Vergleiche zwischen Geschwistern, mittels offensichtlicher Bevorzugung bzw. Benachteiligung einzelner oder nicht altersgemäßer Erwartungen sowie Behandlung lancieren bzw. befördern. ${ }^{51}$ Durch eine weitgehende Gleichbehandlung altersnaher Geschwister bei gleichzeitiger Wahrnehmung der geschwisterlichen Einheit und der jeweiligen Individualität könnten Eltern oder weitere Bezugspersonen zudem eine besondere Verbundenheit sowie eine annähernd synchrone Ausgangs- und Entwicklungsbasis stiften. ${ }^{52}$ Andererseits protegierten sie aber auch eine De-Identifikation sowie Abgrenzung vom jeweils anderen Geschwister ${ }^{53}$, indem sie beispielsweise selbst in erster Linie die Unterschiede ihrer Kinder fokussieren, artikulieren und folglich ihre jeweilige Individualisierung unterstützen. ${ }^{54}$

\section{Geschlechtszugehörigkeit}

Große Bedeutung wird gegenwärtig des Weiteren dem vor allem in der Geschwisterpositionsforschung lang vernachlässigten Moment des Geschlechts zugesprochen. Neben differenzierteren Untersuchungen hinsichtlich homogener und heterogener Geschlechtskonstellationen zwischen Geschwistern erhalten dabei vor allem Schwestern(-beziehungen) in den letzten Jahren verstärkte Aufmerksamkeit. ${ }^{55}$

50 Vgl. Kaiser: Schwestern, S. 77 u. 83.

51 Vgl. Ley: Geschwisterliche Räume, S. 72; Kasten: Geschwisterbeziehung, Bd. 1, S. 167 u. 170; Fishel: Schwestern, S. 56; Schmidt-Denter: Soziale Beziehungen, S. 62 u. Bollmann: Schwestern, S. 241.

52 Bollmann expliziert konkret hinsichtlich der Schwesternbeziehung: „Ein enger Altersabstand in der Kindheit hingegen evoziert häufig Nähe zwischen Schwestern, dies allerdings auch deshalb, weil sie von der Außenwelt als Paar (spacing) wahrgenommen werden, denen ähnliche Verhaltenserwartungen und -muster zugeschrieben werden. Diese frühe Prägung durch eine von außen rhythmisierende Alterstradierung führt dazu, dass sich zwei Schwestern als ähnlich empfinden und bestätigen bzw. reproduzieren die Norm durch Rollenübernahme.“ Ebd., S. 233.

53 Vgl. auch Kaiser: Schwestern, S. 73 u. Onnen-Isemann; Rösch: Schwesterherz, S. 75.

54 Vgl. diesbezüglich die Wiedergabe der Forschungsergebnisse der Hallenser Geschwisterforscherin Inés Brock in: Sitzler, Susann: Geschwister. Die längste Beziehung des Lebens. Stuttgart 2014, S. 109.

55 Vgl. z.B. die bereits angeführten Abhandlungen: Bollmann: Schwestern; Fishel, Schwestern; Labouvie: Schwestern und Freundinnen; Onnen-Isemann; Rösch (Hrsg.): Schwestern; dies.: Schwesterherz. 
Bei der Fokussierung von Geschwisterverhältnissen mit (größerem) Altersabstand wurde bereits des Öfteren hinsichtlich des jeweiligen Geschlechts differenziert und hierbei vor allem das Einwirken älterer Schwestern hervorgehoben. ${ }^{56}$ Diese beeinflussen den Studienergebnissen zufolge die soziale und kognitive Entwicklung des bzw. der jüngeren Geschwister zumeist positiv(er), indem sie sich der/dem/den Jüngeren in besonderem Maße annähmen, stärker auf sie eingingen, jene anleiteten, lehrten und prägten ${ }^{57}$ oder als Mentorinnen ${ }^{58}$ fungierten. Hiermit entsprächen sie dann zumeist auch einer passiven ${ }^{59}$ oder aktiven elterlichen resp. gesellschaftlichen Rollenzuschreibung bzw. -erwartung ${ }^{60}$ an ihre Person und könnten bei weitgehender Erfüllung derselben in der Regel entsprechende Anerkennung seitens der Eltern oder anderer (Bezugs-)Personen erwirken.

Demgegenüber werden nahezu übereinstimmend Kindern und Jugendlichen mit geringem Altersabstand und gleichem Geschlecht ein höheres Maß an Konfliktpotenzial und Rivalität, aber auch eine engere Verbundenheit sowie Nähe zugeschrieben als gemischtgeschlechtlichen Geschwister(paare)n mit größerer altersbezogener Distanz. ${ }^{61}$ Primär bei Jungen seien Konkurrenz bzw. Rivalität in besonderem Maße vorherrschend. ${ }^{62}$ Zwar seien diese Konfliktmomente auch hinsichtlich Schwestern (latent) vorhanden, hier heben die meisten Forscherinnen und Forscher aber vorrangig die eruierte exklusive Nähe und Solidarität hervor. $^{63}$

56 Hierauf verweist bereits Walter Toman (vgl. Onnen-Isemann; Rösch: Schwesterherz, S. 76). Onnen-Isemann und Rösch explizieren des Weiteren: „Beträgt der Altersabstand zwischen dem Erstgeborenen und seiner Schwester mehr als zwei Jahre, so akzeptiert der ältere Bruder die Jüngere fürsorglich und entwickelt dabei ein Gefühl der Verantwortung. Das Mädchen hingegen wird leicht die weiblichen Rollenvorgaben akzeptieren, insbesondere wenn die Eltern dieses Verhalten durch ihr eigenes Beziehungsmodell unterstützen. Ist die Reihenfolge umgekehrt und somit das Mädchen das ältere, so wird es leicht veranlasst - auch durch das Vorbild der Mutter -, die Verantwortung und die Fürsorge für den jüngeren Bruder zu übernehmen." Ebd.

57 Vgl. Kaiser: Schwestern, S. 77.

58 Vgl. ebd., S. 83 u. Bollmann: Schwestern, S. 40.

59 Passiv meint hier das Vorleben bzw. die Vorbildfunktion der Bezugspersonen.

60 Kaiser verweist auf höhere Erwartungen, die an ältere Schwestern hinsichtlich des Umgangs mit jüngeren Geschwistern gestellt werden. Vgl. Kaiser: Schwestern, S. 83. Vgl. zum Einfluss gesellschaftlich vermittelter geschlechtsspezifischer Normen auf die Biographie von Schwestern auch Bollmann: Schwestern, S. 79f.

61 Vgl. ebd., S. 40.

62 Vgl. exemplarisch Kasten: Geschwisterbeziehung, Bd. 1, S. 167.

63 Vgl. Bollmann: Schwestern, S. 51. 


\section{Implikationen der Geschwisterbeziehung}

\section{Nähe und Verbundenheit}

Geschwister, die in einem Haushalt aufwachsen, sind allein aufgrund äußerer Bedingungen und Festlegungen oft eng aufeinander bezogen. Sie müssen des Öfteren ein Kinderzimmer bzw. einen Schlafraum teilen. Zudem wird gemeinhin von ihnen erwartet oder sie werden angeregt, sich gemeinsam zu beschäftigen. Auch ihre Sozialisationserfahrungen stimmen ,sowohl im internen (d.h. familialen Kontext, gemeinsames Elternhaus) als auch im externen Kontext (d.h. diachrone Lebensverläufe, geteilte Normen und Werte, gemeinsames Weltbild) ${ }^{\text {‘64 }}$ zumeist größtenteils überein. Folglich sind Gemeinsamkeiten und ähnliche Persönlichkeitsentwicklungen mit Blick auf Lebensentwürfe, -gestaltungen sowie -anschauungen vor allem bei altersnahen Geschwistern ebenso angelegt wie die Ausbildung von Gefühlen der Solidarität, Nähe und Vertrautheit. ${ }^{65}$ Die Geschwisterbeziehung kann daher auch als emotionale Gesinnungs- und Interessengemeinschaft bezeichnet werden. ${ }^{66}$

Eine solche Kongruenz, emotionale Verbundenheit und Intimität wird vor allem hinsichtlich geschlechtshomogener Geschwister(paare) mit geringem Altersabstand - und hier vor allem bezogen auf Schwestern - konstatiert. ${ }^{67}$ Schwestern ständen sich - wie u.a. eine Studie von Bert N. Adams belegt - besonders nahe bzw. am nächsten. So nannten 60 Prozent der Befragten, Verbundenheit', um ihr Schwesternverhältnis zu charakterisieren. ${ }^{68}$

Die letztlich implizierten, jedoch selten untersuchten Gefühle der gegenseitigen Loyalität bzw. Solidarität zeichnen sich laut Ulrich Schmidt-Denter konkret ,dadurch aus, dass die Geschwister ihre Identität wechselseitig während des ganzen Lebens beeinflussten, dass sie sich miteinander identifizierten sowie zu Opfern und Verpflichtungen bereit waren." ${ }^{\text {69 }}$ Das schließt unter anderem die gegenseitige Hilfe und Unterstützung (,,generative Solidarität““70) ein. Katharina Ley betont diesbezüglich zudem die ,primäre positive Bezogenheit“ “ ${ }^{71}$ unter Geschwistern als Ergebnis neuerer Forschungen. Stephen P. Bank und Michael

64 Ebd., S. 46.

65 Vgl. Schmidt-Denter: Soziale Beziehungen, S. 64.

66 Vgl. Bollmann: Schwestern, S. 47.

67 Dieser folgt die Schwester-Bruder-Beziehung und zuletzt die Bruder-Bruder-Beziehung, der somit gemeinhin die geringste Vertrautheit diagnostiziert wird.

68 Vgl. Schmidt-Denter: Soziale Beziehungen, S. 65.

69 Ebd., S. 64.

70 So Stephen Jay Gould (1989), zitiert nach Schmidt-Denter: Soziale Beziehungen, S. 66, vgl. auch Cierpka: Unterschiede, S. 18.

71 Ley: Geschwisterliche Räume, S. 71.

Ulrike Schneider, Helga Völkening and Daniel Vorpahl - 978-3-653-98812-3 
D. Kahn führen wiederum eine Wechselbeziehung von „Identifikation und Differenzierung، ${ }^{672}$ als charakteristische polare Grundstruktur innerhalb Geschwisterkonstellationen an, wobei das jeweilige Überwiegen bzw. eine etwaige Unterrepräsentation eines der beiden Momente die Persönlichkeitsentwicklung beeinträchtigen könne:

Bei Geschwisterpaaren mit starker Identifikation kann es so weit gehen, dass die Geschwister eine symbiotische Einheit bilden und kaum Individualität erkennen lassen. Im Gegensatz dazu gibt es Geschwister, die sich kaum miteinander identifizieren und sich dadurch wechselseitig beeinflussen, dass sie Merkmale des anderen für sich ausschließen. ${ }^{73}$

Identifizierungen figurieren Manfred Cierpka zufolge innerhalb altersunterschiedlicher Geschwisterdyaden konkret in der Form, dass die jüngeren Geschwister dazu neigen, ,ihre älteren Geschwister zu imitieren, zu bewundern und ihnen nachzueifern. ${ }^{674}$ Vor allem von genderhomogenen, altersnahen Geschwistern werde darüber hinaus bereits seitens des ,gesellschaftlichen und sozialen Umfelds erwartet, dass sie sich ähnlich verhalten“" ${ }^{75}$, so dass hier zudem die geschlechtsspezifische Sozialisation bzw. Rollenzuweisung homogenisierend wirke bzw. wirken könne.

Andererseits entstehe gerade aus der genannten Konstellation auch das Bedürfnis der Abgrenzung, der De-Identifikation bezüglich des geschwisterlichen Gegenübers und somit die Betonung und Ausbildung eigener Persönlichkeitsmerkmale sowie Individuationsbestrebungen ${ }^{76}$ Schmidt-Denter setzt diese Entwicklung aus psychoanalytischer Sicht für gleichgeschlechtliche Geschwister zeitlich ab dem sechsten Lebensjahr an: ,Jedes Kind betont nun seine Andersartigkeit, seine eigene Identität. Durch diesen Prozess entstehen Persönlichkeitsunterschiede zwischen den Geschwistern.“77

72 Schmidt-Denter: Soziale Beziehungen, S. 59.

73 Ebd., S. 60.

74 Cierpka: Unterschiede, S. 22.

75 Onnen-Isemann; Rösch: Schwesterherz, S. 18.

76 Cierpka weist ist diesem Zusammenhang zusätzlich auf die Erfahrung hin, eigene Charakterisierungen oft anhand von Vergleichen zu den Geschwistern zu formulieren, wobei Unterschiede prinzipiell eher betont bzw. häufiger angeführt werden, während Gemeinsamkeiten seltener erwähnt werden (vgl. Cierpka: Unterschiede, S. 11). Vgl. zum Wechselverhältnis zwischen dem „Ausleben“ der Ähnlichkeit und dem „Bedürfnis nach Verschiedenheit“, speziell unter Schwestern auch Fishel: Schwestern, S. 146.

77 Schmidt-Denter: Soziale Beziehungen, S. 53. Vgl. auch ebd., S. 62. Willi (1996) und Sulloway $(1995,1997)$ beschreiben diesen Individuationsprozess mit dem bereits angeführten (verhaltens-)biologischen Begriff der „Nischenbildung“ oder der „Nischenspezialisierung als eine Strategie der koexistierenden Konkurrenz“. Die „Vermeidung von Ni- 
Darüber hinaus beeinflussten allerdings ebenfalls die zuvor erwähnten vorgegebenen äußeren Faktoren (Geschwisterfolge, Alter, Geschlecht, Elternverhalten), die letztlich für jedes Individuum divergente familiale Erfahrungen beinhalten und entsprechend unterschiedlich prägen, die Ausbildung verschiedener Geschwisterpersönlichkeiten und -beziehungen. Neben den gemeinsamen Sozialisationserlebnissen (shared environment) werden somit in der gegenwärtigen Familienforschung auch die für die Geschwisterforschung relevanten, individuell unterschiedlichen Erfahrungen (non-shared environment ${ }^{78}$ ) und die divergenten persönlichkeitsbezogenen Voraussetzungen bzw. Ausgangslagen betont. ${ }^{79}$

\section{Abgrenzung und Rivalität}

Den De-Identifikations-, Abgrenzungs-, Differenzierungs- und Individuationsbestrebungen liegt letztlich das Moment der Geschwisterrivalität zugrunde, das sich allerdings nicht ausschließlich bzw. grundsätzlich negativ auswirkt. ${ }^{80}$ Aus tiefenpsychologischer Sicht gründet die Geschwisterrivalität im Trauma der „Entthronung“ der Erstgeborenen bei der Geburt des nachfolgenden Kindes. ${ }^{81}$ Laut einer Studie von Brian Sutton-Smith und Benjamin George Rosenberg ${ }^{82}$ (1970) ist Rivalität insbesondere in männlichen Geschwisterdyaden mit geringem Altersabstand und am niedrigsten zwischen geschlechtsheterogenen Geschwistern ausgebildet. ${ }^{83}$ Dies könne unter anderem in der direkten Vergleichs-

schenüberlappung bzw. „Nischenspezialisierung“ im familiären System gelte folglich als „eines der wichtigsten Motive, warum sich jedes Geschwister gegenüber den anderen möglichst unterscheiden will“. (Cierpka: Unterschiede, S. 16. Vgl. auch Schmidt-Denter: Soziale Beziehungen, S. 54).

78 Der Begriff basiert auf der Vorstellung einer nicht geteilten Umwelt zwischen Geschwistern. Vgl. Bollmann: Schwestern, S. 35; vgl. auch Cierpka: Unterschiede, S. 24

79 So auch Schmidt-Denter: „Längere Zeit nahm man an, dass Geschwister denselben Umwelteinflüssen ausgesetzt sind, da sie in identischen Familien leben und auch sonst ein vergleichbares soziales Netzwerk haben. Die neuere Forschung konnte jedoch einen überraschend großen Anteil nicht-gemeinsamer Umwelt aufzeigen (vgl. Hetherington et al., 1994). Bei der Konstruktion nicht-gemeinsamer Umwelten von Geschwistern sind zwei Mechanismen wirksam, zum einen unterschiedliche Einflüsse auf die Kinder, zum andern aber auch selektive Prozesse, die auf die Individualität der Kinder zurückzuführen sind“. (Schmidt-Denter: Soziale Beziehungen, S. 58).

80 Fishel betont die Relevanz der Rivalität für die Förderung des Differenzierungs- und Individuationsprozesses, der „,im Grunde genommen keine Schranke der Freundschaft, sondern in vielen Fällen ein notwendiger und natürlicher Teil davon" sei (Fishel: Schwestern, S. 146).

81 Vgl. Schmidt-Denter: Soziale Beziehungen, S. 53.

82 Sutton-Smith, Brian; Rosenberg, Benjamin George: The Sibling. New York 1970.

83 Vgl. Schmidt-Denter: Soziale Beziehungen, S. 65f.

Ulrike Schneider, Helga Völkening and Daniel Vorpahl - 978-3-653-98812-3 
möglichkeit und ähnlichen persönlichen, elterlichen und gesellschaftlichen Erwartungen gegenüber gleichgeschlechtlichen Geschwistern begründet sein. Eltern könnten allerdings zumindest verstärkend oder mildernd einwirken. ${ }^{84}$

Zugleich bietet die Geschwisterbeziehung, so Willard W. Hartup, ein „,besonderes Übungsfeld für Kontroll- und Regulationsmechanismen aggressiven Verhaltens ${ }^{\text {“ } 85}$, welches in vertikalen, asymmetrischen Eltern-Kind-Beziehungen nicht angemessen wäre und innerhalb der Peer Group zum Beziehungsabbruch führen könnte:

In Geschwisterbeziehungen wird erprobt, Spannungen unter Fortführung der Beziehung zu meistern. Der stabile Kontext ermöglicht wichtige Erfahrungen in der Bewältigung und Kontrolle aggressiver Motivationen. ${ }^{86}$

\section{Resümee}

Geschwisterbeziehungen gestalten sich somit stets individuell, durch diverse Faktoren unterschiedlich determiniert. Gleichzeitig sind sie dynamisch, da sie sich im Laufe des persönlichen Lebens oder auch in unterschiedlichen zeitsowie kulturgeschichtlichen Kontexten durchaus variabel bzw. wandelbar erweisen und entsprechend unterschiedlich bewertet werden. Ihre Ambivalenz gründet einerseits in der Vorgegebenheit derselben, welche zumeist auf die gesamte Lebensspanne bezogen ist und darüber hinaus in der ihr inhärenten Nähe und Vertrautheit. Diese stellen letztlich eine unmittelbare Konsequenz der gemeinsam erlebten primären Sozialisation, weiterer geteilter Erfahrungen und vielfältiger geschwisterlicher Interaktionen dar und prägen die geschwisterliche Beziehung sowie die individuelle Persönlichkeit gemeinhin lebenslang. Für das Geschwisterverhältnis sind somit Identifikations- und De-Identifikationsprozesse gleichermaßen charakteristisch: Momente der Rivalität, des Neids, der Machtausübung und Aggression alternieren mit Gefühlen der Verbundenheit und Vertrautheit, gegenseitiger Loyalität, Unterstützung sowie Hilfe.

Als ebenfalls weitgehend horizontale, intragenerative Beziehung ähnelt letztlich die Freundschaft in vielerlei Hinsicht der Geschwisterbeziehung. Für beide sind gemeinsame entwicklungs- und zeitbezogene identitätsbildende

84 Vgl. Cierpka: Unterschiede, S. 23.

85 Schmidt-Denter: Soziale Beziehungen, S. 60.

86 Ebd., S. 61. Katharina Ley greift in diesem Zusammenhang den Gedanken der Geschwister als „,Übergangsobjekte“ (Wellendorf 1995)“ auf, „Figuren zwischen den Eltern und späteren Freunden, Freundinnen, Kollegen, Kolleginnen, Geliebten. Mit Bruder und Schwester werden Probeläufe für die große Erweiterung der Lebensbühne durchgeführt, und zwar in der ganzen Vielfalt geschwisterlicher Gefühle von Liebe und Haß, Begehren und Ablehnung, konstruktiver und destruktiver Rivalität." Ley: Geschwisterliche Räume, S. 72. 
Sozialisationserfahrungen ebenso prägend wie die daraus resultierende (annähernde) Egalität innerhalb der Beziehungen, die emotionale Bindung und Fürsorge. Sie unterscheiden sich jedoch durch die freie Wählbarkeit der Freundschaftsbeziehung, durch die Möglichkeit ihrer vollständigen Aufhebbarkeit, die zumeist kürzere Dauer bzw. ihren späteren Beginn sowie hinsichtlich des divergenten familialen Kontextes. ${ }^{87}$ Positiv oder optimistisch ließe sich dies bezogen auf die Geschwisterbeziehung mit den Worten Susann Sitzlers wie folgt ausdrücken: „In dieser Beziehung schaffen wir etwas, was uns mit Freunden oft nicht gelingt: Wir können einen anderen Menschen annehmen, ohne Bedingungen an ihn zu stellen." ${ }^{\circ 8}$

\section{Literatur}

Adler, Alfred: Menschenkenntnis. Köln 2008.

Bank, Stephen P.; Kahn, Michael D.: The Sibling Bond. 2. Aufl., New York 1997. (Deutsche Übersetzung: Geschwister-Bindung. Paderborn 1989).

Bollmann, Vera: Schwestern. Interaktion und Ambivalenz in lebenslangen Beziehungen. Wiesbaden 2012.

Burholt, Vanessa; Wenger, G. Clare: Differences over Time in Older People's Relationshipswith Children and Siblings, in: Ageing and Society, Nr. 18 (1998), S. 537-562.

Cicirelli, Victor G.: Sibling Relationships across the Life Span. New York, London 1995.

Cierpka, Manfred: Unterschiede und Gemeinsamkeiten bei Geschwistern, in: Sohni, Hans (Hrsg.): Geschwisterlichkeit. Horizontale Beziehungen in Psychotherapie und Gesellschaft. Göttingen 1999, S. 10-31.

Fishel, Elizabeth: Schwestern. Liebe und Rivalität innerhalb und außerhalb der Familie. Berlin u.a. 1979.

Kaiser, Peter: Schwestern im familialen Systemkontext, in: Onnen-Isemann, Corinna; Rösch, Gertrud Maria (Hrsg.): Schwestern. Zur Dynamik einer lebenslangen Beziehung. Frankfurt/Main, New York 2005, S. 65-88.

Kasten, Hartmut: Die Geschwisterbeziehung, Bd. 1. Göttingen 1993.

Kasten, Hartmut: Die Geschwisterbeziehung, Bd. 2: Spezielle Geschwisterbeziehungen. Göttingen u.a. 1993.

Kasten, Hartmut: Geschwister. Vorbilder, Rivalen, Vertraute. München 2003.

Klosinski, Gunther: Verschwistert mit Leib und Seele - beglückt oder bestraft, in: Klosinski, Gunther (Hrsg.): Verschwistert mit Leib und Seele. Geschwisterbeziehungen gestern heute - morgen. Tübingen 2000, S. 9-18.

Klosinski, Gunther (Hrsg): Verschwistert mit Leib und Seele. Geschwisterbeziehungen gestern - heute - morgen. Tübingen 2000.

König, Karl: Brothers and Sisters. A Study in Child Psychology. New York 1963.

87 Vgl. hierzu ausführlich: Bollmann: Schwestern, S. 48 u. Onnen-Isemann; Rösch: Schwesterherz, S. 112.

88 Sitzler: Geschwister, S. 17. 
Labouvie, Eva: Zur Einstimmung und zum Band, in: Labouvie, Eva (Hrsg.): Schwestern und Freundinnen. Zur Kulturgeschichte weiblicher Kommunikation. Köln u.a. 2009, S. 1131.

Labouvie, Eva (Hrsg.): Schwestern und Freundinnen. Zur Kulturgeschichte weiblicher Kommunikation. Köln u.a. 2009.

Ley, Katharina: Geschwisterliche Räume. Stimmen der Horizontale im Geschwisterlichen und in der Psychotherapie, in: Sohni, Hans (Hrsg.): Geschwisterlichkeit. Horizontale Beziehungen in Psychotherapie und Gesellschaft. Göttingen 1999, S. 67-81.

Lüscher, Berit: Die Rolle der Geschwister. Chancen und Risiken ihrer Beziehung. Berlin 1997.

Onnen-Isemann, Corinna: Geschwisterbeziehungen aus soziologischer Perspektive, in: Dies.; Rösch, Gertrud Maria (Hrsg.): Schwestern. Zur Dynamik einer lebenslangen Beziehung. Frankfurt/Main, New York 2005, S. 23-36.

Onnen-Isemann, Corinna; Rösch, Gertrud Maria (Hrsg.): Schwestern. Zur Dynamik einer lebenslangen Beziehung. Frankfurt/Main, New York 2005.

Onnen-Isemann, Corinna; Rösch, Gertrud Maria: Schwesterherz - Schwesterschmerz. Schwestern zwischen Solidarität und Rivalität. Heidelberg 2006.

Reberg, Sonja: Die Entwicklung der Geschwisterbeziehung unter handlungstheoretischer Perspektive. Eine Längsschnittstudie an Geschwisterpaaren mit zweijährigem Altersabstand. Frankfurt/Main 2001.

Röbke, Thomas: Geschwister. Wie sie uns lebenslang prägen, in: Senioren-Ratgeber der Apotheke, Juni 2011, S. 63-69.

Schlemmer, Elisabeth: Wie erleben Mädchen und Jungen die Geburt eines Geschwisters? Sozialemotionale Kompetenz und Leistungsverhalten aus Elternsicht, in: OnnenIsemann, Corinna; Rösch, Gertrud Maria (Hrsg.): Schwestern. Zur Dynamik einer lebenslangen Beziehung. Frankfurt/Main, New York 2005, S. 37-64.

Schmid, Christine: Geschwister und die Entwicklung soziomoralischen Verstehens. Der Einfluß von Altersabstand und Geschlecht jüngerer und älterer Geschwister im Entwicklungsverlauf. Berlin 1997.

Schmidt-Denter, Ulrich: Soziale Beziehungen im Lebenslauf. Lehrbuch der sozialen Entwicklung. Weinheim, Basel 2005.

Schütze, Yvonne: Geschwisterbeziehungen, in: Nave-Herz, Rosemarie; Markefka, Manfred (Hrsg.): Handbuch der Familien- und Jugendforschung. Neuwied, Frankfurt/Main 1989, S. 311-324.

Sitzler, Susann: Geschwister. Die längste Beziehung des Lebens. Stuttgart 2014.

Sohni, Hans: Einführung, in: Sohni, Hans (Hrsg.): Geschwisterlichkeit. Horizontale Beziehungen in Psychotherapie und Gesellschaft. Göttingen 1999, S. 5-9.

Sohni, Hans (Hrsg.): Geschwisterlichkeit. Horizontale Beziehungen in Psychotherapie und Gesellschaft. Göttingen 1999.

Thelen, Tatjana; Coe, Cati; Alber, Erdmute: The Anthropology of Sibling Relations. Explorations in Shared Parentage, Experience, and Exchange, in: Dies. (Hrsg.): The Anthropology of Sibling Relations. Shared Parentage, Experience, and Exchange. New York 2013, S. 1-26.

Toman, Walter: Familienkonstellationen. Ihr Einfluss auf den Menschen. 7. Aufl., München 2002. 
Zukow, Patricia Goldring (Hrsg.): Sibling Interaction across Cultures. Theoretical and Methodological Issues. New York 1989. 


\section{Exegetische Studien zur Präsenz von Geschwisterbeziehungen in religiösen Traditionen}


Ulrike Schneider, Helga Völkening and Daniel Vorpahl - 978-3-653-98812-3

Downloaded from PubFactory at 01/11/2019 10:54:37AM

via free access 


\title{
Geschwisterlichkeit als sozialethische Matrix des Volkes Israel in der Tora
}

\author{
Daniel Vorpahl
}

\begin{abstract}
The Tora tells not alone about biological siblings, but uses the word 'brothers' likewise in a broader meaning. The figuratively use of sibling-terms reaches from an institutionalized status of legal protection within the extended family, to an allegorical abstraction as a collective brotherhood of tribal comrades, to an instrumentalization as a national etiological brotherhood for the purpose of historical interpretation of Israel's relations to neighboring people. This article exposes how all this is already laid out in the stories of biological brothers and sisters within the Tora to work out a socio-ethical matrix for Israel's sense of national identity.
\end{abstract}

Am 10. Dezember 1948 verabschiedete die Generalversammlung der Vereinten Nationen in Paris die Allgemeine Erklärung der Menschenrechte. Die 30 Artikel umfassende UN-Menschenrechtscharta bedeutet ein ausdrückliches Bekenntnis zur freiheitlichen Gleichstellung und Wertschätzung aller Menschen. Und sie ist nicht etwa ein westliches Diktum, sondern hat Ideengeber und Vorläufer in verschiedensten Kulturkreisen. ${ }^{1}$

Artikel 1 dieser Menschenrechtserklärung beginnt in der offiziellen deutschsprachigen Fassung wie folgt:

Alle Menschen sind frei und gleich an Würde und Rechten geboren. Sie sind mit Vernunft und Gewissen begabt und sollen einander im Geist der Brüderlichkeit begegnen. $^{2}$

Der Begriff der Brüderlichkeit ist hier zweifelsohne dem legendären Schlachtruf der Französischen Revolution, „liberté, égalité, fraternité“, entlehnt. Auch die anderen beiden Begriffe dieser Losung, Freiheit und Gleichheit, finden sich in der UN-Menschenrechtserklärung wieder. ${ }^{3}$ Demnach steht der „Geist der Brüderlichkeit“" an dieser Stelle als ein weltumspannendes Instrument zur Wahrung der Menschenrechte, zum Erhalt von Frieden und gegenseitiger Wertschätzung.

1 Exemplarisch lässt sich dies an der sogenannten „Goldenen Regel“ ersehen, die in jeweiliger geistesgeschichtlicher Autonomie in verschiedensten Kulturen, Glaubens- und Denkrichtungen weltweit nahezu gleichlautend formuliert worden ist. Vgl. Hertzler, Joyce: The Golden Rule and Society, in: Gensler, Harry J. u.a. (Hrsg.): Ethics. Contemporary Readings. New York u.a. 2004, S. 158-166, hier S. 159-162.

2 Allgemeine Erklärung der Menschenrechte, in: Menschenrechte. Dokumente und Deklarationen. Hrsg. v. Bundeszentrale für politische Bildung. Bonn 2004, S. 54-59, hier S. 55.

3 Vgl. ebd., S. 55f. (Artikel 3, 7 und 10).

Ulrike Schneider, Helga Völkening and Daniel Vorpahl - 978-3-653-98812-3 
Tatsächlich war die Fraternité-Forderung der Französischen Revolution vielleicht der früheste Zeitpunkt, zu dem der Begriff der Brüderlichkeit tatsächlich eher als geschlechteräquivalente Geschwisterlichkeit gemeint war, insofern er keinen Männerbund auszurufen suchte, sondern die soziopolitische Gleichstellung verschiedener gesellschaftlicher Klassen anstrebte. ${ }^{4}$

Blickt man auf die gemeinhin populärsten Geschwister der Tora, ${ }^{5}$ so scheint ein ,friedliches Miteinander" zumindest nicht vorrangig konstitutiv für deren Zusammenleben und Auskommen. Insbesondere aus der diametralen Umsetzung der gesetzten Erbfolge ergeben sich wiederholt Konflikte zwischen älteren und jüngeren Geschwistern. Denn bevorzugte jüngere Geschwister kennt die Tora einige: Abel gegenüber Kain, Isaak anstelle von Ismael, Josef vor seinen Brüdern, Efraim gegenüber Manasse oder Rachel gegenüber Leah. ${ }^{6}$

Dieser ersteindrückliche Konflikt-Befund hinsichtlich Geschwistern in der Tora lässt sich allerdings nicht anhand des antiken Alters ihrer Texte gegenüber der freiheitlich aufgeklärten UN-Menschenrechtscharta erklären. Schließlich kann die Tora in einiger Hinsicht als Vorreiter neuzeitlichen Rechtsverständnisses gelten, ${ }^{7}$ während auch im Jahre 2014 noch immer schlimmste Menschenrechtsverletzungen dokumentiert werden mussten.

Auch die Erkenntnisse soziologischer und psychologischer Geschwisterforschung zeichnen ein wesentlich differenzierteres Beziehungsbild als das der reinen Geschwisterliebe. ${ }^{8}$ Und wer aus der persönlichen Erfahrung eigener

4 Jedoch kann keine Rede davon sein, dass sich demnach die gesellschaftliche Situation der Frau gebessert hätte. Vgl. dazu Beauvoir, Simone de: Das andere Geschlecht. Sitte und Sexus der Frau. Reinbek b. Hamburg 2005, S. 150-153 sowie den Artikel von Helga Völkening „,Dann sei dir darüber im Klaren, daß du auch ein Bruder bist‘. Prämissen, Implikationen und Funktionen geschwisterbezogener Terminologie, Rezeption und Metaphorik - Versuch einer disziplinübergreifenden Systematisierung" in diesem Band. Auch jüngst, seit 2014, müssen die Vereinten Nationen durch die Kampagne „HeForShe“ immer noch um das „,brüderliche“ Eintreten von Männern im Kampf für geschlechtliche Gleichstellung werben. Vgl. www.heforshe.org.

5 Gemeint ist hier die schriftliche Tora im engsten Sinne der fünf Bücher Mose.

6 Vgl. Greenspahn, Frederick E.: When Brothers Dwell Together. The Preeminence of Younger Siblings in the Hebrew Bible. New York 1994, S. 13 u. Vaux, Roland de: Das Alte Testament und seine Lebensordnungen. Bd. 1: Fortleben des Nomadentums, Gestalt des Familienlebens, Einrichtungen und Gesetze des Volkes. Freiburg u.a. 1960, S. 79.

7 Vgl. dazu Azzola, Axel: Recht, Freiheit und Bündnis in der Tora. Grundlegungen für eine jüdische systematische Theologie. Berlin 2006, S. 26f. u. 56f. und Vorpahl, Daniel: „Es war zwar unrecht, aber Tradition ist es.“ Der Erstgeburtsrechts- und Betrugsfall der Brüder Jakob und Esau. Potsdam 2008, S. 83f.

8 Vgl. dazu Petri, Horst: Geschwister. Liebe und Rivalität. Die längste Beziehung unseres Lebens. Stuttgart 2006, S. 8-11 sowie den Artikel von Helga Völkening ,Themen, Kon- 
Geschwister zu schöpfen vermag, wird Geschwisterlichkeit womöglich auch vielmehr als ein jahrelanges Auskommen und Festhalten aneinander erlebt haben, trotz zahlreicher Differenzen - und zwar genau deshalb, weil man eben im engsten Sinne verwandt ist.

Ein Stück weit gehorcht leibliche Geschwisterlichkeit schlichtweg dem Gesetz der biographischen Ausweglosigkeit, was die Toleranzschwelle gegenüber Geschwistern nicht selten vergrößert, mitunter nahezu ins Unendliche ausdehnen mag. Solch individualistische Aspekte von Geschwisterlichkeit ließen sich durchaus auch im Rahmen einer kulturanthropologischen Behandlung des Gegenstandes reflektieren. Doch halte ich es für elementar, persönliche Geschwistererfahrungen offensiv in die Vorreflexion dieses Begriffes einzubeziehen, da eine kulturgeschichtliche Betrachtung von Geschwisterlichkeit für jeden mit entsprechender familiärer Prägung nicht an eben deren Reflexion vorbeiführt. Dieser individuelle Blickwinkel sollte offen ausgesprochen werden, um klar ins Bewusstsein zu gelangen und dort von objektiver wissenschaftlicher Erkenntnis differenziert werden zu können. Nur so werden Vorkenntnis und individuelle Prägung zu einer bewussten Bereicherung der Forschung: als Motivation und Inspiration, aber auch als Mahnung zu weitgehender wissenschaftlicher Objektivität. Eben jene Form der Vorreflexion ist im Übrigen auch einer der ersten methodischen Schritte bibelwissenschaftlicher Hermeneutik und demnach ein idealer Einstieg in die Untersuchung des Geschwisterbegriffes der Tora.

Eine gewisse Spannung wohnt der Geschwisterlichkeit nicht nur in ihrer jeweiligen individuellen familialen Ausprägung inne. Sie ergibt sich in besonderem Maße auch für deren Begriff, sobald er in einem übertragenen Sinne Anwendung findet. So bedeutet die weltpolitische „Brüderlichkeit“, wie sie die UNMenschenrechtscharta lanciert, die ideologische Instrumentalisierung eines allegorisch fixierten Begriffes. ${ }^{9}$ Dabei bleibt jedoch bislang weitgehend ungeklärt, inwiefern dieser allegorische Begriff auf die Erfahrung leiblicher Geschwisterlichkeit zurückgeht, also auf welche derer vermeintlichen Eigenschaften oder Aspekte er rekurriert. Diese mangelnde Reflexion ist umso er-

texte und Perspektiven sozial- und individualpsychhologischer Geschwisterforschung Ein Überblick" in diesem Band.

9 Der hier und im Folgenden verwendete Allegorie-Begriff beruht auf der Auffassung, dass die reale zwischenmenschliche Beziehung von Geschwistern jeweils mithilfe des Geschwisterbegriffs als rational fassbares Bild zur Darstellung eines abstrakten Begriffes dient. Jeweilige Bedeutung und Spektrum jenes abstrakten Begriffs sollen im Rahmen dieses Artikels ermittelt werden. Die Geschwisterlichkeit dient demnach also der Rationalisierung eines anderen, abstrakten Begriffes, womit eine Allegorie vorliegt. 
staunlicher, als dass der Geschwisterbegriff gar keinen anderen Ursprung haben kann als den der biologischen Verwandtschaft.

Was also ist mit einer Geschwisterlichkeit gemeint, die wie selbstverständlich ein positives, gemeinschaftsstiftendes Ideal, wie das der allgemeinen Menschrechte oder des Freiheitsgeistes der Französischen Revolution, verkörpern soll, dafür aber einen Begriff verwendet, der in der individuellen und sozialen Erfahrungswelt für ein wesentlich ambivalenteres, um nicht $\mathrm{zu}$ sagen schwieriges Beziehungsverhältnis steht?

Von der familialen Lebenswelt bis zur Allegorisierung und schließlich Ideologisierung von Geschwisterlichkeit müssen vielschichtige Prozesse kultureller Tradierung und Transformation überwunden werden. Diese Prozesse sind keineswegs eine Erfindung der Moderne. Sie lassen sich bereits innerhalb der Antike feststellen und nachvollziehen. So auch in der Tora, als einer der ältesten und komplexesten Zusammenstellungen von Textzeugnissen antiker Sozialisation und Kulturbildung. Bereits innerhalb jener narrativen Texte, die von den eingangs erwähnten streitenden Geschwistern handeln, ist so etwas wie eine idealisierte Institutionalisierung und schließlich eine allegorische Übertragung von Geschwisterlichkeit angelegt. Die Entwicklung von einem leiblich-biographischen hin zu einem idealisiert-allegorischen Geschwisterbegriff lässt sich daher auch innerhalb der Tora beobachten und untersuchen. Die daraus ermittelbaren Prozesse der Entwicklung und Wandlung des Geschwisterbegriffs können und sollen freilich nicht als allgemeingültige Phänomene erschlossen werden. Ich möchte sie aber im Folgenden als einen Ausgangspunkt einer Kulturgeschichte des Geschwisterbegriffs innerhalb eines frühen literarischen Dioramas verstehen und darlegen.

\section{Die stufenweise Abstraktion des Geschwisterbegriffs}

\section{Innerfamiliale Anwendung}

Das Wortfeld des Geschwisterbegriffs ist im biblischen Hebräisch recht übersichtlich. Für Bruder (אח, Pl. אחים) und Schwester (אחיות) Pl. אחיות) gibt es jeweils nur ein Wort. Für gemischtgeschlechtliche Gruppen wird die maskuline Pluralform (אחים) verwendet. ${ }^{10}$ Jedoch reicht die Anwendung und Bedeutung der hebräischen Bruder- und Schwester-Begriffe wesentlich weiter.

10 Vgl. Gesenius, Wilhelm: Hebräische Grammatik. Überarb. v. E. Kautzsch, Leipzig 1909, S. 490 ( $\$ 146 d)$. Die Subsummierung von Schwestern bzw. Brüdern unter einem grammatisch eingeschlechtlichen Begriff gilt in vielen Sprachen, im Deutschen etwa für die Verwendung des Wortes ,Geschwister", ursprünglich eine Pluralform für den Begriff ,Schwester'. Vgl. Grimm, Jacob; Grimm, Wilhelm: Deutsches Wörterbuch. Bd. 5. Leipzig 1854-1961, Sp. 4003. 
Leibliche Geschwister gehören zunächst einmal, gemäß der Tora, zu den engsten Verwandten, ${ }^{11}$ worüber uns vor allem Lev 18 aufklärt, wenn dort der Geschlechtsverkehr unter den nächsten Verwandten verboten wird. Auch soll man Geschwistern Unterstützung angedeihen lassen, sie nicht übervorteilen, keine Zinsen von ihnen nehmen ${ }^{12}$ und die Frau des eigenen Bruders ggf. durch die Leviratsehe absichern (Dtn 25,5-9; Gen 38,6-11). Letztere Aufforderung richtet sich zunächst eindeutig an den Schwager (יבם) der Witwe (Dtn 25,5), überträgt sich aber im Falle dessen Todes bzw. Fehlen auf den nächsten männlichen Verwandten (Rut 2,20 u. 3,12). Im Buch Genesis (Bereschit) treten schließlich gar Formen eines Fratriarchats zutage, ${ }^{13}$ wenn sich Abram, nach dem frühen Tod seines Vaters (Gen 11,31f.), des Sohnes seines ebenfalls verstorbenen Bruders Haran (11,27f.) annimmt $(12,4 \mathrm{f}$.).

All diese ethischen und sozialen Verhaltensrichtlinien gegenüber Geschwistern lassen auf eine besondere Wertschätzung, aber auch Reinheit der Geschwisterbeziehung schließen. ${ }^{14}$ Worauf sich diese allerdings begründen, gilt es hier noch zu ermitteln. Ich werde daher im letzten Teil meines Artikels konkreter auf die leiblichen Geschwister der Tora zu sprechen kommen. Um den Prozessen der Entwicklung des Geschwisterbegriffs von seinem leiblich-biographischen Ursprung hin zu dessen übertragener Anwendung nachzuspüren, also gewissermaßen nach dem allegorischen Fußabdruck der Geschwisterlichkeit in anderen soziokulturellen Ebenen zu suchen, sei jedoch zunächst nicht der „Fuß“ selbst, sondern tatsächlich dessen jeweiliger „Abdruck“ betrachtet.

Verfolgen wir also zuerst, auf welche Weise der Geschwisterbegriff der Tora über leibliche Geschwister hinausgehend allegorisiert bzw. institutionalisiert, wenn nicht gar instrumentalisiert wird. Dabei lassen sich mehrere Abstraktionsstufen feststellen. Ausgehend von leiblichen Geschwistern finden wir zunächst die Ausdehnung des Geschwisterverständnisses auf verwandtschaftliche Beziehungen im weiteren Sinne, und das in voller sprachlicher Konsequenz, obgleich das biblische Hebräisch auch über alternative Begriffe verfügt.

11 Ferner zählen dazu Mutter, Vater, Tante und Onkel. Grundsätzlich gilt zudem, dass auch Halbgeschwister als Geschwister zählen. Vgl. Lev 18,11; 2 Sam 3,2f. u. 13,4 sowie dazu Wolff, Hans W.: Anthropologie des Alten Testaments. München 1990, S. 273 (FN 9).

12 Vgl. Lev 25,25.35-37; Dtn 15,2f. und dazu Wolff: Anthropologie, S. $273 \mathrm{f}$.

13 Vgl. ebd., S. 271.

14 Als Reinheit ist hier v.a. die ethische und sexuelle Unschuld in der Begegnung von Geschwistern, wie generell engster Verwandter, zu verstehen. Allerdings spricht Friedrich Fechter Lev 18 einen normativen Stellenwert zumindest für die früheste Zeit des Volkes Israel ab. Vgl. Fechter, Friedrich: Die Familie in der Nachexilszeit. Untersuchungen zur Bedeutung der Verwandtschaft in ausgewählten Texten des Alten Testaments. Berlin u.a. 1998, S. 314. 
Als Abram und sein Neffe Lot - nach dem Tode beider Väter - über ihre Viehherden in Streit geraten, befriedet Abram Lot mit den Worten „Wir sind doch verbrüderte Männer“'15 (Gen 13,8). Auch als Lot später in Not gerät und Abram ihm helfen will, wird Lot unmittelbar „Bruder“ (Gen 14,14.16) Abrams genannt. M.E. kann hier nicht allein das lexikographische Argument geltend gemacht werden, der hebräische Bruder-Begriff אח bezeichne schlichtweg auch den Verwandten im Allgemeinen. ${ }^{16}$ Gerade für die Bezeichnung ,Neffe ${ }^{6}$ stehen im biblischen Hebräisch auch alternative Wendungen zur Verfügung, allen voran der "Sohn des Bruders“ (בן־אח), wie er auch auf Lot an anderer Stelle Anwendung findet (Gen 12,5 u. 14,12).

Obwohl das biblische Hebräisch verschiedene Verwandtschaftsbegriffe kennt, ${ }^{17}$ wird der Begriff ,Bruder' also innerhalb der eigenen Sippe auf Verwandte dritten oder gar vierten Grades ausgedehnt, und das nicht erst wenn wie im Falle Abrams und Lots - der jeweils nähere Verwandte bereits gestorben ist. In der anthropologischen bzw. ethnosoziologischen Erforschung von Verwandtschafterminologien kennt man dieses wechselhafte System zur Bezeichnung von Verwandtschaftstypen unter dem Begriff des ,bifurcate merging". Verwandte gleichen Grades werden demnach unterschiedlich bezeichnet, beispielsweise die Brüder der Eltern mütterlicherseits als ,Onkel', väterlicherseits dagegen ebenfalls als ,Vater ${ }^{6}{ }^{18}$ Dieses differente Bezeichnungssystem mag der Regulierung von innerfamilialen Eheschließungen dienen oder auch schlicht unterschiedlich empfundene und gelebte Nähe zu Verwandten gleichen Grades zum Ausdruck bringen, wobei die Anwendung der Bezeichnungen auch je nachdem variieren kann, ob über die Verwandten in der dritten Person gesprochen wird oder sie direkt angeredet werden. ${ }^{19}$ Bei der hier dargelegten Handhabung des Brüderbegriffes innerhalb der Tora werden jedoch dieselben Verwandten sowohl in indirekter als auch in direkter Rede entweder mit dem regulären Verwandtschaftsbegriff oder als ,Bruder' bezeichnet (Gen 14,12.14.16). Der Grund des Wechsels der Verwandtschaftsbezeichnung, genauer die Ausdehnung

15 Sämtliche Übersetzungen von Bibelzitaten stammen vom Autor, auf der Grundlage der Biblia Hebraica Stuttgartensia/תורה נביאים וכתובים. Hrsg. v. Karl Ellinger; Wilhelm Rudolph u.a. Stuttgart 2007.

16 Vgl. Gesenius, Wilhelm: Hebräisches und Aramäisches Handwörterbuch über das Alte Testament. Berlin u.a. 2013, S. 32.

17 So etwa דוד für ,Onkel', ,Verwandter' oder ,Neffe‘, מודע für ,Bekannter“ oder ,Verwandter', קרוב für ,Verwandtschaft', ,Verwandter' oder ,Freund' und רעוד für ,Stammverwandter', , Volksgenosse‘ oder, Verwandter'. Vgl. ebd., S. 243, 634, 1191 u. 1251f.

18 Vgl. Weisberg, Dvora E.: Levirate Marriage and the Family in Ancient Judaism. Waltham 2009, S. 52f.

19 Vgl. ebd.

Ulrike Schneider, Helga Völkening and Daniel Vorpahl - 978-3-653-98812-3 
des Geschwisterbegriffes auf Verwandte dritten oder vierten Grades, kann in der Tora demnach nicht systematischer Natur sein.

Der Erklärungszugang zur innerfamilialen Ausdehnung des Geschwisterbegriffs in der Tora dürfte stattdessen in deren jeweiligem situativen Kontext liegen bzw. in der Gemeinsamkeit aller entsprechenden Situationen bestehen. In Gen 29,13 wird Labans Neffe Jakob als ,Sohn seiner [gemeint ist Laban, D.V.] Schwester“ (בן־אחתו) bezeichnet, zwei Verse später aber von seinem Onkel als „mein Bruder“ (אחי, 29,15) angeredet. Laban, der im Folgenden den Lohn für Jakobs Dienstzeit aushandeln will und ihm schließlich seine ältere Tochter Lea anstatt der vereinbarten jüngeren Rachel unterschiebt (Gen 29,25), dürfte hier mit voller Absicht von dem nächstmöglichen Verwandtschaftsbegriff Gebrauch machen. Denn es zeigt sich, dass die Praxis der Anrede naher und ferner Verwandter als ,Bruder' jeweils vorrangig zur eigenen Vorteilsbildung Anwendung findet. Dies geschieht innerhalb von Streitigkeiten (Gen 13,8; 31,32.37.46.54), Notlagen $(14,14)$ oder anderen Situationen von existenzieller Relevanz $(29,4$; Num 36,2), wie etwa wenn sich Misael und Elizafan der Leichname ihrer Großcousins - hier „Brüder“ genannt - annehmen sollen (Lev 10,4). Auch Jakob bezeichnet sich gegenüber der von ihm auf Anhieb geliebten Rachel als Bruder ihres Vaters und Sohn Rebekkas (Gen 29,12), schafft damit Vertrauen und schickt nicht zuletzt die Legitimität ihrer späteren Heirat vorweg.

Die Berufung auf die Brüderlichkeit fungiert in den Erzählungen der Tora also immer wieder als Vertrauensgrundlage, zur Einforderung gewisser Rechte und in Gefahrensituationen noch konkreter als Schlichtungsargument, um zumindest eine unmittelbare Eskalation zu vermeiden. Doch nur an drei Stellen der Tora gilt dies entsprechend auch für den Schwester-Begriff: Sowohl Abraham als auch Isaak geben ihre Frauen gegenüber Fremden als ihre Schwestern aus, so dass sie selbst am Leben bleiben, ja gar um ihrer vermeintlichen Schwester willen gut versorgt werden. ${ }^{20} \mathrm{Um}$ ihr eigenes Leben zu schützen, setzen beide Stammväter Sarah bzw. Rebekka körperlicher Gewalt und Entwürdigung aus. ${ }^{21}$ Gerade an diesen Stellen mag man wieder darauf verweisen, dass der SchwesterBegriff אחות auch allgemein die Verwandte bezeichnen kann. ${ }^{22}$ Verstanden wird er in allen drei Texten jedoch als Ausdruck einer Beziehung, die von der Ehe ausgeschlossen ist. Vor allem aber belegt bereits die dementsprechende Argumentation Abrahams in Gen 20,12 ihrem eigenen Kontext nach, dass die

20 Vgl. Gen 12,11-16; 20,2 u. 26,7.

21 Eine Entwürdigung meint hier, neben der in der Tora unerwähnt bleibenden persönlichen Demütigung der Frauen, vor allem die theologisch relevante Bedrohung der ethnischen Unversehrtheit der stammelterlichen Erblinie Israels. Vgl. Gen 20,3-7 u. 26,10.

22 Vgl. Gesenius: Handwörterbuch, S. 35.

Ulrike Schneider, Helga Völkening and Daniel Vorpahl - 978-3-653-98812-3 
Anwendung des Geschwisterbegriffs, ohne nähere Spezifikation, existenzstabilisierende Konsequenzen nach sich zieht bzw. genau diese auch zum Ziel hat.

Soweit lässt sich festhalten, dass Geschwisterlichkeit im erweiterten familialen Sinne in der Tora als Vertrauens- und Rechtsschutzstatus fungiert. Hintergrund der Inanspruchnahme einer solchen innerfamilialen Immunität dürften die zugleich an leibliche Geschwisterlichkeit geknüpften Pflichtverhältnisse sein: So hatten Geschwister, spätestens nach dem Tode der gemeinsamen Eltern, füreinander Verantwortung zu übernehmen; bzw. rückten nahe Verwandte - wie etwa Abram gegenüber Lot - in diesen geschwisterlichen Verpflichtungsstatus. Im Alten Orient, als Handlungsschauplatz biblischer Erzählungen, bedeutete dies den Gesetzen der Ökonomie nach in erster Linie, Bruder oder Schwester bzw. deren Hausstand im eigenen Haushalt aufzunehmen und zu versorgen, sofern sie selbst dazu nicht in der Lage waren. ${ }^{23}$ Seine konsequenteste Anwendung erlebt dieser Grundsatz dann im Levirat, der Heirat der kinderlosen Witwe mit dem Bruder ihres verstorbenen Mannes. Auch wenn die praktische Ausübung dessen in der Regel erst im Todesfall der Eltern bzw. des Bruders erforderlich wurde, bestand das Bewusstsein um diese Verantwortung von jeher unter Geschwistern.

Aktive wie passive Verantwortung - vor allem im ökonomischen Sinne und daraus folgende Rücksichtnahme und Unterstützung sind demnach innerhalb der Tora zentrale Merkmale des familialen Status der Geschwisterlichkeit. Eben diese Merkmale werden durch den Geschwister-Begriff (אחות oder) auf das Verhältnis zu Verwandten dritten und vierten Grades ausgedehnt. Da ein familialer Status, wie der der Geschwisterlichkeit, in erster Linie die Beziehung von Verwandten, vor allem hinsichtlich ihrer Rechte und Pflichten, bestimmt, ${ }^{24}$ werden also mittels der Zuschreibung bestimmter Verwandtschaftskategorien innerhalb des Familien- bzw. Sippenverbandes der Israeliten zugleich auch „soziale Handlungsmuster beschrieben “ ${ }^{\text {25 }}$ bzw. weiter transportiert.

In einem Fall innerhalb der Tora reicht diese Ausdehnung des Geschwisterbegriffs, als eine Art Chiffre eingeforderten Sozialverhaltens, sogar über die unmittelbare Familien-, Stammes- oder Volksebene hinaus: ${ }^{26}$ Als Lots Haus in

23 Vgl. Blenkinsopp, Joseph: The Family in First Temple Israel, in: Perdue, Leo G. u.a. (Hrsg.): Families in Ancient Israel. Louisville 1997, S. 48-103, hier S. 76 u. Meyers, Carol: The Family in Early Israel, in: ebd., S. 1-47, hier S. 23 u. 32-35. Lot und Abraham trennen sich dann, nachdem Lot ökonomisch unabhängig geworden ist. Vgl. Gen 13,510. Dennoch leistet Abraham ihm auch danach noch Hilfe. Vgl. Gen 14,12-16.

24 Vgl. Weisberg: Levirate, S. 52.

25 Fechter: Familie, S. 119.

26 Als vermeintlicher zweiter Fall könnte allenfalls Gen 29,4 gelten, wo Jakob nach seiner Ankunft in Padan Aram auf unbekannte Viehhirten trifft und diese vorsorglich als seine Brüder anspricht, ohne wissen zu können, dass es sich um Nachfahren Harans, seines 
Sodom - wo er als Fremder lebt (Gen 19,9) - belagert wird, redet er die aufgebrachte Menge als „Brüder“ an und versucht, sie zu beschwichtigen $(19,7)$. Wieder wird der Geschwisterbegriff im Kontext einer Notsituation und im Gemahnen an gegenseitige Verantwortung verwendet. Doch vor dem Hintergrund der bisherigen Erkenntnisse zu genau solcher Verwendung des Geschwisterbegriffs in Momenten mit akutem sozialen Konfliktpotenzial wirkt Lots Geschwisterappell gegenüber fremden Pöbeln wie eine bloße Schlichtungsformel. Es handelt sich um den augenscheinlich verzweifelten Versuch, Geschwisterlichkeit gegenüber Fremden, zu denen keinerlei genealogische Verbindung besteht, verbal als Rechtsschutzstatus in Anspruch zu nehmen. Doch während der Geschwisterbegriff auf der erweiterten Familienebene sehr wohl dergestalt institutionalisiert ist, verfehlt er hier offenbar seine Wirkung (Gen 19,9), scheint als Allegorie für Rücksichtnahme und Verantwortung nicht stark genug. Lot wird weiterhin hart bedrängt und nur durch das Eingreifen der anwesenden Gottesboten gerettet (Gen 19,9f.). Dass er mit seinem Appell an die Brüderlichkeit gegenüber Fremden einen Einzelfall in der $\mathrm{Tora}^{27}$ darstellt und damit zudem ohne Erfolg bleibt, mag dafür sprechen, dass der Geschwisterbegriff zwar auf der erweiterten Familienebene zu einer Art Rechtsschutzstatus institutionalisiert worden ist, dessen Geltungsbereich aber jenseits der Verwandtschaftsebene zur bloßen Allegorie wird, sich als solche jedoch nicht instrumentalisieren lässt, sondern jäh endet. An anderen Stellen zeigt die Tora wiederum von diesem Schema entkoppelte Entwicklungen des Geschwisterbegriffs, die ihn an sich aus der Familienebene abstrahieren. Ein Phänomen, das nicht ungewöhnlich ist für einen Schriftkorpus, der eine ausgesprochen heterogene Text- und Traditionsgeschichte, aber auch eine ebensolche Systematik und Theologie aufweist.

\section{Volksgeschichtliche Anwendung}

In den meisten deutschen Bibelübersetzungen bleibt die Abstrahierung des Geschwisterbegriffs - und der mit ihm verbundenen sozialen Handlungsrichtlinien - von Personen mit gemeinsamen Eltern auf weitere Ebenen sozialer Gemeinschaft leider nicht durchgängig transparent. Findet etwa im Hebräischen eine Wendung wie אִיש אֶל אָחִיו (,ein Mann zu seinem Bruder") ${ }^{28}$ Anwendung, so lautet diese in der Übertragung ins Deutsche meist „einer zum andern“ oder

Großonkels $(11,31)$, handelt. Jakob könnte zunächst davon ausgehen, dass die Viehhirten nicht mit ihm verwandt sind, obwohl dies tatsächlich im weiteren Sinne der Fall ist.

27 Ein paralleles Ereignis findet sich jedoch in Ri 19,23, wo es ebenfalls einen als Fremden in der Stadt Lebenden betrifft (Ri 19,16).

28 Diese und ähnliche Wendungen, auch in femininen Wortformen, finden sich in Gen 9,5; 13,$11 ; 26,31 ; 37,19 ; 42,21 ; 42,28 ;$ Ex 10,23; 16,15; 25,20; 26,3.5.6; 37,9; Lev 7,10; 26,37 und Num 14,4 . 
schlichtweg „einander“. Der verallgemeinernden Bedeutung einer solcher Wendung nach ist auch genau das gemeint, ${ }^{29}$ aber die deutschen Übersetzer assimilieren bereits den Schritt der Abstraktion, der im Hebräischen les- bzw. hörbar bleibt: Dass auch das Mit- und das Voneinander, die gemeinschaftliche Zuordnung von einem und dem anderen, seine Wurzeln im Geschwisterbegriff hat.

In diesem Sinne wird der Geschwisterbegriff schließlich vor allem in den Büchern Exodus (Schemot) bis Deuteronomium (Dewarim), der Geschichte von Auszug und Wüstenwanderung des Volkes Israel, über die Familienebene hinaus auf die Bezeichnung der Volksgenossen ausgeweitet, und zwar auch in deren konkreter Anrede mit der zumeist kollektiven maskulinen Pluralform „Brüder“ (אחים). ${ }^{30}$ Und abermals geschieht dies vorrangig in Kontexten sozialer Spannung sowie im Appell zur gegenseitigen Rücksichtnahme. ${ }^{31}$ Es sind überwiegend gemeinschaftliche Notlagen, wie die Sklaverei in Ägypten oder der Hunger und andere Sorgen während der Wüstenwanderung, die den Geschwisterbegriff im Volkskollektiv Israel evozieren (Ex 2,11; 4,18; Num 20,3), da sie der eine mit dem anderen brüderlich teilt (Ex 10,23; 16,15; Num 14,4). Doch auch der Streit der Volksbrüder untereinander findet Erwähnung und soll geschlichtet werden (Dtn 1,16). Immerhin annähernd positiv kontextualisiert findet sich der Brüderbegriff allein im futuristischen Ausblick auf die Landnahme, die Gebiets- und Ämterverteilung des Volkes Israel (Dtn 3,18.20; 18,7.15). ${ }^{32}$

Gemäß dem situativen Kontext seiner Anwendung bringt der Geschwisterbegriff auch auf der Volksebene keine besondere emotionale Nähe zum Ausdruck, sondern mahnt an die kollektive Verantwortung für- sowie die gegenseitige Rücksichtnahme aufeinander. Dass er überhaupt auf diesen Bereich adaptiert werden kann, liegt nicht allein an einer etablierten hebräischen Redensart wie אִיש אֶת (sinngemäß ,einer dem anderen“), die den Geschwisterbegriff enthält. Die Bezeichnung ,Bruder“ als direkte Anrede unter Volksgenossen basiert vor allem auf dem identitätsstiftenden Bewusstsein vom Ursprung der

29 Dies beweisen insbesondere Ex 25,20; 26,3.5.6.17 u. 37,9, wo die Wendungen ,einer zum anderen“ (איש אל־אחיו) bzw. ,eine mit der anderen“ (אשה אל־אחתה) nicht auf Menschen, sondern auf Gegenstände angewandt werden.

30 Dies geschieht mehr als dreißig Mal in den Büchern Exodus bis Deuteronomium. Die seltenere Singularform „Bruder“ findet sich dabei ausschließlich in Lev 25,36; Dtn 1,16; 15,3.7.9.11; 17,15; 19,18f.; 22,1-4 u. 23,20f.

31 Vgl. Ex 2,11; 4,18; 32,27; Lev 25,46; Num 32,6; Dtn 1,16; 15,3.7.11; 22,1-4; 23,20f.

32 Außerhalb der Tora kulminiert der Geschwisterbegriff interessanter Weise kaum zur Bezeichnung des Beziehungsverhältnisses der Bruderstaaten Israel und Juda (2 Sam 19,13) und sogar nur ein einziges Mal in der Hebräischen Bibel im Begriff der Bruderschaft (אחוה), und zwar hinsichtlich der bedrohten Verbindung Judas und Israels (Sach 11,14). Vgl. Gesenius: Handwörterbuch, S. 34 sowie dazu Wolff: Anthropologie, S. 273. 
zwölf Stämme Israels als den zwölf Söhnen Jakobs (Num 18,2; Dtn 18,2; Ri 20,13.23). Nicht ohne Grund macht die Geschichte um Josef und seine elf Brüder (Gen 37-47) knapp ein Drittel der gesamten Stammelternerzählungen im Buch Genesis aus. Sie ist die familiengeschichtliche Grundlage der während des Exodus etablierten Volksstruktur der zwölf Stämme Israels.

Das Verständnis gesamtgesellschaftlicher Verantwortung und gegenseitiger Rücksichtnahme basiert innerhalb der Tora demnach auf der direkten Übertragung familialer Strukturen auf das Nationalbewusstsein. Diese Beobachtung wird auch aus historischer Perspektive bestätigt, wenn etwa Rainer Kessler in seiner Sozialgeschichte des alten Israel zu dem ähnlichen Schluss gelangt, dass die „Familien- und Verwandtschaftsbeziehungen [...] seit den vorstaatlichen Anfängen die Basis der Gesellschaft Israels ${ }^{\text {‘33 }}$ darstellten. Insbesondere für jene frühen Phasen gesellschaftlichen Wachstums, in denen es dem Volk Israel noch an staatlichen Strukturen mangelte, spricht Kessler von einer „,verwandtschaftsbasierten Gesellschaft ${ }^{\star 34}$. Dieser geschichtliche Befund steht zweifelsohne auch in unmittelbarem Zusammenhang mit der Erfahrung des Babylonischen Exils (597-539 v.d.Z.), auf deren Grundlage wiederum die Entstehung der meisten der hier zitierten Texte der Tora historisch-kritisch ins 6.-5. Jahrhundert v.d.Z. verortet wird. ${ }^{35}$ Demnach versuchte man offenbar gezielt, den Mangel identitätsstiftender Gesellschaftstrukturen in Babylonien - aber auch das Zerreißen tatsächlicher Familienbande infolge der Entwurzelung durch das Exil - mithilfe der literarischen Re-Etablierung familialer Strukturen, u.a. in Genealogien, zu kompensieren. ${ }^{36}$ Die entstandenen Genealogien und Familiengeschichten erklären aber mitunter auch Fremdvölker zu Brüdern Israels und bringen dabei eine dunkle Kehrseite der Geschwisterlichkeit zum Vorschein, wie etwa in der an die Sintflut anschließenden Geschichte um Noah und seine drei Söhne: Sem, Ham und Jafet (Gen 9,18-29). Nachdem Ham die Blöße seines Vaters aufgedeckt hat, bedecken Jafet und Sem ihren Vater mit abgewendetem Blick (Gen 9,23). Hams Tat wird als ausgesprochen verwerflich verurteilt (Gen 9,24f.; vgl. Lev 18,7). In der Folge gehen aus Jafet die Völker nördlich Israels hervor (Gen 10,1-5), aus Sem entstehen die Semiten (11,10-26), einschließlich Israel. Ihr Bruder Ham

33 Kessler, Rainer: Sozialgeschichte des Alten Israel. Darmstadt 2006, S. 175.

34 Ebd., S. 57. Vgl. dazu auch Fechter: Familie, S. 119.

35 Vgl. dazu Römer, Thomas: Die Entstehung des Pentateuch: Forschungsgeschichte, in: ders. u.a. (Hrsg.): Einleitung in das Alte Testament. Die Bücher der Hebräischen Bibel und die alttestamentlichen Schriften der katholischen, protestantischen und orthodoxen Kirchen. Zürich 2013, S. 120-137, hier S. 135f. sowie Nihan, Christophe; Römer, Thomas: Die Entstehung des Pentateuch: Die aktuelle Debatte, in: ebd., S. 138-164, hier S. 160-162.

36 Vgl. Kessler: Sozialgeschichte, S. 142.

Ulrike Schneider, Helga Völkening and Daniel Vorpahl - 978-3-653-98812-3 
jedoch wird zum Ursprung des Sklavenhauses Mizraim (Ägypten) sowie der Kanaanäer, den Siedlungserzfeinden des Volkes Israel $(10,6)$.

Ein grundähnlich angelegtes Beispiel stellt das Schwesternpaar der Töchter Lots dar: Die Ältere stiftet die Jüngere dazu an, gemeinsam ihren Vater betrunken zu machen und jeweils mit ihm zu schlafen (Gen 19,30-35). Aus dem verwerflichen Inzest gehen zwei Söhne hervor: Moab, der Stammvater der Moabiter, und Ben-Ammi, Stammvater der Ammoniter (Gen 19,36-38). Beide Völker werden später streng verurteilt und geraten immer wieder in kriegerische Auseinandersetzungen mit den Israeliten (Num 21,24.29; 22,3-6; Dtn 23,4).

Die volksätiologische Intention dieser beiden Beispielerzählungen dürfte nahezu offensichtlich sein: Die vorgeordneten Genealogien und Familiengeschichten dienen dazu, die Stammväter von Feindesnationen gezielt zu denunzieren. Bemerkenswert ist, dass dafür ausgerechnet Geschwisterbeziehungen zugrundegelegt werden.

Gerade aus dem divergenten Handeln von Geschwistern, die nicht nur dem gleichen, sondern einem gemeinsamen, ethisch normativen Verwandtschaftsverhältnis unterliegen, lässt sich ein verwerfliches Fehlverhalten feindlich gesinnter Völker bzw. derer Stammväter generieren. Neben den Eltern - deren Ehrung laut der Tora allerhöchsten Stellenwert besitzt (Ex 20,12; Lev 19,3 u.ö.) - nehmen Geschwister den engsten familialen Beziehungsstatus ein. Entsprechend hoch sind die an diese familiale Nahbeziehung angelegten ethischen Normen ${ }^{37}$ und umso verwerflicher folglich auch deren Missachtung. Diese Kehrseite der Geschwisterlichkeit kommt in den gegebenen Beispielen zum Tragen. Im Falle Sems, Hams und Jafets geschieht dies vor allem dadurch, dass sich an den Geschwistern auf absolut ebenbürtigem Niveau das Einhalten und die Missachtung ethischer Normen gegenüberstellen lassen, bei denen es auf familialer Ebene jeweils um Vergehen gegenüber dem Vater geht.

Die ambivalente Spannung der Geschwisterbeziehung gestaltet sich aber auch auf der Volksebene wesentlich komplexer denn in der Gegenüberstellung sozialethischer Fehlbarkeit und Rechtschaffenheit. So werden die Moabiter und Ammoniter in Dtn 2,9 und 2,19 wiederum mit Verweis auf Lot in Schutz genommen. Und noch deutlicher heißt es im selben Kapitel hinsichtlich der Nachfahren Esaus, dem Nachbarvolk Edom, dass sie als Brüder gelten, an denen Israel keinen Landgewinn gutzumachen habe (Dtn 2,4f.8). Demnach fungiert die volksätiologische Geschwisterbeziehung als ambivalentes Instrument der Geschichtsdeutung: Als Argument der Rücksichtnahme und Verantwortung unter Brüdervölkern einerseits (Num 20,14; Dtn 23,8) und als Abmahnung eklatanten Fehlverhaltens nahverwandter Nachbarvölker andererseits (Gen 9,18-29; 19,30- 
38). Im Falle der Edomiter existiert mit der konfliktreichen Geschichte der Zwillingsbrüder Jakob und Esau zudem ein komplexer familiengeschichtlicher Hintergrund des geschwisterlichen Verhältnisses zu Israel.

Bis hierher sind im Wesentlichen drei Ausprägungen eines idealisiertallegorischen Geschwisterbegriffes innerhalb der Tora zu konstatieren: die Geschwisterlichkeit als institutionalisierter Rechtsschutzstatus auf der erweiterten Familienebene, die allegorische Abstraktion dieses Geschwisterverständnisses als kollektive Brüderlichkeit der Volksgenossen durch die unmittelbare Übertragung familialer Strukturen auf das Nationalbewusstsein des Volkes Israel und schließlich die Instrumentalisierung der volksätiologischen Geschwisterlichkeit zum Zwecke der Geschichtsdeutung von Israels Verhältnissen zu den Nachbarvölkern. Alle drei Formen begegnen vorrangig in Konfliktsituationen, meist im Sinne einer Deeskalation oder des Appells an gegenseitige Verantwortung und Rücksichtnahme bzw. auf der volksätiologischen Ebene auch als Grundlage der Schmähung einer Konfliktpartei.

\section{Die leiblich-biographischen Grundlagen des Geschwisterbegriffs}

Ich will mich nun abschließend der Frage zuwenden, ob und inwiefern die originär leiblich-biographischen Geschwisterbeziehungen der Tora Grundlage, Voraussetzung oder auch nur Ausgangspunkt der ermittelten Formen des übertragenen Geschwisterbegriffes bilden. Dabei gilt es von vornherein zu beachten, dass die Familiengeschichte in einigen der betreffenden Texte permanent an der Schwelle zur Volksebene steht. Dieses traditionsgeschichtliche Phänomen muss man als Leser von Genesis wie einen Grundrhythmus im Hinterkopf behalten, während man sich der Melodie folgender Familiengeschichten widmen mag.

Das erste leibliche Geschwisterpaar der Tora sind Kain und Abel. Die Handlung ihrer Geschichte ist weitläufig bekannt und mit wenigen Worten zusammengefasst: Kain und Abel bringen dem Ewigen die ersten Opfergaben dar, gemäß ihrem Broterwerb Feldfrüchte bzw. Fleisch und Fett (Gen 4,2-4). Der Ewige wertschätzt die Gabe Abels, nicht jedoch die Kains (Gen 4,4f.), den daraufhin der Neid packt, sodass er seinen Bruder Abel erschlägt (4,5.8). Eine vollkommen sinnlose Tat, zumal Kains Wut nicht gegen seinen Bruder Abel, sondern allenfalls gegen Gott hätte gerichtet sein müssen. Abel konnte nichts dafür, dass Gott ihn bevorzugt und auch der Leser erfährt nicht, was den Ewigen dazu bewog. Für die Aussage der Geschichte der beiden Brüder ist genau das aber letztlich irrelevant. Kain hatte weder das Recht noch eine plausible Rechtfertigung und noch nicht mal einen Vorteil davon, dass er Abel erschlug. Sein Totschlag 
bleibt eine reine Affekthandlung, basierend auf der Unfähigkeit, das Handeln des Menschen und das Reagieren Gottes als zweierlei Ebenen zu betrachten.

Ein ähnliches Problem liegt dem Konflikt der Brüder Jakob und Esau zugrunde. Deren Mutter erhält vor der Geburt der Zwillinge die göttliche Prophezeiung, dass aus ihrem Leibe zwei Völker hervorgehen und das größere dem kleineren dienen werde (Gen 25,23). Rebekka macht jedoch keinen Unterschied zwischen den Völkern der Zukunft und ihren geborenen Söhnen, sieht in dem Jüngeren einen von Gott Auserwählten und meint zudem, für die Erfüllung Gottes Prophezeiung verantwortlich zu sein (Gen 27,6-17). Ihr Irrtum führt dazu, dass Jakob seinen Bruder Esau um dessen väterlichen Erstgeburtssegen betrügt (Gen 27,18-29). Als der schwer erschütterte Esau daraufhin seinen Bruder töten will, schickt Rebekka Jakob ins Ausland, zu ihrem eigenen Bruder Laban (Gen 27,41-44). Erst als Jakob zwanzig Jahre später von dort zurückkehrt, kommt es zum Wiedersehen der beiden Brüder. Dabei versucht Jakob, der sich vor Esaus später Rache fürchtet, seinen Bruder mit kostbaren Geschenken zu beschwichtigen (Gen 32,1-16), auf deren Annahme er besteht, um sich zu vergewissern, dass ihr Konflikt beigelegt ist (33,1-11).Von einer tatsächlichen Versöhnung der beiden Brüder kann jedoch kaum die Rede sein, insofern Jakob allein auf die symbolische materielle Entschädigung für den gestohlenen Segen insistiert (Gen 33,11). ${ }^{38}$ Bis dies erreicht ist, tritt Jakob gegenüber dem älteren Esau betont demütig auf, wirft sich sogar als seines Bruders Knecht mehrfach vor ihm nieder (Gen 32,5; 33,3.5.8). Kaum aber hat Esau den quasi materiell zurückerstatteten Segen angenommen (Gen 33,11), weist Jakob die zukunftsorientierten Beziehungsbemühungen seines Bruder jäh zurück und stößt ihn durch sein Desinteresse an Gemeinsamkeit und brüderlicher Nähe erneut vor den Kopf, bis dass die Zwillinge schließlich ohne einander aufbrechen $(33,12$ 16). In der Folge wird Jakob vom Ewigen in Israel umbenannt und schließlich zum Stammvater des gleichnamigen Volkes (Gen 35,10f.21-26). Der Streit mit seinem Bruder Esau hatte auf diese Entwicklung letztlich keinerlei Einfluss. Er betraf allein die Familienebene und deshalb konnte er auch nur von den Brüdern selbst aus der Welt geschafft werden, ja musste es sogar, ehe die Volksgeschichte Israels ihren weiteren Lauf nehmen konnte. ${ }^{39}$

Auch Josef, einer der zwölf Söhne Jakobs, droht von seinen Brüdern aus Neid getötet zu werden (Gen 37,18-20). Ruben, der Älteste der Geschwister, interveniert jedoch und hält seine Brüder von der Bluttat $a b$, so dass sie Josef

38 Vgl. Vorpahl: Erstgeburtsrechts- und Betrugsfall, S. 49.

39 Vgl. ebd., S. 59. Eine symbolische Vorwegnahme der Überwindung des Brüderkonflikts wie auch der volksgeschichtlichen Umbenennung Jakobs findet sich in der in vielerlei Hinsicht rätselhaft bleibenden Kampfszene mit einem Boten Gottes am Ufer des Jabbok in Gen 32,23-33. Vgl. dazu ebd., S. 43-47.

Ulrike Schneider, Helga Völkening and Daniel Vorpahl - 978-3-653-98812-3 
stattdessen in eine Zisterne werfen (Gen 37,21-24). Nachdem Josef von reisenden Händlern befreit worden ist, die ihn schließlich nach Ägypten verkaufen (Gen 37,28.36), finden seine Brüder nurmehr eine leere Zisterne vor und beschließen, dem gemeinsamen Vater den Tod Josefs vorzutäuschen (37,29-35). Nachdem Josef im Dienste des Pharao Karriere gemacht hat, erscheinen seine Brüder aufgrund einer Hungersnot in Ägypten (Gen 41,54-42,6). Während Josef seine Brüder wiedererkennt, bleibt ihnen seine Identität verborgen (Gen 42,7f.). Geraume Zeit lässt er sie im Unklaren und prüft mehrfach ihr Vertrauen und ihre Rechtschaffenheit, während sie erst nach Kanaan und dann wieder nach Ägypten zurückkehren (Gen 41,9-44,34). Doch irgendwann kann Josef nicht mehr an sich halten, gibt sich aus emotionalen Zwängen statt aus taktischem Kalkül zu erkennen und es kommt zu einer tränenreichen Versöhnungsszene (Gen 45,1-15). Dabei vergibt Josef seinen bestürzten Brüdern und hält sie sogar an, sich selbst nicht zu grämen, insofern sein Schicksal letztlich von Gott gefügt sei und zu einem glücklichen Ausgang für alle zwölf Brüder geführt habe (Gen 45,5-8), die sich nun aussprechen $(45,15)$ und in der Folge die familiäre Basis der Zwölf-Stämme-Struktur Israels bilden (49,1-28).

Was sich aus diesen drei Geschwistergeschichten zwischen dem vierten und fünfundvierzigsten Kapitel des Buches Genesis ersehen und schlussfolgern lässt, ist eine allmähliche moralisch-sittliche Entwicklung, ein familialer Sozialisationsprozess, der anhand von Geschwisterbeziehungen das soziale Wachstum einer ganzen Gesellschaft nach- bzw. vorzeichnet. Während Kain seinen Bruder in blinder Wut erschlägt, gereichen die innerfamiliären Umstände im Falle Jakobs und Esaus zumindest dazu, die beiden Brüder rechtzeitig und auf ausreichende Distanz hin voneinander zu trennen, bis dass sie ihren Konflikt nach Jahren des Abstands beilegen. In der Josefsgeschichte schließlich sind die Brüder dann so weit entwickelt, dass sie zumindest einen Mord aus eigenem Antrieb unterbinden, ehe sie am Ende gar zu einer herzlichen Versöhnung finden. ${ }^{40}$

Das Buch Genesis demonstriert somit anhand von Geschwistergeschichten in einem fortlaufenden sozialethischen Narrativ bzw. einer entsprechend verflochtenen Traditionssammlung, dass innerfamiliale Konflikte aus sich selbst heraus eigenständig gelöst werden müssen und dass insbesondere zwischen der innerfamilialen Ordnung und der transzendenten Ordnung Gottes unterschieden werden muss. Darum taucht der Ewige in den letzten fünfzehn Kapiteln des Buches Genesis auch so gut wie gar nicht mehr auf. Erzählte Geschwisterlichkeit findet in der Tora vorrangig als Sozialisationsprozess statt. Die Funktionalität der Familie, erprobt durch schwere Konflikte, gilt dann als Basis der Stabilität der Gesellschaft. Insofern fungieren die Geschwistergeschichten des Buches

40 Vgl. ebd., S. 58.

Ulrike Schneider, Helga Völkening and Daniel Vorpahl - 978-3-653-98812-3 
Genesis als Grundstein einer sozialethischen Matrix des Volkes Israel, wie sie am Geschwisterbegriff der gesamten Tora manifest wird.

Die Lösung von Geschwisterkonflikten bedeutet somit letztlich für das gesamte Volk einen Gewinn und wird auch deshalb anhand des Geschwisterbegriffs gern bis auf die Volksebene hin abstrahiert. Dabei tritt der aus Geschwisterkonflikten tatsächlich zu extrahierende Gewinn für die Gesellschaft Israels nirgendwo mit so tragweiter Symbolkraft zutage wie bei den Schwestern Rachel und Leah. Für ihr Wetteifern um die Liebe ihres gemeinsamen Mannes Jakob finden sie eine konstruktive und vor allem biologisch effektive Lösung: Sie bemühen und streiten sich darum, jeweils so viele Kinder wie möglich von Jakob zu empfangen (Gen 29,31-30,24). Dies führt so weit, dass die beiden Schwestern untereinander aushandeln, mit wem der gemeinsame Ehemann die Nacht verbringen darf (Gen 30,14-16). Ihr Gebärwettstreit beschert Jakob am Ende zwölf Söhne - die zwölf Stämme Israels - und eine Tochter (Gen 30,21). Von der Familienebene aus betrachtet, lässt sich also sagen, dass sogar die ZwölfStämme-Struktur des Volkes Israel auf einem Geschwisterstreit beruht. Eine Perspektive, die ausgesprochen interessantes soziologisches Erkenntnispotential birgt: Geschwisterrivalität ist also auch eine Form von Wettbewerb; und gemäß eines konstruktiven Verständnisses dessen, kann genau dies im besten Falle ausgesprochen anspornend und motivierend auf alle Beteiligten wirken.

Familiale Strukturen und insbesondere Geschwisterbeziehungen fungieren in der Tora demnach nicht nur als Matrix des Nationalbewusstseins Israels. Mittels Geschwistergeschichten wird letztlich die sozialethische Basis für eine funktionierende Gesellschaft des Volkes Israel vorskizziert. Besonders nachdrücklich geschieht dies innerhalb des langwierigen Brüderkonflikts der Josefsgeschichte, wofür nochmals einige Eckpunkte deren Handlung ins Bewusstsein gerufen seien: Nachdem sie sich Josefs entledigt haben, belügen seine Brüder den gemeinsamen Vater Jakob hinsichtlich des Todes seines Sohnes (Gen 37,31f.). Erst kurz zuvor hatte Ruben noch gegen die Ermordung Josefs intervenieren müssen (Gen 37,21f.). In Ägypten verweigert Josef dann den Ehebruch mit der Frau seines Herrn Potifar (Gen 39,7-12). Deren Falschaussage bringt Josef jedoch ins Gefängnis (Gen 39,19f.), obgleich er weder Potifars Frau noch dessen Besitztümer begehrt hatte. Als Josefs Brüder dann wegen einer Hungersnot nach Ägypten und zurück nach Kanaan ziehen, machen sie sich wiederum vermeintlich des Diebstahls schuldig (Gen 44,1-12). - Diese wenigen Handlungsskizzen der Josefsgeschichte offenbaren ein Ensemble religionsgesetzlicher Marksteine: Elternehrung, Mord, Ehebruch, Diebstahl, Lügenaussagen und das Begehren des Nächsten Frau und Haus. Was hier narrativ vorgezeichnet wird, sind die sozialethischen Eckpfeiler des Dekalogs, der Mitte und halachisches Herzstück des an die Josefsgeschichte anschließenden Buches Exodus (Schemot) markiert. Inso- 
fern ist die Josefsgeschichte auch gezielte literarische Vorbereitung auf den folgenden Exodus des Volkes Israel. Zu dessen Durchführung wiederum formiert sich dann mit Aaron und Mose ein Brüderpaar, das sich erfolgreich ergänzt und dennoch seine Konflikte auszutragen hat (Num 12). Deren Quintessenz aber besteht darin, beiden Brüdern auf den Weg in ihre ureigene Rolle im Heilsplan Gottes und der Geschichte Israels zu verhelfen: als Anführer eines Volkes und als dessen Priester.

\section{Fazit}

Die in der Tora dargelegte Geschwisterlichkeit ist also bereits auf der leiblichbiographischen Ebene von Konflikten geprägt. In ihrer Gesamtheit widerspiegeln diese jedoch, insbesondere im Buch Genesis, die vorrangige Entwicklung und Notwendigkeit, solche Auseinandersetzungen aufzulösen. Dabei darf nicht der Fehler begangen werden, sämtlichen Geschwisterkonflikten der Tora einen glücklichen Ausgang zu attestieren und so am Ende zu deren positiver Verklärung beizutragen. Vielmehr stellten sich das Glück Jakobs, Josefs oder Leahs und Rachels nicht wegen, sondern trotz ihrer Geschwisterkonflikte ein, und zwar eben weil sie diese eigenständig lösen konnten.

An dieses Potenzial des Geschwisterbegriffs gemahnend, kommt die allegorische Übertragung dessen in der Tora ebenfalls überwiegend in Momenten sozialer Spannung zum Tragen und appelliert dann an gegenseitige Verantwortung und Rücksichtnahme. Die Verbundenheit, die durch den Geschwisterbegriff zum Ausdruck kommt, ist aber weder auf der erweiterten Familien-, noch auf der Volksebene und auch nicht in völliger Abstraktion emotionaler Natur. Wenn die Tora weitere sozialethische Verhaltensrichtlinien gegenüber Geschwistern ausgibt, sind diese nicht nur Ausdruck einer Wertschätzung, sondern streben vielmehr eine Vermeidung innerfamilialer Konflikte an, da die funktionierende, stabile Familie zugleich kleinste Zelle und Spiegelbild der Gesellschaft Israels ist. Geschwisterlichkeit in der Tora ist nicht per se Synonym für Verbundenheit, aber auch keine Allegorie für Streit und fehlenden Konsens, sondern Sinnbild für die Überwindung und Lösung von Konflikten.

In der Tat scheint es absurd, Geschwistern überhaupt von vornherein Nähe und Verbundenheit unterstellen zu wollen. Naturgemäß sind sie in eine Konkurrenzsituation hineingeboren, von der Liebe der Eltern und weiteren Verwandten bis hin zu materiellen Dingen des Alltags alles teilen zu müssen. Eltern stellt dies bis heute immer wieder vor die enorme Herausforderung, ihren Kindern Grundlagen für ein gutes Verhältnis zueinander zu vermitteln. Doch auch diese feien sie nicht vor chronischer Unterschiedlichkeit und stetiger Auseinandersetzung. Zugleich liegt darin, im Austragen und Überwinden von Konflikten, das 
größte Pozential der Geschwistererfahrung, die erwiesenermaßen die sozialen Kompetenzen Heranwachsender stärkt. ${ }^{41}$

Geschwisterlichkeit lässt sich also nicht einfach in Geschwisterliebe und -hass klassifizieren. Denn Geschwister dienen letztlich auch der Reflexion, der Auseinandersetzung mit dem eigenen Selbst. Und ist diese Reflexion einmal angeregt, kann man ihr kaum mehr ausweichen. Geschwister konfrontieren einander permanent mit der eigenen Existenz und deren eingeschränkter Einzigartigkeit, allein schon dadurch, dass sie im gleichen Maße Kinder ihrer gemeinsamen Eltern sind. An Geschwistern lernt man deshalb nicht nur, sich selbst ins Verhältnis zu setzen, sondern auch die Beschränkung der eigenen Bedürfnisse. Diese Fähigkeit ist eine Grundvoraussetzung für gegenseitigen Respekt und Rücksichtnahme und kann demnach im Geschwisterbegriff als allegorisierte Matrix gesellschaftlichen Sozialverhaltens fungieren. Dabei können Geschwister gleichermaßen zur sozialen Gehhilfe wie auch zum schnürenden Korsett werden. Die Tora lehrt das Volk Israel und jeden anderen Leser mit ihm, durch die Überwindung von Geschwister-Konflikten darin das Gleichgewicht zu finden. Die anhaltende Auseinandersetzung, die jenes zum Ziel hat, ist jedenfalls laut der Tora der eigentliche Sinn allegorisch idealisierter Geschwisterlichkeit.

\section{Quellen und Literatur:}

Allgemeine Erklärung der Menschenrechte, in: Menschenrechte. Dokumente und Deklarationen. Hrsg. v. Bundeszentrale für politische Bildung. 4. aktual. u. erw. Aufl., Bonn 2004, S. 54-59.

Azzola, Axel: Recht, Freiheit und Bündnis in der Tora. Grundlegungen für eine jüdische systematische Theologie. Aus Religion und Recht 7. Berlin 2006.

Beauvoir, Simone de: Das andere Geschlecht. Sitte und Sexus der Frau. 5. Aufl., Reinbek b. Hamburg 2005.

Biblia Hebraica Stuttgartensia/תורה נביאים וכתובים. Hrsg. v. Karl Ellinger; Wilhelm Rudolph u.a. Wide margin edition (5., verbesserte Aufl.), Stuttgart 2007.

Blenkinsopp, Joseph: The Family in First Temple Israel, in: Perdue, Leo G. u.a. (Hrsg.): Families in Ancient Israel. Louisville 1997, S. 8-103

Fechter, Friedrich: Die Familie in der Nachexilszeit. Untersuchungen zur Bedeutung der Verwandtschaft in ausgewählten Texten des Alten Testaments. BZAW 264, Berlin u.a. 1998.

Gesenius, Wilhelm: Hebräische Grammatik. Überarb. v. E. Kautzsch, 28. vielf. verb. u. verm. Aufl., Leipzig 1909.

Gesenius, Wilhelm: Hebräisches und Aramäisches Handwörterbuch über das Alte Testament. 18. Aufl., Berlin u.a. 2013.

41 Vgl. den Artikel von Helga Völkening „Themen, Kontexte und Perspektiven sozial- und individualpsychhologischer Geschwisterforschung - Ein Überblick“" in diesem Band. 
Greenspahn, Frederick E.: When Brothers Dwell Together. The Preeminence of Younger Siblings in the Hebrew Bible. New York 1994.

Grimm, Jacob; Grimm, Wilhelm: Deutsches Wörterbuch. 16 Bde. in 32 Teilbde. Leipzig 1854-1961.

Hertzler, Joyce: The Golden Rule and Society, in: Gensler, Harry J. u.a. (Hrsg.): Ethics. Contemporary Readings. New York u.a. 2004, S. 158-166.

Kessler, Rainer: Sozialgeschichte des Alten Israel. Darmstadt 2006.

Meyers, Carol: The Family in Early Israel, in: Perdue, Leo G. u.a. (Hrsg.): Families in Ancient Israel. Louisville 1997, S. 1-47.

Nihan, Christophe; Römer, Thomas: Die Entstehung des Pentateuch: Die aktuelle Debatte, in: Römer, Thomas u.a. (Hrsg.): Einleitung in das Alte Testament. Die Bücher der Hebräischen Bibel und die alttestamentlichen Schriften der katholischen, protestantischen und orthodoxen Kirchen. Zürich 2013, S. 138-164.

Petri, Horst: Geschwister. Liebe und Rivalität. Die längste Beziehung unseres Lebens. Stuttgart 2006.

Römer, Thomas: Die Entstehung des Pentateuch: Forschungsgeschichte, in: Römer, Thomas u.a. (Hrsg.): Einleitung in das Alte Testament. Die Bücher der Hebräischen Bibel und die alttestamentlichen Schriften der katholischen, protestantischen und orthodoxen Kirchen. Zürich 2013, S. 120-137.

Vaux, Roland de: Das Alte Testament und seine Lebensordnungen. Bd. 1: Fortleben des Nomadentums, Gestalt des Familienlebens, Einrichtungen und Gesetze des Volkes. Freiburg u.a. 1960.

Vorpahl, Daniel: „Es war zwar unrecht, aber Tradition ist es.“ Der Erstgeburtsrechts- und Betrugsfall der Brüder Jakob und Esau. Pri ha-Pardes 4. Potsdam 2008.

Weisberg, Dvora E.: Levirate Marriage and the Family in Ancient Judaism. Waltham 2009.

Wolff, Hans Walter: Anthropologie des Alten Testaments. 5. Aufl., München 1990. 
Ulrike Schneider, Helga Völkening and Daniel Vorpahl - 978-3-653-98812-3

Downloaded from PubFactory at 01/11/2019 10:54:37AM

via free access 


\title{
Kinder Israels und Gottes Kinder - Geschwisterlichkeit in der Hebräischen Bibel und im Neuen Testament
}

\author{
Rainer Kessler
}

\begin{abstract}
In the early Christian communities the idea that all members of the Jewish people are one family because they belong to the same lineage is combined with the idea that all those who believe in Christ are children of God and, in consequence, brothers and sisters. This article shows this metaphor's roots in the Hebrew Bible itself.
\end{abstract}

Die folgenden Zeilen widmen sich der metaphorischen Verwendung der Rede von Geschwisterlichkeit im Neuen Testament. Sie fragen danach, wie diese begründet wird, oder anders gesagt, wer eigentlich als gemeinsamer Vater (oder gemeinsame Eltern) der metaphorischen Geschwister angesehen wird. Des Weiteren gehe ich sodann den Wurzeln dieser Vorstellung in der Hebräischen Bibel, dem Alten Testament der christlichen Bibel, nach.

Natürlich gibt es in den Schriften des Neuen Testaments auch leibliche Geschwister. Jesus selbst hatte eine ganze Schar von Brüdern und Schwestern, von denen wir einige sogar mit Namen kennen. Als er einmal in der Synagoge in Nazaret lehrt, fragen die Leute: „Ist das nicht der Sohn des Zimmermanns? Heißt seine Mutter nicht Maria, und sind nicht Jakobus, Josef, Simon und Judas seine Brüder? Und leben nicht alle seine Schwestern bei uns?" (Mt 13,55f. par. Mk 6,3). Auch unter Jesu Anhängerschaft gibt es Geschwister, z.B. Jakobus und Johannes, die im Reich Gottes gerne an seiner Seite sitzen möchten (Mt 20,2023 par. Mk 10,35-40). In seinen Beispielerzählungen verwendet Jesus gelegentlich das Motiv des Geschwisterpaares, und zwar als Kontrastmotiv. Einmal erzählt er von zwei Brüdern, die der Vater zur Arbeit schickt. Der eine sagt erst „Nein“, geht dann aber hin, der andre sagt „Ja“, geht aber nicht hin (Mt 21,2832). Oder das berühmte Gleichnis vom verlorenen Sohn, den der Vater nach allen Verfehlungen wieder aufnimmt, worüber der immer anständig gebliebene Bruder wenig erfreut ist (Lk 15,11-32).

Doch nicht von solchen leiblichen Geschwistern soll, wie gesagt, im Folgenden die Rede sein.

Ich gehe in meinen Ausführungen zur metaphorischen Rede von Geschwisterlichkeit von dem aus dem Neuen Testament vielfach belegten Brauch der Christusgläubigen aus, sich als Brüder und Schwestern zu verstehen und sich auch so anzureden. Paulus adressiert so die Empfängerinnen und Empfänger 
seiner Briefe (Röm 1,13; 7,1.4 u.ö.). Die Predigten der Apostelgeschichte richten sich an die Geschwister (Apg 1,16; 2,29; 3,17 u.ö.), und ansonsten ist Bruder bzw. Schwester der übliche terminus technicus für die Bezeichnung der Mitchristen. ${ }^{1}$

Das Griechische hat kein Wort für ,Geschwister'. Es verwendet dazu den Plural von $\alpha \dot{\delta} \varepsilon \lambda \varphi o ́ \varsigma$ (adelphós), ,Bruder'. Wenn nicht ausdrücklich nur Männer angeredet sind, ist dieser Plural korrekt nicht mit ,Brüder', sondern mit ,Geschwister' oder ,Brüder und Schwestern' wiederzugeben. Es verhält sich so wie im Spanischen und Portugiesischen, wo es kein Wort für ,Eltern' gibt und stattdessen der Plural los padres bzw. os pais verwendet wird. In 90\% der Fälle ist eine Übersetzung von los padres / os pais mit „die Väter“ einfach falsch. Ge-

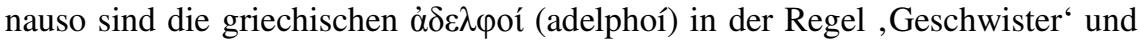
nicht ,Brüder'.

Der Gebrauch als Anrede unter der Christusanhängerschaft ist offenkundig metaphorisch. Nun mag die Metapher durchaus eine gewisse Haltung transportieren, die man als Geschwisterlichkeit bezeichnen kann. In ihr käme „die Horizontale der Verbundenheit untereinander, die sich dem Engagement für die gleiche Sache verdankt, zum Ausdruck“"2. Doch hat Geschwisterlichkeit in Wirklichkeit oft viel mehr mit Rivalität bis hin zu erbitterter Feindschaft zu tun als mit Solidarität und Liebe. Wie dem auch sei, was auf jeden Fall für Geschwisterlichkeit konstitutiv ist - ob in Solidarität oder in Rivalität -, ist die gemeinsame Abstammung. Wir sind Brüder und Schwestern dadurch, dass wir dieselben Eltern haben.

\section{Israel als genealogisch-ethnischer Verwandtschaftsverband}

Wie verhält es sich nun mit solcher gemeinsamen Abstammung beim metaphorischen Gebrauch der Bezeichnung? Das Neue Testament selbst zeigt, dass die urchristliche Anrede als Brüder und Schwestern ihre Wurzeln in der Hebräischen Bibel und in der jüdischen Tradition hat. Ganz offenkundig ist das in neutestamentlichen Zitaten aus der Hebräischen Bibel. Da ist die Ankündigung Moses, Gott werde „einen Propheten wie mich [...] aus der Mitte eurer Brüder [erwecken]" (Zitat von Dtn 18,18 in Apg 3,22; 7,37). Hebr 2,12 zitiert Ps 22,23, wenn der Beter gelobt: „Ich werde deinen Namen meinen Brüdern

1 Es ist bezeichnend für die lange Zeit herrschende Genderblindheit, wenn H. von Soden in seinem einschlägigen Artikel im Theologischen Wörterbuch zum Neuen Testament in ,1. Leibliche Geschwisterschaft“ und „2. Geistliche Bruderschaft“ unterteilt. Es gibt aber keineswegs nur leibliche Schwestern, sondern durchaus auch geistliche, vgl. ausdrücklich Mt 12,50 par. Mk 3,35; Röm 16,1; 2 Kor 7,15; 9,5; Phlm 2; Jak 2,15; 2 Joh 13.

2 Roloff, Jürgen: Die Kirche im Neuen Testament. Göttingen 1993, S. 82. 
verkünden, inmitten der Gemeinde werde ich dich loben." Solcher, von der Hebräischen Bibel geprägter Sprachgebrauch liegt aber auch vor, wenn in der Jesusüberlieferung von Brüdern oder Geschwistern die Rede ist. Ich nenne nur einige Beispiele aus der Bergpredigt. Jesus legt das Verbot zu töten so aus: „Jeder, der seinem Brüder zürnt, sei dem Gericht übergeben“ (Mt 5,22). Vor dem Gang zum Altar fordert er auf, sich zuerst mit dem Bruder zu versöhnen, mit dem man im Streit liegt (Mt 5,23f.). Oder das bekannte Bildwort: „Was siehst du den Splitter im Auge deines Bruders, den Balken in deinem Auge aber nimmst du nicht wahr" (Mt 7,3). Die Beispiele ließen sich reichlich vermehren.

Die Vorstellung, dass alle Israelitinnen und Israeliten Geschwister sind, wird nun in der Hebräischen Bibel tatsächlich mit der gemeinsamen Abstammung begründet. Alle stammen von Abraham und Sarah, von Isaak und Rebekka und von Jakob und den zwölf Söhnen, die er mit vier verschiedenen Frauen hatte, ab. Umfängliche Genealogien, wie wir sie vor allem in den fünf Büchern der Tora und dann in einer breit ausgebauten Genealogie in den ersten neun Kapiteln der Chronikbücher finden, ermöglichen es jedem Angehörigen des jüdischen Volkes, sich in dieser Abstammungslinie zu verorten. Die Bezeichnung der Israeliten als „Söhne Israels“ oder „Kinder Israels“ spiegelt dieses genealogische Denken wider, denn Jakob bekam nach dem Buch Genesis den Namen Israel (Gen 28,29; 35,10). Die „Kinder Israels“ sind die Nachfahren Jakobs.

Die ethnologische Forschung, vor allem an afrikanischen Gesellschaften, hat längst gezeigt, dass solche Genealogien meistens fiktiv sind. Sie sind auch veränderbar, sogar in recht kurzen Zeiträumen. Spalten sich Untergruppen von der Hauptgruppe dauerhaft ab, werden die Vorfahren aus der Genealogie entfernt, schließen sich bis dahin Fremde der Gruppe an, wird die Liste der gemeinsamen Vorfahren um den Ahn der neuen Gruppe ergänzt. Trotz dieser Variabilität ist der Zusammenhalt solcher auf gemeinsamer realer oder fiktiver Abstammung beruhender Gesellschaften in der Regel groß. ${ }^{3}$

Auch im Neuen Testament wird der Gedanke, dass Juden und Jüdinnen deshalb Geschwister sind, weil sie gemeinsame Vorfahren haben, aufgegriffen. Paulus spricht im Römerbrief ausdrücklich von „meinen Geschwistern, meinen Landsleuten nach dem Fleisch, die Israeliten sind, [...] die die Väter haben [...]“ (Röm 9,3-5).

Aus der Reihe der Patriarchen erhält in neutestamentlicher Zeit Abraham als gemeinsamer Vorfahr den Vorrang vor Jakob, wofür bereits in der Hebräischen Bibel der Grund gelegt wird. So heißt es bei Deuterojesaja: „Schaut auf Abra-

3 Vgl. die zusammenfassenden Bemerkungen zum Konzept genealogisch strukturierter Gesellschaften in Kessler, Rainer: Sozialgeschichte des alten Israel. Eine Einführung. Darmstadt 2008, S. 60-62. 
ham, euren Vater, und auf Sarah, die euch geboren hat" (Jes 51,2). Nach der Erzählung der Apostelgeschichte redet Stephanus, der der erste Märtyrer wird, die Mitglieder des Synhedrions mit „Brüder und Väter“ an und spricht gleich darauf von „unserem Vater Abraham“ (Apg 7,2). Lukas, der Verfasser der Apostelgeschichte, lässt Paulus bei einer Predigt in einer Synagoge die Anwesenden als „Israeliten und Gottesfürchtige“ anreden, unterscheidet also zwischen Juden und Anhängern des Judentums aus den Völkern, die nicht konvertiert sind (Apg 13,16). Bei einer erneuten Anrede variiert Lukas dann so, dass es heißt: „Brüder, Söhne aus dem Geschlecht Abrahams, und Gottesfürchtige“ (Apg 13,26). Es ist ebenfalls Lukas, der verschiedene Gestalten im Evangelium von „unserem Vater Abraham“ (Lk 1,73; vgl. 3,8 par. Mt 3,9) oder nur vom „Vater Abraham“ (Lk 16,24) reden lässt. Schließlich ist auch bei Johannes in einer Diskussion Jesu vom „Samen Abrahams“, von „unserem Vater Abraham“ und „Kindern Abrahams“ die Rede, und immer geht es um Jüdinnen und Juden (Joh 8,37.39). ${ }^{4}$

\section{Ausweitung der Geschwistermetaphorik im Neuen Testament}

So weit also geht das Neue Testament noch nicht über das hinaus, was aus der Hebräischen Bibel und im Judentum üblich und bekannt ist. Doch dabei bleibt es nicht. Die Erfahrung - und ihre gläubige Interpretation -, dass mit der Auferweckung Jesu von den Toten die Endzeit angebrochen ist, führte dazu, dass nun auch

Menschen aus den Völkern der Botschaft von Jesus Glauben schenkten, als sie von griechisch sprechenden Juden außerhalb des Landes Israel verkündigt wurde. Weil damit Gott selbst sie durch seinen Geist dazu bewegte, ,sich von den Götzen zu Gott zu wenden ...' (1 Thess 1,9), hielt man es nicht für angemessen, daß diese Menschen - soweit sie Männer waren - sich auch noch nachträglich beschneiden lassen, also Juden werden mussten. ${ }^{5}$

In den Gemeinden der Christusgläubigen gibt es also neben Jüdinnen und Juden, die sich auf ihre Abstammung von den Erzeltern berufen können, Menschen aus

4 Dass dieser Sprachgebrauch auch außerhalb des neutestamentlichen Kanons besteht, zeigt z.B. das Nazaräerevangelium, in dem Jesus zu dem Reichen sagt: „,... siehe, viele deiner Brüder, Söhne Abrahams, starren vor Schmutz ..."; zit. nach Evangelien, in: Neutestamentliche Apokryphen. Hrsg. v. Wilhelm Schneemelcher. Bd. 1. Tübingen 1987, S. 135 .

5 Wengst, Klaus: Was ist das Neue am Neuen Testament, in: Crüsemann, Frank u.a. (Hrsg.): Ich glaube an den Gott Israels. Fragen und Antworten zu einem Thema, das im christlichen Glaubensbekenntnis fehlt. Gütersloh 1999, S. 25-28, hier S. 27. 
den Völkern, die genauso dazu gehören, ohne vorher jüdisch geworden zu sein. Und auch diese sind Brüder und Schwestern.

Diese Differenz ist in den neutestamentlichen Schriften noch allgegenwärtig. Paulus spricht die Mitglieder der korinthischen Gemeinde als Geschwister an. Aber in einer bestimmten Situation erinnert er sie an die Zeit, ,als ihr Völker wart“, oder: ,als ihr noch Heiden wart“6 (1 Kor 12,2). Die Verkündung der Beschlüsse des sogenannten Apostelkonvents von Jerusalem wird nach Apg 15,23 mit den feierlichen Worten eingeleitet: „Die Apostel und Ältesten, eure Geschwister, grüßen die Geschwister aus den Völkern in Antiochia, Syrien und Kilikien." Alle sind Brüder und Schwestern, die jüdischen Christusgläubigen und jene aus den Völkern, die keine Juden geworden sind; aber die letzteren werden gezielt als „Geschwister aus den Völkern“ angeredet. Wenn aber alle Brüder und Schwestern sind, wie lässt sich dann gemeinsame Abstammung als wesentliches Kennzeichen von Geschwistern denken? Denn an der leiblichen Herkunft - ,nach dem Fleisch“, wie Paulus sagt (Röm 9,3) - kann man sich demnach nicht mehr orientieren.

Ich sehe zwei Antworten auf diese Frage, wobei die zweite streng genommen nur die Kurzfassung der ersten ist. Beginnen wir also mit der Langfassung. Der zufolge sind auch die nichtjüdischen Geschwister „Kinder Abrahams“, nur eben nicht nach dem Fleische, sondern aus dem Glauben. So argumentiert Paulus vor allem im Galaterbrief. Demzufolge wurde Abraham selbst aus Glauben gerecht, wie Paulus mit dem Zitat aus Gen 15,6 belegt: „Er glaubte Gott, und das wurde ihm als Gerechtigkeit angerechnet“. Außerdem sah die Schrift selbst Paulus zufolge voraus, dass Gott die Heidenvölker aus Glauben gerecht machen würde. Deshalb hat er Abraham vorweg verkündet: „In dir werden alle Völker gesegnet werden", ein Zitat aus Gen 12,3. Eigentlich genügt diese Argumentation aus Gal 3,6-9 schon, um zu zeigen, dass „die aus dem Glauben Lebenden gesegnet werden, zusammen mit dem glaubenden Abraham“ $(3,9)$. Aber verstärkend fügt Paulus noch den Hinweis hinzu, dass das Gesetz vom Sinai überhaupt erst 430 Jahre später entstanden sei (Gal 3,17). Gerechtigkeit entsteht also, wenn sie lange vor dem Gesetz zugesprochen werden kann, nicht aus dem Gesetz, sondern aus dem Glauben. Wie könnte dieses Gesetz, das nur den Juden, nicht aber den Völkern gegeben ist, die Gerechtigkeit, die aus dem Glauben kommt, hinfällig machen?

Paulus geht noch einen Schritt weiter. In Gal 3,29 formuliert er: „Wenn ihr Christus angehört, dann seit ihr Same Abrahams, Erben gemäß der Verheißung." Hier wird der Begriff „Same“, griechisch $\sigma \pi \varepsilon \dot{\varepsilon} \mu \alpha$ (spérma), der auf genealogi-

6 So die Zürcher Bibel 2007.

Ulrike Schneider, Helga Völkening and Daniel Vorpahl - 978-3-653-98812-3 
sche, auf leibliche Nachkommenschaft zielt, verwendet. Abraham hat gewissermaßen eine zweifache Nachkommenschaft, die Jüdinnen und Juden, die fleischlich aus seinem Samen hervorgegangen sind, und die Christusgläubigen aus den Völkern, die aufgrund ihres Glaubens „Same Abrahams“ sind. Derselbe Paulus sagt von sich: „Ich bin ein Israelit, aus dem Samen Abrahams, dem Stamm Benjamin“ (Röm 11,1). Er gehört zur biologischen Nachkommenschaft Abrahams. Aber er kennt eben auch die, die aufgrund ihres Glaubens „Same Abrahams" sind.

Allerdings wird dieser etwas umständliche Weg, die Geschwisterlichkeit aller Christusgläubigen aus dem Volk Israel und den übrigen Völkern zu begründen, im Neuen Testament in der Regel abgekürzt. Dort heißt es einfach: „Ihr seid alle Söhne und Töchter Gottes durch den Glauben an Jesus Christus" (Gal 3,26). Von Abraham ist nicht die Rede. Nach dem Prolog des Johannesevangeliums sind die, die den in die Welt gekommenen Logos aufgenommen haben, zu Gottes Kindern geworden (Joh 1,12). Noch abgekürzter werden die Empfänger des Kolosserbriefs als "Geschwister in Christus“ angeredet (Kol 1,2). Ja selbst die ausdrückliche Erwähnung des Christusglaubens, der die Gläubigen aus den Völkern mit denen aus Israel gleichstellt, kann wegfallen. Ebenso kann nämlich davon die Rede sein, dass die, die „,vom Geist Gottes getrieben“ sind, „Kinder Gottes“ sind. Im „Geist der Kindschaft“ rufen sie: „Abba! Vater!“ (Röm 8,14-15). Ohne die Nennung von Christus oder dem Geist können die Christusgläubigen schließlich einfach als „Kinder Gottes“ bezeichnet werden (Phil 2,15). Dass auch bei dieser Vorstellung der Gedanke des gemeinsamen Vaters zugrunde liegt, zeigt der 1. Johannesbrief. Denn er setzt die „Kinder Gottes“ mit solchen gleich, die ,aus Gott gezeugt“ sind (1 Joh 3,9).

Es ist ein langer Weg von der genealogisch konstruierten Geschwisterlichkeit des Volkes Israel bis hin zu dem Gedanken, dass alle, die an den Gott Israels glauben, Gottes Kinder sind, unabhängig von ihrer ethnischen Herkunft. Wir haben gesehen, dass für die Vorstellung einer genealogischen Gemeinschaft aller Jüdinnen und Juden in der Hebräischen Bibel der Grund gelegt ist. Die Frage, der ich nun nachgehen will, ist, ob auch die Vorstellung einer Gotteskindschaft der Glaubenden über die genealogische Abstammungslinie von Abraham und Jakob hinaus in der Hebräischen Bibel Wurzeln hat oder ob hier das Neue Testament einen Weg geht, der über die Schrift des Alten Testaments hinausgeht.

\section{Die Gotteskindschaft Israels}

Es geht im Folgenden nicht mehr um die Vorstellung vom Judentum als genealogischem Verwandtschaftsverband. Diese ist im Neuen Testament zwar aufge- 
nommen, aber eben auch ausgeweitet. Auch diese Ausweitung hat, meinem Verständnis nach, ihre Wurzeln in der Hebräischen Bibel. Dazu sind zwei Gedankenlinien zu verfolgen, die zunächst gar nichts miteinander zu tun haben. Die erste spricht von einer Gotteskindschaft der Israelitinnen und Israeliten, die nicht über ihre gemeinsame Abstammung von den Erzeltern definiert ist.

Es finden sich in der Hebräischen Bibel etliche Stellen, die eine Gotteskindschaft Israels voraussetzen, ohne dass der Gedanke eines genealogisch konstruierten Verwandtschaftsverbandes eine Rolle spielt. Sie lassen sich noch einmal differenzieren in solche, die von einer kollektiven, und solche, die von einer individuellen Gotteskindschaft sprechen.

„Israel ist mein erstgeborener Sohn“ (Ex 4,22), so soll Mose nach der Exoduserzählung zum Pharao sagen. Er soll ihm weiter sagen, dass der Pharao „meinen Sohn“ ziehen lassen soll, ihm zu dienen. Andernfalls werde er den erstgeborenen Sohn des Pharao töten (Ex 4,22f.). Jhwh ${ }^{7}$ und Pharao stehen sich gegenüber. Das ist die Grundkonstellation der gesamten Exoduserzählung. ${ }^{8}$ Beide haben einen Sohn. Beim Pharao ist es der Thronfolger. Bei Jhwh ist es sein Volk Israel. Der Gedanke wird beim Propheten Hosea aufgegriffen, wenn er das Exodusereignis in die Worte Jhwhs fasst: „Aus Ägypten rief ich meinen Sohn“ (Hos 11,1).

Wenn Israel Jhwhs Sohn ist, dann ist Jhwh Israels Vater. Dtn 32,6 spricht von ihm als ,dein Vater, der dich geschaffen hat, der dich gemacht und gefestigt hat". Angeredet ist dabei das Volk. Auch bei Jeremia taucht der Gedanke auf, wenn es im Mund Jhwhs heißt: „Ich bin für Israel zum Vater geworden, und Efraim, er ist mein Erstgeborener“ (Jer 31,9). Jer 3 verwendet eine Ehemetaphorik, nach der Jhwh die Rolle des Ehemannes und Israel die der Ehefrau einnimmt. Israel wird also als weibliche Gestalt vorgestellt, von der es in einer gewissen Verkehrung der Rollen heißt, sie habe eben noch „Mein Vater!“ gerufen (Jer 3,4). ${ }^{9}$ Denselben Ausruf „Mein Vater!“ erwartet Jhwh dann im selben Kapitel auch noch von der Frau Israel für die Zukunft (Jer 3,19).

7 Im Judentum, beginnend mit der Hebräischen Bibel, wird der Name Gottes nicht ausgesprochen. Geschrieben wird er nur mit den Konsonanten „Jhwh“, die meist als „Adonaj“ gesprochen wurden und werden. Im Gefolge der griechischen Übersetzung der Hebräischen Bibel, die den Gottesnamen mit „Kyrios“ wiedergibt, hat sich in christlichen Übersetzungen die Wiedergabe mit „,er Herr“ eingebürgert.

8 Kessler, Rainer: Die Ägyptenbilder der Hebräischen Bibel. Ein Beitrag zur neueren Monotheismusdebatte. Stuttgart 2002, S. 111-114.

9 Nach Fischer, Georg: Jeremia 1-25. Freiburg u.a. 2005, S. 187 ,verläßt [die Anrede ... ,Mein Vater!'] die bisher vorherrschende Ehemetaphorik“. 
Es lässt sich feststellen, dass die Beziehung zwischen Jhwh und Israel in die Metaphorik einer Vater-Sohn- oder Vater-Tochter-Relation gekleidet werden kann. Israel als Kollektiv ist Kind Gottes.

Einen Schritt näher an die neutestamentliche Rede von den Brüdern und Schwestern als Söhnen und Töchtern Gottes kommt die Vorstellung der Hebräischen Bibel, dass nicht nur Israel als Kollektiv Kind Gottes ist, sondern jedes einzelne Glied des Volkes, ohne dass von einer gemeinsamen Abstammung von den Erzeltern als den gewissermaßen leiblichen Vorfahren die Rede wäre. In Dtn 14,1 wird ein neuer Abschnitt von Gesetzesbestimmungen mit der Anrede eingeleitet: „Kinder seid ihr Jhwhs, eures Gottes.“ In Ps 73 spricht das betende Ich davon, bei einer bestimmten Art zu reden, ,hätte ich das Geschlecht deiner Kinder" verraten $(73,15)$. An beiden Stellen sind die Israeliten als Einzelne Kinder Gottes. Im Blick auf die Beendigung der Zerstreuung lässt Deuterojesaja Gott zum Norden und zum Süden sagen: „Bring meine Söhne aus der Ferne und meine Töchter vom Ende der Erde“ (Jes 43,6). Hier wird also nicht nur geschlechtsübergreifend von Kindern, sondern ausdrücklich von Söhnen und Töchtern Gottes geredet.

Wie bei der kollektiven Vorstellung von Israel als Sohn Gottes entsprechen sich auch bei der individualisierten Redeweise die Kindschaft der Israeliten und die Vaterschaft Gottes. In Mal 2,10 wird die Vorstellung von Gottes Vaterschaft in die Form einer rhetorischen Frage gekleidet: „Haben wir nicht alle einen einzigen Vater?“ Tritojesaja drückt das selbe affirmativ-positiv aus: „Nun aber bist doch du, Jhwh, unser Vater" (Jes 64,7). Dominiert in diesen Texten noch das Kollektiv, indem von „wir“ und „unserem Vater“ die Rede ist, so erscheint im hebräischen Text von Jesus Sirach im 2. Jahrhundert v.d.Z. auch die individuelle Redeweise, bei der Gott als „mein Vater“ angeredet wird: „Ich will dich preisen, mein Gott, meine Rettung, / ich will dich loben, mein Gott, mein Vater [...]" (Sir 51,1 hebr.). ${ }^{10}$

In der Tat ,drückt die Metapher von der Gotteskindschaft [...] eine besonders enge, eben nahezu familiäre Zugehörigkeit aus". ${ }^{11}$ Alle Stellen aber, ob sie kollektiv oder individualisiert von der Gotteskindschaft sprechen, erwähnen die genealogische Abstammung, die ja in gewisser Weise diese „,nahezu familiäre Zugehörigkeit" verdoppelt, mit keinem Wort. Sie bereiten damit die neutestamentliche Rede, dass alle Glaubenden Kinder Gottes und somit Schwestern und Brüder seien, vor. Am weitesten geht dabei Jes 63,16. Denn diese Stelle kontras-

10 Hebräischer Text nach: The Book of Ben Sira in Hebrew. A Text Edition of All Extant Hebrew Manuscripts and a Synopsis of All Parallel Hebrew Ben Sira Texts. Hrsg. v. Pancratius C. Beentjes. Leiden u.a. 1997, S. 91.

11 Grund, Alexandra: „Wer steht mir bei wider die Übeltäter?“ (Ps 94,16), in: Jahrbuch für Biblische Theologie 26 (2011), S. 55-84, hier S. 78 (Anm. 111). 
tiert als einzige die Vorstellung, dass die Israeliten Kinder Gottes sind, mit der, dass sie Kinder Abrahams sind. Es heißt da: „Du [sc. Gott] bist doch unser Vater! Abraham hat nichts von uns gewusst, und Israel kennt uns nicht. Du, Jhwh, bist unser Vater [...]“. „Offensichtlich wird hier die Vaterschaft Gottes der Vaterschaft der Erzväter Abraham und Jakob gegenübergestellt, ja Gott wird regelrecht gegen jene ausgespielt." ${ }^{\text {"12 }}$ Allerdings wird damit nicht etwa die Abstammung der Israeliten von Abraham und Isaak geleugnet. Sie ist vielmehr vorausgesetzt. Aber, wie Claus Westermann kommentiert, „Gott ist in einer vollkommen anderen Weise Israels Vater als Abraham und Jakob Väter des Volkes sind; er ist lebendiger, gegenwärtiger Vater, er weiß, er kennt, er sieht.“13

In der Hebräischen Bibel ist nie die Rede davon, dass andere als die Kinder Israels Söhne oder Töchter Gottes sind. Aber indem in Jes 63,16 die Geschwisterlichkeit der Israelitinnen und Israeliten primär in der Gotteskindschaft und nur sekundär in der Abstammung von Abraham und Jakob begründet wird, wird eine Voraussetzung geschaffen, dass im Neuen Testament dann auch die, die zum Glauben an den Gott Israels gekommen sind, Kinder Gottes und somit Geschwister heißen können.

Das leitet über zu einer weiteren Gedankenlinie, die mit der Frage der Abrahamkindschaft oder Gotteskindschaft als Begründung der Geschwisterlichkeit des Volkes gar nichts zu tun hat.

\section{Das Hinzutreten der Völker}

Wir haben gesehen, dass die Geschwisterlichkeit im Neuen Testament auf doppelte Weise begründet wird. Die Angehörigen des Volkes Israel sind Geschwister, weil sie Nachfahren von Abraham und Sarah sind, „,nach dem Fleisch“, wie es heißt. So steht es auch in der Hebräischen Bibel. Die Angehörigen aus den Völkern sind dagegen Geschwister, weil sie durch den Glauben an Jesus als den Messias zum Glauben an den Gott Israels gekommen sind. Sie sind Geschwister im Geist, im Glauben, in Christus. Und auch dieser Gedanke, dass die Völker zu Israel hinzutreten, hat seine Wurzeln in der Hebräischen Bibel. Und wie im Neuen Testament heißt das immer, dass die Gläubigen aus den Völkern in der Tat zu Israel hinzutreten und nicht, wie es später häufig verstanden wurde, an die Stelle Israels treten. ${ }^{14}$

12 Böckler, Annette: Gott als Vater im Alten Testament. Traditionsgeschichtliche Untersuchungen zu Entstehung und Entwicklung eines Gottesbildes. Gütersloh 2000, S. 284.

13 Westermann, Claus: Das Buch Jesaja. Kapitel 40-60. Göttingen 1966, S. 312. Zu weiteren Deutungen der Stelle vgl. den Exkurs bei Böckler: Gott, S. 284-286.

14 Zum Folgenden vgl. grundlegend Crüsemann, Frank: Das Alte Testament als Wahrheitsraum des Neuen. Die neue Sicht der christlichen Bibel. Gütersloh 2011, S. 192-204. 
Schon der anfängliche Segen für Abram enthält die Völkerperspektive. Mit dem Befehl zum Aufbruch ins Land Kanaan empfängt Abram nicht nur selbst Segen, sondern bekommt seinerseits den Befehl, „Segen“ zu werden. Was das heißt, führt der folgende Vers aus, indem er Gott sagen lässt: „Segnen will ich, die dich segnen, und wer dich erniedrigt, den verfluche ich. In dir sollen gesegnet werden alle Sippen der Erde" (Gen 12,3). Deutlich ist, dass es keinen Segen an Abraham und seinen Nachfahren vorbei gibt. Deutlich ist aber auch, dass es die Möglichkeit des Segens für alle Völker der Erde gibt. Diese Linie wird in verschiedenen Ausdrucksformen durch die Hebräische Bibel hindurch beibehalten. Nach der prophetischen Vision, die sich sowohl bei Jesaja als auch bei Micha findet (Jes 2,1-5 par. Mi 4,1-5), werden künftig die Völker zum Zion kommen und von dort Tora, also Weisung aus Gottes Mund, empfangen, die ihnen ein friedliches Miteinander ermöglicht. Deuterojesaja spricht von dem Gott Israels, der sich an ,alle Enden der Erde“ wendet und dessen Wort unverbrüchlich ist: „Mir werden sich beugen alle Knie“ (Jes 45,22f.).

Der Perspektive für die Völker entspricht die Rolle Israels. Wie die Priester für das Volk vor Gott treten, soll Israel ein „Königreich von Priestern“ sein (Ex 19,6), das die Völker zum Gott Israels führt. Israel ist „Zeuge“ Jhwhs vor den Völkern (Jes 43,10; 55,4). Israel, der Knecht Gottes, wird zum „Licht für die Völker“ $(42,6 ; 49,6 f.){ }^{15}$ All diese Stellen eröffnen eine Perspektive für die Völker, ohne die der Gedanke des Neuen Testaments, dass Menschen aus den Völkern zum Glauben an den Gott Israels kommen und Brüder und Schwestern auch der Israeliten und Israelitinnen werden, nicht denkbar ist. All diese Stellen machen aber auch klar, dass es keinen Glauben an den Gott Israels und Vater Jesu Christi an Israel vorbei geben kann.

Am weitesten gehen einige Stellen der Hebräischen Bibel, die zwar den Unterschied zwischen dem Volk Israel und den übrigen Völkern nicht aufheben, aber seine Bedeutung auf erstaunliche Weise relativieren. So stellt Am 9,7 die rhetorische Frage: „Gehört ihr nicht genauso zu mir wie die Kuschiten, ihr Israelkinder - Spruch Jhwhs? Habe ich nicht Israel aus dem Land Ägypten heraufgeführt und die Philister aus Kaftor und Aram aus Kir?" Gott ist und bleibt der Gott Israels. Aber er ist zugleich der Gott der Ägypter, der Philister und der Aramäer, und er hat seine eigene Geschichte mit ihnen. An einer der

15 Vorausgesetzt ist, dass der sogenannte ,Gottesknecht" in Deuterojesaja in seinem Wirken darauf abzielt, „,dass Israel so wird wie er“, so dass man „,von einer ,perspektivischen Identifizierung' von eved [= Knecht] und Israel sprechen“ kann; Zitate: Kessler, Rainer: Kyros und der eved bei Deuterojesaja. Gottes Handeln in Macht und Schwäche, in: Crüsemann, Marlene; Jochum-Bortfeld, Carsten (Hrsg.): Christus und seine Geschwister. Christologie im Umfeld der Bibel in gerechter Sprache. Gütersloh 2009, S. 141-158, hier S. 150 . 
jüngsten Stellen im Jesajabuch wird die Vision eines Dreierbundes zwischen Israel, Ägypten und Assur vor Augen gestellt. Sie endet mit dem Gotteswort: „Gesegnet ist mein Volk, Ägypten, und das Werk meiner Hände, Assur, und mein Erbbesitz, Israel“ (Jes 19,25). Prädikate, die bisher Israel vorbehalten waren - „mein Volk“ (Ex 3,7.10; 5,1 u.ö.), „,das Werk meiner Hände“ (Jes 64,7; vgl. 43,1; 44,2 u.ö.) - werden nun auf andere Völker übertragen. Und ebenfalls für die Zukunft sieht Sacharja voraus, dass sich viele Völker Jhwh anschließen werden. Und er lässt Gott sagen: „Sie werden mir zum Volk“ (Sach 2,15).

Ohne solche Aussagen könnte das Neue Testament nicht davon sprechen, dass Menschen aus den Völkern zu Israel hinzutreten und im Glauben an Jesus als den Messias zu Geschwistern der Kinder Israels werden können. Der Gedanke der Geschwisterlichkeit im Neuen Testament - dies wollte ich zeigen ersetzt nicht das Motiv einer genealogisch-ethnisch begründeten Geschwisterlichkeit der Israeliten. Er lässt diese vielmehr weiter in Geltung, ergänzt sie aber um den Gedanken einer Geschwisterlichkeit aus Glauben, indem er Menschen aus den Völkern zu Israel hinzutreten lässt. Doch auch dieser Gedanke hat seine tiefen Wurzeln in der Hebräischen Bibel, die sowohl von einer Gotteskindschaft ohne Bezug auf die genealogische Abstammung sprechen kann als auch den Gedanken des Hinzutretens der Völker zu Israel kennt.

\section{Ausblick}

Der Gedanke der Geschwisterlichkeit hat eine große Karriere gemacht. In den Klöstern sind die Mönche Brüder und die Nonnen Schwestern. Die französische Revolution feierte die Brüderlichkeit der Freien und Gleichen: liberté - égalité fraternité. Es ist die Brüderlichkeit der Bürger. Auf dem Rütli verbindet Schiller den Gedanken der Freiheit mit dem der nationalen Einheit:

Wir wollen sein ein einzig Volk von Brüdern,

In keiner Not uns trennen und Gefahr

(Schiller, Wilhelm Tell 2,2).

Derselbe Schiller kann in der Ode An die Freude die Brüderlichkeit aber auch universal vorstellen. Er besingt die Freude:

Alle Menschen werden Brüder,

Wo dein sanfter Flügel weilt.

Seid umschlungen, Millionen!

Diesen Kuß der ganzen Welt!

Brüder - überm Sternenzelt

muß ein lieber Vater wohnen. 
Ich lasse den Genderaspekt hier beiseite, da in dieser Welt ohnehin nur Brüder und Väter sichtbar wurden, keine Schwestern und Mütter. Wir konnten sehen, dass die Bibel Alten und Neuen Testaments schon weiter war. Der äußerst knappe Ausblick will nur auf eines aufmerksam machen, was sich beim Studium der Geschwisterlichkeitsgedanken in Hebräischer Bibel und Neuem Testament aufdrängt. Es genügt nicht, nur von Brüdern und Schwestern zu sprechen. Man muss auch fragen, durch welche Art gemeinsamer Abstammung - auch wenn man „Abstammung“ dabei metaphorisch auffasst - solche Geschwisterlichkeit zustande kommt. Auch Schiller braucht einen ,lieben Vater“, der über dem Sternenzelt wohnt, damit alle Menschen Brüder werden können.

\section{Quellen und Literatur}

Böckler, Annette: Gott als Vater im Alten Testament. Traditionsgeschichtliche Untersuchungen zu Entstehung und Entwicklung eines Gottesbildes. Gütersloh 2000.

Crüsemann, Frank: Das Alte Testament als Wahrheitsraum des Neuen. Die neue Sicht der christlichen Bibel. Gütersloh 2011.

Evangelien, in: Neutestamentliche Apokryphen. Hrsg. v. Wilhelm Schneemelcher. Bd. 1. Tübingen 1987.

Fischer, Georg: Jeremia 1-25. Freiburg u.a. 2005.

Grund, Alexandra: „Wer steht mir bei wider die Übeltäter?“ (Ps 94,16), in: Jahrbuch für Biblische Theologie (JBTh) 26 (2011), S. 55-84.

Kessler, Rainer: Die Ägyptenbilder der Hebräischen Bibel. Ein Beitrag zur neueren Monotheismusdebatte. SBS 197. Stuttgart 2002.

Kessler, Rainer: Kyros und der eved bei Deuterojesaja. Gottes Handeln in Macht und Schwäche, in: Crüsemann, Marlene; Jochum-Bortfeld, Carsten (Hrsg.): Christus und seine Geschwister. Christologie im Umfeld der Bibel in gerechter Sprache. Gütersloh 2009, S. 141-158.

Kessler, Rainer: Sozialgeschichte des alten Israel. Eine Einführung. 2. Aufl., Darmstadt 2008. Roloff, Jürgen: Die Kirche im Neuen Testament. GNT, NTD Ergänz. 10. Göttingen 1993.

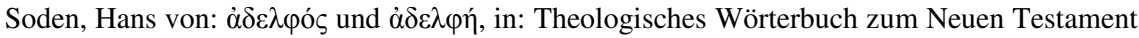
(ThWNT). Bd. 1. Stuttgart 1933, S. 144-146.

The Book of Ben Sira in Hebrew. A Text Edition of All Extant Hebrew Manuscripts and a Synopsis of All Parallel Hebrew Ben Sira Texts. Hrsg. v. Pancratius C. Beentjes. Leiden u.a. 1997.

Wengst, Klaus: Was ist das Neue am Neuen Testament, in: Crüsemann, Frank u.a. (Hrsg.): Ich glaube an den Gott Israels. Fragen und Antworten zu einem Thema, das im christlichen Glaubensbekenntnis fehlt. KT 168. Gütersloh 1999, S. 25-28.

Westermann, Claus: Das Buch Jesaja. Kapitel 40-60. ATD 19. Göttingen 1966. 


\title{
Isaak und Ismael in der islamischen Überlieferung - Ein widersprüchliches Bild
}

\author{
Hans-Michael Haußig
}

\begin{abstract}
This article investigates the relation between Isaac and Ismael in the Quran and early Islamic tradition. Early parts of the Quran mention only Isaak as Abraham's son, although Ismael is known and in later parts clearly identified as son of Abraham. Notwithstanding that today Muslims identify Ismael as the son Abraham was ordered to sacrifice, the Quranic story about this event does not mention the son's name at all. This resulted in discussions among early Muslim exegetes, whether it was Isaac or Ismael. The fact, that later Islamic tradition identifies Ismael as this son can be explained by the fact, that the Quran as well as early Islamic tradition connect him with Mekka and the foundations of the pilgrimage.
\end{abstract}

Neben dem Fastenbrechen ('ìd al-fitr) am Ende des Monats Ramadan ist das Opferfest ('ìd al-aḍha) das einzige kanonische Fest, das ohne Einschränkung von allen Muslimen gefeiert wird. Bei diesem Fest wird der Bereitschaft Abrahams (Ibrāhìm), seinen Sohn zu opfern, gedacht. Als Gott die große Bereitschaft Abrahams erkannte, gebot er ihm Einhalt und Abraham und sein Sohn opferten stattdessen zusammen einen Widder. Mit diesem Ereignis knüpft der Islam an die jüdische bzw. christliche Tradition an, denn die Vorlage findet sich in der Bibel in Gen 22; gleichzeitig wird aber der Opferung des Sohnes im Islam durch das Opferfest eine Bedeutung beigemessen, die sie weder im Judentum noch im Christentum besitzt, denn bei letzteren wird dieses Ereignisses nicht im Rahmen ihres rituellen Festkalenders thematisiert. Während nun aber in der Bibel und somit sowohl in jüdischer als auch christlicher Überlieferung Isaak als derjenige Sohn genannt wird, der geopfert werden sollte, ist es nach Ansicht der heutigen Muslime Ismael gewesen. Somit stellt das Thema der Opferung des Sohnes Abrahams ein zentrales heilsgeschichtliches Ereignis dar, an dem sich die drei abrahamitischen Religionen scheiden. Dies trifft auch auf die generelle Bewertung der beiden Söhne Abrahams zu. Während die Bewertung Ismaels im Judentum ambivalent ist, dominiert im Christentum eine eindeutig negative Auffassung seiner Person, die bereits in den Schriften des Neuen Testaments angelegt ist. ${ }^{1}$ Demgegenüber findet sich in der islamischen Überlieferung keine negative Sichtweise Isaaks (Isḥa q). Dies hängt nicht nur damit zusammen, dass der Islam dem eigenen Selbstverständnis nach die Offenbarungen des Judentums und des Christentums in sich einschließt, sondern ist nicht zuletzt auch in einer

1 Vgl. Löhr, Helmut: Isaak, Jakob, Esau, Josef, in: Öhler, Markus (Hrsg.): Alttestamentliche Gestalten im Neuen Testament. Darmstadt 1999, S. 86-88. 
positiven Sichtweise Isaaks im Offenbarungsbuch des Islam, dem Koran, begründet. Es mag nun aber geradezu überraschen, dass der Koran an keiner Stelle den Namen des Sohnes bei der Wiedergabe der Opfererzählung erwähnt. Darüber hinaus hält aber der Koran auch an der aus der jüdischen Tradition herrührenden Abfolge Abraham - Isaak - Jakob fest; zudem lassen die frühen Suren des Koran noch überhaupt keinen Bezug zwischen Abraham und Ismael (Ismā'ill) erkennen. Dies ist natürlich auch den muslimischen Exegeten nicht entgangen und so zeigt sich hinsichtlich des Verhältnisses zwischen Isaak und Ismael nicht nur im Koran ein widersprüchliches Bild, sondern auch in der frühen islamischen Tradition. Erst allmählich sollte sich dann Ismael gegenüber Isaak als der entscheidende Sohn Abrahams durchsetzen. Im Folgenden soll die Entwicklung des Verhältnisses der beiden Brüder innerhalb der frühen islamischen Überlieferung exemplarisch skizziert werden. Den Ausgangspunkt bildet dabei der Koran. Im Anschluss wird auf die spätere historiographische Tradition sowie die hierzulande wenig bekannte Gattung der Prophetenerzählungen eingegangen.

\section{Koran}

Sowohl Isaak als auch Ismael werden zwar an mehreren Stellen des Koran erwähnt, doch treten sie im Vergleich zu anderen biblischen Gestalten nicht allzu häufig auf. Biographische Einzelheiten werden so gut wie gar nicht überliefert. Während von Isaak praktisch nur der Name genannt wird, finden sich über Ismael einige wenige Aussagen. Dennoch wird im Koran nicht einmal die Erzählung darüber, wie Hagar (Hāğar) und Ismael nach Mekka gelangten, nichts von der Suche Hagars nach Wasser für ihren Sohn und auch nichts von der Entdeckung des Brunnens Zamzam erzählt. Diese Ereignisse, die immerhin im Rahmen der Wallfahrt ( $h a g \breve{g} \breve{g}$ ) nach Mekka eine Rolle spielen, werden erst in nachkoranischen Quellen überliefert. ${ }^{2}$ Darüber hinaus scheint der Bezug Ismaels zu Abraham in den frühen Suren noch überhaupt nicht präsent zu sein. Vielmehr überwiegt hier die auch aus der Bibel bekannte Abfolge über Isaak, so etwa in der Sure al-Anbiyā' (Die Propheten - Sure 21), die der späten zweiten mekkanischen Periode zugerechnet wird. Dort findet sich eine Aufzählung der biblischen Propheten - einige außerbiblische Propheten werden ebenfalls genannt -, die hier gewissermaßen als Vorläufer Muhammads erscheinen und wie dieser zu ihrem Volk gesandt wurden, um es vor dem drohenden Gericht zu warnen und

2 Zwar werden im Koran die beiden Hügel aṣ-Ṣafā und al-Marwa als Teil der Wallfahrt erwähnt (2,158), jedoch wird nicht der Grund für dieses Ritual genannt, nämlich die Erinnerung daran, dass Hagar zwischen ihnen auf der Suche nach Wasser für ihren Sohn hin- und hergelaufen sein soll.

Ulrike Schneider, Helga Völkening and Daniel Vorpahl - 978-3-653-98812-3 
zur Umkehr aufzurufen. Ein längerer Abschnitt referiert die Geschichte Abrahams (21,51-73), wobei auch zahlreiches außerbiblische Material, so etwa aus dem frühjüdischen Jubiläenbuch, eingeflossen ist. Interessant sind in unserem Zusammenhang nun aber die letzten beiden Verse des Stückes (72-73): ${ }^{3}$

Und Wir schenkten ihm Isaak und Jakob dazu. Und jeden machten Wir rechtschaffen. Und Wir machten sie zu Vorbildern, die (die Menschen) nach unserem Befehl leiteten Und wir offenbarten ihnen, die guten Werke zu tun, das Gebet zu verrichten und die Abgabe zu entrichten. Und Uns haben sie gedient.

Hier ist von Ismael nicht die Rede. Vielmehr wird hier nur die Nachfolgelinie über Isaak erwähnt. Doch auch Ismael taucht in der vorliegenden Sure auf, allerdings erst einige Verse danach (21,85-86):

Und (erwähne) Ismael und Idrīs und Dhū l-Kifl. Jeder (von ihnen) gehörte zu den Geduldigen. Und Wir ließen sie in unsere Barmherzigkeit eingehen. Wahrlich, sie gehören zu den Rechtschaffenen.

Hier erscheint Ismael also in einer Aufzählung rechtschaffener Propheten. Während Idrīs im Allgemeinen mit dem biblischen Henoch identifiziert wird, sind sich die Kommentatoren bezüglich der Identität von Dhū l-Kifl uneinig. In jedem Fall erscheint Ismael hier ganz unabhängig von Abraham. Weder wird erwähnt, dass er Abrahams Sohn ist, noch steht er anderweitig mit ihm in einer Beziehung. Im Gegensatz zu zahlreichen anderen in dieser Sure genannten Propheten werden über ihn auch keine biographischen Details mitgeteilt.

Ein ähnliches Bild finden wir in der ebenfalls aus der zweiten mekkanischen Periode stammenden Sure Maryam (Maria - Sure 19), wo in 41-50 von Abraham die Rede ist und sich in Vers 49 folgende Aussage findet:

Als er sich [gemeint ist Abraham, H.-M.H.] von ihnen und von dem, was sie anstelle Gottes verehrten, abgesondert hatte, schenkten Wir ihm Isaak und Jakob; und beide machten Wir zu Propheten.

Auch hier wird zunächst nur die Nachfolgereglung über Isaak und Jakob erwähnt. Ismael taucht wiederum ohne Bezug zu Abraham erst einige Verse später $(19,54)$ auf, nachdem zuvor $(19,51-53)$ von Moses die Rede war:

Und gedenke im Buch des Ismael. Er war treu zu seinem Versprechen, und er war ein Gesandter und Prophet.

Hier erfahren wir zunächst zwei Dinge, die zwar mit Ismael, aber niemals mit Isaak im Koran in Verbindung gebracht werden: (a) Ismael hat ein Buch erhal-

3 Die Zitate aus dem Koran erfolgen nach der Ausgabe Der Koran. Arabisch - Deutsch. Übers. u. komm. v. Adel Theodor Khoury. Gütersloh 2004. 
ten; (b) Ismael war sowohl Gesandter (rasül) als auch Prophet (nabī). Insofern kommt ihm hier schon eine etwas herausgehobenere Rolle zu, denn keineswegs alle biblischen Propheten werden im Koran auch als Gesandte bezeichnet. ${ }^{4}$ Dennoch ergibt sich aus den beiden genannten Stellen der zweiten mekkanischen Periode insgesamt der Eindruck, dass, wie Walter Beltz es formulierte, „Mohammed an einer besonderen Betonung der Rolle Ismaels zunächst nicht interessiert war"5.

Auch gegen Ende der mekkanischen Periode (620-622) hat sich die Sichtweise des Korans auf Isaak und Ismael nicht grundlegend gewandelt. So paraphrasiert die Sure Hüd (Sure 11) in den Versen 69-76 die aus Gen 18 bekannte Erzählung vom Besuch der Boten bei Abraham und erwähnt in Vers 71, dass diese Abrahams Frau - ihr Name Sara wird im Koran an keiner Stelle erwähnt, ebenso wenig der Name Hagars, der Mutter Ismaels - „Isaak, und nach Isaak Jakob“ verkündeten. $^{6}$ Im Gegensatz zum ansonsten viel ausführlicheren biblischen Bericht fällt auf, dass Abraham hier nicht nur ein Sohn, sondern gleichzeitig auch der Enkel verkündet wird und darüber hinaus beide mit Namen erwähnt werden. Von der in der Bibel zuvor (Gen 16) berichteten Geburt Ismaels ist allerdings an keiner Stelle die Rede. In der aus der gleichen Periode stammenden Sure Ibrāhìm (Abraham - Sure 14) wird allerdings erstmals Ismael neben Isaak als Sohn Abrahams genannt (14,39):

Lob sei Gott, der mir trotz meines Alters Ismael und Isaak geschenkt hat! Mein Herr erhört das Rufen.

Speyer vertrat die Ansicht, dass Muhammad „sich im Unklaren darüber befunden hat", ob Jakob der Sohn Abrahams oder dessen Enkel war. Er habe in mekkanischer Zeit ,eine unklare Vorstellung von der Aufeinanderfolge der biblischen Stammväter gehabt", deren Namen zwar durch die Liturgie bei den Juden überaus populär waren, ihn ,aber im Zweifel darüber ließen“, wo er in der

4 Vgl. zur Unterscheidung zwischen Prophet und Gesandter Tottoli, Roberto: Biblical Prophets in the Qur'ān and Muslim Literature. London, New York 2002, S. 71-79. Insbesondere die spätere islamische Theologie hat die Unterschiede zwischen beiden eingehend diskutiert.

5 Beltz, Walter: Sehnsucht nach dem Paradies. Mythologie des Korans. Berlin 1979, S. 107.

6 Die Geschichte taucht bereits in den mekkanischen Suren 15,51-60 und 51,24-38 auf, allerdings wird an beiden Stellen nicht der Name des Sohnes, der Abraham verheißen wird, erwähnt. 
Reihe der Namen Ismael unterbringen sollte, den weder Juden noch Christen zu den Erzvätern zählten und der nach Muhammads Lehre doch zu ihnen gehörte. ${ }^{7}$

Vollends scheint die Zuordnung Ismaels zu Abraham jedoch dann in der medinensischen Periode etabliert zu sein, wo er in der Sure al-Baqara (die Kuh - Sure 2) mehrfach zusammen mit Abraham, Isaak und Jakob erwähnt wird ${ }^{8}$ so etwa in Vers 136:

Sprecht: Wir glauben an Gott und an das, was zu uns herabgesandt wurde, und an das, was herabgesandt wurde zu Abraham, Ismael, Isaak, Jakob und den Stämmen, und an das, was Mose und Jesus zugekommen ist, und an das, was den (anderen) Propheten von ihrem Herrn zugekommen ist. Wir machen bei keinem von ihnen einen Unterschied. Und wir sind ihm ergeben [mиslimün].

Dies ist offensichtlich eine Polemik gegen Juden und Christen, denen gegenüber Muhammad seine Gemeinschaft nun als eigenständige wahre Religion versteht, ${ }^{9}$ durch die der reine Monotheismus, der nichts von den Streitereien zwischen den von ihm gleichermaßen anerkannten Propheten weiß, wiederhergestellt werden soll. In diesem Sinne fährt auch Vers 140 entsprechend fort:

Oder wollt ihr sagen, dass Abraham, Ismael, Isaak, Jakob und die Stämme Juden oder Christen gewesen sind? Sprich: Wisst ihr es besser oder Gott?

Diese Sure überliefert auch ein wichtiges biographisches Detail, nämlich dass Gott Abraham und Ismael auftrug, sein Haus - gemeint ist die Ka'ba - ,für diejenigen, die den Umlauf vollziehen und die eine Einkehrzeit einlegen und die sich verneigen und niederwerfen" (Vers 125), zu reinigen. Hier wird auf die Riten der Wallfahrt ( hăğğg angespielt.

Von wesentlicher Bedeutung für die islamische Überlieferung ist nun das Ereignis der Opferung des Sohnes. Dieses bildet, wie bereits erwähnt, die Grundlage des islamischen Opferfestes, das auch mit der alljährlichen Wallfahrt nach Mekka in Verbindung steht. Die Geschichte findet sich in der Sure alȘâffät (die sich reihen - Sure 37), 101-113, die in die Anfänge der zweiten mek-

7 Speyer, Heinrich: Die biblischen Erzählungen im Qoran. Gräfenhainchen 1931, Nachdr. Hildesheim u.a. 1988, S. 170-171.

8 Entsprechende Stellen finden sich auch in den medinensichen Suren 3,84 und 4,163.

9 Entsprechend könnte der letzte Satz „Und wir sind ihm ergeben“ verstanden werden. Das Partizip ,muslim“ (Pl. ,muslimūn') bedeutet zunächst nichts anderes als ,ergeben“, gewinnt aber, wie auch der Infinitiv islām, im Rahmen der Auseinandersetzungen mit Juden und Christen immer mehr die Bedeutung einer eigenständigen Religionsbezeichnung, mit der sich Muhammad und seine Anhänger gegenüber anderen als eigenständige Gemeinschaft abgrenzen konnten. Vgl. dazu Haußig, Hans-Michael: Der Religionsbegriff in den Religionen. Studien zum Selbst- und Religionsverständnis in Hinduismus, Buddhismus, Judentum und Islam. Berlin, Bodenheim bei Mainz 1999, S. 196-204. 
kanischen Periode datiert wird. Zum besseren Verständnis der Problematik sei der Text hier im vollen Wortlaut wiedergegeben:

101 Da verkündeten Wir ihm einen langmütigen Knaben. 102 Als dieser das Alter erreichte, dass er mit ihm laufen konnte, sagte er: „Mein lieber Sohn, ich sehe im Schlaf, dass ich dich schlachte. Schau jetzt, was du meinst.“ Er sagte: „O mein Vater, tu, was die befohlen wird. Du wirst finden, so Gott will, dass ich zu den Standhaften gehöre." 103 Als sie sich beide ergeben gezeigt hatten und er ihn auf die eine Stirnseite niedergeworfen hat, 104 da riefen Wir ihm zu: „O Abraham, 105 du hast das Traumgesicht wahr gemacht.“ So entlohnen Wir die Rechtschaffenen. 106 Das ist die offenkundige Prüfung. 107 Und Wir lösten ihn mit einem großen Schlachtopfer aus. 108 Und Wir ließen seinen Ruf unter den späteren Generationen fortbestehen. 109 Friede sei über Abraham! 110 So entlohnen Wir die Rechtschaffenen. 111 Er gehört zu unseren gläubigen Dienern. 112 Und Wir verkündeten ihm Isaak als einen Propheten von den Rechtschaffenen. 113 Und Wir segneten ihn und Isaak. Unter ihren Nachkommen gibt es welche, die rechtschaffen sind, und welche, die sich selbst offenkundig Unrecht tun.

Der Bericht ist im Vergleich zur biblischen Erzählung recht kurz gehalten. Problematisch für die frühe Generation der muslimischen Exegeten war aber, dass der Sohn, der Abraham in Vers 101 verkündet wird und den er zu opfern bereit ist, namentlich nicht genannt wird. Dies sollte nun dazu führen, dass unter den frühen Generationen der Muslime darüber debattierte wurde, ob es sich nun um Isaak oder Ismael handelte. Entscheidend für die Beantwortung dieser Frage mag nun Vers 112 sein, wo explizit von Isaak die Rede ist. Man könnte hierin einen neuen Abschnitt sehen, wodurch die vorangehenden Verse zwangsläufig auf Ismael zu beziehen wären. Der ganze Abschnitt kann aber auch als Abschluss des ganzen Stücks gelesen werden und somit wäre es dann der zuvor nicht namentlich erwähnte Sohn Isaak gewesen. In der frühislamischen Diskussion sind beide Möglichkeiten erwogen worden, doch scheint einiges eher auf die zweite Möglichkeit hinzuweisen. Wie bereits erwähnt, ist Ismael in der zweiten mekkanischen Periode zwar als Prophet bekannt, doch erfolgt an keiner Stelle eine Zuordnung zu Abraham. Die einschlägigen Stellen zu Abraham und seinen Nachkommen aus dieser Periode erwähnen vielmehr nur die Nachkommenschaft über Isaak und Jakob und halten sich somit an das heilsgeschichtliche Modell der Bibel. Daher spricht vieles dafür, auch an dieser Stelle anzunehmen, dass bei dem zu opfernden Sohn zunächst an Isaak gedacht wurde.

Insofern ergibt sich aus den koranischen Erzählungen das Bild, dass Isaak und Ismael zwar ab der zweiten mekkanischen Periode belegt sind, doch sind die Berichte über sie äußerst spärlich. In jedem Fall lässt sich in der Frühphase noch keine Beziehung zwischen Abraham und Ismael erkennen, die erst in der dritten mekkanischen Periode Gestalt zu gewinnen scheint. Während über Isaak 
nicht viel mehr gesagt wird, als dass er zu den rechtschaffenen Nachkommen Abrahams gehörte und ein Prophet war, erfahren wir von Ismael in den späteren Versen wenigstens, dass er seinem Vater bei der Wiederherstellung der Ka'ba geholfen hat.

\section{Die nachkoranische Traditionsliteratur}

Ein deutlich erweitertes Bild des Verhältnisses zwischen Isaak und Ismael gibt uns die nachkoranische Literatur. Die im Koran erwähnten Prophetengestalten tauchen in nahezu allen Literaturgattungen auf, jedoch sind es im wesentlichen vier Genres, die in dieser Hinsicht das wesentliche Material in sich vereinigen: (1) Korankommentare (tafsìr); (2) Traditionen des Propheten Muhammad (sun$n a$ ), die in den sogenannten Hadithen übermittelt werden; (3) Historiographie und (4) Prophetengeschichten. Alle diese Literaturgenres enthalten außerkanonisches Material über die Propheten, das sich auf weiten Strecken überschneidet, jedoch in den einzelnen Texten eine unterschiedliche Funktion wahrnimmt. Beim Korankommentar dient dieses Material zur Erklärung und Vervollständigung der im Koran meist nur fragementarischen Berichte über die Propheten. Ziel der Hadithe ist wiederum die Erläuterung einer religiösen Praxis oder eines Glaubensgrundsatzes, die, sofern das Heilige Buch nicht eindeutige Aussagen enthält, nur dann als legitim gelten, wenn sie auf den Propheten zurückgeführt werden können. Im Rahmen dieser kurzen, meist in Erzählform gehaltenen Hadithe werden nun auch einige Erzählungen über vorislamische Propheten überliefert. ${ }^{10}$ In den beiden genannten Quellen werden allerdings die Berichte nicht chronologisch fortlaufend übermittelt, denn im Falle der Korankommentare sind die entsprechenden Berichte der Anordnung des Korantextes untergeordnet, wogegen im Falle der Hadithe das jeweils behandelte Thema der übermittelten Tradition das Ordnungsprinzip darstellt. Demgegenüber ist das Material sowohl innerhalb der Historiographie als auch in den Prophetengeschichten nach chronologischen Gesichtspunkten geordnet.

Da hier nicht das Auftreten von Isaak und Ismael in sämtlichen Literaturgattungen besprochen werden kann, werden sich die folgenden Ausführungen auf das Auftreten Isaaks und Ismaels in Historiographie und Prophetengeschichten beschränken.

\section{Historiographie}

Im Gegensatz zu den Korankommentaren und den Hadithen ist die Historiographie (ta'rīh) am Gang der Erzählung orientiert. Der Ausdruck ta'rīh wird im

10 Tottoli: Prophets, S. 83-84.

Ulrike Schneider, Helga Völkening and Daniel Vorpahl - 978-3-653-98812-3 
Allgemeinen als 'Geschichte"' übersetzt, doch handelt es sich hierbei tatsächlich nicht um eine strenge Historiographie in modernem Sinne, sondern um eine chronologisch geordnete Zusammenfassung nach heilsgeschichtlicher Vorgabe. Demgemäß orientiert sich die Auswahl und Beschreibung der Ereignisse am Koran und bemüht sich, die dort nur fragmentarisch enthaltenen Angaben unter Heranziehung anderer Quellen zu einer weltgeschichtlichen Darstellung auszubauen. Fehlendes wurde dabei aus der Bibel und anderen Quellen ergänzt, soweit das dort enthaltene Material dem Koran nicht widersprach. Demgegenüber blieb der Rückgriff auf antike heidnische und christliche Schriftsteller ausgeschlossen, da ihre Werke im Gegensatz zur Bibel keinen Bezug zur vorislamischen Heilsgeschichte aufwiesen. Weltgeschichte war nur insofern von Interesse, als sie auf den Islam vorbereitete. Eine Ausnahme bildete diesbezüglich allerdings die Geschichte des vorislamischen Irans, bei der islamische Vorstellungen auf die vorislamischen Verhältnisse zurückprojiziert wurden, was wohl der Tatsache geschuldet war, dass die bedeutendsten frühislamischen Historiker Iraner waren. ${ }^{11}$

Dies gilt auch für die ta'rīh ar-rusul wa-l-mulūk (Geschichte der Propheten und der Könige) des Abū Dja far al-Ṭabarī (839-923), die wohl als der bedeutendste Entwurf der frühislamischen Historiographie gelten kann. ${ }^{12}$ Das Werk stellt, gemäß chronologischem Aufbau, die Geschichte der Welt von ihren Anfängen bis zur Zeit des Autors dar, wobei die Geschichte der alten Israeliten und der alten Perser synchron behandelt wird. Dem liegt eine ganz grundlegende Geschichtsauffassung zugrunde: Wie den Israeliten das Prophetenamt, so kam den Persern das Königtum als von Gott gegeben zu; Prophetenamt und Königtum konvergieren dann in dem von Gott eingesetzten Kalifat. ${ }^{13}$

Im Zusammenhang mit der Geschichte der alten Israeliten überliefert uns Ṭabarī nun auch einiges über Isaak und Ismael. Tabarīs Darstellung ist zwar einerseits chronologisch geordnet, doch führt er alle ihm bekannten Überlieferungen zu den jeweiligen Geschichten an, zunächst ohne die identischen Meinungen zusammenzufassen oder eingehender zu diskutieren. Insofern wird ein bestimmtes Ereignis mehrfach berichtet, jeweils aus der Sicht unterschiedlicher Überlieferer. Dies ist für den Gang der Erzählung zwar störend, doch der Tatsache geschuldet, dass nach Ansicht der islamischen Traditionswissenschaft eine Aussage oder ein geschildertes Ereignis in erster Linie dadurch Glaubwürdigkeit besitzt, dass es sich auf zuverlässige Überlieferer stützen kann. Insofern fügt

11 Vgl. Busse, Heribert: Arabische Historiographie und Geographie, in: Gätje, Helmut (Hrsg.): Grundriß der Arabischen Philologie II: Literaturwissenschaft. Wiesbaden 1987, S. 264-297, hier S. 269.

12 Vgl. Tottoli: Prophets, S. 132.

13 Busse: Historiographie, S. 271.

Ulrike Schneider, Helga Völkening and Daniel Vorpahl - 978-3-653-98812-3 
sich Țabarīs Darstellung in den Rahmen der üblichen Traditionswerke ein, doch hebt es sich von diesen dadurch ab, dass es in quantitativer Hinsicht, zumindest hinsichtlich der Isaak- und Ismael-Erzählungen, die bei weitem meisten Traditionen zu den einzelnen Ereignissen zusammengestellt hat. ${ }^{14}$ Dies ist, insgesamt gesehen, dennoch ziemlich wenig. Über Isaak wird so gut wie kein eingehenderes biographisches Material überliefert, aber selbst die Berichte über Ismael sind nicht sehr umfangreich, was etwa bei der Geschichte über die Geburt Ismaels auffällt, die, insbesondere wenn man sie mit dem biblischen Bericht vergleicht, äußerst knapp gehalten ist. Dies entspricht der generellen Darstellung der Geburt Ismaels innerhalb der Traditionsliteratur, die von diesem Ereignis auch sonst eher beiläufig berichtet. ${ }^{15}$ Es dürfte aber auch darin begründet liegen, dass die wesentliche Person bei all diesen Ereignissen Abraham ist, dessen segensreiches Wirken hier beschrieben werden soll. Die ganze Geschichte wird inhaltlich mit der im Buch Genesis in zwei Fassungen übermittelten Erzählung über Abrahams Aufenthalt bei einem Gewaltherrscher, wo er Sarah als seine Schwester ausgab, verknüpft. ${ }^{16}$ Es wird dann berichtet, dass Abraham und Sarah, nachdem sie der Gewaltherrscher ziehen ließ, neben anderen Dingen auch die Dienerin Hagar mitgegeben wurde. Wie auch im biblischen Bericht veranlasst Sarah hier ihren Mann Abraham, mit Hagar den Beischlaf zu vollziehen, damit diese ihm einen Sohn gebäre. ${ }^{17}$ Nicht unwesentlich scheint in diesem Zusammenhang auch die von Țabarī angeführte Tradition von Hagar und Ismael als Stammmutter bzw. Stammvater der Araber, ${ }^{18}$ ein Topos der im Koran überhaupt nicht angesprochen wird, jedoch in späteren innerislamischen Auseinandersetzungen eine Rolle spielen sollte. ${ }^{19}$

14 Vgl. Tottoli: Prophets, S. 133; Firestone, Reuven: Journey in Holy Lands. The Evolution of the Abraham-Ishmael Legends in Islamic Exegesis. Albany 1990, S. 144.

15 Vgl. Firestone: Journey, S. 39-40. Dort findet sich auch eine intensive Diskussion der einzelnen Traditionsquellen, die mehreren Traditionswerken zugrunde liegen und auf die hier nicht im Einzelnen eingegangen werden kann.

16 Bei Țabarī findet sich hier die Bezeichnung malik az-ẓil „König des Schattens“, das in den hier verwendeten Übersetzungen meist als „,tyrant“ (Brimmer) oder „Gewaltherrscher" (Busse) wiedergegeben wird. In der Bibel wird die Geschichte in einem Fall auf den Pharao, im anderen Fall auf Abimelech aus Gerar bezogen.

17 Vgl. The History of al-Tabarī. Vol. II: Prophets and Patriarchs. Transl. and annot. by William M. Brinner. Albany 1987, S. 65.

18 Vgl. ebd.

19 Vgl. Bakhos, Carol: The Family of Abraham. Jewish, Christian, and Muslim Interpretations. Cambridge (Massachusetts), London 2014, S. 142-146. Sie weist darauf hin, dass im 9. Jh. in den Auseinandersetzungen der sogenannten Šu ūbiyya, als es um die Frage ging, ob die Araber gegenüber anderen Muslimen einen besonderen Vorzug genössen, 
Im Folgenden wird nun die Erzählung über den Besuch der drei Engel bei Abraham wiedergeben. Hier bringt Țabarī gegenüber der koranischen Erzählung keine wesentlichen Erweiterungen. Von größerem Interesse als die Verkündigung der Nachkommenschaft scheint im Zusammenhang mit diesem Bericht für den Autor jedoch die Ankündigung des Strafgerichts über das Volk Lots zu sein.

Im Folgenden ist nun von Isaak überhaupt nicht mehr die Rede. Die von Ṭabarī angeführten Berichte erzählen nur davon, wie Ismael mit seiner Mutter Hagar von Abraham nach Mekka gebracht wird und fahren dann mit den Erzählungen über sein dortiges Wirken fort. Lediglich eine von Tabarī angeführte Tradition erwähnt, dass Isaak und Ismael miteinander stritten und Sarah wegen Ismael auf Hagar eifersüchtig wurde. ${ }^{20}$ In jedem Fall befahl Gott Abraham, Hagar und Ismael nach Mekka zu bringen. Hier wird nun von dem Lauf Hagars zwischen den Hügeln aṣ-Șafā und al-Marwah berichtet, wo sie nach Wasser für ihren Sohn sucht, und der Entdeckung des Brunnens Zamzam. Dieses Ereignis ist notwendigerweise bedeutsam, denn es sollte in den späteren Riten zur Wallfahrt ( hağğg ) verarbeitet werden. Tabarī berichtet des Weiteren von der Heirat Ismaels mit zwei Frauen der Ğumhuriten ${ }^{21}$ und den Besuchen Abrahams bei ihm. Von wesentlicher Bedeutung ist dann auch der Bericht über die Wiedererrichtung der $\mathrm{Ka}{ }^{\circ} \mathrm{ba}$, die Abraham zusammen mit Ismael vornimmt. Im Mittelpunkt dieser Erzählung steht jedoch eindeutig Abraham, wogegen Ismael dabei eine eher nebensächliche Rolle zukommt. Zum Ende der gesamten Erzählungen über Ismael geht Țabarī dann auf das zentrale Ereignis der Opferung des Sohnes ein, wofür er sowohl Traditionen anführt, die Isaak als den zu opfernden Sohn ansehen, als auch Traditionen, die diese Rolle Ismael zuschreiben:

Die Altvorderen (salaf) unter den Gelehrten der Nation unseres Propheten - Gott segne ihn und schenke ihm Heil - waren unterschiedlicher Meinung darüber, welchen der beiden Söhne Abraham zu opfern befohlen wurde. Einige sagen, dass es Isaak, der Sohn Abrahams, war, wogegen andere meinen, dass es Ismael, der Sohn Abrahams, war. Beide Ansichten werden durch Aussagen, die sich auf die Autorität des Gesandten Gottes - Gott segne ihn und schenke ihm Heil - zurückführen, unterstützt. Wenn beide Gruppen von Aussagen gleichermaßen zuverlässig (șah̄ihh) sind, da sie ja beide vom Propheten Gottes - Gott segne ihn und schenke ihm Heil -

Perser argumentiert haben, dass im Gegensatz sogar die Nichtaraber einen Vorzug genössen, da sie eine Abkunft von Isaak geltend machen könnten.

20 Vgl. History, S. 72.

21 Die Ğumhuriten werden innerhalb der arabischen Historiographie als einer der ältesten Stämme angesehen, der zur Zeit Abrahams und Ismaels in Mekka siedelte. Sie haben im Rahmen der Erzählung die Funktion, Ismael in den kulturellen Rahmen der Araber zu integrieren. Vgl. Firestone: Journey, S. 72. 
stammen, kann nur der Koran als Beweis dafür dienen, dass die Überlieferung, die Isaak nennt, eindeutig die zuverlässigere der beiden ist. ${ }^{22}$

Hier wird von TTabarī nun eindeutig Isaak favorisiert, was aus heutiger Sicht überraschend scheinen mag. Dennoch ist seine Ansicht ganz durch die methodischen Vorgaben der traditionellen Überlieferungswissenschaft bestimmt, die der Aussage des Heiligen Buches in jedem Fall das Primat über die Aussagen der Überlieferung gibt. Freilich ist eben die Aussage des Koran, wie wir gesehen haben, nicht so eindeutig. Insofern stellt sich die Frage, wie Tabarī seine Sichtweise begründet.

Zunächst werden einige Traditionen angeführt, nach denen Isaak derjenige Sohn war, den zu opfern Abraham befohlen war; anschließend folgen einige Meinungen, nach deren Ansicht es Ismael gewesen ist. Interessanterweise führen sowohl die einen als auch die anderen immer wieder den Koranvers 37,107 als Beweis für ihre jeweilige Ansicht heran: „Und Wir lösten ihn mit einem groBen Schlachtopfer aus." - Bemerkenswert unter den Vertretern der Ansicht, dass Ismael der Sohn gewesen sei, ist in einem Fall auch die genealogische Komponente, von der im Koran noch nicht die Rede war:

Dann sandte $\mathrm{er}^{23}$ nach einem Mann, der bei ihm in $\operatorname{Syrien}^{24}$ war, einem ehemaligen Juden, der zum Islam konvertiert und ein guter Muslim geworden war. Er wurde als einer der größten jüdischen Gelehrten angesehen. 'Umar ibn 'Abd ul-'Azīz befragte ihn darüber: . . . Er sagte zu ihm: „Welchen seiner beiden Söhne ist Abraham zur Opferung befohlen worden?“ Der Mann antwortete: „Ismael, bei Gott, o Fürst der Gläubigen! Die Juden wissen das, aber sie sind auf euch neidisch, o Araber, denn es war euer Vater, der in Gottes Befehl genannt wurde und dem Gott den Verdienst für seine Standfestigkeit im Gehorsam gegenüber seinem Befehl zuerkannte. Sie weisen das zurück und behaupten, dass es Isaak war, weil Isaak ihr Vater war.“25

Es ist merkwürdig, dass die Polemik hier nur gegen die Juden geführt wird, da auch die Christen aufgrund der biblischen Vorgabe daran festhalten, dass Isaak der Sohn war, der zur Opferung bestimmt wurde.

22 al-Ṭabarī, Abu Ğa far Muḥammad ibn Ğarīr: ta'rīh ar-rusul wa-l-mulūk. Bd. 1. o.O., o.J, S. 135 u. History, S. 82.

23 Gemeint ist 'Umar ibn 'Abd ul- 'Azīz (etwa 680-720), der 717-720 als achter Kalif der Umayyaden-Dynastie amtierte und von dem zuvor die Rede war.

24 In den islamischen Quellen umfasst der Begriff „Syrien“ (aš-Šām) diejenigen Gebiete, die im neuzeitlichen politischen Diskurs als „Großsyrien“ bezeichnet werden und die Territorien der heutigen Staaten Syrien, Libanon, Jordanien, Israel, die West-Bank und einige türkische Provinzen umfassen. Vgl. Bosworth, Charles: Art. Shām, in: Encyclopaedia of Islam. 2nd Edition. Bd. 9. Leiden 1997, S. 261-262, hier S. 261.

25 al-Ṭabarī, S. 138-139 u. History, S. 88. 
Neben dem genealogischen Argument werden aber von den Anhängern der unterschiedlichen Auffassungen weitere Argumente zur Stützung ihrer jeweiligen Ansicht vorgebracht. Da der Koran nicht nur nicht den Namen des zu opfernden Sohnes nennt, sondern sich auch hinsichtlich der Chronologie der Ereignisse und der Lokalisierung des Opfers ausschweigt, kreisen ihre Argumente in erster Linie um die Erläuterung der Frage, ob das Opfer in Syrien stattgefunden habe - was für Isaak spräche - oder in Mekka - was für Ismael spräche. Von den Anhängern der Ismael-These wird geltend gemacht, dass Abraham in 37,112 Isaak und Jakob verheißen werden und dass sein Sohn Isaak ein Prophet sein werde. Würde Gott jedoch nach dieser Verheißung Abraham befehlen, Isaak zu opfern, stünde dies im Widerspruch zu seiner Verheißung und insofern kann der Sohn, den Abraham zu opfern befohlen wurde, nur Ismael gewesen sein. ${ }^{26}$

Gegen Ende seines Überblicks über die verschiedenen Traditionen kommt Țabarī dann zur Begründung seiner eigenen Position, die Isaak als denjenigen Sohn, der geopfert werden sollte, favorisiert und dabei einige der bereits genannten Argumente zugunsten Isaaks aufnimmt:

Hinsichtlich des Beweises des Korans, den wir angeführt haben, ist [die Ansicht, dass es] Isaak war, zuverlässiger. Gottes Wort $(37,101)$ überliefert seines Freundes Abrahams Gebet, [das er sprach] als er sich von seinem Volk trennte, um zusammen mit seiner Frau Sarah zu seinem Herrn in Syrien zu emigrieren: „Er sagte: ,Ich gehe zu meinem Herrn. Er wird mich rechtleiten. O mein Herr, schenk mir einen von den Rechtschaffenen. ““ (37, 99-100). Dies war, bevor er Hagar kannte und bevor sie die Mutter von Ismael wurde. Dann antwortete unser Herr auf das Gebet mit der Verkündigung eines rechtschaffenen Sohnes und der Schilderung der Vision Abrahams, wonach er diesen Jungen opfern würde, wenn er „das Alter erreichte, dass er mit ihm laufen könnte.“ (37,102) Das Buch erwähnt keinerlei Verheißungen eines männlichen Kindes, das Abraham gegeben wird außer in dem Fall, wo es sich auf Isaak bezieht . . . Einige sagen, Gott hätte nicht Isaak zu opfern befohlen, weil er seine Geburt und die von Jakob danach vorausgesagt habe, bevor es geschah. Diese Behauptung beweist jedoch nicht notwendigerweise, dass ihre Ansicht korrekt ist. Gott befahl Abraham Isaak zu opfern, ,als er mit ihm laufen konnte“ und es ist vorstellbar, dass Jakob ihm geboren sein könnte, bevor seinem Vater befohlen wurde, ihn zu opfern. Einige sagen auch, dass das Widderhorn in der Ka'ba gesehen wurde (was annehmen ließ, dass das Opfer an einem Platz nahe Mekka stattgefunden habe und daher Ismael darin involviert war, denn Isaak war in Syrien). Auch dies ist kein vernünftiges Argument, da das Horn von Syrien zur Ka'aba gebracht und dort aufgehängt worden sein könnte. ${ }^{27}$

26 Vgl. al-Ṭabarī, S. 138 u. History, S. 88.

27 al-Ṭabarī, S. 139 u. History, S. 89; vgl. Firestone: Journey, S. 136-137. 
Tabarī, obwohl er intensiv die Ansichten beider Parteien anführt, neigte also zu der Ansicht, dass Isaak der Sohn war, der geopfert werden sollte. Damit repräsentiert dieser frühe große islamische Historiker eine Ansicht, die sich langfristig nicht durchsetzen sollte.

\section{Prophetengeschichten (qișaș al-anbiyā')}

Die sogenannten Prophetengeschichten (qișaș al-anbiya $\left.\bar{a}^{\prime}\right)$ haben sich im Laufe der Zeit als ein eigenes Genre herauskristallisiert, das erzählerisches Material über die Propheten der Hebräischen Bibel, Jesus und einige außerbiblische Materialien enthält. Dabei sind zahlreiche Stoffe, sowohl aus der jüdischen als auch aus der christlichen Überlieferung, eingeflossen, jedoch sind die Einflüsse auch in umgekehrter Richtung gegangen. ${ }^{28}$ Unter den Werken der Prophetengeschichten ragt dasjenige des Abū Isḥāq Aḥmad b. Muḥammad b. Ibrāhīm at-Ṭa labī aus dem 11. Jahrhundert eindeutig hervor und kann wohl als das bedeutendste Werk dieser Gattung angesehen werden, dessen bis heute anhaltende Popularität auch daran deutlich wird, dass es aus dem Arabischen in zahlreiche andere Sprachen innerhalb der islamischen Welt übersetzt worden ist. ${ }^{29}$ Über das Leben des Autors ist nicht allzu viel bekannt; er hat neben den Prophetengeschichten noch einen Korankommentar verfasst, der jedoch nur teilweise erhalten ist. Ta ${ }^{a}$ labī greift zu einem großen Teil auch auf diejenigen Traditionen zurück, die bereits Tabarī verwendet hat. Er weist auf die unterschiedlichen Ansichten hin, favorisiert jedoch stets eine bestimmte. Auch wenn dabei die einzelnen Tradenten genannt werden, dominiert bei Ta ${ }^{\circ} l a b i ̄$ die erzählerische Darstellung und insofern ist der Gang der Erzählung flüssiger als bei Tabarī, dem es auf eine Zusammenstellung der unterschiedlichen Traditionen ankam. Wie bei Tabarī steht auch hier die Person Abrahams im Mittelpunkt der Handlung, wogegen seine Söhne eher eine Nebenrolle spielen.

Wie auch in einer von Ṭabarī angeführten Tradition wird bei Talabī betont, dass Hagar die Stammmutter der Araber ist, denn Abraham wohnte ihr bei und

28 Vgl. Nagel, Tilman: Die Qișaș al-anbiyā'. Ein Beitrag zur arabischen Literaturgeschichte. Bonn 1967; Nagel: Tilman: Art. Kișaș al-anbiyā', in: Encyclopaedia of Islam. 2nd Edition. Bd. 5. Leiden 1986, S. 180-181; Schussman, Aviva: Stories of the Prophets in Muslim Tradition. Mainly on the basis of „Kisas al-Anbiya“ by Muhammad b. 'Abdallah alKisa’̄i. Jerusalem 1981, S. 1-2 u. Tottoli: Prophets, S. 138. Die Geschichten sind, sofern es sich um die altisraelitischen Propheten handelt, auch als ,isrā'̄̄liyyāt' bekannt. Vgl. Bakhos: Family, S. 46.

29 Vgl. Tottoli: Prophets, S. 146 u. 151. Erwähnt werden sollte in diesem Zusammenhang jedoch auch noch Muḥammad ibn 'Abdullāh al-Kisā'̄', dessen Werk eine ähnliche Bedeutung zukommt, wie demjenigen at-Talabīs. Vgl. dazu ebd., S. 151-155. 
sie gebar ihm Ismael. ${ }^{30}$ Er berichtet dann von dem Besuch der Engel und der Verkündigung von Isaak und Jakob. ${ }^{31}$ Obwohl bereits erwähnt wurde, dass Hagar Ismael geboren hatte, wird nun unmittelbar im Anschluss daran berichtet, dass Sarah und Hagar beide zusammen ihre Söhne gebaren. ${ }^{32}$ Dies stellt nun einen wesentlichen Unterschied zur biblischen Überlieferung dar, wonach Ismael dreizehn Jahre älter als sein Bruder Isaak war.

Nur wenig umfangreicher als bei Tabarī wird die Geschichte des Verhältnisses von Ismael und Isaak beschrieben, an deren Ende es schließlich dazu kam, dass Abraham Hagar und Ismael nach Mekka brachte. Es wird berichtet, dass die Jungen heranwuchsen und als beide eines Tages miteinander um die Wette liefen. Abraham, der sich an diesem Wettlauf beteiligte, nahm, nachdem er Ismael eingeholt hatte, diesen auf den Schoß und setzte Isaak daneben. Sarah ärgerte sich daraufhin und ,wurde eifersüchtig, wie das bei den Frauen so üblich ist $^{\star 33}$. Zur Strafe durchbohrte Sarah Hagar die Ohrläppchen, wodurch dies bis heute eine Sitte bei Frauen wurde. ${ }^{34}$ Bei dieser Erzählung scheinen jedoch weniger Ismael und Isaak im Mittelpunkt zu stehen, als vielmehr die Spannungen zwischen den beiden Frauen.

Dies ist zunächst auch bei dem Bericht über die zwangsweise erfolgte Migration Hagars und Ismaels der Fall. Eines Tages balgten sich Ismael und Isaak, „wie Kinder das tun“. Sarah wurde darüber sehr zornig gegen Hagar und befahl Abraham schließlich, sie fortzuschicken. Gott seinerseits befahl Abraham nun, Hagar und ihren Sohn nach Mekka zu bringen. Im Folgenden steht dann, wie auch bei Tabarī, Hagar im Mittelpunkt der Erzählung, die nun von dem Lauf zwischen den beiden Felsen al-Şafä und al-Marwa und der Entdeckung des Zamzam-Brunnens berichtet. ${ }^{35}$ Schließlich kehrt die Erzählung nochmals kurz zu Ismael zurück und berichtet davon, dass er eine Frau der Ğurhum heiratete, deren Sprache annahm und durch sie zum Araber wurde; ,seine Kinder sind Araber, die das Arabertum angenommen haben ${ }^{\star 36}$. Anschließend wird die auch bei Tabarī überlieferte Erzählung von den zwei Frauen Ismaels und der Begeg-

30 Vgl. at-Ta ${ }^{\top} l a b \overline{1}$, Abū Isḥāq Aḥmad b. Muḥammad b. Ibrāhīm: Islamische Erzählungen von Propheten und Gottesmännern. Qișaș al-anbiyā' oder 'Arā'is al-mağālis von Abū Isḥāq Aḥmad b. Muḥammad b. Ibrāhīm aț-Ṭa labī. Übers. u. komm. v. Heribert Busse. Wiesbaden 2006, S. 108.

31 Vgl. ebd., S. 109.

32 Vgl. ebd.

33 Ebd., S. 109-110.

34 Vgl. ebd.

35 Vgl. ebd., S. 110.

36 Ebd., S. 111.

Ulrike Schneider, Helga Völkening and Daniel Vorpahl - 978-3-653-98812-3 
nung Abrahams mit ihnen berichtet, in der von Ismael selbst allerdings gar nichts vorkommt.

Intensiv setzt sich Talabī nun mit der Frage auseinander, welchen Sohn Abraham geopfert hat. Die Feststellung, dass ,die älteren muslimischen Theologen . . . unterschiedlicher Meinung“" waren, ,welchen von seinen beiden Söhnen Abraham opfern sollte" ${ }^{37}$ lässt erkennen, dass sich die Frage der Identität des Sohnes zu Zeiten des Autors bereits erledigt und sich die Ansicht, dass Ismael derjenige Sohn sei, durchgesetzt hat. Dennoch sieht sich Talabī genötigt, ähnlich wie Tabarī, die unterschiedlichen Ansichten zugunsten des einen wie des anderen Sohnes anzuführen. Verwiesen wird bei ihm auch darauf, dass die Schriftbesitzer einhellig der Meinung sind, dass es Isaak gewesen sei. Im besonderen Maße werden jedoch für diese Ansicht bei Talabī die Juden der Lüge beschuldigt. Daraus wird deutlich, dass Talabī die Ansicht vertritt, dass Ismael derjenige Sohn war, der zum Opfer bestimmt war. ${ }^{38}$ Schließlich berichtet Talabī die eigentliche Geschichte von der Opferung Ismaels, wobei hier zahlreiche Motive eingeflossen sind, die auch im Zusammenhang der jüdischen Aggadah, allerdings mit Bezug auf Isaak, auftauchen. Unerwähnt bleibt der Hinweis aus der Bibel, dass Isaak und Ismael zusammen ihren Vater begruben (Gen 25,7-11). Demgegenüber bringt er eine Tradition, wonach Ismael kurz vor seinem Tod, seinem Bruder Isaak das Vermächtnis hinterlassen haben soll, seinen Sohn Esau mit seiner, Ismaels, Tochter, zu verheiraten, womit deutlich wird, dass er annahm, dass ein einvernehmliches Verhältnis zwischen den beiden Brüdern herrschte. $^{39}$

Talabīs Beschreibung zeigt also, dass sich zu seiner Zeit bereits diejenige Meinung durchgesetzt hat, die auch für die zukünftigen Generationen der Muslime die maßgebliche Ansicht bleiben sollte, nämlich dass Ismael derjenige Sohn war, den zu opfern Abraham befohlen wurde. Dies schließt eine positive Sicht auch auf Isaak nicht aus, der jedoch nicht dieselbe heilsgeschichtliche Relevanz wie Ismael besitzt, da mit ihm nicht die für den Islam zentralen Riten der Wallfahrt und des Opferfestes in Verbindung gebracht werden können.

\section{Fazit}

Weder im Koran noch in der nachkoranischen Literatur wird allzu viel über Isaak und Ismael erzählt. Es findet sich in den islamischen Berichten nur ein schwaches Echo von den umfangreichen Erzählungen innerhalb der Hebräischen Bibel. Von den speziell auf Isaak bezogenen Geschichten, etwa der Beziehung

37 Ebd., S. 121.

38 Vgl. ebd., S. $123 \mathrm{f}$.

39 Vgl. ebd., S. 135.

Ulrike Schneider, Helga Völkening and Daniel Vorpahl - 978-3-653-98812-3 
mit Rebekka oder der Frage des Erstgeburtsrechts, findet sich weder im Koran noch in den angeführten nachkoranischen Quellen etwas. Lediglich die Frage, um welchen Sohn es sich bei der Opferung handelt, und die eigentliche Opferungsgeschichte werden intensiver erzählt, was sich dadurch erklären lässt, dass dieses Ereignis in den Riten der Wallfahrt (hağğ $)$ nach Mekka, einer der zentralen rituellen Handlungen des Islam, gedacht wird. Im Wesentlichen steht bei allen Erzählungen aber die Person Abrahams im Mittelpunkt, wogegen dessen Söhne eher eine Nebenrolle spielen.

Das Verhältnis zwischen beiden Brüdern ist im Koran unklar; die nachkoranische Literatur erwähnt aber kleinere Auseinandersetzungen. Diesen wird jedoch nicht die Schärfe zuerkannt, die sie in den jüdischen und christlichen Überlieferungen besitzen, was durch den Hinweis ,wie Kinder das tun“ deutlich wird. Sowohl Isaak als auch Ismael werden aber als Propheten und zur Familie Abrahams gehörig angesehen. Der Islam weiß auch nichts von einem Gegensatz zwischen den beiden Brüdern, wie wir ihn im Judentum und vor allem im Christentum finden. Im Gegenteil dazu lässt sich z.T. sogar die Tendenz beobachten, jegliche Polarisierung zu überbrücken, wie etwa bei Ta ${ }^{c}$ labī durch die Tradition über das Vermächtnis Ismaels, dass Isaak seinen Sohn mit seiner Tochter verheiraten möge, deutlich wird.

Auch wenn im Koran kaum von Ismael die Rede ist, war seine Dominanz gegenüber Isaak in der nachkoranischen Literatur vielleicht schon dadurch angelegt, dass er in der späteren Sure 2 seinem Vater bei der Wiederherstellung der Ka'ba assistiert hat. Dadurch entstand eine enge Beziehung zwischen Ismael und Mekka, die ebenfalls in der nachkoranischen Literatur inhaltlich noch ausgebaut wurde und die insofern bedeutsam ist, als dass die Wallfahrt, eine der fünf Grundpflichten des Islam, dorthin stattfindet und eben nicht nach Jerusalem. Durch die Zuordnung nach Mekka war es langfristig möglich, Ismael als den geopferten Sohn anzusehen, denn das in die Wallfahrt inkorporierte Opferfest gedenkt der Opferung des Sohnes. Es wäre dann jedoch wenig sinnvoll gewesen, in Isaak den zu opfernden Sohn zu sehen, der mit Mekka und dem Heiligtum der Ka'ba und den Wallfahrtsriten überhaupt nicht in Verbindung gebracht wird; ebenso wenig schiene es sinnvoll, in Mekka eines Ereignisses zu gedenken, dass, wenn es sich bei dem zu opfernen Sohn um Isaak gehandelt hätte, in Palästina stattgefunden haben müsste. Insofern liegt in der Auffassung, dass Ismael der zur Opferung bestimmte Sohn war, eine gewisse logische Konsequenz.

Ismaels Rolle konnte zudem auch dadurch gegenüber Isaak gestärkt werden, als er als der Stammvater der Araber angesehen wurde (und somit letztendlich auch als der Stammvater der Muslime) und in gewissem Sinne auch polemisch 
ein Gegengewicht zu dem von Juden und Christen beanspruchten Isaak darstellen konnte.

\section{Quellen}

al-Kisai, Muhammad ibn Abd Allah: The Stories of the Prophets. Translated from the Arabic, Preface, Annotations and Index by Aviva Schussman. Tel Aviv 2013 (in Hebrew).

Der Koran. Arabisch - Deutsch. Übersetzt u. kommentiert v. Adel Theodor Khoury. Gütersloh 2004.

al-Ṭabarī, Abu Ğa`far Muhammad ibn Ğarīr: ta'rīh ar-rusul wa-l-mulūk, Bd. 1, bi-l-țab'at alḥuseyniyat al-mișriya 'alā nafqat al-Sayyid Muḥammad 'Abd al-Laṭif wa-šurakāhu, o.O., o.J.

The History of al-Tabarī. Vol. II: Prophets and Patriarchs, translated and annoted by William M. Brinner. Bibliotheca Persica. Albany, 1987.

at-Tạ labī, Abū Isḥāq Aḥmad b. Muḥammad b. Ibrāhīm: Islamische Erzählungen von Propheten und Gottesmännern. Qiṣaș al-anbiyā' oder 'Arā’'is al-mağālis von Abū Isḥāq Aḥmad b. Muhammad b. Ibrāhīm aț-Ta 'labī. Übers. u. komm. v. Heribert Busse. Diskurse der Arabistik 9. Wiesbaden 2006.

\section{Literatur}

Bakhos, Carol: The Family of Abraham. Jewish, Christian, and Muslim Interpretations. Cambridge (Massachusetts), London 2014.

Beltz, Walter: Sehnsucht nach dem Paradies. Mythologie des Korans. Berlin 1979.

Bosworth, Charles: Art. Shām, in: Encyclopaedia of Islam. 2nd Edition. Bd. 9. Leiden 1997, S. 261-262.

Busse, Heribert: Arabische Historiographie und Geographie, in Gätje, Helmut (Hrsg.): Grundriß der Arabischen Philologie II: Literaturwissenschaft. Wiesbaden 1987, S. 264-297.

Firestone, Reuven: Journey in Holy Lands. The Evolution of the Abraham-Ishmael Legends in Islamic Exegesis. Albany 1990.

Haußig, Hans-Michael: Der Religionsbegriff in den Religionen. Studien zum Selbst- und Religionsverständnis in Hinduismus, Buddhismus, Judentum und Islam. Berlin, Bodenheim bei Mainz 1999.

Löhr, Helmut: Isaak, Jakob, Esau, Josef, in: Öhler, Markus (Hrsg.): Alttestamentliche Gestalten im Neuen Testament. Beiträge zur Biblischen Theologie. Darmstadt 1999, S. 75-96.

Nagel, Tilman: Art. Kịsạa al-anbiyā', in: Encyclopaedia of Islam. 2nd Edition. Bd. 5. Leiden 1986, S. 180-181.

Nagel, Tilman: Die Qișaș al-anbiyā’’ Ein Beitrag zur arabischen Literaturgeschichte, Inaugural-Dissertation zur Erlangung des Doktorgrades der Philosophischen Fakultät der Rheinischen-Friedrich-Wilhelms-Universität zu Bonn. Bonn 1967.

Schussman, Aviva: Stories of the Prophets in Muslim Tradition. Mainly on the basis of „Kisas al-Anbiya“" by Muhammad b. 'Abdallah al-Kisa'î. Thesis Submitted for the Degree "Doctor of Philosophy". Submitted to the Senate of the Hebrew University of Jerusalem in 1981 (in Hebrew). 
Speyer, Heinrich: Die biblischen Erzählungen im Qoran. Gräfenhainchen 1931, Nachdr. Hildesheim u.a. 1988.

Tottoli, Roberto: Biblical Prophets in the Qur'ān and Muslim Literature. London, New York 2002. 


\section{Historische Untersuchungen zur gesellschaftlichen Relevanz von Geschwisterbeziehungen}


Ulrike Schneider, Helga Völkening and Daniel Vorpahl - 978-3-653-98812-3

Downloaded from PubFactory at 01/11/2019 10:54:37AM

via free access 


\title{
Zwischen Macht und Ohnmacht - Zur Bedeutung der Kaiserschwestern im Principat von Augustus bis Commodus (27 v. Chr. - 192 n. Chr.)
}

\author{
Sandra Kaden
}

\begin{abstract}
In the Roman Principate, due to her familial relationship, the emperor's sister occupied a special position among the domus Augusta. By exploiting her dynastic potential and presenting her as a female role model, she made a vital contribution to the strengthening of the brotherly auctoritas. When demonstrating an alternative to the current leadership, her connection to opposing forces, however, were regarded as a menace to the brother's imperial existence.
\end{abstract}

\section{Einleitung}

Mit einem dreitägigen Staatsakt besiegelte Augustus im Jahr 27 v. Chr. das Ende der römischen Republik und stellte die entscheidenden Weichen für die Etablierung einer neuen Regierungsform in Rom, den Principat. Als Erster unter Gleichen (princeps) regierte er fortan unter dem Deckmantel der wiederhergestellten Republik (res publica restituta) an der Spitze des Staates.

Mit dem Princeps stand auch dessen Familie, die domus Augusta, als neues Zentrum der Macht im Fokus der Öffentlichkeit. Innerhalb des Kaiserhauses nahmen die weiblichen Mitglieder eine bedeutende Stellung ein, auch wenn ihnen nach römischer Auffassung eine Herrschaftspartizipation grundsätzlich verwehrt blieb. ${ }^{1}$ Neben den Müttern und Ehefrauen waren es vor allem die Schwestern, die aufgrund ihrer familialen Bindung ein ganz besonderes Nahverhältnis zum Kaiser kennzeichnete, das sich nach Ann-Cathrin Harders wie folgt charakterisieren lässt:

Die Kaiserschwester befand sich [...] in einer fast konkurrenzlos nahen verwandtschaftlichen Position zum Kaiser, und im Gegensatz zur Kaisermutter oder zur Ehefrau des princeps teilte sie aufgrund der gleichen Filiation mit dem Kaiser das dynastische Prestige. Während die Kaisergattin ihren Status allein vom Ehemann ableiten konnte, verwies die kaiserliche Schwester aufgrund der gleichen Abstammung auf die dynastische Linie, den Namen und die Blutsverwandtschaft. ${ }^{2}$

1 Bewusst grenzten sich die Römer auf diese Weise von den hellenistischen Monarchien des Ostens ab. Vgl. Kunst, Christiane: Die Rolle der Römischen Kaiserfrau. Eine Einleitung, in: dies.; Riemer, Ulrike (Hrsg.): Grenzen der Macht. Zur Rolle der römischen Kaiserfrauen. Stuttgart 2000, S. 1-6, insb. S. 1.

2 Harders, Ann-Cathrin: Suavissima Soror. Untersuchungen zu den Bruder-SchwesterBeziehungen in der römischen Republik. München 2008, S. 308f. 
Für die Kaiserschwestern bildeten die genannten Vorzüge die Voraussetzung für eine gesonderte Position, die ihnen im Herrschaftsgefüge per se zukam, deren präzise Bestimmung allerdings weitreichende Fragen aufwirft. Konkret gilt es zu klären, welche Auswirkungen sich durch die naturgemäße Rangzuweisung für die betroffenen Frauen im gesellschaftspolitischen Alltag ergaben. Diesbezüglich ist es erforderlich, die spezifischen Privilegien und Pflichten sowie die daran geknüpften Handlungs- und Gestaltungsoptionen herauszuarbeiten, die den Schwestern durch die brüderliche Politik ermöglicht wurden. Auf Grundlage der erzielten Resultate lässt sich die Frage nach dem Vorhandensein eines zeitlich übergreifenden Systemcharakters stellen, innerhalb dessen die individuellen Schwesternpersönlichkeiten als singuläre oder repräsentative Phänomene zu beurteilen sind. Anhand ausgewählter Fallbeispiele soll im Folgenden die Signifikanz der Kaiserschwestern in ihrem substantiellen Gehalt aufgezeigt und in ihren Kontinuitäten bzw. Zäsuren bewertet werden. ${ }^{3}$

Die Untersuchung konzentriert sich auf die Zeit von Augustus bis Commodus, womit sie eine zwei Jahrhunderte währende Epoche umfasst, in der insgesamt 18 Kaiser das römische Reich regierten. Für diese lassen sich 21 Schwestern nachweisen, von denen 15 aufgrund einer unzureichenden Quellenbasis bzw. durch den frühzeitigen Tod vor Regierungsantritt ihres Bruders für die folgende Analyse ungeeignet sind. ${ }^{4}$ Es verbleiben lediglich sechs Frauen, die den Voraussetzungen einer angemessenen Bearbeitung im vordefinierten Zeitraum unter den genannten Fragestellungen entsprechen: für die iulischclaudische Dynastie Octavia (minor), Schwester des Augustus, sowie Drusilla, Agrippina (minor) und Livilla, Schwestern des Caligula; für die ulpischantoninische Dynastie Marciana, Schwester des Traian, und Lucilla, Schwester des Commodus.

Die Betrachtung der genannten Personen erfolgt vornehmlich anhand von Schriftzeugnissen, deren analytischer Gebrauch aufgrund eines allgemein tendenziösen Charakters von vornherein mit schwerwiegenden Interpretationsproblemen behaftet ist. Im Kontext einer bewusst angelegten Herrscherkritik erfolgte die Darstellung der weiblichen Mitglieder der domus Augusta über das

3 In der Forschung haben diese Fragen bisher kaum Beachtung gefunden. Für die BruderSchwester-Beziehung in der Republik hat Harders eine Studie vorgelegt, die ausblickartig auch die Kaiserzeit bis Caligula berücksichtigt (vgl. Harders: Soror, S. 297-311).

4 Der Vollständigkeit halber seien diese zumindest namentlich erwähnt: Octavia (maior) (Augustus); Claudia Livia Iulia (Claudius); Sulpicia (Galba); Flavia Domitilla (minor) (Titus und Domitian); Cocceia (Nerva); Domitia Paulina (Hadrian); Annia Cornificia Faustina (M. Aurel); Ceionia Fabia und Ceionia Plautia (L. Verus); Domitia Faustina, Annia Aurelia Galeria Faustina, Fadilla, Cornificia und Vibia Aurelia Sabina (Commodus). Adoptivschwestern wurden generell von der Untersuchung ausgeschlossen.

Ulrike Schneider, Helga Völkening and Daniel Vorpahl - 978-3-653-98812-3 
Aufzeigen von Tugenden und Lastern, die dem römischen Werte- und Normenkanon entsprachen. Die Frauen sind damit in erster Linie als literarisch konstruierte Figuren fassbar, wohingegen sie als historische Persönlichkeiten kaum in Erscheinung treten. Neben den Schriftquellen interessieren die materiellen Hinterlassenschaften, die nicht nur zu einer erweiterten Perspektive beitragen, sondern die historiographischen Aussagen durch das Aufdecken von Diskrepanzen zuweilen sogar korrigieren. ${ }^{5}$

\section{Octavia (minor) und Augustus}

Als Octavia zwischen den Jahren 12 und 9 v. Chr. verstarb, ${ }^{6}$ wurden ihr von ihrem Bruder Augustus außergewöhnliche Ehren erwiesen, die ihren herausgehobenen Status innerhalb der domus Augusta bekundeten. Auf die Anordnung einer öffentlichen Staatstrauer folgte die prunkvolle Aufbahrung ihres Leichnams im Tempel des Divus Iulius, wo der Princeps selbst die Totenrede hielt. Nach einer zweiten Rede, vorgetragen von ihrem Schwiegersohn Drusus maior auf der Rostra des Forum Romanum, geleitete man die Verstorbene in einer Prozession durch Rom bis zum Mausoleum des Augustus, wo sie schließlich neben ihrem Sohn Marcellus beigesetzt wurde. Mit dieser bewusst genealogisch angelegten Inszenierung wurde sie nicht nur als bedeutendes Mitglied der iulischen Familie hervorgehoben, sondern innerhalb jener durch die ihr gewidmete Grabinschrift „OCTAVIA C(ai) F(ilia) SOROR AVG[VSTI CAESARIS]“ für alle Zeiten auf den Status einer Kaiserschwester festgelegt. ${ }^{7}$

Seine Entsprechung fand diese Bestimmung in der literarischen Überlieferung, die Octavia in ihren Schilderungen zum Principat vornehmlich als

5 Zur antiken Historiographie vgl. Späth, Thomas: ,Frauenmacht“ in der frühen Kaiserzeit? Ein kritischer Blick auf die Konstruktion der ,Kaiserfrauen“, in: Dettenhofer, Maria H. (Hrsg.): Reine Männersache? Frauen in Männerdomänen der antiken Welt. Köln u.a. 1994, S. 159-205, insb. S. 181-196. Zur statuarischen, epigraphischen und numismatischen Überlieferung vgl. Alexandridis, Annetta: Die Frauen des römischen Kaiserhauses. Eine Untersuchung ihrer bildlichen Darstellung von Livia bis Iulia Domna. Mainz 2004.

6 Eine exakte Datierung von Octavias Sterbejahr ist aufgrund der teils differenten (Cons. ad Liviam 69f.; Dio 54,35,4f.; Suet. Aug. 61,2), teils unpräzisen Quellenaussagen (Liv. per. 140,2; Sen. dial. 15,3; Zonar. 10,34) nicht möglich.

7 AE 1928, 88 = CIL VI 40356 = AE 1994, 219. Zu den Beisetzungsfeierlichkeiten vgl. Dio 54,35,4f. Zur genealogischen Ausdeutung der augusteischen Handlungen vgl. u.a. Fischer, Robert A.: Fulvia und Octavia. Die beiden Ehefrauen des Marcus Antonius in den politischen Kämpfen der Umbruchszeit zwischen Republik und Principat. Berlin 1999, S. 123. Für die z.T. beispiellosen postumen Ehrungen für Octavia vgl. Harders: Soror, S. 302f. u. Sandels, Friedrich: Die Stellung der kaiserlichen Frauen aus dem julischclaudischen Hause. Darmstadt 1912, S. 33f. 
Schwester des Augustus erwähnt. ${ }^{8}$ Die Beziehung zum Bruder wird dabei fast ausnahmslos als ein von Einvernehmen gekennzeichnetes Verhältnis beschrieben, das sich insbesondere durch emotionale Verbundenheit ausgezeichnet habe. So berichtet Seneca (ad Pol. cons. 15,3), römischer Philosoph und Zeitzeuge des Augustus, anlässlich von Octavias Tod von der großen Trauer, die den Princeps durch den Verlust der "teuerste[n] Schwester“ (soror carissima) erfasste.

Auch Plutarch (Ant. 31,2) lässt es sich in seiner Biographie zu Octavias zweitem Ehemann M. Antonius nicht nehmen, die ,große Liebe zu dieser Schwester" zu erwähnen, die, so der Autor weiter, ,eine Frau von vortrefflichen

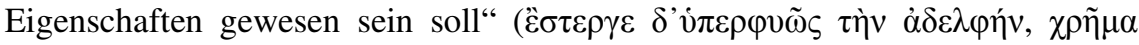

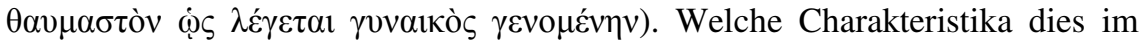
Einzelnen waren, gibt Plutarch nur oberflächlich wieder, indem er an späterer

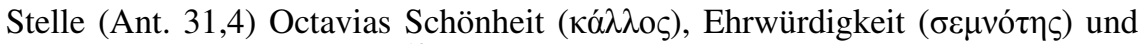
Klugheit (voṽv है $\chi \varepsilon เ v$ ) preist. ${ }^{10}$ Erst unter Heranziehung weiterer antiker Autoren lässt sich dieses positive Octavia-Bild präzisieren. Wiederholt hervorgehoben werden ihre Fruchtbarkeit (fertilitas), die sie mit der Geburt von insgesamt fünf Kindern unter Beweis gestellt hatte, ihre Haushaltsführung und fürsorgliche Erziehung der eigenen sowie ihrer Stiefkinder (facilitas), ihr pflichtgemäßes Verhalten gegenüber Göttern und Menschen (pietas), demonstriert an dem Respekt und der Loyalität, die sie ihrem Bruder als Princeps sowie ihrem verstorbenen Sohn angedeihen ließ, schließlich ihre Tüchtigkeit in der Wollarbeit (lanificia), womit sie die ökonomische Produktivität ihres Hauses sinnbildlich zum Ausdruck brachte. Die genannten Vorzüge zusammengenommen, repräsentierte Octavia das Bild einer vorbildhaften matrona Romana, die die traditionellen Wertvorstellungen der Republik mustergültig verkörperte. Sie fügte sich damit vortrefflich in die von Augustus propagierte moralische Erneuerung der Gesellschaft ein, durch die dem römischen Volk nach Beendigung einer jahrzehntewährenden Bürgerkriegsperiode die Restauration der staatlichen Ordnung suggeriert werden sollte. Mehr noch: Durch ihr tugendhaftes Auftreten bestätigte sie

8 Octavias Präsenz in den Zeugnissen zum augusteischen Principat ist verglichen zur Zeit vor dem Herrschaftsantritt ihres Bruders stark reduziert, was auf Augustus' Bemühen um die Etablierung eines neuen Frauenbilds zurückzuführen ist. Dieses hielt entgegen spätrepublikanischer Praxis die weiblichen Familienangehörigen bewusst aus der Öffentlichkeit heraus. Vgl. Kunst, Christiane: Frauenzimmer in der römischen domus, in: HarichSchwarzbauer, Henriette; Späth, Thomas (Hrsg.): Gender Studies in den Altertumswissenschaften. Räume und Geschlechter in der Antike. Trier 2005, S. 111-131, hier S. 122128.

9 Vgl. ferner Suet. Aug. 61,2; Cons. ad Liviam 441f.

10 Unpräzise in seiner Würdigung bleibt auch Valerius Maximus $(9,15,2)$, der Octavia als „die erhabenste und tadelloseste Schwester“ (soror clarissima ac sanctissima) beschreibt. 
die gelungene Hauspolitik ihres Bruders, der als Familienoberhaupt (pater familias) für das matronenhafte Verhalten der weiblichen Familienmitglieder verantwortlich zeichnete, womit er sich ebenso als würdiger Staatslenker profilierte. $^{11}$

Im Kontext kaiserlicher Selbstpräsentation sind auch Augustus' baupolitische Maßnahmen zur Neugestaltung Roms zu sehen, in die er Octavia bewusst miteinbezog. So ließ er die Porticus Metelli, eine Säulenhalle, nach erfolgreichem Wiederaufbau plakativ in Porticus Octaviae umbenennen. Indem er Octavia auf diese Weise als Patronin des Monuments auswies und ihr eine allgegenwärtige Präsenz im römischen Stadtbild zubilligte, dokumentierte er zugleich ihren hohen Stellenwert, den sie innerhalb der domus Augusta einnahm. Octavia selbst engagierte sich durch die Stiftung einer Kunstsammlung eigeninitiativ an der Ausgestaltung des Baus. Ferner ließ sie dort eine öffentliche Bibliothek mit lateinischen und griechischen Werken einrichten und gab sich auch sonst durch den regen Austausch mit bedeutenden Schriftstellern und Gelehrten als eine im hohen Maße gebildete Frau (matrona docta). Welche Wirkkraft von dieser Position ausging, zeigt sich an dem Einfluss, den sie als Vermittlerin bei der Durchsetzung etwaiger Bittgesuche an den Kaiser geltend machen konnte. ${ }^{12}$ Durch diese vielfältigen kulturellen Handlungen nahm Octavia aktiv an der kaiserlichen Fürsorgepolitik teil und trug über die Steigerung ihrer eigenen Beliebtheit wesentlich zur Mehrung des brüderlichen Ansehens (auctoritas) bei, was diesem wiederum die erforderliche Legitimierung und Stabilisierung seiner Herrschaft verschaffte. ${ }^{13}$

11 Zu Octavias fertilitas: Liv. per. 140,2; Plin. nat. 19,241; 37,11; Plut. Ant. 87,3; facilitas: Dio 51,15,7; Plut. Ant. 87,1f.; Prop. 3,18,11; pietas: Hor. c. 3,14,5-7 (Götter, Augustus); Plut. Mc. 30,6; Prop. 3,18,11f.; Sen. ad Marc. cons. 2f. (Marcellus); lanificia: Suet. Aug. 73. Nach Fischer (Fulvia und Octavia, S. 222) vereinigte das ,Geschwisterpaar [...] damit alles [...], was man in Rom mit traditioneller Moral und Weltanschauung in Verbindung bringen konnte." Zur domus disciplina des Augustus vgl. Kunst, Christiane: Livia. Macht und Intrigen am Hof des Augustus. Stuttgart 2008, S. 120.

12 Zur Porticus Octaviae und ihrer kulturellen Ausgestaltung: Dio 49,43,8; Liv. per. 140,2; Ov. ars 1,69f.; 3,391; Plin. nat. 34,31; 35,114. 139; 36,15f. 22. 24. 28f. 34f. 42; Plut. Mc. 30,6; Suet. Aug. 29,4; Vell. 1,11,3. Belegt ist Octavias Einsatz für den Architekten Vitruv, der ihr Dank abstattet, vgl. Vitr. 1, praef. 2f. Zu weiteren intellektuellen Kontakten mit z.T. patronalem Hintergrund vgl. Hemelrijk, Emily A.: Matrona Docta. Educated women in the Roman élite from Cornelia to Julia Domna. London u.a. 1999, S. 104-108.

13 Vgl. Fischer: Fulvia und Octavia, S. 115. Auch Strabon $(5,3,8)$ lobt Octavias persönliches und materielles Engagement zur Verschönerung Roms. Voraussetzung dafür bildete das Recht einer eigenständigen Vermögensverwaltung, welches die Kaiserschwester seit 35 v. Chr. aufgrund ihrer Befreiung von der Geschlechtsvormundschaft (tutela mulierum) besaß, vgl. Dio 49,43,8. 
Am deutlichsten zeigt sich Octavias Signifikanz im Bereich der augusteischen Nachfolgepolitik. Um seine Macht zu erhalten und die Kontinuität des Principats zu wahren, bestand für Augustus die dringlichste Aufgabe in der Etablierung einer Dynastie. Die Voraussetzungen dafür gestalteten sich jedoch denkbar ungünstig, da ihm ein eigener männlicher Nachkomme zeitlebens verwehrt blieb. Neben den beiden Stiefsöhnen, Tiberius und Drusus (maior), die von seiner Gattin Livia stammten, konnte er lediglich auf eine Tochter, Iulia (maior), aus einer früheren Ehe verweisen. Angesichts dieser Familienkonstellation stellte Octavia als Blutsverwandte des Augustus und darüber hinaus als Mutter eines Sohnes, dem 42 v. Chr. geborenen M. Claudius Marcellus, die entscheidende dynastische Stütze für ihren Bruder dar. ${ }^{14}$ Entsprechend wurde Marcellus durch eine intensive politische Förderung, zahlreiche Ehrerweisungen und die 25 v. Chr. vollzogene Eheschließung mit Iulia (maior) eine beträchtliche Stellung von Augustus zuerkannt, womit Letzterer seine Bestrebungen hinsichtlich einer Herrschaftsfortsetzung über den iulischen Familienzweig klar zum Ausdruck brachte. ${ }^{15}$ Octavia, die durch die Hervorhebung ihres Sohnes zusätzlich an Prestige gewann, rangierte jetzt innerhalb der domus Augusta noch vor der Kaisergattin Livia, deren eigene Söhne hinter Marcellus zurückstanden. ${ }^{16}$

Als Marcellus zwei Jahre später unerwartet verstarb, war dies für Octavia mit erheblichen gesellschaftlichen Konsequenzen verbunden. Ihre Position erfuhr eine deutliche Schmälerung, da eine Partizipation am Ruhm und Ansehen des Sohnes allenfalls noch postum erfolgen konnte und auch dessen Ehe mit der Kaisertochter Iulia (maior) kinderlos geblieben war. ${ }^{17}$ Weitaus verheerender wirkte sich daneben die persönliche Isolation Octavias aus, in die sie sich, folgt man den Schilderungen Senecas, aufgrund ihrer maßlosen Trauer begab. Betrof-

14 Der Sohn stammte aus Octavias erster Ehe mit C. Claudius Marcellus, der 40 v. Chr. verstarb. In den Quellen wird Marcellus stets als Sohn der Octavia und/oder Neffe des Augustus bezeichnet, wohingegen die Rolle des leiblichen Vaters auffälligerweise unerwähnt bleibt (Ausnahme: Plut. Mc. 30,6). Auch auf Octavias übrige Kinder griff Augustus zum Zweck der Machtsicherung zurück. Vgl. Harders: Soror, S. 303f.; Fischer: Fulvia und Octavia, S. 109-112. Daneben engagierte sich Octavia selbst an der Heiratspolitik ihrer (Stief-)Kinder, so belegt für Marcella (maior) (Plut. Ant. 87,4f.; dagegen: Suet. Aug. 63,1f.) und Kleopatra Selene (Plut. Ant. 87,2).

15 Anders Brandt, Hartwin: Marcellus „,successioni praeparatus“? Augustus, Marcellus und die Jahre 29-23 v. Chr., in: Chiron 25 (1995), S. 1-17, der sich gegen die Auffassung von Marcellus als designierter Thronfolger ausspricht. Die diesbezügliche Forschungskontroverse zusammenfassend: Harders: Soror, S. 306 und Anm. 154.

16 Nach Kunst: Livia, S. 126f. stand Livia deutlich in Octavias Schatten.

17 Insofern verwundern die Gerüchte nicht, wonach Livia die Hauptschuld am Tod des Marcellus zukam, vgl. Dio 53,33,4 (allerdings mit Zweifeln). Ein angespanntes Verhältnis zwischen Kaiserschwester und -gattin suggeriert auch Sen. ad Marc. cons. 2. 
fen waren davon nicht nur ihre Kinder und Enkel, sondern selbst der Princeps, dem Octavia fortan die erforderliche Wertschätzung verweigert und stattdessen mit innerer Bosheit gezürnt haben soll. ${ }^{18}$ Mit einer derart missachtenden Haltung widersprach Octavia ihrer Tadellosigkeit als Mutter und Schwester zutiefst. Dass Augustus ihr dennoch anlässlich ihres Todes ein ehrerbietendes Verhalten nicht verweigerte, demonstriert dessen Willen, das öffentliche Bild von der Eintracht (concordia) des Kaiserhauses unbedingt aufrechtzuerhalten. An der Seite ihres Sohnes begraben und als Schwester des Augustus definiert, wurde Octavia noch im Tode ausschließlich in jenen zwei Rollen effektvoll in Szene gesetzt, die sie zu Lebzeiten und postum innerhalb der domus Augusta zu spielen hatte.

\section{Drusilla, Agrippina (minor), Livilla und Caligula}

Die Schwestern des C. Caesar Germanicus (Caligula), dem dritten iulischclaudischen Kaiser, treten in erster Linie durch die vielfältigen und zum Teil außergewöhnlichen Ehrungen in Erscheinung, die ihr Bruder für sie veranlasste. Aufsehen erregt in diesem Zusammenhang eine römische Kupferprägung, die Caligula unmittelbar nach seiner Princepserhebung zwischen den Jahren 37 und 38 emittieren ließ. Während der Münzavers den lorbeerbekränzten Kopf des Princeps darstellt, zeigt die Reversabbildung Drusilla, Agrippina und Livilla, ausgestattet mit Füllhörnern und weiteren göttlichen Attributen, als die personifizierten Gottheiten Securitas, Concordia und Fortuna in Ganzkörpergestalt. ${ }^{19}$ Die Münze stellt in doppelter Hinsicht eine Novität der römischen Reichsprägung dar, denn zum ersten Mal wurden an dieser Stelle lebende Frauen des Kaiserhauses mit ihrem Portrait und Namen, des Weiteren in expliziter Götterangleichung öffentlich präsentiert. Vordergründig diente eine derartige Inszenierung dazu, den herausragenden Status der Schwestern unter der Regierung ihres Bruders reichsweit zu verkünden. Überdies evozierte die Verknüpfung mit den genannten Gottheiten einen politischen Kontext, in welchem die Frauen neben dem Kaiser als entscheidende Garanten einer zukunftsverheißenden Regierung fungierten. Weitere Privilegien und Ehrerweisungen verstärken diesen Eindruck. Neben dem Erhalt der vestalischen Vorrechte (darunter die Befreiung von der Geschlechtsvormundschaft) und der Zuweisung von Ehrenplätzen bei der Austragung von Spielen wurden die Schwestern in die Eidesformeln auf den Kaiser

18 Vgl. Sen. ad Marc. cons. 2.

19 RIC I, S. 110, Nr. 33. Über die entsprechenden Namenszusätze sind die weiblichen Figuren eindeutig als die Schwestern des Caligula identifizierbar. 
und die öffentlichen Gelübde einbezogen. Wiederholt hob man sie auf diese Weise in ihrer staatstragenden Bedeutung hervor. ${ }^{20}$

Waren bis dahin alle drei Schwestern als Einheit geehrt worden, so wurde Drusilla durch weitergehende Gunstbezeugungen eine Sonderrolle in der kaiserlichen Politik zugewiesen, über die Sueton in seiner Caligula-Vita $(24,1 \mathrm{f}$.) ausführlich Auskunft gibt:

Man glaubt, daß er [Caligula] von den Schwestern Drusilla die Jungfernschaft geraubt hat, als er noch im Knabenalter war, [...]; er [...] behandelte sie in aller Öffentlichkeit wie seine rechtmäßig angetraute Gattin. Auch als Erbin seines Vermögens und als Nachfolgerin in der Regentschaft setzte er sie ein, als er erkrankte. Als sie starb, ordnete er den Stillstand der Gerichte an; und es wurde als Verbrechen, auf das die Todesstrafe stand, angesehen, zu lachen, zu baden, mit den Eltern, der Frau oder den Kindern gemeinsam zu speisen. Der Schmerz über den Verlust war ihm unerträglich; so verließ er plötzlich bei Nacht Hals über Kopf die Stadt und eilte nach Kampanien, dann nach Syrakus, dann machte er wieder kehrt und kam schnell nach Hause; er hatte sich den Bart stehen und das Haar wachsen lassen. Seitdem hat er niemals mehr bei sehr gewichtigen Angelegenheiten, selbst nicht einmal mehr vor versammeltem Volk oder vor den Soldaten, einen Eid abgelegt, ohne bei der „Gottheit Drusilla“" zu schwören. (übers. v. Hans Martinet)

Mit solchen Äußerungen knüpfte Sueton an jene Topoi moralischer Verwerflichkeit an, die für die antike Tyrannenzeichnung charakteristisch waren. Indem er Caligula ein inzestuöses Verhältnis mit der leiblichen Schwester ${ }^{21}$ sowie ein maßloses, zuweilen in Wahnsinn und Willkürherrschaft mündendes Trauerverhalten bei deren Tod unterstellte, ${ }^{22}$ rechtfertigte er eine retrospektive Herrscherkritik, die in erster Linie als Negativbeispiel für die kaiserlichen Repräsentanten seiner eigenen Gegenwart diente. ${ }^{23}$ Ebenfalls in diesen Kontext fällt die Aussage um Caligulas testamentarische Verfügung, die Drusilla im Falle seines Todes

20 Zu den Ehrungen: Dio 59,3,4. 7,4. 9,2. 22,9; Suet. Cal. 15,3f. (wirft Caligula „Popularitätshascherei“" [popularitas] vor). Eine staatspolitische Motivation unterstellen u.a. Alexandridis: Frauen, S. 90 u. Wood, Susan E.: Diva Drusilla Panthea and the Sisters of Caligula, in: AJA 99, 3 (1995), S. 457-482, hier S. 461.

21 Vgl. auch Dio 59,11,1; Ios. ant. Iud. 19,2,5. Ein Verhältnis mit allen drei Schwestern äußern: Aur. Vict. 3,10f.; Dio 59,3,6. 22,6. 26,5 (Xiph.; Exc. Val.); Suet. Cal. 24,1; 36,1.

22 Kritik an Caligulas Trauerverhalten übt auch Sen. ad Pol. cons. 17,4f. Dagegen Meise, Eckhard: Untersuchungen zur Geschichte der Julisch-Claudischen Dynastie. München 1969, S. 103, der nicht daran zweifelt, dass ,,diese große Trauer Caligulas bei aller Überspanntheit seiner Handlungsweise echt war, daß er seine Schwester sehr geliebt hatte“.

23 Zur Widerlegung des Inzestvorwurfs als bewusste Falschinformation Suetons vgl. Barrett, Anthony A.: Agrippina. Sex, Power, and Politics in the Early Empire. London 1996, S. 54. Vgl. ferner Winterling, Aloys: Caligula. Eine Biographie. München 2004, S. 7-11 u. 175-180, der Caligula zudem vom Ruf des ,wahnsinnigen“ Kaisers entlastet. 
nicht nur als Erbin des Vermögens, sondern auch der Herrschaft vorsah. Da nach römischer Auffassung eine weibliche Regentschaft als undenkbar galt, muss eine derartige Behauptung zwangsläufig als weitere Provokation Suetons gedeutet werden, womit das Bild vom unsittlichen Kaiser unterstrichen werden sollte. Über Caligulas Nachfolgeambitionen zu diesem Zeitpunkt ist damit nichts Konkretes gesagt. Es ist lediglich davon auszugehen, dass im Todesfall des Kaisers seinem Schwager und engem Vertrauten, M. Aemilius Lepidus, die Ausübung der Regierungsgeschäfte in Platzhalterfunktion zugefallen wäre. Drusilla als dessen Ehefrau hätte in dieser Situation aufgrund ihrer direkten Abstammung von Augustus die Principatsnachfolge durch die Geburt iulischer Söhne gesichert. ${ }^{24}$ Wie zuvor Octavia wurde Drusilla auf diese Weise, noch vor den die gleiche Herkunft aufweisenden Geschwistern Agrippina und Livilla, in ihrer dynastischen Wertigkeit für den Bruder hervorgehoben. ${ }^{25}$

Unter den postumen Ehren, die Sueton als Handlungen Caligulas anlässlich von Drusillas Tod im Jahr 38 aufzählt, verdient die Erwähnung ihrer Vergöttlichung besondere Aufmerksamkeit. ${ }^{26}$ Sie musste von den Zeitgenossen als radikale Maßnahme wahrgenommen werden, zieht man in Betracht, dass zuvor einzig die Imperatoren Iulius Caesar und Augustus eine Divinisierung erfahren

24 Angedeutet bei Dio 59,22,6f. Caligula hatte die Heirat zwischen seiner Schwester und Lepidus, dem er daraufhin eine bevorzugte politische Behandlung angedeihen ließ, selbst initiiert. Die tiefe Freundschaft, die beide Männer augenscheinlich verband, wurde zuweilen von der antiken Historiographie in ein sexuelles Verhältnis umgedeutet, vgl. Suet. Cal. 36,1; Dio 59,11,1. 22,6. Die Ansicht von Lepidus als prädestinierten Thronfolger ist in der Forschung weit verbreitet. Vgl. u.a. Meise: Untersuchungen, S. 109; vorsichtiger: Barrett: Agrippina, S. 58.

25 Dass neben Drusilla die anderen Schwestern eine unterminierte Rolle in Caligulas Nachfolgeplänen spielten, zeigt die abschätzige Behandlung, die er seinem im Jahr 37 geborenen Neffen, dem späteren Kaiser Nero, und dessen Mutter Agrippina (minor) angedeihen ließ, vgl. Suet. Ner. 6,2. Dazu Meise: Untersuchungen, S. 100f.; ferner Barrett: Agrippina, S. 57, der außerdem betont, dass weder Agrippinas noch Livillas Ehemann unter Caligula eine Herausstellung erfuhren, vgl. ebd., S. 54f. u. 58.

26 Vgl. auch Sen. apocol. 1,2f. Nach Dio 59,11,1-6. 13,8f. 24,7f. wurde Drusilla ein Kult als

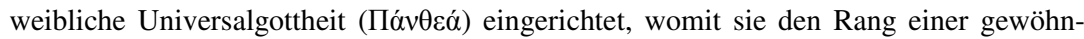
lichen Staatsgottheit übertraf. Zur consecratio und den Ehren, die Drusilla zu Lebzeiten Caligulas als diva zukamen, vgl. Sandels: Stellung, S. 46-49. Über ihre göttliche Verehrung v.a. in den östlichen Provinzen führt Hahn, Ulrike: Die Frauen des römischen Kaiserhauses und ihre Ehrungen im griechischen Osten anhand epigraphischer und numismatischer Zeugnisse von Livia bis Sabina. Saarbrücken 1994, S. 151-168 den quellenprofunden Nachweis. In der römischen Münzprägung wird an Drusillas Konsekration auffälligerweise nicht erinnert. Den fehlenden numismatischen Befund deutet Wood: Diva, S. 462 als bewusste Vermeidung Caligulas, Diva Drusilla mit Divus Augustus sowie der verstorbenen Mutter Agrippina (maior) gleichzustellen. 
hatten. Neben dem augenscheinlichen Effekt, das Andenken seiner Schwester auf diese Weise dauerhaft in der römischen memoria zu verankern, ist ein gewisser Eigennutzen Caligulas unverkennbar. Nicht nur als Urenkel des Divus Augustus, sondern nunmehr als Bruder einer Diva sorori partizipierte er an einer göttlichen Aura, die ihn dem Kreis des auf Gleichrangigkeit basierenden römischen Gemeinwesens entrückte und in eine übergeordnete Sphäre aufsteigen ließ. ${ }^{27}$

Insgesamt betrachtet, dienten die von Caligula seinen Schwestern entgegengebrachten Ehrungen vornehmlich einer politischen Zweckmäßigkeit. Durch das demonstrative Herausstellen aller drei Frauen wurden sie der Öffentlichkeit nicht nur als zentrale Persönlichkeiten innerhalb des Staatsgefüges präsentiert, sondern über ihre gemeinsame Abkunft zudem als Repräsentanten des iulischen Geschlechts glorifiziert. Für Caligula erwies sich Letzteres in zweifacher Hinsicht als vorteilhaft: Zum einen erlaubte es ihm den Rückbezug auf den Dynastiebegründer Augustus, in dessen Herrschertradition er sich bewusst stellte, um der eigenen Regierung Legitimation zu verleihen. Zum anderen war damit die Weiterführung der Dynastie über den iulischen Familienzweig aufgezeigt, obgleich es ihm selbst an eigenen männlichen Nachkommen mangelte. ${ }^{28} \mathrm{Ob}$ neben diesen rationalen auch emotionale Beweggründe das Handeln Caligulas bestimmten, ist in Anbetracht der kollektiven Erfahrung des gewaltsamen Todes der Mutter und Brüder während der tiberianischen Regierungszeit durchaus erwägenswert. ${ }^{29}$ Rückschlüsse auf das Geschwisterverhältnis als solches oder gar auf politische Einflussmöglichkeiten seitens der Frauen können damit allerdings nicht gezogen werden, da die Überlieferung lediglich ein einseitiges Beziehungsgeflecht widerspiegelt, innerhalb dessen die Schwestern ausschließlich in der Rolle der Ehren empfangenden Objekte zum Tragen kommen. ${ }^{30}$

27 Vgl. ebenso die politische Deutung bei Wood: Diva, S. 460.

28 Die Schwestern als Herrschaftslegitimierung bei Barrett: Agrippina, S. 53 und als „dynastische Alternative“ bei Harders: Soror, S. 310.

29 Nach Winterling: Caligula, S. 61 waren die Schwestern zu Caligulas Regierungsbeginn aufgrund der gemeinsamen Vergangenheit dessen ,engste[] Vertraute[]“. Ähnlich Barrett (Agrippina, S. 53f.), der Caligulas Handlungen als ,,an element of genuine and naive affection“"wertet, die das ,close bond between Caligula and his sisters“ unterstreichen. Dagegen Harders: Soror, S. 309.

30 Eine politische Einflussnahme der Schwestern auf den Bruder wird in der Forschung dennoch angenommen. Vgl. Winterling: Caligula, S. 69. Zu Drusilla vgl. Meise: Untersuchungen, S. 100. In keinem Fall dürfen die Ehren jedoch mit faktischer Macht gleichgesetzt werden, wie Späth (,Frauenmacht‘, S. 190) betont: „Die Vorrechte von Frauen erweisen sich letztlich als Privilegien, die der Kaiser beansprucht [...]: keine der Auszeichnungen verleiht einer Frau in irgendeiner Weise eine Magistratsaufgabe oder eine institutionelle politische Position.“ 
Eine modifizierte Quellenwahrnehmung erfolgt erst mit der Nachricht über Livillas und Agrippinas Verwicklung in die Verschwörung, welche sich im Jahr 39 gegen den Kaiser formiert hatte. Dem Komplott vorausgegangen war Caligulas Eheschließung mit der schwangeren Milonia Caesonia, auf die nur kurze Zeit später die Geburt der Tochter Iulia Drusilla folgte, die Caligula über die entsprechende Namensgebung sogleich als sein Kind anerkannte. ${ }^{31}$ Damit war die Absicht einer Erbfolge über die eigene Nachkommenschaft und die Zurücksetzung der verbliebenen Schwestern in ihrer dynastischen Bedeutung für den brüderlichen Principat endgültig aufgezeigt. ${ }^{32}$ Für außerhalb der Kaiserfamilie stehende männliche Personen boten die Frauen in dieser Situation den entscheidenden Anknüpfungspunkt, über den ein Zutritt zum Machtzentrum möglich erschien. Nur vor diesem Hintergrund ist schließlich die Behauptung hinsichtlich einer Liaison beider Kaiserschwestern mit Lepidus verständlich, der nach Drusillas Tod massiv an kaiserlicher Popularität eingebüßt und sich daraufhin an die Spitze des Aufstands gestellt hatte. Wie konkret sich Agrippinas und Livillas Beteiligung gestaltete, lässt sich nicht mehr rekonstruieren, doch offenbarte ihre bloße Anbindung an die oppositionellen Kräfte ein Missverhältnis, das die Beziehung zum Bruder augenblicklich bestimmte. ${ }^{33}$ Dieser musste ein solches Gebaren als aufrührerische Geste und existenzielle Bedrohung seiner Herrscherposition werten, weswegen die Reaktion nach Aufdeckung der Verschwörung entsprechend unnachgiebig ausfiel: Lepidus wurde hingerichtet, die leiblichen Schwestern in die Verbannung geschickt. ${ }^{34}$ Die Geschehnisse hatten

31 Zur Heirat s. Dio 59,23,7; Suet. Cal. 25,3f.; Geburt und Ehren der Tochter bei Dio 59,28,7 (Xiph.; Exc. Val.); Ios. ant. Iud. 19,1,2; Suet. Cal. 25,3-26,1; 42. Über die kindliche Namensgebung zollte Caligula der Diva Drusilla postumen Tribut und vertraute seiner Tochter deren besonderen Schutz an. Vgl. Wood: Diva, S. 460.

32 Vgl. Harders: Soror, S. 309f., die eine dynastische Umorientierung Caligulas annimmt. Ähnlich Meise: Untersuchungen, S. 104f.

33 In den Quellen wird die Verschwörungsbeteiligung der Schwestern höchstens angedeutet: Dio 59,22,8. 23,1; Suet. Cal. 24,3. Trotz der insgesamt spärlichen Quellenaussagen fehlt es in der Forschung nicht an möglichen, v.a. herrschaftspartizipatorischen Motiven, welche die Schwestern zum Aufbegehren gegen ihren Bruder veranlasst haben sollen, wobei gerade Agrippina, ganz im Sinne von Tacitus (ann. 14,2,2), aufgrund ihrer späteren Position als Kaisergattin (Claudius) und Kaisermutter (Nero) immer wieder eine Sonderrolle attestiert wird. Vgl. z.B. Meise: Untersuchungen, S. 111, insb. S. 119.

34 Zur Verbannung vgl. Dio 59,3,6; Suet. Cal. 29,1f.; 39,1; Suet. Ner. 6,3f. Als Beleg der Tyrannei Caligulas wird die Bestrafung von den antiken Berichterstattern zuweilen als ungerecht dargestellt, vgl. Dio 59,23,8; 60,4,1; Suet. Cal. 24,3. Dagegen Winterling: Caligula, S. 106, der Caligulas Vorgehen als „,milde Behandlung“ wertet, was die „,enge Beziehung" zwischen den Geschwistern dokumentiere; ähnlich Barrett: Agrippina, S. 69. Nicht zuletzt spricht die pietätvolle Behandlung von Caligulas Leichnam durch beide 
Caligula unumwunden vor Augen geführt, welches Gefahrenpotenzial sich aus dem dynastischen Kapital seiner Schwestern für ihn selbst ergab. ${ }^{35}$

\section{Marciana und Traian}

Für Ulpia Marciana ging die Regierungsübernahme ihres Bruders M. Ulpius Traianus im Jahr 98 mit einer imposanten Standeserhöhung einher. In den Rang einer Kaiserschwester versetzt, galt sie nunmehr als exklusives Mitglied der domus Augusta, womit sie schlagartig im Fokus der Öffentlichkeit stand. Auch in der antiken Überlieferung findet sie erstmalig in dieser neuen Position Erwähnung. ${ }^{36}$ Ihre Darstellung folgt dabei im Wesentlichen einem Idealbild, wie es im plinianischen Panegyrikus (Paneg. 84,1) zum Ausdruck kommt. In der Lobrede, die neben Traians Werdegang, seiner Adoption durch den vorherigen Princeps Nerva sowie seinem Lebens- und Regierungsstil auch das kaiserliche Privatleben thematisiert, äußert sich der jüngere Plinius über Marciana wie folgt:

Und nun deine Schwester! Wie lebt sie im Bewusstsein, deine Schwester zu sein! Wie erkennt man an ihr dein offenes Wesen, dein ehrliches Herz, deinen redlichen Sinn! Würde sie jemand mit deiner Frau [Pompeia Plotina] vergleichen, dann müssten ihm Zweifel kommen, ob eine richtige Lebensführung mehr das Ergebnis einer guten Erziehung oder einer edlen Geburt ist. (übers. v. Werner Kühn)

Die wiedergegebene Passage demonstriert eindrucksvoll den Stellenwert, der Marciana im Principat des Traian beigemessen wurde. So preist Plinius sie als Person von edler Abstammung, die neben einer makellosen Lebensweise auch eine sittenreine Gemütsart vorzuweisen habe. Sie folge damit dem brüderlichen Vorbild, zu dessen Spiegelbild und Aushängeschild sie avanciert. Der Umstand schließlich, dass sie neben der Ehefrau Traians überhaupt Erwähnung in der plinianischen Schrift findet, lässt sie als eine der ranghöchsten Damen des römischen Imperiums erscheinen. ${ }^{37}$

Schwestern nach deren Rückkehr aus der Verbannung für ein ungebrochen enges Geschwisterverhältnis, vgl. Suet. Cal. 59.

35 Vgl. Harders: Soror, S. 310f.

36 Fakten über Marcianas Leben vor dem Jahr 98 sind spärlich. Nur das Geburtsdatum zwischen 44 und 62 sowie die Ehe mit Salonius und die Geburt der Tochter Salonia Matidia (maior) sind gesichert. Vgl. dazu Temporini, Hildegard: Die Frauen am Hofe Trajans. Ein Beitrag zur Stellung der Augustae im Principat. Berlin, New York 1978, S. 184-187.

37 Die wahrscheinlich im Jahr 101 publizierte Version des Panegyrikus stellt die stark überarbeitete, vielleicht sogar eine gänzliche Neufassung der am 1. September 100 von Plinius vorgetragenen gratiarum actio dar, die er anlässlich seines Antritts als Suffektkonsul im Senat hielt. Mit dieser Rede erwies er dem anwesenden Kaiser den traditionsgemäßen Dank für das erworbene Amt, das zugleich den Höhepunkt seiner bisherigen politischen 
Verstärkt wird dieser Eindruck durch die Ehrungen, die Marciana zu Lebzeiten von ihrem Bruder im reichlichen Maße zuteil wurden und die, jede für sich, eine Novität für eine Kaiserschwester darstellten. Bereits kurz nach Traians Regierungsantritt bot ihr der Senat den Ehrennamen Augusta an, dessen tatsächliche Verleihung spätestens im Jahr 105 erfolgte, nachdem sie die Ehre zunächst in aller Bescheidenheit (modestia) abgelehnt hatte. ${ }^{38}$ Daneben wurden zwei neugegründete Provinzstädte nach Marciana benannt, die ihre allgegenwärtige Präsenz als wichtige Vertreterin der gens Ulpia über die Stadtgrenzen Roms hinaus gewährleistete. ${ }^{39}$ Ferner bekam sie im Jahr 112 das Ehrenmünzrecht zugesprochen, welches sie zur Prägeherrin erhob und damit zur Herausgabe eigener Münzserien ermächtigte. ${ }^{40}$ Noch im selben Jahr erschienen Aurei und Denari, die das mit Hochsteckfrisur und Stephane geschmückte Portrait Marcianas auf dem Avers abbildeten. In der Umschrift, die ihren Namen im Nominativ anführt, wird sie als Augusta und Schwester des Traian ausgewiesen: MARCIANA AVG(usta) SOROR IMP(eratoris) TRAIANI. Eine Erweiterung erfährt Marcianas Rollenspektrum mit der Reversdarstellung, die ihre Tochter Salonia Matidia (maior) in Gestalt der Pietas, sitzend im Beisein von zwei kleinen Figuren, zuweilen gedeutet als deren eigene Kinder Vibia Sabina und

Karriere markierte. Zum panegyrischen Charakter der Rede und seinen Auswirkungen vgl. Roche, Paul A.: The public image of Trajan's family, in: CPh 97 (2002), S. 41-60.

38 Vgl. Plin. Paneg. 84,6-8. Neben dem Motiv der Bescheidenheit führt Plinius die recusatio auf den Umstand zurück, dass Traian zur selben Zeit noch nicht offiziell pater patriae war, womit auf die Vermeidung einer Gleichstellung von Kaiser und Kaiserschwester angespielt wurde. Dazu und den Datierungsproblemen von Senatsangebot und recusatio vgl. Temporini: Frauen, S. 23-27, die in Marcianas Augusta-Benennung ,nicht nur eine formale Ehrung, sondern die Zuerkennung einer wenn auch abgeleiteten realen staatspolitischen Stellung“ sieht, vgl. ebd., S. 41f. Auch Hahn: Frauen, S. 253, Anm. 11, betont das Außergewöhnliche der Ehrung, mit der ,nicht einmal Caligula [...] seine Schwester Drusilla [...] ausgezeichnet" hatte.

39 In Numidia legte Traian im Jahr 100 die Stadt Colonia Marciana Traiani Thamugadi an. Vgl. Watkins, Thomas H.: Colonia Marciana Traiana Thamugadi: Dynasticism in Numidia, in: Phoenix 56 (2002), S. 84-108, der neben Marciana ebenso die kaiserlichen Eltern, Marcia und M. Ulpius Traianus (pater), als Reverenzsubjekte im Stadtnamen annimmt. Eine weitere traianische Neugründung aus dem Jahr 106 stellte Marcianapolis in Thracia dar. Zum legendären Entstehungsanlass vgl. Iord. Get. 92f. Zur Datierung und politischen Relevanz der Stadt vgl. Temporini: Frauen, S. 88-90 u. 188f.

40 Um die familiäre Eintracht innerhalb der domus Augusta außenwirksam zu präsentieren, war auch Traians Ehefrau Plotina durch Ehrenmünzrecht, Augusta-Titel und eine ihr gewidmete Stadtbenennung ausgiebig geehrt worden. Auch Plinius (Paneg. 84,3-5) betont in diesem Sinne ausdrücklich die Ranggleichheit beider Frauen (par fortuna). 
Mindia Matidia (minor), zeigt. ${ }^{41}$ Die bildkompositorische Inszenierung der weiblichen Angehörigen des ulpischen Familienzweigs über zwei, wenn nicht gar drei Generationen hinweg hebt die staatstragende Signifikanz von Marcianas Nachkommenschaft hervor. Aufgrund der Tatsache, dass Traian selbst kinderlos geblieben war, kam es darauf an, über die repräsentative Demonstration der schwesterlichen fecunditas (Fruchtbarkeit, Kinderreichtum) die gesamte domus Augusta in dieser Eigenschaft herauszustellen. ${ }^{42}$ Unter Berücksichtigung der zuvor aufgeführten Ehren war damit die traianische Präferenz zu einer dynastisch konzipierten Herrschaftsnachfolge unmissverständlich offengelegt.

Nur kurze Zeit nach dieser Münzemission, am 29. August 112, verstarb Marciana, womit die Reihe an außergewöhnlichen Ehrungen jedoch nicht abbrach, sondern sogar noch an Exklusivität gewann. So folgte auf den Tod der Kaiserschwester deren unverzügliche Divinisierung, was durch eigene Konsekrationsprägungen eilends im Reich propagiert wurde. ${ }^{43}$ Für Traian, der sich auf keine blutsmäßigen Verwandtschaftsbeziehungen $\mathrm{zu}$ früheren principes stützen konnte, bot Marciana den entscheidenden Anknüpfungspunkt, nicht nur der eigenen Herrschaft, sondern der gesamten gens Ulpia einen göttlichen Legitimationsrahmen (domus divina) zu verschaffen. ${ }^{44}$ Nur folgerichtig erscheint in

41 RIC II, S. 299, Nr. 742. Matidia (maior) ist durch die beigefügte Umschrift MATIDIA AVG(ustae) F(ilia) eindeutig identifiziert. Zur Deutung der Pietas-Referenz (Schleierattribut) ,als das die Abfolge der Generationen verbindende Glied“ zur Betonung des dynastischen Gedankens vgl. Seelentag, Gunnar: Taten und Tugenden Traians. Herrschaftsdarstellung im Principat. Wiesbaden 2004, S. 354f. u. 450-453; hier: S. 451.

42 Ähnlich Temporini: Frauen, S. 193f.; zurückhaltender Alexandridis: Frauen, S. 21.

$43 \mathrm{Zu}$ funus und consecratio vgl. Fast. Ost. 22,39-43. Nachweislich handelt es sich bei dem abgewandelten Konsekrationszeremoniell (Divinisierungsbeschluss vor Leichenverbrennung) um ein singuläres Phänomen. Vgl. Temporini: Frauen, S. 194-235. Zu den Konsekrationsmünzen, die bedeutende Neuerungen aufwiesen, vgl. RIC II, S. 299f., Nr. 743750. Neben der Benennung Marcianas als DIVA AVGVSTA MARCIANA auf dem Avers ist v.a. die Vielgestaltigkeit der Reversbilder auffällig, die neben bekannten Motiven (carpentum: Nr. 746, 749; Elefantenbiga: Nr. 747, 750) auch die bisher ausschließlich für Divus Augustus verwendete Adlerdarstellung zeigt (Nr. 743-745,748). Als zusätzliches Element sind die Reverse erstmalig durch die Legende CONSECRATIO gekennzeichnet (Ausnahme: Nr. 747, 750). Das numismatische Material wird ausführlich diskutiert bei Temporini: Frauen, S. 201f., 236-243 u. 255-257.

44 Vgl. Temporini: Frauen, S. 234. Neben Marciana ließ Traian im Jahr 113 seinen leiblichen Vater konsekrieren, der bereits vor Regierungsantritt seines Sohnes verstorben und zudem niemals Augustus war. Auch für ihn wurden Konsekrationsmünzen geprägt, die ihn auf einem Exemplar gemeinsam mit Traians Adoptivvater, Divus Nerva, zuzüglich der Umschrift DIVI NERVA ET TRAIANVS PATER abbilden, vgl. RIC II, S. 297, Nr. 726f. Nach Seelentag: Taten, S. 451 ließ sich durch die Herausstellung beider Väter Traians Anspruch auf die eigene Divinisierung verbinden. 
diesem Zusammenhang die sofortige Erhebung der Kaisernichte Matidia (maior) zur Augusta, die jetzt offiziell den Platz der Mutter einnahm, um so die Weiterführung der ulpischen Familie nach außen sinnbildlich zu kommunizieren. ${ }^{45}$

Zur öffentlichkeitswirksamen Verbreitung der angestrebten dynastischen Kontinuität wurde neben dem numismatischen, epigraphischen wie archäologischen Material ${ }^{46}$ auf weitere Medien zurückgegriffen. Erhalten ist ein Sardonyx aus traianischer oder hadrianischer Zeit, auf dem sich die Abbildung von insgesamt vier Personen befindet: auf der rechten Seite Kaiser Traian mit seiner Gattin Plotina, ihnen gegenüber seine Schwester Marciana und deren Tochter Matidia (maior). Die im Staffelportrait angeordneten Paare weisen eine markante Platzierung auf: Während die Geschwister Traian und Marciana ebenbürtig im Vordergrund rangieren, erscheinen Plotina und Matidia hinter den beiden zurückgesetzt nur im zweiten Glied. ${ }^{47}$ Mit dem gewählten Figurenarrangement kann auch dieses Zeugnis als Bestätigung der herausragenden Position Marcianas herangezogen werden, die ihr in erster Linie aufgrund ihres Schwestern- und Mutterdaseins im Principat des Bruders zugeschrieben wurde. Wie die zuvor aufgeführten Ehren erlaubt jedoch auch diese Quelle weder Rückschlüsse auf ihre politischen Einflussmöglichkeiten noch generelle Aussagen über das Beziehungsverhältnis, wie es sich zwischen Marciana und Traian realiter gestaltete. Für die Nachwelt bleibt Marciana zuletzt einzig in der objekthaften Stellung greifbar, die ihr Bruder ihr als Trägerin des ulpischen Blutes zum Zweck der Durchsetzung eigener Herrschaftsvorstellungen auferlegte. ${ }^{48}$

Mit dieser offensiv angelegten Inszenierung der Kaiserschwester wurde schließlich auch das Grundprinzip des „Adoptivkaisertums“ ad absurdum geführt, wonach die Kaiserernennung nicht mehr auf Basis einer Erbmonarchie, sondern durch die Adoption des Besten erfolgen sollte. ${ }^{49}$ Eine dynastisch orientierte Familienpolitik, wie sie für Augustus und Caligula in Bezug auf Octavia und Drusilla nachgewiesen werden konnte, erschien mit diesem Anspruch überflüssig. Unweigerlich musste sich eine derartige Entwicklung auf die Position

45 Im römischen Münzbild wird Matidia fortan als MATIDIA AUG(usta) DIVAE MARCIANEA F(ilia) bezeichnet, vgl. RIC II, S. 300f., Nr. 758-761.

46 Vgl. z.B. den zu Ehren Traians 115 gefertigten Bogen am Hafen von Ancona. Dazu Temporini: Frauen, S. 258 und Anm. 280.

47 Zur ikonographischen Auswertung vgl.. Temporini: Frauen, S. 258.

48 Im Endeffekt war es Traians Anliegen, ein bestimmtes Bild seiner domus zu präsentieren, das mit der Wirklichkeit nur wenig gemeinsam haben musste, solange es in der Öffentlichkeit in seiner intendierten Form wahrgenommen und akzeptiert wurde. Vgl. die diesbezüglichen Ausführungen bei Roche: The public image, S. 60.

49 Eine solche Idealverklärung hatte sich aus dem biologischen Zufall ergeben, dass es den Kaisern Nerva bis Antoninus Pius an leiblichen Söhnen mangelte. 
der Kaiserschwester auswirken, für die zumindest hinsichtlich ihres dynastischen Potenzials ein erheblicher Bedeutungsverlust zu erwarten war. Mit der Betrachtung Marcianas sind solche Überlegungen eindeutig widerlegt, offenbart sich doch gerade an ihrer Person der Widerspruch, der zwischen dem neuem Herrschaftsprinzip und dessen faktischer Umsetzung vorherrschte.

\section{Lucilla und Commodus}

Als M. Aurelius Commodus Antoninus im Jahr 180 mit 18 Jahren die Regentschaft über das römische Imperium übernahm, ${ }^{50}$ konnte seine zwölf Jahre ältere Schwester Annia Aurelia Galeria Lucilla bereits auf eine beachtenswerte Lebensbilanz verweisen, die aus ihrer frühen Integration in die dynastische Konzeption des Vaters, Kaiser M. Aurel, resultierte. So war sie zum Zeitpunkt des Herrschaftsantritts ihres Bruders seit annähernd anderthalb Dekaden im Besitz des Augusta-Titels ${ }^{51}$ und des Ehrenmünzrechts ${ }^{52}$. Ferner nahm sie als Ehefrau des L. Verus ${ }^{53}$, der von 161 bis zu seinem Tod 169 als gleichrangiger Princeps neben M. Aurel amtierte, den Status einer Kaisergattin ein und zählte zumindest für diesen Zeitraum gemeinsam mit ihrer Mutter Faustina (minor) zu den ranghöchsten Frauen im Reich. Die wenig später erfolgte zweite Eheschließung mit dem kaiserloyalen und erfolgreichen Feldherrn Ti. Claudius Pompeianus bestätigte ihre herausgehobene Stellung innerhalb der domus Augusta und dürfte durch die zeitnahe Geburt eines Sohnes eine weitere Festigung erfahren haben. ${ }^{54}$

50 Mit Commodus, den sein Vater M. Aurel als designierten Thronfolger aufgebaut hatte, trat nach annähernd 100 Jahren wieder ein leiblicher Sohn die Principatsnachfolge an.

51 Die in der Forschung kontrovers diskutierte zeitliche Bestimmung der Verleihung des Augusta-Titels muss spätestens im Jahr 165 und damit noch vor der Geburt von Lucillas erstem Kind erfolgt sein, wie eine Inschrift aus Dakien nahelegt, vgl. CIL III 1307. Dazu Wallinger, Elisabeth: Die Frauen in der Historia Augusta. Wien 1990, S. 64.

52 Zum Ehrenmünzrecht vgl. die numismatischen Zeugnisse, die Lucillas Namen im Nominativ (LVCILLA AVGVSTA) nennen: RIC III, S. 274-276 u. 352-355, Nr. 755, 759, 764-766, 768-770, 772f., 779-781, 785-787, 1728-1731, 1736-1741, 1744, 1746, 1751f., 1754f., 1760, 1765f., 1768 u. 1777f. Über Prägebeginn und -ende, die zwischen Lucillas Annahme des Augusta-Titels und ihrem Tod im Jahr 182 liegen, herrscht in der Forschung große Uneinigkeit. Dazu Alexandridis: Frauen, S. 284, Anm. 1213.

53 Vgl. H.A. M.A. 7,7; 9,4-6; Ver. 2,4; Dio 71,1,3 (Xiph.); Herodian. 1,8,3.

54 Zur Eheschließung mit Pompeianus: Herodian. 1,8,3. Vgl. auch H.A. M.A. 20,6f., wo aufgrund der niederen Geburt des Pompeianus eine Statusminderung für Lucilla, die doch immerhin ,Augusta und Tochter einer Augusta war“ (Augusta esset et Augustae filia), suggeriert wird. Der Ehegatte selbst hatte durch die Heirat mit Lucilla die besten Aussichten auf eine Herrschaftsübernahme, sollte M. Aurel etwas zustoßen. Vgl. Priwitzer, Stefan: Faustina minor - Ehefrau eines Idealkaisers und Mutter eines Tyrannen. 
Dokumentiert wird Lucillas zentrale Familienposition durch die antike Überlieferung, in der sie neben fünf anderen weiblichen Geschwistern die mit Abstand höchste Präsenz aufweist. ${ }^{55}$ Quellenbasierte Rückschlüsse, die das Verhältnis zu Commodus erhellen, lassen sich jedoch erst mit dessen Herrschaftsantritt ziehen. In den entsprechenden Schriftzeugnissen wird die Geschwisterbeziehung durchweg negativ gezeichnet. Sie zeigen Lucilla als eine der führenden Agitatoren eines fehlgeschlagenen Verschwörungskomplotts gegen den Kaiserbruder und infolgedessen als Opfer seiner Sanktionierungsmaßnahmen, die zunächst in Verbannung, später sogar mit ihrer Hinrichtung endeten. ${ }^{56}$

Während über die Beteiligung der Kaiserschwester an der wohl bereits in der zweiten Hälfte des Jahres $181^{57}$ ausgeführten Verschwörung gegen Commodus in den Quellen Einigkeit besteht, ${ }^{58}$ zeigt sich hinsichtlich Lucillas funktionalen Anteils an der Erhebung sowie ihrer diesbezüglichen Ambitionen ein ambivalentes Bild. Von den zeitgenössischen Historiographen Cassius Dio und Herodian wird Lucilla als initiative Kraft hinter dem gescheiterten Mordanschlag dargestellt. Als zentrales Motiv verweist Dio auf den Hass, den Lucilla gegenüber dem Ehemann ihrer Tochter und Neffen ihres eigenen Gatten, C. Pompeianus Quintianus, gehegt haben soll, woraufhin sie diesen zu dem Anschlag überredete und damit seinen Tod besiegelte. Die Darstellung des Schwiegersohns als Lucillas Handlanger findet sich auch bei Herodian, der als Ursache ihres Verhaltens allerdings die Zurücksetzung hinter die Kaisergattin Bruttia Crispina anführt. ${ }^{59}$ Beide antike Autoren benennen damit ausschließlich niedere Beweggründe, die bei der Kaiserschwester ein zügelloses Hervorbrechen weiblicher Charakterschwächen wie Eifersucht und ein übersteigertes Geltungs- wie Machtbedürfnis evozierten. ${ }^{60}$ Ein moderateres Bild von der Kaiserschwester

Quellenkritische Untersuchungen zum dynastischen Potential, zur Darstellung und zu Handlungsspielräumen von Kaiserfrauen im Prinzipat. Bonn 2009, S. 191 und Anm. 111.

55 Aufschlussreich erweist sich das numismatische Material, auf dem von allen Töchtern M. Aurels ausschließlich Lucilla Berücksichtigung findet. Vgl. die Beispiele in Anm. 52.

56 Vgl. Dio 73,4,5 (Xiph.); H.A. Comm. 4,4; 5,7f.

$57 \mathrm{Zu}$ den Datierungsschwierigkeiten vgl. Hekster, Olivier: Commodus. An emperor at the crossroads. Amsterdam 2002, S. 52.

58 Eine Ausnahme bildet die Schilderung des Ammianus Marcellinus $(29,1,17)$, in der Lucilla keine Erwähnung findet. Dazu vgl. Hekster: Commodus, S. 53, Anm. 76.

59 Vgl. Dio 73,4,3-6,1 (Xiph.); Herodian. 1,8,4-6. Zur Deutung von Lucillas vermeintlichem Neid und Ehrgeiz als topische Elemente konkurrierender Kaiserfrauen vgl. Priwitzer: Faustina, S. 192 und Anm. 116. Bereits ihren ersten Ehemann L. Verus soll Lucilla aus Eifersucht zu dessen Schwester ermordet haben, vgl. H.A. Ver. 10,3-5.

60 Lucillas moralische Verwerflichkeit wurde durch den Vorwurf des Ehebruchs mit dem Schwiegersohn (Dio 73,4,4 [Xiph.]) und M. Ummidius Quadratus (Herodian. 1,8,4), einem Verwandten und Hauptbeteiligten der Verschwörung, noch unterstrichen. Nach 
zeichnet nur die Historia Augusta. In diesem spätantiken Geschichtswerk tritt Lucilla in Reaktion auf den despotischen Herrschaftsstil ihres Bruders als aktive Mitverschwörerin neben dem ihr verwandtschaftlich verbundenen Senator M. Ummidius Quadratus sowie dem Gardepräfekten Tarrutenius Paternus in Erscheinung. Vor dem Hintergrund des von Commodus bewirkten staatsbedrohenden Zustands, den alle drei Personen mithilfe ihrer Tat zu beenden trachteten, erfährt deren gemeinsame Handlung zwangsläufig eine positive Konnotation. ${ }^{61}$

Als Gemeinsamkeit aller drei antiken Schilderungen erweist sich schließlich die Beschreibung der Umsetzung des Anschlagplans, den Lucilla mittels des bewussten Rückgriffs auf männliche Verbündete aus ihrer familiären Umgebung zu realisieren suchte. Sie selbst tritt dem Betrachter als souveräne Frau entgegen, die im Wissen um ihre Position innerhalb der domus Augusta eine Veränderung auf dem Kaiserthron zu bewirken beabsichtigt, auch wenn dies unweigerlich den Sturz des eigenen Bruders zur Folge haben musste. Noch stärker als zuvor bei Agrippina (minor) und Livilla unter Caligula lassen sich damit anhand von Lucillas Person die weitreichenden Handlungsoptionen einer Kaiserschwester aufzeigen. ${ }^{62}$ Nichtsdestotrotz unterlag schließlich auch ihre Darstellung einer literarischen Funktionalisierung, die in erster Linie auf die Negativzeichnung des Bruders abzielte. Dessen grausames Gebaren gegenüber der leiblichen Schwester sowie die ausbleibende Unterbindung der in seiner domus vorherrschenden Disharmonie stellten bevorzugte topische Elemente dar, die der exemplarischen Bestätigung seiner Tyrannenhaftigkeit entsprachen. ${ }^{63}$

\section{Fazit}

Im römischen Principat kam der Schwester des Kaisers eine exponierte Stellung innerhalb der domus Augusta zu, die ihr eine entscheidende gesellschaftspolitische Position im Machtgefüge zu eröffnen vermochte. Neben dem Erlangen diverser Ehrerweise und Privilegien mit zum Teil weitreichenden Gestaltungs-

Dio (73,4,5 [Xiph.]) gebärdete sich Lucilla demnach ,ebenso wenig einwandfrei und sitt-

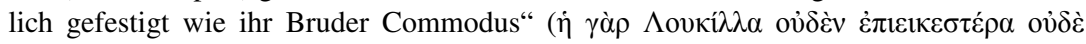

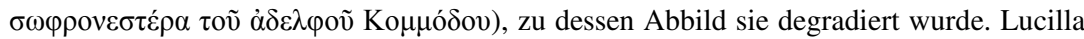
und Commodus erscheinen damit als negatives Pendant zu Marciana und Traian, die in ihrer Ebenbürtigkeit die römischen Wertvorstellungen mustergültig verkörperten, womit sie dem gesamten Reich zum Wohle gereichten.

61 H.A. Comm. 4,1-4. Zur Darstellung der Verschwörung und den involvierten Personen in der Historia Augusta vgl. Wallinger: Historia Augusta, S. 66-69. Zur staatsnutzenden Stilisierung der Tat vgl. Priwitzer: Faustina, S. 158.

62 Vgl. Hekster (Commodus, S. 25), der auf die Gefahren der verwandtschaftlichen Bande im Kaiserhaus für die Princepsstellung aufmerksam macht.

63 Detailliert dazu Priwitzer: Faustina, S. 108-159, insb. S. 122-126. 
optionen schloss dies konkrete Pflichten für die Frauen ein, die jedoch an die individuellen Kaiservorstellungen einer bestimmten Herrschaftspraxis geknüpft waren. Mit der Betrachtung der unterschiedlichen Fallbeispiele lassen sich dennoch wiederkehrende Rollenzuweisungen aufzeigen, die in ihrer Musterhaftigkeit eine zeitenübergreifende und personenunabhängige Konstante aufweisen.

Als Repräsentantin der höchsten domus kam der Kaiserschwester in erster Linie eine Vorbildfunktion zu. Über eine sittenkonforme Handlungs- und Verhaltensweise trug sie wesentlich zur Stärkung der kaiserlichen auctoritas bei, auf der die herrschaftliche Legitimation vornehmlich basierte. Für die gesamte Spanne des betrachteten Zeitraums erwiesen sich die idealisierten Wert- und Tugendgrundsätze der Republik hierfür als normgebend. Das Ansehen der Kaiserschwester erfuhr durch die Übertragung zusätzlicher Auszeichnungen und Sonderrechte eine eindrucksvolle Steigerung, was sich wiederum auf die gesamte domus Augusta glorifizierend auswirkte. Selbst die postume Ehrung ließ sich noch gewinnbringend für den brüderlichen Principat gestalten, so dass sie im Fall ihrer consecratio sogar einen göttlichen Herrschaftsanspruch evozierte.

Der sichtbarste Ausweis einer übergeordneten Signifikanz der Kaiserschwester lag jedoch in ihrer dynastischen Wirkmächtigkeit, die ihr aus derselben Abstammung und Blutsverwandtschaft zum Princeps erwuchs und sie vor allen anderen Kaiserfrauen auszeichnete. Mit der Funktionalisierung dieses Potenzials ergab sich aus Kaiserperspektive eine ambivalente Situation: Eine positive Vereinnahmung lag vor, wenn der Bruder in Ermangelung leiblicher Abkömmlinge alternativ auf den schwesterlichen Nachwuchs zurückgriff, um auf diese Weise eine Herrschaftskontinuität über die eigene gens zu gewährleisten. Negativ erwies es sich hingegen, wenn sich die Kaiserschwester ihrer herrschergeschlechtlichen Qualifikation in Abhängigkeit männlicher Unterstützung bemächtigte und den Bruder durch bewusstes Opponieren in dessen unmittelbarer Existenz bedrohte. Insbesondere letzteres zeigt deutlich, dass eine einvernehmliche Geschwisterbeziehung im Kaiserhaus stets eine Grundvoraussetzung für stabile Herrschaftsverhältnisse bildete, auch wenn diese keinen umfassenden Schutz vor eventuellen Usurpationsversuchen bieten konnte.

Insgesamt ist damit wiederholt auf die außerordentliche Relevanz der kaiserlichen Schwester verwiesen. Von allen Beteiligten, an erster Stelle vom Kaiser selbst, wurde sie in dieser Wertigkeit wahrgenommen, deren ausgreifende Geltungsmöglichkeiten sich in einem Zeitraum von 200 Jahren nicht wesentlich wandelten. Vielmehr erlaubte die zunehmende Systemfestigung des Principats ein vielgestaltigeres Angebot, die Kaiserschwester zweckdienlich in der Öffentlichkeit zu inszenieren, was diese andererseits befugte, die ihr gebotenen Handlungs- und Gestaltungsspielräume in ihrem kapazitären Gehalt bis zum 
Letzten auszuschöpfen. Damit war die Spannweite von Macht auf der einen und Ohnmacht auf der anderen Seite für jede Kaiserschwester praktisch vorgegeben, innerhalb derer die individuelle Ausgestaltung die einzelnen Schwesternpersönlichkeiten in ihrer Einzigartigkeit kennzeichnete.

\section{Literatur}

Alexandridis, Annetta: Die Frauen des römischen Kaiserhauses. Eine Untersuchung ihrer bildlichen Darstellung von Livia bis Iulia Domna. Mainz 2004.

Barrett, Anthony A.: Agrippina. Sex, Power, and Politics in the Early Empire. London 1996.

Brandt, Hartwin: Marcellus „,successioni praeparatus“? Augustus, Marcellus und die Jahre 29-23 v. Chr., in: Chiron 25 (1995), S. 1-17.

Fischer, Robert A.: Fulvia und Octavia. Die beiden Ehefrauen des Marcus Antonius in den politischen Kämpfen der Umbruchszeit zwischen Republik und Principat. Berlin 1999.

Hahn, Ulrike: Die Frauen des römischen Kaiserhauses und ihre Ehrungen im griechischen Osten anhand epigraphischer und numismatischer Zeugnisse von Livia bis Sabina. Saarbrücken 1994.

Harders, Ann-Cathrin: Suavissima Soror. Untersuchungen zu den Bruder-SchwesterBeziehungen in der römischen Republik. München 2008.

Hekster, Olivier: Commodus. An emperor at the crossroads. Amsterdam 2002.

Hemelrijk, Emily A.: Matrona Docta. Educated women in the Roman élite from Cornelia to Julia Domna. London u.a. 1999.

Kunst, Christiane: Die Rolle der Römischen Kaiserfrau. Eine Einleitung, in: dies.; Riemer, Ulrike (Hrsg.): Grenzen der Macht. Zur Rolle der römischen Kaiserfrauen. Stuttgart 2000, S. 1-6.

Kunst, Christiane: Frauenzimmer in der römischen domus, in: Harich-Schwarzbauer, Henriette; Späth, Thomas (Hrsg.): Gender Studies in den Altertumswissenschaften. Räume und Geschlechter in der Antike. Trier 2005, S. 111-131.

Kunst, Christiane: Livia. Macht und Intrigen am Hof des Augustus. Stuttgart 2008.

Meise, Eckhard: Untersuchungen zur Geschichte der Julisch-Claudischen Dynastie. München 1969.

Priwitzer, Stefan: Faustina minor - Ehefrau eines Idealkaisers und Mutter eines Tyrannen. Quellenkritische Untersuchungen zum dynastischen Potential, zur Darstellung und zu Handlungsspielräumen von Kaiserfrauen im Prinzipat. Bonn 2009.

Roche, Paul A.: The public image of Trajan's family, in: Classical Philology [CPh] 97 (2002), S. 41-60.

Sandels, Friedrich: Die Stellung der kaiserlichen Frauen aus dem julisch-claudischen Hause. Darmstadt 1912.

Seelentag, Gunnar: Taten und Tugenden Traians. Herrschaftsdarstellung im Principat. Wiesbaden 2004.

Späth, Thomas: ,Frauenmacht" in der frühen Kaiserzeit? Ein kritischer Blick auf die Konstruktion der ,Kaiserfrauen', in: Dettenhofer, Maria H. (Hrsg.): Reine Männersache? Frauen in Männerdomänen der antiken Welt. Köln u.a. 1994, S. 159-205. 
Temporini, Hildegard: Die Frauen am Hofe Trajans. Ein Beitrag zur Stellung der Augustae im Principat. Berlin, New York 1978.

Wallinger, Elisabeth: Die Frauen in der Historia Augusta. Wien 1990.

Watkins, Thomas H.: Colonia Marciana Traiana Thamugadi: Dynasticism in Numidia, in: Phoenix 56 (2002), S. 84-108.

Winterling, Aloys: Caligula. Eine Biographie. 3. Aufl., München 2004.

Wood, Susan E.: Diva Drusilla Panthea and the Sisters of Caligula, in: American Journal of Archaeology [AJA] 99, 3 (1995), S. 457-482. 
Ulrike Schneider, Helga Völkening and Daniel Vorpahl - 978-3-653-98812-3

Downloaded from PubFactory at 01/11/2019 10:54:37AM

via free access 


\title{
Adlige Geschwisterbeziehungen im 18. und 19. Jahrhundert - Ideale und gelebte Praxis
}

\author{
Denise von Weymarn-Goldschmidt
}

\begin{abstract}
This article discusses the rarely examined horizontal aspects of family history, the interrelation of siblings within the Baltic German Nobility of the 18th and 19th century. It highlights their pragmatic approach to (illegitimate) half-, step- and foster-siblings. The examination of egodocuments reveals how the actual relationships differed from a social ideal.
\end{abstract}

\section{Einleitung}

Da ich neben Amalie immer die Inferiore war und schlechte deutsche Aufsätze über die meine unreife Entwicklung übersteigenden Themen schrieb, die Papa mit Missfallen las, so hielt er mich überhaupt für ganz untüchtig in Schulsachen. Das kränkte mich weniger als meinen für mich so eingenommenen Bruder. ${ }^{1}$

Das obige Zitat von Ida Baronin Wrangell ist typisch und atypisch zugleich: Typisch, weil es Aussagen über ein Vater-Kind-Verhältnis macht, atypisch, weil selten so viele Informationen in so wenigen Zeilen über Geschwisterbeziehungen enthalten sind. Ganz deutlich artikuliert sie das Gefühl, neben der (älteren) Schwester Amalie minderwertig zu sein und verweist nebenbei auf eine emotionale Verbundenheit mit dem (jüngeren) Bruder Nikolai, der wiederum unter der Zurücksetzung der Schwester leidet. Basierend auf Selbstzeugnissen deutschbaltischer Adliger ${ }^{2}$ geht der folgende Aufsatz der Frage nach, wer im Adel zu den Geschwistern gezählt wurde. In einem zweiten Schritt wird das soziokulturelle Ideal der Geschwisterbeziehung im 18. und 19. Jahrhundert den tatsächlich gelebten Formen gegenübergestellt. Die Untersuchung der horizontalen Beziehungsebene der Geschwister erlaubt einen weiteren Blick auf das zeitgenössische Familienverständnis, das bis dahin beinahe ausschließlich vertikal betrachtet wurde.

Wie verbreitet die vertikale Sichtweise ist, zeigt etwa ein Blick in das Lexikon der Geschichtlichen Grundbegriffe. Auf 48 Seiten werden dort unter dem

1 Aus den Erinnerungen der Ida Baronin Wrangell (ca. 1843-1925 od. 1926), enthalten in Andronikow, Fürst Wladimir: Margarethe von Wrangell. Das Leben einer Frau 18761932. Aus Tagebüchern, Briefen und Erinnerungen. München 1935, S. 21.

2 Die russischen Ostseeprovinzen Estland, Livland und Kurland, die den Territorien der heutigen Staaten Estland und Lettland entsprechen, wurden von einer deutschsprachigen lokalen Herrscherschicht verwaltet, welche den deutschbaltischen Adel bildete. Ein ausführlicher Überblick bietet Pistohlkors, Gert von (Hrsg.): Baltische Länder. Berlin 1994. 
Lemma ,Familie' etliche Familienkonstellationen behandelt, wobei die unterschiedlichsten rechtlichen Verpflichtungen von Ehemann und Ehefrau in den verschiedenen Epochen sowie die Rechte und Pflichten gegenüber ihren Kindern betrachtet werden. ${ }^{3}$ Das Wort Geschwister fällt im ganzen Artikel nicht, noch existiert ein eigener Eintrag, Geschwister'. Ähnlich sieht es in anderen historischen Arbeiten der letzten dreißig Jahre aus: Heiratsstrategien und das Eltern-Kind-Verhältnis wurden untersucht, die Kindersterblichkeit, das generative Intervall, die Anzahl der Kinder oder die Erziehung und Ausbildung derselben. Die innerfamiliäre horizontale Beziehungsebene, die Geschwisterebene, gelangt nur selten in den Fokus: Wenn doch, dann handelt es sich häufig um Bruder-Bruder-Konflikte in Sukzessionsfragen oder um berühmte Männer und der Einfluss ihrer mehrheitlich unbekannten Geschwister. ${ }^{4}$

Im deutschen Sprachraum wurden bisher kaum Geschwisterbeziehungen unter historischer Perspektive betrachtet. Die Entwicklungspsychologie befasst sich seit den 1980er Jahren im angloamerikanischen, seit den 1990ern Jahren im deutschen Raum ${ }^{5}$ ausgiebig mit dieser Thematik, doch galten im 18. und 19. Jahrhundert andere Beziehungsstrukturen und Persönlichkeitskonzepte, so dass die aktuellen Erkenntnisse nicht ohne weiteres übernommen werden können. ${ }^{6}$ Hilfreiche Anregungen bieten gewisse ethnologische Studien, die Verwandtschaftssysteme aufzeigen wie den Kindertausch, Ehen unter Verwandten

3 Vgl. Schwab, Dieter: Familie, in: Brunner, Otto u.a. (Hrsg.): Geschichtliche Grundbegriffe. Historisches Lexikon zur politisch-sozialen Sprache in Deutschland. Bd. 2. Stuttgart 2004, S. 253-301.

4 Zum Beispiel skizziert Rosine De Dijn das Leben von Großmutter, Mutter, Tante, Schwester, Gemahlin und unehelicher Tochter von Karl V. Dijn, Rosine De: Des Kaisers Frauen. Eine Reise mit Karl V. von Flandern durch Deutschland bis in die Estremadura. Stuttgart 1999. Susanne Knackmuss berichtet von den Beziehungen des Humanisten Willibald Pirckheimer (1470-1530) zu seinen verschiedenen Schwestern im Kloster. Knackmuss, Susanne: „Meine Schwestern sind im Kloster ...“. Geschwisterbeziehungen des Nürnberger Patriziergeschlechts Pirckheimer zwischen Klausur und Welt, Humanismus und Reformation, in: Historical Social Research, Vol 30, No. 3 (2005), S. 80-106.

5 Vgl. Frei Gerlach, Franziska: Geschwister. Ein Dispositiv bei Jean Paul und um 1800. Berlin, Boston 2012, S. 36.

6 Persönlichkeitskonzepte sind kulturell und historisch zu kontextualisieren. Die Psychologie arbeitet mit dem Bewussten, Vorbewussten und Unbewussten respektive Ich, Es und Über-Ich Konzepte, die auf Sigmund Freud zurückgehen. Kritik an einer Anwendung von Freudschen Konzepten an einer vorfreudschen Gesellschaft übt Greyerz, Kaspar von: Ego-Documents: The Last Word?, in: German History (2010), Vol. 28, S. 273-282, hier S. 280. Ähnliche Überlegungen siehe auch Ruppel, Sophie: Verbündete Rivalen. Geschwisterbeziehungen im Hochadel des 17. Jahrhunderts. Köln 2006, S. 21 oder Bähr, Andreas u.a.: Räume des Selbst. Eine Einleitung, in: ders. u.a. (Hrsg.): Räume des Selbst. Selbstzeugnisforschung transkulturell. Köln u.a. 2007, S. 1-12, hier S. 3. 
oder die systematische Bevorzugung eines Geschlechts ${ }^{7}$ - Phänomene, die auch in westlichen Gesellschaften verbreitet waren.

Dass Geschwisterbeziehungen jenseits der Kunst und Mythologie ${ }^{8}$ bis heute nicht näher betrachtet werden, überrascht, handelt es sich doch hierbei um eine fundamental wichtige menschliche Beziehung. In Adelsfamilien stellte sie oft die primäre emotionale Verbindung dar, welche die Kinder in ihren Familien erlebten; ${ }^{9}$ Familien, die durch Ehearrangements zustande gekommen waren und von Leitideen wie Gehorsam, Repräsentation und Pflichten geprägt waren. Von Liebe zu den Eltern wurde zwar gesprochen, doch wurde darunter primär Respekt verstanden und nicht zwingend emotionale und schon gar nicht körperliche Nähe. Dass sich Historiker und Historikerinnen wenig mit Geschwisterbeziehungen beschäftigen, hängt nicht zuletzt mit der schlechten Quellenlage zusammen. Zeugnisse von Kindern sind rar und spiegeln oft die Handschrift der Erzieher wider, etwa wenn den Kindern vorgegeben wurde, wie ein Brief formgerecht aufzusetzen war. Doch Geschwisterschaft bezieht sich nicht nur auf die Kindheit, sie dauert ein Leben lang und kann selbst über den Tod des einzelnen hinaus als Vorstellung wichtig bleiben. ${ }^{10}$ Mit der Definition der Geschwisterschaft als einer lebenslänglichen Beziehung verbessert sich die Ausgangslage für die Quellensuche. Hier bieten sich Selbstzeugnisse an. Selbstzeugnisse sind Dokumente, die über das Leben des Autors oder der Autorin Auskunft geben und von ihm bzw. ihr selbst verfasst oder diktiert wurden. Die gängigsten Formen sind Briefe, Tagebücher, Autobiographien aber auch Testamente und in einem sehr breiten Verständnis Zeugenaussagen in Gerichtsakten. ${ }^{11}$ Gerade Tagebücher, Autobiographien oder Briefe scheinen geeignet, sich den gelebten

7 Vgl. ausführlicher Ruppel: Rivalen, S. 15-21.

8 Verschiedene Kulturen führen die Entstehung der Menschheit auf ein Geschwisterpaar zurück. Legendär sind die Geschwisterkonflikte der griechischen und römischen Götter.

9 Vgl. Ruppel: Rivalen, S. 11. Dies ist die einzige der Verfasserin bekannte deutsche Monographie zu Geschwistern.

10 So feierte Elisa von der Recke den Geburtstag ihres Bruders noch lange nach seinem Tod. Wiederholt schlossen sich auch Freunde dieser Gedenkfeier an. Siehe die Aufzeichnungen in: Träger, Christine (Hrsg.): Elisa von der Recke: Tagebücher und Selbstzeugnisse. Leipzig 1984.

11 Zum Umgang mit Selbstzeugnissen siehe etwa Claudia Ulbrich oder Kaspar von Greyerz. Krusenstjerns Aufsatz zeigt die ganze Bandbreite an möglichen Formen der Quellengattung der Selbstzeugnisse. Ihre grundlegenden Überlegungen lassen sich problemlos auf das 18. und 19. Jahrhundert übertragen. Vgl. Krusenstjern, Benigna von: Selbstzeugnisse der Zeit des Dreißigjährigen Krieges. Beschreibendes Verzeichnis. Berlin 1997, insb. S. 18. 
Beziehungen von Geschwistern anzunähern. Autobiographien ${ }^{12}$ bieten hierbei den Vorteil, dass sie Veränderungen von Beziehungen aufzeigen. In der rückblickenden reflektierten Aufzeichnung eines Lebens wird die besondere positive oder negative - Rolle einzelner Personen deutlich. Dem gegenüber stehen Tagebücher, welche die momentanen Befindlichkeiten wiedergeben, Befindlichkeiten, die auch Gedanken, welche dem geltenden Ideal widersprechen, enthalten können, insbesondere wenn die Tagebücher nicht für eine Veröffentlichung gedacht waren. Gerade weil die Geschwisterschaft als eine lebenslängliche Beziehung verstanden wird, müssen die Selbstzeugnisse nicht eine ganze Lebensspanne abdecken. Selbst Dokumente, die nur eine kurze Zeitspanne umfassen, können aussagekräftig sein. Deshalb sind für die Auswertung auch Dokumente brauchbar, die nur gewisse Lebensabschnitte beschreiben. Da die relativ überschaubare Gruppe der deutschbaltischen Adligen ein vielfältiges, meist unveröffentlichtes, autobiographisches Schrifttum hinterlassen hat, wurden für den vorliegenden Artikel Zeugnisse dieser wenig bekannten Gruppe ausgewertet.

\section{Wer wird zu den Geschwistern gezählt?}

Der Begriff der Geschwister ist mit jenem der Familie verbunden. Betrachtet man westliche Adelsfamilien, so kommen Konzepte vom „Ganzen Haus“", ${ }^{13}$ die sämtliche Bewohner eines Hauses zur Familie zählen, nicht in Frage, denn ein wesentliches Merkmal dieser Schicht war die deutliche Abgrenzung von den arbeitenden Schichten, so dass auf der nominellen Ebene keine statusniedrigeren Personen zur Familie gezählt wurden. Anders konnte das auf der emotionalen Ebene aussehen; dort konnten durchaus statusniedrigere Leute wie ein altgedientes Kindermädchen zur Familie zugehörig empfunden werden. Margaretha

12 Weil sie eine zusätzliche Perspektive ermöglichen, sind Autobiographien von Laien für den Historiker genauso aussagekräftig wie die Zeugnisse von Prominenten. Diese Einschätzung steht jener von Philippe Lejeune gegenüber. Lejeune vertritt die Meinung, der Leser einer Autobiographie müsse den Text in den anderen Schriften dieses Autors verorten können, was seine Aussagekraft steigern würde. Den Autobiographien von unbekannten Autoren fehle der Bezugsrahmen, so Lejeune. Vgl. Lejeune, Philippe: Der autobiographische Pakt, in: Niggl, Günter: Die Autobiographie. Zu Form und Geschichte einer literarischen Gattung. Darmstadt 1989, S. 214-257, hier S. 227.

13 Das Konzept des „Ganzen Hauses“ basiert auf Otto Brunners Aufsatz: Das „ganze Haus“ und die alteuropäische „Ökonomik“, in: ders. Neue Wege der Verfassungs- und Sozialgeschichte. Göttingen 1968, S. 103-127. Eine kurze und prägnante Kritik hat etwa Claudia Opitz verfasst. Opitz, Claudia: Neue Wege der Sozialgeschichte? Ein kritischer Blick auf Otto Brunners Konzept des ,Ganzen Hauses', in: Geschichte und Gesellschaft. Zeitschrift für historische Sozialwissenschaft 20 (1994), S. 88-98. 
Hildebrandt, eine Schneiderstochter, die von allen nur Haninka genannt wurde, war während 50 Jahren im Hause von Jenny von Vegesacks Großeltern und Eltern tätig. Zu ihrem 80. Geburtstag schenkten ihr Jenny und ihre Geschwister zwei goldene Kerzenständer. Auf dem einen standen die innerfamiliären Rufnamen aller Jungen, auf dem anderen diejenigen der Mädchen. Als Haninka starb, gab Jennys ältester Bruder eine Todesanzeige auf. ${ }^{14}$ Die heutige Definition der Kernfamilie - Mutter, Vater und gemeinsame Kinder - wird den Verhältnissen im 18. und 19. Jahrhundert auch nicht gerecht. Zu berücksichtigen gilt, dass in diesem Zeitraum noch eine viel höhere Sterblichkeit herrschte, jede Krankheit konnte tödliche Folgen haben und Mütter im Kindbett waren besonders gefährdet. Weil jemand die Rolle der verstorbenen Frau übernehmen musste, heirateten verwitwete Väter in der Regel relativ schnell wieder. Aus diesem Kontext heraus kam es häufig zu dem heute sogenannten Phänomen der „Patchworkfamilien“. Stiefmütter, Halbgeschwister und Stiefgeschwister waren keine Seltenheit. Hier ist auf einen unterschiedlichen Sprachgebrauch der analytischen Begriffe Stief- und Halbgeschwister bei Sophie Ruppel und der Autorin hinzuweisen. Werden die beiden Konstellationen im Sprachgebrauch der Verfasserin und der Schweiz klar getrennt, fallen sie bei Ruppel zusammen. ${ }^{15}$ Im Folgenden werden unter Halbgeschwistern Kinder verstanden, die nur einen gemeinsamen Elternteil haben. Stiefgeschwister hingegen stammen aus früheren Ehen des neuen Ehepaares und sind nicht direkte Blutsverwandte. Da im Adel Ehen zwischen Vettern und Cousinen vielfach als unproblematisch betrachtet wurden, können Stiefgeschwister natürlich auf entfernteren Wegen miteinander verwandt sein. Die unterschiedlichen Verwendungsweisen zeigen sich auch in den entsprechenden Artikeln in Zedlers Grossem vollständigem Universallexicon aller Wissenschaften und Künste von 1731-1754. Dort werden unter dem Lemma ,Halb-Bruder' Halb- und Stiefbrüder gleichgesetzt, während im Artikel ,Schwester“ „Stiefschwestern“ aufgeführt und als Personen, ,,welche sowohl unterschiedliche Väter, als Mütter haben“ definiert werden. ${ }^{16}$ Die Unterscheidung in Voll-, Halb- und Stiefgeschwister ist eine analytische Unterscheidung, die in den Quellen selbst nicht immer vorgenommen wird, doch in der Regel rekonstruierbar ist. Sollen die gemeinsamen Eltern betont werden, so wird in den

14 Vgl. DSHI 110 Campenhausen 591: Jenny von Vegesack, Bilder der Vergangenheit. Ca. 1920, S. 20 u. 23.

15 Vgl. Ruppel: Rivalen, S. 171-176.

16 Das Universallexicon von Zedler ist ein Sammelwerk verschiedenster Autoren, weshalb der unterschiedliche Sprachgebrauch leicht zu erklären ist. Leider sind die jeweiligen Verfasser der Artikel nicht aufgeführt, so dass man keine Rückschlüsse über ihre Herkunft ziehen kann. Zedlers Grosses vollständiges Universallexicon aller Wissenschaften und Künste (1731-1754). Bd. 12, Sp. 228 und Bd. 36, Sp. 480. 
Selbstzeugnissen von leiblichen Geschwistern gesprochen. Die Differenz kann also im Bedarfsfall aktiviert werden. In den Tagebüchern und autobiographischen Schriften des deutschbaltischen Adels werden Halbgeschwister entweder unspezifisch als Geschwister oder aber als Stiefgeschwister bezeichnet. Dass die Unterscheidung Halb- und Stiefgeschwister nicht gemacht wird, überrascht, hat der Unterschied doch weitreichende erbrechtliche Konsequenzen.

Neben Halb- und Stiefgeschwistern existierten noch Pflegegeschwister. Im Todesfall eines Elternteils wurden Kinder häufig zu Verwandten gegeben, bis sich die Situation in der Herkunftsfamilie geklärt hatte. ${ }^{17}$ Auch zu Erziehungszwecken wurden Kinder teilweise mehrere Jahre bei Verwandten untergebracht. Dabei konnte es durchaus vorkommen, dass ein Onkel oder eine Tante einen Neffen oder eine Nichte zur Erziehung einforderte, so etwa Fürst Michael Barclay de Tolly, der seine Schwestertochter Auguste Christine von Lueder zur Erziehung in sein Haus nehmen wollte, weil er selbst keine Tochter hatte. ${ }^{18}$ Diese Einforderungen waren in der Regel an das Versprechen gekoppelt, den Kindern eine bessere Zukunft zu bieten. Je nach Stellung der Eltern gegenüber diesem Bruder oder dieser Schwester konnte so eine Forderung nicht ohne weiteres abgelehnt werden.

Wer soll nun alles zur adligen Kernfamilie gezählt werden? Für dieses Problem bieten sich Ansätze aus der Netzwerkanalyse, ${ }^{19}$ wie sie in der Soziologie verbreitet sind, an. Aus den Selbstzeugnissen wird das Familienverständnis der Autorinnen und Autoren rekonstruiert, indem man alle Personen erfasst, die als Familienmitglieder, insbesondere als Geschwister, genannt werden. In den Autorenbenennungen wird ersichtlich, ob der Autor bzw. die Autorin Halb-, Stief-, illegitime Halbgeschwister oder Pflegegeschwister als zur Familie zugehörig oder nicht zugehörig auffasste. Dieses Familiennetz muss weder mit dem Stammbaum noch mit juristischen Definitionen übereinstimmen. Es können Familienzweige fehlen, weil Verwandte aufgrund eines Fehlverhaltens ausgeschlossen wurden, gleichzeitig können Personen auftauchen, die nicht blutsverwandt sind, aber trotzdem eine wichtige Rolle für die Familie spielen. Dieses Netzwerk gibt aber nicht nur über die Ebene der Schreibenden und ihrer Geschwister Auskunft, sondern auch über jene der Eltern; dann etwa, wenn Stiefoder Halbgeschwister der Eltern einfach als Onkel oder Tante bezeichnet werden. In gewissen Fällen gibt dieses Vorgehen selbst über die Geschwister-

17 Vgl. Whelan, Heide W.: Adopting to Modernity. Family, Cast and Capitalisme among the Baltic German Nobility. Köln 1999, S. 107.

18 Vgl. Weymarn, Auguste Christine von (geborene von Lueder): Erinnerungen aus meinem Leben. Druckort unbekannt, wahrscheinlich 1887.

19 Zur Einführung siehe etwa Jansen, Dorothea: Einführung in die Netzwerkanalyse. Grundlagen, Methoden, Forschungsbeispiele. Wiesbaden 2006. 
beziehungen der Großeltern Auskunft. Gerade bei großem Altersunterschied zwischen leiblichen Brüdern und Schwestern der Großeltern oder zu ihren Halbgeschwistern konnten diese als Groß(stief)onkel respektive Groß(stief)tante noch immer eine Rolle spielen.

Anhand von multiplexen Netzwerken sollen die Geschwisterbeziehungen näher betrachtet werden. Aus der ersten Ebene, der Benennung der Familienmitglieder, wird deutlich, wer als Geschwister aufgefasst wurde, und zwar in der eigenen wie auch der elterlichen und großelterlichen Generation. Über dieses Familiennetz wird ein zweites aufgespannt, indem danach gefragt wird, wen die Autoren um Rat oder um Hilfe bitten. Darüber wird ein drittes Netz gelegt, das die besonderen emotionalen Verbindungen aufzeigt. Ebene zwei und drei überschneiden sich vielfach; Nahestehende bittet man leichter um Hilfe. Trotzdem gibt es auch deutliche Unterschiede: Diese Abweichungen verdeutlichen diejenigen Beziehungen, die auf Rollenerwartungen basieren, etwa die Pflicht des Stammhalters, seine Geschwister standesgemäß auszustatten oder die Erwartungen an ledige Schwestern, sich in einem Haushalt der Familie nützlich zu machen. Fehlen gewisse Verbindungen, weil der Stammhalter nie um Rat oder Hilfe gebeten wurde respektive die ledige Schwester nie in einem familiären Haushalt mithalf, scheint die Geschwisterbeziehung nach zeitgenössischem Verständnis gestört zu sein. Eine Ausgangslage kann noch so gut erscheinen und muss trotzdem nicht zu einem freundschaftlichen Geschwisterverhältnis führen: Christoph von Campenhausen war bereit, für seinen 31 Jahre jüngeren Halbbruder Balthasar die Patenschaft zu übernehmen und legte damit die Basis für eine enge Beziehung. Nach dem Tod des Vaters wurde er Balthasars Vormund. Trotz dieser doppelten Funktion scheint das Verhältnis sehr distanziert gewesen zu sein, nennt Balthasar Christoph in seinem Tagebuch doch nur „mein Bruder, der $\mathrm{H}$ [err] Regierungsrath“. Auf der ersten Ebene haben wir hier eine klare Benennung des Halbbruders als Bruder. Auf der zweiten Ebene des Rats und der Verpflichtungen erfolgt die Übernahme der Vormundschaft für die jungen Halbgeschwister durch den Stammhalter. Die Übernahme der Patenschaft gehört zwar noch zur zweiten Ebene, stellt allerdings eine gute Voraussetzung für die dritte Ebene der emotionalen Verbindung dar. Doch erfolgt bei den Brüdern Campenhausen dieser Schritt nicht, was wohl am problematischen Verhältnis von Christoph und seiner Stiefmutter Juliana lag. ${ }^{20}$

20 Vgl. DSHI 110 Campenhausen 91: Ein Diarium so wohl von meinem Geschlecht als von meinen eigenen Geburt wie auch Was in meinem und meiner Familie Leb-Zeit an Merckwurdigkeiten vorgekommen. Geschrieben und aufgezeichnet von Helena Juliana von Campenhausen gebohrne von Straelborn, ca.1773; und DSHI 110 Campenhausen 


\section{Das Ideal der Geschwisterbeziehung}

Die Beziehung von Brïdern und Schwestern wird gesellschaftlich zum Archetypus der Beziehung zwischen Männern und Frauen stilisiert, allerdings als asexuelle Verbindung. Für die Gesellschaft des 19. Jahrhunderts bestand das ideale Geschwisterpaar jeweils aus einem Bruder und einer Schwester. ${ }^{21}$ Aber dass eine deutschbaltische Adlige acht Kinder gebar, kam immer wieder vor. Auch wenn normalerweise nicht alle Geschwister überlebten, hatten die meisten Familien immer noch mehr als zwei Kinder. Das Ideal bestand also neben den tatsächlichen Familienverhältnissen. Die Idealisierung des gemischtgeschlechtlichen Geschwisterpaares weist aber auch darauf hin, dass für eine gut funktionierende Gesellschaft beide Geschlechter mit den ihnen zugeschriebenen Eigenschaften relevant sind.

In ihrem Aufsatz über Geschwister als Metapher im Spätmittelalter verweist Gabriela Signori darauf, dass der (metaphorische) Gebrauch von Bruder und Schwester für eine Nähe, die Gleichheit impliziert, steht. Dem gegenüber steht der übertragene Gebrauch von Vater/Mutter respektive Tochter/Sohn, der ein Abhängigkeitsverhältnis verdeutlicht. ${ }^{22}$ Der norddeutsche Hochadel des 17. Jahrhunderts pflegte in seinen Briefen ausgiebig diese Metaphorik. Wer statusmäßig den gleichen Rang belegte, durfte, wenn man sich nahe stand, als Bruder oder Schwester bezeichnet werden. War diese Nähe nicht gegeben, griff man auf den Begriff des Cousins zurück. ${ }^{23}$ Diese Anrede verweist auf die Zugehörigkeit zur Adelsfamilie. Doch jenseits dieses hochadligen ritualisierten Gebrauchs haftete dem Begriff der Geschwister bereits im Spätmittelalter die Vorstellung der Gleichheit an. Eine Gleichheit, die relativ zu sehen ist und die immer wieder von den Faktoren „Geburtenrang“, „Geschlecht“ und „Ehestand“ beeinflusst wurde. Wurde allerdings keines der Geschwister über Maßen bevorzugt oder benachteiligt, d.h. sein Erbteil widersprach nicht den sozial anerkannten Regeln betreffend Geburtenrang und Geschlecht, akzeptierte eine Mehrheit der Geschwister diese nur bedingte Gleichheit. ${ }^{24}$

205: Abschrift des Tagebuchs Senateur Balthasar von Campenhausen 1757, 1761-1769, 1776-1783, 1791, 1793, hier 1757-1764.

21 Vgl. Davidoff, Leonore: Kinship as a Categorial Concept: A Case Study of Nineteenth Century English Siblings, in: Journal of Social History, No. 2 Kith and Kin: Interpersonal Relationships and Cultural Practices, Vol. 39 (Winter 2005), S. 441-428, hier S. 414.

22 Vgl. Signori, Gabriela: Geschwister: Metapher und Wirklichkeit in der spätmittelalterlichen Denk- und Lebenswelt, in: Historical Social Research, Vol. 30, No. 3 (2005), S. 15-30, hier S. 17.

23 Vgl. Ruppel: Rivalen, S. 66-73.

24 Vgl. Harris, Amy: That Fierce Edge: Sibling Conflict and Politics in Georgian England, in: Journal of Family History Vol. 37 (2012), S. 159 u. 167. 
Das soziokulturelle Ideal im Europa des 18. und 19. Jahrhunderts beschwört die Einigkeit unter den Geschwistern, die Schutz- und Absicherungsaufgabe des Stammhalters sowie die Unterstützung des Stammhalters durch die jüngeren Geschwister, auch wenn das schmerzliche Konsequenzen wie ein Eheverzicht zur Folge haben konnte. Trat eine Familie nicht geschlossen auf, konnten andere Familien diese Schwäche für ihre Interessen nutzen, womit wiederum ein Machtverlust der eigenen Familie drohte. Scherten einzelne Familienmitglieder aus der gesellschaftlichen Ordnung aus, drohte der ganzen Familie ein Reputationsverlust. Dass diese Einigkeit insbesondere zwischen Brüdern nicht immer gegeben war, zeigen die väterlichen testamentarischen Ermahnungen, individuelle Konflikte zum Wohle der Familie beizulegen oder gar nicht erst aufkommen zu lassen. ${ }^{25}$ Da Schwangerschaftsverhütung nicht toleriert war, wurden Kinder bis zum Ende der fruchtbaren Phase einer Frau gezeugt, was wiederum zu einem großen Altersunterschied zwischen den Geschwistern führen konnte. Dies konnte zur Folge haben, dass einige Geschwister gar nie längere Zeit zusammen unter einem Dach lebten, insbesondere, wenn die Ältesten Jungen waren und zu Ausbildungszwecken außer Haus weilten.

Das Ideal sieht die Vorherrschaft des Erstgeborenen vor, doch ist von einer doppelten Geburtenrangfolge auszugehen: einerseits diejenige der Jungen, andererseits diejenige der Mädchen. In den einzelnen Geburtenrangfolgen gilt ein Senioritätsprinzip, das aber bei ähnlich alten gegengeschlechtlichen Geschwistern situationsbedingt aufgebrochen und innerfamiliär gestaltet werden konnte. Solche Geburtenrangfolgen waren nicht stabil. Berücksichtigt man die Mortalitätsrate, so konnte sich die geschwisterliche Hierarchie über längere Zeit mehrfach verändern. ${ }^{26}$ Von besonders großem Einfluss war der Tod des Stammhalters. Oft ist die Rede vom Konfliktpotenzial, welches die Bevorzugung des erstgeborenen Sohnes gegenüber den Nachgeborenen in sich birgt. Doch war die Rolle des Stammhalters nicht immer beneidenswert: Von ihm wurde erwartet, dass er heiratet und Kinder zeugt, egal, ob er wollte oder nicht. Auch sollte er die Familiengüter übernehmen, völlig unabhängig von seinen landwirtschaftlichen oder verwalterischen Fähigkeiten. Mit dieser Situation sah sich die Familie Stenbock nach dem Tod des Großvaters konfrontiert. Als Majoratshof konnte das Gut nicht vom Gutsverwalter Nikolai Stenbock übernommen werden, sondern fiel an den ältesten Sohn seines ältesten verstorbenen Bruders. Der neue Majoratsherr, Eric Stenbock, war ein verschwenderischer, opiumsüchtiger junger Mann, der sich nicht im Geringsten für das Gut interessierte. Sowohl Nikolai als nicht erbberechtigter Sohn wie auch Eric als Stammhalter waren mit

25 Vgl. Ruppel: Rivalen, S. 52.

26 Vgl. Harris: Fierce Edge, S. 163.

Ulrike Schneider, Helga Völkening and Daniel Vorpahl - 978-3-653-98812-3 
ihren Rollen nicht glücklich: Doch die unterschiedlichen Lebenseinstellungen verhinderten eine pragmatische Lösung. ${ }^{27}$

Die beruflichen Wahlmöglichkeiten der nachgeborenen Söhne waren oft größer als jene der Erstgeborenen. Ihrem Stand entsprechend stand ihnen eine Offizierslaufbahn, eine Beamtenkarriere oder die Stelle eines Gutsverwalters bevor. In der zweiten Hälfte des 19. Jahrhunderts wurde vermehrt auch ein Studium toleriert. Starb nun der Erstgeborene, musste der Zweitgeborene seine Ziele aufgeben und die Verwaltung der väterlichen Güter übernehmen. Starb mit dem Stammhalter der einzige Sohn, verbesserten sich die Erb- und Heiratschancen der Töchter. Welche würde den passenden Kandidaten finden, dem man die Stammgüter mit in die Ehe geben konnte? Dies konnte zur Rivalität unter den Schwestern führen, denn die älteste Tochter erbte nicht zwingend das repräsentative Familiengut, wie das Beispiel der Familie von Wistinghausen zeigt, wo Schloss Leal (estnisch Lihula) an die drittgeborene Tochter Anna und ihren Mann Baron Buxhoeveden überging. ${ }^{28}$ Auch im Erwachsenenalter stehen Männer nicht automatisch über ihren Schwestern. Insbesondere ältere Schwestern, die mit einflussreichen Persönlichkeiten verheiratet waren, gaben ihr Mitspracherecht und ihren Einfluss in der Herkunftsfamilie nicht ohne Weiteres auf. Die effektive Geschwisterhierarchie unterlag somit einer steten Aushandlung. Obwohl man vom ältesten Bruder erwartete, dass er seine Schwestern ihrem Rang entsprechend verheiraten würde, bestanden erwachsene Geschwistergruppen nicht nur aus Verheirateten. Schwestern, die von Anfang an für die Pflege der Eltern bestimmt worden waren, finanzielle Engpässe, die dazu führten, dass gewisse Geschwister erst spät oder nie heiraten konnten, oder Witwenschaft führten dazu, dass zu den meisten Geschwistergruppen Alleinstehende gehörten. ${ }^{29}$

Ein großes Konfliktpotenzial zwischen Geschwistern bargen Erbschaften. Doch bereits vorher gab es immer wieder Rivalitäten, vor allem um die Gunst der Eltern wurde gebuhlt. ${ }^{30}$ Die untersuchten Quellen weisen in eine unerwartete Richtung, nämlich dass Mütter eher ihren ältesten Sohn bevorzugten, während für die Väter das Geschlecht des Lieblingskindes zweitrangig war. Ida Baronin Wrangell kommentierte die Situation folgendermaßen:

27 Vgl. Wistinghausen, Henning von (Hrsg.): Theophile von Bodisco. Versunkene Welten. Erinnerungen einer estländischen Dame. Weißenhorn 1997, S. 71-75.

28 Vgl. den Stammbaum zu Theophile von Bodisco, in: ebd. (Buchdeckel).

29 Vgl. Harris: Fierce Edge, S. 156.

30 Vgl. Wilhelmi, Anja: Lebenswelten von Frauen der deutschen Oberschicht im Baltikum (1800-1939). Eine Untersuchung anhand von Autobiografien. Wiesbaden 2008, S. 146.

Ulrike Schneider, Helga Völkening and Daniel Vorpahl - 978-3-653-98812-3 
In meiner ersten Kindheit glaubte ich, es sei höchst unglücklich und ungünstig, das mittelste Kind zu sein, und bis in das erwachsene Alter argumentierte ich: „Über das älteste Kind freuen sich die Eltern immer am meisten, und das jüngste wiederum bleibt der Liebling aller.“31

In ihrer Wahrnehmung spielte die Kategorie Geschlecht überhaupt keine Rolle. In die Ausbildung der Söhne wurde mehr investiert, dies stieß vor allem bei wissbegierigen gelehrsamen Schwestern auf wenig Verständnis und führte teilweise zu Neid auf den Bruder. Doch es gab auch Brüder, die das Potenzial ihrer Schwester erkannten und sie dann unterrichteten - mit oder ohne die Zustimmung der Eltern. Nikolai von Wrangell bereitete es sichtlich Vergnügen, seine Schwester Margarethe in die Algebra einzuführen. Seine Zufriedenheit drückte er mit der foppenden Bemerkung aus, sie sei nicht zu „knüppeldumm“332. Ebenfalls geschlechtlich beeinflusst war der Bewegungsdrang, den man den Kindern zugestand. Doch fällt in den autobiographischen Schriften deutschbaltischer Adliger aus der zweiten Hälfte des 19. Jahrhunderts auf, dass Frauen ebenfalls vom wilden gemeinsamen Herumtoben während des Sommeraufenthalts berichten. Strikt getrennt waren nur die Badezeiten. Kamen die Geschwister ins heiratsfähige Alter, beeinflusste die Anzahl der Bewerber die Position der einzelnen Schwestern, vor allem, wenn die jüngere Schwester mehr Bewerber als die ältere hatte. Die Anzahl der Bewerber spiegelte zu einem gewissen Teil die gesellschaftliche Akzeptanz der jungen Frau wider, was wiederum ihre innerfamiliäre Machtposition verändern konnte. Eine gute Partie mit einem höherstehenden Partner färbte zwar auf alle Geschwister positiv ab, brachte aber auch einen gewissen Leistungsdruck mit sich. Die geschiedene Elisa von der Recke beklagte sich in ihrem Journal wiederholt darüber, dass man von ihr, als der Schwester der Herzogin von Kurland, eine standesgemäße Garderobe und Haushaltung erwartete, gesellschaftliche Erwartungen, die Ausgaben verursachen, die sie sich in ihrer prekären finanziellen Situation nicht leisten könne. ${ }^{33}$ Die Aufforderung der Herzogin an Elisa, sie auf ihrer Reise zu begleiten, war als Gunstbeweis gedacht, wurde aber zur finanziellen Herausforderung, wollte es sich Elisa von der Recke nicht wieder mit ihrer jüngeren Halbschwester verscherzen.

31 Aus den Erinnerungen von Ida Baronin Wrangell, enthalten in Andronikow: Margarethe von Wrangell, S. 17. Kein Autor, keine Autorin sagt von sich selbst, dass er oder sie der Liebling von Mutter oder Vater gewesen sei. Es wird nur die Bevorzugung der andern erwähnt. Erst eine Summe von Einzelheiten lassen Rückschlüsse auf die Lieblingskinder von Mutter oder Vater zu - allerdings gebrochen durch die subjektive Wahrnehmung der Berichtenden.

32 Aus Briefen Daisy (Margarethe) Wrangells an Ebba Husen, enthalten in: ebd., S. 62.

33 Vgl. Träger: Elisa von der Recke.

Ulrike Schneider, Helga Völkening and Daniel Vorpahl - 978-3-653-98812-3 
In Diskursen zur Herrschaftsstruktur werden Familie und Reichsführung symbolisch gleichgesetzt. Eine wohl funktionierende Familie mit dem Hausherrn an der Spitze entspricht einem gut funktionierenden Reich mit König, Kaiser oder Zar an der Spitze. Die Familienangehörigen, vor allem Ehefrau und Kinder, stehen für die Reichsangehörigen. Verändert sich in breiten Kreisen die Gestaltung des Familienlebens, hat dies Auswirkungen auf das gesellschaftliche Leben und vice versa haben gesellschaftliche Reformen Auswirkungen auf das familiäre Leben. Exemplarisch sei hier auf die Veränderung der indirekten Anerkennung von illegitimen Kindern des deutschbaltischen Adels im 18. und 19. Jahrhundert verwiesen. ${ }^{34}$ - eine Zeit, in der es teilweise möglich war, illegitime Kinder zusammen mit ihren legitimen Halbgeschwistern zu erziehen. ${ }^{35}$ Einen anderen Weg wählten die Brüder Karl (1756-1816) und Joachim Otto von Tiesenhausen (1777-1813) mit ihren insgesamt neun illegitimen Kindern. ${ }^{36}$ Indem alle illegitimen Kinder den Familiennamen Hausen erhielten, gaben sie einen Hinweis auf die wahre Vaterschaft. Joachim Otto muss von den außerehelichen Kindern seines älteren Bruders gewusst haben, sonst hätte er nicht den gleichen Familiennamen gewählt. Mit dem frei gewählten, ähnlichen Familiennamen schufen sie gleichzeitig für die illegitimen Kinder eine eigene Familie. Im deutschbaltischen Adel bestand durchaus eine gewisse Erwartungshaltung, dass sich ein Vater um seine illegitimen Kinder zu kümmern habe. So schrieb Elisa von der Recke ihrer Freundin Mademoiselle Stoltz empört von den zerlumpten Bauernjungen, die Gänse und Schweine hüten und ihrem Mann sehr ähnlich sähen. Die Empörung bezog sich dabei auf ihren Mann, der die Jungen zerlumpt herumlaufen ließ. Zudem bemerkte sie, wären es Mädchen gewesen, hätte sie versucht, sie ins Haus zu nehmen. ${ }^{37}$ Sie wäre also bereit gewesen, die vorehelichen Kinder zusammen mit ihren legitimen Kindern zu erziehen. Dies stellt eine Lebensform dar, die durch das Aufkommen der romantischen Vorstellung der ,Liebesheirat' im 19. Jahrhundert und der damit verbundenen restriktiveren Sexualmoral in bürgerlichen Kreisen verpönt wurde. Als alte Frau schrieb

34 Vgl. Amburger, Erik: Erfundene Familiennamen für illegitime Kinder insbesondere in den baltischen Provinzen und in Russland, in: Jahrbücher für Geschichte Osteuropas, 41. Jhrg., Heft 4 (1993), S. 562-577.

35 Ein besonders eindrückliches Beispiel stellt Emilie Colline (1791-1893) dar, die in der Abwesenheit ihrer jüngeren legitimen Halbbrüdern, den von Bergs, das Familiengut leitete und die Familie vor Ort repräsentierte. Das französische „colline“ bedeutet wörtlich übersetzt „Hügel“, was als Entsprechung für das deutsche „Berg“ gesehen wird.

36 Vgl. Amburger: Familiennamen, S. 567.

37 Vgl. den Brief Elisa von der Reckes an Mademoiselle Stoltz, 6. Juli 1771, in: Rachel, Paul (Hrsg.): Elisa von der Recke. Aufzeichnungen und Briefe aus ihren Jugendjahren. Leipzig 1900, S. 194. 
Theophile von Bodisco während des Zweiten Weltkriegs ihre Erinnerungen nieder. Doch sie konnte noch immer ganz offen darüber sprechen, dass einer ihrer Onkel in erster Ehe mit der illegitimen Tochter des Grafen Berg verheiratet war und dass jene Tante eine ganz gräfliche Erziehung erhalten hatte. ${ }^{38}$ Weder die Tante noch die gemeinsame Tochter Adda, Theophiles Cousine, werden in den Erinnerungen in irgendeiner Weise wegen der Illegitimität diskreditiert. Die bürgerlichen Vorstellungen der ,Liebesheirat" und die daraus resultierenden Folgen, wurden vom Adel somit nur teilweise aufgenommen. Da es äußerst schwierig ist, Selbstzeugnisse von nicht anerkannten außerehelichen Adelskindern zu finden, kann über deren Erfahrungen nur spekuliert werden. Die oben erwähnten Beispiele zeigen jedoch, dass es von der völligen Distanzierung der Väter bis zur Erziehung im familiären Kreis alles gab.

$\mathrm{Zu}$ den gesellschaftlichen Herausforderungen gehörten in der zweiten Hälfte des 19. Jahrhunderts russische Reformen, denen viele Deutschbalten feindlich gegenüber standen und die den Zugang zu den gewohnten Verwaltungsstellen erschwerten, sowie fallende Getreidepreise in den $1880 \mathrm{er} \mathrm{Jahren}^{39}$, welche in weiten Kreisen des Adels zu einer einsetzenden Pauperisierung führten. Die Stammhalter waren wiederholt nicht in der Lage, ledigen Schwestern eine ausreichende Mitgift zu stellen. Einige adlige Frauen waren gezwungen, einem Broterwerb nachzugehen, wobei nur Tätigkeiten zur Verfügung standen, die mit ihrem Stand und der Frauenrolle vereinbar waren: Erziehen, Musik oder Pflege. Etliche Frauen nutzten die Gunst der Stunde und erwarben eine höhere Bildung und das Lehrerinnendiplom. Inzwischen war der Beruf der Lehrerin gesellschaftlich akzeptiert und ledige Schwestern genossen einen gewissen Grad an Unabhängigkeit. Manchmal ermöglichten gerade diese ledigen Schwestern den Kindern ihrer finanzschwachen Geschwister die Ausbildung, indem sie sie selbst unterrichteten oder für deren Ausbildung aufkamen.

\section{Schlussfolgerungen}

Im 18. und 19. Jahrhundert standen sich widersprechende Ideale gegenüber: Einerseits wies der Begriff der Geschwister auf eine Gleichheit hin, andererseits stellte man sich die idealen Geschwister als ein gemischtgeschlechtliches Paar mit einem älteren, führenden und vorsorgenden Bruder und einer jüngeren dienenden Schwester vor. In heutigen Rückprojektionen auf vergangene Gesellschaften sind Vorstellungen von der Bevorzugung des Erstgeborenen und der Zurücksetzung der Mädchen weit verbreitet. Dieses Bild ist nicht völlig falsch, es ist jedoch zu relativieren. Allein die hohe Anzahl von Geschwistern, bei der

38 Vgl. Wistinghausen: Theophile von Bodisco, S. 51.

39 Vgl. Whelan: Adapting, S. 297.

Ulrike Schneider, Helga Völkening and Daniel Vorpahl - 978-3-653-98812-3 
längst nicht immer das erstgeborene Kind ein Junge war, und die hohe Mortalitätsrate führten $\mathrm{zu}$ wesentlich komplexeren Konstellationen, als es das Ideal vorsah. Insbesondere die Kategorien ,Geschlecht ' und ,Position in der Geburtenrangfolge" sind sich oft widersprechende Größen, die im Einzelfall geklärt werden müssen - und zwar von Fall zu Fall, weil sich einmal die Kategorie ,Geschlecht" im anderen Fall die Kategorie ,Geburtenrangfolge' bei denselben Geschwistern durchsetzen konnte. Ob nur leibliche Geschwister als Geschwister gezählt wurden oder auch (illegitime) Halb-, Stief- oder Pflegegeschwister ist stark vom Untersuchungszeitraum sowie vom Definitionsrahmen abhängig, denn die persönlich-emotionale, die familiäre, die gesellschaftliche und die juristische Ebene sind nicht deckungsgleich. Aus den Quellen geht hervor, dass eine Mehrheit der deutschbaltischen Adligen auf der sprachlichen und der persönlich-emotionalen Ebene kaum leibliche von legitimen Halbgeschwistern unterschied. In den autobiographischen Schriften und Tagebüchern wird die analytische Dichotomie von Halb- und Stiefgeschwister aufgehoben. Damit werden letztlich Voll-, Halb- und Stiefgeschwister auf der sprachlichen Ebene gleichgesetzt. Irrelevant sind die Unterschiede deshalb nicht, doch werden sie nur in kritischen Situationen betont. Obwohl der Adel einen vielfältigen Pragmatismus im Umgang mit illegitimen Kindern an den Tag legte, wurden diese nicht automatisch zu den Halbgeschwistern gezählt. Ein Vater hatte verschiedene Möglichkeiten, ein illegitimes Kind zu unterstützen. Holte er es zur Erziehung in sein Haus, legte er den Grundstein für eine offizielle Geschwisterbeziehung.

Wie die oben erwähnte Benennungspraxis gezeigt hat, funktioniert die Netzwerkanalyse zur Erforschung von Geschwisterbeziehungen auf der ersten Ebene der Benennung problemlos. Um mit den Angaben aus den autobiographischen Schriften ein dichtes komplexes, mehrlagiges Netzwerk aufzuspannen, ist die Datenlage auf der Ebene der Pflichten und der Ebene der emotionalen Verbundenheit in den meisten Fällen zu dünn. Trotzdem hilft dieses Vorgehen, die einzelnen Funktionen von Geschwisterschaft zu unterscheiden und näher zu analysieren.

Im Verlauf des Lebens dehnte sich das ursprünglich horizontale Netz bestehend aus Schwestern und Brüdern aus, und es wurden auch Geschwister der (Stief-)Eltern und Kinder der eigenen Geschwister integriert. Dabei verband sich die horizontale Ebene mit der vertikalen. Somit spielten Geschwisterbeziehungen in den adligen Familien des 18. und 19. Jahrhunderts eine Generationen übergreifende Rolle. 


\section{Quellen}

DSHI $=$ Dokumentensammlung des Herder-Instituts, Marburg/Lahn.

DSHI 110 Campenhausen 91: Ein Diarium so wohl von meinem Geschlecht als von meinen eigenen Geburt wie auch Was in meinem und meiner Familie Leb-Zeit an Merckwurdigkeiten vorgekommen. Geschrieben und aufgezeichnet von Helena Juliana von Campenhausen gebohrne von Straelborn, ca. 1773.

DSHI 110 Campenhausen 205: Abschrift des Tagebuchs Senateur Balthasar von Campenhausen 1757, 1761-1769, 1776-1783, 1791, 1793, hier 1757-1764.

DSHI 110 Campenhausen 591: Jenny von Vegesack, Bilder der Vergangenheit. ca. 1920.

Andronikow, Fürst Wladimir: Margarethe von Wrangell. Das Leben einer Frau 1876-1932. Aus Tagebüchern, Briefen und Erinnerungen. München 1935.

Les souvenirs de Mlle. Emilie Colline (1791-1893). Handschrift 1895 (Privatbesitz G. A. Tammann).

Rachel, Paul (Hrsg.): Elisa von der Recke. Aufzeichnungen und Briefe aus ihren Jugendjahren. Leipzig 1900.

Träger, Christine (Hrsg.): Elisa von der Recke: Tagebücher und Selbstzeugnisse. Leipzig 1984.

Weymarn, Auguste Christine von: Erinnerungen aus meinem Leben. Druckort unbekannt, wahrscheinlich 1887 (Privatbesitz C. von Weymarn).

Wistinghausen, Henning von (Hrsg.): Theophile von Bodisco. Versunkene Welten. Erinnerungen einer estländischen Dame. Weißenhorn 1997.

\section{Literatur}

Amburger, Erik: Erfundene Familiennamen für illegitime Kinder insbesondere in den baltischen Provinzen und in Russland. (Mit Verwendung hinterlassenen Materials von Robert Lemm), in: Jahrbücher für Geschichte Osteuropas, 41. Jhrg., Heft 4 (1993), S. 562-577.

Bähr, Andreas; Burschel, Peter; Jancke, Gabriele: Räume des Selbst. Eine Einleitung, in: Bähr, Andreas; Burschel, Peter; Jancke, Gabriele (Hrsg.): Räume des Selbst. Selbstzeugnisforschung transkulturell. Selbstzeugnisse der Neuzeit. Bd. 19. Köln u.a. 2007, S. 1-12.

Brändle, Fabian; Greyerz, Kaspar von u.a.: Texte zwischen Erfahrung und Diskurs. Probleme der Selbstzeugnisforschung, in: Greyerz, Kaspar von; Medick, Hans; Veit, Patrice (Hrsg.): Von der dargestellten Person zum erinnerten Ich. Europäische Selbstzeugnisse als historische Quellen (1500-1850). Selbstzeugnisse der Neuzeit. Bd. 9. Köln 2001, S. 3-31.

Brunner, Otto: Das „ganze Haus“ und die alteuropäische „Ökonomik“, in: ders.: Neue Wege der Verfassungs- und Sozialgeschichte. 2. Aufl., Göttingen 1968, S. 103-127.

Davidoff, Leonore: Kinship as a Categorical Concept: A Case Study of Nineteenth Century English Siblings, in: Journal of Social History, Vol. 39, No. 2 Kith and Kin: Interpersonal Relationships and Cultural Practices (Winter 2005), S. 411-428.

Doller, Carolin: „Ach, liebe Schwester, wie sehr sehn ich mich nach Dir!“ Beziehungen adliger Schwestern zwischen persönlicher Nähe und räumlicher Distanz, in: Labouvie, Eva 
(Hrsg.): Schwestern und Freundinnen. Zur Kulturgeschichte weiblicher Kommunikation. Köln u.a. 2009, S. 335-355.

Frei Gerlach, Franziska: Geschwister. Ein Dispositiv bei Jean Paul und um 1800. Studien zur deutschen Literatur. Bd. 198. Berlin, Boston 2012.

Greyerz, Kaspar von: Ego-Documents: The Last Word?, in: German History, Vol. 28 (2010), S. 273-282.

Harris, Amy: That Fierce Edge: Sibling Conflict and Politics in Georgian England, in: Journal of Family History, Vol. 37 (2012), S. 155-174.

Jancke, Gabriele; Ulbrich, Claudia: Vom Individuum zur Person. Neue Konzepte im Spannungsfeld von Autobiographietheorie und Selbstzeugnisforschung, in: Jancke, Gabriele; Ulbrich, Claudia (Hrsg.): Vom Individuum zur Person. Neue Konzepte im Spannungsfeld von Autobiographietheorie und Selbstzeugnisforschung. Querelles. Jahrbuch für Frauen- und Geschlechterforschung. Bd. 10. Göttingen 2005, S. 7-27.

Jansen, Dorothea: Einführung in die Netzwerkanalyse. Grundlagen, Methoden, Forschungsbeispiele. 3. überarbeitete Aufl., Wiesbaden 2006.

Knackmuss, Susanne: „Meine Schwestern sind im Kloster ...“ Geschwisterbeziehungen des Nürnberger Patriziergeschlechts Pirckheimer zwischen Klausur und Welt, Humanismus und Reformation, in: Historical Social Research, Vol. 30, No. 3 (2005), S. 80-106.

Krusenstjern, Benigna von: Selbstzeugnisse der Zeit des Dreißigjährigen Krieges. Beschreibendes Verzeichnis. Selbstzeugnisse der Neuzeit, Quellen und Darstellungen zur Sozialund Erfahrungsgeschichte. Bd. 6. Berlin 1997.

Lejeune, Philippe: Der autobiographische Pakt, in: Niggl, Günter (Hrsg.): Die Autobiographie. Zu Form und Geschichte einer literarischen Gattung. Wege der Forschung. Bd. 565. Darmstadt 1989, S. 214-257.

Opitz, Claudia: Neue Wege der Sozialgeschichte? Ein kritischer Blick auf Otto Brunners Konzept des ,Ganzen Hauses', in: Geschichte und Gesellschaft. Zeitschrift für historische Sozialwissenschaft, Vol. 20, (1994), S. 88-98.

Pistohlkors, Gert von (Hrsg.): Baltische Länder. Deutsche Geschichte im Osten Europas. Berlin 1994.

Prieur, Jutta: Von Detmold nach Dessau und zurück. Der Briefwechsel der Schwestern Leopoldine, Gräfin zur Lippe und Casimire, Prinzessin von Anhalt-Dessau 1765-1769, in: Labouvie, Eva (Hrsg.): Schwestern und Freundinnen. Zur Kulturgeschichte weiblicher Kommunikation. Köln u.a. 2009, S. 321-333.

Reif, Heinz: Adel im 19. und 20. Jahrhundert. Enzyklopädie Deutscher Geschichte. Bd. 55. 2., um einen Nachtrag erweiterte Auflage, München 2012.

Ruppel, Sophie: Verbündete Rivalen. Geschwisterbeziehungen im Hochadel des 17. Jahrhunderts. Köln 2006.

Schwab, Dieter: Familie, in: Brunner, Otto; Conze, Werner; Koselleck, Reinhart: Geschichtliche Grundbegriffe. Historisches Lexikon zur politisch-sozialen Sprache in Deutschland. Bd. 2 (1. Aufl. 1975), 1. Studienauflage. Stuttgart 2004, S. 253-301.

Signori, Gabriela: Geschwister: Metapher und Wirklichkeit in der spätmittelalterlichen Denkund Lebenswelt, in: Historical Social Research, Vol. 30, No. 3 (2005), S. 15-30.

Whelan, Heide W.: Adapting to Modernity. Family, Caste and Capitalism among the Baltic German Nobility. Ostmitteleuropa in Vergangenheit und Gegenwart. Bd. 22. Köln 1999. 
Wilhelmi, Anja: Lebenswelten von Frauen der deutschen Oberschicht im Baltikum (18001939). Eine Untersuchung anhand von Autobiografien. Veröffentlichungen des NordostInstituts. Bd. 10. Wiesbaden 2008.

Zedlers Grosses vollständiges Universallexicon aller Wissenschaften und Künste, Leipzig 1731-1754 (www.zedler-lexikon.de). 
Ulrike Schneider, Helga Völkening and Daniel Vorpahl - 978-3-653-98812-3

Downloaded from PubFactory at 01/11/2019 10:54:37AM

via free access 


\section{Motivgeschichtliche Analysen zur Darstellung von Geschwisterbeziehungen in Literatur, Musik und Bildender Kunst}


Ulrike Schneider, Helga Völkening and Daniel Vorpahl - 978-3-653-98812-3

Downloaded from PubFactory at 01/11/2019 10:54:37AM

via free access 


\title{
„Hiermit Gott befohlen und seyd hübsch alle, ihr viere brüderlich, ihr zwei schwesterlich, getreu"61 - Die Darstellung von Geschwisterbeziehungen in den Kinder- und Hausmärchen in ihrem soziokulturellen Kontext
}

\author{
Jenny Vorpahl
}

\begin{abstract}
This article assorts eight types of relations between siblings in the Children's and Household Tales of the Brothers Grimm. Changes in the different editions of the collection and social conditions in the 19th century are considered in the analysis and interpretation of the siblingconstellations, which are anything but black and white. In fact they supported a bourgeois family ideal.
\end{abstract}

\section{Einführendes}

Ein Viertel, genauer gesagt 48 von 200 Erzählungen der Kinder- und Hausmärchen $^{2}$ erwähnen Geschwister. Hinzu kommen elf weitere, welche sich nur in früheren Ausgaben zwischen 1812 und 1850 finden sowie vier Kinderlegenden, die ab der zweiten Auflage 1819 den Anhang füllen. In diesen insgesamt 63 Texten begegnet der Leser in 29 Fällen Brüdern, in 19 Schwestern und in 18 gemischtgeschlechtlichen Geschwisterbeziehungen. Die Darstellung neutraler bis positiv-harmonischer Beziehungen überwiegt mit 37 Fällen im Vergleich zu 29, welche von einem konfliktgeladenen Verhältnis zeugen. Lediglich vier Mal wird die Bezeichnung ,Bruder" nicht im Sinne leiblicher Geschwisterlichkeit verwendet. Trotz dieser allein quantitativen Relevanz des Geschwisterthemas in den Märchen wurde es im Gegensatz zu den Mutter-Bildern bisher innerhalb der Forschung kaum in den Blick genommen. Auch in der geschichtswissenschaftlichen Forschung zu Auswirkungen von Aufklärung, Industrialisierung und Nationalismus auf Familienkonstellationen, Schichtverhältnisse, Erziehungsideale und Geschlechterrollen sind Geschwister, wenn überhaupt, nur Randfiguren. Dieser Umstand ist u.a. der Tatsache geschuldet, dass vorhandene Selbstzeug-

1 Aus der Vorrede eines Gedenkkalenders für die Geschwister von Jacob Grimm. Zit. nach: Denecke, Ludwig u.a.: Die Brüder Grimm in Bildern ihrer Zeit. Kassel 1980, S. 92.

2 Zugrunde liegt die sog. Ausgabe letzter Hand von 1857. Wird aus der Sammlung zitiert, so wird die Abkürzung des Werkes, die Nummer der Erzählung, des Bandes und der Seitenzahl angegeben, z.B.: KHM 3 I, 37. In der sog. Kleinen Ausgabe sind auch in ca. einem Viertel der Erzählungen Geschwister zu finden (14 von 50). 
nisse kaum auf Geschwisterverhältnisse eingehen. ${ }^{3}$ Laut demographischer Studien lag die Kinderzahl in der ersten Hälfte des 19. Jahrhunderts noch bei durchschnittlich sechs Kindern. ${ }^{4}$ Kontrafaktisch dazu finden sich in den KHM vornehmlich zwei oder drei Geschwister. Möglichen Gründen dieser Feststellungen soll im Folgenden nachgegangen werden, indem v.a. nach Funktionen der Geschwisterfiguren in den Erzählungen gefragt wird.

\section{Bestandsaufnahme}

\section{Typen geschwisterlicher Beziehungen in den Kinder- und Hausmärchen}

Nimmt man die 63 Erzählungen genauer in den Blick, lassen sich acht Typen ausmachen, welche in weiten Teilen gemeinsame Motive und Handlungssequenzen in Bezug auf die Geschwisterkonstellationen und ein ähnliches Geschwisterbild aufweisen. ${ }^{5}$

Dem ersten Typ ,Geschickte Brüder' sind vier Erzählungen zuzuordnen, welche z.T. Züge eines Schwanks tragen: Tischchen deck dich, Goldesel und

3 Gunilla-Friederike Budde widmet ihnen in ihren auf zahlreichen Briefen, Tagebüchern, Lebenserinnerungen, Autobiographien, Familienchroniken o.ä. beruhenden Untersuchungen nur wenige Seiten, während Beziehungen zwischen Eltern und Kindern detailliert nachgezeichnet werden. Vgl. dies.: Auf dem Weg ins Bürgerleben. Kindheit und Erziehung 1840-1914. Göttingen 1994, S. 256-262.

4 Vgl. Hausen, Karin: „... eine Ulme für das schwankende Efeu“. Ehepaare im Bildungsbürgertum. Ideale und Wirklichkeiten im späten 18. und 19. Jahrhundert, in: Frevert, Ute (Hrsg.): Bürgerinnen und Bürger. Geschlechterverhältnisse im 19. Jahrhundert. Göttingen 1988, S. 85-117, hier S. 97 sowie Rosenbaum, Heidi: Formen der Familie. Untersuchungen zum Zusammenhang von Familienverhältnissen, Sozialstruktur und sozialem Wandel in der deutschen Gesellschaft des 19. Jahrhunderts. Frankfurt/Main 1996, S. 353f. Ende des Jahrhunderts sind es durchschnittlich nur noch drei Kinder. Vgl. ebd.

5 Die hier vorgenommene Einteilung konzentriert sich allein auf die Geschwisterbeziehung - folgt also nicht bekannten Klassifikationen von Märchentypen und Erzählmotiven wie von Antii Aarne, Stith Thompson und Hans-Jörg Uther. Die hier vorgenommene Unterteilung widerspricht diesem internationalen Index nicht, sondern hat einen anderen inhaltlichen Fokus. Im Rahmen dieses Beitrags ist auch nicht der Platz für eine Analyse der Feinstruktur der Erzählungen, wie sie z.B. Spörk, Ingrid: Studien zu ausgewählten Märchen der Brüder Grimm. Frauenproblematik, Struktur, Rollentheorie, Psychoanalyse, Überlieferung, Rezeption. Königstein/Ts. 1985 für einige Märchen bietet.

Einige Stücke der Sammlung können den folgenden Kategorien nicht zugeordnet werden, da sie keine vergleichbaren Handlungsverläufe aufweisen und so verschieden sind, dass man unter ihnen schwerlich weitere Typen ausmachen könnte. Z.T. sind es nur kurze Schwänke oder Kinderlegenden, aussortierte Fragmente oder ,Einzelstücke‘. In einigen sind Geschwister lediglich kurz erwähnt oder stehen unverbunden nebeneinander, sodass sich ihre Darstellung und Beziehung kaum analysieren lässt. 
Knüppel aus dem Sack (KHM 36), Die drei Glückskinder (KHM 70), Die drei Brüder (KHM 124), Die vier kunstreichen Brüder (KHM 129). Sie zeichnen sich darin aus, dass keine Bevorzugung und Benachteiligung einzelner der drei oder vier Brüder durch den Vater zu erkennen und ein brüderlich-freundliches Verhältnis ablesbar ist. Motivation für einen Weggang vom Vaterhaus ist entweder das Problem der Erbfolge oder einer Mangelsituation. Obwohl diese Ausgangssituation potenziell konfliktfördernd ist, stellen sich die eingeschlagenen Lebenswege nicht als Konkurrenz, sondern als fairer Wettstreit oder gegenseitige Ergänzung dar. Einvernehmen, Treue und Nähe der Brüder werden als Leitmotive stilisiert.

Ein zweiter Typ ,Treue Geschwisterpaare " erzählt vom gegenseitigen Beistand von gemischtgeschlechtlichen Geschwistern in Notzeiten. Das gemeinsam ertragene Leid lässt sie aneinander besonders festhalten. In Brüderchen und Schwesterchen (KHM 11), Hänsel und Gretel (KHM 15), Das Lämmchen und Fischchen (KHM 141) ist eine Stiefmutter Quelle des Unglücks, in Die Wassernixe (KHM 79) eine funktional ähnliche weibliche Figur. Fundevogel (KHM 51) stellt eine Besonderheit im Kontext von Geschwisterbeziehungen dar, da der Held ein Findelkind und die Heldin somit nicht seine leibliche Schwester ist. Ungeachtet dessen agieren die beiden wie sonst die leiblichen Geschwisterpaare dieser Gruppe. Ihre Loyalität und Zuneigung bringen sie bisweilen durch Schwüre lebenslanger Treue zum Ausdruck. Außer der Flucht bleibt den Geschwistern dieser Kategorie noch das sogenannte Wiedergängermotiv im Sinne des Erscheinens und erlösenden Wiederbelebens Verstorbener nach einem gewaltsamen Tod.

Unter den dritten Typ ,Antagonistische Stiefschwestern“ lassen sich sechs Märchen subsumieren: Die drei Männlein im Walde (KHM 13), Aschenputtel (KHM 21), Frau Holle (KHM 24), Der liebste Roland (KHM 56), Einäuglein, Zweiäuglein und Dreiäuglein (KHM 130) und Die weiße und die schwarze Braut (KHM 135). ${ }^{6}$ Da die genannten Märchen besonders bekannt sind, ist diese Konstellation prägend für das Geschwisterbild der KHM geworden. ${ }^{7}$ Konstitutiv

6 „Von dem Machandelboom“ (KHM 47) ist die einzige Darstellung von gemischtgeschlechtlichen Stiefgeschwistern in den KHM, welche zusätzlich die Besonderheit aufweist, dass die Stiefschwester die Erlösung des Stiefbruders ermöglicht.

7 Die Darstellung von Stiefgeschwistern spiegelt auch eine zeitgenössische Realität, die mit einer gesellschaftlich ungleichen Stellung einherging. Deren Relevanz sollte in den KHM aber nicht überschätzt werden, da nur sechs Märchen von Stiefschwestern sprechen. Eventuell ist diese Konstellation mit den KHM verhältnismäßig eng assoziiert, da bis auf KHM 56 alle in der sogenannten Kleinen Ausgabe enthalten sind, welche maßgeblich zum Erfolg der KHM beigetragen hat, der sich u.a. in zehn Auflagen innerhalb von 33 Jahren widerspiegelt. 
für diese Gruppe sind die Belohnung des mit positiven Charaktereigenschaften ausgezeichneten Mädchens und die Bestrafung ihrer boshaften Stiefschwestern. Des Weiteren ist das beschriebene Verhältnis von einseitiger Rivalität geprägt, d.h. sie wird lediglich durch die Stiefschwestern angeregt, gegebenenfalls unterstützt durch deren Mutter. Das demütige Verhalten der Heldin trägt indirekt zur Steigerung von Neid- und Hassgefühlen der anderen Familienmitglieder bei, welche sie geduldig erträgt. Als erzählerisches Mittel dient das Schwesternverhältnis der Hervorrufung einer Notsituation, aus welcher die Heldin gerettet werden muss. Grundlage ist häufig die Ungleichbehandlung durch die Eltern, vornehmlich der Stiefmutter. Stilistisch funktioniert die Gegenüberstellung durch plakative Zuschreibungen von kontrastierenden Eigenschaften wie gut vs. böse, schön vs. hässlich oder weiß vs. schwarz. Schwester und Stiefschwester verkörpern jeweils Ideale und deren Gegensatz.

Der vierte Typ ,Das Jüngste als Erlöser' zeichnet sich durch seine besondere Komplexität aus. Die zwölf Brüder (KHM 9), Die sieben Raben (KHM 25), Die sechs Schwäne (KHM 49) und Der Löwe und der Frosch (KHM 129a) stehen einander in den Geschwistermotiven besonders nahe. Brüder werden verwünscht und verwandeln sich in Tiere. Aus dieser Lage kann sie nur die aufopferungsbereite Schwester erlösen. Bisweilen ist ihre Existenz sogar Ursache für die Not der Brüder. Die Geschwister erretten sich gegenseitig. ${ }^{8}$ In Das singende, springende Löweneckerchen (KHM 88) und Die drei Schwestern (KHM 82a) ist es der Vater, welcher seine Kinder in eine erlösungsbedürftige Lage treibt, indem er die Töchter in Anwendung des Jephta-Motivs (vgl. Ri 11,30-39) an Tierbräutigame verspricht. Die Rolle der Schwestern beschränkt sich hier auf die Herausstellung der Jüngsten und die Anregung des Handlungsfortgangs. Die Begegnungen zwischen den gesuchten Geschwistern innerhalb dieses Typs sind stets von großer Herzlichkeit und Intimität bestimmt, auch wenn sie einander vorher gar nicht kannten.

Ein fünfter Typ ,Das erfolgreichste jüngste Geschwisterkind“ meint die Erzählungen Der Bärenhäuter (KHM 101), Das Waldhaus (KHM 169), Das Meerhäschen (KHM 191), Die Kristallkugel (KHM 197) ${ }^{9}$ und die erste Kinderlegende der Sammlung Der heilige Joseph im Walde. Leibliche Geschwister müssen eine Prüfung bestehen, wobei das jüngste Kind als siegreicher Held hervorgeht, ohne dass eine Feindseligkeit zwischen den Geschwistern Erwähnung findet.

8 In „Blaubart“ (KHM 62a) sind die Brüder weniger Erlöser als ritterliche Retter mit Hervorhebung des Jüngsten.

9 Da die einmütig handelnden Brüder als Rettungsobjekte und Helfer in Tiergestalt fungieren, besteht in diesem Fall auch große Nähe zu Typ eins und vier. 
Die Herabsetzung des Jüngsten ist Wesensmerkmal des sechsten Typs ,Antagonistische leibliche Geschwister', welchem dreizehn Erzählungen zugeordnet werden können. Davon berichten elf von Brüdern. ${ }^{10}$ Es handelt sich eher um eine Sonderform des zuvor umrissenen Typs, da auch hier dem jüngsten Geschwisterglied mehr Erfolg beschert ist als den älteren. In der gegensätzlichen Zuschreibung von Attributen ähneln die Geschwister dieses Typs den Stiefschwestern aus Typ drei, was z.B. besonders in Der Bärenhäuter (KHM 101) deutlich wird. Einen Gegensatz bilden Armut und Reichtum, wovon vor allem Simeliberg (KHM 142) und Die Rübe (KHM 146) handeln. Der arme Bruder kommt zufällig zu Reichtum, bleibt aber redlich und steht dem neiderfüllten, raffgierigen Bruder gegenüber, dem die Nachahmung misslingt. In seiner gewalttätigen Einforderung von Anerkennung durch die spöttischen Brüder fällt daher der Jüngste in Der Ranzen, das Hütlein und das Hörnlein (KHM 54) in dieser Reihe auf. ${ }^{11}$

Ein zweiter Gegensatz besteht in dumm und klug, welcher in Der singende Knochen (KHM 28), Die Bienenkönigin (KHM 62), Die drei Federn (KHM 63), Die goldene Gans (KHM 64), Dat Erdmänneken (KHM 91), Der goldene Vogel (KHM 57) und Das Wasser des Lebens (KHM 97) präsentiert wird. Ausschlaggebend für die Charakterisierung ist die Handlungsmotivation: Während die vermeintlich listigeren Brüder aus Hochmut handeln, gelingt dem angeblich Dummen jede Prüfung aufgrund seines guten Herzens. In KHM 28, 57, 97 und 146 münden Ärger und Neid sogar in brüderliche Mordversuche durch die Älteren. KHM 62, 63 und 64 gehören zu den sogenannten „Dummlingsmärchen" entsprechend des Spottnamens für den jüngsten Bruder, der sich im Gegensatz zu den älteren durch Mitgefühl und Freundlichkeit auszeichnet. Drei Prüfungen decken deren Fehlverhalten und die Stärken des verkannten Bruders auf, der stets mit Hilfe dankbarer Wesen aufsteigt. Die Arglosigkeit bewirkt, dass die herabgesetzten Geschwister auch nach ihrem Aufstieg nie auf Vergeltung aus sind, sondern immer wieder Vertrauen schenken. Wie beim dritten Typus entzieht sich der zurückgesetzte Held dem Kreislauf aus Rache, dem die unverbesserlichen Geschwister zum Opfer fallen und findet so ,automatisch“ zum Glück.

Der siebte Typ ,Treue Zwillingsbrüder' ist mit nur zwei Erzählungen in den KHM vertreten. Die zwei Brüder (KHM 60) und Die Goldkinder (KHM 85) er-

10 In „De drei Vügelkens“ (KHM 96) ist diese Konstellation mit Schwestern mit Hervorhebung der Ältesten besetzt. Die darin enthaltene zweite Geschwistergeneration realisiert den Geschwistertyp „Das Jüngste als Erlöser“. KHM 133 hebt sowohl die Älteste als auch die Jüngste hervor.

11 „Von der Serviette, dem Tornister, dem Kanonenhütlein und dem Horn“ (KHM 37a) ist eine kurze Variante von KHM 54 und stand 1812 in der Sammlung. 
zählen von Zwillingen, die nach dem Aufwachsen bei Zieheltern in die Welt aufbrechen. ${ }^{12}$ Als sich ihre Wege trennen, versprechen sie ,sich brüderliche Lie-

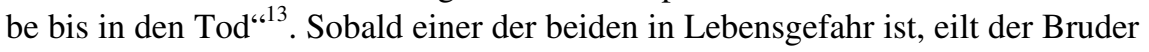
ohne Zögern zu Hilfe. In beiden Märchen ist das Wiedersehen innig und herzlich geschildert. Dennoch kommt es in KHM 60 aufgrund eines Missverständnisses zu einem Brudermord, der rückgängig gemacht werden kann, sodass sich die Treue des fälschlich beschuldigten Bruders zeigt. In dieser Erzählung wird selbst bei einem Zwillingspaar die Unterscheidung in älterer und jüngerer Bruder vorgenommen und der jüngere als der aktive, erfolgreiche Held des Märchens ausgestaltet, während der andere seitenlang in Vergessenheit gerät.

In Typ acht ,Verbündete als Brüder' wird die Bezeichnung ,Bruder' als Anrede verwendet, um einen Fremden zum Verbündeten zu machen oder zu beschwichtigen. So ruft der Fuchs dem Wolf in Der wunderliche Spielmann (KHM 8) in seiner Not „Bruder Wolf, komm mir zu Hilfe“"14 zu. In Bruder Lustig (KHM 81) spiegelt der titelgebende Spitzname den Charakter des Protagonisten wider. Er bewegt den heiligen Petrus mittels Anreden wie „Bruderherz“"15 zu Unterstützung oder Nachsicht. Auch in Des Teufels rußiger Bruder (KHM 100) ist die Bezeichnung eines abgedankten Soldaten titelbestimmend und in einem kumpelhaften Sinne gemeint, da der Soldat dem entdämonisierten Teufel so selbstbewusst und unerschrocken gegenübertritt wie Bruder Lustig dem Petrus. Der schankhafte Euphemismus zeugt von dem Agieren auf Augenhöhe. Vergleichbar ist weiterhin Der Stiefel von Büffelleder (KHM 199). Wieder wird ein Weggefährte über ein Charakteristikum identifiziert, diesmal als „Bruder Wichsstiefel“". Dies sind die einzigen Erzählungen der Sammlung, die die Geschwisterbezeichnung in einem übertragenen, durchaus positiven Sinne verwenden.

\section{Auffällige Änderungen zwischen 1810 und 1857 am Beispiel dreier ,Geschwistermärchen ${ }^{16}$}

Bekannt ist die Einfügung oder Verstärkung moralisch-pädagogischer Absichten hinsichtlich bürgerlicher Ideale von Arbeits- und Gehorsamsverpflichtungen,

12 In KHM 60 ist eine Erzählung um zwei andere Brüder vorgeschaltet. Es handelt sich um den leiblichen Vater und den Onkel der Zwillinge, die den Kontrast arm und gut vs. reich und böse wiedergeben und somit Typ sechs entsprechen.

13 KHM 60 I, S. 317

14 KHM 8 I, S. 70.

15 KHM 81 I, S. 398f.

16 Diese Bezeichnung meint im Rahmen dieses Beitrags vereinfachend sämtliche Erzählungen, in welchen Geschwisterbeziehungen eine Rolle spielen, wenn diese auch nicht immer handlungsbestimmend sind. 
Familiensinn und christlicher Frömmigkeit durch die Brüder Grimm. Doch muss betont werden, dass Jakob und Wilhelm Grimm sich zwar offensichtlich literarischer Vorlagen bedienten, aber dabei häufig verschiedene Versionen zusammenfügten oder eine geeigneter scheinende bevorzugten. ${ }^{17}$ Sie notierten sich die zentralen Motive und Handlungsstränge, die sie dann immer weiter ausformulierten. Diminutive, veranschaulichende Ergänzungen, das Ersetzen von Fremdwörtern, vermehrt verwendete direkte Rede, Streichung von satirischen Bemerkungen oder sexuellen Anspielungen sowie formelhafte Wiederholungen sind nur einige der Methoden, die die Herausgeber anwandten und welche dazu beitrugen, die Sammlung für damalige Maßstäbe kindgerechter zu gestalten. Daher ist es nicht verwunderlich, wenn die Urfassungen von 1810 eher Exzerpten entsprechen und die Endfassungen von 1857 bisweilen den doppelten Umfang aufweisen. ${ }^{18}$ Zur Verdeutlichung der Veränderungen innerhalb Märchen mit ausgeprägten Geschwisterfiguren wurden exemplarisch drei Erzählungen ausgewählt, die ein relativ großes $\mathrm{Ma} ß$ an Umgestaltung erfahren haben. Sie vertreten einige der oben genannten Typen oder verbinden sogar zwei wie Die weiße und die schwarze Braut (KHM 135).

In der handschriftlichen Urfassung des Märchens Die zwölf Brüder bleibt der Entschluss des Königs, seine zwölf Söhne im Falle der Geburt eines Mädchens umzubringen, unbegründet. ${ }^{19}$ In der Endfassung von 1857 dient die Zusprechung des alleinigen Erbes durch das Mädchen der abmildernden Erklärung des väterlichen Mordplans. Die Brüder müssen also nach der Geburt einer Schwester um ihr Leben fliehen und schwören im Gegenzug, jedes Mädchen, das sie finden, zu töten. Die Zwölfzahl wird augenscheinlich aufgegriffen, um eine Verbindung zu den biblischen Jakobssöhnen herzustellen. Auch hier kommt dem jüngsten Sohn eine besondere Rolle zu: Während die traurige Königin zuerst alle ihre Söhne warnt, wird in der späteren Fassung ein inniges Gespräch zwischen dem Jüngsten, nun wie der jüngste biblische Sohn Benjamin genannt,

17 Zum Nachvollziehen verschiedener Inhalte und Funktionszusammenhänge anderer Fassungen sowie der Überlieferungswege einzelner KHM vgl. Clausen-Stolzenburg, Maren: Märchen und mittelalterliche Literaturtradition. Heidelberg 1995; Mazenauer, Beat u.a.: Wie Dornröschen seine Unschuld gewann. Archäologie der Märchen. München 1998 u. Uther, Hans-Jörg: Märchen vor Grimm. München 1990.

18 Vgl. Derungs, Kurt: Die ursprünglichen Märchen der Brüder Grimm. Handschriften, Urfassung und Texte zur Kulturgeschichte. Bern 1999, S. 9-22. Zu Arbeitsweisen, Gewährsleuten sowie der Quellenkritik: Rölleke, Heinz: „Alt wie der Wald“. Reden und Aufsätze zu den Märchen der Brüder Grimm. Trier 2006, S. 4. Lehnert, Nicole: Brave Prinzessin oder freie Hexe? Zum bürgerlichen Frauenbild in den Grimmschen Märchen. Münster 1996, S. 7f. u. 16ff. zeigt Filterprozesse auf, denen die Märchen unterlagen.

19 Vgl. Derungs: Die ursprünglichen Märchen, S. 86.

Ulrike Schneider, Helga Völkening and Daniel Vorpahl - 978-3-653-98812-3 
und der Mutter wiedergegeben, die einander in ihrer Not Trost zusprechen und einen Rettungsplan beschließen. ${ }^{20}$ Auch der mütterliche Segen zum Abschied und ihre fürsorgliche Zusicherung, jede Nacht für sie zu beten, fehlen in der Urfassung. Während ursprünglich jeder der Brüder im Wald abwechselnd mit der Haushaltsführung an der Reihe war, wird später dezidiert Benjamin damit beauftragt, mit der Begründung, er sei „,der jüngste und schwächste“. ${ }^{21}$ Diese exklusive Stellung des Jüngsten gegenüber der übrigen, undifferenzierten Brüderschar hat immerhin eine geringfügige Grundlage in der Version von 1810. Dort hält der jüngste Bruder Fürsprache für das im Waldhaus eingetroffene Mädchen, indem er argumentiert, es könne ihnen doch den Haushalt machen, sodass sie von ihrem Racheschwur absehen. Begründet wird die Verschonung noch nicht mit der geschwisterlichen Verbindung, sondern mit ihrer Nützlichkeit. ${ }^{22}$ An die Stelle des zufälligen Findens der Brüder tritt die entschlossene Suche der Schwester. 1810 noch mit wenigen Eigenschaften ausgestattet, ist sie nun „gut von Herzen und schön von Angesicht und hatte einen goldenen Stern auf der Stirne. ${ }^{، 23}$ Das Wiedersehen ist, wie der Abschied von der Mutter, von Emotionalität und Liebe geprägt: „Und sie fing an zu weinen vor Freude, und Benjamin auch, und sie küssten und herzten einander vor großer Liebe.“24 Die Brüder nehmen eine fast väterliche Position ein und blicken wohlwollend auf das fleißige Schwesterchen. Es wird in der Endfassung eine idyllische Hausgemeinschaft gezeichnet, die einen geordneten bürgerlichen Haushalt wiedergibt, in der die Männer ausziehen, um für den Lebensunterhalt zu sorgen, während die Frau den Haushalt ,hübsch weiß und rein“'25 hält.

Um die Opferbereitschaft der Schwester zu unterstreichen, wird die Erlösungsbedingung für die Rückverwandlung der unbeabsichtigt in Raben verwünschten Brüder als unmöglich realisierbar dargestellt. Ohne zu zögern, ist die Schwester bereit zu sterben, wenn sie nur ihre Brüder erlösen kann. Aus der ursprünglich kurzen Erwähnung der Rettung der Schwester vor dem Feuertod durch die Brüder wird sodann ein heldenhafter Akt. Zum vollständigen Glück

20 An KHM 9 wird die Stärkung der biologischen Mutter-Kind-Beziehung in der Endfassung, z.B. mittels wiederholten Anreden „Weine nicht, liebe Mutter“, „Liebstes Kind“, „Mein liebster Benjamin“, besonders deutlich. KHM 9 I, S. 72.

21 KHM 9 I, S. 73.

22 Vgl. Derungs: Die ursprünglichen Märchen, S. 36. Das bleibt auch 1812 noch so. Dort erbarmt sich der Jüngste wegen ihrer Schönheit und die anderen lassen von ihr ab, da sie den Haushalt führen wollte. Erst dann gibt sie sich als Schwester zu erkennen. Die Freude über die Zusammenkunft wird ohne Tränen, Küsse und Umarmungen erwähnt.

23 KHM 9 I, S. 73.

24 KHM 9 I, S. 74.

25 KHM 9 I, S. 75.

Ulrike Schneider, Helga Völkening and Daniel Vorpahl - 978-3-653-98812-3 
gehört nicht nur die Aufklärung der falschen Verleumdung und die Bestrafung der Gegenspielerin, sondern auch das gemeinsame Zusammenleben aller Geschwister bis zum Tod.

In den überarbeiteten Fassungen der Erzählungen mit dem jüngsten, einfältigen Bruder (Typ sechs) wird Wert darauf gelegt, gleich zu Beginn die Unterschiede zwischen den beiden älteren Brüdern und dem Jüngsten deutlich zu machen. Ursprünglich haben die Handlungen der Brüder noch stärker für sich gesprochen. ${ }^{26} 1810$ heißt der Jüngste in Die drei Federn noch „Däumling“, später dann „Dummling“. 27 Die vom Vater gestellte Aufgabe ist 1857 mit der Suche nach einem passenden Erben begründet. Wiederholt wird angeführt, dass die älteren Brüder von dem Jüngeren meinen, er habe keinen Verstand und sei daher ungeeignet als Nachfolger. Selbst als er drei Aufgaben in Folge aufs Beste erfüllt, beharren sie auf ihrer Einschätzung und drängen ihren nachgiebigen Vater bis aufs Äußerste, immer weitere Prüfungen zu stellen. Diese Hetze gegen den Bruder fehlt 1810 und ist 1812 nur in Ansätzen vorhanden. Über die Qualität ihrer Bemühungen wird 1810 nichts bemerkt, hingegen wird 1812 sogar gesagt, dass der Dummling seine Brüder übertroffen hatte, obwohl sie sich bemüht hatten, aus aller Herren Länder das Schönste beizubringen. ${ }^{28}$ Ab 1819 wird hingegen immer wieder ihre Nachlässigkeit betont, da sie sich auf das Versagen des Bruders verlassen, obwohl er zu einer immer ernster zu nehmenden Konkurrenz wird und am Ende aller Widerspruch verstummt. Ergänzt ist auch der Schluss: „Also erhielt er die Krone und hat lange in Weisheit geherrscht.“" ${ }^{\text {29 }}$ Er weist auf die Funktion der Dummlings-Geschichten in den KHM hin, die vor dem Hintergrund älterer Vorlagen deutlicher wird. Sie sollen dazu anhalten, das gute Wesen hinter einer tölpelhaften, schwächlichen oder hässlichen Fassade zu erkennen: „Aus dem Gewand des Tölpels schält sich ein gewitzter Dümmling, der über die Geringschätzung seiner Umwelt und über die hergebrachte Ordnung triumphiert. ${ }^{\text {30 }}$

26 Vgl. die Vorstellung des Märchenpersonals in der Endfassung von „Die drei Federn“. In „Die Bienenkönigin“ wird 1857 der Jüngste als „Dummling“ vorgestellt, was 1810 noch fehlt. Die Verteidigung der Tiere gegenüber den Brüdern wird mit dem Mitgefühl des Jüngsten näher bestimmt. Abschließend wird betont, dass er sich mit der jüngsten und liebsten Königstochter vermählt. Vgl. Derungs: Die ursprünglichen Märchen, S. 57f.

27 Vgl. ebd., S. 60. Die Bezeichnung „Däumling“ stammt wahrscheinlich aus der Sammlung Charles Perraults. Dort ist in „Le petit poucet“ die Zartheit und Wortkargheit des jüngsten Sohnes Anlass anzunehmen, er sei dumm, was sich als Fehlschluss erweist.

28 Vgl. ebd., S. 147.

29 KHM 63 I, S. 346.

30 Mazenauer u.a.: Archäologie der Märchen, S. 295.

Ulrike Schneider, Helga Völkening and Daniel Vorpahl - 978-3-653-98812-3 
Gravierende Änderungen hat das Märchen Die weiße und die schwarze Braut, welches 1810 noch Die goldene Ente hieß, bereits nach der ersten Bearbeitungsphase erfahren. Es gab keine Gegenüberstellung durch die leibliche Tochter der Tante, sondern die hilfsbereite, fleißige und schöne Pflegetochter hat für sich gesprochen und wird entsprechend mit Gaben anstelle von Tränen belohnt. Ihre Verwandlung in eine Ente ist ein Unfall, den die Tante ausnutzt und ihre Tochter als Braut für den König ausgibt. Diese war nur „lange nicht so schön und anmutig “31 und stirbt nach der Aufdeckung des Betrugs. 1812 gibt die leibliche Tochter nicht mehr einer guten Fee, sondern Gott spöttische Antworten, weswegen sie mit Hässlichkeit und einem schwarzen Äußeren bestraft wird. Aus der Tante wurde die Stiefmutter der Protagonistin. Letztere antwortet im Gegensatz zur früheren Fassung selbstbewusst auf die Frage nach drei Wünschen, dass sie Schönheit und Reichtum und nach göttlicher Ermahnung auch die ewige Seligkeit begehrt. Die hexenartige Stiefmutter arbeitet mit ihrer neidischen Tochter jetzt Hand in Hand, um die Konkurrentin aus dem Weg zu räumen. ${ }^{32}$

Des Weiteren fungiert der leibliche Bruder der Protagonistin als Heiratsmittler zwischen seiner Schwester und dem Königssohn. In der Fassung von 1810 führen die Geschwister nach dem Tod ihres königlichen Ehemannes gemeinsam „ein ruhiges Leben bis an ihr gottseliges Ende. ${ }^{\text {33 }}$ In der redigierten Fassung ist der Bruder der engste Vertraute der Schwester, dem sie ihr Leid klagt, und er wiederum betet sie so sehr an, dass er ein Bild von ihr malt, um sie jederzeit betrachten zu können: „Alle Tage ging er davor stehen und dankte Gott für das Glück seiner lieben Schwester. ${ }^{634}$ Die innige geschwisterliche Beziehung wird durch die eingefügte formelhafte Rede auf der Reise noch verstärkt und durch die beiden Antagonistinnen ausgenutzt. Die Rolle der Schwester als Wiedergängerin wird durch die direkte Rede mit dem allabendlichen Erkundigen nach dem Wohl des zwischenzeitlich gefangenen Bruders in den Vordergrund gerückt. So wird stärker deutlich, dass sie die Befreiung des Bruders erwirkt. Das Märchen endet nicht mehr mit der Vereinigung der Geschwister, sondern in der Ehe mit dem König, während der Bruder mit Ruhm und Reichtum belohnt wird.

31 Derungs: Die ursprünglichen Märchen, S. 68.

32 Vgl. ebd., S. 245 und KHM 135 II, S. 230. Vergleichbar ist die Entwicklung zur stiefschwesterlichen Antagonistin in KHM 11 und 13. 1812 stehen sie noch ganz im Hintergrund, wandeln sich aber bis 1857 zur aktiven Mittäterin. Vgl. KHM 11 I, S. 84 und Derungs: Die ursprünglichen Märchen, S. 89f. Äußere Kontraste werden gekoppelt an charakterliche Defizite.

33 Ebd., S. 69.

34 KHM 135 II, S. 230. Vgl. auch Derungs: Die ursprünglichen Märchen, S. 244. 
Zusammenfassend kann man die zunehmend besondere Rolle des Jüngsten, die Erhöhung der Emotionalität hin zur innigen Geschwisterliebe, die gesteigerte Aufmerksamkeit bezüglich der Rettungsfunktion und Opferbereitschaft sowie die stärkere Ausformung der Widersacherrollen bei konkurrierenden Geschwistern feststellen. Mehr Gewicht erhalten idyllische Familienbilder sowie fromme Züge der positiv besetzten Figuren. ${ }^{35}$ Die Umarbeitung von Die zwölf Brüder und auch von Die sechs Schwäne sowie zahlreiche Wiederbegegnungsszenen zwischen Geschwistern ${ }^{36}$ verweisen auf eine Betonung der unsichtbaren Verbindung zwischen leiblichen Geschwistern, deren Wege sich trennen, die aber eigentlich zusammengehören. Selbst wenn sie einander unbekannt sind, resultiert aus der Blutsverbindung eine verantwortungsbewusste Zuneigung für die Geschwister in Notsituationen. ${ }^{37}$ Die zunehmende Kontrastierung zwischen feindlich gesonnenen Geschwistern macht deutlich, dass solch eine Geschwisterbeziehung im Gegensatz zur ersten weniger Bindungspotenzial besitzt, was häufig mit der fehlenden Blutsverwandtschaft begründet wird. ${ }^{38}$ Diese „Schwarz-Weiß-Malerei“ - z.T. im wörtlichen Sinne - vereinfacht eine klare Zuordnung aus moralischer Sicht.

\section{Das Geschwisterbild in den Kinder- und Hausmärchen}

Die klassische Komposition des Märchens lässt sich stark vereinfacht in drei Schritten beschreiben: eine Mangelsituation oder ein Konflikt erfordert die Bewältigung von Prüfungen, welche zu Rettung und Aufstieg führen. ${ }^{39}$ Warum

35 Die Protagonistinnen in KHM 21, 49, 161, KL 1 werden als fromm bezeichnet. Drei Mal (KHM 81, 100, 135) wünschen sich Hauptfiguren ewige Seligkeit. Die Hölle ist Schauplatz in KHM 81 und 100. In KHM 25, 101, 130, 169, KL 1 finden sich Gebetshandlungen.

36 Vgl. die herzliche Begrüßung unter Geschwistern in KHM 9, 25, 49, 60, 85, 129.

37 Vgl. KHM 9, 25 und 82a.

38 In der Sammlung steigt von 1812 bis 1857 die Anzahl toter guter leiblicher Mütter, deren Ersetzung durch böse Stiefmütter eine Verlagerung des Bösen weg von der guten leiblichen Mutter ermöglichen. Andere bleiben passiv im Hintergrund. Ab 1819 wird der Status ,rechte Tochter“ und „Stieftochter“ und damit die fehlende Blutsbindung betont. Vgl. KHM 11,13, 24, 56, 135 sowie Blaha-Peillex, Nathalie: Mütter und Anti-Mütter in den Märchen der Brüder Grimm. Tübingen 2008, S. 63-90 u.ö. Eine Ausnahme stellt KHM 130 mit der schwer zu rechtfertigenden selektiven Mutterliebe dar. Die leibliche Geschwisterlichkeit ermöglicht offenbar sogar die Auflösung der Rivalität, da die Protagonistin den Schwestern vergibt.

39 Dem etablierten Gattungskonzept Lüthis zufolge, welches sowohl morphologische als auch phänomenologische Charakteristika berücksichtigt, kennzeichnet ein Märchen v.a. „die Neigung zu einem bestimmten Personal, Requisitenbestand und Handlungsablauf und [...] zu einer bestimmten Darstellungsart (Stil).“ Lüthi, Max: Märchen. Stuttgart 
wird dabei gerade in der Exposition so häufig auf Geschwisterbeziehungen zurückgegriffen? Laut Weber-Kellermann geben das Eltern-Kind-Schema, das Geschwister-Schema oder das Brautwerbungsschema „dem Märchen das Gerüst und die Möglichkeit variierender Entfaltung. “40 Den abstrakten Stil des Märchens kennzeichnen vor allem die starken Kontraste und Extreme, die Typenhaftigkeit und Leuchtkraft der Figuren sowie eine schnell voranschreitende, einsträngige Handlung. ${ }^{41}$ Lüthi zufolge sind die Handlungsträger keine vielschichtigen Persönlichkeiten, die fähig zur Veränderung sind, sondern repräsentieren einen bestimmten Typus. ${ }^{42}$ Geschwisterkonstellationen dienen als Kontrastmittel, um verschiedene Charakterzüge auf Figuren zu verteilen und einander gegenüberzustellen. Inhaltliche Oppositionen finden sich am häufigsten in formal gleichwertigen Situationen wie drei Prüfungen, die nacheinander alle Geschwister eines Märchens auf sich nehmen. ${ }^{43}$ Sicher kann man auch jeweils drei Freunden oder Kameraden verschiedene Aufgaben und Eigenschaften zuweisen. Doch Geschwister teilen Elternhaus und Heimat, haben einen gemeinsamen Ursprung, von dem aus die unterschiedliche Entwicklung besonders deutlich ablesbar ist. In der Regel wird nicht ohne Weiteres ersichtlich, warum eines der Kinder gut und schön genannt werden kann, während andere böse und hässlich geraten sind. Zudem können eigene lebensweltliche Erfahrungen zeigen, dass Geschwister unter vergleichbaren Umständen äußerst verschiedene Charakterzüge mitbringen und ausbilden.

Die harmonische Darstellung von Geschwistern lässt selten charakterliche oder äußerliche Differenzierungen unter ihnen erkennen. Sie treten vor allem als symbiotische Einheit auf, deren Trennung nicht auf Dauer angelegt ist. Ihr

2004, S. 25. Dabei muss beachtet werden, dass die KHM eine zentrale Grundlage der Analyse der Märchengattung darstellen und oft als Maßstab für folgende Sammlungen fungierten, sodass die Merkmale besonders gut mit ihnen in Einklang zu bringen sind.

40 Weber-Kellermann, Ingeborg: Die deutsche Familie. Versuch einer Sozialgeschichte. Frankfurt/Main 1981, S. 34. Vgl. Lüthi, Max: Familie und Natur im Märchen, in: ders.: Volksliteratur und Hochliteratur. Menschenbild, Thematik, Formstreben. Bern u.a. 1970, S. 63-78, hier S. 63.

41 Vgl. Lüthi, Max: Das europäische Volksmärchen. Form und Wesen. Tübingen u.a. 2005, S. 25-36.

42 Vgl. ebd., S. 13-24. Gemeint ist ein Verzicht auf Tiefengliederung, etwa auf die nähere Beschreibung von Körperlichkeit, Innenwelt oder Umwelt der Figuren.

43 Vgl. Spörk: Studien, S. 135. Neben formalistischen Gründen argumentiert Max Lüthi mit einem seiner Ansicht nach märchentypischen Menschenbild, welches durch die Dominanz innerfamilialer Disharmonie im Gegensatz zur harmonischen Verbindung von Mensch und Natur gekennzeichnet sei. Selbst im Falle harmonischer Märchengeschwister seien die Familienbeziehungen als ganze gestört. Vgl. ders.: Familie und Natur, S. 6378 . 
Glück besteht wesentlich darin, zusammen zu bleiben. Solche persistenten Verbindungen sind v.a. bei Geschwisterpaaren des ersten, zweiten und vierten Typs zu finden. Die meisten harmonischen Geschwistererzählungen handeln von Geschwistern verschiedenen Geschlechts oder von Brüdern, seltener von Schwestern. ${ }^{44}$ Im Unterschied zu jenen, welche ihren Weg gemeinsam gehen, handeln die geschickten Brüder (Typ eins) und Erlöserkinder (Typ vier) während des Hauptteils der Erzählung - der Prüfungszeit - separat. In Typ eins und zwei gibt es keinen durchweg dominierenden Helden. Bei letzteren wird die Zusammengehörigkeit sogar durch die Titel unterstrichen: Brüderchen und Schwesterchen, Hänsel und Gretel, Das Lämmchen und Fischchen, Schneeweißchen und Rosenrot. In Typ vier ist stets das jüngste Kind Held des Märchens, seine Geschwister fungieren als verkörperte Prüfungsaufgabe. Ihre Erlösungsbedürftigkeit lässt die Qualitäten der Hauptfigur aufscheinen, welche dementsprechend auch detaillierter charakterisiert wird. Die Geschwister als Objekt der Rettung treten als undifferenzierte Gruppe auf, von der bisweilen nur das jüngste Kind kurz heraustritt. ${ }^{45}$ Sowohl Brüder als auch Schwestern treten als Retter und treue Gefährten auf. Zwillingsbrüder verkörpern entweder entsprechend der Kontrastästhetik Gegensätze oder ihre Ähnlichkeit wird zur Täuschung gebraucht. Trennung und glückliche Wiedervereinigung funktioniert übergreifend. Zwar wird in Märchen selten auf Empfindungen der Handelnden eingegangen - es sei denn, sie sind handlungsfördernd -, aber einträchtige Geschwisterbeziehungen bieten am ehesten Raum, um emotionale Verbindungen, Familienidylle und Verantwortungsgefühl zu zeigen, was die Brüder Grimm nutzten.

Die antithetische Beschreibung von Stiefschwestern bezieht sich sowohl auf äußerliche als auch charakterliche Unterschiede, während konkurrierende Brüder ohne die Hervorhebung optischer Merkmale auskommen. Selten geraten gemischtgeschlechtliche Geschwister miteinander in einen Konflikt. ${ }^{46}$ Auch das Schema der missglückten Nachahmung wird nur bei gleichgeschlechtlichen Ge-

44 Insgesamt handelt es sich um 15 gemischtgeschlechtliche Geschwisterkonstellationen, 15 Mal sind es Brüder und sieben Mal Schwestern, wobei hier auch Geschwister berücksichtigt sind, deren Beziehung nicht näher charakterisiert wird, sie also neutral nebeneinander gestellt sind oder agieren. Daher kann man von wirklich harmonischen Schwestern lediglich in KHM 133 und 161 sprechen.

45 Einzig in „Blaubart“ ist dieses Verhältnis umgekehrt. Vgl. hier FN 10.

46 In KHM 11 agiert die Stiefschwester gegen Bruder und Schwester, wobei der Fokus auch hier auf der Schwester liegt. In dem 1812 bezeichnenderweise aussortierten Märchen KHM 8a agieren Brüder im Auftrag der Mutter gegen ihre Schwester. Ansonsten stehen sich in 19 Fällen Brüder und in 17 Fällen Schwestern gegenüber. 
schwistern angewendet. ${ }^{47}$ Mit Blick auf die Geschwisterkonstellation bergen Differenzen hinsichtlich innerer und äußerer Werte, des Alters, des Verhältnisses zu den Eltern sowie der fehlenden Blutsverwandtschaft Konfliktpotenzial. Konkurrenz im Sinne eines Mitbewerbens um ein bestimmtes Gut, wie dem Erbe der Eltern, materieller Güter oder der Zuneigung eines potenziellen Ehepartners ist ohne Zweifel häufig in Märchen anzutreffen, muss aber keinesfalls negativ konnotiert sein, wie Vertreter des ersten Typs verdeutlichen. Bisweilen wird die Konkurrenzsituation lediglich von einer Partei forciert, wie mehrere Beispiele aus Typ drei sowie fünf und sechs zeigen. ${ }^{48}$ Zweifellos einträchtige Schwestern sind nur Schneeweißchen und Rosenrot.

Die Gegenüberstellung von Geschwistern impliziert ein enormes Identifikationspotential für Leser und Hörer der Märchen. Sie können klar Partei ergreifen und die Verwerflichkeit von Handlungen scheint durch ihre nahe verwandtschaftliche Bindung noch gesteigert. Das Verhalten der Protagonisten gegenüber den Geschwistern zeigt hingegen, wie man sich eigentlich gegenüber den Seinigen verhalten sollte: brüderlich oder schwesterlich nachsichtig, treu, hilfsbereit und aufopfernd. Werden die Antagonisten entsprechend des Gerechtigkeitsprinzips bestraft, dann meist nicht direkt durch ihr ehemaliges Opfer, dessen Reinheit dadurch gewährt bleibt, sondern z.B. über die Instanz eines Erlösers.

Aufgrund der gesteigerten Aufmerksamkeit, die die Brüder Grimm den jüngsten Geschwistern zukommen ließen, welche bereits innerhalb ihrer Vorlagen oft eine besondere Stellung eingenommen hatten, stellt sich die Frage nach möglichen Gründen für dieses bevorzugte Schema in Geschwistermärchen. Die Position des Jüngsten und seine Interaktion mit den Geschwistern bietet eine Erzählstruktur, an der sich das Herauskristallisieren einer Figur als Held sowie bestimmte Abläufe und Botschaften besonders gut ausbilden lassen. Folgt man Lüthi, müssen die älteren Geschwister falsch handeln, um die Notsituation zu konstruieren, welche die Handlung initiiert, und um am Helden das richtige Verhalten zu demonstrieren. Dieses Gerüst trifft man in Dreibrüder- oder Dreischwestermärchen am häufigsten, was wiederum mit der in Märchen beliebten

47 Die Nachahmung durch gleichgeschlechtliche Geschwister macht den Unterschied jeweils noch eindringlicher, zumal sich die Prüflinge in Situationen bewähren sollen, die z.T. geschlechterspezifisch zugeordnet werden wie Kampfsituationen oder Hausarbeit.

48 Genau genommen implizieren die Begriffe ,Konkurrenz ' und ,Rivalität‘ ein aktives Streben mindestens zweier Personen, um ein bestimmtes Ziel zu erreichen. Vgl. Kluge, Friedrich: Etymologisches Wörterbuch der deutschen Sprache. Berlin u.a. 2011, S. 524 u. 769. In den Märchen wird meist nur von den Antagonisten eine Konkurrenzsituation unterstellt und provoziert. Selbst wenn z.B. Aschenputtel vereinzelt aus ihrer Passivität ausbricht, geschieht dies nicht offensichtlich als Mittel zum Gewinn, zu dessen Annahme sie erst aufgefordert werden muss. Vgl. auch KHM 13 und 24. 
Dreizahl korreliert, die Steigerungen und Kontraste durch die beiden Älteren und das Exeptionsprinzip mit dem Jüngsten als Ausnahme ermöglicht. Zu diesen stilistischen Funktionen gehört auch das Gesetz des Achtergewichts, dem zufolge bei Aufzählungen das wichtigste Glied am Schluss steht. ${ }^{49}$

Doch wie ist das stets beste jüngste Kind anthropologisch zu fassen? Entsprechend bekannter Erbfolgeregeln sollte man meinen, das älteste Kind hat eine Vorrangstellung. Zudem stellt das erste Kind eine einzigartige Erfahrung für die Eltern dar und muss deren Aufmerksamkeit noch nicht mit anderen Geschwistern teilen. Der Sonderstatus kann aus einer vermeintlichen Bedürftigkeit als kleinstes und damit schwächstes Kind resultieren, während die Älteren bereits eigenständiger agieren können. Diese Stellung kann Zuneigung und Behüten durch die Eltern und älteren Geschwister bedeuten, aber auch ein Streben des Jüngsten nach Aktivität, Anerkennung und Vertrauen. Das Etikett als unterschätzter ,Dummling ' mag daher rühren, dass der Jüngste bislang stets hinter den Älteren zurückgeblieben war und seine scheinbare Dummheit an äußerlichen Zügen abgelesen wurde. Nur verharrt er im Märchen nicht in dieser Erniedrigung, sondern findet zufällig einen Weg, seine Brüder doch noch zu übertreffen und seine eigentlichen Qualitäten zu entfalten. Sein Zurückstecken scheint ein besonderes Mitgefühl gegenüber Anderen zu wecken und steht im Gegensatz zu seinen egoistischen Brüdern. Das Schicksal des Jüngsten als erniedrigter Schwächster, der trotz seiner Unfähigkeit Bedeutendes erreichen kann, bietet großes Identifikationspotenzial. ${ }^{50}$ Als Verkörperung eines Wunschtraumes impliziert die Gestalt des verkannten Jüngsten, der über alle Widerstände hinweg erfolgreich ist, die Bestrafung der Widersacher sowie den Sieg der Gerechtigkeit. ${ }^{51}$ Zudem zeugt dieses Schema von einem zentralen Anliegen der Märchen: Es stellt den Zusammenhang von Schein und Sein in Frage und fordert so dazu auf, sich nicht von Äußerlichkeiten täuschen zu lassen. ${ }^{52}$

Resümierend ist festzustellen, dass Helden der KHM ihre Geschwister brauchen, meist dringender als die Eltern. Häufig ist es sogar das Versagen der Eltern in Form von Vernachlässigung, Erniedrigung oder Verwünschung, das

49 Vgl. Holbek, Bengt: Art. Achtergewicht, in: Enzyklopädie des Märchens. Bd. 1. Berlin u.a. 1977, Sp. 65.

50 Laut Lüthi ist jeder Mensch ,letztlich immer irgendwie ein solcher ,Jüngster ‘ [...] ein Schwacher und Kleiner, dem es doch gegeben ist, Mächtiges zu besiegen und Großes zu erreichen“. Zit. nach: Horn, Katalin: Art. Jüngste, Jüngster, in: Enzyklopädie des Märchens. Bd. 7. Berlin u.a. 1993, Sp. 801. Die unterhaltende und didaktische Funktion des Jüngsten und Kleinsten hatte bereits Charles Perrault erkannt und bewusst eingesetzt. Vgl. Clausen-Stolzenburg: Literaturtradition, S. 361.

51 Vgl. Horn: Jüngste, Sp. 808.

52 Vgl. ebd., Sp. 806.

Ulrike Schneider, Helga Völkening and Daniel Vorpahl - 978-3-653-98812-3 
Geschwister in die Rollen gegenseitiger Beschützer, treuer Begleiter und Retter in der Not wachsen lässt. Als Gegenspieler drängen sie die Herabgesetzten in eine rettende Situation und bessere Stellung. So gut wie nie sind die Eltern handlungsbegleitend, sondern Ausgangspunkt und eventuell auch Heimat, zu der die Helden zurückkehren. In seltenen Fällen verfolgt die Stiefmutter die Stieftochter weit in die Handlung hinein. Märchenväter mischen sich in die innerfamiliären Probleme selten ein, bleiben oft passiv oder machtlos. In ihrer Distanz zu Erziehungsfragen und dem Auftreten auf der Bühne bei Eheschließungen scheinen sie dem bürgerlichen Rollenbild zu entsprechen, in ihrer Schwäche jedoch nicht. ${ }^{53}$ Häufiger sind es Geschwister, die auch in der Zeit der Prüfungen gegenwärtig sind, was lebensweltlicher Realität entsprechen kann, da eine Gemeinsamkeit zwischen Geschwistern darin besteht, dass sie in der Regel aus dem Elternhaus ausziehen und untereinander vergleichen können, wie der jeweils andere seinen Weg geht.

Die Kinderlegende Der heilige Joseph im Walde bleibt das einzige Stück der Sammlung, in dem ein Geschwisterkind vorkommt, das ambivalente Züge trägt: Drei Töchtern wird nacheinander die gleiche Aufgabe gestellt und sie müssen sich durch Freundlichkeit, Selbstlosigkeit und Gehorsam bewähren. Während die älteste Schwester unartig und böse war, war ,die zweite schon viel besser, obgleich sie auch ihre Fehler hatte, die jüngste aber war ein frommes, gutes

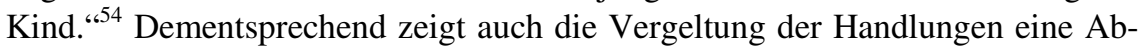
stufung. Sonst stellen Märchengeschwister als abschreckende Beispiele oder nahezu unerreichbare Ideale Extreme dar, deren Erfolg und Misserfolg als Anregung zur Besserung des eigenen Verhaltens in den Dienst genommen wurde. Realistisch erscheinende Einzelerfahrungen von Geschwistern finden sich entsprechend des konsequenten Stils des Märchens zu Schicksalen innerhalb einer wirklichkeitsfernen Welt verabsolutiert. ${ }^{55}$

Erzählenswert, traditionstüchtig ist immer nur, was die banale Alltäglichkeit übersteigt. Deshalb kommen hier die extremen Formen der Kommunikation zwischen Geschwistern besonders zur Geltung: der Wettstreit, die Auseinandersetzung bis aufs Blut einerseits, und die durch nichts auf der Welt zu erschütternde Geschwister-

53 Vgl. KHM 13, 15, 21, 49, 60, 88, 169.

54 KL 1 II, S. 431.

55 Ingeborg Weber-Kellermann weist darauf hin, dass Märchen Gesellschaftskonflikte wie den gesellschaftlichen Standeswechsel auf Familienniveau zeigen können. Zugleich warnt sie davor, Märcheninhalt mit sozialer Wirklichkeit zu identifizieren, da dies nur bei einzelnen Phänomenen möglich sei. Vgl. dies.: deutsche Familie, S. 35-37. 
treue andererseits. Das übliche in der Realität sind dagegen Mischungsverhältnisse, wechselnde Stimmungen und Haltungen [....$^{56}$

\section{Das Geschwisterbild der Kinder- und Hausmärchen in seiner erzieherischen Funktion und dessen sozio-kultureller Kontext}

\section{Einflussfaktoren auf Stellung und Funktion der Kinder- und Hausmärchen}

Vor allem Jack Zipes hat Lüthis Diktum, die poetisch-ästhetische Form von Märchen sei ein Selbstzweck und alles nicht den formalen Gattungskriterien Entsprechende seien fremde Ausschmückungen, revidiert. ${ }^{57}$ Er hat darauf aufmerksam gemacht, dass seit Ende des 18. Jahrhunderts

educated writers purposely appropriated the oral folk tale and converted it into a type of literary discourse about mores, values, and manners so that children would become civilized according to the social code of that time. ${ }^{58}$

Durch die „literary 'bourgeoisification' of oral tales ${ }^{\text {“59 }}$ wollten die Brüder Grimm die allgemeine Akzeptanz der bisher stiefmütterlich behandelten Volksliteratur fördern. Jacob und Wilhelm Grimms Anschauung zufolge sind Märchen letzte Überreste deutscher Volksdichtung und tragen Fragmente einer genuin deutschen Mythologie, welche ihre Verwandtschaft mit skandinavischen und keltischen Traditionen bezeugen. ${ }^{60}$ Die Wiederentdeckung altdeutscher Überlieferungen hatte einheitsstiftende und patriotische Funktionen vor dem Hinter-

56 Bausinger, Hermann: Geschwister gehen bis zum Rhein ... . Perspektiven der Volkstradition, in: Klosinski, Gunther (Hrsg.): Verschwistert mit Leib und Seele. Geschwisterbeziehungen gestern - heute - morgen. Tübingen 2000, S. 21-30, hier S. 29.

57 Das Märchen als pädagogisches Werkzeug zu verstehen, würde seiner Ansicht nach dessen Degradierung bedeuten. Er wendet sich damit v.a. gegen André Jolles` Annahme des Waltens einer naiven Moral im Märchen. Vgl. Lüthi: Form und Wesen, S. 83f. Er gesteht jedoch die verschiedene kontextabhängige Ausprägung des Märchenstils ein, sodass die reine Grundform selten verwirklicht wird. Vgl. ebd., S. 94.

58 Zipes, Jack D.: Fairy tales and the art of subversion. The classical genre for children and the process of civilization. Milton Park u.a. 2012, S. 3, vgl. auch S. 6. Die Attraktivität der Märchen erklärt er u.a. mit der dortigen stark hierarchisierten Welt, in der jeder aufsteigen kann. Vgl. ebd., S. 7f. Gunilla-Friederike Budde belegt anhand einer „Bestsellerliste" deutscher und englischer Kinderliteratur im 19. Jh., wie Geschichten individuelle Leistung als Weg zu materieller Unabhängigkeit und gesellschaftlichem Ansehen statt geburtsständische Privilegien propagierten. Die KHM belegten in Deutschland Platz zwei und in England den elften Platz. Vgl. dies.: Bürgerleben, S. 112 u. 129.

59 Zipes: art of subversion, S. 59.

60 Vgl. Clausen-Stolzenburg: Bürgerleben, S. 41f. Die oft diskutierte Behauptung der Brüder, alles Gesammelte treu zu bewahren, bezieht sich v.a. auf die Inhalte. Dass Erzählungen Umwandlungsprozessen in formaler Hinsicht unterlagen, war ihnen durchaus bewusst, wovon ihre Vorreden und Anmerkungen zeugen. Vgl. ebd., S. 44ff. 
grund der Wirren der Napoleonischen Jahre. ${ }^{61}$ Nationalistische Tendenzen zeigen sich im Überarbeitungsprozess, z.B. im Ersetzen von französischen Fremdwörtern sowie am Aussortieren von Märchen, die eine zu offensichtliche Nähe zu französischen und italienischen Vorgängern aufwiesen. Denn die „Märchen sollten den Kindern des Bürgertums, das damals als innovatorische Kraft in Gesellschaft und Kultur gelten konnte, die Vergangenheit und den geistigen Besitz des deutschen Volkes näherbringen. “62 ${ }^{62}$ Sie dienten der Integration in die Gesellschaft durch die Bestärkung der Normen und Werte, die sie legitimierten und trugen.

Die Umgestaltung durch Wilhelm Grimm bestand daher nicht zuletzt in einer stärkeren Hervorhebung moralischer Grundsätze unter Einbeziehung religiöser Motive: „Wilhelm Grimm hat bei seiner Bearbeitung häufig für diese [moralische] Instanz Gott eingesetzt oder die impliziten Anforderungen explizit gemacht, um die Moral oder die ,gute Lehre", die sich aus dem Verlauf der Handlung ergibt, zu verdeutlichen."63 Durch eine symbolische Sprache und exemplarische Charaktere sollten Märchen Verstehenszugänge zu Glaubenswahrheiten und ethischem Verhalten ermöglichen, die vor allem kleinen Kindern mit rationalen Erklärungen nur schwer zu vermitteln sind. ${ }^{64}$

Das deutsche Bürgertum des 19. Jahrhunderts war zu großen Teilen durch eine zunehmende Distanzierung vom kirchlichen Leben geprägt, gehörte

61 Vgl. Schmitt, Ludwig E. (Hrsg.): Jacob Grimm und Wilhelm Grimm. Werke. Forschungsausgabe. Bd. 31, Abt. 2: Die Werke Wilhelm Grimms. Kleinere Schriften 1. Hildesheim u.a. 1992, S. 12.

62 Spörk: Studien, S. 51.

63 Solms, Wilhelm: Die Moral von Grimms Märchen. Darmstadt 1999, S. 97. Dementsprechend wurde mit jeder neuen Auflage der Anteil jener Märchen größer, die eine Veränderung in Bezug auf Gottesfurcht, Frömmigkeit und Anstand erfuhren. Vgl. Kitzler, Marianne: Kirchenlehre und Märchen. Wien 2010, S. 180.

64 Werden in den Geschwistermärchen Gott, Engel oder Heilige bemüht, handelt es sich meist um kurze Anmerkungen, die selten eine handlungsfördernde Rolle spielen. Sie stellen einen losen Zusammenhang her zu ,Zuständigkeitsbereichen“ Gottes oder greifen Traditionen der Heiligenverehrung auf. Zugleich wirkt die scheinbar beiläufige Erwähnung von Gott, Engeln, Frömmigkeit oder Gebet in den untersuchten Erzählungen selbstverständlich. „Der liebe Gott“ als beschützende und lenkende Instanz, welche in der Not angerufen wird, wird in den Geschwistermärchen KHM 9, 11, 13, 21, 24, 25, 28, 83, 85, 100 und 180 genannt. In KHM 135 ist er sogar aktiver Teil des Märchenpersonals als Prüfer und Richter der Tugenden und Laster der Schwestern. Laut Kitzler handelt es sich um sekundäre Einfügungen und atmosphärisches Beiwerk, die Geschehnisse mit dem Wirken Gottes in Verbindung bringen sollen, was der Märchenleser von sich aus nicht tun würde. Vgl. ebd., S. 66-78. Zur Erklärung biblisch oder christlich anmutender Züge in den KHM vgl. Clausen-Stolzenburg: Literaturtradition. 
dennoch mehrheitlich dem Protestantismus an. Gerade in der zweiten Jahrhunderthälfte zeichnete sich eine abnehmende Bedeutung von Religion und Kirche ab. ${ }^{65}$ Das muss einer innerfamilialen Religionspraxis, vor allem im Rahmen der Kindererziehung nicht widersprechen. Hier konnten weiterhin Gebete, biblische Geschichten, Gebote und Gesänge eine Rolle spielen, während andere Bürger eine religiös indifferente Haltung einnahmen und religiöse Gepflogenheiten weniger ausübten. ${ }^{66}$

Unabhängig von dem Grad, in dem die Ablösung der Wertorientierung von religiösen Begründungszusammenhängen fortgeschritten war, nutzten deutsche und englische Bürgereltern überdies die sozialmoralischen Religionsgebote, mehr oder minder entkleidet von ihrem sakralen Charakter, für die Kindererziehung. Ihre $\mathrm{Zu}-$ hilfenahme erleichterte die Tradierung von bürgerlichen Lebensmaximen wie Fleiß, Bescheidenheit und nicht zuletzt Gehorsam. Gerade die patriarchale Struktur der Religion trug zur Stützung der Autorität des pater familias bei. ${ }^{67}$

Kinder waren Teil des bürgerlichen Familienideals und man widmete ihnen nun mehr Aufmerksamkeit, während traditionelle Moral- und Ordnungsvorstellungen nicht an Aktualität verloren. Einzelkinder waren trotz hoher Kindersterblichkeit und verschiedener Methoden der Geburtenbeschränkung die Ausnahme. Die wirtschaftlichen Entwicklungen, das niedrige Heiratsalter der Frauen und die sinkende Kindersterblichkeit führten zu einem Bevölkerungswachstum in der ersten Hälfte des 19. Jahrhunderts. Frühestens Ende des Jahrhunderts kann von einer Realisierung der Vorstellung einer bürgerlichen Kleinfamilie mit zwei bis drei Kindern gesprochen werden, wenn es auch noch häufig vier bis sechs Geschwister gab. ${ }^{68}$ Erst dann korrelierte die niedrige Geschwisterzahl mit der in den Märchen. Kinder bedeuteten Arbeitskraft, Bestandssicherung und Zukunftshoffnung. Sie machten eine Familie als Gegenkonzept und Rückzugsort gegenüber Modernisierung und Versachlichung erst komplett. In diese Zeit fallen auch

die erstmalige Einrichtung von Kinderzimmern und die Herstellung von Kinderkleidung und Kinderspielzeug [...]. Zugleich entsteht ein Bedarf nach Kinderliteratur, die sowohl Wissen vermitteln als auch eine moralische Erziehung ga-

65 Budde führt als Indikatoren für Kirchennähe und -ferne Zahlen zu Gottesdienstbesuchen an. Inklusive der Pfarrfamilien besuchten lediglich 23\% regelmäßig den Gottesdienst. Vgl. Budde: Bürgerleben, S. 385f.

66 Vgl. McLeod, Hugh: Weibliche Frömmigkeit, männlicher Unglaube? Religion und Kirchen im bürgerlichen 19. Jahrhundert, in: Frevert: Geschlechterverhältnisse, S. 134-156, hier S. 141f.

67 Budde: Bürgerleben, S. 392.

68 Vgl. ebd., S. 402. Das Zusammenleben von mehreren Generationen und Verwandtschaftsgraden war noch lange der Normalfall. Vgl. ebd., S. 254. 
rantieren soll. Diese Marktlücke haben die Brüder Grimm mit den Kinder- und Hausmärchen gefüllt, ${ }^{69}$

sodass sie den Platz der Moralerzählungen einnehmen konnten, ${ }^{70}$ welche aufgrund ihrer ,penetrant hervorstechenden Moral“" ${ }^{\text {71 }}$ abgelehnt wurden. Dies entspricht der Auffassung der Grimms, wenn sie die KHM als Erziehungsbuch verstehen, das keiner zusätzlichen Erklärungen bedarf, da die Poesie in ihrer natürlichen Unschuld und Kraft Wahrheit überträgt, während sie unterhält. ${ }^{72}$

Märchen erzählen nicht von Individuen, sondern von Funktionsträgern. Als Rolleninhaber leisten sie in einer Zeit der Wandlung und Entwicklung sozialer Systeme ihren Beitrag zur Etablierung, Stabilisierung und, während der regen Rezeption der KHM im 19. Jahrhundert, zur Aufrechterhaltung dieser Syste-

69 Solms: Moral, S. 42. In diesem Zusammenhang kam damals die Frage auf, inwieweit die KHM für die Kinder geeignet seien und Wilhelm Grimm äußerte sich diesbezüglich in einem Brief vom 19.11.1812 wie folgt: „daß wir bei den Kindermärchen recht eigentlich den Wunsch haben, es möge ein Erziehungsbuch werden, da ich mir nichts ernährender, unschuldiger und erfrischender weiß für kindliche Kräfte und Natur". Schnack, Ingeborg u.a.: Briefe der Brüder Grimm an Savigny. Bd.1. Berlin 1953, S. 143. Vgl. Rölleke, Heinz (Hrsg.): Kinder- und Hausmärchen. Mit den Originalanmerkungen der Brüder Grimm. Bd. 1. Stuttgart 2008, S. 17. Einwände, die dargestellte Derbheit in den Märchen sei für Kinder nicht geeignet, erwiderte er mit der Aussage, sie hätten als Kinder schließlich schon die Bibel gelesen. Vgl. Steig, Reinhold (Hrsg.): Achim von Arnim und Jacob und Wilhelm Grimm. Stuttgart 1904, S. 266. In der Vorrede zu den KHM meint er, man dürfe ,gewisse Zustände und Verhältnisse, wie sie täglich vorkommen“, nicht verbergen und Eltern könnten eine Auswahl treffen, wenn sie dies für angebracht halten. Rölleke, Heinz: Originalanmerkungen. Bd. 1. S. 17.

70 Sog. „Moralische Geschichten“ wurden von Pädagogen und Geistlichen seit den 1780er Jahren verfasst, um als didaktisches Instrument zur Exemplifizierung bürgerlicher $\mathrm{Tu}$ genden zu dienen. Damit haben sie ,,den Märchen der Romantiker als moralische Gattung den Weg“ geebnet. Vgl. Alzheimer, Heidrun: Moral im Kinderbuch des 18. Jahrhunderts. Die Moralische Geschichte als Wegbereiterin des Märchenbooms im 19. Jahrhundert, in: Beisbart, Ortwin u.a. (Hrsg.): Märchen. Geschichte - Psychologie - Medien. Hohengehren 2007, S. 7-28, hier S. 7f. u. 15.

71 Franz, Kurt: „Sagen lassen sich die Menschen nichts, aber erzählen kann man ihnen alles“. Das Volksmärchen als Erziehungs- und Bildungsmedium vom 19. Jahrhundert bis in die Gegenwart, in: ders. (Hrsg.): Märchenwelten. Das Märchen aus der Sicht verschiedener Fachdisziplinen. Baltmannsweiler 2008, S. 72-102, hier S. 75. Dem Lesebuchherausgeber Dittmar zufolge werden durch die Märchen ,gottinnige Gefühle“ und ,sittliche Gesinnung“ gefördert, da aus ihnen ,die gute Lehre und die Anwendung auf die Gegenwart sich so leicht von selbst ergibt, wie eine gute Frucht aus einer gesunden Blüte ohne Zuthun der Menschen“. Zit. nach: ebd., S. 76.

72 Vgl. Auswertung der Vorreden in Clausen-Stolzenburg: Literaturtradition, S. 48f. 
me. $^{73}$ So wurden u.a. innerhalb eines Systems der Zweigeschlechtlichkeit Charakteristika wie Aktivität und Rationalität im Gegensatz zu Passivität und Emotionalität als natürlich gegebener Teil des männlichen bzw. weiblichen Wesens erklärt. ${ }^{74}$ Die aus der Anpassung an Kapitalismus und Industrialisierung entstandene Arbeitsteilung, Individualisierung und Mobilität mündete einigen Sozialtheoretikern zufolge in das Konzept der affektiven Kleinfamilie mit Eltern und Kindern, welches guter Mutterschaft, liebevollen Eltern-Kind- und harmonischen Geschwisterbeziehungen Raum bot. ${ }^{75}$ Die zunehmend betonte Verantwortung der Eltern in der Kindererziehung baute auf der Verstärkung der natürlichen Bande zwischen Eltern und Kinder auf. Deren Überhöhung bedeutete eine Aufwertung der Blutsverwandtschaft, ${ }^{76}$ welche sich auch in dem Überarbeitungsprozess der KHM spiegelt. Die Konzentration auf den Kult der Innerlichkeit in Abgrenzung zum Adel erklärt Rosenbaum mit dem Kompensationsbedürfnis des Bürgertums angesichts ihrer noch politischen Machtlosigkeit um die Jahrhundertwende. Bildung und die Pflege privater Beziehungen gaben ihnen in ihrer sozialen Situation Sicherheit und daraus entstehende Leitbilder beeinflussten wiederum soziales Handeln und somit gesellschaftliche Realität. ${ }^{77}$ Als be-

73 „Das Märchen leistet diese Stabilisierung, in dem es den Helden in Situationen gelangen läßt, die vom Kind als Konflikte erlebt werden und deren Lösung ihm Einsichten in Möglichkeiten und Konsequenzen von rollen(in)adäquatem Verhalten gibt.“ Spörk: Studien, S. 13.

74 Vgl. Lehnert: Frauenbild, S. 5f. Die Verlagerung der Legitimation der Vorherrschaft des Mannes über die Frau von einst religiösen und ökonomischen auf biologische Grundlagen ermöglichte ein Bestehen dieser vor den Diskursen der Aufklärung. Vgl. BlahaPeillex: Mütter, S. 18.

75 Edward Shorter, Max Weber oder Laurence Stone gelten als Vertreter solcher Modernisierungstheorien. Jack Goody erinnert daran, dass traditionale Gesellschaften trotz ökonomischer Nöte und hoher Kindersterblichkeit Zuneigung, Individualismus und elterliche Autorität kannten. Ebenso findet sich in bürgerlichen Schichten die Priorität von Pflicht gegenüber der Liebe. Vgl. ders.: Geschichte der Familie. München 2002, S. 204-214.

76 Vgl. Rosenbaum: Formen der Familie, S. 268.

77 Vgl. ebd., S. 259-263 u. 272-276. Auch die Wertschätzung der individuellen Leistung durch Tüchtigkeit diente der Erarbeitung einer gesellschaftlichen Position in Anbetracht der fehlenden sozialen Verortung. Diese Aufstiegsorientierung bieten auch verschiedene KHM, wenn Fleiß und Tüchtigkeit belohnt werden und Statuswechsel relativ leicht möglich erscheinen. Rosenbaum erklärt, dass die frühbürgerlichen Ideale, vertreten durch Beamte und Gelehrte, sich angesichts des aufgestiegenen Wirtschaftsbürgertums wandelten. Im Kaiserreich dominierten weniger Bescheidenheit und Innerlichkeit, sondern der repräsentative Lebensstil. Die zunehmende politische Rolle und ökonomische Macht lässt sie von einer Aristokratisierung sprechen. Zugleich rückte die Arbeit an sich mehr in den Mittelpunkt. Vgl. ebd., S. 310-330. 
liebtes Element in der Primärsozialisation konnten die Märchen die Übermittlung und Verinnerlichung dieser ,Selbstverständlichkeiten ' fördern. ${ }^{78}$

Geschwister nahmen auch in der Familie Grimm einen herausragenden Stellenwert ein und diese Form der verwandtschaftlichen Beziehung wurde über die Kinderjahre hinaus durch das gesamte gemeinsame Leben gepflegt. Jacob Grimm oblag nach dem frühen Tod der Eltern als Ältester die Leitung der sechs Geschwister, die dem Junggesellen wohl die am nächsten stehenden Personen waren. Die einzige Schwester führte lange den Haushalt. Hinzu kamen die Schwägerinnen, zu denen ebenfalls ein schwesterliches, im Sinne eines nahestehenden verwandtschaftlichen Verhältnisses bestand, sowie das gemeinsame Aufwachsen der Neffen und Nichten. Private und politische Umbrüche, Krankheiten und berufliche Schwierigkeiten forderten immer wieder das Verantwortungsgefühl und die gegenseitige Versorgungsbereitschaft der Geschwister. Jacob und Wilhelm Grimm teilten ein Leben lang Wohnung und Arbeit sowie Sorgen und Freuden des Familienlebens, ergänzten und achteten sich in ihren Neigungen und Temperamenten und waren somit lebendige Repräsentanten geschwisterlichen Zusammenhalts und brüderlicher Herzlichkeit. Bausinger führt hier den Nachruf Jacobs auf seinen Bruder Wilhelm an, in dem er die Festigkeit des geschwisterlichen Bandes als noch stärker beschreibt als das zwischen Eltern und Kinder, weil Geschwister ein ganzes und nicht nur ein halbes Leben teilen. $^{79}$

\section{Märchengeschwister und rollenadäquates Verhalten}

Kaum eine Verwandtschaftsbeziehung ist in der Belletristik des 19. Jahrhunderts mit solch schönfärberischer Feder gezeichnet worden wie die zwischen Brüdern und Schwestern. Märchen, Balladen, Novellen, Romane und Dramen aus aller Welt schufen und popularisierten das Image einer besonderen Qualität und Intimität der geschwisterlichen Bindung. In Tagebüchern und Memoiren hingegen führten die Geschwister ein stiefschwesterliches und -brüderliches Dasein. ${ }^{80}$

78 Die synchrone Verbreitung und Wechselwirkung von Kulturidealen und den KHM ändert nichts daran, dass weder das eine noch das andere als detailgetreue Widerspiegelung der realen Gesellschaft aufgefasst werden sollte. Die Umsetzung der Prinzipien war von Familie zu Familie und Generation zu Generation verschieden.

79 Vgl. Bausinger: Volkstradition, S. 24. In „Die Brüder Grimm in Bildern ihrer Zeit“ geben Denecke u.a. mit Korrespondenzen und Bildzeugnissen Einblick in die Gemeinschaft der Grimm-Geschwister sowie in die zahlreichen familienähnlichen Freundschaften, die dem Geselligkeitsideal der Zeit entsprochen zu haben schienen.

80 Budde: Bürgerleben, S. 256. 
In Bezug auf die Geschwisterfiguren in den KHM und ihrer Funktion ist zu fragen, ob sie auch Erwartungen an bürgerliche Rollen transportierten. ${ }^{81}$ Hierzu zählt die Zuschreibung von geschlechtsspezifischen Attributen, sozialen Positionen und Aktivitäten. Weibliche Geschwister müssten sich dementsprechend durch Fleiß, Duldsamkeit, Heiratswillen auszeichnen und vor allem im häuslichen Familienverband als Hausfrau und Mutter tätig sein. Ihr Status hängt von dem ihres Vaters oder Mannes ab. Männliche Figuren müssten in die konkurrenzorientierte Arbeits- und Außenwelt ziehen. Das bürgerliche Leistungsethos ist bei Mädchen in Bezug auf ihre hauswirtschaftlichen, fürsorglichen und repräsentativen Qualitäten als zukünftige Ehefrau und bei Jungen im Hinblick auf den sozialen Aufstieg durch beruflichen Erfolg relevant. ${ }^{82}$ Entsprechend der klassischen Erbregelungen müsste wiederum ihr Alter bestimmend sein. ${ }^{83}$

Das frühe Sterben von Geschwistern und Trennungsphasen durch Ausbildung und Heirat ermöglichten damals engere Beziehungen nur in begrenztem Maß. Geschwisterharmonie war vor allem in den ersten Kinderjahren durch gemeinsames Erleben denkbar. Das Übernehmen von Verantwortung durch Ältere konnte sich positiv auf die Beziehung auswirken, bisweilen statt einem gleichberechtigten ein Erzieher-Zögling-Verhältnis entstehen lassen. Beides findet sich in KHM wie Hänsel und Gretel, Brüderchen und Schwesterchen, Das Lämmchen und Fischchen oder Die Zwölf Brüder. Unterschiedliche Positionen innerhalb der Geschwisterhierarchie führten aber auch zu gegenseitiger Geringschätzung und Bevormundung. ${ }^{84}$ Schon früh wirkten vorgeformte Zukunftsmuster trennend zwischen Brüdern und Schwestern. Dieser Ausschluss aus genuin weiblichen oder männlichen Bereichen und darauf ausgerichtete unterschiedliche Ausbildungsförderung führte zwar selten zur Revolte der Bürgertöchter und -söhne, aber doch zu Konflikten zwischen den Geschwistern. Eltern erwarteten von ihren Söhnen Selbstständigkeit, Durchsetzungsfähigkeit und

81 Die Verwendung des Begriffs , bürgerlich“ für einen sozialen Status erfolgt meist assoziativ statt systematisch. Kriterien wie Besitz, Beruf, Bildung und Geschmack ergeben einen bürgerlichen Lebensstil, dem u.a. autobiographische Zeugnisse nach 1800 als Maßstab dienen. Der Gebrauch materieller Güter, Bezug auf ideelle Werte und deren Umsetzung fungieren als Identitätsmodell und Distinktionsmittel. Vgl. Kaschuba, Wolfgang: Deutsche Bürgerlichkeit nach 1800. Kultur als symbolische Praxis, in: Kocka, Jürgen (Hrsg.): Bürgertum im 19. Jahrhundert. Bd. 3. München 1988, S. 9-44, hier S. 10-20.

82 Vgl. Budde: Bürgerleben, S. 115 u. 121. So schreiben Kinder rückblickend den Eltern verschiedene Qualitäten zu - bei dem Vater zählt der berufliche Werdegang und Verdienste, bei der Mutter die äußere Erscheinung. Vgl. ebd., S. 150.

83 Hermann Bausinger belegt, dass im dörflichen Milieu das ,ständige Ineinander von Kooperation und Konkurrenz" zwischen Geschwistern v.a. im Hinblick auf Erbverteilungen stark ausgeprägt war. Vgl. ders.: Volkstradition, S. 21f.

84 Vgl. Budde: Bürgerleben, S. 256-261.

Ulrike Schneider, Helga Völkening and Daniel Vorpahl - 978-3-653-98812-3 
Wagemut, um sie auf zukünftige Führungspositionen vorzubereiten. Die frühe Absonderung in getrenntgeschlechtlichen Sozialisationsräumen erschwerte das Verständnis füreinander. Schon als Kinder sollten Töchter ihre Bedürfnisse hintanstellen, als moralische Instanz auf das Verhalten der Brüder ausstrahlen, aber sich nicht in den Vordergrund drängen, sondern vernünftig und nachgiebig sein. ${ }^{85}$ Sie wurden mit Aufgaben im Haushalt und der Betreuung von Geschwistern beauftragt, während Jungen meist davon freigestellt waren. Eifersucht und Konkurrenz ergab sich häufig aus der Bevorzugung Einzelner, welche als Vorbild für die Geschwister dienen sollten. Man konkurrierte sowohl um Zuwendung als auch um Freiräume und Erbangelegenheiten. Als Erwachsene konnten Spannungen lebendig bleiben durch ein Wohlstandsgefälle zwischen den Geschwistern, wie es Brüder in KHM 142 und 146 widerspiegeln. Dennoch standen Geschwister unter dem Druck, zumindest nach außen die Loyalität in der Familie aufrecht zu erhalten und sich untereinander solidarisch zu verhalten, um das bürgerliche Familienkonzept als privaten und stabilen Rückzugsraum zu vertreten. ${ }^{86}$

Die Belohnung von Demut, Leidensfähigkeit, Opferbereitschaft, Fleiß und Schönheit steht bei Frauen in den KHM im Vordergrund. Dennoch werden sowohl von Helden als auch von Heldinnen Mut, Entschlossenheit, Gehorsam, Mitgefühl und Hilfsbereitschaft demonstriert. ${ }^{87}$ Als Heldinnen ziehen auch Schwestern in die Welt und Brüder übernehmen mal den Haushalt, wenn es an Frauen mangelt. Alle sind generell heiratswillig, aber Heirat bleibt in Geschwistermärchen oft ein Nebeneffekt. Wird von Berufen gesprochen, handelt es sich stets um Männer. Frauen übernehmen häufig eine mütterliche Rolle, auch in Bezug auf ihre Geschwister. Die Auflösung problematischer Situationen, wie die Not und Drangsalierung von Protagonistinnen trotz ihres Fleißes und ihrer Demut, durch Belohnung und Bestrafung ermöglichte die Aufrechterhaltung gesellschaftlicher Normen. Innerhalb der KHM erfuhr nicht nur die Emotionalität der Mütter eine Intensivierung in der Darstellung, sondern auch die zwischen

85 Geschwister berichten, dass Schwestern belehrend und mütterlich auftraten, während bei Brüdern Weichlichkeit als unmännlich deklariert wurde. Vgl. ebd., S. 204, 210 u. 222. Budde stellt fest, dass ,,die Jungen ihre Männerwelt en miniature vehement vor dem Eindringen von Schwestern, Cousinen und Nachbarinnen zu schützen trachteten, [...]. Besonders wenn es darum ging, ihre Knabenverachtung für Mädchen nachzuempfinden, zeigten sich die Autobiographien bemüht, [...] mit Nachdruck die mangelnde Eignung der Schwestern für ihre wilde Welt zum Ausdruck zu bringen.“ Ebd., S. 203.

86 Vgl. Bausinger: Volkstradition, S. 25.

87 Z.B. sind die Erlöserkinder in KHM 49 und 82a nicht von ihren Rettungsvorhaben abzubringen, obwohl sie eindringlich von den Geschwistern vor der Lebensgefahr gewarnt werden. 
Geschwistern. Brüder und Schwestern nehmen im Gegensatz zu Eltern oder anderen Verwandten sowohl die Rolle der Erlösungsbedürftigen als auch der Retter ein und können in Einzelfällen, wie KHM 9 zeigt, sogar in diesen Funktionen wechseln. Sie geben zumindest zeitweise aufgrund eines Pflichtgefühls gegenüber den Geschwistern ihre beschützende Heimat sowie ihre soziale Stellung auf. Laut Spörk sind es gerade die Frauen, deren Handeln sich vorrangig auf die Erlösung anderer auf Kosten eigener Bedürfnisse und Karriereziele konzentriert. Sie handeln stets aus Liebe und Treue und werden vor allem in Notsituationen aktiv. ${ }^{88}$ Durch hilfebedürftige Brüder können die Schwestern eine mütterliche Position einnehmen, was Vertreter des zweiten und des vierten Typs zeigen. ${ }^{89}$ Ist dies nicht der Fall, treten Brüder als ritterliche Retter auf. Die Vernachlässigung ihrer Position als Geschwister der Helden, um die eigene gesellschaftliche Position zu verbessern, zeichnet die Gegenspieler aus und wird bestraft. ${ }^{90}$ Geschwister mit einem einvernehmlichen Verhältnis haben also in erster Linie die Funktion, deutlich zu machen, dass das Wohl der Familienmitglieder an oberster Stelle steht. Außerdem sind gemischtgeschlechtliche Geschwisterharmonien eher denkbar, da z.B. eine Abgrenzung von Brüdern gegen Schwestern aufgrund deren geringerer Rechte weniger erforderlich war.

Bezeichnenderweise setzt die Herauslösung aus diesem Zwang materiellen Denkens, die Emotionalisierung und Aufwertung von Geschwisterbeziehungen vor allem bei Frauen und Mädchen an. Sie werden zum Sinnbild einer anderen, in Gefühlen der Zuneigung begründeten Geschwister- und Familienbeziehung. ${ }^{91}$

Geschwister in Konkurrenzsituationen sind hingegen auf einen Aufstieg, z.B. durch Heirat, ausgerichtet. Angesichts dessen, dass ein Heiratsanwärter gegebenenfalls nicht verheiratete Schwestern mitversorgen müsste und daher vor einer Heirat zurückschreckte, ist ein getrübtes schwesterliches Verhältnis nachvollziehbar. Ebenso ist die Nachfolgefrage angesichts mehrerer Brüder ein Streit-

88 Vgl. Lehnert: Frauenbild, S. 25f. u. Spörk: Studien, S. 58. „Der Großteil der behandelten Texte zeigt jedoch die Gebundenheit der Märchenheldin an die familiäre Arbeits- und Gehorsamspflicht, auch wenn ihr die gesellschaftliche Position mehr Macht und Freiräume zubilligen würde.“ Aber ihre Unterordnung führt immer zur Verbesserung der gesellschaftlichen Stellung, z.B. vom Hausmädchen zur Hausfrau. Ebd., S. 213.

89 Dem Aufgehen der Schwesternfiguren in der Mutterrolle widerspricht in KHM 49 die Missachtung des Wohls der eigenen Kinder zugunsten der Erlösung der Brüder.

90 Vgl. Spörk: Studien, S. 85 u. 120.

91 Bausinger: Volkstradition, S. 23. Dabei mussten gerade in finanziell angespannten Situationen Mädchen hinsichtlich Bildung und Ausstattung zurückstecken, da der elterliche Ehrgeiz sich dann auf die Ausbildung des Sohnes konzentrierte. Umso wichtiger war somit das Üben in Nachsicht und Verzicht für andere durch die Schwestern, was sich mit dem Schwesternbild der KHM deckt. Vgl. Rosenbaum: Formen der Familie, S. $360 \mathrm{f}$. 
punkt sowie Vermögensteilung generell. Gerade die Figur des stigmatisierten Jüngsten oder Schwächsten spricht von Spannungen innerhalb von Familien. Ihr Triumph im Gegensatz zu bestraften Geschwistern widerspricht anscheinend dem Geschwisterideal, das durch die Identifikation mit dem Zurückgesetzten in den Hintergrund tritt. Das Märchenglück kann zwar auch hier im Zusammenführen der Geschwister bestehen, aber eben häufig auch in der Trennung von alten Familienbanden. ${ }^{92}$ Die Diskriminierung in ihrer Herkunftsposition kann als Rechtfertigung dafür dienen, dass ihnen die Verbesserung ihrer sozialen Position wichtiger ist als ihre Verpflichtungen gegenüber der Familie. ${ }^{93}$

Es finden sich also sowohl geschlechterspezifische Tugenden als auch allgemein verbindliche. Man kann weder von einem einheitlichen Geschwisternoch Geschlechterbild sprechen, vor allem wenn man alle Untergattungen der KHM einbezieht und nicht nur die sogenannten „Zaubermärchen“. Die Erzähltradition ist nicht nur durch bürgerliche, sondern auch bäuerliche, christliche, feudale und aufklärerische Einflüsse geprägt. Inwieweit Märchen sich tatsächlich auf die Sozialisation auswirken, ist von Individuum zu Individuum verschieden und bedingt durch weitere Faktoren. ${ }^{94}$ Ausgesuchte Kinderliteratur hat sicher eine Art Kontrollfunktion in der Ausbildung und Internalisierung konformen Rollenverhaltens ausgeübt. ${ }^{95}$ Der Erfolg der KHM darf nicht darüber hinwegtäuschen, dass dieser lange Zeit auf die gesellschaftliche Schicht beschränkt war, aus welcher sie, zumindest in ihrer überarbeiteten Fassung, stammten. Diese schichtspezifische Unterscheidung diente der Abgrenzung zu anderen Klassen wie dem Proletariat und wurde pädagogisch begründet: Die Märchenwelt und ihre Schätze würden in Kindern der Armen Sehnsüchte we-

92 Vgl. Bausinger: Volkstradition, S. 21-30.

93 Ingrid Spörks Einschätzung zufolge, welche auf einer Analyse der sog. „MutterMärchen“" in den KHM basiert, werden Konflikte in diesem Märchentypus nicht ausgetragen, sondern ,,verschoben“. So werden ungünstige familiäre, bzw. gesellschaftliche Grundstrukturen nicht in Frage gestellt und es gebe in den KHM kein wirkliches weibliches Analogon zu Heldenmärchen. Vgl. dies.: Studien, S. 215 u. 240.

94 Kay F. Stone untersuchte Reaktionen von Amerikanern auf Märchen. Z.B. erklärt sie die Beliebtheit des Aschenputtel-Märchens u.a. mit dem amerikanischen Idealbild einer Haus- und Ehefrau sowie dem Traum vom sozialen Aufstieg und die Verstärkung der Inhalte durch Filme, Lieder und andere soziale Kontakte. Vgl. dies.: Mißbrauchte Verzauberung. Aschenputtel als Weiblichkeitsideal in Nordamerika, in: Doderer, Klaus (Hrsg.): Über Märchen für Kinder von heute. Weinheim u.a. 1983, S. 78-93. Nicole Lehnert stellt Untersuchungen vor, die durch den Vergleich mit anderen Märchensammlungen die Kulturabhängigkeit und Widersprüchlichkeit von Geschlechterbildern aufzeigen. Vgl. dies.: Frauenbild, S. 16-24.

95 Der Büchertausch zwischen gemischtgeschlechtlichen Geschwistern zeigt, dass dies nicht immer umgesetzt wurde. Vgl. Budde: Bürgerleben, S. 129. 
cken, die aufgrund ihrer begrenzten Möglichkeiten unerfüllt bleiben und somit zu Unzufriedenheit mit den gegebenen Verhältnissen führen würden. ${ }^{96}$ Hier zeigt sich schon ein nahezu aristokratisches Schichtbewusstsein des Bürgertums, das sich zwar ein mögliches Erarbeiten von höheren sozialen Stellungen auf die Fahnen schrieb, welches unabhängig von der Geburt sei, aber, als es sich etabliert hatte, doch nur innerhalb der eigenen Klassengrenzen funktionieren sollte.

\section{Resümee}

Die Untersuchungen haben gezeigt, dass Geschwisterlichkeit in den KHM in ihren überarbeiteten Fassungen vorrangig leibliche Verwandtschaftsbeziehungen meint, die u.a. der Darstellung verschiedener Ideale der bürgerlichen Gesellschaft dienten. Dabei gibt es Strukturen, die in erster Linie nur von Schwestern oder nur von Brüdern getragen werden, aber auch solche, die geschlechtsübergreifend funktionieren. Sowohl harmonische als auch konfliktgeladene Beziehungen haben erzähltechnische sowie pädagogische Funktionen. Sie ermöglichen eine klare Wertung von missglückten Geschwisterkonstellationen, die von Rivalität, Neid und Misshandlung geprägt sind, sowie die Bestärkung eines Zusammengehörigkeitsgefühls, familiärer Nähe und gegenseitiger Verantwortung. Ambivalente Beziehungen funktionieren offenbar weniger gut als Erzählschema und galten nicht als erzählenswert. In den seltenen Fällen konstruierter Geschwisterlichkeit handelt es sich um gemeinschaftsstiftende oder humorvollkameradschaftliche Momente.

Eine weiterführende intertextuelle Analyse und Interpretation von Geschwisterbeziehungen in anderen zeitgenössischen Märchensammlungen oder in vergleichbaren Volkserzählungen anderer Epochen, Regionen, Religionen und Gattungen wären mögliche zukünftige Forschungsbereiche.

\section{Quellen und Literatur}

Alzheimer, Heidrun: Moral im Kinderbuch des 18. Jahrhunderts. Die Moralische Geschichte als Wegbereiterin des Märchenbooms im 19. Jahrhundert, in: Beisbart, Ortwin u.a. (Hrsg.): Märchen. Geschichte - Psychologie - Medien. Hohengehren 2007, S. 7-28.

Bausinger, Hermann: Geschwister gehen bis zum Rhein ... . Perspektiven der Volkstradition, in: Klosinski, Gunther (Hrsg.): Verschwistert mit Leib und Seele. Geschwisterbeziehungen gestern - heute - morgen. Tübingen 2000, S. 21-30.

Blaha-Peillex, Nathalie: Mütter und Anti-Mütter in den Märchen der Brüder Grimm. Tübingen 2008.

96 Vgl. Richter, Dieter u.a.: Märchen, Phantasie und soziales Lernen. Berlin 1974, S. 25 f. 
Budde, Gunilla-Friederike: Auf dem Weg ins Bürgerleben. Kindheit und Erziehung 18401914. Göttingen 1994.

Clausen-Stolzenburg, Maren: Märchen und mittelalterliche Literaturtradition. Heidelberg 1995.

Denecke, Ludwig u.a.: Die Brüder Grimm in Bildern ihrer Zeit. 2. Aufl., Kassel 1980.

Derungs, Kurt: Die ursprünglichen Märchen der Brüder Grimm. Handschriften, Urfassung und Texte zur Kulturgeschichte. Bern 1999.

Franz, Kurt: „Sagen lassen sich die Menschen nichts, aber erzählen kann man ihnen alles“. Das Volksmärchen als Erziehungs- und Bildungsmedium vom 19. Jahrhundert bis in die Gegenwart, in: ders. (Hrsg.): Märchenwelten. Das Märchen aus der Sicht verschiedener Fachdisziplinen. Baltmannsweiler 2008, S. 72-102.

Goody, Jack: Geschichte der Familie. München 2002.

Hausen, Karin: „,... eine Ulme für das schwankende Efeu“. Ehepaare im Bildungsbürgertum. Ideale und Wirklichkeiten im späten 18. und 19. Jahrhundert, in: Frevert, Ute (Hrsg.): Bürgerinnen und Bürger. Geschlechterverhältnisse im 19. Jahrhundert. Göttingen 1988, S. 85-117.

Kaschuba, Wolfgang: Deutsche Bürgerlichkeit nach 1800. Kultur als symbolische Praxis, in: Kocka, Jürgen (Hrsg.): Bürgertum im 19. Jahrhundert. Bd. 3. München 1988, S. 9-44.

Kitzler, Marianne: Kirchenlehre und Märchen. Wien 2010.

Kluge, Friedrich: Etymologisches Wörterbuch der deutschen Sprache. 25. Aufl., Berlin u.a. 2011.

Lehnert, Nicole: Brave Prinzessin oder freie Hexe? Zum bürgerlichen Frauenbild in den Grimmschen Märchen. Münster 1996.

Lüthi, Max: Familie und Natur im Märchen, in: ders.: Volksliteratur und Hochliteratur. Menschenbild, Thematik, Formstreben. Bern u.a. 1970, S. 63-78.

Lüthi, Max: Märchen. Stuttgart 2004.

Lüthi, Max: Das europäische Volksmärchen. Form und Wesen. Tübingen u.a. 2005.

Mazenauer, Beat u.a.: Wie Dornröschen seine Unschuld gewann. Archäologie der Märchen. München 1998.

McLeod, Hugh: Weibliche Frömmigkeit - männlicher Unglaube? Religion und Kirchen im bürgerlichen 19. Jahrhundert, in: Frevert, Ute (Hrsg.): Bürgerinnen und Bürger. Geschlechterverhältnisse im 19. Jahrhundert. Göttingen 1988, S.134-156.

Ranke, Kurt u.a. (Hrsg.): Enzyklopädie des Märchens. Handwörterbuch zur historischen und vergleichenden Erzählforschung. Berlin 1997-2014.

Richter, Dieter u.a.: Märchen, Phantasie und soziales Lernen. Berlin 1974.

Rölleke, Heinz: „Alt wie der Wald“. Reden und Aufsätze zu den Märchen der Brüder Grimm. Trier 2006.

Rölleke, Heinz (Hrsg.): Kinder- und Hausmärchen. Mit den Originalanmerkungen der Brüder Grimm. 3 Bde. Stuttgart 2008.

Rosenbaum, Heidi: Formen der Familie. Untersuchungen zum Zusammenhang von Familienverhältnissen, Sozialstruktur und sozialem Wandel in der deutschen Gesellschaft des 19. Jahrhunderts. Frankfurt/Main 1996.

Schmitt, Ludwig E. (Hrsg.): Jacob Grimm und Wilhelm Grimm. Werke. Forschungsausgabe. Bd. 31. Abt. 2: Die Werke Wilhelm Grimms. Kleinere Schriften 1. Hildesheim u.a. 1992.

Schnack, Ingeborg u.a.: Briefe der Brüder Grimm an Savigny. Bd. 1. Berlin 1953. 
Solms, Wilhelm: Die Moral von Grimms Märchen. Darmstadt 1999.

Spörk, Ingrid: Studien zu ausgewählten Märchen der Brüder Grimm. Frauenproblematik, Struktur, Rollentheorie, Psychoanalyse, Überlieferung, Rezeption. Königstein/Ts. 1985.

Steig, Reinhold (Hrsg.): Achim von Arnim und Jacob und Wilhelm Grimm. Stuttgart 1904.

Stone, Kay F.: Mißbrauchte Verzauberung. Aschenputtel als Weiblichkeitsideal in Nordamerika, in: Doderer, Klaus (Hrsg.): Über Märchen für Kinder von heute. Weinheim u.a. 1983, S. 78-93.

Uther, Hans-Jörg: Märchen vor Grimm. München 1990.

Uther, Hans-Jörg: Handbuch zu den „Kinder- und Hausmärchen” der Brüder Grimm. Entstehung - Wirkung - Interpretation. Berlin u.a. 2008.

Weber-Kellermann, Ingeborg: Die deutsche Familie. Versuch einer Sozialgeschichte. 6. Aufl., Frankfurt/Main 1981.

Zipes, Jack D.: Fairy tales and the art of subversion. The classical genre for children and the process of civilization. Milton Park u.a. 2012. 
Ulrike Schneider, Helga Völkening and Daniel Vorpahl - 978-3-653-98812-3

Downloaded from PubFactory at 01/11/2019 10:54:37AM

via free access 


\title{
Schwestern am Scheideweg - Zur Schwesternbeziehung in der Literatur der Restaurationszeit
}

\author{
Anna Głowacka
}

\begin{abstract}
This article discusses sister relationships within the German literature from enlightenment to the mid 19th century, focusing especially the profile of sisters in the period from 1815 to 1848. The author concluded that within this period sisters were presented with a strong physical and personal contrast. The relationship between sisters is used as a personification of harmony and also as a figuration of conflict. That contrast of sisters perfectly represents the ambivalence of the era. ${ }^{1}$
\end{abstract}

\section{Einleitung}

Die Schwesternkonstellation ist eine Beziehung, die in der Literaturgeschichte sowie in den Biographien von Frauen seit der Antike bis in die Gegenwart vorkommt. Bisher wurde jedoch der Betrachtung des Schwesternverhältnisses weniger Aufmerksamkeit in den Literatur-, Geschichts- und Sozialwissenschaften entgegengebracht als der Untersuchung von Brüderkonstellationen und dem Bruder-Schwestern-Verhältnis. ${ }^{2}$ Von wenigen Ausnahmen abgesehen (Elisabeth Fishel, Helga und Karin Kraus), bildet die Schwesternbeziehung ein Randphänomen, das erst nach der Wende zum 21. Jahrhundert ins Zentrum des Interesses rückte und intensiver untersucht wurde. ${ }^{3}$

In diesem Beitrag wird die Entwicklung der Darstellung der Schwesternbeziehung in der deutschsprachigen Literatur seit der Aufklärung bis zur Mitte des 19. Jahrhunderts (1848) betrachtet. Es werden einige epochenübergreifende Parallelen bzw. Charakteristika in der Darstellung der Schwesternkonstellation sowie die antiken und biblischen Schwesternmuster veranschaulicht. Im zweiten Teil befasse ich mich mit Schwesternfiguren in der Literatur der Restaurationszeit, in der Schwesternpaare überraschend oft dargestellt wurden. Ich untersuche dabei den Zusammenhang zwischen der Popularität der Schwesternthematik und den damaligen Diskursen über die Familie und die Frau. Die analysierten Texte

1 Die Verfasserin arbeitet an der Dissertation „Das Schwesternmotiv in der Literatur des 19. Jahrhunderts“" an der Universität Wien.

2 Vgl. Onnen-Isemann, Corinna; Rösch, Gertrud Maria (Hrsg.): Schwestern. Zur Dynamik einer lebenslangen Beziehung. Frankfurt/Main 2005, S. 7f.

3 Vgl. den aktuellen Forschungsstand und die Bibliographie bei Labouvie, Eva (Hrsg.): Schwestern und Freundinnen. Zur Kulturgeschichte weiblicher Kommunikation. Köln 2009. 
werden somit auf die schwesterliche Beziehung, als wichtigen Aspekt im Familien- und Geschlechterdiskurs, hin befragt. Im Beitrag wird in Anlehnung an Gertrud Maria Rösch zwischen der biologischen Schwesternschaft (Abstammung von den gleichen leiblichen Eltern) und der ethischen und emotionalen Schwesterlichkeit (eine sich in Worten und Verhalten artikulierende Nähe und Solidarität) differenziert. ${ }^{4}$

\section{Schwestern in literarischen und kulturellen Leitbildern}

Obwohl sich einige Differenzen in der Darstellung der Schwesternkonstellation in einzelnen Epochen und Perioden ergeben, lassen sich bestimmte Parallelen in der Darstellung der Schwesternbeziehung feststellen. Für die literarischen Schwesternfiguren ist eine ausgeprägte Gegensätzlichkeit kennzeichnend, die bereits für die antiken (Antigone und Ismene, Elektra und Chrysothomis) und biblischen Paare (Lea und Rachel, Marta und Maria) sowie Märchenfiguren (Schneeweißchen und Rosenrot, Goldmarie und Pechmarie, Aschenputtel und ihre Stiefschwestern) charakteristisch ist. ${ }^{5}$ Dabei ist nicht zu übersehen, dass die biblischen Schwesternpaare ebenso wie Schwestern im Märchen eher Konkurrenz, Neid, Abgrenzung und Geschwisterrivalität symbolisieren. Ihre Beziehung ist somit dichotomisch und durch ihre Grundverschiedenheit sind potenzielle Konflikte begünstigt. So werden antithetische Schwesternfiguren - gute vs. böse, ${ }^{6}$ schöne vs. hässliche, helle vs. dunkle, bodenständige vs. leidenschaftliche, widerspenstige vs. folgsame, zarte vs. starke - konstruiert.

In kulturellen Leitbildern seit der Aufklärungszeit sind jedoch die Schwestern zu Harmonie, Solidarität und schwesterlicher Liebe moralisch verpflichtet, weil die biologische Schwesternschaft mit Schwesterlichkeit verbunden wurde: „Schwesterliches Verhalten erhält [...] den Rang eines Ideals, denn es bezeich-

4 Rösch, Gertrud Maria: Die unzärtlichen Schwestern. Zur Binnendifferenzierung des Weiblichen am Beispiel der Schwesterbeziehung, in: Wiesinger, Peter (Hrsg.): Zeitenwende. Die Germanistik auf dem Weg vom 20. ins 21. Jahrhundert. Akten des X. Internationalen Germanistenkongresses. Bd. 10. Bern u.a. 2003, S. 57-66, hier S. 58.

5 Vgl. Fishel, Elisabeth: Schwestern. Liebe und Rivalität innerhalb und außerhalb der Familie. Frankfurt/Main 1980, S.167-168; Onnen-Isemann, Rösch: Schwestern, S.13; Schahadat, Schamma: Schwesternmord: Poetik, Politik und Gender in der polnischen Romantik, in: Hotz-Davies, Ingrid; Schahadat, Schamma (Hrsg.): Ins Wort gesetzt, ins Bild gesetzt: Gender in Wissenschaft, Kunst und Literatur. Bielefeld 2007, S. 234-256, hier S. 245 u. Głowacka, Anna: Sense and Sensibility im deutschsprachigen Roman. Das Schwesternmotiv in der Literatur des 19. Jahrhunderts, in: Jahrbuch des Wissenschaftlichen Zentrums der Polnischen Akademie der Wissenschaften in Wien. Bd. 3 (20102012). Wien 2012, S. 389-401, hier S. 390-393.

6 Vgl. Schahadat: Schwesternmord.

Ulrike Schneider, Helga Völkening and Daniel Vorpahl - 978-3-653-98812-3 
net indirekt ein positiv besetztes menschliches Verhalten.“"7 Mit dem Adjektiv „schwesterlich“, das auf die Gesinnung und Eigenart einer Schwester zielt, sind ausgesprochen positive Werte wie Mitgefühl, Nähe, Zusammenhalt und Hilfe verbunden, ${ }^{8}$ und diesen hohen Idealen sollten Figuren (und reale Frauen) entsprechen: „Obwohl dieser Anspruch bereits damals in Frage gestellt wurde, wird diese Erwartung bis in die Gegenwart stereotyp an Schwestern herangetragen. “9 Im Folgenden wird veranschaulicht, wie die Literatur dieses harmonische Leitbild mitgestaltete, bestätigte oder in Frage stellte.

\section{Harmonische Schwesternbeziehung}

Die Schriftsteller_innen der Aufklärung und Empfindsamkeit bis um 1800 gestalteten das Leitbild der bürgerlichen Familie mit. ${ }^{10}$ Im 19. Jahrhundert entwickelte sich ein neues Familienmodell: die bürgerliche Kleinfamilie. ${ }^{11}$ Innige Familiengemeinschaft wurde in der Literatur propagiert, Eheliebe und Geschwisterliebe wurden zu Idealen von allgemeiner Anziehungskraft. Das Prinzip der Blutsverwandtschaft verkörperte Antigone aus der gleichnamigen Tragödie von Sophokles, die rege rezipiert wurde und das als schönstes Drama galt. ${ }^{12} \mathrm{Um}$ 1800 sind Geschwister omnipräsent, und es lässt sich eine Obsession in Bezug auf die Geschwisterproblematik feststellen. ${ }^{13}$ Es entwickelte sich die politische Idee der fraternité, die Schwesterlichkeit dient dagegen als Utopie einer anderen Art. Schwesterlichkeit wird hier als ,eine Chiffre eingesetzt, um altruistisches Verhalten glaubhaft machen zu können“14. Zur Zeit der Aufklärung wird „die biologisch codierte Schwesternschaft mit den altruistischen Tugendpostulaten vermittelt und Schwesterlichkeit wird als Beitrag zum Humanisierungspro-

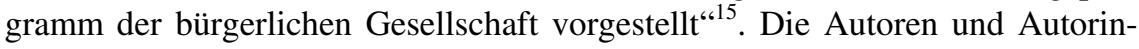

7 Onnen-Isemann, Corinna; Rösch, Gertrud Maria: Schwesterherz Schwesterschmerz. Schwestern zwischen Solidarität und Rivalität. Heidelberg 2006, S. 23.

8 Rösch: Schwestern, S. 58.

9 Onnen-Isemann; Rösch: Schwesterherz, S. $22 \mathrm{f}$.

10 Vgl. Rosenbaum, Heidi: Formen der Familie. Untersuchungen zum Zusammenhang von Familienverhältnissen, Sozialstruktur und sozialem Wandel in der deutschen Gesellschaft des 19. Jahrhunderts. Frankfurt/Main 1982, S. 263-271.

11 Vgl. Gestrich, Andreas: Neuzeit, in: ders. u.a. (Hrsg.): Geschichte der Familie. Stuttgart 2003, S. 387-392.

12 Vgl. Steiner, George: Die Antigonen. Geschichte und Gegenwart eines Mythos. München, Wien 1988, S. 13.

13 Vgl. Frei-Gerlach, Franziska: Geschwister. Ein Dispostiv bei Jean Paul und um 1800. Berlin, Boston 2012, S. 1-22.

14 Rösch: Schwestern, S. 57.

15 Ebd., S. 65. 
nen inszenieren eine harmonisch-utopische Version der Schwesternschaft. Die als zärtliche Schwestern dargestellten Figuren realisieren mit tugendhafter Opferbereitschaft die hohen Ideale der Treue, Humanität und Solidarität. In dem Lustspiel Die zärtlichen Schwestern (1747) von Christian Fürchtegott Gellert erreicht schwesterliche Liebe und Treue „ein nahezu übermenschliches Maß“16. Zwischen der vernünftigen, uneigennützigen, aber unattraktiven Charlotte (,Je nun, du bist freilich nicht die Schönste; aber der Himmel wird dich schon versorgen." - so ihr Vater, I,1,18-19) und der schönen, widerspenstigen Juliane gibt es keine Spur der Rivalität um das Erbe oder die Verehrer. Die ältere, vernünftige Schwester realisiert die Tugenden der Schwesterlichkeit, indem sie eine Intrige zu Gunsten ihrer Schwester knüpft, an deren Folgen sie letztendlich selbst leidet. Sie ist jedoch davon überzeugt, dass sie richtig handelt: „Ich mache mir eine Ehre daraus, mich an dem günstigen Schicksale meiner Schwester aufrichtig zu vergnügen und mit dem meinigen zufrieden zu sein.“ (I, 1, 18-20) In Mozarts Oper Così fan tutte (1790) werden die emotionale Treue, schwesterliche Liebe und Solidarität der beiden Schwestern Dorabella und Fiordiligi trotz eines inneren Konflikts an keiner Stelle in Frage gestellt. ${ }^{17}$

In der Erzählung von Sophie La Roche Die zwey Schwestern (1783) will die jüngere, schöne, von den Eltern geliebte Schwester Laura mit ihrer älteren Schwester Adelinde, von der sie bisher nichts gewusst hat, weil diese als ungeliebte hässliche Tochter vor vielen Jahren vom zornigen Vater von zu Hause verbannt worden ist, ihr Vermögen teilen. Das führt schließlich zur Versöhnung der älteren Schwester mit dem Vater. Auch hier wird die Schwesternschaft mit Humanität und Schwesterlichkeit gleichgesetzt. Literarische Schwesternfiguren symbolisieren Möglichkeiten einer harmonischen Lösung der Konflikte und damit „humanerer Gestaltung der bürgerlichen Gesellschaft" ${ }^{\text {“18 }}$.

Die ungleichen Schwestern ergänzen einander komplementär und bilden eine harmonische Beziehung ohne strikte Bipolarität. Gegenseitige Unterstützung, Erziehung und schwesterliche Liebe können mit dem Aufklärungsoptimismus alle Konflikte überwinden. So wird die positive Wirkung der Familienbände und Schwesternbunde betont und das Ideal der schwesterlichen (und zwischenmenschlichen) Solidarität und Harmonie bestätigt.

16 Onnen-Isemann; Rösch: Schwestern, S. 15.

17 Vgl. Kleinertz, Rainer: Schwestern auf der Opernbühne. Mozarts „Così fan tutte“ unter der Berücksichtigung der Schwesternkonstellation, in: Onnen-Isemann; Rösch: Schwestern, S. 187-208.

18 Onnen-Isemann; Rösch: Schwesterherz, S. 22. 


\section{Der zerbrochene Schwesternbund}

In der Literatur der ersten Hälfte des 19. Jahrhunderts war die Schwesternkonstellation sehr verbreitet. ${ }^{19}$ Im Rahmen der Etablierung des Bürgertums, der Privatisierung des Familienlebens und der starken Akzentuierung der Familie als Gefühls- und Werteverband nahm auch die Schwesternbeziehung an Bedeutung zu. In der Literatur der Epoche zwischen 1815 und 1848, die Restaurationszeit, Biedermeier oder Vormärz genannt wird, ${ }^{20}$ häufen sich die Schwesternpaare. Eine Akkumulation ist in den 1830ern und 1840ern zu beobachten. ${ }^{21}$ Besonders österreichische Autoren, wie Adalbert Stifter und Franz Grillparzer, bedienen sich gern des Schwesternmotivs. In zahlreichen Erzählungen von Adalbert Stifter, wie Feldblumen (1841/1844), ${ }^{22}$ Der Hochwald (1842/1844), Die Schwestern (1846), Zwei Schwestern (1850), und in Franz Grillparzers Dramen Libussa (1848) und Die Jüdin von Toledo (1851) werden Schwesternkonstellationen aufgegriffen. Auch bei anderen Schriftsteller_innen wie Eduard Mörike (Lucie Gelmeroth [1839], Gedichte) und Annette von Droste-Hülshoff (Die Schwestern [1841]) ist die Schwesternproblematik präsent.

In der Literatur finden sich zahlreiche Schwesternbeziehungen, die zum einen die damalige Situation der Familie widerspiegeln, zum anderen als Muster der schwesterlichen Liebe dienen. In dieser Zeit kommt es zum ersten Höhepunkt des neuen Familienmodells und zur Entwicklung eines Familienkultes. ${ }^{23}$ Die gefühlsmäßige Bindung der einzelnen Familienmitglieder untereinander wird betont und propagiert. Die Gatten- und Geschwisterliebe wird zum elemen-

19 Vgl. Rösch: Schwestern, S. 171.

20 Zum Begriff der ambivalenten Epoche und ihrer literarischen Strömungen herrscht keine Einstimmigkeit. „Biedermeierzeit“ von Sengle hat sich nicht durchgesetzt; als Vormärz wird sowohl die Periode 1830-1848 als auch die ganze Epoche 1815-1848 bezeichnet. Da ich die Texte von den frühen 1820ern bis 1848 behandle, entscheide ich mich für den allgemeineren Begriff. Vgl. Sengle, Friedrich: Biedermeierzeit. Deutsche Literatur im Spannungsfeld zwischen Restauration und Revolution 1815-1848. Bd. 1-3. Stuttgart 1971-1980 u. Witte, Bernd (Hrsg.): Eine Sozialgeschichte der deutschen Literatur. Bd. 6. Hamburg 1980.

21 Vgl. Bartl, Andrea: Ungleiche Zwillinge. Adalbert Stifters „Zwei Schwestern“ - mit einem anthropologischen Seitenblick auf Ernst von Feuchtersleben, in: Onnen-Isemann, Corinna; Rösch, Gertrud-Maria (Hrsg.): Schwestern. Zur Dynamik einer lebenslangen Beziehung. Frankfurt/Main 2005, S. 153-169, hier S. 153.

22 Erstdrucke in „Iris“ und überarbeitete Ausgaben in „Studien“. Die in „Iris“ publizierte Erzählung „Die Schwestern“ wurde sehr stark überarbeitet und erschien in „Studien“ unter dem Titel „Zwei Schwestern“. Vgl. Hoffmann, Werner: Adalbert Stifters Erzählung „Zwei Schwestern“. Ein Vergleich der beiden Fassungen. Marburg 1966.

23 Vgl. Rosenbaum: Familie, S. 252.

Ulrike Schneider, Helga Völkening and Daniel Vorpahl - 978-3-653-98812-3 
taren Moment, mit dessen Hilfe die häusliche Sphäre als Gefühlsgemeinschaft dargestellt wird. ${ }^{24}$ In den literarischen Texten wird die innige Liebe und angeborene Verbundenheit der Schwestern unterstrichen. So schreibt Caroline Pichler (Die Belagerung Wiens 1828):

So waren diese beiden Schwestern durch Natur und Umstände geworden und liebten sich trotz aller Verschiedenheit des Sinns und mancher Mißverhältnisse, welche die Vorliebe der Mutter für die ältere erzeugte, herzlich. ${ }^{25}$

Weiterhin wird das Ideal des schwesterlichen Verhaltens betont, das mit positiven Werten wie Treue, Solidarität, Mitgefühl, Nähe und Zusammenhalt aufgeladen ist. Die Schwesternfiguren erscheinen oft gemeinsam, man kann sie kaum voneinander unterscheiden und verwechselt sie mitunter (z.B. Zwei Schwestern von Adalbert Stifter). Somit verkörpern sie eine ursprüngliche zwischenmenschliche Einheit, die enge Bindung zweier Hälften.

In der Literatur der Restaurationszeit befestigt sich jedoch eine strikte äußere und innere Antithetik der Schwesternfiguren, die kein völlig harmonisches Paar bilden. Besonders für viele Texte der erfolgreichsten deutschen und österreichischen Schriftstellerinnen dieser Epoche wie Caroline de la Motte Fouqué, Caroline Pichler, Luise Mühlbach und Ida Hahn-Hahn ist die Präsenz zweier antagonistischer Frauen- und Schwesternfiguren kennzeichnend. ${ }^{26}$ Das Motiv ungleicher Schwestern wird aufgegriffen, „um völlig verschiedene Frauenschicksale komplementär zueinander darstellen zu können““27. So betont Luise Mühlbach im Roman Glück und Geld (1842) die Gegensätzlichkeit der Schwestern: „Und so verschieden, wie ihre äußere Erscheinung, war auch das Wesen dieser beiden Schwestern. “28 Die Schwestern stehen am Scheideweg, müssen sich trennen und gehen einen völlig anderen Lebensweg. Eine der Schwestern wählt die Konvenienzehe und Geld, die andere Liebesehe und Glück, welche jedoch durch Armut und Krankheit bald enden.

24 Vgl. Frevert, Ute: Frauen-Geschichte. Zwischen bürgerlichen Verbesserung und neuer Weiblichkeit. Frankfurt/Main 1986, S. 20.

25 Pichler, Caroline: Die Belagerung Wiens. Wien 1828, S. 13.

26 Vgl. Möhrmann, Renate: „Die Teilnahme der weiblichen Welt am Staatsleben ist eine Pflicht!“ Frauenrechte - Menschenrechte. Vormärzautorinnen ergreifen das Wort, in: Gnüg, Hiltrud; Möhrmann, Renate (Hrsg.): Frauen Literatur Geschichte. Schreibende Frauen vom Mittelalter bis zur Gegenwart. Stuttgart 1999, S. 377-402, hier S. 383.

27 Möhrmann, Renate: Die andere Frau. Emanzipationsansätze deutscher Schriftstellerinnen im Vorfeld der Achtundvierziger-Revolution. Stuttgart 1977, S. 108.

28 Mühlbach, Luise: Glück und Geld. Bd. 1. Altona 1842, S. 6. 
Gegensätzliche Schwesternfiguren repräsentieren die widerspruchsvolle Epoche geradezu ideal. ${ }^{29}$ Darin erweisen sich Autoren und Autorinnen als echte Repräsentanten der Metternichschen Restauration, die „zu den uneinheitlichsten und widerspruchsvollen Epochen gehört und in der das Nebeneinander von revolutionären und reaktionären Elementen geradezu strukturbildend war. ${ }^{\text {‘30 }}$ Theodor Mundt wies darauf in seiner Geschichte der Literatur der Gegenwart (1842) hin:

In Deutschland hat die Julirevolution eine Meinungsrevolution zu Wege gebracht. Es bildeten sich seitdem zwei Gegensätze in einer unter den Deutschen noch nicht gekannten Weise zu förmlichen Parteirichtungen aus, die auch das Privatleben heftig berührten, und in die Literatur ganz neue Zündstoffe schleuderten. Diese eine Nachgeburt der Julirevolution war der Liberalismus [...] Die andere Nachgeburt ... der Reactionarismus. ${ }^{31}$

Der Dualismus von „biedermeierlich-restaurativen und liberal-avantgardistischen Tendenzen, der dieser Ära ihr Gepräge gab ${ }^{\text {“32 }}$, spiegelt sich in den Figuren der gegensätzlichen Schwestern wider. Die revolutionäre Schwester erscheint an der Seite der häuslichen Schwester. Die emanzipierte Frau wird mit ihrer konventionellen Leibschwester kontrastiert, ihrem Gegenbild. Während eine der Schwestern mit ihrem Beruf als Dichterin, Künstlerin oder Schauspielerin den Ausbruch aus der den Frauen zugeschriebenen Rolle wagt, ist die andere musterhafte Hausfrau, Gattin und Mutter. So wird der künstlerisch begabten Faustine im Roman Gräfin Faustine von Ida Hahn-Hahn (1840) ihre bescheidene häusliche Schwester gegenübergestellt. In Schauspielerin (1836) von Heinrich Laube bilden die Titelheldin und ihre genügsame Schwester ebenfalls eine strikte Dichotomie. Der Protagonist wendet am Ende seine Liebe von der tätigen und ehrgeizigen Schauspielerin ab (die sich mit diesem Beruf in einer fragwürdigen Position befindet ${ }^{33}$ ) und der häuslichen Schwester der Komödiantin zu. Die unangepassten Schwestern enden meist unglücklich oder sterben. ${ }^{34}$ Dieses wiederkehrende Erzählschema zeigt, dass die Gesellschaft nicht bereit

29 Als reales Beispiel der gegensätzlichen Schwestern und Schriftstellerinnen dieser Epoche können die radikale Louise Aston und die religiöse Eulalia Merx angeführt werden.

30 Möhrmann: Frau, S. 66.

31 Zit. nach: ebd., S. 40-41.

32 Ebd., S. 41.

33 Vgl. Lorenz, Dagmar: Weibliche Rollenmodelle bei Autoren des „Jungen Deutschland“ und des „Biedermeier“, in: Burkhard, Marianne (Hrsg.): Gestaltet und gestaltend. Frauen in der deutschen Literatur. Amsterdam 1980, S. 155-184, hier S. 173.

34 Dieses Muster bleibt noch 1899 aktuell in der Erzählung von Helene Böhlau „Halbtier!“, in der sich der Protagonist von der künstlerischen klugen Isolde abwendet, um schließlich deren häusliche Schwester zu heiraten. 
für die emanzipierte Frau war bzw. eine freie Frau nicht duldete. Mit dieser Opposition werden die Konventionalität der einen Schwester und die Fortschrittlichkeit der anderen unterstrichen. Daraus lassen sich Rückschlüsse auf die höchst gespaltene Epoche und ihre beiden ideellen Grundkonzepte ziehen.

Die Biedermeierfamilie wurde gern als Paradebeispiel der verinnerlichten zwischenmenschlichen Gemeinschaft gesehen. Das Bild, dass sich das „Bürgertum resigniert in den Innenraum der Familie zurückgezogen und dort eine Kultur bescheidener Häuslichkeit gepflegt habe“, erscheint jedoch als ,ideologisches Zerrbild ‘ ${ }^{435}$. Das Ideal biedermeierlicher Häuslichkeit und Familienidylle traf mithin auf Frauen zu, die die Familie ,zu einem Ort wohlgeordneter Intimität, beschaulicher Harmonie, gediegener Entspannung ${ }^{636}$ machen wollten: „Nach außen schien es, als ob hier nichts als Gefühl, Liebe und Zärtlichkeit residierten. ${ }^{\text {“37 }}$ Man darf aber der Fiktion der unproblematisch heilen Biedermeierzeit nicht unterliegen. Obwohl z.B. Henriette Hanke in ihren Romanen ein reines Familienglück entfaltet und in ihrer Darstellung des Familienlebens die behutsam waltenden Mütter und Schwestern schildert, geriet bei den VormärzAutorinnen der pietätvolle Familienkult ins Wanken. ${ }^{38}$ Besonders Luise Mühlbach schildert die Pathologie der Familie (Elternfluch, Verbannung der Kinder aus dem Haus, Enterbung) und der Schwesternbeziehung, in der - im Extremfall - eine Schwester die andere verfolgt und Schuld an ihrem Selbstmord ist (Luise Mühlbach, Gisela [1845]).

Die Schwesternbeziehung dient für die Autorinnen des Vormärz als Figuration des Konflikts, der sich nicht friedlich lösen lässt und zum tragischen Ende führt. Im Zusammenhang mit der Festschreibung der Geschlechtscharaktere nahm die Schwesternbeziehung andere Qualitäten an. ${ }^{39}$ In den Schwesternfiguren ,verschränken sich Stereotypen aus dem Weiblichkeitsdiskurs des 19. Jahrhunderts ${ }^{\text {40 }}$, wie die Einordnung der Frau entweder als Heilige oder Hure, asexuell kontra sexuell, keusche Madonna oder erotische Mätresse (z.B. in der Ballade Die Schwestern (1841) von Annette von Droste-Hülshoff). Anhand der Schwesternbeziehung lässt sich die Abhängigkeit der Frau von der patriarchalischen Familie und Gesellschaft und ihre Verstrickung zeigen

35 Frevert: Frauen-Geschichte, S. 66. Der Begriff ,Biedermeier' stammt aus den fünfziger Jahren des 19. Jahrhunderts und bezeichnete despektierlich-spöttisch die Lebensart und Kultur des Bürgertums in der Restaurationsphase. Vgl. ebd., S. 66.

36 Ebd., S. 67.

37 Ebd.

38 Vgl. Möhrmann: Frau, S. 38.

39 Vgl. Onnen-Isemann; Rösch: Schwestern, S. 15.

40 Rösch: Schwestern, S. 63.

Ulrike Schneider, Helga Völkening and Daniel Vorpahl - 978-3-653-98812-3 
in fremdes Wollen - entweder in das elterliche und damit theologisch-moralische Gebot oder in das erotische und damit männliche Begehren. So verharren sie in der Schwesternschaft mit tödlichen Ausgang, statt eine von Selbstbestimmtheit geprägte, horizontale Beziehung verwirklichen zu können. ${ }^{41}$

Die Beziehung der Schwesternfiguren ist vom oppressiven Willen der Eltern (Zwang zur Heirat, Übernahme der Mutterrolle durch die ältere Schwester) oder den Handlungen der Männer (Ausnutzung, Untreue, Wechsel zwischen Schwestern) abhängig. Der anfängliche Bund der Schwesternfiguren wird gebrochen, am Anfang des Textes stehen sie häufig bereits am Scheideweg und werden getrennt. Ihre einzige Kontaktmöglichkeit bleibt oft nur der Briefwechsel (z.B. Ida Hahn-Hahn, Zwei Frauen [1845]).

\section{Schwesternpolarität als Geschlechterpolarität}

Die sich verstärkende Antithetik der Schwesternfiguren kann man als Opposition der Geschlechter im bürgerlichen Zeitalter lesen. Die gegensätzlichen Schwestern können die kulturell konstruierten Unterschiede zwischen Frau und Mann symbolisieren:

[Die] Schwesternbeziehung wird von den binären Oppositionen der weiblichen und männlichen Natur erfasst, d. h. aus dem harmonischen Verband gleichgestimmter Frauen wird ein Paar, das die kulturell codierten Gegensätze von Frau und Mann mit verkörpert. Die daraus erwachsenden Konflikte treiben vielfach auf eine tragische Lösung zu. ${ }^{42}$

Strikte Teilung und Grenzen zwischen den Geschlechtern werden in den kontrastiven Persönlichkeiten und Lebenswegen der Schwestern sichtbar. Bipolarität tritt in der Beziehung zwischen der extrem weiblichen (jüngeren, femininen, leidenschaftlichen, melancholischen, folgsamen, zarten) Schwester und der extrem männlichen (älteren, starken, vernünftigen, aktiven, lebensbejahenden) Schwester hervor. Als Beispiel kann die Erzählung Zwei Schwestern von Adalbert Stifter dienen, in der eine zarte, feminine Schwester mit ihrer starken, virilisierten Schwester kontrastiert wird. ${ }^{43}$ Die Grundverschiedenheit der Schwestern ist so groß wie die der Geschlechter. ${ }^{44}$

In der untersuchten Epoche, in der die Vorstellung der „Geschlechtscharaktere" (Karin Hausen) stark verfestigt war, symbolisieren die Schwesternfiguren Pole, die sich nicht mehr verbinden können. Eine strikte Grenze zwischen den

41 Ebd.

42 Onnen-Isemann; Rösch: Schwestern, S. 15.

43 Vgl. Bartl: Zwillinge.

44 „Die jungdeutschen Männer und Frauen sind so grundverschieden“. Lorenz: Rollenmodelle, S. 168. 
Geschlechtern, die die ungleichen Schwestern symbolisieren, macht eine harmonische Verbindung unmöglich. Die Kluft zwischen den Schwestern, wie zwischen den Geschlechtern, ist zu tief; man kann die entstehenden Konflikte mit dem aufklärerischen, optimistischen Erziehungsprogramm und der gegenseitigen Therapierung nicht mehr überwinden. Die lebensbejahende, fröhliche Schwester in der Erzählung von Caroline de la Motte Fouqué Dornen und Blüthen des Lebens (1820) kann ihre zarte, melancholische Schwester nicht verstehen und ihr nicht helfen, ihre Melancholie und ihren Schwermut zu überwinden. Jede Schwester bleibt in ihrer Welt, es gibt keine Brücke, die sie verbinden könnte. In Glück und Geld von Mühlbach kann die vernünftige, stolze Schwester die leidenschaftliche Liebe ihrer Schwester zu einem enterbten jungen Mann nicht nachvollziehen. Die gegensätzlichen Schwesternfiguren gehen völlig unterschiedliche und damit getrennte Lebenswege.

\section{Zusammenfassung}

Das Idealbild der harmonischen Schwesternbeziehung erweist sich in der Literatur dieser widerspruchsvollen Epoche als nicht zu realisierendes Konstrukt, die Darstellung dichotomischer Schwesternfiguren wird vielmehr zum Spiegelbild der Jahre 1815 bis 1848. Die Frage nach der Darstellung der Schwesternbeziehung kann als eine Untersuchungsfolie dienen, um über ein scheinbares Randphänomen an zentrale Fragestellungen einer ganzen Epoche zu gelangen. ${ }^{45}$ Zusammenfassend lässt sich festhalten, dass die Schwesternbeziehung ebenso als Bild der Solidarität als auch der Harmonie sowie als Figuration des Konflikts und als Symbol der Gegensätze metaphorisch verwendet wird.

\section{Quellen}

Böhlau, Helene: Halbtier!, in: Gesammelte Werke. Bd. 5. Berlin, Wien 1915, S. 7-183.

Droste-Hülshoff, Annette von: Die Schwestern, in: Sämtliche Werke in zwei Bänden. Bd. 1: Gedichte. Hrsg. v. Bodo Plachta u. Winfried Woesler. Frankfurt/Main 1996.

Fouqué, Caroline de la Motte: Dornen und Blüthen des Lebens, in: Frauentaschenbuch für das Jahr 1820. Hrsg. v. Friedrich de la Motte Fouqué. Nürnberg 1820, S. 125-183.

Gellert, Christian Fürchtegott: Gesammelte Schriften III: Lustspiele. Hrsg. v. Bernd Witte. Berlin, New York 1988.

Grillparzer, Franz: Die Jüdin von Toledo. Historisches Trauerspiel in fünf Aufzügen. Hrsg. v. Wolfgang Paulsen. Stuttgart 1990.

Grillparzer, Franz: Libussa. Trauerspiel in fünf Aufzügen. Stuttgart 1989.

Hahn-Hahn, Ida: Gräfin Faustine. Bonn 1986.

Hahn-Hahn, Ida: Zwei Frauen. Berlin 1845.

45 Vgl. Onnen-Isemann; Rösch: Schwestern, S. 14.

Ulrike Schneider, Helga Völkening and Daniel Vorpahl - 978-3-653-98812-3 
Laube, Heinrich: Schauspielerin. Mannheim 1836.

La Roche, Sophie von: Die zwey Schwestern, in: Moralische Erzählungen der Frau Verfasserin der Pomona. Sammlung 1.2. Speier 1783/1784, S. 176-247.

Mühlbach, Luise: Gisela. Altona 1845.

Mühlbach, Luise: Glück und Geld. Altona 1842.

Pichler, Caroline: Die Belagerung Wiens. Wien 1828.

Stifter, Adalbert: Gesammelte Werke in 14. Bänden. Hrsg. v. Konrad Steffen. Basel, Stuttgart 1962-1972.

\section{Literatur}

Bartl, Andrea: Ungleiche Zwillinge. Adalbert Stifters „Zwei Schwestern“ - mit einem anthropologischen Seitenblick auf Ernst von Feuchtersleben, in: Onnen-Isemann, Corinna; Rösch, Gertrud Maria (Hrsg.): Schwestern. Zur Dynamik einer lebenslangen Beziehung. Frankfurt/Main 2005, S. 153-169.

Fishel, Elisabeth: Schwestern. Liebe und Rivalität innerhalb und außerhalb der Familie. Frankfurt/Main 1980.

Frei-Gerlach, Franziska: Geschwister. Ein Dispostiv bei Jean Paul und um 1800. Berlin, Boston 2012.

Frevert, Ute: Frauen-Geschichte. Zwischen bürgerlichen Verbesserung und neuer Weiblichkeit. Frankfurt/Main 1986.

Gestrich, Andreas: Neuzeit, in: ders.; Krause, Jens-Uwe; Mitterauer, Michael (Hrsg.): Geschichte der Familie. Stuttgart 2003, S. 364-400.

Głowacka, Anna: Sense and Sensibility im deutschsprachigen Roman. Das Schwesternmotiv in der Literatur des 19. Jahrhunderts, in: Jahrbuch des Wissenschaftlichen Zentrums der Polnischen Akademie der Wissenschaften in Wien. Bd. 3 (2010-2012). Wien 2012, S. 389-401.

Hausen, Karin: Die Polarisierung der „Geschlechtscharaktere“. Eine Spiegelung der Dissoziation von Erwerbs- und Familienleben, in: Conze, Werner (Hrsg.): Sozialgeschichte der Familie in der Neuzeit Europas. Stuttgart 1976, S. 363-393.

Hoffmann, Werner: Adalbert Stifters Erzählung „Zwei Schwestern“. Ein Vergleich der beiden Fassungen. Marburg 1966.

Kleinertz, Rainer: Schwestern auf der Opernbühne. Mozarts „Così fan tutte“ unter der Berücksichtigung der Schwesternkonstellation, in: Onnen-Isemann, Corinna; Rösch, Gertrud Maria (Hrsg.): Schwestern. Zur Dynamik einer lebenslangen Beziehung. Frankfurt/Main 2005, S. 187-208.

Labouvie, Eva (Hrsg.): Schwestern und Freundinnen. Zur Kulturgeschichte weiblicher Kommunikation. Köln 2009.

Lorenz, Dagmar: Weibliche Rollenmodelle bei Autoren des „Jungen Deutschland“ und des „Biedermeier“, in: Burkhard, Marianne (Hrsg.): Gestaltet und gestaltend. Frauen in der deutschen Literatur. Amsterdam 1980, S. 155-184.

Möhrmann, Renate: „Die Teilnahme der weiblichen Welt am Staatsleben ist eine Pflicht!“ Frauenrechte - Menschenrechte. Vormärzautorinnen ergreifen das Wort, in: Gnüg, Hiltrud; Möhrmann, Renate (Hrsg.): Frauen Literatur Geschichte. Schreibende Frauen vom Mittelalter bis zur Gegenwart. Stuttgart 1999, S. 377-402. 
Möhrmann, Renate: Die andere Frau. Emanzipationsansätze deutscher Schriftstellerinnen im Vorfeld der Achtundvierziger-Revolution. Stuttgart 1977.

Onnen-Isemann, Corinna; Rösch, Gertrud Maria: Einleitung, in: dies. (Hrsg.): Schwestern. Zur Dynamik einer lebenslangen Beziehung. Frankfurt/Main 2005, S. 7-20.

Onnen-Isemann, Corinna; Rösch, Gertrud Maria: Schwesterherz - Schwesterschmerz. Schwestern zwischen Solidarität und Rivalität. Heidelberg 2006.

Rosenbaum, Heidi: Formen der Familie. Untersuchungen zum Zusammenhang von Familienverhältnissen, Sozialstruktur und sozialem Wandel in der deutschen Gesellschaft des 19. Jahrhunderts. Frankfurt/Main 1982.

Rösch, Gertrud Maria: Die unzärtlichen Schwestern. Zur Binnendifferenzierung des Weiblichen am Beispiel der Schwesterbeziehung, in: Wiesinger, Peter (Hrsg.): Zeitenwende. Die Germanistik auf dem Weg vom 20. ins 21. Jahrhundert. Akten des X. Internationalen Germanistenkongresses Wien 2000. Bd. 10. Bern u.a. 2003, S. 57-66.

Rösch, Gertrud Maria: Auf der Suche nach der anderen: Schwesternbeziehungen in der deutschen Gegenwartsliteratur, in: dies.; Onnen-Isemann, Corinna (Hrsg.): Schwestern. Zur Dynamik einer lebenslangen Beziehung, Frankfurt/Main 2005, S. 171-186.

Schahadat, Schamma: Schwesternmord: Poetik, Politik und Gender in der polnischen Romantik, in: Hotz-Davies, Ingrid; Schahadat, Schamma (Hrsg.): Ins Wort gesetzt, ins Bild gesetzt: Gender in Wissenschaft, Kunst und Literatur. Bielefeld 2007, S. 234-256.

Sengle, Friedrich: Biedermeierzeit. Deutsche Literatur im Spannungsfeld zwischen Restauration und Revolution 1815-1848. Bd. 1-3. Stuttgart 1971-1980.

Steiner, George: Die Antigonen. Geschichte und Gegenwart eines Mythos. München, Wien 1988.

Witte, Bernd (Hrsg.): Eine Sozialgeschichte der deutschen Literatur. Bd. 6: Vormärz: Biedermeier, Junges Deutschland, Demokraten. Hamburg 1980. 


\title{
Geschwister, Geschwisterlichkeit und Serien bei Robert Walser
}

\author{
Dagmar Bruss
}

\begin{abstract}
Starting from Juliet Mitchell's theory of sibling relations and Georg Simmel's figure of the stranger, this article focuses on the importance of sibling relations in Robert Walser's work. By tracing the way from the literal notion of siblings to an entire series of peers, its relevance for early 20th century's mass society is shown.
\end{abstract}

Ist im Zusammenhang mit Robert Walser von Geschwistern die Rede, denkt man unwillkürlich an den ersten seiner drei Berliner Romane, Geschwister Tanner. Weil die dort auftretenden Geschwister aber, wie so viele der Figuren in Walsers Prosatexten, zugleich auf dessen reale Geschwister verweisen, ${ }^{1}$ gerät man ohne viele Umwege zu den Geschwistern Walser und von dort zu deren bekanntestem Paar: den Brüdern Karl und Robert Walser. Deren Geschichte habe „etwas von der Polarität eines Märchenstoffs“ - während der eine zu Lebzeiten als Maler erfolgreich war, der andere jedoch scheiterte, kehrt sich dieses Verhältnis nach dem Tod der beiden um. Robert Walser ist heute als Verfasser zahlloser Prosastücke und der Mikrogramme weithin bekannt, während der Maler und Bühnenbildner Karl Walser fast völlig in Vergessenheit geraten ist. ${ }^{2}$

Den Vergleich mit dem Märchen kann man allerdings über das Tertium der Polarität hinaus bemühen. Denn gerade unter den für unseren Kulturkreis so prägend gewordenen Grimmschen Märchen findet sich eine ganze Anzahl, in denen Geschwisterpaaren eine prominente Rolle zufällt. In Märchen wie Brüderchen und Schwesterchen oder Hänsel und Gretel verbünden sich die Geschwister angesichts der Erfahrung von Aussetzung und Verwahrlosung, die ihnen von Seiten der bösen Eltern oder Stiefeltern zu Teil wird. Man kann diese Beispiele tiefenpsychologisch durchaus als Hinweis auf eine von Außeneinflüssen unabhängige, primäre Geschwisterliebe deuten. ${ }^{3}$ Und genau darum soll es im vorliegenden Beitrag über Robert Walser gehen: Um eine horizontale

1 Zur Problematik des Ineinandergreifens von Leben und Werk bei Robert Walser vgl. unter anderen Sauvat, Catherine: Vergessene Weiten. Eine Robert Walser-Biographie. Frankfurt/Main 1995, S. 7f., sowie Villwock, Peter: Räuber Walser. Beschreibung eines Grundmodells. Würzburg 1993, S. 7-11.

2 Vgl. Echte, Bernhard; Meier, Andreas: Einleitung, in: dies. (Hrsg.): Die Brüder Karl und Robert Walser. Maler und Dichter. Stäfa 1990, S. 5-6, insb. S. 5.

3 Vgl. Petri, Horst: Geschwister - Liebe und Rivalität. Die längste Beziehung unseres Lebens. Zürich 1994, S. $21 \mathrm{ff}$. 
Ebene der Beziehungen, die im Begriff ist, sich strukturell von der genealogisch-vertikalen Dimension zu emanzipieren; dies betrifft sowohl den konkreten Sinn des Wortes ,Bruder' wie auch dessen metaphorische Verwendung. Damit rückt zugleich die biographische Perspektive der Walser-Brüder wieder in den Hintergrund. Vielmehr wird es mir um die in ausgewählten Texten Robert Walsers sedimentierten Geschwistererfahrungen und deren Strapazierfähigkeit für weitere gesellschaftliche Zusammenhänge gehen. Dass es um 1900 - jenseits der rein privat-biographischen - auch zu einer über mehrere Jahre andauernden Auseinandersetzung mit der darstellenden Kunst des Bruders kam, hat Dominik Müller in seinem Aufsatz Künstlerbrüder - Schwesterkünste. Robert und Karl Walser auf einleuchtende Weise gezeigt. Diese Auseinandersetzung trägt ähnliche Züge wie sie auch in anderem Zusammenhang in Walsers Texten zum Ausdruck kommt. So stiftet sie in Walsers zahlreichen Porträts großer Dichter Nähe zu den Porträtierten, während der eigene Bruder in den Malerporträts in eine stilisierende Distanz rückt. Auf diese Weise entstehe eine ,einheitliche Familiengalerie, in welcher die fiktiven Brüder nun auch mit dem realen Bruder verschwistert sind“"

Das hier skizzierte Prinzip der horizontalen Verkettung als ein Nebeneinander von leiblichen und metaphorischen Geschwistern soll bei Walser mit Blick auf die Zeit der Jahrhundertwende beleuchtet werden. Dabei gehe ich mit Peter Utz davon aus, dass Walser - trotz oder gerade wegen seiner Ausnahmestellung unter den Literaten seiner Zeit - ein besonders feines Sensorium für die zeitgeschichtlichen Umbrüche der Jahrhundertwende entwickelt hat. ${ }^{5}$ An vielen Stellen scheinen seine Texte von einem Geist der Brüderlichkeit durchweht zu sein. In der Erzählung Wenzel, in der Walser die Erfahrung seiner Stuttgarter Zeit mit ihren begeisterten Theaterbesuchen verarbeitet hat, wohnt ein siebzehnjähriger Drahtfabriklehrling einer Aufführung von Schillers Die Räuber bei. Die Szene, in der sich Franz Moor wie irr am Boden wälzt, löst im Publikum einen Protestruf aus, es entsteht ein Tumult, woraufhin der „betrunkene Neujahrsbruder [...] hinausspediert" wird. Fortan soll das Schillersche Drama mit den beiden die entgegengesetzten Prinzipien aufklärerische Rationalität und Sturm und Drang

4 Müller, Dominik: Künstlerbrüder - Schwesterkünste. Robert und Karl Walser, in: Stadler, Ulrich (Hrsg.): Zwiesprache. Beiträge zur Theorie und Geschichte des Übersetzens. Stuttgart, Weimar 1996, S. 382-395, hier S. 382. Von Böschenstein stammt der Ausdruck der „,brüderlichen Spiegelbilder“ sowie die Metapher des Bruders im Sinne einer Wahlverwandtschaft zu den Porträtierten, vgl. Böschenstein, Bernhard: Zu Robert Walsers Dichterporträts, in: Deuchler, Florens u.a. (Hrsg.): Von Angesicht zu Angesicht. Porträtstudien. Bern 1983, S. 286-292; hier S. 289 u. 292.

5 Vgl. dazu Utz, Peter: Tanz auf den Rändern. Robert Walsers „Jetztzeitstil“. Frankfurt/Main 1998. 
verkörpernden Brüdern eine besondere Faszination auf den jungen Walser ausüben. So steht er seinem Bruder Karl im Jahr 1894 für ein Aquarell Modell, in dem er in einer von Karl Moors Räuberdasein inspirierten Kostümierung zu sehen ist. In dem sehr viel später erschienenen, unvollendeten Räuber-Roman bezieht sich Robert Walser unmittelbar auf dieses Aquarell:

Er trug einen Dolch im Gürtel. [...] Die Augen blickten blau. Es lag gleichsam etwas Blondes in diesen Augen, die die Brüder der Wangen zu sein auf das Innigste vorgaben. Diese Behauptung erwies sich als schlichte Wahrheit. ${ }^{6}$

Man kann neben diesen noch zahllose weitere Beispiele für eine am Brüderlichen oder Geschwisterlichen inspirierte Metaphorik finden. Doch inwieweit ist dem romantisierenden Walser hier zu trauen? Und, dies die vielleicht entscheidende Frage: Wie steht es, am Beispiel von Geschwister Tanner und Der Gehülfe, mit den unmittelbaren Beziehungen der Geschwister und in welcher Weise strahlen sie auf die metaphorische Verwendung des Begriffs ab?

Dementsprechend ist die theoretische Einbettung meines Beitrags eine doppelte: Einerseits hinsichtlich der psychoanalytischen Verankerung der konkreten Beziehung zweier oder mehrerer Kinder innerhalb einer Familie. Zum anderen geht es um die Situierung der Thematik an der Schwelle zum 20. Jahrhundert und damit zu einer Moderne mit den beginnenden Erscheinungen des Großstadtlebens und der Anonymität der Massen. Vorab soll daher ein kurzer Abriss über Theorie und kulturwissenschaftliche Einordnung gegeben werden.

\section{Ambivalente Geschwister}

In ihrem Kommentar zur Nikomachischen Ethik beschreibt Ursula Wolf die Geschwisterbeziehung als die unter den anderen verwandtschaftlichen ,am wenigsten in der Familienbeziehung verankerte“. Denn ,dieselbe Art der Freundschaft, die zwischen Geschwistern besteht, kann nach Aristoteles auch zwischen anderen Gleichaltrigen bestehen, die zusammen aufwachsen; diese Freundschaft gleicht der zwischen Gefährten““7. Die Annäherung des Brüderverhältnisses an das von Kameraden legt also eine gewisse Offenheit in der Definition der Geschwisterbeziehung nahe. Dieser bereits seit der Antike bekannten Perspektive entspricht eine abendländische Tradition der Priorisierung der Eltern-KindBeziehung. Lässt sie sich zum Teil mit der Offenheit der Geschwisterbeziehung

6 Beide Zitate nach Echte, Meier: Karl und Robert Walser, S. 42. (Hervorhebung D.B.)

7 Wolf, Ursula: Aristoteles' „Nikomachische Ethik“. Darmstadt 2007, S. 22. Die entsprechenden Stellen bei Aristoteles sind folgende: Nikomachische Ethik, 1161b33ff. und 1162a9ff. Als Kriterium von Lust und Nutzen der besonderen Freundschaft zwischen Verwandten wird hier die Enge der Lebensgemeinschaft angegeben. 
selbst erklären, so erscheint der blinde Fleck in Bezug auf laterale Beziehungen auf der anderen Seite bestimmten kulturellen Traditionen geschuldet. Dass die Kindheit im europäischen 17. Jahrhundert als prägende Phase des Menschseins entdeckt wurde, deren Studium jedoch den Erwachsenen vorbehalten war, führte zu einer ersten Beschränkung des Sichtfeldes. Ihre hermeneutische Engführung erfährt diese Tradition aber insbesondere um 1900 in Gestalt der Psychoanalyse, die ja gerade mit der Übertragung der Gefühle des Kindes gegenüber den Eltern auf das Verhältnis Patient-Analytiker operiert. ${ }^{8}$

In ihrer 2003 erschienenen Studie Siblings. Sex and Violence nimmt Juliet Mitchell eine Relektüre dieser Tradition vor. Während die Anwesenheit oder die Möglichkeit eines Geschwisterkindes in der klassischen Psychoanalyse auf eine sexuelle Beziehung der Mutter hindeutet - die Triade Vater-Mutter-Kind steht dabei im Zentrum -, weist Mitchell auf polygyne Verwandtschaftsverbände hin, bei denen die sexuelle Dimension von viel größerer Reichweite ist. Sexualität wird dort nicht primär ,as genitality but as a many-faceted or a ,polymorphous ‘ libidinal love" verstanden, ,,a love that can love a range of objects with a range of feelings" "9 . Eine solche Art der Liebe hegt das Kleinkind immer auch für das neugeborene Geschwisterchen. Sie trägt noch narzisstische Züge und wird zugleich von einem Gefühl der Unwilligkeit durchkreuzt, bedeutet doch die Existenz des Neuankömmlings für das ältere Kind einen nunmehr unerreichbaren Platz. ${ }^{10}$ Die Liebe einem Wesen gegenüber, das ebenso ist wie man selbst, wird zeitgleich mit der Erfahrung empfunden, von einem Wesen, das den eigenen Platz eingenommen hat, verdrängt zu werden. Insofern kann die besondere Ambivalenz des Geschwisterverhältnisses als eine Aufgabe für die kindliche Psyche beschrieben werden, Hass und Gewalt in Liebe zu verwandeln. Mitchell schreibt: „loving one's sibling like oneself is neither exactly narcissism nor object-love. It is narcissism transmuted by a hatred that has been overcome." "11 Geschwisterliebe und Geschwisterhass sind also aufs Engste miteinander verbunden.

Worin sich das Geschwisterverhältnis von dem Verhältnis zwischen Vater (oder Mutter) und Kind aber noch grundsätzlicher unterscheidet, ist die Tatsache, dass es die Zahl Zwei übersteigt: Indem es sich nicht auf die binäre Opposition zweier entgegengesetzter Geschlechter reduzieren lässt, stellt es eine

$8 \mathrm{Zu}$ den kulturellen Traditionen vgl. Mitchell, Juliet: Siblings. Sex and Violence. Cambridge 2003. Außerdem: Ariès, Philippe: Geschichte der Kindheit. München 1996, S. 23-41.

9 Mitchell: Siblings, S. 10.

10 Vgl. ebd., S. 10.

11 Ebd., S. 36.

Ulrike Schneider, Helga Völkening and Daniel Vorpahl - 978-3-653-98812-3 
potentielle Vielzahl von Beziehungen dar. ${ }^{12}$ Analog zum Gesetz des Vaters, der mit Kastration droht, und dem Gesetz der Mutter, die dem Kleinkind bedeutet, dass es selbst noch keine eigenen Kinder hervorbringen kann und ein Kind neben anderen ist, ${ }^{13}$ wird die „Serialität" anhand des „Antigone-Komplexes“ plausibel gemacht. Es ist die Figur der Antigone, die als lebendes Symbol dafür steht, dass es nicht nur einen Bruder zu beerdigen gilt, sondern zwei, im Sinne eines ,even if they are different from each other and at war, they are equal in death“"14. Nicht Oppositionen, sondern graduelle Unterschiede innerhalb einer Reihe bestimmen das Geschwisterverhältnis, weshalb Mitchell fordert: „We need a place in psychoanalytical theory for the minimal difference that needs to be set up between sisters and brothers to turn replication into seriality ${ }^{\text {“15; }}$; eine neben der vertikalen Dimension des Ödipuskomplexes zweite, horizontale Dimension, deren Herausforderung in einem sensiblen Austarieren der gleichen Position in der Geschwisterreihe bei dennoch vorhandenen Unterschieden liegt, der Herausforderung der „likeness in unlikeness, unlikeness in likeness“"16. Geschwister kann es stets mehrere oder viele geben, was die Dimension dehnbar macht für andere laterale Beziehungen.

\section{Der Fremde bei Georg Simmel}

Gegenüber dem 19. Jahrhundert, das zumeist mit dem Glauben an den Fortschritt und ein Fortschreiten von Geschichte verbunden wird, manifestiert sich der Riss im genealogischen Prinzip am anbrechenden 20. Jahrhundert als Figuration von Gottes Tod und dem Sturz des Vaters. Die damit einhergehenden Veränderungen schlagen sich im Gesellschaftlichen und Politischen in Gestalt der Demokratie nieder. Doch werden mit dem rituellen Vatermord nicht zugleich auch alle Machtungleichgewichte beseitigt. Nicht nur bleibt das väterliche Gesetz in Gestalt einer zu respektierenden Grenze in Kraft, auch ist die

12 Vgl.: „As a part of a series, girls and boys are ,equilateral', in other words, they are not defined by what is missing. Girls and boys explore what is there, not what is not." Ebd., S. 128.

$13 \mathrm{Vgl} .:$,One is a child in the same position as one's sibling in regard to one's parent or parents, as one's peers in relation to one's teacher or boss, but one is also different: there is room for two, three, four or more." Ebd., S. 53.

14 Ebd., S. 128.

15 Ebd., S. 151. Dass sich die Nichteinhaltung minimaler Unterschiede zwischen benachbarten Gruppen und Ethnien in Form von Gewaltausbrüchen und ,Bruderkriegen “ niederschlagen kann, zeigt Anton Blok mit Blick auf Freuds Begriff des „Narzißmus der kleinen Differenzen“. Vgl. Blok, Anton: The Narcissism of Minor Differences, in: ders.: Honour and Violence. Cambridge 2001, S. 115-135.

16 Mitchell: Siblings, S. 125.

Ulrike Schneider, Helga Völkening and Daniel Vorpahl - 978-3-653-98812-3 
neue Gleichheit unter den Söhnen fraglich und droht ihrerseits in eine Fratriarchie zu münden. ${ }^{17}$

In seiner Philosophie des Geldes beschreibt Georg Simmel die Tendenz zur potenziell unendlichen Multiplikation sozialer Kontakte. Bindungen werden zunehmend austauschbar, der moderne Großstadtmensch steht in abstrakter, durch Geld vermittelter Beziehung zu anderen. ${ }^{18}$ Vor diesem Hintergrund einer grundsätzlichen, unüberwindlichen Distanz zwischen den Individuen der Moderne entwirft Simmel seinen Typus des Fremden:

Es ist hier also der Fremde nicht in dem bisher vielfach berührten Sinn gemeint, als der Wandernde, der heute kommt und morgen geht, sondern als der, der heute kommt und morgen bleibt - sozusagen der potenziell Wandernde, der, obgleich er nicht weitergezogen ist, die Gelöstheit des Kommens und Gehens nicht ganz überwunden hat. ${ }^{19}$

Die Figur des Fremden findet sich klar in einen räumlichen Kontext eingebettet. Er ist innerhalb eines bestimmten Raums - der Raum hier verstanden als ,eine Tätigkeit der Seele ${ }^{620}$ - fixiert, bringt aber in ihn von draußen kommende Qualitäten ein. Ist das Verhältnis zwischen Menschen grundsätzlich von der Spannung zwischen Nähe und Entfernung geprägt, bedeutet „Fremdsein“ nichts anderes, als „,daß der Ferne nah ist ${ }^{\text {‘21 }}$. Andererseits hat sich, in historischer Betrachtung, der Übergang zu rationelleren politischen Gebilden, wie Simmel zeigt, empirisch oft durch die Abkehr von bluts- bzw. stammesverwandtschaftlichen Organisationsprinzipien hin zu territorialen vollzogen. Zwangsläufig wurden dann qualitativ verschiedenste Elemente politisch vereinigt, deren einzige Gemeinsamkeit ist, dass sie sich lokal berühren. ${ }^{22}$ Mit Blick auf meine weiteren Überlegungen könnte man auch sagen: Das moderne Nebeneinander bedeutet keine Wesensähnlichkeit.

17 Vgl. Matt, Peter von: Verkommene Söhne, mißratene Töchter. Familiendesaster in der Literatur. München, Wien 1995, S. 327-335. Zum Mythos des Vatermords und der Suche nach den Grenzen des väterlichen Gesetzes am Beginn der Moderne bei Freud vgl. Schuller, Marianne: Moderne. Verluste. Literarischer Prozess und Wissen. Basel, Frankfurt/Main 1997, S. 111f.

18 Vgl. Simmel, Georg: Die Philosophie des Geldes. Hrsg. v. David P. Frisby; Klaus Christian Köhnke, in: Rammstedt, Otthein (Hrsg:): Georg Simmel Gesamtausgabe. Bd. 6. Frankfurt/Main 1989, S. 254ff. u. S. 542f.

19 Simmel, Georg: Soziologie. Untersuchungen über die Formen der Vergesellschaftung. Leipzig 1908, S. 685.

20 Ebd., S. 616.

21 Ebd., S. 685.

22 Vgl. ebd., S. 691-695.

Ulrike Schneider, Helga Völkening and Daniel Vorpahl - 978-3-653-98812-3 


\section{Bruder oder Freund in Geschwister Tanner}

Auf ihre Frage, an wen Simon Tanner einen Brief verfasst habe, erhält dessen neue Vermieterin die Antwort, es handele sich um einen inzwischen in Paris lebenden Freund. Es schließt sich eine Lebensbeschreibung an, aus der hervorgeht, dass es in Wirklichkeit um Simons eigenen Bruder, Kaspar Tanner, geht. Simon hält der sichtlich irritierten Vermieterin folgenden Kurzmonolog:

Freilich, mein Bruder, aber viel mehr mein Freund! Solch einen Bruder muß man Freund nennen, wenn man die richtige Bezeichnung haben will. Wir sind nur zufällig Brüder, aber Freunde sind wir mit Bewußtsein, und das ist viel wertvoller. Was ist Bruderliebe? Als wir noch Brüder waren, packten wir uns eines Tages am Halse, beidseitig, und wollten uns den Garaus machen. Hübsche Liebe! Unter Brüdern ist der Neid und der Haß nichts Außerordentliches. Wenn Freunde sich hassen, gehen sie auseinander; wenn Brüder sich hassen, denen das Geschick das Zusammenleben unter einem Dache vorschreibt, geht es nicht so gelinde zu. Aber das ist eine alte und unschöne Geschichte. ${ }^{23}$

In dem Zitat ist eine ganze Reihe von Komplexen gebündelt. Geht man chronologisch vor, ist da zunächst die Rivalität zwischen den Brüdern, die, ganz im Gegensatz zum Wahlcharakter einer Freundschaft, kein Entkommen zulässt. Glaubt man Simons Schilderung, dann reichten Neid und Hass in der Vergangenheit sogar bis zu dem Wunsch nach Auslöschung des jeweils anderen. In der Retrospektive erscheint diese Unversöhnlichkeit wie eine längst vergangene Zeit. Und tatsächlich geht der Zweifel an der „Bruderliebe“ scheinbar ohne Umweg in die Bezeichnung des Bruders als Freund über. Indem für Simon „Freund [...] die richtige Bezeichnung“ für einen Bruder wie Kaspar ist, kehrt er Montaignes Diktum, dass ,in Wahrheit [...] Bruder ein schöner Name“ für „Freund“ sei, gleichsam um. ${ }^{24}$ Der Ausweg aus einer solchen identifizierenden Logik, innerhalb derer Unterschiede eingeebnet werden, indem die Fiktion eines gemeinsamen Ursprungs unterstellt wird, ist die von Mitchell postulierte minimal difference. Nicht nur bezieht Simon vor der Vermieterin seinem eigenen Bruder gegenüber Distanz, indem er ihn zuerst als „ein Freund in Paris“ ins Gespräch einführt. Auch substituiert er, mit vollem Bewusstsein, den verpflichtenden Charakter der Verwandtschaft durch die Freiheit, die dem Akt der Wahl eines Freundes eigen ist.

In einer anderen Episode wohnt Simon einem Gespräch zwischen zwei Wirtshausgästen bei. Sie unterhalten sich über einen begabten, jungen Mann, der, allen hochfliegenden Erwartungen zum Trotz, nach etlichen Stationen und

23 Walser, Robert: Geschwister Tanner. Frankfurt/Main 1975, S. 213f. Im Folgenden als GT im Text zitiert.

24 Vgl. Montaigne, Michel de: Essais. Frankfurt/Main 1998, S. 99.

Ulrike Schneider, Helga Völkening and Daniel Vorpahl - 978-3-653-98812-3 
Stellen im In- und Ausland geisteskrank geworden und schließlich in der Irrenanstalt gelandet sei. Simon erkennt in ihm seinen Bruder Emil wieder, schiebt jedoch die Vermutung des Erzählers, bei dessen Leiden handle es sich um eine Familienkrankheit, harsch beiseite:

Was da? In der Familie? Da irren Sie sich, mein edler Herr Erzähler. [...] Entdecken Sie an mir vielleicht auch so etwas, das in der Familie liegen könnte? Muß ich auch ins Irrenhaus kommen? Das müßte ich ohne Zweifel, wenn es in der Familie läge, denn ich bin auch aus der Familie. Der junge Mann ist mein Bruder. Ich schäme mich durchaus nicht, einen nur unglücklichen und keineswegs verderblichen Menschen offen meinen Bruder zu nennen. [...] Die Menschen denken immer gleich an grausige Vererbung und so weiter. (GT, S. 237f.)

Es folgt ein flammendes Bekenntnis zu den Lehren, die die jüngeren Geschwister von dem jetzt unglücklichen Bruder empfangen hatten: ,[Z]u einer Zeit, da wir noch die wüstesten Schlingel waren, [...] tranken wir das Feuer der Begeisterung für die Kunst" (GT, S. 239). Wenn auch in anderer Weise als bei Kaspar, begegnen sich auch hier Simons Wunsch nach Ausschöpfung der vollen Potenzialität der Bruderbeziehung einerseits und der Widerwille gegen die als fesselnd begriffenen familiären Bande, seien sie nun genealogischer oder psychosozialer Natur. In dem Beispiel rückt Emil, der für Simon einst so wichtige Bruder, in weite Ferne.

\section{Ferne Wege, nahe Wege}

In seiner episodischen Struktur, dem ständigen Wechsel von einer Arbeitsstelle zur nächsten, einem Wohnort zum folgenden, einer menschlichen Begegnung zur anderen, lässt der Roman Geschwister Tanner den Gedanken an einen langen Spaziergang aufkommen. Trotz zahlreicher, von der Forschung festgehaltener Parallelen kann man Simon Tanner damit im Gegensatz zu dem Wanderer sehen, wie er seine ideale Verkörperung in Gestalt von Eichendorffs Taugenichts gefunden hat. ${ }^{25}$ Denn im Unterschied zum Taugenichts, der seine Erfüllung endlich in einer göttlich-überhöhten Form der Liebe findet ${ }^{26}$, ist Simons

25 Vgl. dazu Bichsel, Peter: Reading Geschwister Tanner, in: The Review of Contemporary Fiction, Vol. 12, No. 1 (1992), S. 66-78. Bezeichnendes Beispiel für Walsers Affinität zu diesem Modus der Fortbewegung ist darüber hinaus „Der Spaziergang“, vgl. Walser, Robert: Der Spaziergang, in: ders.: Dichtungen in Prosa. Bd. 5: Komödie. Geschichten und Der Spaziergang. Hrsg. v. Carl Seelig. Genf, Frankfurt/Main, S. 259-343.

26 Der Taugenichts bleibt ohne Namen, als ,romantische Allegorie auf ein menschliches Leben, das sich 'Gottes Führung' empfiehlt“, siehe Prill, Meinhard: Aus dem Leben eines Taugenichts, in: Jens, Walter (Hrsg.): Kindlers Neues Literatur Lexikon. Bd. 5. München 1989, S. 72-74, hier S. 73. 
Weiterziehen auf kein bestimmbares Ziel gerichtet. Ich meine, man kann in ihm vielmehr den Typus des Fremden im Sinne von Simmel sehen. Dabei kommt es besonders auf die Potenzialität an: Die „Gelöstheit des Kommens und Gehens“ nicht überwindend, könnte er ,potenziell stets weiterziehen“. In diesem Raum, der Möglichkeitsraum bleibt, ohne sich aktualisieren zu müssen, manifestiert sich Walsers ateleologischer Weltentwurf. ${ }^{27}$

Der Gestus des ständigen Unterwegsseins überträgt sich auch auf die Beziehungen zum Anderen. ${ }^{28}$ In einem fortwährenden Prozess der Anziehung und Abstoßung beschreibt Walser die Begegnungen seiner Figuren. Auch direkt, über die räumliche Einbettung, besteht ein Bezug zu dem Fremden bei Simmel: Einmal handelt es sich bei dem Raum um einen, der physisch durchschritten wird, zweitens findet man ihn auch im übertragenen Sinn wieder. Ohne die Bedeutung der Mutterbeziehung im Werk Walsers schmälern zu wollen, bietet sich ein Blick auf die ihm zugrundeliegende „Psycho-Logik“ aus der Perspektive der Geschwisterbeziehung an. ${ }^{29}$ Anhand von zwei Beispielen soll gezeigt werden, wie sich hinter und jenseits der Mutterbeziehung Räume für die Geschwisterdimension auftun und wie, zweitens, die Rollen zwischen Mutter und Schwester fließend ineinander übergehen können.

Im Roman Der Gehülfe bringt Joseph als rechte Hand des Ingenieurs und Erfinders Tobler zusammen mit dessen Familie einige Monate in der „Villa zum Abendstern“ zu. Hier fungiert eine Kindheitserinnerung Josephs ex negativo als Scharnier für eine Vermittlung im Sinne des Gesetzes der Mutter. Das Erlebnis eines unbeschwerten Zusammenseins der Kinder und ihrer Mutter in einer Sandsteingrube am Waldrand - angesichts der seit langem währenden Schwermut der Mutter ein kleines Wunder - lenkt den Blick auf die überstarke Sensibilität, die

27 Vgl. dazu Hong, Kil-Pyo: Selbstreflexion von Modernität in Robert Walsers Romanen „Geschwister Tanner“, „Der Gehülfe“ und „Jakob von Gunten“. Würzburg 2002, S. 1650 .

28 In seiner Dissertation zu Walsers „Räuber“-Roman untersucht Fischer den Weg des Protagonisten zum Anderen mithilfe der Philosophie Emmanuel Lévinas', vgl. Fischer, Anton: Der Weg zum Anderen in Robert Walsers „Räuber“-Roman. Norderstedt 1995.

29 Schmidt-Hellerau verwendet den Begriff der Psycho-Logik im Sinne der Analyse einer das Werk Walsers durchziehenden fiktiven Figur, um Aufschluss über die beim Schreiben wirkenden unbewussten Impulse zu erhalten. Bei der Nachzeichnung der Psychogenese der Figur des Grenzgängers - dieser Verhaltenstypus entspricht der Erfahrung, die sich in Walsers Werk vermittelt -, beschränkt sich die Autorin jedoch ,trotz unseres Wissens um die Geschwister Robert Walsers“ auf die Eltern-Kind-Triade, vgl. SchmidtHellerau, Cordelia: Der Grenzgänger. Zur Psycho-Logik im Werk Robert Walsers. Zürich 1986, S. 23. Diese Beschränkung ist hier Gegenstand der Kritik. 
die Kinder für deren Empfindlichkeiten entwickeln mussten, ${ }^{30}$ und damit zugleich auf die Leerstelle, die sich auftut, wenn die Mutter der ihr zukommenden Vermittlung zwischen den Kindern nicht mehr gewachsen ist. Auch lange Zeit danach bleibt Josephs Sensorium für einen Ausgleich unter den Geschwistern geschärft, wenn er über die unterschiedliche Behandlung der Kinder der Familie Tobler reflektiert. Nicht Mutterliebe ist es, die er dabei sinnierend einklagt, sondern die fehlende Gerechtigkeit. Gegenüber der „,kleine[n], verhutzelte[n] und verschuggte[n] Silvi“ (DG, S. 97) wird ihre engelsgleiche Schwester Dora nach Strich und Faden verwöhnt. Und auch wenn von den beiden Brüdern Edi der Scheue, Walter dagegen der Hansdampf ist, sind beide Buben insgesamt besser gestellt als Silvi, da ,in gewissen Familien [...] Knaben höher im allgemeinen geschätzt [sind] als Mädchen“ (DG, S. 111). ,[E]in sehr ungleichmäßiges Viereck" stellen die Tobler-Kinder aus Josephs Sicht dar. Das Bild wird weiter getrieben, wenn davon die Rede ist, wie sich das „unregelmäßige Viereck“ verschiebt und „die Kinder [sich] zerstreuen, jedes in seine Art und Weise hinein, in die Stunden und Tage und in die geheimen Kinderempfindungen, und in den Weltraum rund um das Haus Tobler herum [...] in die Demütigungen und in die kosenden Worte" (DG, S. 113f.). Schließlich fragt sich Joseph, ob die Bewegung der vier nicht sogar einen ,gewissen richtungbeeinflussenden Druck auf das Steuerruder des Toblerschen Unternehmungenschiffes aus[übe]“ (DG, S. 114), einer Unternehmung, deren Niedergang sich schon abzuzeichnen beginnt.

Mit dem Verweis auf das „Unternehmungenschiff“ deutet sich in dem unregelmäßigen Viereck, das in seine unterschiedlichen Richtungen strebt, die Verbindung von Mikro- und Makrokosmos an. Man kann es insofern auch als Bild für eine nicht mehr zähmbare Disparatheit der Moderne lesen, deren Erkenntnis bei Joseph zum Abschied von der Idee des Sozialismus führen musste. Von ihm und seiner älteren Freundin Klara wird nämlich rückblickend gesagt: „Sie liebten beide, wie es damals Mode war, die ,Menschheit““ und, in Bezug auf das diffuse Becken ,Sozialismus':

Unter dem Namen ,Sozialismus“ hatte sich, einer üppigen Schlingpflanze ähnlich, eine zugleich befremdende und anheimelnde Idee in die Köpfe und um die Körper der Menschen, alte und erfahrene nicht ausgenommen, geworfen [...] Die Arbeiter und ihre Interessen nahm man damals allgemein mehr geräuschvoll als ernst. [...] Was nur immer mit den Verhältnissen und Ordnungen der Welt unzufrieden war,

30 „Die Kinder schauten von Zeit zu Zeit auf die Mutter, ob sie böse war oder nicht, nein, sie schaute gütig und im übrigen gemessen gradaus“. In: Walser, Robert. Der Gehülfe. Hrsg. v. Jochen Greven. Zürich, Frankfurt/Main 1985, S. 102. Im Folgenden als DG im Text zitiert. 
schloß sich dieser leidenschaftlichen Gedanken- und Gefühlsbewegung hoffnungsvoll und zufrieden an, und was die Abenteuerlust einer gewissen Sorte von Schreiern, Krakeelmachern und Schwätzern vermochte, die Bewegung einesteils prahlerisch hochzuheben und anderteils in die Gemeinheit des Tages herabzuziehen, das bemerkten die Feinde dieses, Gedankens ‘ mit einer Art vergnüglichem Hohnlächeln. Die ganze Welt, Europa und die übrigen Erdteile, so hieß es damals unter den jungen und halbreifen Geistern, verbände und vereinige diese Idee zu einer fröhlichen Menschenversammlung [...]. (DG, S. 134f.)

Diese expressionistische Beschreibung - man kann darin eine Bezugnahme auf das historische Zürich um 1900 sehen $^{31}$ - greift das Thema der Solidarität im Sinne einer universalisierten Idee der Brüderlichkeit auf. ${ }^{32}$ Sie bezieht jedoch zugleich Distanz zu einer pauschalisierenden Haltung, wie sie sich unter dem Etikett ,Sozialismus‘ zu verbergen schien. Unter all dem Wust an unterschiedlichen politischen Positionen, von reformistischen bis hin $\mathrm{zu}$ anarchosyndikalistischen, zeichnet sich als gemeinsamer Nenner lediglich die allgemeine Tendenz zur Massengesellschaft ab. Sie spiegelt sich auch in den Bezügen auf die Welt der kleinen Angestellten, an deren Übergang Josephs Stellung als Gehülfe in der Toblerschen Unternehmung zu sehen ist. Denn während die Dienerschaft in dem alten Sozialmodell noch Teil der ,Familie" war, tritt der Angestellte ab den 1890er Jahren zunehmend in seiner ausschließlichen Funktion als abhängig Beschäftigter auf die Bildfläche. ${ }^{33}$ In dem hier nur skizzenhaft angerissenen Übergang von einem Nachdenken Josephs über das auseinanderstrebende Viereck der Tobler-Geschwister, über die Phase des brüderlich angehauchten ,Sozialismus' bis hin zu dem Abschied davon zeichnet sich die Ausweitung der horizontalen Linie weit über die innerfamiliäre Sphäre hinaus ab.

\section{Zwischen Mutter und Schwester}

Wenn die Realität im Großen wie im Kleinen auch aus den Fugen ist - im Traum bleibt die mütterlich-vermittelnde Instanz noch intakt. Gegen Ende von Geschwister Tanner sieht Simon seine empfindsame Freundin und einstige Zimmerwirtin Klara Agappaia in einer Pariser Wohnung, wie sie eine Zimmertür nach der anderen öffnet, um ihm seine Geschwister vorzuführen. Paris bietet sich als Ort der Traumhandlung für Simon an, weil sein Bruder Kaspar dorthin gegangen ist, um zu malen. Auf ihrem Rundgang zeigt Klara, die als Zauberin

31 Vgl. Rüsch, Lukas: Ironie und Herrschaft. Untersuchungen zum Verhältnis von Herr und Knecht in Robert Walsers Roman „Der Gehülfe“. Königstein 1983, S. 195.

32 Zum Zusammenhang der Begriffe Brüderlichkeit und Solidarität vgl. u.a. Zoll, Rainer: Was ist Solidarität heute? Frankfurt/Main 2000, S. 34-77.

33 Zum Sozialmodell des ,ganzen Hauses“ vgl. Wagner, Karl: Herr und Knecht. Robert Walsers Roman „Der Gehülfe“. Wien 1980, S. 148f. 
auftritt, Simon zuerst den ältesten, in der Romanwirklichkeit väterlichkonservativen Bruder Klaus, dessen Fleiß sie lobt, auf dessen Liebe und Sorge um Simon sie aber gleichzeitig hinweist. Das Bild von Klaus schwindet und es öffnet sich eine weitere Tür, hinter der die aufgebahrte Schwester Hedwig auftaucht. Hier zeigt sich Klaras Rolle als Vermittlerin besonders deutlich. Denn sie wirbt bei Simon um Verständnis für Hedwigs zartes Wesen, das den Grobheiten des Lebens im Traum offenbar nicht standhalten konnte: „Wie sie [Hedwig] wortlos scheidet: so mädchen- und blumenhaft! Wie lieb sie war. Du als Bruder empfindest das lange nicht so, wie ich als Freundin“ (DG, S. 223). Andererseits werden die Rollen der beiden Frauen im Traum invertiert: Hatte Klara noch kurze Zeit nach ihrer ersten Begegnung mit Hedwig einen Brief an diese verfasst, in dem sie ihre ganze Bewunderung für die Schwester Simons ausgedrückt hatte dieser war in ihrer Eigenschaft als Pflegerin der eigenen Mutter und als Lehrerin der überlegene Part zugekommen ${ }^{34}$-, so ist Klara im Traum die Fürsorgende, die zwischen den Geschwistern um Ausgleich bemüht ist; zum Beispiel, wenn sie Simon in Erinnerung ruft: „Ihr [Kaspar und Simon] ließt sie [Hedwig] leiden, das, das war schmerzhaft" (GT, S. 223). Schließlich lässt sie eine dritte Tür aufgehen, hinter der sich das Atelier von Simons liebstem Bruder Kaspar befindet. Da die Arbeit am Kunstwerk es verlange, alles auf den Schaffensprozess zu konzentrieren, dürfe dieser nicht gestört werden.

Zwischen Traum und Wirklichkeit kommt es zu einer Verkehrung von Mutter- und Schwesterrolle. In Wirklichkeit sind beide Frauen eher Schwestern denn Mütter: Hedwig als leibliche Schwester und Klara als schwesterliche Freundin der beiden Tanner-Geschwister. Über ihre Freundschaft zu Simon, ihre Liebe zu Kaspar und ihre Bewunderung für Hedwig reiht sie sich unmerklich in den Reigen der Geschwister ein. Was aber zeigen die mütterlichen Anteile im Kontext dieses Beitrags? Die Verlagerung der Vermittlertätigkeit Klaras in den Traum und damit in einen von der Wirklichkeit separierten Ort, stellt, im Sinne Freuds, den Wunsch Simons nach einer regulierenden mütterlichen Instanz zwischen den Geschwistern dar. Und damit macht er zugleich dessen Fehlen in der Realität des Romangeschehens nur allzu deutlich; Simons Bewusstsein für die Geschwisterperspektive wird geschärft. Dass sie sich über den Kreis der leiblichen Geschwister hinaus erstreckt, wird zudem aus dem Verweis auf das Tätigkeitsfeld des Pflegerischen deutlich. Während Hedwig als Erzieherin arbeitet

34 Vgl. dazu Simon: „Meine Mutter und meine Schwester Hedwig ergeben in meinem Kopf immer ein innig verbundenes und zusammengewobenes Bild. Hedwig hat die Mutter, als diese krank wurde, besorgt und gepflegt, wie man ein kleines Kind pflegen muß." (GT, S. 324). 
und die eigene Mutter pflegend umsorgt hatte, wird Klara als „Königin der Armen“ (GT, S. 295) zur Wohltäterin.

\section{Geschwister und Serien}

Eine ganz ähnliche Konzeption der Serie, wie sie für Mitchell eingangs mit dem Begriff der Serialität angeklungen ist, findet man bei Deleuze und Guattari in ihrer Schrift über Franz Kafka. Den Autoren zufolge stellt die laterale Beziehung zur Schwester, aber auch zu anderen gleichgestellten Figuren in den Texten einen Ausweg aus den verfahrenen Vater-Beziehungen in Kafkas Werk dar. Nur die Beziehungen zu Geschwistern und deren Fortsetzbarkeit in gesellschaftlich offenen Serien - die Autoren geben das Beispiel Schwester - Dienstmädchen - Huren - erlaubten es der jeweiligen Figur, sich zu ,entfamilialisieren" und durch die Ausbildung seitlicher Fluchtlinien eine gewisse Freiheit vom väterlichen Gesetz zu erlangen. ${ }^{35}$

Als eine Serie unter anderen erscheint bei Walser die der ,leiblichen Schwester - Krankenschwester - Fremden'. Dies lässt sich mithilfe einer weiteren Stelle aus Der Gehülfe verdeutlichen. Als Joseph bei Frau Tobler eine Narbe am Hals bemerkt, fragt er nach deren Herkunft. Frau Tobler

erzählte [...] Joseph den Hergang der Operation. Wie man sie aufgefordert habe, in einen großen, leeren Saal zu treten, in welchem nichts anderes zu sehen gewesen sei als ein hohes Bett oder Gestell und vier gleichmäßig angezogene Krankenschwestern. Diese Schwestern hätten eine wie die andere ausgeschaut, so leer und fühllos. Ihre Gesichter seien einander so ähnlich gewesen wie vier gleich große und gleichfarbige Steine. [...] Nicht ein Zug, nicht ein Fingernagel voll Freundlichkeit sei um sie herum gewesen, sondern es habe ihr alles den Eindruck der Härte und der Herzensverlassenheit gemacht. (DG, S. 64. Hervorhebungen D.B.)

Indem Frau Tobler, die sonst so Souveräne, Joseph hier ihre schwache Seite anvertraut, gleicht sich der Statusunterschied zwischen beiden zusehends an. In ihrem Erlebnis im Operationssaal wird die ihrem eigentlichen Auftrag nach der Fürsorge und Nächstenliebe verpflichtete Krankenschwester mit den denkbar unmenschlichsten Folgen der Uniformität der Masse im frühen 20. Jahrhundert in Verbindung gebracht. Wie Kopien voneinander erscheinen die leeren und fühllosen Schwestern in der Erzählung der Frau Tobler. Mit Mitchell könnte man daher sagen, sie seien im Status des Immer-Gleichen, der Reproduktion

35 Vgl. Deleuze, Gilles; Guattari, Félix: Kafka. Für eine kleine Literatur. Frankfurt/Main 1976. Die Autoren bringen die unterschiedlichen Freiheitsgrade in der Eltern-Kind- bzw. der Bruder-Schwester-Beziehung mit zwei unterschiedlichen Arten des Inzests in Verbindung, dem paranoischen und dem Schizo-Inzest, vgl. S. 93. Darauf kann im gegebenen Zusammenhang nicht weiter eingegangen werden. 
(replication) stecken geblieben. Erst mithilfe eines minimalen Abstands (minimal difference) kann daraus eine Serie werden, die es erlauben würde, den Anderen als Anderen und damit vom Ich Verschiedenen anzusehen.

Im Zusammenhang mit der Krankenschwester, die ihre Tätigkeit in den Dienst des Nächsten stellt, ergibt sich als weiteres mögliches Glied der Serie die Ordensschwester im christlichen Gewand. Tatsächlich tauchen Bezugnahmen auf das Christentum in Geschwister Tanner meist in Verbindung mit weiblicher Konnotation auf: Zum einen ist es Klara als Helferin der Armen, zum anderen sind es die christlichen Wanddekorationen im Zimmer eines befreundeten Krankenwärters, die Simon den Gedanken eingeben, eine Schwester des Wärters habe das Zimmer in dieser Weise ausgeschmückt. Auch darüber hinaus gibt es bei Walser zahlreiche, oft versteckte Anklänge an das Christentum, insbesondere in seiner pietistischen Variante. ${ }^{36}$

\section{Zum Schluss}

Auch das Ende von Geschwister Tanner scheint zunächst in eine Utopie universaler Geschwisterlichkeit zu münden. „Sind wir nicht alle zusammen, wir Menschen auf diesem einsamen, verlorenen Planeten, Geschwister? Brüder und Schwestern? Brüder zu Schwestern, Schwestern zu Schwestern und wieder Schwestern zu Brüdern?" (GT, S. 312) fragt die Vorsteherin des Volkskurhauses Simon am Ende des Romans. Doch es geht auch pragmatischer: ,[E]in Bruder“, fährt sie fort, „muß ja nicht gerade zu den feinsten und erlesensten Menschen gehören und kann doch, vielleicht aus, sagen wir, etwas abgemessener Entfernung, Bruder sein.“ (GT, S. 312f.) An kaum einer anderen Stelle findet sich die Verwendung der wörtlichen und der metaphorischen Komponenten des Begriffs ,Bruder' und ,Geschwister' in so unmittelbarer Nähe wie an dieser. Während er hier im Kontext eines Übergangs von „Christenpflicht“ zu „Menschenpflicht“ steht, mutmaßt die Vorsteherin über den ihr fremden Simon, er müsse wohl „,bedeutende Menschen zu Geschwistern haben“" (GT, S. 319).

Auch der Übergang von Christenpflicht zu Menschenpflicht entspricht einem Weg, der auf der horizontalen Ebene zurückgelegt wird. Was so ansetzt wie eine Utopie der Geschwisterlichkeit, entpuppt sich bei näherer Lektüre der beiden besprochenen Walser-Romane als sensible, aber weitgehend unsentimentale Zustandsaufnahme einer Zeit und deren Beziehungsmuster. Die Texte

36 Für nähere Ausführungen zu dem Thema vgl. Mächler, Robert: Robert Walser und das Christentum, in: Kerr, Katharina (Hrsg.): Über Robert Walser. Bd. 2. Frankfurt/Main 1978, S. 115-124 sowie Zimmermann, Hans D.: Walser und die pietistische Ethik, in: Chiarini, Paolo (Hrsg.): „Immer dicht vor dem Sturze ...“. Zum Werk Robert Walsers. Frankfurt/Main 1987, S. 237-251. 
machen plausibel, wie der Geschwisterbeziehung mit der wachsenden Uniformität der Massen am Beginn des 20. Jahrhunderts eine bislang ungeahnte Relevanz als kleinster Einheit beliebig ausdehnbarer kollateraler Beziehungen erwächst.

In Der Gehülfe kann die Figur Wirsich, vormals Angestellter, als so ein Bruder aus ,abgemessener Entfernung“ gelten, wie ihn die Vorsteherin des Volkskurhauses aus Geschwister Tanner im Sinn hat. Die Ungerechtigkeiten, die Joseph im Verhältnis der Tobler-Kinder umtreiben, lassen ihn auch hinsichtlich seines wegen Trunkenheit entlassenen Vorgängers nicht los. Immer wieder ist es ihm um Ausgleich zwischen Wirsich und dem bald gar nicht mehr so souveränen Tobler zu tun. Nicht um euphorische Verbrüderungsgesten geht es dabei, vielmehr um eine innere Haltung Josephs, die die sozialen Unebenheiten im Modus der Reflexion auszugleichen sucht. Der Bezug auf die Raumdimension ergibt sich aus dem Weg, der durchschritten wird von dem jeweils nächsten Vertrauten oder Bruder zu einem Kameraden wie dem betrunkenen Wirsich. Als er diesen - aus seiner neuen Stellung frisch entlassen - in trostlosem Zustand im Wirtshaus trifft, spricht auch Joseph dem Alkohol ziemlich zu, ,um dem Kameraden um eine Seelenstufe und um ein Stück Verständnis näher zu rücken, indem er fühlte, daß hier der nüchterne Sinn und Verstand beinahe unpassend gewesen wäre." (DG, S. 284f.) Dennoch führt die Annäherung an Wirsich nicht zu einer Freundschaft, schon gar nicht zu einer Identifizierung mit dem Los des Kameraden. Dieser bleibt auf Distanz. Vielmehr spiegeln sich im Verhältnis zu ihm die ganze Ambivalenz der Geschwisterbeziehung und deren Fortsetzbarkeit zu einer potenziell unendlichen Serie.

Die Bedeutung, die Fremdheitserfahrungen und das Oszillieren zwischen Ferne und Nähe für das Schreiben Walsers haben, ist verschiedentlich dargestellt worden. ${ }^{37}$ Die Ausweitung einer immer schon ambivalenten Geschwisterbeziehung auf die Beziehungen der horizontalen Linie schlechthin - ein raumgreifender Prozess - bringt ein weiteres Zitat von Deleuze und Guattari über Kafkas Proze $\beta$ noch einmal auf den Punkt:

Der Vater und die Mutter (z.B. Verwandlung) sind nahe und in Distanz; sie sind Emanationen des Gesetzes. Die Schwester jedoch ist nicht nahe: Sie ist nebenan, in Kontiguität und Ferne. Desgleichen der Beamte und Bürokrat: Der „andere“ Beamte ist immer nebenan, in Kontiguität und Ferne. ${ }^{38}$

37 Vgl. u.a. Groddeck, Wolfram u.a. (Hrsg.): Robert Walsers „Ferne Nähe“. Neue Beiträge zur Forschung. München 2007. Sowie Utz, Peter: „Eigentümlich, zwiefach, übertragen“: Figuren des Fremden bei Robert Walser, in: Caduff, Corina (Hrsg.): Figuren des Fremden in der Schweizer Literatur. Zürich 1997, S. 18-35.

38 Deleuze; Guattari: Kafka, S. 107. (Hervorhebungen D.B.) 
Die Verbindung von Geschwistern und Raum erwächst aus dem Nebeneinander, in dem die Serie zum Ausdruck kommt. Auch der Walser-Bewunderer Kafka, der so tief in die Wucherungen der Angestelltenwelt eingedrungen ist, hat dafür ein Gespür entwickelt. Im Vergleich dazu zeigt sich die horizontale Verkettung in Der Gehülfe noch weitgehend über den Umweg der Reflexion, den Joseph nimmt. Dessen so sehr um Ausgleich bemühtes, vermittelndes Denken macht gerade indem es zumeist beim Denken bleibt - das Fehlen einer gesetzgebenden mütterlichen Instanz nur umso stärker offen. Und damit lenkt es den Blick auf die Beziehungen der Geschwister, Kameraden und weiter Entfernten untereinander.

\section{Quellen und Literatur}

Ariès, Philippe: Geschichte der Kindheit. München 1996.

Bichsel, Peter: Reading Geschwister Tanner, in: The Review of Contemporary Fiction, Vol. 12, No. 1 (1992), S. 66-78.

Blok, Anton: The Narcissism of Minor Differences, in: ders.: Honour and Violence. Cambridge 2001, S.115-135.

Böschenstein, Bernhard: Zu Robert Walsers Dichterporträts, in: Deuchler, Florens u.a. (Hrsg.): Von Angesicht zu Angesicht. Porträtstudien. Bern 1983.

Deleuze, Gilles; Guattari, Félix: Kafka. Für eine kleine Literatur. Frankfurt/Main 1976.

Echte, Bernhard; Meier, Andreas (Hrsg.): Die Brüder Karl und Robert Walser. Maler und Dichter. Stäfa 1990.

Fischer, Anton: Der Weg zum Anderen in Robert Walsers „Räuber“-Roman. Norderstedt 1995.

Groddeck, Wolfram u.a. (Hrsg.): Robert Walsers „Ferne Nähe“. Neue Beiträge zur Forschung. München 2007.

Hong, Kil-Pyo: Selbstreflexion von Modernität in Robert Walsers Romanen „Geschwister Tanner“, „Der Gehülfe“ und „Jakob von Gunten“. Würzburg 2002.

Mächler, Robert: Robert Walser und das Christentum, in: Kerr, Katharina (Hrsg.): Über Robert Walser. Bd. 2. Frankfurt/Main, 1978, S. 115-124.

Matt, Peter von: Verkommene Söhne, mißratene Töchter. Familiendesaster in der Literatur. München, Wien 1995.

Mitchell, Juliet: Siblings. Sex and Violence. Cambridge 2003.

Montaigne, Michel de: Essais. Frankfurt/Main 1998.

Müller, Dominik: Künstlerbrüder - Schwesterkünste. Robert und Karl Walser, in: Stadler, Ulrich (Hrsg.): Zwiesprache. Beiträge zur Theorie und Geschichte des Übersetzens. Stuttgart, Weimar 1996, S. 382-395.

Petri, Horst: Geschwister - Liebe und Rivalität. Die längste Beziehung unseres Lebens. Zürich 1994.

Prill, Meinhard: Aus dem Leben eines Taugenichts, in: Jens, Walter (Hrsg.): Kindlers Neues Literatur Lexikon. Bd. 5. München 1989, S. 72-74. 
Rüsch, Lukas: Ironie und Herrschaft. Untersuchungen zum Verhältnis von Herr und Knecht in Robert Walsers Roman „Der Gehülfe“. Königstein 1983.

Sauvat, Catherine: Vergessene Weiten. Eine Robert Walser-Biographie. Frankfurt/Main 1995. Schmidt-Hellerau, Cordelia: Der Grenzgänger. Zur Psycho-Logik im Werk Robert Walsers. Zürich 1986.

Schuller, Marianne: Moderne. Verluste. Literarischer Prozess und Wissen. Basel, Frankfurt/Main 1997.

Simmel, Georg: Die Philosophie des Geldes. Hrsg. v. David P. Frisby; Klaus Christian Köhnke, in: Georg Simmel Gesamtausgabe. Bd. 6. Hrsg. v. Otthein Rammstedt. Frankfurt/Main 1989.

Simmel, Georg: Soziologie. Untersuchungen über die Formen der Vergesellschaftung. Leipzig 1908.

Utz, Peter: Tanz auf den Rändern. Robert Walsers „Jetztzeitstil““. Frankfurt/Main 1998.

Utz, Peter: „Eigentümlich, zwiefach, übertragen“: Figuren des Fremden bei Robert Walser, in: Caduff, Corina (Hrsg.): Figuren des Fremden in der Schweizer Literatur. Zürich 1997, S. 18-35.

Villwock, Peter: Räuber Walser. Beschreibung eines Grundmodells. Würzburg 1993.

Wagner, Karl: Herr und Knecht: Robert Walsers Roman „Der Gehülfe“. Wien 1980.

Walser, Robert: „Der Spaziergang“, in: ders.: Dichtungen in Prosa. Bd. 5: Komödie. Geschichten und Der Spaziergang. Hrsg. v. Carl Seelig. Genf, Frankfurt/Main 1961, S. 259343.

Walser, Robert: Der Gehülfe. Hrsg. von Jochen Greven. Zürich, Frankfurt/Main 1985.

Walser, Robert: Geschwister Tanner. Frankfurt/Main 1975.

Wolf, Ursula: Aristoteles” „Nikomachische Ethik“. Darmstadt 2007.

Zimmermann, Hans D.: Walser und die pietistische Ethik, in: Chiarini, Paolo (Hrsg.): „Immer dicht vor dem Sturze ...“. Zum Werk Robert Walsers. Frankfurt/Main 1987, S. 237-251.

Zoll, Rainer: Was ist Solidarität heute? Frankfurt/Main 2000. 
Ulrike Schneider, Helga Völkening and Daniel Vorpahl - 978-3-653-98812-3

Downloaded from PubFactory at 01/11/2019 10:54:37AM

via free access 


\title{
Moses und Aron in der musikalischen Rezeption Arnold Schönbergs
}

\author{
Yael Kupferberg
}

\begin{abstract}
This article takes a look at Arnold Schoenberg's opera Moses und Aron (1923-1937, 1954 premiere) which deals with the concept of 'Bilderverbot' in Jewish context. Within the opera Moses and Aron are antipodal figures: Aron demonstrates the human need for sensuality; whereas Moses believes this inherent need diametrically opposes biblical law. This article analyzes the brotherly dispute in Schoenberg's libretto as a conflict of two different concepts of Jewish identity and contextualizes the 'Bilderverbot' within an aesthetic and ethical context.
\end{abstract}

Der Prophet Moses erscheint dem Kulturwissenschaftler Jan Assmann als Faszinosum. ${ }^{1}$ Moses gilt ihm als die Verkörperung der kulturellen und religiösen Konstellation, deren antagonistische Dynamik zu den bestimmenden Faktoren abendländischer, jüdischer sowie christlicher, Religions- und Geistesgeschichte gehört. ${ }^{2}$ Moses steht für Monotheismus:

Mit seinem Namen verbindet sich die normative Verkündigung des Einen Gottes, normativ im Sinne der strikten Exklusivität und der strengen Unterscheidung zwischen dem Einen wahren Gott und den vielen , anderen', fremden, verbotenen, falschen, eingebildeten Göttern. ${ }^{3}$

Allein Moses war es gegeben, so der biblische Bericht, den Namen Gottes zu erfahren, und zwar in einer semantischen Dichte und Vielschichtigkeit, der es an

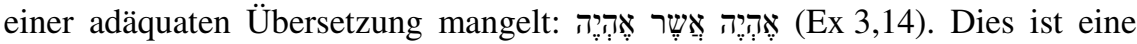
sprachliche Wendung, die variantenreich übersetzt werden kann, jedoch grammatikalisch im Verb ,sein \%,existieren“ wurzelt und insofern auf eine historische Gegenwart, kommende Zukünftigkeit und Unendlichkeit anspielt. Diese Sequenz, „Ich werde sein, der ich sein werde“, ist jenes doppelte Futurum des Verbs ,sein` in der ersten Person des Singulars, deren grammatikalisch, nicht

1 Vgl. Assmann, Jan: Einleitung, in: Hartwich, Wolf-Daniel: Die Sendung Moses. Von der Aufklärung bis Thomas Mann. München 1997, S. 9-16, hier S. 9.

2 Vgl. ebd.

3 Assmann, Jan: Die Mosaische Unterscheidung in Arnold Schönbergs Oper Moses und Aron, in: http://www.aroumah.net/agora/assmann03-schoenbergEF.pdf, S. 5, abgerufen am 29.08.2014. Es ist die „mosaische Unterscheidung“, so Assmann weiter, „die sich in den 613 Geboten und Verboten äußert und zu entsprechender Entscheidung aufruft. Denn dem Einzelnen wird die Reflexion über sein Handeln abverlangt.“ Ebd. Insofern ist das Judentum Praxis und kein Glaubensbekenntnis. 
aber semantisch, identische Termini durch ein Relativpronomen verbunden sind. Linguistisch ist die Sequenz ein Sprechakt, der seinem Gegenüber die unendliche Idee Gottes, seiner Kompetenz der Wandlung in der Geschichte und die Permanenz seiner Existenz vor Augen hält. ${ }^{4}$

In dieser Sequenz offenbart sich also jene intellektuelle Potenz, die der theologischen und philosophischen Reflexion Raum bietet, darüber nachzudenken, was dem jüdischen Monotheismus genuin ist. Als zentral erscheint das Bilderverbot. ${ }^{5}$ Dieser anthropomorphe, personale Gott ohne Bild ist Anlass einer Reflexion innerhalb der Ästhetik der Moderne. ${ }^{6}$ Für die Kunst resultiert daraus eine spezifische Dialektik: Sofern Kunst immer performativ ist und der sinnlichen Erfahrung Rechnung trägt, birst sie an der theologisch geforderten Geistigkeit, am Verbot der Darstellung. In Moses selbst thematisiert sich der Konflikt von Unverfügbarkeit und Freiheit auf der einen und Zuwendung und Nähe auf der anderen Seite. $^{7}$

Die ästhetische, musikalische Auseinandersetzung mit der genannten Dialektik ist das Thema einer Oper Arnold Schönbergs. Moses und Aron widmet sich diesem Nexus ,negativer Theologie“" ${ }^{4}$, dem Verbot, sich ein Bild von Gott zu machen.

Der Meister der Wiener Schule und Begründer der ,Neuen Musik', Arnold Schönberg, musikalisiert das Verbot nach der Zwölftontechnik, unter der er Folgendes verstanden wissen wollte: „Diese Methode besteht [...] aus der ständigen und ausschließlichen Verwendung einer Reihe von zwölf verschiedenen Tönen. “9 Diese zwölf Töne werden innerhalb einer Serie nicht wiederholt, jeder Ton ist gleichwertig. Darüber hinaus existiert kein tonales Zentrum, sondern es bestehen Serien von Tönen, die die gleiche rhythmische, melodische und harmonische Wertigkeit besitzen. Diese Komposition bricht bewusst mit der

4 Vgl. dazu ausführlich Mosès, Stéphane: Gesetz und Eros. Zehn Lektüren der Bibel. München 2004, S. 65-79, hier S. 67f.

5 „Du sollst dir kein Bildnis noch irgendein Gleichnis machen, weder von dem, was oben im Himmel, noch von dem, was unten auf Erden, noch von dem, was im Wasser unter der Erde ist: Bete sie nicht an und diene ihnen nicht!“ (Ex 20,1-5).

6 Vgl. u.a. Brumlik, Micha: Schrift, Wort und Ikone. Wege aus dem Bilderverbot. Frankfurt/Main 1994.

7 Vgl. ebd., S. 29.

8 Engel, Ulrich: Von der (Un-)Möglichkeit des sakralen Kunstwerks. Zur Wort-BildDialektik in Arnold Schönbergs Oper „Moses und Aron“ im Anschluss an Theodor W. Adorno, in: Engelhardt, Paul; Strube, Claudius (Hrsg.): Die Sprachlichkeit in den Künsten. Berlin 2007, S. 238-245, hier S. 242.

9 Schönberg, Arnold: Stil und Gedanke. Aufsätze zur Musik. Hrsg. v. Ivan Vojtěch. Frankfurt/Main 1976, S. 75. 
traditionellen Form- und Harmonielehre und sie bricht insbesondere mit der Hörgewohnheit des Publikums. Denn diese ,Neue Musik‘ möchte etwas anderes sein: Für Schönberg dient Musik durchaus nicht der genussreichen Unterhaltung, sondern sie ist vielmehr Ausdruck und Produkt eines Musik-Dichters, eines Musik-Denkers; sie ist Ausdruck einer intellektuellen Reflexion. Musik ist ein Teil dessen, was der Mensch geistig wahrnehmen und durchdenken kann. ${ }^{10}$ Insofern erscheint die ,Neue Musik' als eine Ästhetik der Erkenntnis und nicht eben als ein Medium des Konsums, der Unterhaltung, der Befriedigung sinnlicher Bedürftigkeit, der Apologie des Bestehenden.

Das Bilderverbot erweist sich als prädestiniert dafür, über den philosophischen Konnex hinaus ästhetisch das auszuarbeiten, was Kunst bzw. die ,Neue Musik“ im Sinne Schönbergs zu leisten vermag. Denn diese ,Neue Musik“ bindet die Geschichte und die Philosophie des Judentums mit ein, reflektiert darüber und bringt sie zu Gehör. Jene Paradigmen, die Philosophie des Bilderverbots und die Geschichte des Judentums, auszukomponieren, avanciert zu einem Kunstwerk - zu einer neuen Ästhetik -, das dem Intellekt verschrieben ist.

Dieses ,großartige[] Oratorium“11, wie der Wiener Schriftsteller Soma Morgenstern notierte, trägt das Bilderverbot über das ungleiche Brüderpaar aus, über die Antipoden Moses und Aron. ${ }^{12}$ Moses, der jüngere Bruder, verteidigt den Gedanken und der ältere Bruder Aron hält ihm die Relevanz des Wortes bzw. des Bildes als Instanz der Vermittlung entgegen.

Der Konflikt zwischen den Brüdern ist ein genuin jüdischer Konflikt, der bereits innerhalb der biblischen Geschichte existiert und mit dem sich Arnold Schönberg seit 1923 beschäftigte. 1925 griff er in Vier Stücken für gemischten Chor, op. 27- in dem zweiten Stück „Du sollst nicht, du musst“ - erstmals das zentrale Thema der Oper auf: ${ }^{13}$

Du sollst dir kein Bild machen!

Denn ein Bild schränkt ein,

begrenzt, faßt

Was unbegrenzt und unvorstellbar bleiben soll. ${ }^{14}$

10 Vgl. Schönberg: Stil, 76f.

11 Morgenstern, Soma: Alban Berg und seine Idole: Erinnerungen und Briefe. Hrsg. u. mit einem Nachwort v. Ingolf Schulte. Lüneburg 1995, S. 35.

12 Die unübliche Schreibweise des Namens „Aron“ geht auf Arnold Schönberg zurück und wird hier übernommen, insofern es sich um die Operngestalt handelt.

13 Vgl. Strecker, Stefan: Der Gott Arnold Schönbergs. Blicke durch die Oper Moses und Aron. Münster 1999, S. 122.

14 Zit. nach: Strecker: Gott, S. 121. 
Der Oper Moses und Aron, deren erste zwei Akte zwischen 1928 und 1932 entstanden sind und die Fragment, das heißt unvollendet blieb, ${ }^{15}$ ging thematisch 1915 das Werk Die Jakobsleiter voraus. Später, 1939, im US-amerikanischen Exil bearbeitete Schönberg den Psalm 130, die Vertonung des Kol Nidrej ${ }^{16}$. Unter dem Eindruck der Katastrophe des europäischen Judentums entstand 1947 Ein Überlebender von Warschau.

Schönberg selbst rekonvertierte 1933 in einer Synagoge in Paris zum Judentum - ein Zeugnis des Bekenntnisses zum Judentum angesichts des sich zusehends aggressiv gerierenden Antisemitismus. Ihm selbst wurde 1933 die Professur der Klasse für musikalische Komposition an der Preußischen Akademie der Künste zu Berlin entzogen. ${ }^{17}$ Diese politischen und historischen Erfahrungen, die zu biographischen wurden, setzte er künstlerisch um; es galt insbesondere die Vergötterung des Bildes, die Idolatrie seiner Zeit, zu problematisieren und zu dekonstruieren.

Die Oper Aron und Moses, deren Inhalt sich um den Auszug der Israeliten aus Ägypten ins Gelobte Land konzentriert, galt Schönberg explizit als religiöses Werk und er verwahrte sich damit gegen jegliche biographische Interpretation: „Das ist Ende des 19ten Jahrhunderts, aber nicht ich. Der Stoff und seine Behandlung sind rein religionsphilosophisch. “18 Schönberg gibt somit den Weg der Deutung an. Er habe ,aus dem mächtigen Stoff vor allem diese Elemente in den Vordergrund gerückt: Der Gedanke des unvorstellbaren Gottes, des auserwählten Volkes und des Volksführers“" ${ }^{19}$ Insbesondere Theodor W. Adorno, Zeitgenosse und der Philosoph der ,Neuen Musik', nimmt diese Intention

15 Obgleich Schönberg noch bis 1950 nach einem angemessenen Schluss suchte, beließ er das Werk in dieser fragmentarischen Gestalt.

16 Das Kol Nidrej (aram. ,alle Gelübde“) ist ein bedeutsames, emotional und historisch hoch besetztes Zitat, das vor dem Abendgebet an Jom Kippur (Versöhnungstag), dem höchsten Feiertag des Judentums, im Gottesdienst gesprochen wird. Im Wortlaut: „Alle Gelübde, Entsagungen, Bannungen, Entziehungen, Kasteiungen und Gelöbnisse unter jedem Namen, auch alle Schwüre, so wir gelobt, geschworen, gebannt und entsagt haben werden - Von diesem Versöhnungstage, bis zum Versöhnungstage, der zu unserem Wohle heran kommen möge - bereuen wir hiermit allesamt; sie alle seien aufgelöst, ungültig, unbündig aufgehoben und vernichtet; ohne Verbindlichkeit und ohne Bestand. Unsere Gelübde seien keine Gelöbnisse; was wir entsagt, sollen keine Entsagungen, und was wir beschwören, keine Schwüre sein.“(Übersetzung: Salomo Gottlieb Stern)

17 Vgl. Freitag, Eberhard: Schönberg. Reinbek bei Hamburg 2000, S. 133.

18 Schönberg, Arnold: Briefe. Ausgew. und hrsg. v. Erwin Stein. Mainz 1958, S. 298.

19 Ebd., S. 188. 
Schönbergs auf und erkennt in der Oper ein „sakrales Fragment ${ }^{\text {‘20 }}$, das eben um das jüdische Bilderverbot zentriert ist. Diese große Leistung des Judentums, das Bilderverbot, das im „Verbot, das Falsche anzurufen, das Endliche als das Unendliche, die Lüge als Wahrheit“, bewahre und beherberge „,das Unterpfand der Rettung “21.

Diese Denkfigur Adornos und Max Horkheimers aus der Dialektik der Aufklärung (1944) trifft wohl den Kern des Verbots. Nur durch das Verbot des Bildes existiere Rettung. Gott ist dadurch zu bewahren, dass die Menschen es vermeiden, mit ihm in einen vermeintlich unmittelbaren, sinnlichen Kontakt zu treten: „Erst die durch das Bilderverbot erzielte Entmächtigung der Magie [....] garantiert Befreiung. “22

Dieses ist der Standpunkt Adornos und Horkheimers, die mit Sigmund Freud eine Überlegenheit des Judentums über das Christentum, gerade im Verbot, sich von Gott ein Bild zu machen, konstatierten. Hierin also offenbart sich die bedeutsame, zivilisatorische Leistung, denn: „Gott als Geist tritt der Natur als das andere Prinzip entgegen, das nicht bloß für ihren blinden Kreislauf ein-

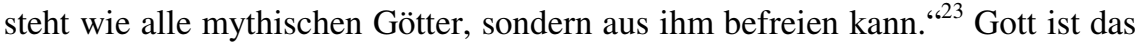
absolut Andere, das allerdings eingreift als Gesetzesgeber, der den sozialen Kodex im Gesetz verankert und somit Gerechtigkeit und Frieden, also Vollkommenheit (Schalom), unter den Menschen fundiert. Während das Judentum durch das Bilderverbot dem Geist höchste Abstraktion abverlange, Gott außerhalb des weltlichen Prinzips steht, und, wie die messianische Verheißung verkündet, aus dieser Weltlichkeit befreien kann, habe das Christentum die Furcht vor dem Absoluten durch die Menschwerdung in Jesu mildern können - und das Unendliche dem Endlichen gleichgemacht. Freud, Adorno und Horkheimer sehen darin gleich Schönberg - einen Rückschritt und argumentieren dafür im historischen Kontext, verorten jedoch die Konfrontation zwischen Juden- und Christentum, zwischen dem übernationalen Konzept und der nationalen Konkretion der Anderen. Es ist sowohl ein theologischer als auch ein politischer Konflikt.

20 Adorno, Theodor W.: Sakrales Fragment. Über Schönbergs Moses und Aron, in: ders.: Musikalische Schriften I-III. Gesammelte Schriften 16. Hrsg. v. Rolf Tiedemann. Frankfurt/Main 1997, S. 458.

21 Adorno, Theodor W.; Horkheimer, Max: Begriff der Aufklärung. Dialektik der Aufklärung, in: Adorno, Theodor W.: Dialektik der Aufklärung. Gesammelte Schriften 3. Hrsg. v. Rolf Tiedemann. Frankfurt/Main 1981, S. 19-60, hier S. 40.

22 Brumlik: Schrift, S. 28.

23 Adorno, Theodor W.; Horkheimer, Max: Elemente des Antisemitismus. Grenzen der Aufklärung, in: Adorno, Theodor W.: Dialektik der Aufklärung. Gesammelte Schriften 3. Hrsg. v. Rolf Tiedemann. Frankfurt/Main 1981, S. 192-234, hier S. 201. 
Das ist er auch für Schönberg in der Oper Moses und Aron. Schönberg jedoch trägt diesen Konflikt in den jüdischen Monotheismus hinein. Hier werden nicht die verwandten Kulturen gegeneinander polarisiert, sondern es ist ein innerjüdischer Konflikt, ein innerfamiliärer - ein Bruderstreit.

Aron ist der Mund Moses', dessen „schwere Zunge“ (Ex 4,10) ihn an seiner Rolle zweifeln lässt, und dem Gott als kommunikative Unterstützung den älteren Bruder an die Seite stellt. Das Bruderpaar harmoniert vorerst. Beide bedienen ihre Rolle: Moses ist der Religionsstifter, Aron fungiert volksnah als sozialer Kommunikator. Sie begegnen sich erstmals in der Wüste. Nach anfänglicher Anerkennung ihrer Bruderschaft und Allianz schleicht sich der Konflikt ein:

Aron: Du Sohn meiner Väter, schickt dich mir der grosse Gott?

Moses: Du Sohn meines Vaters, Bruder des Geistes, aus dem der Einzige sprechen will: Vernimm mich und ihn; und sage, was du verstehst!

Aron: Mein Bruder, gab der Allmächtige mich dir als Gefäss, auszuschütten über unsre Brüder des Ewigen Gnade?

Moses: Gnade schenkt er dir aus Erkenntnis.

Aron: Glückliches Volk, einem einzigen Gott zu gehören, den zu bekämpfen kein andrer Macht besitzt.

Moses: Andre gibt es nur im Menschen, nur in der Vorstellung. In ihr hat der Allgegenwärtige nicht Raum.

Aron: Gebilde der höchsten Phantasie, wie dankt sie dir's, dass du sie reizest zu bilden!

Moses: Kein Bild kann dir ein Bild geben vom Unvorstellbaren. ${ }^{24}$

Dabei spricht Moses - Schönberg weist ihm also eine reine Sprechrolle zu -, während Aron im lyrischen Tenor singt. Es ist bezeichnend: „Aron, der Mann der Bilder und der Vermittlung, muss in der Oper singen, bedient sich der bilderlosen Sprache“25, nämlich der Musik, die - so Adorno - bilderlose Kunst ist. Moses hingegen, der Verfechter des Bilderverbots, singt nicht, sondern spricht: „,nicht anders kann er [Schönberg] dramaturgisch das alttestamentarische Tabu über den Ausdruck fassen, als dadurch, dass er ihn [Moses] sich so mitteilen lässt, wie er es nach biblischer Erzählung kaum recht vermag“. ${ }^{26}$

Die vorgesehene Arbeitsteilung der Brüder, zwischen Gesetz und Gnade, Entscheidung und Versöhnung, bricht in der Verunsicherung um Moses

24 Schönberg, Moses und Aron 1,1. Hier und im Folgenden als MuA zit. nach: Schönberg, Arnold: Moses und Aron. Oper in drei Akten. Libretto. Arnold Schönberg Archiv: http://www.schoenberg.at/index.php?option=com_content\&view=article\&id=231\&Itemi d=399\&lang=de, abgerufen am 29.08.2014.

25 Adorno: Sakrales Fragment, S. 458.

26 Ebd. 
Verbleib jäh zusammen, als er vierzig Tage auf dem Berg Sinai verbringt. Die siebzig Ältesten um Aron werden unruhig und zweifeln an dem Unterfangen. Das Vertrauen in Moses und vorerst noch in „seinen“ Gott steht auf tönernen Füßen. Derweil hat die Stunde Arons, des älteren Bruders, geschlagen: Er revidiert das Gesetz. Aron lässt in Abwesenheit Moses' das Goldene Kalb errichten, das als Sinnbild einer der schwersten Verfehlungen Israels gegenüber dem Prinzip Gottes gilt. ${ }^{27}$ In der dritten Szene des zweiten Akts wird in Abwesenheit Moses' ein großes Fest vor dem Altar vorbereitet, es wird Vieh geschlachtet. Das Volk ist in Trunkenheit, vier Jungfrauen werden geopfert, eine Orgie der Vernichtung und der Erotik endet in der totalen Erschöpfung. Und es kommt zur Auseinandersetzung,

die Schönberg, dem es auf die Konfrontation von Mose und Aron ankommt, herausgreift und in großem Stil zum zweiten Akt der Oper ausgestaltet. Ging es im ersten Akt um das Verbot des, Vorstellens', des Erzeugens mentaler und sprachlicher Bilder, [...] so geht es jetzt um ein materielles Bild, wie es auch die Bibel aufs schärfste verbietet. ${ }^{28}$

In der Gestalt des Goldenen Kalbes, in diesem Bild, wird ein Götze angebetet, das Verbot des Bildes verworfen und damit das Prinzip des jüdischen Monotheismus verraten. In einer Notiz in den Entwürfen zur Oper hält Schönberg fest:

Ein falscher Gott ist in allem enthalten, das uns umgibt, er kann so aussehen wie alles, er entspringt allem, alles entspringt ihm; [...]. Dieser Gott ist der Ausdruck einer Naturverehrung und setzt jedes Lebewesen Gott gleich. ${ }^{29}$

Ein falscher Gott wohnt jedem Bild inne; das bzw. jedes Bild entbehrt der Sakralität, die der jüdische Monotheismus fordert.

Aron singt - postulierend: „Verehrt euch selbst in diesem Sinnbild!“ (MuA 2,3). Das verlangt der ältere Bruder; denn der Gott, den Aron herbeischwört, ist das Volk selbst, es ist die nationale Geburt des jüdischen Volkes und „Ethnotheismus“, der die Verabsolutierung des Volkes betreibt, eine „Anbetung des eigenen Kollektivs“, das in der „Gestalt des goldenen Kalbes sichtbare Gestalt ${ }^{630}$ gewinnt. Insofern vergeht sich Aron an der zentralen mosaischen Unter-

27 Vgl. dazu auch Mandelbaum, Irving J.: Tannaitic Exegesis of the Golden Calf Episode, in: Davies, Philip R.; White, Richard T. (Hrsg.): Tribute to Geza Vermes: Essays on Jewish and Christian Literature and History. Sheffield 1990, S. 207-223.

28 Assmann: Mosaische Unterscheidung, S. 13.

29 Zit. nach Strecker: Gott, S. 134.

30 Assmann: Mosaische Unterscheidung, S. 18. 
scheidung, wozu Assmann konstatiert: „Weiter hätte sich Aron nicht von dem Gedanken entfernen können, den zu verkünden er berufen “31 ${ }^{\text {ward. }}$

Während Aron die sinnliche, spürbare Vermittlung und das Leben im Auge behält, vertritt der jüngere Bruder Moses in der Oper den reinen Gedanken. Das eingeforderte Bilderverbot lässt sich jedoch nur unter Verlust an Sinnlichkeit leben. Diesen Verzicht erkennt Aron und billigt dem Volk genau jene Sinnlichkeit zu, die Moses ihm vorenthält. Diese jedoch schlägt zur Raserei um. Dieses Umschlagen, von Sinnlichkeit zur Raserei, komponiert Schönberg aus. Denn das thematische, musikalische Material entfernt sich immer weiter von den Tonsymbolen, die für den Gottesgedanken stehen. Mit dem symphonischen Prunk und der rhythmischen Schwungkraft des sich verselbstständigenden Orchesters steigert sich die Ekstase des sich an sich selbst berauschenden Volkes ${ }^{32}$ und konterkariert die Absichten Moses. Die von Moses geforderte „Reinheit des Denkens“", die das Volk in der Wüste „nähren, erhalten und entwickeln“ (MuA 1,4) soll, scheitert am Leben, an dem Bedürfnis von Sinnlichkeit. Doch ,abgespalten von der Offenbarung des einzigen Gottes und ohne Aussicht auf Erfüllung seines spezifischen Rechts wird Sinnlichkeit destruktiv. Sie schlägt, wie der zweite Akt es drastisch darstellt, um in Raserei. ${ }^{“ 33}$ Diese Regression mag nicht allein Resultat der Schwäche des Volkes sein, das nach den Worten Arons eines „,von Kindern ist" (MuA 1,2). Vielmehr entbrennt hier der Konflikt zwischen Geist und Körper, zwischen Idee und Leben. Das Übermenschliche, das, was Moses einzufordern versucht, opponiert dem grundlegend menschlichen Bedürfnis nach dem sinnlichen Moment, das dem „Leben mit Gott ${ }^{\star 34}$, so Walter Benjamin, als vorschnelles Opfer entwunden wurde.

Die Absicht Arons mag als „Konzession“35 - wenn auch als eine fragwürdige - an das elementare Bedürfnis des Volkes erscheinen, das sich von Moses und seinem Gott überfordert und verlassen fühlt. ${ }^{36}$ Jedoch verweist Aron auf das diesseitige, lebendige Bestehen des Volkes und auf die politische Dimension, auf die Konkretion. Im Volk Israel und nicht in der reinen Idee erblickt Aron die lebendige Verbundenheit mit Gott: „Israels Bestehn bezeuge den Gedanken des

31 Ebd.

32 Vgl. dazu Wörner, Karl H.: Gotteswort und Magie. Die Oper Moses und Aron von Arnold Schönberg. Heidelberg 1959, S. 45-58.

33 Buchholz, René: Zerfallende Traditionen - verwandelnde Rettung des Judentums auf dem Hintergrund des europäischen Judentums. Rottenburg-Stuttgart 2004/2013, S. 9f.

34 Benjamin, Walter: Das Passagen-Werk - Frühe Entwürfe, in: ders.: Gesammelte Schriften. Hrsg. v. Rolf Tiedemann u. Hermann Schweppenhäuser. Bd. 5. Frankfurt/Main 1972-1999, S. 1056.

35 Buchholz: Traditionen, S. 18f.

36 Vgl. ebd.

Ulrike Schneider, Helga Völkening and Daniel Vorpahl - 978-3-653-98812-3 
Ewigen!“ (MuA 2,3), postuliert Aron. Hier werden die zwei nicht ohne weiteres in Einklang zu bringenden Konzepte von Judentum konfrontiert und verhandelt: Dem Geist und der Idee steht das Bedürfnis des Volkes nach nationaler Konkretion entgehen, d.h. sich in die Ordnung der Welt zu fügen. Das Judentum selbst handelt die Konzepte bereits im biblischen Kontext - als biblischen Text - aus: „Die Forderung, die Bindung an Blut und Boden zu lockern, hält sich durch das ganze Alte Testament durch“37, so schreibt der Psychoanalytiker und Religionssoziologe Erich Fromm und verweist damit auf die Spannung zwischen Geist und Land, Diaspora und Nation. Die Auserwählung des Volkes gründet sich, gemäß der Auslegung Fromms, ${ }^{38}$ darin - und hier folgt er seinen Zeitgenossen Horkheimer und Adorno -, die Vergötzung von Boden und Staat aufzugeben und vielmehr nach Wahrheit, Liebe und Gerechtigkeit zu streben und dadurch Freiheit zu erlangen, sich nicht dem Prinzip der „Nation“ zu beugen und sich somit über die weltlichen Strukturen zu erheben. Schönbergs Figuren Moses und Aron stehen hernach für die kontradiktorischen Prinzipien: Religion kontra Nation, Geist kontra Volk, Wüste kontra Kanaan, Diaspora kontra Zionismus. Das ist das politische und ideelle Dilemma des Judentums, das Schönberg angesichts der historisch existentiellen Bedrohung ausficht.

Aron verkündet die (nationale) Lösung: In der Gestalt des Goldenen Kalbes gesteht er dem Volk ,die sinnlich vermittelten Götter zu, die ,Euch gemäß“ und ,gegenwärtigen, alltagsnahen Inhalts“ sind“" (MuA 3,2)“:

„Volk Israels! [...] Lasset die Ferne dem Ewigen! Euch gemäss sind Götter gegenwärtigen, alltagsnahen Inhalts. Ihr spendet diesen Stoff, ich geb' ihm solche Form: [...] Ihr sollt glücklich werden!“ (MuA 3,2)

Die Konkretion in der Gestalt des Kalbes repräsentiert eine „farbige Gegenwart, die nicht länger von einer ungewissen, noch unerfüllten Verheißung und einem ,Leben im Aufschub ““39 kündet, sondern für das sinnliche Leben, für Eretz Jisrael, für die Geschichte steht. Der Preis dafür ist jedoch die Aufgabe des Geistes und somit wird das Judentum den Anderen gleichgemacht. Insofern bedeutet auch der Zionismus eine Form der Assimilation, denn die Verehrung - so Fromm - gilt dann nicht mehr dem namenlosen Gott, sondern „,der Gruppe, die in seinem Namen zu sprechen behauptet ${ }^{\text {“40 }}$. In der ersten Szene des dritten Aktes, die unvertont bleibt, heißt es dann in aller Kürze: „Aron: Das gelobte Land ...“" und Moses entgegnet: „Ein Bild ...“(MuA 3,1).

37 Fromm, Erich: Psychoanalyse und Religion. München 1986, S. 76.

38 Vgl. Fromm: Psychoanalyse, S. 76.

39 Buchholz: Traditionen, S. 10.

40 Fromm: Psychoanalyse, S. 77.

Ulrike Schneider, Helga Völkening and Daniel Vorpahl - 978-3-653-98812-3 
Die große Leistung des Judentums, das Bilderverbot, musikalisiert Schönberg in seiner ganzen dramatischen Dialektik. Ohne Gestalt, ohne Bild - und das heißt auch ohne Nation - zu werden, existiert kein Leben. Der Preis des Bildes ist jedoch hoch. Das Bild zeitigt den Verlust des „Fortschritt[s] in der Geistigkeit“41 . Es ist der Verlust jüdischer Ethik, die auch darin besteht, jedweden Götzen, d.h. jede Identifikation abzulehnen.

Die Orgie ist bereits verrauscht, als Moses mit den Gesetzestafeln vom Berge herabsteigt und mit bloßem Wort macht er das Kalb zunichte: „Vergeh, du Abbild des Unvermögens, das Grenzenlose in ein Bild zu fassen!“" (MuA 2,4). Und Moses hält Aron die Tafeln entgegen: „Das ist kein Bild, kein Wunder! Das ist das Gesetz." (MuA 2,4). Moses verlangt vom Volk, dass es allein dem Gedanken nach leben soll: „Es muß den Gedanken erfassen! Es lebt nur deshalb!“ (MuA 2,5). Darin liegt die jüdische Exklusivität - artikuliert in einem Vers

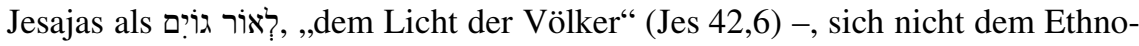
zentrismus hinzugeben, sondern das geistige Prinzip zu verinnerlichen.

Aron hingegen kämpft für die nationale, gemeine Existenz. Das Volk lebt nur, „wenn es sehen, fühlen, hoffen darf“ (MuA 2,5). Aron verlangt danach, den Gedanken in Gebote und Verbote zu kleiden und somit zu leben. Da das Volk nicht im Stande sei, den Gedanken bewusst zu erfassen, wird dann ,unbewusst getan, wie du willst“" (MuA 2,5), argumentiert er und versucht, das lebbare Konzept durchzusetzen. Für den Moses Schönbergs jedoch erscheint das Konzept Arons als Verrat am Gedanken:

Aron [...] umschreibend, ohne auszusprechen: „Verbote, furchterregend, doch befolgbar, sichern das Bestehen; die Notwendigkeit verklärend: Gebote, hart, doch Hoffnung erweckend, verankern den Gedanken. Unbewußt wird getan, wie du willst ... Menschlich schwankend wirst du dein Volk dann finden, doch liebenswert!“ $(\mathrm{MuA} 2,5)$

Das Konzept Arons erscheint in der Tat als lebensnah. Denn es geht dem älteren Bruder darum, das Bestehen des Volkes zu sichern und den Gedanken Gottes zumindest unbewusst zu verankern. Die Ausgestaltung des Dekalogs in 613 Gebote und Verbote in der Tora wäre jener lebbare Weg. Doch Schönberg verlangt noch mehr. Und insofern lehnt Moses ab: „Das will ich nicht erleben!“ (MuA 2,5) Sein Moses bleibt kompromisslos. „Der Gedanke läßt, so wie Gott, keine Vorstellung“" erlaubt, ,keine materielle Verwirklichung zu. “42

41 Freud, Sigmund: Der Mann Moses und die monotheistische Religion, in: ders.: Fragen der Gesellschaft. Ursprünge der Religion. Studienausgabe Bd. 9. Hrsg. v. Alexander Mitscherlich u.a. Frankfurt/Main 1994, S. 455-576, hier S. 557.

42 Strecker: Gott, S. 109.

Ulrike Schneider, Helga Völkening and Daniel Vorpahl - 978-3-653-98812-3 
Moses zerschellt an diesem Konflikt, während Aron ihn sucht: Er hält Moses vor, dass auch die Gesetzestafeln ,nur ein Bild, ein Teil des Gedankens sind“ (MuA 2,5). Auf diese Worte hin zertrümmert Moses die Tafeln. Er tut dies auch in Ex 34,4, wo die Tafeln jedoch erneuert werden. Das Volk wird bestraft, der biblische Aaron wird verschont und die Geschichte setzt sich fort.

Schönberg hingegen ist radikal: Die Tafeln bleiben zertrümmert und Feuerund Wolkensäule werden nur als weitere Götzenbilder Arons entlarvt, denen das Volk ebenso blind folgt wie zuvor dem Goldenen Kalb, nun aber begleitet von dem Gesang der Auserwähltheit und Verheißung. Moses wird nicht nochmals auf den Berg steigen, sondern er zweifelt an seiner Sendung: „So war alles Wahnsinn, was ich gedacht habe, und kann und darf nicht gesagt werden. O Wort, du Wort, das mir fehlt! ‘“43 (MuA 2,5)

Am Ende des nicht mehr musikalisierten dritten Aktes und, anders als im Buch Exodus, bleibt allein Moses - jedoch mit einer Botschaft an die Israeliten:

Immer, wenn ihr euch unter die Völker/ mischt und verwendet euere Gaben, die/ zu besitzen ihr auserwählt seid, um/ für den Gottesgedanken zu kämpfen,/ und ihr verwendet euere Gaben zu falschen/ und nichtigen Zwecken, um im Wettbewerb/ mit fremden Völkern an ihren niedrigen/ Freuden teilzunehmen, immer, wenn ihr/ die Wunschlosigkeit der Wüste verlasst/ und euere Gaben euch zur höchsten Höhe/ geführt haben, immer werdet ihr wieder/ heruntergestürzt werden vom Erfolg des/ Missbrauches, zurück in die Wüste. (MuA 3,1)

Indes gibt Moses den gefesselten Aron frei: „,wenn er es vermag, so lebe er“ (MuA 3,1). Aron, nun frei, steht auf und stirbt. Moses lebt - und siegt. Es ist jedoch ein bitterer Sieg, den das Ideal der Geistigkeit errang, um den Preis der Lebendigkeit Gottes erkauft. $^{44}$

43 In der Oratoriumsfassung hielt Schönberg sich enger an die biblische Vorlage und lässt Moses die Tafeln aus Zorn über das Goldene Kalb zertrümmern: „Sieh hier die Tafel: Gottes Wort! Ihr seid nicht würdig, es zu hören. Merk auf, ich zerschmettere sie, wie ich das Goldene Kalb zertrümmert habe“. Vgl. Schmidt: Entstehungsgeschichte, S. 89; Gadzinski, Anna Christina: Arnold Schönberg - Moses und Aron. Realpolitischer Anspruch, religiöse Propaganda und optische Umsetzung Höchster Unwirklichkeit. Mag. Arbeit. Wien 2003, S. 67.

44 Vgl. auch Scholem, Gerschom: Zur Kabbala und ihrer Symbolik. Zürich 1960, S. 119: „Läßt sich doch immer weniger von diesem Gott aussagen, wenn die Furcht, seine Erhabenheit durch kreatürliche Bilder anzutasten, zu einem entscheidenden Faktor wird. Die Reinheit, um es kurz zu sagen, wird mit der Gefährdung der Lebendigkeit erkauft. Der lebendige Gott geht nie im reinen Begriffe auf ... Die Reinheit des Gottesbegriffs zu bewahren, ohne die Lebendigkeit dieses Gottes anzutasten - das ist die unendliche Aufgabe der Theologie, die, immer wieder neu gestellt, nicht restlos lösbar ist.“ 
Anton von Webern, Zeitgenosse Schönbergs und gleichfalls Komponist der Wiener Schule, dem das Libretto des Opernfragments vorlag, formulierte1929 in einem Brief an Arnold Schönberg:

Wie wundervoll $\mathrm{u}$. für alle Zeiten klar formuliert $\mathrm{u}$. auch erstmalig ist Deine Gegenüberstellung des reinen Gottesgedankens u. des Zerrbildes davon, das die große Masse braucht. Aber mit welcher Güte und so von Herzen verzeihend hast Du diesen Abgrund aufgedeckt. ${ }^{45}$

Über das religionsphilosophische Motiv der Oper geht es von Webern auch darum, was Kunst leisten soll und kann. Die Dialektik zwischen Idee und Vermittlung hat Schönberg in der Oper Moses und Aron musikästhetisch ausgetragen. Musik soll nicht schmücken, sondern wahr sein, so das musikalische Postulat Schönbergs. Es ist „die vertrackte Aufgabe der Musik aber, Bild des Bilderlosen zu sein. “46 Für Adorno gehört es zur Größe Schönbergs, eben diesen Widerspruch nicht unterschlagen, sondern in der musikalischen Komposition in der fast nicht konsumierbaren Oper - ausgetragen zu haben. Und so endet der Aufsatz Adornos über das sakrale Fragment, Über Moses und Aron, mit einer bemerkenswerten Anekdote:

Als man Schönberg angesichts eines unaufgeführten Stückes fragte: Sie haben das also noch nicht gehört, antwortete er: „Doch, als ich es schrieb.“ In solcher Imagination wird das Sinnliche unmittelbar vergeistigt, ohne an Konkretion etwas einzubüßen. Was vollkommen in der Vorstellung sich verwirklicht, ist dadurch objektiv zu Einem geworden, so als ob das musikalische Ingenium in Schönberg noch einmal jene Bewegung von den Stammesgottheiten zum Monotheismus vollbrächte, deren Geschichte von Moses und Aron konzentrierte. ${ }^{47}$

Schönberg bezieht Position. Im Geiste obliegt Moses und im Leben Aron.

Der Bruderstreit ist noch kein historischer. Die Frage nach der ,richtigen " jüdischen Existenz - in der Diaspora oder in Eretz Jisrael - bleibt ein spannungsreicher - und Schönberg legt , seinem` Moses die Worte in den Mund, mit denen uns die Oper entlässt:

Aber in der Wüste seid ihr unüberwindlich und werdet das Ziel erreichen:

Vereinigt mit Gott. (MuA 3,1)

45 Brief vom 18.04.1929. Vgl. Schmidt, Christian Martin (Hrsg.): Arnold Schönberg. Sämtliche Werke III. Band 8, Teil 2: Moses und Aron, Entstehungsgeschichte. Texte und Testentwürfe zum Oratorium und zur Oper. Mainz, Wien 1998, S. 7.

46 Adorno: Sakrales Fragment, S. 458.

47 Ebd., S 475. 


\section{Quellen und Literatur}

Adorno, Theodor W.: Sakrales Fragment. Über Schönbergs Moses und Aron, in: ders.: Musikalische Schriften I-III. Gesammelte Schriften 16. Hrsg. v. Rolf Tiedemann. Frankfurt/Main 1997, S. 454-475.

Adorno, Theodor W.; Horkheimer, Max: Begriff der Aufklärung, in: Adorno, Theodor W.:

Dialektik der Aufklärung. Gesammelte Schriften 3. Hrsg. v. Rolf Tiedemann. Frankfurt/Main 1981, S. 19-60.

Adorno, Theodor W.; Horkheimer, Max: Elemente des Antisemitismus. Grenzen der Aufklärung, in: Adorno, Theodor W.: Dialektik der Aufklärung. Gesammelte Schriften 3. Hrsg. v. Rolf Tiedemann. Frankfurt/Main 1981, S. 192-234.

Assmann, Jan: Einleitung, in: Hartwich, Wolf-Daniel: Die Sendung Moses. Von der Aufklärung bis Thomas Mann. München 1997.

Assmann, Jan: Die Mosaische Unterscheidung in Arnold Schönbergs Oper Moses und Aron, in: http://www.aroumah.net/agora/assmann03-schoenbergEF.pdf, abgerufen am 29.08.2014

Benjamin, Walter: Das Passagen-Werk - Frühe Entwürfe, in: ders.: Gesammelte Schriften. Hrsg. v. Rolf Tiedemann u. Hermann Schweppenhäuser. Bd. 5. Frankfurt/Main 19721999

Buchholz, René: Zerfallende Traditionen - verwandelnde Rettung des Judentums auf dem Hintergrund des europäischen Judentums. Rottenburg-Stuttgart 2004/2013.

Brumlik, Micha: Schrift, Wort und Ikone. Wege aus dem Bilderverbot. Frankfurt/Main 1994.

Engel, Ulrich: Von der (Un-)Möglichkeit des sakralen Kunstwerks. Zur Wort-Bild-Dialektik in Arnold Schönbergs Oper „Moses und Aron“ im Anschluss an Theodor W. Adorno, in: Engelhardt, Paul; Strube, Claudius (Hrsg.): Die Sprachlichkeit in den Künsten. Berlin 2007, S. 238-245.

Freitag, Eberhard: Schönberg. Reinbek bei Hamburg 2000.

Freud, Sigmund: Der Mann Moses und die monotheistische Religion, in: ders.: Fragen der Gesellschaft. Ursprünge der Religion. Studienausgabe Bd. 9. Hrsg. v. Alexander Mitscherlich u.a. Frankfurt/Main 1994, S. 455-576.

Fromm, Erich: Psychoanalyse und Religion. München 1986.

Gadzinski, Anna Christina: Arnold Schönberg - Moses und Aron. Realpolitischer Anspruch, religiöse Propaganda und optische Umsetzung Höchster Unwirklichkeit. Mag. Arbeit. Wien 2003.

Mandelbaum, Irving J.: Tannaitic Exegesis of the Golden Calf Episode, in: Davies, Philip R.; White, Richard T. (Hrsg.): Tribute to Geza Vermes: Essays on Jewish and Christian Literature and History. Sheffield 1990, S. 207-223.

Morgenstern, Soma: Alban Berg und seine Idole: Erinnerungen und Briefe. Hrsg. u. mit einem Nachwort v. Ingolf Schulte. Lüneburg 1995.

Mosès, Stéphane: Gesetz und Eros. Zehn Lektüren der Bibel. München 2004.

Schmidt, Christian Martin (Hrsg.): Arnold Schönberg. Sämtliche Werke III. Band 8, Teil 2: Moses und Aron, Entstehungsgeschichte. Texte und Testentwürfe zum Oratorium und zur Oper. Mainz, Wien 1998.

Scholem, Gershom: Zur Kabbala und ihrer Symbolik. Zürich 1960.

Schönberg, Arnold: Briefe. Ausgew. und hrsg. v. Erwin Stein. Mainz 1958. 
Schönberg, Arnold: Stil und Gedanke. Aufsätze zur Musik. Hrsg. v. Ivan Vojtěch. Frankfurt/Main 1976.

Schönberg, Arnold: Moses und Aron. Oper in drei Akten. Libretto. Arnold Schönberg Archiv: http://www.schoenberg.at/index.php?option=com_content\&view=article\&id=231\&Itemi $\mathrm{d}=399$ \&lang=de, abgerufen am 29.08.2014.

Stern, Salomo Gottlieb: Machsor. Die sämtlichen Festgebete der Israeliten. Wien 1887.

Strecker, Stefan: Der Gott Arnold Schönbergs. Blicke durch die Oper Moses und Aron. Münster 1999.

Wörner, Karl H.: Gotteswort und Magie. Die Oper Moses und Aron von Arnold Schönberg. Heidelberg 1959, S. 45-58. 


\title{
Der schöne Schein - \\ Untersuchungen zu Geschwisterdarstellungen in der Kunst des 20./21. Jahrhunderts
}

\author{
Constanze Musterer
}

\begin{abstract}
This article is a first contribution to chart the sibling motif within the 20th/21st century arts, to analyse the variations in depicted siblings, taking into account their respective (art-)historical contexts. The adaptations of the sibling motif presented in this article cover various media of the visual arts and were selected based on whether they have an allegorical, ideological or idealistic impetus as well as on the relationships between the siblings that are conveyed.
\end{abstract}

\section{Einleitung}

Geschwister als Sujet in der Bildenden Kunst ist ein bisher kaum analysiertes Thema der Kunstgeschichte bzw. Kunstwissenschaft. Die vorliegende Studie bietet einen ersten Überblick zu Geschwisterdarstellungen in der Bildenden Kunst ab dem 20. Jahrhundert bis heute. Sie untersucht die grundsätzliche Frage, ob es Darstellungen von Geschwistern in diesem Zeitraum gibt, die über das reine Porträt (im Sinne einer formalen Inszenierung zur Repräsentation) oder die Interpretation schriftlicher Quellen, wie der Bibel oder anderer Literatur, hinausgehen. Vordergründig für diese Recherche von Geschwisterdarstellungen als Sujet in unterschiedlichen Medien der Bildenden Kunst war der Aspekt, welche Beziehung zwischen den Geschwistern vermittelt wird und ob diese einen allegorischen, ideologischen oder idealisierenden Impetus haben. Es wurden hierbei nur Kunstwerke ausgewählt, bei denen aus dem Titel oder aus Quellen ersichtlich ist, dass es sich um Geschwister handelt bzw. dass Geschwister gemeint sind. Die Auswahl bezieht sich vorrangig auf Deutschland und Europa. Ziel ist es, die Spannbreite des Geschwistermotivs und die Variationen der künstlerischen Umsetzungen zum Thema zu untersuchen und zusammenzutragen.

Im Gegensatz zu Geschwisterdarstellungen in Kunstwerken weckten die Person des Künstlers und seine realen wie ideellen Geschwister, wie etwa Künstler-Bruderschaften, bereits verschiedentlich das Interesse der Kunsttheorie wie im ersten Abschnitt vorgestellt wird. Im zweiten Abschnitt erfolgt ein zusammenfassender historischer Blick auf künstlerische Bildtraditionen, der sich darin begründet, dass in vorherigen Jahrhunderten Geschwisterdarstellungen wesentlich häufiger vorkommen, jedoch in Familien- und Genrebilder eingebettet sind. Mit der späteren Entwicklung der Fotografie werden diese Gattungen der Malerei vorwiegend von Fotografen übernommen, wodurch die Künst- 
ler_innen sich anderen Themen zuwenden. Folge der technischen und gesellschaftlichen Entwicklungen im 19. Jahrhundert ist, dass Geschwisterdarstellungen zwar aus der bisher dominierenden Einbindung in das Familienbild herausgelöst werden und fortan verstärkt als separates Motiv existieren, dieses jedoch im Euvre der meisten Künstler_innen ein singuläres und als Sujet in der Bildenden Kunst ab Beginn des 20. Jahrhunderts ein marginales bleibt. Geschwisterdarstellungen sind also ab dieser Zeit Einzelmotive und in dieser Konsequenz bisher kein Forschungsthema der Kunstwissenschaft.

Um das Spektrum und die Vielfältigkeit der singulären Geschwistermotive zu verdeutlichen, werden im dritten Abschnitt einige Bildbeispiele besprochen. Die Chronologie steht dabei hinter dem formalen Aspekt. Einen Schwerpunkt der Analyse bildet die Frage, ob der schöne Schein der Darstellungen von Geschwisterbeziehungen aus dem 19. Jahrhundert, d.h. Stereotypen von implizierter Geschwisterliebe, durchbrochen wird und Momente etwa von Distanz oder Aggression in das Motiv einfließen. Geschwisterdarstellungen in der Kunst der Moderne, im politischen und ideologischen Kontext sowie abschließend von einer jüngeren Generation von Künstler_innen werden in den folgenden Abschnitten beispielhaft untersucht.

\section{Forschungsüberblick zu Geschwistern in der Kunst}

Bisher werden Geschwistermotive in kunsttheoretischen Forschungen vorrangig unter anderen Prämissen als der Beziehung der Geschwister zueinander oder eines möglichen übergeordneten Symbolgehalts analysiert. In Künstlermonographien oder Ausstellungskatalogen werden Kunstwerke mit Geschwisterdarstellungen vor allem im Hinblick auf den biographischen oder sozialhistorischen Kontext des Künstlers beschrieben, zumeist ohne mögliche inhärente Aussagen der dargestellten Beziehungen im Geschwistermotiv selbst zu analysieren.

Häufiger waren in der Forschung zum Thema Geschwister in der Kunst bereits die Künstler_innen selbst Gegenstand der Analyse. Immanent ist hier insbesondere die Frage nach der Vererbbarkeit von sogenannter kreativer Genialität und den sozialpsychologischen Auswirkungen von Kreativität in Künstlerfamilien, aus denen zumeist Künstlergeschwister stammen. ${ }^{1}$ Untersucht wurde beispielsweise, ob Künstlergeschwister zusammenarbeiten, ob sie gleiche oder andere künstlerische Wege gehen oder sich gar von der Kunst abwenden, da dieses Feld bereits durch ein Geschwisterkind besetzt ist. Vorherrschend ist hier somit ein genetischer, biographischer, psychologischer und sozialer Ansatz in der Erforschung von Künstlergeschwistern durch die Historie, der sich auf die

1 Vgl. Krempel, León (Hrsg.): Künstlerbrüder von den Dürers bis zu den Duchamps. Petersberg 2006. 
Beziehung untereinander, nicht aber auf eventuelle Geschwistermotive in deren Werken bezieht. ${ }^{2}$

Bereits in den 1990er Jahren waren unter diesem Aspekt Künstlerzwillinge ein Thema, das von der Psychoanalyse, die sich mit dem Zwillingsphänomen verstärkt seit Beginn des 20. Jahrhunderts beschäftigt, in die Kunstwissenschaft hinüberglitt. So stellte beispielsweise die Fachzeitschrift Kunstforum International $^{3}$ in ihrer Ausgabe zu Künstler-Paaren Künstlerzwillinge in einem gesonderten Kapitel vor. ${ }^{4}$

Ebenfalls auf die Person des Künstlers beziehen sich umfassendere kunsthistorische Forschungen zu ideellen Bruderschaften, den Künstlergruppen. Vor dem 20. Jahrhundert wird der Terminus Künstler-Bruderschaften auch direkt verwendet, z.B. bei den Präraffaeliten oder anfänglich bei den Nazarenern im 19. Jahrhundert, ${ }^{5}$ was sich aus dem christlich-religiösen wie oft auch sozialen Impetus dieser Vereinigungen im künstlerischen Schaffen herleitet. ${ }^{6}$ Spätestens ab dem 20. Jahrhundert nannten sich die Künstlergruppen nicht mehr ,Bruderschaft", auch wenn die Mitglieder untereinander, in Briefen oder Schriften, durchaus die Begrifflichkeiten ,Brüder', ,brüderlich“ oder ,Schwester' benutzten. $^{7}$

2 Vgl. ebd. Die Ausstellung „Künstlerbrüder von den Dürers bis zu den Duchamps“ im Haus der Kunst, München, widmete sich im Jahr 2005 dieser Fragestellung. Die aufgeführten Künstlergeschwister reichen bis in die aktuelle Kunst mit einigen wenigen Künstlerschwestern als Beispielen.

3 Vgl. Kunstforum International 107 (1990).

41994 wurde die Ausstellung Künstler-Zwillinge, im Rahmen derer ein Symposium stattfand und der gleichnamige Katalog erschien, in Kloster Irsee, München und Engelhartszell, Oberösterreich, gezeigt: Jehl, Rainer; Terlinden, Roswitha (Hrsg.): Künstler-Zwillinge. München 1995.

5 Vgl. Zuch, Rainer: Nischen, Dyaden und das Geheimnis der Zwillinge, in: Krempel: Künstlerbrüder, S. 64f. Siehe z.B. auch: Köster, Gabriele: Künstler und ihre Brüder, Archivierung der Bruderschaften in Venedig ca. 1600. Berlin 2008 - eine der umfangreichen Untersuchungen zu Brudergemeinden unter Künstlern im Venedig des 16. Jahrhundert.

6 Vereinzelt waren Künstlerinnen Mitglieder dieser Künstlergruppen, das Pendant sog. Schwesternschaften gab es nicht. Die zweitälteste Künstlervereinigung, der Verein der Künstlerinnen und Kunstfreundinnen zu Berlin (heute: Verein Berliner Künstlerinnen), wurde bereits 1867 gegründet, kümmerte sich aber vorrangig um die Rechte und Chancen von Künstlerinnen und initiierte deren gesellschaftlich-politische Gleichberechtigung. Einen gemeinsamen künstlerischen Anspruch, wie bei männlichen Künstlergruppen, gab und gibt es dabei nicht.

7 Vgl. Moeller, Magdalena M. (Hrsg.): Expressionistische Grüsse. Stuttgart 1991. 


\section{Geschwisterdarstellungen: Vom Familienbild zum Einzelmotiv}

Im Hinblick auf künstlerische Auseinandersetzungen in Darstellungen von Beziehungen mit der Mutter, dem Vater oder auch der Familie, die zum Ende des 20. Jahrhunderts durch kunsttheoretische Analysen ${ }^{8}$ thematisiert und hervorgehoben wurden, ist das Auslassen der Geschwisterbeziehung eine auffällige wie bemerkenswerte Tatsache. In der Kunstgeschichte sind Geschwisterdarstellungen in der Familien- und Genremalerei ab Ende des 16. Jahrhunderts zu finden, die dem Sujet Geschwister eine quasi natürliche Erscheinungsform in der Darstellung von Alltagsszenerien bot. Zur Alltags- und Arbeitswelt gehörten selbstverständlich Kinder, die im Allgemeinen mehrere Geschwister hatten. Sie dienten dem Erhalt oder der Versorgung der Familie als das wesentliche und prägende Umfeld. Entsprechend spiegelte die Kunst diese Verhältnisse. Genrebilder waren dabei durchaus allegorisch gemeint in dem Sinne, dass sie bestimmte moralische, didaktische und repräsentative Lebensanschauungen vermitteln sollten. Die verschiedenen Stände (bäuerlich, bürgerlich, höfisch) abbildend, hatten sie warnende oder vorbildhafte Wirkung ${ }^{9}$ und somit neben dem oft vordergründig humorvollen oder unterhaltsamen Gehalt ${ }^{10}$ eine direkte Funktion. Die Beziehungen der Geschwisterkinder untereinander haben hier jedoch kaum Relevanz, auch ist das Geschwistermotiv selten separiert, sondern bleibt in der Regel im Kontext von Familie und Alltag.

Während die Genremalerei einen scheinbar eingefangenen Moment aus dem Alltag suggeriert und somit einen Identifikations- und Wiedererkennungswert intendiert, dienen Familienbilder vordergründig der Repräsentation. ${ }^{11}$ Sie sind

8 Die Feministische Kunstgeschichte setzte sich z.B. kritisch mit dem Werk von Käthe Kollwitz auseinander, indem sie die Rolle der Mutter im Hinblick auf den Muttermythos analysierte. Der Beziehung zum Vater wurde die Ausstellung „Dein Wille geschehe. Das Bild des Vaters in zeitgenössischer Kunst und Wissenschaft" im Haus am Waldsee Berlin, 2000, gewidmet; es erschien ein gleichnamiger Katalog. Vgl. hierzu auch die Fotoserie von Christian Borchert, in der er Familien in der DDR und nach 1989 fotografierte. Bei Familienbildern in Fotografie und Malerei im 20./21. Jahrhundert sind Geschwister weiterhin implizit.

9 Aufgrund der typischen Ausschnitte auch Sittenbild genannt. Vgl. Jahn, Johannes; Haubenreisser, Wolfgang: Wörterbuch der Kunst. Bd. 165. Stuttgart 1995. Die meisten Menschen konnten nicht lesen und schreiben, so waren Bilder entscheidend für Erziehung und Zusammenleben.

10 Bekannt und beispielhaft ist hier die Niederländische Malerei bis in das 18. Jahrhundert mit ihren ironischen und humorvollen Darstellungen von Familienalltag und Lebenssituationen.

11 Sie gehen auf die Darstellungen der Heiligen Familie im 15. Jahrhundert zurück, das Arrangement der Personen wird bis heute zitiert. 
ein konstruiertes und konzipiertes Arrangement der Szenerie, in der sich die Personen nach formalen Vorgaben und Konventionen präsentieren. Entsprechend gehören Familienbilder in die Kategorie Porträtbilder. Diese Konventionen lockerten sich zunehmend, als sich die starren Hierarchien in den Gesellschaften zu lösen begannen und Künstler nicht mehr an einzelne Auftraggeber gebunden waren. Die Entwicklung der Fotografie trug weiterhin wesentlich zu einer künstlerischen Befreiung bei, infolge derer sich viele Künstler nun vorrangig mit der Auslotung der Grenzen ihres künstlerischen Mediums beschäftigten, mit Darstellungsformen, wissenschaftlichen Beziehungen und anderen Kulturen bis hin $\mathrm{zu}$ philosophischen Fragestellungen ihres und des künstlerischen Seins in der Welt. Porträtbilder gab es weiterhin, doch bei vielen Künstlern stand nun nicht mehr die Repräsentation oder eine Didaktik, sondern der künstlerische Stil im Vordergrund. Klassische Porträt- und Familienbilder wurden nun zunehmend von Fotografen gemacht. In diesen Weiterentwicklungen hin zur künstlerischen Moderne des 20. Jahrhunderts begründet sich zudem, warum auch Geschwisterdarstellungen seltener werden oder nicht mehr eindeutig als solche identifizierbar sind.

\section{Geschwisterdarstellungen ab dem 20. Jahrhundert}

Mit Beginn der Moderne ist auffällig, dass Geschwistermotive insbesondere als Einzelmotive auftreten, d.h. das Sujet ist zumeist einmalig im Euvre einer Künstlerin/eines Künstlers, und es gibt selten Werkserien zu diesem Thema. Dennoch bzw. wohl deswegen fällt im 20./21. Jahrhundert für das Sujet Geschwister eine Vielfältigkeit in der Darstellung auf, schließt man das Porträtbild als Gattung aus. Formal führen zunächst die Künstler_innen einerseits die kompositorischen Traditionen, d.h. konzipierte Arrangements der Szenerien und Platzierung der Personen, fort, wie sie zuvor von der Fotografie aus der Malerei adaptiert und weitergeführt wurden: Eine Mischung aus Genre- und Familienbild, die eine natürlich wirkende, in dem Moment eingefangene Präsentation der Personen zeigt, mit den inhaltlich entsprechenden klassischen Konnotationen einer Geschwisterbeziehung von Liebe, Schutz und Hilfe. Hingegen unterliegen malerische Ausarbeitung und Duktus der Sujets dem eigenen oder vorherrschenden Stil der Künstler bzw. der Künstlergruppe. ${ }^{12}$

In der Moderne entstehen zahlreiche Porträts von Freunden, Freundinnen oder Gleichgesinnten, Geistesbrüdern und -schwestern also, die sich gleichwohl in Künstlergruppen zusammenschließen und für künstlerische Ideale engagie-

12 Z.B. die Gemälde von Edvard Munch „Die Kinder Esche“ (1905) und „Die Söhne des Dr. Max Linde“ (1903), von Lovis Corinth „Thomas und Wilhelmine“ (1916) und von André Derrain „Die zwei Schwestern“ (1914). 
ren. ${ }^{13}$ Porträts freundschaftlicher Beziehungen lösen in den Avantgarden die Familienbilder ab, Freundschaften unter dem Aspekt einer übereinstimmenden Weltanschauung und gleicher künstlerischer Ideale scheinen wichtiger als die Konstrukte familiärer Situationen. Hieraus ergibt sich, dass auch Geschwisterdarstellungen seltener werden und nur noch als Einzelmotive in einem künstlerischen Gesamtwerk entstehen.

Aus dem Überblick zu Geschwistermotiven in der Bildenden Kunst ab dem 20. Jahrhundert sollen im Folgenden einige Beispiele die Vielfältigkeit der Geschwisterdarstellungen demonstrieren, die sich in dieser Singularität begründet. Die Präsentation erfolgt in lockerer Chronologie, die hinter die formalen Aspekte tritt. Dabei werden die Darstellungen in Bezug auf die inhärente Beziehung der Geschwister und eines etwaigen Symbolgehalts mit der Frage analysiert, ob stereotype Konnotationen der Geschwisterbilder vorheriger Jahrhunderte durchbrochen werden.

\section{Beispiele des Geschwistermotivs in der Moderne}

Das 20. Jahrhundert zeugt von mehreren künstlerischen Avantgarden und man könnte vermuten, dass sich die gewollte Abgrenzung der Künstler_innen von bisherigen formalen Bildtraditionen auch auf Inhalte des Geschwistersujets auswirkt. Künstler der frühen Moderne wie Edvard Munch, Lovis Corinth oder André Derrain beispielsweise bleiben jedoch in ihren Geschwistermotiven nahe am traditionellen Bildaufbau und in den klassischen Inhalten ${ }^{14}$ verhaftet, obwohl sie als Avantgardisten neue Bildsprachen und Bildmomente einführten. Beispielsweise ebnete Lovis Corinth mit seinem kraftvollen Pinselstrich dem Expressionismus den Weg, während Edvard Munch Vorreiter der Abstraktion war und allgemeine Gefühlszustände allein mit seiner neuen Farbigkeit zu vermitteln versuchte. Pablo Picasso bricht in seinem Geschwisterbild diese Bildtradition: Er malte in seiner ,Rosa Phase' zwei Varianten des Bildes Die beiden Brüder (1906). Ein nackter, schreitender älterer Junge trägt seinen kleinen Bruder auf dem Rücken. Picasso adaptiert hier zum einen die christliche Ikonografie mit

13 Z.B. malten die Künstler der Gruppen „Der Blauer Reiter“ und „Die Brücke“ häufig ihre Künstlerfreunde und Modelle als Freundinnen. Auch wurden Musen, insbesondere bei den Surrealisten, und Mäzene als Freunde und ideell Gleichgesinnte porträtiert.

14 Vgl. die Familien- und Genrebilder sowie Paardarstellungen, bei denen die Porträtierten stehend oder sitzend bestimmten Kompositionsmustern folgen. Munchs Geschwisterbild ist hier sowohl Porträt- als auch Genrebild. Die klassischen Bildkompositionen werden auch im 20. Jahrhundert immer wieder von Künstler_innen aufgegriffen und bestehen weiterhin fort. 
dem Motiv der Heimsuchung des Christophorus ${ }^{15}$ und rezipiert zum anderen die Antike in der Nacktheit der Jünglinge, die er in ein Bewegungsmotiv übersetzt und mit eigenen stilistischen Elementen koppelt. ${ }^{16}$ Die bildlichen Experimente mit der Rezeption historischer Motive ergeben bei Picasso eine formale Neuerung in der Darstellung des Geschwistermotivs. Eine inhaltliche Interpretation desselben erweist sich als schwierig. Der Künstler referiert auf die Lehren der Antike wie auf die Visionen des Christentums mit deren körperbewussten wie körperfeindlichen Ansichten und setzt diesen seine Suche nach neuen künstlerischen Darstellungsmöglichkeiten von Mensch, Raum und Bewegung hinzu. Die Aufopferung und Hilfe könnte als Metapher für eine ideale Geisteshaltung gelesen werden und würde hier das klassische Geschwisterbild noch überspitzen.

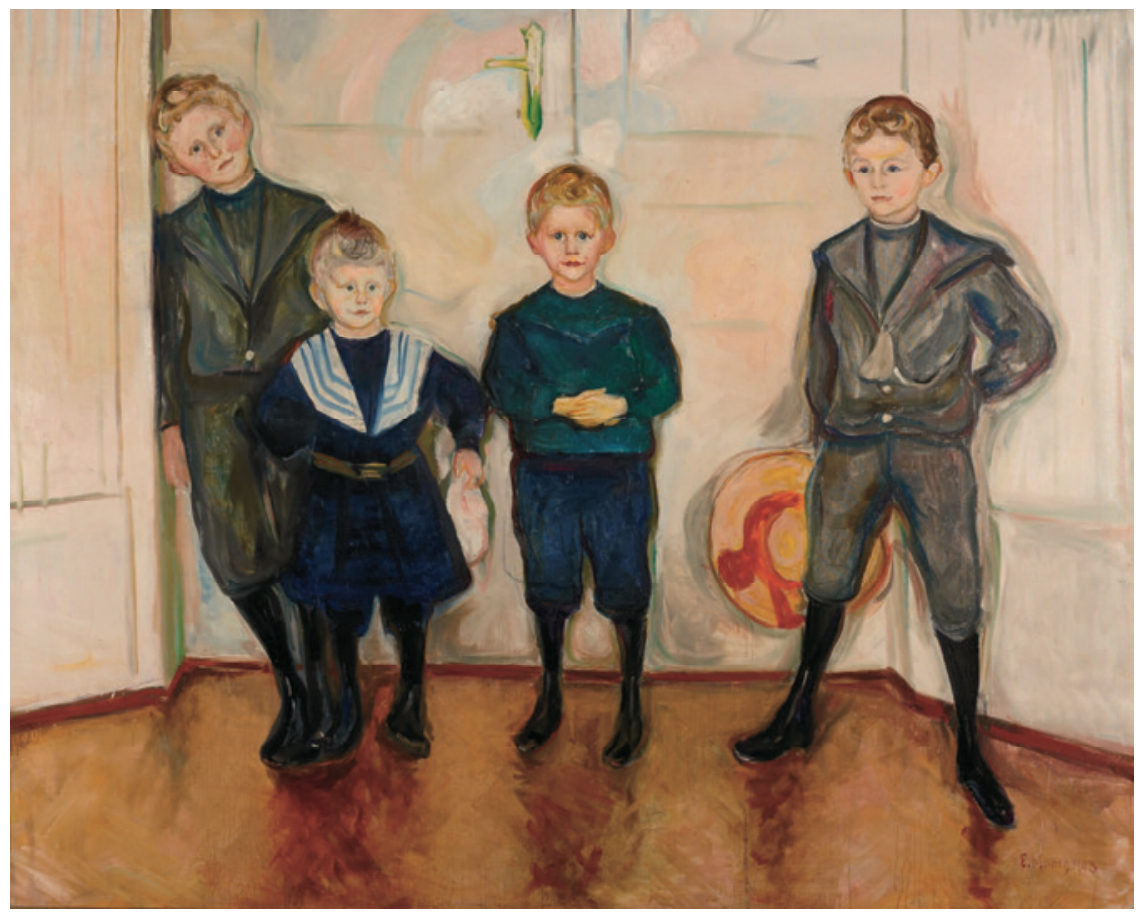

Abb. 1: $\quad$ Edvard Munch, Die Söhne des Dr. Linde, 1903, Öl auf Leinwand (C) Lübecker Museen, Museum Behnhaus Drägerhaus

15 Der Name bedeutet „Christusträger“. Vgl. zu den Legenden um Christophorus: Schäfer, Joachim: Art. Christophorus, in: Ökumenischen Heiligenlexikon. http://www. heiligenlexikon.de/BiographienC/Christophorus.htm, abgerufen am 29.08.2013.

16 Vgl. Walther, Ingo E. (Hrsg.): Pablo Picasso 1881-1973. Köln 1995, S. $134 \mathrm{f}$. 
Die Künstler des Expressionismus nahmen das Sujet Geschwister in Relation zu anderen avantgardistischen Kunstströmungen häufiger auf. Die Mitglieder der Künstlergruppe Die Brücke wollten mit expressivem Malstil inhaltlich sowohl zu einer Erneuerung der Kunst als auch neuen Lebens- und Gesellschaftsformen führen. Ihre Ideale waren kurzgefasst ein naturverbundenes, unbefangenes Leben entgegen bürgerlichen Konventionen. Die Wiedergabe von Geschwisterbeziehungen als ein ungezwungenes, vertrautes, nicht hierarchisches Miteinander unter dem Deckmantel der Geschwisterliebe passten also gut in die von der Gruppe proklamierte und angestrebte neue Lebensgestaltung. Beispiele für Darstellungen sind das Gemälde von Max Pechstein Geschwister mit Mutter (1913), in dem der kleine nackte Bruder in die Arme der älteren, ebenfalls nackten Schwester läuft, sowie das Gemälde von Otto Müller Zwei Schwestern (1919), der zwei Frauen mit nacktem Oberkörper porträtierte. Sie stehen mit dem Blick zum Betrachter eng aneinander, leicht zueinander gewandt, so dass sich ihre Brustwarzen zu berühren scheinen. In ihrer Selbstverständlichkeit und Unbefangenheit vermittelt sich durch den Blick des Künstlers zusätzlich ein erotisches Moment. ${ }^{17}$ Die Künstler präsentieren anhand der Darstellungen der Geschwisterbeziehungen die Ideologie der Künstlergruppe. In der Nacktheit der vornehmlich jungen Frauen oder Mädchen sind die angestrebten Ideale eines Urzustandes verkörpert. Die scheinbar eingefangenen Momente der Beziehungen bedienen inhaltlich vorrangig die traditionellen Stereotype von Geschwisterbeziehungen wie Fürsorge für das jüngere Geschwisterkind und körperliche Unbefangenheit, auch wenn die Künstler stilistisch neue künstlerische Ausdrucksformen schaffen. ${ }^{18}$

Einen anderen Aspekt der Geschwisterbeziehung zeigt Oskar Kokoschka 1914 mit seinem Gemälde Die Geschwister ${ }^{19}$ in einem expressiven Duktus. Die beiden Kinder sitzen auf einem Bett, der Bruder links im Bild wirkt regungslos mit gesenktem Kopf und Blick. Die Finger der rechten Hand haben eine verkrampft wirkende Haltung, als hielten sie gerade noch etwas fest, das es nun nicht mehr gibt. Das Mädchen schaut ernst mit geneigtem Kopf auf zum Betrachter. Ihre Finger halten etwas Gelbes, blau Umrandetes, und wiederholen dabei die Handhaltung des Jungen. Die Szene wirkt bedrückend und die Kinder verharren in einer deprimierenden Leere. Ein Verlust oder Mangel, ob materiell

17 Die „Zwei Schwestern“ hat Otto Müller auch mit Bluse porträtiert, dabei umarmt die eine die andere.

18 Vgl. hierzu auch das Gemälde von Erich Heckel „Die beiden Schwestern“ (1910), auf dem zwei Frauen nackt an einem Tisch sitzen und ein Brettspiel spielen.

19 In der Kokoschka-Retrospektive „Humanist und Rebell“ im Kunstmuseum Wolfsburg wird das Gemälde „Proletarierkinder (Bruder und Schwester)“ tituliert, Kunstmuseum Wolfsburg 26.04.-17.08.2014.

Ulrike Schneider, Helga Völkening and Daniel Vorpahl - 978-3-653-98812-3 
oder persönlich, scheint hier beschrieben, der als das verbindende Moment die Beziehung der Geschwister als eine Schicksalsgemeinschaft zu definieren scheint.

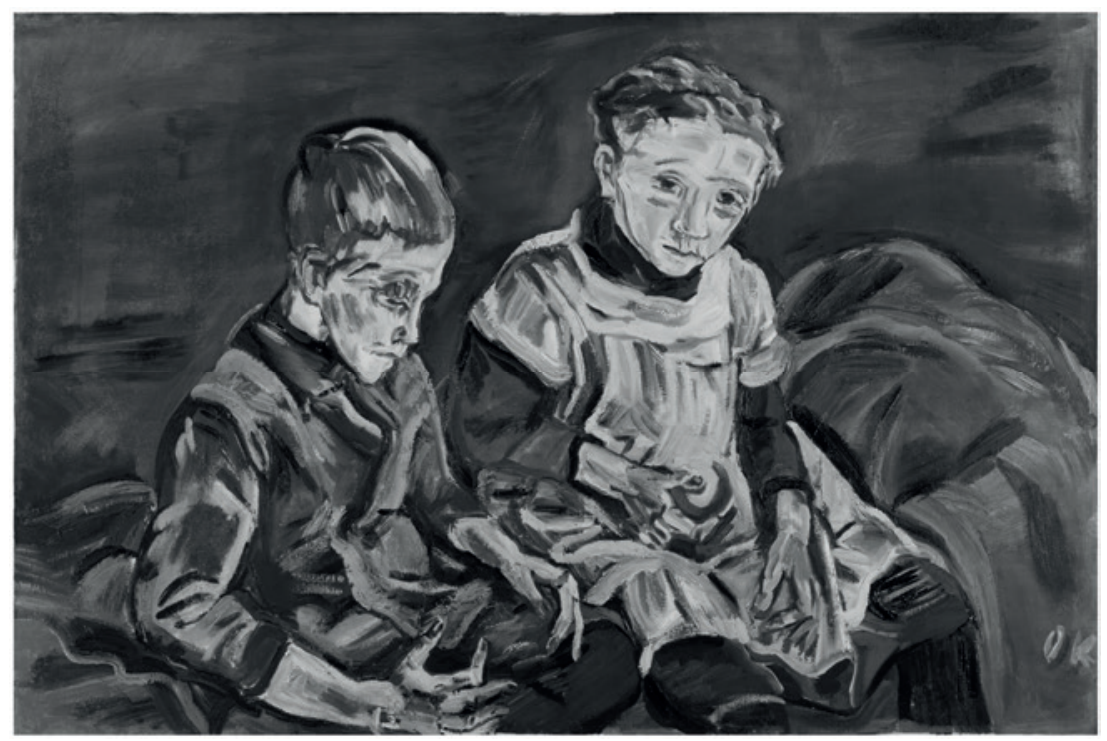

Abb. 2: $\quad$ Oskar Kokoschka, Bruder und Schwester, 1914, Öl auf Leinwand, LeopoldHoesch-Museum \& Papiermuseum Düren, Foto: Peter Hinschläger (c) Fondation Oskar Kokoschka/ VG Bild-Kunst, Bonn 2015

Einer der wenigen Künstler, der in seiner Schaffensperiode häufiger das Geschwistermotiv in differierenden Variationen aufgreift, ${ }^{20}$ ist Erich Heckel. Der Holzschnitt Geschwister von 1913 tritt hier mit einer besonderen Bildsprache hervor. Er adaptiert das klassische Mutter-Kind-Motiv, bei dem das Kind auf dem Schoß der Mutter sitzt - eine Darstellung, die Schutz, Fürsorge, aber auch Zukunft impliziert. ${ }^{21}$ Bei Heckel sitzt der kleine Bruder auf dem Schoß des älteren Bruders. Weiterhin vermittelt die Szene eine liebevolle Umarmung, wie sie bei Paardarstellungen vorkommt. Die vermeintliche Bruderliebe irritiert durch die Diskrepanz zwischen schutzspendender und gleichzeitig vereinnahmender Pose sowie dem erwachsen wirkenden Ausdruck des auf dem Schoß Sitzen-

20 Die Gemälde: „Die beiden Schwestern“ (1910), „Die Geschwister“ (1911) und „Zwei Brüder" (1937).

21 Vgl. die Darstellungen von Maria auf dem Thron mit dem segnenden Jesuskind als künftiger Heilbringer auf dem Schoß. 
den. ${ }^{22}$ Es scheint eine der wenigen frühen Darstellungen zu sein, in denen eine Ambivalenz in einer Geschwisterbeziehung gelesen werden kann, die über die vordergründige Geschwisterliebe hinausgeht. Der fürsorgliche, schutzspendende Anteil wird durch die harten Kontraste des Holzschnitts gebrochen.

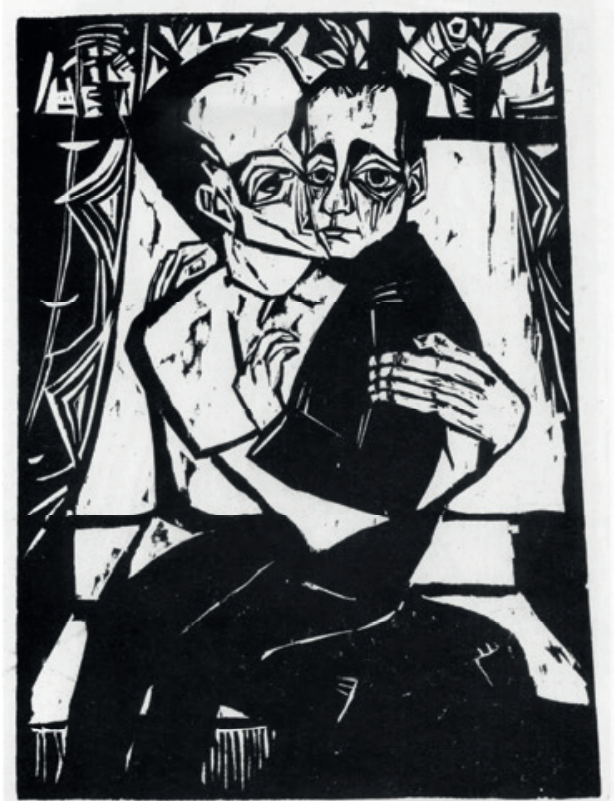

Abb. 3: $\quad$ Erich Heckel, Geschwister, 1913, Holzschnitt, Nachlass Erich Heckel, Hemmenhofen (C) VG Bild-Kunst, Bonn 2015

Im Gegensatz hierzu benutzt beispielsweise Emy Roeder das Mutter-KindMotiv in seiner klassischen Konnotation für ihre Geschwisterdarstellungen sowohl in der Skulptur Geschwister (1933/34) als auch in ihren Zeichnungen Geschwister (1947). Das jüngere Geschwisterkind ist auf dem Arm des älteren und schmiegt sich mit seinem kleinen Körper an dessen Oberkörper. Das beschützende Moment, das Vertrauen und der Zusammenhalt prägen offensichtlich

22 Es könnte sich um eine Anlehnung an oder einen Verweis auf die Darstellungen aus dem Mittelalter handeln, in denen das Jesuskind wie ein kleiner Erwachsener dargestellt wurde und oft die Insignien eines zukünftigen Weltherrscher hatte. Ob sich der erwachsene Ausdruck in der groben Technik des Holzschnitts begründet oder bewusst gestaltet ist, steht in Frage. Heckel war allerdings versiert in der Technik des Holzschnitts. 
die Beziehung in dieser liebevollen Umarmung der Darstellungen. ${ }^{23}$ Historisches Umfeld dieser Kunstwerke ist die Zeit des Nationalsozialismus bzw. die Nachkriegszeit, in der ideologisch die Frau auf die Rolle der Mutter reduziert, aber in der Umkehrung dessen durch die Verherrlichung der Mutterschaft als ,Mutter der Nation' gefeiert wurde. ${ }^{24}$ In der künstlerischen Auseinandersetzung Roeders scheint im Widerspruch zu dem, der gemeinsame Zusammenhalt gegen dieses herrschende Umfeld versinnbildlicht zu sein. Diese Schlussfolgerung legt die Titulierung „Geschwister“ nahe, anstelle der beim Namen zu nennenden offensichtlicheren Mutter-und-Kind-Darstellung.

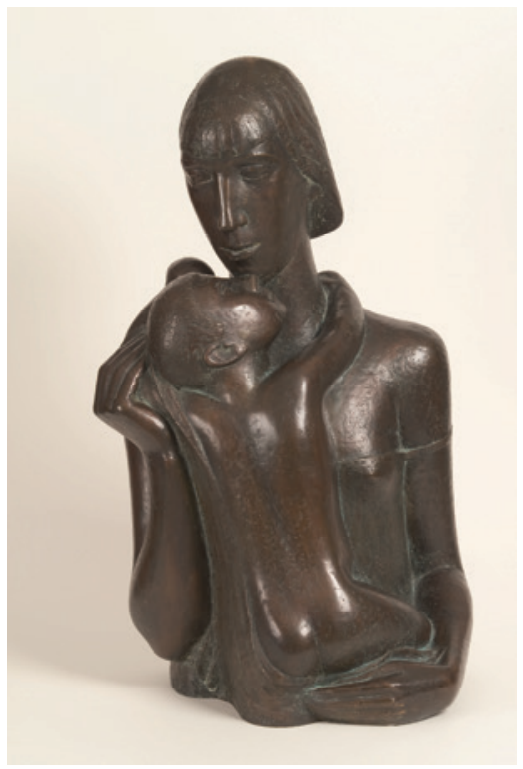

Abb. 4: $\quad$ Emy Roeder, Geschwister. Mädchen, von einem Kleinkind umhalst, 1933/34 (C) Museum im Kulturspeicher, Würzburg

23 Die Bildhauerin Emy Roeder war Mitglied der Berliner Sezession und der Novembergruppe. Ihre Werke wurden als ,entartete Kunst' 1937 beschlagnahmt und Emy Roeder erhielt fortan Ausstellungsverbot in Deutschland. So kann der Fokus auf das beschützende Moment in der Geschwisterdarstellung durchaus aus den Restriktionen in Deutschland resultieren, auch wenn sie während des NS-Regimes in Rom lebte. Ab der NS-Zeit scheint das Sujet Geschwister deutlich seltener zu werden.

24 Vgl. hierzu: Horváth, Szilvia: Reorganisation der Geschlechterverhältnisse. Familienpolitik im faschistischen Deutschland, in: Neue Gesellschaft für Bildende Kunst (Hrsg.): Inszenierung der Macht. Berlin 1987, S. 129-142, hier insb. S. 136-138. Man beachte auch die Einführung des Feiertages ,Muttertag' 1934 und des ,Mutterkreuzes“ im Jahr 1938 als besondere Anerkennung für das Gebären zahlreicher deutscher Kinder. 
Eine aktive Beziehung unter Geschwistern zeigt Ernst Ludwig Kirchner in dem Gemälde Zwei Brüder M. (1921). Zwei Männer wandern im Gebirge in modischer Kleidung einen steilen Pfad hintereinander empor und sind offensichtlich im Gespräch. Der perspektivisch hintere Bruder hebt den Kopf und redet auf den vorauslaufenden Bruder ein, der als Zuhörender seinen Kopf im Profil leicht zu ihm senkt. Der Zuhörende scheint der ältere Bruder zu sein, womit die Tradition des Wortrechts des Älteren hier unterlaufen wäre. Das vertraute Gespräch, die Diskussion und Reflexion scheinen hier der wesentliche Moment in der Darstellung der Bruderbeziehung zu sein, eine Beziehung auf Augenhöhe.

Die Künstler des Surrealismus der frühen 1920er Jahre waren von der Psychiatrie und Psychoanalyse, insbesondere von Sigmund Freud, inspiriert. Giorgio de Chirico malte Die Schwestern (1915), Max Ernst sein gleichnamiges Gemälde im Jahr 1926.

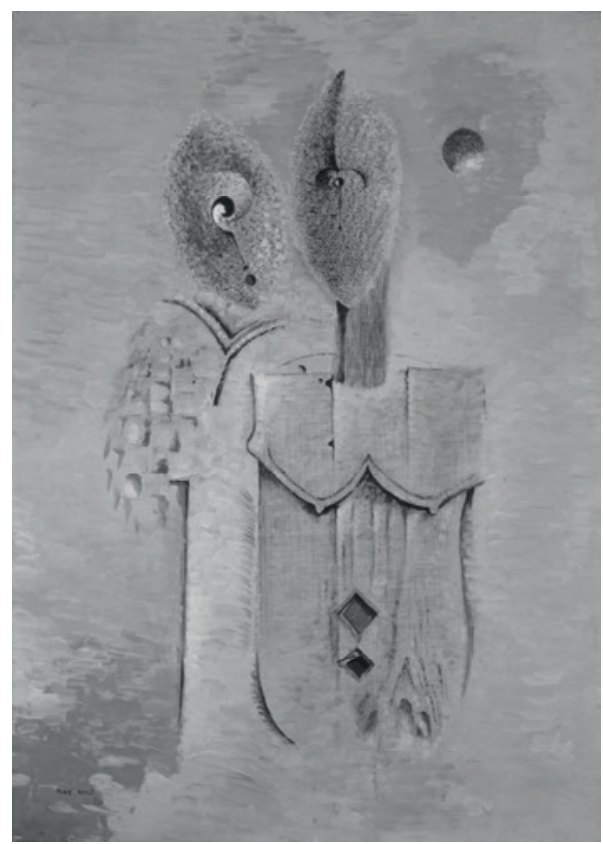

Abb. 5: $\quad$ Max Ernst, Zwei Schwestern, 1926, Öl auf Leinwand, The Menil Collection, Houston, Foto: Paul Hester @ (C) VG Bild-Kunst, Bonn 2015

Bei beiden Künstlern stehen die abstrahierten Figuren versetzt hintereinander, trotz ihrer klaren Körperlichkeit sind sie gesichtslos. Die Vertreter der Surrealisten adaptieren hierfür das Geschwistermotiv als Schatten- und Doppelgänger- 
Motiv. ${ }^{25}$ In ihrer Komposition des Hintereinander-Stehens bei gleichwertiger visueller Präsenz ergibt sich die Frage, welche Figur die ,reale " und welche der ,Schatten" ist, stellvertretend können sie für das Bewusste und Unterbewusste verstanden werden. Frauen waren für die Surrealisten Muse und Inspiration, vor allem aber war für sie die Weiblichkeit der Zugang zum Unbewussten. Damit kann die Betonung auf die Frau als Schatten- oder Doppelgänger-Motiv erklärt werden, das in der Literatur des 19. Jahrhunderts noch ausschließlich von Männern besetzt war. ${ }^{26}$ Diese Darstellungen des Geschwistermotivs referieren auf die unbewusst prägenden und abhängigkeitsstiftenden Aspekte in einer untrennbar gegebenen Beziehung, gleichzeitig ist es eine Metapher für das Unterbewusste im eigenen Ich.

\section{Geschwisterdarstellungen im politischen und ideologischen Kontext}

Die Herrschaft des Nationalsozialismus, der Zweite Weltkrieg und die daraus folgende Teilung Deutschlands in Ost und West bringen einen weiteren Aspekt in die Darstellungen von Geschwistern: Die metaphorische, allegorische oder ideologische Nutzung des künstlerischen Geschwistermotivs in einem politischen Kontext. Vereinzelt gab es diese Zuschreibungen bereits nach dem Ersten Weltkrieg, vorherrschend waren in dieser Zeit jedoch die Darstellungen von Familienkonstellationen wie das Mutter-Kind-Motiv oder die Vater-MutterKind-Gruppe zur künstlerischen Verarbeitung des Kriegstraumas, von Gewalt und Trauer. Bekannteste Vertreter_innen sind sicher Käthe Kollwitz, die sich mit ihren zahlreichen Mutter-Sohn-Darstellungen nicht ideologisch funktionalisieren ließ, sondern stellvertretend mit ihrer Kunst mahnend und kritisch gegen Krieg und Diktatur positionierte, sowie Henry Moore mit seinen verschiedenen abstrakt-figurativen Familiengruppen. An der Grenze der Motivzuschreibung befindet sich hier die zuvor erwähnte Künstlerin Emy Roeder mit ihren Geschwisterdarstellungen. Ihre künstlerische Formulierung des Motivs adaptiert eindeutig das Mutter-Kind-Thema, das sie jedoch über den Titel in den Geschwisterkontext überführt. Einige Künstler_innen gingen in der Zeit des Nationalsozialismus in die ,innere Emigration“ und schufen ,harmlose‘ Darstellungen

25 Das Schatten- und Doppelgänger-Motiv wurde häufig in der Literatur des 19. Jahrhunderts verarbeitet. Ab der Jahrhundertwende interessierte sich die Psychoanalyse für diese Thematik, woraus Sigmund Freud und Carl Gustav Jung ihre verschiedenen Theorien zum Unbewussten ableiteten, vgl. hierzu Zuch: Nischen, S. 88f.

26 Braun, Christina von: Frauenkörper und medialer Leib, in: Müller-Funk, Wolfgang; Reck, Hans Ulrich (Hrsg.): Inszenierte Imagination. Beiträge zu einer historischen Anthropologie der Medien. Wien u.a. 1996, S. 125-146, hier S. 139f. 
von Familie, Landschaft oder Stillleben. ${ }^{27}$ Drastisch veränderte beispielsweise der bereits genannte frühere Avantgardist Erich Heckel seine Malweise in seinem Gemälde Zwei Brüder von $1937 .^{28}$

Andere Künstler umgingen Verbote oder Einschränkungen der künstlerischpolitischen Freiheit und Kritik, indem sie sich auf die Allegorie besannen. Beispiel für eine der bekanntesten Allegorien für Krieg, Unrecht und politischen Verrat ist hier aus seiner Geschichte heraus das biblische Bruderpaar Kain und Abel, das in den Zeiten der Weltkriege von einigen Künstlern zitiert wurde. Lovis Corinth, Karl Hofer und George Grosz nahmen in ihrer Kunst mit dem gewaltvollen Kain-und-Abel-Motiv Stellung zu den vor allem brutalen Kriegserlebnissen. ${ }^{29}$

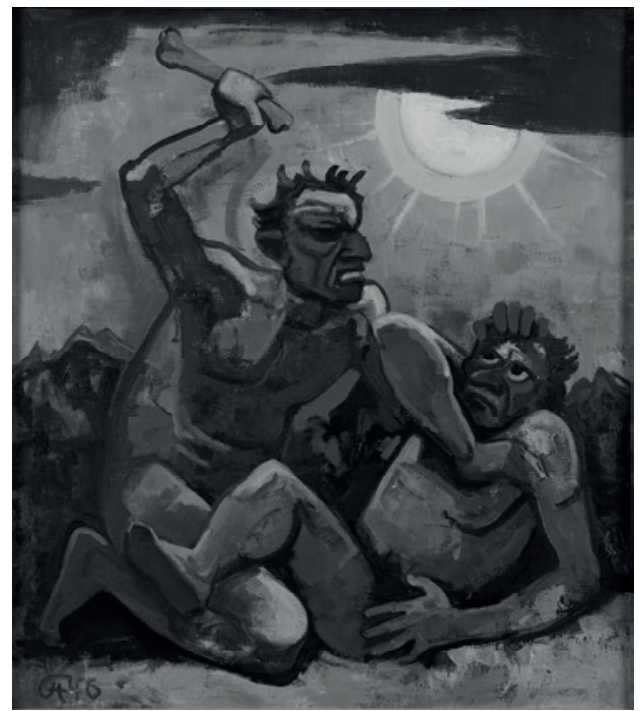

Abb. 6: $\quad$ Karl Hofer, Kain und Abel, 1946, Öl auf Leinwand @ VG Bild-Kunst, Bonn 2015

27 Otto Dix ist hierfür ein bekanntes Beispiel.

28 Der Bruder von Erich Heckel stirbt im November 1936. Erich Heckel erhielt, wie alle Künstler_innen der Moderne, 1937 Ausstellungsverbot, obwohl er den Aufruf der Kulturschaffenden von 1934 unterzeichnet hatte, der ein Vertrauensbekenntnis zu Adolf Hitler bekundete und das diesem in der Konsequenz die Mehrheit für die Vereinigung der Ämter des Reichskanzlers und Reichspräsidenten 1934 brachte, vgl. Nachlass Erich Heckel, unter: http://www.erich-heckel-nachlass.de und Der Spiegel 23 (1989), S. 234f. Max Beckmann hingegen kommentiert aggressiv den politischen Wandel in seinem Gemälde „Geschwister“ (1933) und bleibt auch nach 1933 seinem künstlerischen Stil treu.

29 Lovis Corinth „Kain und Abel“ (1917), George Grosz „Kain oder Hitler in der Hölle“ (1944) und Karl Hofer „Kain und Abel“ (1946). 
Dargestellt ist bei allen der Moment des Erschlagens oder kurz danach. Diese Implikationen von Hass, Aggression oder Wut in der Geschwisterbeziehung scheint lange Zeit einzigartig und hier in ihrer Extremform, des Tötens des Anderen, nur darstellbar, weil sie eine schriftliche Quelle rezitieren. Später in der DDR nahmen der Maler Wolfgang Mattheuer und der Bildhauer Wolfgang Kuhle das Motiv der biblischen Erzählung erneut auf. ${ }^{30}$

Künstlerische Konsequenzen zog der französische Maler Fernand Léger aus seinen persönlichen Erfahrungen im Ersten Weltkrieg und änderte seinen Stil des späten Kubismus ab Mitte der 1930er Jahre komplett. Seine Bilder sollten fortan ohne elitäre Codes unmittelbar für die breite Öffentlichkeit lesbar sein. So sind auch seine Geschwisterbilder Zwei Schwestern (1935) und Die drei Schwestern (1952) der Versuch, ein neues demokratisches Menschenbild zu gestalten. ${ }^{31}$ Die Beziehung der Geschwister zueinander ist nicht unmittelbar thematisiert, die Darstellung des Geschwisterpaars bzw. der Personengruppe ist eine moderne Allegorie für das ideale (schwesterliche) Miteinander in einer neuen Gesellschaftsform, die für Léger der Kommunismus zu sein schien.

Die metaphorische und ideologische Nutzung des Geschwistermotivs für politische Inhalte in der Kunst wird subtil bei einigen Künstlern in der DDR deutlich. Verwendet werden hier die idealisierenden Stereotype von Geschwisterbeziehungen wie Fürsorge, Hilfe und Schutz unter der Prämisse der Geschwisterliebe. Die gefundenen Darstellungen sind Beispiele aus der Bildhauerei ${ }^{32}$ in denen immer ein älteres Geschwisterkind in der liebevollen Verantwortung eines jüngeren steht, es auf den Schulter trägt (Lore Plietzsch Geschwister, 1960 ${ }^{33}$ ), bei den ersten Gehversuchen hilft (Siegfried Krepp Geschwister, 1959) oder Trost spendet in der Umarmung (Gerhard Thieme Geschwister Peter und Gerd, 1963). Die Darstellungen implizieren Zusammenhalt, Hilfe für vermeintlich Schwächere und Geborgenheit in einem vertrauensvollen Miteinander. Hieraus kann durchaus die ideologisch gewollte Repräsentation der

30 Wolfgang Mattheuer „Kain“ (1965) und Wolfgang Kuhle „Kain und Abel“ (1976).

31 Vgl. Müller, Hans-Joachim: Massigkeit gegen Massenschicksal, in: Die Zeit, Nr. 19 (06.05.1988); Léger trat 1945 in die Kommunistische Partei Frankreichs ein.

32 Diese Künstler schufen Skulpturen für den öffentlichen Raum, ihre Darstellungen richteten sich somit an die breite Bevölkerung in der DDR und spiegelten die idealistischen Proklamationen der SED, von der die Kunst im öffentlichen Raum genehmigt werden musste.

33 Hier wird die christliche Ikonografie des Christophorus für die weiblichen Figuren adaptiert. 
Regierung der DDR zum Aufbau des Sozialismus, die insbesondere die Jugend vereinnahmen wollte, abgeleitet werden. ${ }^{34}$

An der Grenze des Themas Geschwisterdarstellungen liegt qua Titel zwar das Gemälde Der Zwilling (1984) von Ralf Kerbach, ${ }^{35}$ doch ergänzt es die vorherigen Ausführungen um die kritische Formulierung, die als politische Allegorie zu lesen ist.

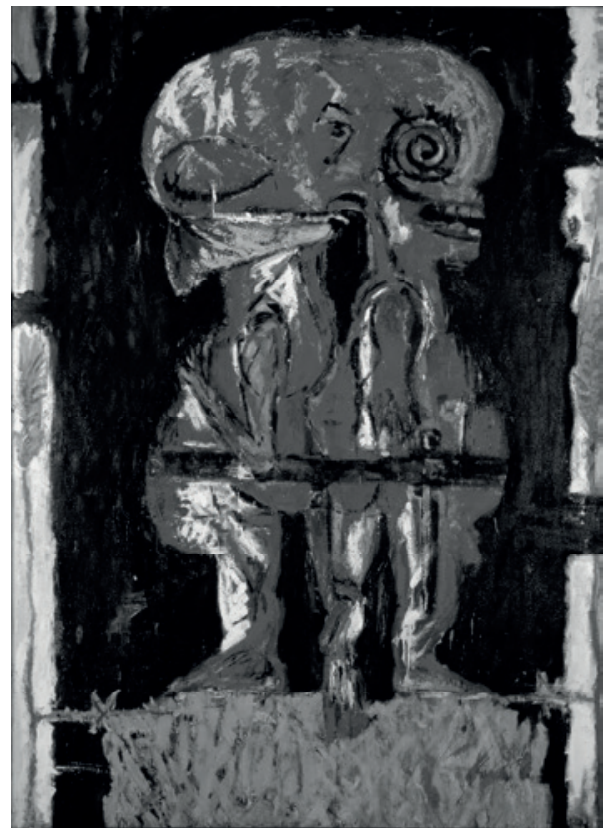

Abb. 7: $\quad$ Ralf Kerbach, Der Zwilling, 1984, Öl auf Leinwand (C) VG Bild-Kunst, Bonn 2015

Zwei blutrote, an Embryonen erinnernde Figuren stehen Rücken an Rücken und scheinen hier wie am Kopf miteinander verwachsen. Geknebelt ist der eine, der

34 Kinder werden oft als Allegorie für die Erneuerung einer Gesellschaft oder eines politischen Systems verwendet. In dem Jugendverband „Freie Deutsche Jugend“ (FDJ) in der DDR kamen Kinder und Jugendliche unabhängig von den Eltern zusammen. Kinder bekamen Verantwortung, Autonomie, Zutrauen und Respekt vermittelt und erhielten eine, im Sinne der Ideologie der DDR, antifaschistische und demokratische Erziehung, die die FDJ parallel zur Schule übernahm. Die Einflussnahme der Eltern auf die Kinder wurde so vermindert und eine Erziehung im Sinne der Staatsideologie gefördert.

35 Ralf Kerbach wurde 1982 von der DDR ausgebürgert und ging nach West-Berlin. 
andere fletscht die Zähne, beide schauen zwangsläufig voneinander weg und sind in dieser Darstellung unfähig, sich zu bewegen. Kerbach definiert selbst sein Zwillingsmotiv als eine Allegorie für die Deutsche Teilung im Kalten Krieg. Das Gemälde wurde wegen seiner politischen Bildsprache seinerzeit von Eberhard Roters für die Berlinische Galerie angekauft. ${ }^{36}$

Weitaus subtiler hingegen ist die Skulptur von Thomas Schütte Vier Schwestern im Bad (1989). Sie kann aus dem Wissen um die Arbeit des Künstlers, dessen Intention für seine künstlerischen Werke vor allem eine politischgesellschaftskritische ist, als Metapher für die vier Himmelsrichtungen im Sinne politischer Systeme gelesen werden. Als deutscher Künstler könnte er hier ironisch auf die Frage einer neuen Weltordnung anspielen, die sich nach dem Fall der Mauer 1989 zukünftig ergeben könnte: Die vier Schwestern als Allegorien für Ost und West, Süden und Norden sitzen, anstatt am Verhandlungstisch, im Bade mit Blick auf das große Meer, einstige Systeme scheinen hier untergegangen.

Diesen ideologischen Inhalten diametral entgegen steht die Skulptur Schwester (1968) von der ungarischen Künstlerin Erzsébet Schaár. Sie ist formal wie inhaltlich eine Ausnahme und zeigt eine vielschichtig reflektierende Position in ihrem Werk. Die Künstlerin kreiert eine Rücken-an-RückenKomposition, eine Abwandlung des Schattenmotivs, das hier insbesondere einen Erinnerungsmoment zu beschreiben scheint. Die Spiegelung der beiden nahezu identischen Frauengestalten am Rücken lassen diesen zu einer Wand werden, die jegliche Kommunikation oder Kontaktaufnahme unmöglich macht. Dabei ist die Präsenz der ,gleichen' Anderen permanent gewiss. Ein psychologisches Moment tritt hier im Geschwistermotiv hervor: Durch das Rücken-an-RückenMotiv kann sowohl die Annäherung wie auch die Lossagung nur in einer Ausweglosigkeit oder einem extrem gewaltvollen Akt enden. Die Arbeit kann als Metapher für einen Verlust gelesen werden, indem die zweite Frauengestalt das bleibende Bild einer Erinnerung an jemanden darstellt. ${ }^{37}$

36 Vgl. Gillen, Eckhart (Hrsg.): Deutschlandbilder. Kunst aus einem geteilten Land. Köln 1997, S. 19f.

37 Erzsébet Schaàr (1908-1975) war eine Ausschwitz-Überlebende. Ob Verwandte oder Freunde von ihr getötet wurden, war bisher nicht zu ermitteln, sicher aber wirkte sich diese Erfahrung auf ihre Kunst aus, vgl. auch das Werk „Die Strasse“. Der starke psychologische Aspekt im Werk von Erzsébet Schaár wird belegt in Schaár, Erzsébet: Die Strasse. Hrsg. v. Kunstmuseum Luzern. Luzern 1975, anlässlich der Ausstellung „Kunst in Ungarn 1900-1950“ von 1975 publiziert. 


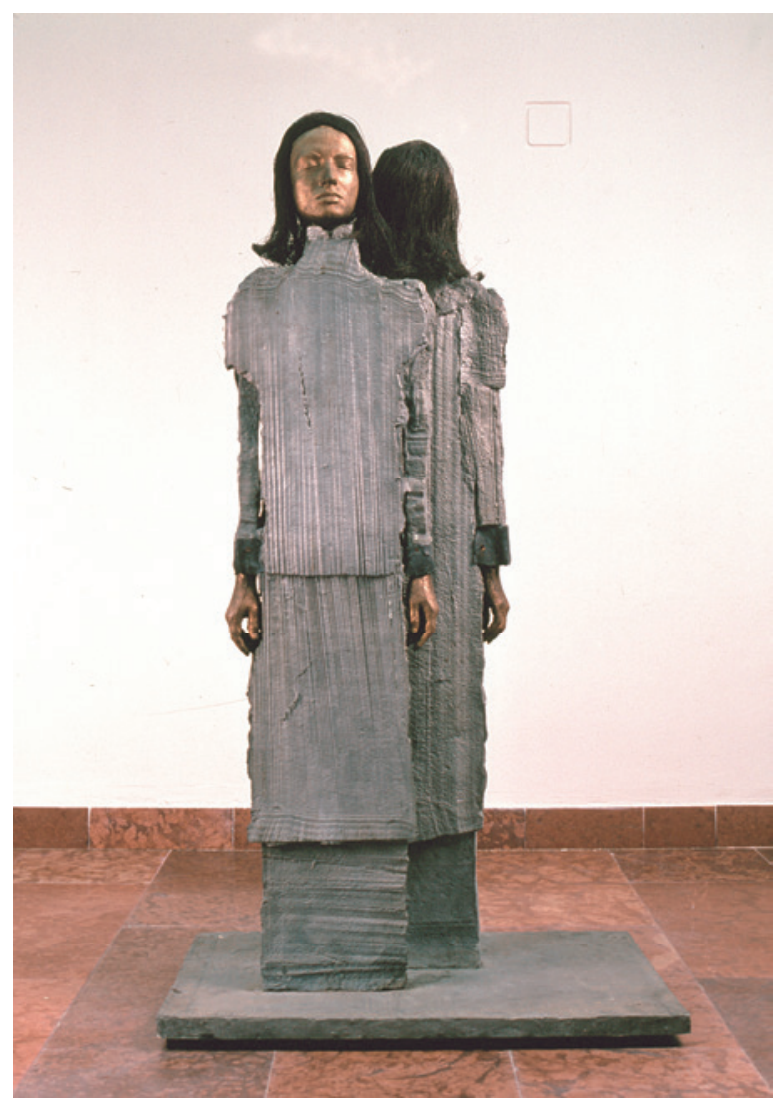

Abb. 8: $\quad$ Erzsébet Schaár, Sister, 1968

(C) Szépmüvészeti Múzeum / Museum of Fine Arts Budapest

\section{Beispiele dargestellter Geschwisterbeziehungen in der aktuellen Kunst}

Im letzten Drittel des 20. Jahrhunderts werden Darstellungen von Geschwistern in der Bildenden Kunst seltener. Viele von ihnen sind formal dem Porträt zugehörig oder sind Inszenierungen nach bestimmten formalen Vorgaben. Sie sagen daher über die Beziehung der Geschwister untereinander genauso wenig aus wie über eine etwaige Inanspruchnahme als Metapher, Allegorie oder biographische Bildgebung. ${ }^{38}$ Die Schwierigkeit in der zeitgenössischen Kunst besteht zuneh-

38 Beispiele sind Gerhard Richter „Drei Geschwister“ (1965), „Schwestern“ (1967); Andy Warhol „The two sisters (After de Chirico)“ (1982); Richard Avedon „Claude und 
mend darin, Geschwisterdarstellungen seltener über den Titel identifizieren zu können. Der Ausblick mit einigen Beispielen auf eine jüngere Künstlergeneration zeigt aber, dass, trotz der Vereinzelung des Geschwistermotivs in der aktuellen Kunst, durchaus die Vielschichtigkeit einer Geschwisterbeziehung in deren Werken reflektiert und deren stereotype Konnotationen analysiert werden.

Der Fotograf Nicholas Nixon $(* 1947$ Detroit/USA) ist einer der wenigen, der das Geschwistermotiv in einer Werk-Serie präsentiert. Für die Foto-Serie The Brown Sisters hat er vier Schwestern von 1975 bis 2011 jedes Jahr fotografiert. Die Reihenfolge der Frauen im Bild ist stets die gleiche: Heather, Mimi, Bebe (seine Frau) und Laurie, sie waren zu Beginn der Serie im Jahr 1975 zwischen 15 und 25 Jahre alt. Die Schwestern entschieden selbst, wie sie sich präsentieren wollten. Mit der über 36 Jahre fortlaufenden Serie hebt Nixon hervor, dass sich Beziehungen verändern und nicht frei sind von äußeren Einflüssen. Neben den unterschiedlichen Moden, angedeuteten Lebensphasen (z.B. Schwangerschaft) und dem Prozess des Älterwerden, deuten hier vor allem die unterschiedlichen Gesten das Verhalten und das Verhältnis der Geschwister untereinander zu verschieden Zeiten an.

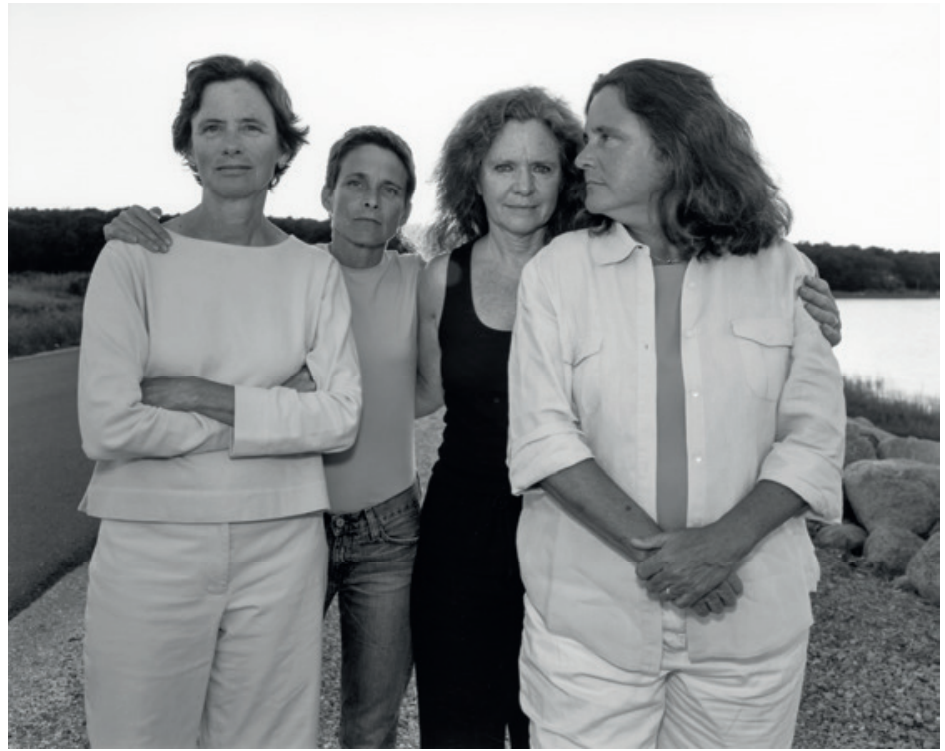

Abb. 9: $\quad$ Nicholas Nixon, The Brown Sisters, 2005

(C) Nicholas Nixon, courtesy Fraenkel Gallery, San Francisco

Paloma Picasso (Pablo Picassos Kinder)“ (1966). Eine Ausnahme ist das abstrahierte

Geschwistermotiv bei Louise Bourgeois „Brother and Sister“ (1949). 
Die Künstlerin Sabine Dehnel (*1971 Ludwigshafen/D) griff das Geschwistermotiv bereits dreimal in ihrem künstlerischen Schaffen auf. Der Vergleich der Bilder deutet eine interessante Verschiebung in den dargestellten Beziehungen der Geschwister untereinander an, die sich zum einen im Älterwerden der Protagonisten spiegelt, aber ebenso übertragbar ist auf die Entwicklung des Geschwistermotivs in der Kunstgeschichte. Im Gemälde Geschwister (2006) laufen die große Schwester und der kleine Bruder als Rückenfiguren umarmt nebeneinander. Die Schwester führt dabei den Bruder, beide neigen die Köpfe, als entdeckten sie etwas im Gras oder müssten ein Hindernis überwinden. Die vertraute Beziehung mit der helfenden, schützenden Geste der älteren Schwester gegenüber dem jüngeren Bruder steht hier im Vordergrund und referiert inhaltlich auf die klassische und meist verwendete Konnotation in der Darstellung von Geschwisterbeziehungen im 20. Jahrhundert. Sie ist jedoch mit den Rückenfiguren formal weiterentwickelt und offenbart in dieser Typisierung die Stereotype, die dadurch ins Bewusstsein treten.

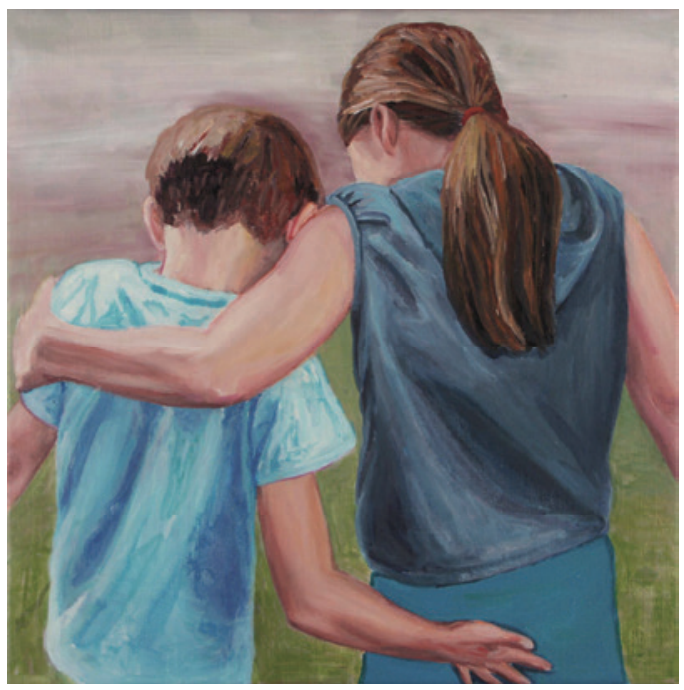

Abb. 10: $\quad$ Sabine Dehnel, Geschwister, 2006, Acryl auf Leinwand

(C) VG Bild-Kunst, Bonn 2015

Im Gemälde Stillschweigen (2007) stehen sich zwei Schwestern frontal gegenüber, ihr Blick von Angesicht zu Angesicht wird allerdings je zur Hälfte von einem Baum verdeckt. Für den Betrachter ist nur der Hinterkopf der einen, Wange, Haare und die linke Schulter der anderen zu sehen. Die Figuren bleiben so anonym, nur die Körperhaltung verrät, dass die beiden noch Mädchen sind. 
Diese Komposition kann als eine Umdeutung des Schattenmotivs gelesen werden: Sabine Dehnel wendet die passive, beinahe ohnmächtige Gewissheit der verfolgenden Schwester im Hintergrund in ein aktives Sich-Auseinandersetzen in der Beziehung durch die Konfrontation und mit dem Bewusstsein des ,blinden Flecks' oder der Differenz in der Gleichheit gegenüber der Anderen - versinnbildlicht durch den die Gesichtspartien verdeckenden Baum. Im Geschwisterbild Spandau (2010) sind die Unterkörper zweier pubertierender Mädchen in einer Turnhalle zu sehen. Offensichtlich ,verkleidet" mit hochhackigen Schuhen und Leggings deutet sich ein verspielter, tänzerischer Kampf an, bei dem eine mit der Hand eine Pistole nachahmt - zwei Großstadt-Cowgirls, die die vorgegebenen Linien der irrealen Turnhalle durchbrechen wollen. Die Beziehung der Geschwister vermittelt sich in der Darstellung als eine auf Augenhöhe, in der mit den Ambivalenzen humorvoll und spielerisch umgegangen wird. Die Künstlerin interessiert an der malerischen Umsetzung der Geschwisterbeziehung genau diese spielerische Spannung und der Zustand des sich stets wiederholenden Bemühen-Müssens um den anderen, denn „die Geschwisterbeziehung ist die längste Teilung des Lebensweges ${ }^{\star 39}$.

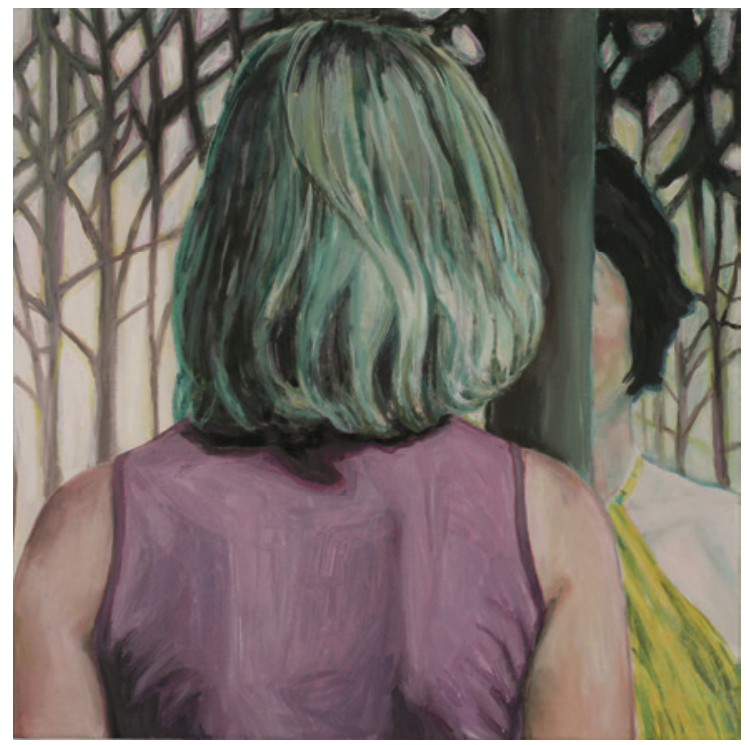

Abb. 11: $\quad$ Sabine Dehnel, Stillschweigen, 2007, Acryl auf Leinwand (C) VG Bild-Kunst, Bonn 2015

39 Zitat Sabine Dehnel, aus einem Gespräch mit der Autorin, Berlin 05.09.2013, unveröffentlicht. 


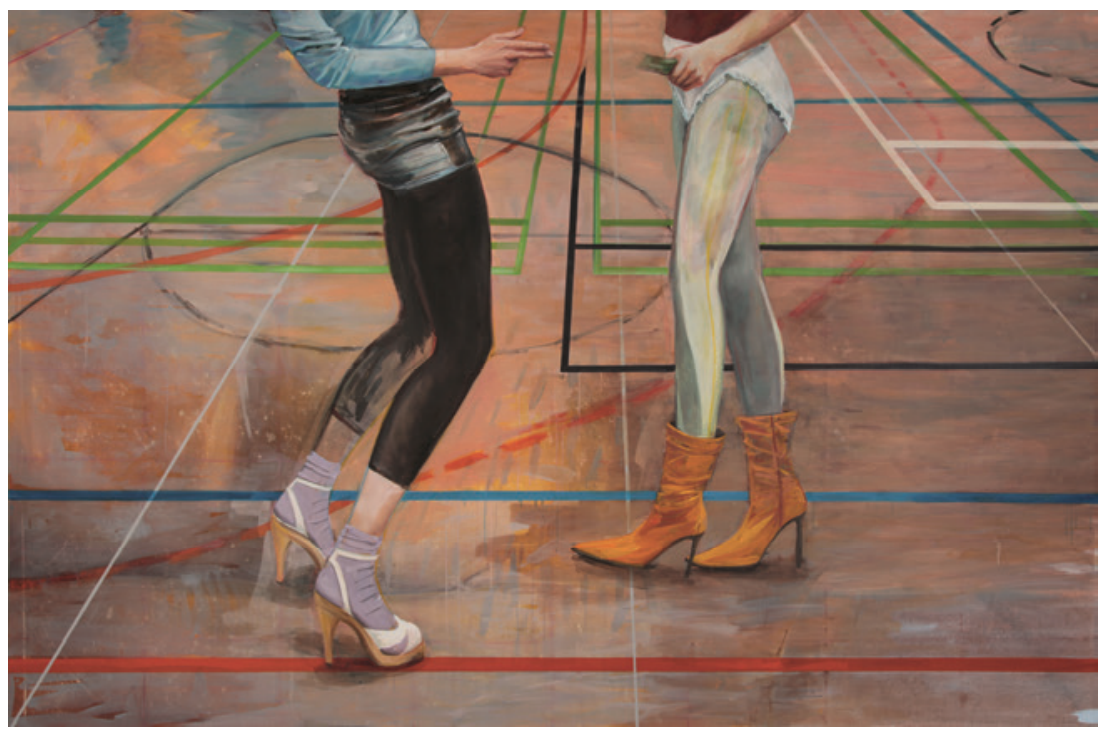

Abb. 12: $\quad$ Sabine Dehnel, Spandau, 2010, Acryl auf Leinwand

(C) Sabine Dehnel, VG Bild- Kunst, Bonn 2015

Die Künstlerinnen Liesbeth und Angelique Raeven (*1971 Heerlen/NL) sind als eineiige Zwillinge geboren und arbeiten unter dem Künstlernamen L.A. Raeven seit 2000 zusammen. In ihrer Videoarbeit Love knows many faces (2005) thematisieren sie ihre Geschwisterbeziehung und sind dabei selbst die Protagonistinnen. Bei einem Bade in einem See durchläuft das Geschwisterpaar alle emotionalen Etappen einer Beziehung, vom Versuch einer der beiden Schwestern, ihre Doppelgängerin zu ertränken, bis hin zur suchenden Nähe und liebevollen Versöhnung. Die Schwestern zitieren dazu eine Passage aus dem Buch All or nothing von John Cowper Powys (1872-1963), dem Sohn einer vielköpfigen Künstlerfamilie. Ausschnitt aus dem Zitat:

Man nennt es Inzest, wenn Brüder und Schwestern einander wie Liebhaber begegnen, aber wie ich nicht nur aus diesem Fall gelernt habe, ist die Aussprache darüber für jedermann, gleich ob Eltern, Verwandte oder Außenstehende, gefährlich. Denn der Unterschied zwischen dem Gefühl von Liebenden und dem Gefühl von Bruder und Schwester ist so delikat, fein und von Leidenschaften durchkreuzt, dass äußerste Vorsicht und behutsames Vorgehen erforderlich sind. ${ }^{40}$

Die Videoarbeit von L.A. Raeven bringt eindrücklich die spannungsvolle Beziehung von Geschwistern auf die Endpunkte Liebe und Hass und den vielen

40 Vgl. hierzu: Krempel: Künstlerbrüder, S. $272 \mathrm{f}$.

Ulrike Schneider, Helga Völkening and Daniel Vorpahl - 978-3-653-98812-3 
erschöpfenden Stadien dazwischen. Es ist einer der ehrlichsten Geschwisterdarstellungen, die die bisher nur selten benannte emotionale Spannbreite einer Geschwisterbeziehung offenlegt und zur Diskussion stellt.

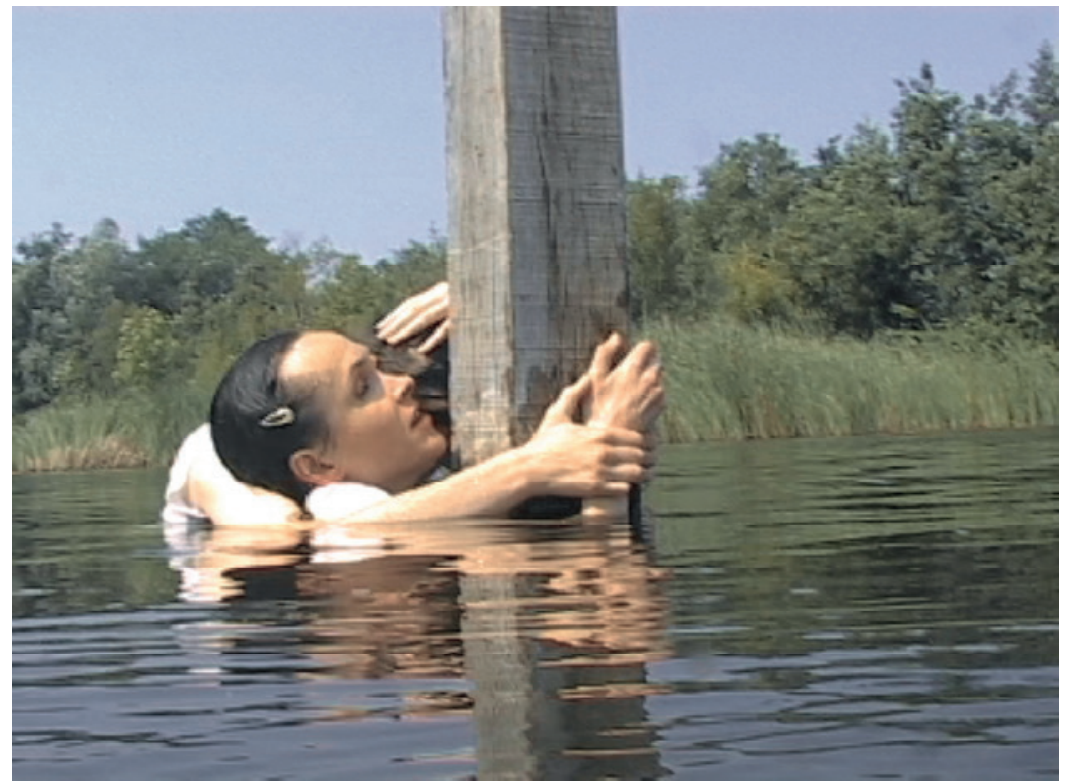

Abb. 13: L.A. Raeven, Love Knows Many Faces, 2005, video, 6 min. loop, courtesy the artists and Ellen de Bruijne Projects Amsterdam

(C) Liesbeth and Angelique Raeven

\section{Zusammenfassung}

Es kann aus den Beispielen gefolgert werden, dass idealisierende Darstellungen der Geschwisterbeziehung zu jeder Zeit präsent sind. Sie beinhalten vorrangig das liebevolle, vertraute, sich beschützende Miteinander und die gegenseitige Hilfe, insbesondere älterer Geschwister gegenüber jüngeren. Der Zusammenhalt ist hierbei eine wichtige Konnotation. Die allegorische Inanspruchnahme des Geschwistermotivs in der Kunst des 20. Jahrhundert ist nur marginal vorhanden. Hingegen wird es des Öfteren als Metapher verwendet und hier ideologisch für politische Konzepte gebraucht, um Werte wie Fürsorge, Hilfe, Schutz oder Verbundenheit (Bruderschaft) zu vermitteln. Vorherrschend sind insgesamt die stereotypen idealisierenden Darstellungen der Geschwisterbeziehung als eine sich von Natur aus liebende und verbündete Gemeinschaft. Zusammenfassend kommt diese Studie zu der Feststellung, dass die Darstellung von Geschwistern, 
Brüdern und Schwestern für Künstler_innen bisher nicht wirklich ein Thema ist. Die mindere Beachtung und Analyse des Geschwistermotivs seitens der kunstwissenschaftlichen Theorie resultiert sicher aus der Tatsache, dass aufgrund einer mangelnden Zahl an Werken und einer fehlenden historischen Rückführung, da Geschwistermotive bisher in Familien- und Genrebildern integriert sind, keine gesonderte Kategorie aufgemacht wurde.

Es stellt sich somit zunächst die Frage, wie sich Geschwisterbeziehungen definieren und warum sie so wenig von Künstlern bearbeitet wurden und werden. Von beziehungsklärenden Auseinandersetzungen, wie sie mit dem Vater oder der Mutter geschehen, scheinen Geschwisterbeziehungen weitgehend verschont. Sie stehen unter dem natürlichen Schutzmantel der gegenseitigen Solidarität, der meist tatsächlich als Verbündete gegen die Eltern seit frühestem Kindesalter gewachsen ist. Geschwister sind es gewohnt, anders als beispielsweise Paare, Konflikte als temporär anzusehen und den anderen in seinem Sein (gezwungenermaßen) zu tolerieren. Hierbei scheint zudem das Dogma der Familie des 19. Jahrhunderts mit hermetischem Charakter zumindest bis in die 1990er Jahre ungebrochen, was einen implantierten, lebenslangen Zusammenhalt der Familienmitglieder impliziert. So ist zumindest auch bei konfliktreichen Geschwisterbeziehungen das versöhnende Argument der Familie, dieses Bündnis nicht zu brechen. Hierfür gibt es selbstverständlich zahlreiche Ausnahmen. Sieht man die Künstler_innen als Seismographen von gesellschaftlichen Veränderungen, ist die Beleuchtung der jeweiligen Gesellschafts- und Persönlichkeitsstrukturen von Relevanz. Demnach waren Geschwisterbeziehungen anscheinend bisher kein ausreichend ausschlaggebendes Moment für eine künstlerische Reflexion. Diese Recherche macht deutlich, dass es aber vereinzelte Schübe dieser Reflexion gab und gibt. Seit dem 21. Jahrhundert verstärkt sich die individualistische Gesellschaftsform weiter mit zunehmenden Migrationsbewegungen in Gesellschaften. Daraus entsteht die Diskrepanz, dass die Familien und Geschwister noch weniger reale Bezugspunkte sind, sie andererseits aus der Distanz aber mehr irrealen Raum als Erinnerungen, Gedanken, Wünsche in der Person selbst einnehmen. Die Distanz und Nähe lassen eine reflektierende Sichtweise zu, die durch die Distanz auch formuliert werden kann, ohne dass ein Konstrukt dabei zu Bruch geht, wie die Beispiele der neueren Generation an Künstler_innen zeigen.

Der schöne Schein der Geschwisterdarstellungen Anfang des 20. Jahrhunderts mit den Konnotationen der sich zu jeder Zeit friedlich liebenden, beschützenden und gegenseitig helfenden Geschwistern hat spätestens im 21. Jahrhundert sein Ende. In der aktuellen Kunst zeigt sich die Wende hin zu analytischen, reflektierenden Darstellungen von Geschwisterbeziehungen seitens der Künstler_innen, die das Idealbild der Geschwisterliebe durchbrechen zugunsten eines 
ehrlichen und souveränen Umgangs mit deren Ambivalenzen. Interessant wäre hierzu eine weitergehende Recherche zu außereuropäischen Kulturen mit anderen Familienbindungen, wie z.B. in afrikanischen oder lateinamerikanischen Ländern, wo zudem u.a. der Aspekt der Familie und die Anzahl der Geschwister als Wirtschaftsgemeinschaft vordergründig ist. In China gibt es einige Künstler, die ein Porträt oder ein Ich in ihren Bilder vielfach reproduzieren, das zum einen auf den entindividualisierten Menschen in China, aber auch auf eine Sehnsucht nach Geschwistern im Rahmen der Ein-Kind-Politik verweisen könnte, also ein anderes Resultat bei gleichem Motiv spiegelt.

Ein Desiderat wäre neben der weiteren Recherche von Kunstwerken des 20. und 21. Jahrhunderts auch eine umfassendere Analyse zu kunsttheoretischen Forschungen zum Geschwistermotiv.

\section{Quellen und Literatur}

Architekten. Langer Abschied. (ohne Autor), in: Der Spiegel 23 (1989), 05.06.1989, S. 234238.

Blume, Eugen; März, Roland (Hrsg.): Kunst in der DDR. Eine Retrospektive der Nationalgalerie, Berlin 2003.

Braun, Christina von: Frauenkörper und medialer Leib, in: Müller-Funk, Wolfgang; Reck, Hans Ulrich (Hrsg.): Inszenierte Imagination. Beiträge zu einer historischen Anthropologie der Medien. Wien u.a. 1996, S. 125-146.

Cherdron, Anja: Emy Röder, in: Neue Deutsche Biographie. Bd. 21. Berlin 2003, S. 707-708.

Schaár, Erzsébet: Die Strasse. Hrsg. v. Kunstmuseum Luzern. Luzern 1975.

Fath, Manfred; Herold, Inge; Kollhofer, Thomas (Hrsg.): Menschenbilder. Figur in Zeiten der Abstraktion. Ostfildern-Ruit 1998.

Feist, Peter H.: Figur und Objekt. Plastik im 20. Jahrhundert. Leipzig 1996.

Geissler, Hans: Nachlass Erich Heckel, in: http://www.erich-heckel-nachlass.de.

Gillen, Eckhart: Deutschlandbilder. Kunst aus einem geteilten Land. Köln 1997.

Google Cultural Institute: https://www.google.com/culturalinstitute/project/art-project. Abgerufen Juli/August 2013.

Haftmann, Werner: Malerei im 20. Jahrhundert. München 1983.

Horváth, Szilvia: Reorganisation der Geschlechterverhältnisse. Familienpolitik im faschistischen Deutschland, in: Neue Gesellschaft für Bildende Kunst (Hrsg.): Inszenierung der Macht. Berlin 1987, S. 129-142.

Jahn, Johannes; Haubenreisser, Wolfgang: Wörterbuch der Kunst. Bd. 165. Stuttgart 1995.

Jehl, Rainer; Terlinden, Roswitha (Hrsg.): Künstler-Zwillinge. München 1995.

Köster, Gabriele: Künstler und ihre Brüder. Archivierung der Bruderschaften in Venedig ca. 1600. Berlin 2008.

Krempel, León (Hrsg.): Künstlerbrüder von den Dürers bis zu den Duchamps. Petersberg 2006.

Moeller, Magdalena M. (Hrsg.): Expressionistische Grüsse. Stuttgart 1991.

Müller, Hans-Joachim: Massigkeit gegen Massenschicksal, in: Die Zeit 19 (06.05.1988). 
Profession ohne Tradition. 125 Jahre Verein der Berliner Künstlerinnen 1867-1992. Hrsg. v. Verein der Berliner Künstlerinnen, Berlinische Galerie. Berlin 1992.

Prometheus Bildarchiv: Das verteilte digitale Bildarchiv für Forschung \& Lehre. Kunsthistorisches Institut der Universität zu Köln, http://prometheus-bildarchiv.de. Abgerufen August 2013.

Schäfer, Joachim: Art. Christophorus, in: http://www.heiligenlexikon.de/BiographienC/ Christophorus.htm, abgerufen am 29.08.2013.

Walther, Ingo E. (Hrsg.): Pablo Picasso 1881-1973. Köln 1995, S. 134ff.

Zuch, Rainer: Nischen, Dyaden und das Geheimnis der Zwillinge, in: Krempel, León (Hrsg.): Künstlerbrüder von den Dürers bis zu den Duchamps. Petersberg 2006, S. 51-95. 


\section{Kulturwissenschaftliche und soziokulturelle Untersuchungen zu Rezeptionen und Funktionen von Geschwistermetaphern}




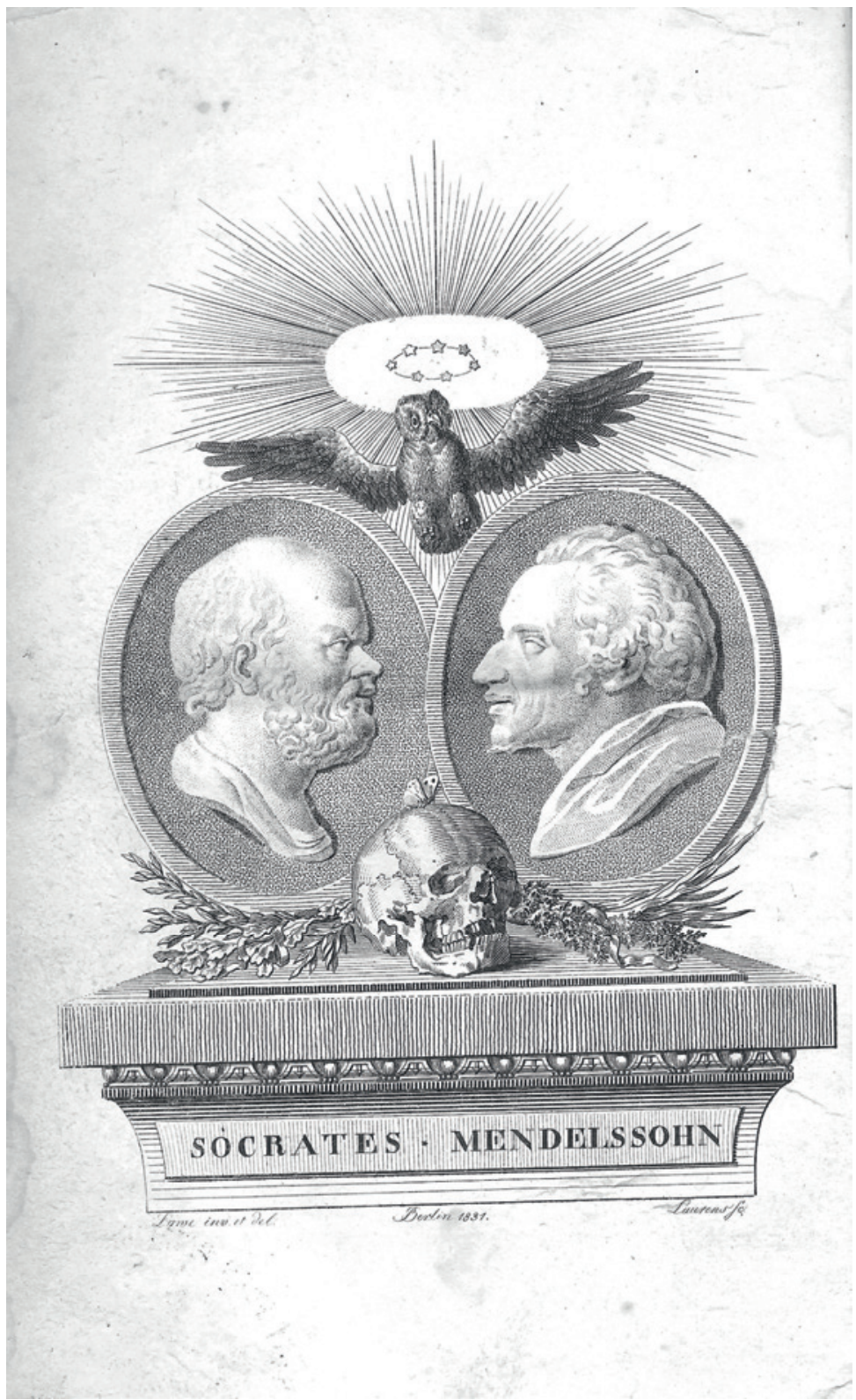

Abb. 1: $\quad$ Moses Samuel Lowe, Mendelssohn und Sokrates im Medaillon, 1818 und 1831, Kupferstich (Privatbesitz Hamburg)

Ulrike Schneider, Helga Völkening and Daniel Vorpahl - 978-3-653-98812-3

Downloaded from PubFactory at 01/11/2019 10:54:37AM 


\title{
Sokrates und Mendelssohn - Zur Bedeutung der Zwillings-Metapher im Bildungskonzept von David Friedländer und Jeremias Heinemann
}

\author{
Uta Lohmann
}

\begin{abstract}
The metaphor of Socrates and Mendelssohn as 'twin-sages' conveys contents and values based on the Socratic tradition, which was upgraded by Mendelssohn's religio-philosophical work Phaedon and subsequently carried on by David Friedlaender and Jeremias Heinemann. At the schools that Friedlaender and Heinemann started off the Socratic-Mendelssohnic philosophy was combined with the teachings of the Tanach (Hebrew Bible), conceiving a new Jewish educational concept. Thereby the 'twins' Socrates and Mendelssohn became symbols of a modern self-image.
\end{abstract}

\section{„Edle Zwillings-Weise!“‘}

Der jüdische Künstler Moses Samuel Lowe (Johann Michael Siegfried Löwe, 1756-1831) schuf 1818 den Kupferstich Mendelssohn und Sokrates im Medaillon. Er erschien 1818/19 und 1820/21 als Titelabbildung zweier Jahrgänge der Zeitschrift Jedidja. Die Zeitschrift verstand sich als ,ein erfahrner Rathgeber der Menschheit und insbesondere der Jugend“. Jedidja sei ,als ein Freund Gottes aus dem Reich des ewigen Lichts herab zur Menschheit“ gekommen, um „religiös, moralisch und pädagogisch auf Erden zu wirken“1. Diese einleitenden Worte des Herausgebers Jeremias Heinemann (1778-1855) knüpfen überraschend deutlich an die sokratische Denkweise an, die wiederum Vorlage für die deutschen Spätaufklärer gewesen ist. Sie begriffen ihre Philosophie als erzieherische Tätigkeit, mit dem Ziel, die Menschen zur Eigenerkenntnis und zum verantwortlichen Handeln anzuleiten und sie so ihrer Aufgaben und Pflichten in der Welt bewusst zu machen. ${ }^{2}$

1 Heinemann, Jeremias: Einleitung, in: Jedidja I/1 (1817), S. 1. Der Name „Jedidja“ ist Zweit- und Alternativname Salomos. Er findet sich nur in 2 Sam 12,24-25.

2 Vgl. Hinske, Norbert; Specht, Rainer: Einleitung, in: Die Philosophie der deutschen Aufklärung. Stuttgart 1990, S. 15. Vgl. auch Lohmann, Uta: „Dieser alte Rheinwein mundet nur noch, wie die Philosophie, unseren Veteranen, die von den Realitäten einen anschaulichen Begriff haben“ - David Friedländer und die Berliner Aufklärung, in: Lehnardt, Andreas (Hrsg.): Wein und Judentum. Jüdische Kulturgeschichte in der Moderne. Bd. 2. Berlin 2014, S. 207-228. 
Wie sehr auch der jüdische Kaufmann, Aufklärer und Emanzipationspolitiker David Friedländer (1750-1834) von diesem Denken geprägt war, ${ }^{3}$ zeigt nicht zuletzt seine Rede, gehalten vor einer Gesellschaft gebildeter Israeliten, die 1817 in Jedidja veröffentlicht worden ist. Friedländer reflektiert hier über die Verpflichtung des Menschen, seine Handlungen mittels ,seiner moralischen Natur“ in einem selbstkritischen Akt „mit den Vorschriften der Religion und der Tugend“ in Einklang zu bringen. ${ }^{4}$ Die Inhalte und Anschauungen, die Friedländer hier vermittelt, basieren auf den Lehrsätzen, die Moses Mendelssohn (1729-1786) in seiner religionsphilosophischen Schrift Phädon oder über die Unsterblichkeit der Seele entwickelt hat, wobei er sich an der Lehre des antiken griechischen Philosophen Sokrates (469-399 v.d.Z.) orientierte, wie sie von dessen Schüler Platon (428/27-348/47 v.d.Z.) überliefert wurde. Mendelssohns Phädon erschien erstmals 1767, also bereits 50 Jahre vor Lowes Kupferstich. ${ }^{5}$

Friedländer war bei Weitem nicht der Einzige, der eine enge Verbindung zwischen Sokrates und Mendelssohn herstellte. Besonders mit den Nachrufen und frühen Biographien nach 1786 festigte sich Mendelssohns Ruf als der „Sokrates seines Zeitalters“6. Die Parallelen, die dabei gezogen wurden, bezogen sich nicht nur auf Unsterblichkeitslehre, Wahrheitsliebe und Lehrtätigkeit, sondern vor allem auch auf gemeinsame Charakterzüge, wie Sanftmut, Freundlich-

3 Vgl. zu David Friedländers Leben und Werk die Biographie und Bibliographie in: www.haskala.net und Lohmann, Uta: David Friedländer. Reformpolitik im Zeichen von Aufklärung und Emanzipation - Kontexte des preußischen Judenedikts vom 11. März 1812. Hannover 2013; dies.: In Geselligkeit und Öffentlichkeit zum Nachdenken anregen und über das Judentum aufklären. Biographische Streiflichter auf David Friedländer. Einführung, in: David Friedländer. Ausgewählte Werke. Hrsg. u. eingeleitet v. Uta Lohmann. Köln u.a. 2013, S. 7-20. Sowie zu Friedländers Bestrebungen als jüdischer Aufklärer dies.: „Kenntnisse, welche der künftige Staatsbürger bedarf“. David Friedländers Gutachten zur Etablierung moderner jüdischer Schulen in Südpreußen, in: Brocke, Michael u.a. (Hrsg.): Neuer Anbruch. Zur deutsch-jüdischen Geschichte und Kultur. Berlin 2001, S. 97-112; dies.: ,Interkulturalität' in der Bildungskonzeption David Friedländers, in: Behm, Britta L. u.a. (Hrsg.): Jüdische Erziehung und aufklärerische Schulreform. Münster u.a. 2002, S. 291-306; dies.: „Ein ganz neues Feld der Erkenntniß“ - David Friedländer zur Bedeutung der Ästhetik für die Bibelexegese der Haskala, in: Trumah 16 (2007), S. 49-71.

4 Friedländer, David: Rede, gehalten vor einer Gesellschaft gebildeter Israeliten, in: Jedidja I/1 (1817), S. 38-56, hier S. 39.

$5 \mathrm{Zu}$ Mendelssohns Lebzeiten erschienen drei weitere Auflagen des „Phädon“ 1768, 1769, 1776, Berlin und Stettin bey Friedrich Nicolai.

6 Moritz, Karl Philipp: Über Moses Mendelssohn, in: Sämtliche Werke. Bd. 11. Hrsg. v. Claudia Stockinger. Berlin, Boston 2013, S. 39. 
keit, Scharfsinnigkeit, Dialogbereitschaft, Wohltätigkeit, und auf eine Wirksamkeit für Gemeinwohl und menschliche Glückseligkeit. ${ }^{7}$ Friedländer war aber der einzige, der metaphorisch eine enge geschwisterliche Beziehung der Gleichheit zwischen Sokrates und Mendelssohn entwarf. Er war seit langem mit Lowe befreundet, der wie er aus Königsberg stammte, wo Lowe von der Familie Friedländer als junger Künstler protegiert worden war. ${ }^{8}$ Und so spricht einiges dafür, dass es David Friedländer war, der den Kupferstich in Auftrag gab, um einer Metapher auch allegorischen Ausdruck zu verleihen:

Sokrates und Mendelssohn.

Edle Zwillings-Weise!

Nennt die Nachwelt Euch mit Recht.

Eurer Lehren Weisheit

Fühlt der Ungelehrte auch.

Aber Denker preisen,

Ihre Wahrheit lauter noch. ${ }^{9}$

Mit diesem Sinnspruch erläuterte Friedländer den Kupferstich im achten Band von Jedidja, der zum zweiten Mal den Stich als Frontispiz erhielt. Im Kupferstich breitet eine Eule ihre Flügel über den beiden portraitierten Philosophen, dem Zwillingspaar Sokrates und Mendelssohn, aus. Als Attribut der Athene symbolisiert sie Weisheit. Auf dem Ende einer Säule liegt ein Totenkopf, Sinnbild der Vergänglichkeit. Darauf sitzt ein Schmetterling, der hier nicht nur ein Symbol für die Unsterblichkeit der menschlichen Seele ist, sondern, wie die Bildunterschrift SOCRATES * MENDELSSOHN, auf Phädon verweist, mit dem sich Mendelssohn „selbst in die Tradition des Sokrates und des sokratischen Philosophierens gestellt ${ }^{\star 10}$ hatte. Aus der Zeitschrift Jedidja wird deutlich, dass es auch noch im frühen 19. Jahrhundert, Jahrzehnte nach Mendelssohns Tod, jüdische Aufklärer gab, die die Sokratisch-Mendelssohnsche Tradition fortsetz-

7 Vgl. Schulte, Christoph: Die jüdische Aufklärung. München 2002, S. 204. Leonard, Miriam: Socrates and the Jews. Hellenism and Hebraism from Moses Mendelssohn to Sigmund Freud. Chicago, London 2012.

8 Vgl. Hagen, A.: Der Maler und Kupferstecher Lowe, in: Der neuen Preußischen Provinzial-Blätter andere Folge III (1853), S. 317-329, hier S. 317. Lowe illustrierte einige Werke der Berliner Maskilim, die im Verlag der Jüdischen Freischule erschienen. Vgl. auch das Gedicht von Lippmann Moses Büschenthal: An den Mahler Lowe in Berlin, in: Jedidja I/2 (1817), S. 83f.

9 Friedländer, David: Sokrates und Mendelssohn. Inschrift zum Titelkupfer des zweiten Jahrgangs dieser Zeitschrift, in: Jedidja III/2 (1820/21), S. 108.

10 Schulte: Aufklärung, S. 199; vgl. hier insb. S. 199-206. 
ten und bemüht waren, ihre Philosophie weiter zu verbreiten und in ihre eigene Lehre zu integrieren. ${ }^{11}$

\section{Religionswahrheiten}

Wahrheit spielt in Friedländers Sinnspruch eine zentrale Rolle. Sie bezieht sich hier auf die von Mendelssohn im Phädon entwickelten Lehrsätze, die Friedländer schon früher zusammenfasste: „Es ist ein Gott“, „Die Seele des Menschen ist unkörperlich“, „Die Bestimmung des Menschen hienieden ist Streben nach höherer Vollkommenheit, und hiemit nach dem Besitz der Glückseligkeit“, „Die Seele des Menschen ist unsterblich“12 und schließlich die Erkenntnis von der Belohnung und Bestrafung in einem künftigen Leben. Diese religiösen Wahrheiten waren Friedländer Fundamente seines aufgeklärten Bildungsverständnisses, das Jahrzehnte später in Jedidja aktualisiert wurde. ${ }^{13}$

Der antike Schauplatz des Phädon ist Ausdruck für die Universalität von Mendelssohns Lehrsätzen, ${ }^{14}$ mit denen er ein Gegengewicht zu den offenbarungsreligiösen Traditionen setzte. Mendelssohn zeigte, dass die Menschen fähig sind, mit eigenen Verstandeskräften die universalen „Vernunftwahrheiten“ selbst zu erkennen. ${ }^{15}$ Die „Wahrheiten der natürlichen oder Vernunftreligion“ seien ,nicht allein in Vergleichung mit den geoffenbarten Begriffen, sondern an und für sich klar, faßlich und deutlich“" setzte auch Friedländer jenen entgegen, die behaupteten, dass diese ,außer dem Horizonte des großen Haufen liegen,

$11 \mathrm{Zu}$ Friedländers diebezüglichen Bemühungen vgl. Lohmann, Uta: „Dem Wahrheitsforscher zur Belehrung“. .Die Herausgaben von Moses Mendelssohns Ha-nefesh (1787) und Phädon (1814-1821) durch David Friedländer: Kontexte, Adressaten, Intentionen, in: Mendelssohn-Studien 19 (2015) (in Vorbereitung).

12 Friedländer, David: Sendschreiben an Seine Hochwürden, Herrn Oberconsistorialrath und Probst Teller zu Berlin, von einigen Hausvätern jüdischer Religion (Berlin 1799). Neu ediert in: Friedländer: Ausgewählte Werke, S. 185-212, hier S. 191f.

13 Hier erschienen unter der Überschrift „Was ist Wahrheit?“ noch 1831 Auszüge aus Mendelssohns Morgenstunden oder Vorlesungen über das „Daseyn Gottes“ (Berlin 1785); vgl. Jedidja VIII (1831), S. 1-29.

$14 \mathrm{Zu}$ „Phädon“ vgl. u.a. Pollok, Anne: Einleitung, in: Moses Mendelssohn: Phädon oder über die Unsterblichkeit der Seele. Hrsg. v. Anne Pollok. Hamburg 2013, S. VII-L; dies.: Facetten des Menschen. Zur Anthropologie Moses Mendelssohns. Hamburg 2010, S. 499-530; Krochmalnik, Daniel: Die Lehre von der Unsterblichkeit der Seele in der Religionsphilosophie der Aufklärung, in: Goodman-Thau, Eveline (Hrsg.): Vom Jenseits. Jüdisches Denken in der europäischen Geistesgeschichte. Berlin 1997, S. 79-107; Behm, Britta L.: Mendelssohn und die Transformation der jüdischen Erziehung in Berlin. Münster u.a. 2002, S. 107-112.

15 Vgl. Strauss, Leo: Einleitung zu „Phädon“, in: Moses Mendelssohn: Schriften zur Philosophie und Ästhetik III,1. JubA. Bd. 3.1 (1932/1972). S. XIII-XXXIII, hier S. XVIIf. 
daß der gemeine Mann dafür nicht empfänglich gemacht werden könne, daß es bereits gebildete, zum Nachdenken gewöhnte Menschen erfordere, um diese Lehrsätze einzusehen“. ${ }^{16}$

In seiner Abhandlung Über den besten Gebrauch der heiligen Schrift in pädagogischer Rücksicht, die er 1788 seiner deutschen Übersetzung von Kohelet, Der Prediger, voranstellte, verfolgte Friedländer den Lehrsatz von der Universalität religiöser Grundwahrheiten so konsequent, dass er das Beispiel des Glaubensbekenntnisses der Brahmanen anführte und einen Auszug daraus abdruckte. ${ }^{17}$ Die „Philosophie der Braminen in Indien“ ist ihm der Beweis dafür, dass sich „die abstraktesten Lehren der Vernunft ohne Hilfe der Offenbarung“, allein durch die „unermessliche Kraft des menschlichen Geistes“ ermitteln lassen. ${ }^{18}$ Schließlich zieht er den Schluss:

Wahrheiten, von welchen der Mensch nothwendig überzeugt seyn muß, wenn er auf dieser Welt als ein vernünftiges Wesen glücklich seyn will, kann die allgerechte Gottheit unmöglich Einem Volke ausschließenderweise mitgetheilt haben. [...] Es giebt kein Volk unter der Sonne, daß nicht mehr oder weniger richtige Begriffe von dem Urheber der Natur und seinen unendlichen Eigenschaften hätte. ${ }^{19}$

Und so ist der Prediger in Friedländers Worten

kein dogmatischer kalter Lehrer, sondern ein feuriger lebhafter Untersucher der Wahrheit. Diesem ist es eigenthümlich, wenn er ein Weiser ist, die entgegengesetzten Meynungen anzuhören. Ohne Rücksicht auf sein eignes System, merkt er auf alle Einwendungen, die ihm gemacht werden können. ${ }^{20}$

Der Prediger gewinnt in der Charakterisierung Friedländers deutliche Züge der „Zwillings-Weisen“ Sokrates und Mendelssohn. Und auch die Religionen gleichen mit den ihnen gemeinsamen Grundwahrheiten Zwillingen. Damit ist ein geschwisterliches Verhältnis aller Menschen als Kinder eines Gottes impliziert.

16 Friedländer, David: Über den besten Gebrauch der h[eiligen] Schrift in pädagogischer Rücksicht, in: Der Prediger. Aus dem Hebräischen v. David Friedländer. Berlin 1788, S. 1-90; hier S. 62 u. 64. Neu ediert in: Lohmann, Uta; Lohmann, Ingrid (Hrsg.): „Lerne Vernunft!“ Jüdische Erziehungsprogramme zwischen Tradition und Modernisierung. Quellentexte aus der Zeit der Haskala, 1760-1811. Münster u.a. 2005, S. 61-81, hier S. 78.

17 Vgl. „Symbol der Braminen“, in: Der Prediger. Berlin 1788, S. 73-78. Vgl. dazu auch Lohmann, Uta: Lessings Einfluss auf David Friedländer - Ideengeschichtliche Hintergründe des Sendschreibens an Propst Teller (1799), in: Kaufmann, Sylke; Siwcyk, Birka (Hrsg.): Lessing und das Judentum im Zeitalter der Aufklärung. Hildesheim u.a. 2015 (in Vorbereitung).

18 Friedländer: Über den besten Gebrauch, S. 30.

19 Ebd., S. 68.

20 Ebd., S. 84f. 


\section{Die hebräische Schrift Ha-Nefesch und ihre institutionellen Kontexte}

Während andere Freunde Mendelssohns nach seinem Tod Biographien und Nachrufe verfassten, ging Friedländer an ein ganz anderes Werk: Er gab 1787 im Verlag der jüdischen Freischule, der Orientalischen Buchdruckerei, ${ }^{21}$ eine hebräische Version des Phädon unter dem schlichten Titel הנפש (Ha-nefesch, Die Seele) heraus. ${ }^{22}$ Die nur zwanzig Blatt umfassende Schrift beinhaltet die Essenz der logischen Beweisführung Mendelssohns. Dieser hatte die hebräische Kurzversion zwar selbst entworfen, die Veröffentlichung von Ha-nefesch ging jedoch auf die Initiative Friedländers zurück. Er wolle damit „,das Verlangen des Verständigen“ befriedigen, der es liebe, „den Ursprung seines Menschseins zu erforschen", heißt es in Friedländers Einleitung. Er zielte auf die schmale Gruppe der Maskilim, wie auch auf die älteren Schüler der Freischule, denen er die zentralen Ideen der Mendelssohnschen Religionsphilosophie näher bringen wollte. ${ }^{23}$ Auszüge aus Ha-nefesch wurden bereits $1784 \mathrm{im}$ Anhang zu Isaac Satanows hebräischer Sittenlehre Sefer ha-middot (ספר המידות, „Buch der Sitten") veröffentlicht. Das Sefer ha-middot kam im Verlag der jüdischen Freischule heraus und verdankte sich einem Preis, den David Friedländer und Isaac Daniel Itzig als Direktoren der Freischule im Jahr zuvor ,auf den besten Entwurf einer nach jüdischen Grundsätzen abgefaßten Sittenlehre" ausgeschrieben

21 Zur Geschichte des Verlags der Freischule vgl. Lohmann, Uta: "Sustenance for the Learned Soul": The History of the Oriental Printing Press at the Publishing House of the Jewish Free School in Berlin, in: Leo Baeck Institute Year Book LI (2006), S. 11-40.

22 Mendelssohn, Moses: Ha-nefesch. Berlin 1787. Hrsg. u. mit einer hebräischen Einleitung versehen v. David Friedländer. Auf dem hebräischen Titelblatt wurde Mendelssohn genannt, doch darunter war ausdrücklich vermerkt, dass das Buch ,durch seinen Schüler und Freund David Friedländer“" zum Druck gebracht wurde. Friedländers Einleitung von Adar 5547 (Februar/ März 1787) ist abgedruckt in: JubA. Bd. 3.1, S. 201-233. Für die deutsche Übersetzung der Einleitung danke ich Rainer Wenzel.

23 In diesem Sinn schrieb Friedländers Neffe später in „Jedidja“: „Herr David Friedländer hat eine kleine Abhandlung über die Unsterblichkeit der Seele, zum Gebrauche der obern jüdischen Klassen, geschrieben, welche alle Beweise aus dem Phädon und andern Werken seines Freundes in summarischer Uebersicht enthält“. Friedländer, Michael: Moses Mendelssohn's Leben, in: Jedidja III/1 (1821), S. 226-249, hier S. 248. Zit. nach dem anonymen Wiederabdruck in Heinemann, Jeremias (Hrsg.): Moses Mendelssohn. Sammlung theils noch ungedruckter, theils in andern Schriften zerstreuter Aufsätze und Briefe von ihm, an und über ihn. Leipzig 1831, S. 27. In JubA. Bd. 23 (1998): Die frühen Mendelssohn-Biographien, Nr. 39, S. 410 ist fälschlicherweise David Friedländer als Autor dieses Artikels angeben. 
hatten. ${ }^{24}$ Die Veröffentlichung dieser Schriften im Umfeld der Freischule zeigt, dass die Sokratisch-Mendelssohnsche Religionsphilosophie ein wichtiges Fundament im Bildungskonzept der Freischule darstellte.

Die Portraitbüste Mendelssohns, in weißem Marmor von dem Bildhauer und Direktor der Akademie der Künste Jean Pierre Antoine Tassaert (1727-1788) gearbeitet, ist ikonographischer Ausdruck dieses Bildungskonzepts. Sie entstand 1784 wahrscheinlich auf Anregung Friedländers und wurde von zwanzig Freunden Mendelssohns finanziert. ${ }^{25}$

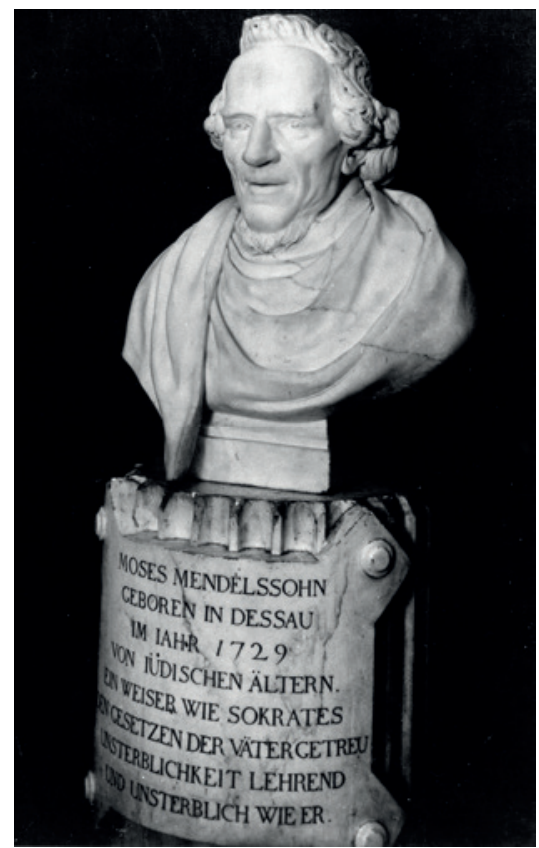

Abb. 2: $\quad$ Jean Pierre Antoine Tassaert, Moses Mendelssohn, 1785, Marmorbüste (C) Gidal-Bildarchiv im Salomon Ludwig Steinheim-Institut, Essen

Aus dem Kunstwerk spricht der Versuch, ,durch die künstlerische Reflexion der Antike das Denkmal Mendelssohns mit seinem philosophischen Werk zu ver-

24 Vgl. Lohmann, Ingrid (Hrsg.): Chevrat Chinuch Nearim. Die jüdische Freischule in Berlin (1778-1825) im Umfeld preußischer Bildungspolitik und jüdischer Kultusreform. Eine Quellensammlung. 2 Teile. Münster u.a. 2001, Dok. 50, S. 209. Satanow gewann den Preis; vgl. Feiner, Shmuel: Haskala - Jüdische Aufklärung. Geschichte einer kulturellen Revolution. Hildesheim u.a. 2007, S. 317.

25 Vgl. Porstmann, Gisbert: Die Portraitbüste, in: JubA. Bd. 24 (1997), S. 50. 
binden“. ${ }^{26}$ Vermutlich diente Tassaert eine antike Büste des Sokrates als Vorlage. Im Februar 1785 wurde die Mendelssohn-Büste in den Räumen der Jüdischen Freischule aufgestellt. ${ }^{27}$ Die von Karl Wilhelm Ramler (1725-1798) verfasste Inschrift auf dem Sockel der Büste nimmt doppeldeutig Bezug auf Mendelssohns Unsterblichkeitslehre:

Moses Mendelssohn

Geboren in Dessau

Im Jahr 1729

Von jüdischen Ältern.

Ein Weiser wie Sokrates

Den Gesetzen der Väter getreu

Unsterblichkeit lehrend

Und unsterblich wie er.

Während der Entstehungszeit der Büste schrieb Friedländer: „Alle Steinmetzen sind freilich nicht Socratesse, alle Kaufleute nicht Mendelssohne: aber daß sie es seyn können, ist doch nicht absolut - unmöglich“ “28 Dieser Aphorismus ist erfüllt von der Idee, dass jeder Mensch dazu bestimmt sei, seine ihm eigenen Anlagen und Fähigkeiten bestmöglich zu vervollkommnen. Im Phädon hatte Mendelssohn die Unsterblichkeitslehre als wesentliche Glaubenswahrheit mit der Idee der Vervollkommnungsfähigkeit verknüpft. In diesem Sinn sagt Friedländer in seiner Rede von 1817:

Nie ist der Sterbliche ganz was er seyn soll und kann. Von Gott berufen, steigt er von Stufe zu Stufe die ganze Leiter seiner Veredlung hinan, bis zu dem Punkt, den seine endliche Kräfte hienieden zu ersteigen gewidmet sind. Und doch wer bestimmt auch hier die Gränze? Kein Mensch steht so hoch, daß er nicht höher steigen könnte. - Wann [...] ist er so wirksam, so wohlthätig, so fehlerfrei, daß er nicht kräftiger, wohlthätiger, tugendhafter werden könnte? [...] Wie leiten diese nie auf Erden sich ganz entwickelnde Fähigkeiten, Kräfte und Talente, den Nachdenkenden auf Fortdauer und Unsterblichkeit. Die Seele des Menschen ist unsterblich. ${ }^{29}$

26 Ebd., S. 52.

27 Vgl. Stern, Moritz: Gutachten und Briefe David Friedländers. Zeitschrift für die Geschichte der Juden in Deutschland VI (1935), S. 121-125. Neu ediert in: Lohmann, Ingrid: Chevrat Chinuch Nearim, Dok. 718, S. 1356. Wegen Platzmangels und aus Furcht vor Beschädigung durch die Schüler sorgte Schuldirektor Isaac Daniel Itzig schon im Folgejahr dafür, dass das Kunstwerk aus den Unterrichtsräumen entfernt wurde und zunächst im Zimmer der Direktoren einen Platz fand.

28 Friedländer, David: Briefe über die Moral des Handelns, geschrieben im Jahr 1785, in: Lesebuch für alle Stände 9 (1790), S. 83.

29 Friedländer: Rede, gehalten vor einer Gesellschaft gebildeter Israeliten, S. 53f. 
In ihren Übersetzungen aus dem Tanach brachten die Berliner Maskilim die biblischen Lehren mit den universalen Grundsätzen der Religionsphilosophie Mendelssohns in Einklang. Die Gesellschaft zur Beförderung des Edlen und Schönen (חברת שוחרי הטוב והתושיה), die kurz nach Mendelssohns Tod in Berlin gegründet wurde, machte Förderung, Produktion und Vertrieb der HaskalaLiteratur zu einer ihrer Hauptaufgaben. ${ }^{30}$ Vor den Mitgliedern der Gesellschaft zur Beförderung des Edlen und Schönen hielt Friedländer 1791 eine Vorlesung bey der erneuerten Todesfeyer Mendelssohns. Hier appelliert er an die Selbstbildung der Juden, mit dem Ziel einer immer weiter fortschreitenden intellektuellen und sittlichen Vervollkommnung nach dem gelebten Vorbild Mendelssohns: „Sein Geist, seine Liebe zur Wahrheit, sein reger Trieb, sie zu verbreiten, seine sittliche Güte, sein untadelhafter Wandel ${ }^{\text {‘31 }}$ seien unter Mendelssohns Zeitgenossen einzigartig und unvergesslich. Das Betrachten „eines solchen edlen Gebildes, einer solchen Zierde der Menschheit“ gewähre „ein reitzendes Vergnügen“32. Wie der Anblick eines vollkommenen Kunstwerks starke Emotionen beim Betrachter hervorzurufen im Stande sei, so soll die Vergegenwärtigung der sittlichen Schönheit Mendelssohns Empfindungen wecken, um die Herzen der Menschen zu öffnen und sie für das Gute empfänglich zu machen. Für Friedländer spiegelte Mendelssohns Lebensweg die „so einleuchtende Wahrheit"“ wider,

daß jeder Mensch, auch der unbedeutendste Judenknabe, unter einer weisen Regierung, sich zum aufgeklärtesten und kultivirtesten Bürger, zum Lehrer und zum Muster seiner Nebenmenschen aufschwingen; daß jeder Mensch, auch der Jude, ein frommer, rechtschaffener, moralisch guter Mann seyn könne, obschon er das höchste Wesen auf eine andere Weise anbete, und obschon er über gewisse, außer dem praktischen Leben liegende, theils übersinnliche, theils historische Wahrheiten, andere Meinungen und einen andern Glauben habe. ${ }^{33}$

Die maskilische Lehre, die sowohl an der Freischule als auch durch die Gesellschaft zur Beförderung des Edlen und Schönen Verbreitung finden sollte, fußte auf den religiösen Grundwahrheiten („Vernunftwahrheiten“) und einer Sittenlehre, deren moralische und soziale Regeln aus den Schriften des Tanach schöpften, sowie auf dem Appell, im Sinne Mendelssohns und nach seinem Vorbild zu handeln und zu wandeln. Diese maskilische Lehre versuchten die

30 Vgl. Lohmann, Uta: Chevrat Schocharej haTov wehaTuschija (Gesellschaft der Beförderer des Edlen und Guten), in: Motschmann, Uta (Hrsg.): Handbuch der Berliner Vereine und Gesellschaften, 1786-1815. Berlin, München, Boston 2015, S. 827-837.

31 Friedländer: Vorlesung bey der erneuerten Todesfeyer Mendelssohns; zit. nach JubA 23, S. 297.

32 Ebd.

33 Ebd., S. 303. 
Berliner Maskilim mit ihren Schriften zu verbreiten und in ihrem Konzept einer allgemeinen Menschenbildung zu etablieren.

Doch Ende des 18. Jahrhunderts zeichnete es sich ab, dass sie mit ihren Bemühungen gescheitert waren. An der Freischule konnte ihr Bildungskonzept wegen Frontstellung der traditionalistischen Gemeinde nicht verwirklicht werden. Die ersten Reformverhandlungen um eine rechtliche Gleichstellung der Juden waren nahezu erfolglos geblieben und viele Mitglieder der jüdischen Gemeinde traten zum Christentum über. ${ }^{34}$ Die Gesellschaft zur Beförderung des Edlen und Schönen hatte sich bereits 1794 aufgelöst, die hebräische Aufklärungsliteratur wurde in größerem Umfang weder gekauft noch gelesen. Und so mussten sich die Maskilim eingestehen, dass sie es nicht geschafft hatten, mehr als nur ein „kleines Häuflein“‘35 Anhänger um sich zu scharen. Resigniert schrieb Friedländer 1799:

Alle unsere hebräisch geschriebene Bücher liest Keiner ... Für Wen wird nun geschrieben? Es schlug ja Einer schon vor, über die jüdische Druckerei zu schreiben: hier werden Bücher gedruckt, die nie gelesen werden! Das ist, nach meiner Meinung, im eigentlichen Sinne des Wortes wahr. ${ }^{36}$

$\mathrm{Zu}$ dieser Zeit beauftragte Friedländer Johann Gottfried Schadow (1764-1850) mit der Federzeichnung Sokrates im Kerker, die 1800 in der Berliner AkademieAusstellung gezeigt wurde. ${ }^{37}$ Im Ausstellungskatalog erhielt das Kunstwerk eine außergewöhnlich ausführliche Bildbeschreibung, die vermutlich Friedländer selbst verfasst hatte. Hier heißt es:

Die Scene, welche der Künstler auf dieser Zeichnung dargestellt hat, ist aus den letzten Lebenstagen des Sokrates [...]. Sie geht in dem Kerker vor, in welchem der Weise wenige Tage nachher den Giftbecher zu sich nahm. ${ }^{38}$

Dann werden Charaktereigenschaften und Reaktionen der „Freunde und Schüler“ des Sokrates beschrieben, der ,die Lehre von der Unsterblichkeit der Seele

34 Vgl. Lohmann: David Friedländer. Reformpolitik, S. 161-184 und Lowenstein, Steven M.: The Berlin Jewish Community. Enlightenment, Family, and Crisis, 1770-1830. New York, Oxford 1994.

35 Unger, Friderike Helene: Über Berlin, in: Jahrbücher der preußischen Monarchie unter der Regierung Friedrich Wilhelm des Dritten. Berlin 1798, Bd. 2. Zit. nach Czok, Claudia: Schadow, Sokrates und das Judentum. Köln 2002, S. 10.

36 Brief David Friedländers an Aaron Wolfssohn von 1799, in: Stein, Leopold: Die Schrift des Lebens. Zweiter Teil. Straßburg i.E. 1877, S. 444f.

37 Czok: Schadow, S. 10.

38 Verzeichnis der zu der Kunstausstellung der Königl. Academie der bildenden Künste und mechanischen Wissenschaften eingesandten Gemälde, Kupferstiche u.s.w. Berlin 1800. Zit. nach: ebd., S. 12f. 
bereits vorgetragen und mit unwiderleglich scheinenden Beweisen unterstützt" habe. Die Bildbeschreibung endet schließlich mit dem Zitat eines Dialogs zwischen Phädon und Sokrates:

Dieser ergreift seine Haare, die herunterhängen, und streichelt sie, ,wie er denn gewohnt war“, sagt Phädon, „mit meinen Locken zu spielen.“ „Morgen“, sprach er, „Phädon! dürftest du wohl diese Locken auf das Grab deines Freundes streuen.“ „Allem Ansehn nach“, erwiederte Phädon. „O thut es nicht“, versetzte Sokrates. „Warum denn das?“ „Noch heute müssen wir beide unser Haar abschneiden, wenn unser schönes Lehrgebäude so dahin stirbt, und wir nicht im Stande sind, es wieder aufzuwecken". 39

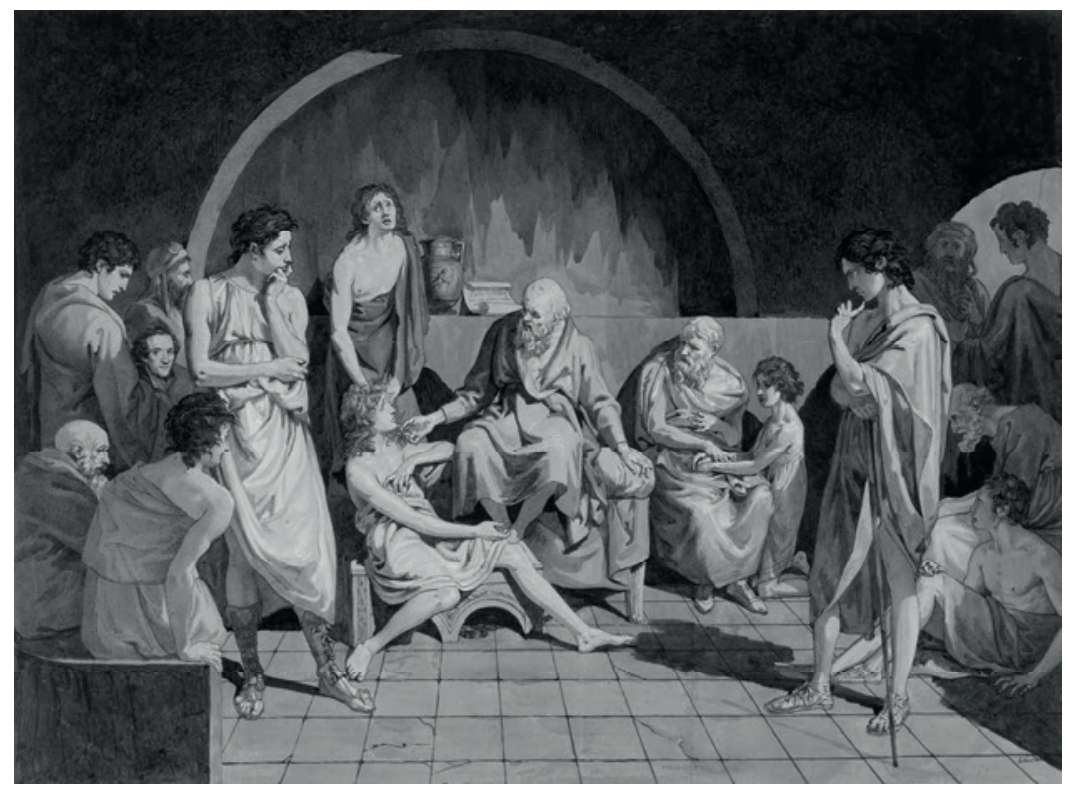

Abb. 3: Johann Gottfried Schadow, Sokrates im Kerker, 1800, Aquarellzeichnung

(C) Kupferstichkabinett, Staatliche Museen zu Berlin (Inv. Nr.: SZ Schadow 2)

Auf dem Hintergrund des eben skizzierten Misserfolgs der Berliner Maskilim und angesichts der Tatsache, dass auch Sokrates" „Zwillings-Weiser“ Mendelssohn auf der Federzeichnung Schadows präsent ist, kann dieser Abschnitt der Bildbeschreibung gelesen werden wie die Klage über die Sterblichkeit der maskilischen Lehre.

39 Ebd. Das Zitat stammt aus dem zweiten Gespräch in Mendelssohns „Phädon“; vgl. JubA. Bd. 3.1, S. 86. 


\section{Die fünfte Auflage des Phädon, Heinemanns Schulen und Jedidja}

Mit einem Abstand von fast vierzig Jahren zur vierten Auflage (1776) gab Friedländer 1814 die fünfte Auflage des Phädon heraus. Seither hatten die Lebensverhältnisse der preußischen Juden gewaltige Veränderungen erfahren. 1812 wurde endlich das lang ersehnte Emanzipationsedikt verabschiedet, das den Juden rechtliche Gleichstellung mit allen anderen Staatsbürgern zusicherte. Das Deutsche ist nun zur allgemeinen Gebrauchssprache geworden. Ein gutes Vierteljahrhundert nach Erscheinen der schmalen hebräischen Schrift $\mathrm{Ha}$ nefesch wandte sich die deutsche Neuauflage des Phädon besonders an die heranwachsende Generation. Befreit von den drückenden rechtlichen und sozialen Beschränkungen, könne sich deren Geist nun frei entwickeln, so Friedländers optimistische Einschätzung. Es eröffnete sich ihm ein neues Feld zur Verbreitung der Sokratisch-Mendelssohnschen Philosophie.

Einen fruchtbaren Teil dieses neuen Feldes stellte die 1816 eröffnete Erziehungs- und Lehranstalt von Jeremias Heinemann dar, der kurze Zeit nach der Schuleröffnung mit der Herausgabe seiner Zeitschrift Jedidja begann und 1818 auch eine Unterrichtsanstalt für Töchter gebildeter Eltern einrichtete. ${ }^{40}$ Dem zweiten und dritten Jahrgang von Jedidja steuerte Friedländer eine ganze Reihe von Beiträgen über und von Mendelssohn bei, darunter Unterhaltung mit Mendelssohn, aus der Erinnerung niedergeschrieben und Über Mendelssohn, seinen Charakter, seinen Wirkungskreis und seine Verdienste um die Israeliten. ${ }^{41}$ Bei diesen Mendelssohn-Fragmenten (1818/19) handelte es sich keineswegs um biographische Aufzeichnungen im üblichen Sinn. Es ging Friedländer hierin vielmehr um die Beschreibung des Wesens Mendelssohns, seines Charakters und der Art seines Umgangs mit seinen Mitmenschen im Allgemeinen und seiner Strategien der Konfliktlösung im Besonderen. Die vorbildliche Handlungsweise Mendelssohns an die jüngere Generation zu vermitteln, war für ihn weit wichtiger, als sich mit Mendelssohns wissenschaftlichen Schriften auseinanderzusetzen. ${ }^{42}$ Dass sich Friedländer im frühen 19. Jahrhundert mit den Mendelssohn-Fragmenten in Jedidja zu Wort meldete, steht in engstem Zusam-

40 Zu Heinemanns Schulen vgl. Fehrs, Jörg H.: Von der Heidereutergasse zum Roseneck. Jüdische Schulen in Berlin 1712-1942. Berlin 1993, S. 48-52.

41 Vgl. im Einzelnen die Bibliographie in Lohmann: David Friedländer. Reformpolitik, S. $533 f$.

42 In diesem Sinn schrieb er auch noch im hohen Alter, Mendelssohn sei ,als Mensch weit seltener, weit ehrwürdiger, weit verehrenswerter [...], als der eigentliche Gelehrte“. David Friedländer an Bernhard Beer, Berlin am 5. Mai 1832. Zit. nach Grunwald, Max: Briefe von David Friedländer, in: Zeitschrift für die Geschichte der Juden in Deutschland VI (1935), S. 171. 
menhang mit Heinemanns Erziehungs- und Lehranstalt für Knaben. Konnte Mendelssohn ,in seiner Seele Gottesverehrung, Gottergebung und Menschenfreundschaft vereinigen, warum nicht mehr und andre Jünglinge dieses Volks? “43, lautet seine Devise. Da Mendelssohn „sich zu einer eminenten Höhe der Sittlichkeit" emporgeschwungen habe, sei er zum Vorbild prädestiniert: "Sein Leben lehrte“. ${ }^{44}$

Eine Besonderheit der Zeitschrift Jedidja ist, dass Heinemann sie als Publikationsort seiner Schulprogrammschriften nutzte, die hier jeweils im „Ersten Hauptteil“" der Zeitschrift erschienen, während „Allgemeine Menschenbildung“ den „Zweiten Hauptteil“" ausmachte, in dem auch die Mendelssohn-Fragmente erschienen. 1817 verkündete Heinemann, dass seine Lehranstalt „,nicht blos eine Schule der wissenschaftlichen Ausbildung, sondern auch ganz besonders eine Schule der Religion und der Sitten seyn “45 solle. Das Konzept der Heinemannschen Schule, das säkulare Fächer mit religiöser Bildung und „Sittenlehre“ verband, entsprach Friedländers Bildungskonzept weitgehend. Wahrscheinlich ist sogar ein direkter Einfluss Friedländers auf Heinemann, denn bevor dieser sich 1815 in Berlin niederließ, war er als Konsistorialrat des Westfälischen Konsistoriums der Israeliten in Kassel vor allem mit Reformen im jüdischen Unterrichtswesen befasst gewesen und hatte in diesem Rahmen Friedländer kennengelernt. ${ }^{46}$ Im Mai 1818 schrieb dieser an Heinemann, er teile mit ihm „Wunsch und Verlangen, alles, was sich von unsrem weisen Mendelssohn noch auffinden läßt, zu sammeln und in Ihre Zeitschrift niederzulegen“. Unter der Rubrik „Allgemeine Menschenbildung" veröffentlichte Heinemann Friedländers Brief in der Jedidja, wo er als Einleitung zu Friedländers Mendelssohn-Fragmenten erschien. Hier heißt es:

Jedidja wird sich ein großes Verdienst erwerben, wenn sein vorzügliches Augenmerk dahin gerichtet ist, für die jungen Männer zu sorgen, deren Beruf und Bestimmung seyn soll, sich selbst auszubilden, und dadurch sich zu Erziehern der Jugend und Volkslehrer geschickt zu machen - dem verewigten Weltweisen soll damit kein Denkmahl gesetzt werden [...]. Aber unsren Jünglingen, welche sich den Studien widmen, erzeigen wir einen großen Dienst, wenn wir sie zu ihm hinweisen, und durch diese kleinen Aufsätze sie auf seine größern Werke aufmerksam machen. Was können sie nicht von diesem Edlen lernen! Wahl der Materie, Schönheit der Spra-

43 Friedländer, David: Ueber Mendelssohn, seinen Charakter, seinen Wirkungskreis und seine Verdienste um die Israeliten. Ein Fragment, in: Jedidja II/1 (1818/19), S. 22-31. Zit. nach JubA. Bd. 23, S. 379.

44 Ebd., S. 378f. (Hervorhebung U.L.)

45 Heinemann, Jeremias: Grundriß der Heinemannschen Erziehungs- und Lehr-Anstalt für Knaben, in: Jedidja I/2 (1817), S. 140-163, hier S. 141.

46 Vgl. Lohmann: David Friedländer. Reformpolitik, S. 275-277. 
che, Richtigkeit des Ausdrucks, vorzüglich aber Frömmigkeit der Gesinnungen und jene nachahmungswürdige Bescheidenheit, die aus allen seinen Vorträgen, wie der Geruch der Veilchen sich sanft verbreitet. Nirgends anmaßender Ton; immer will er nur mit uns lernen, mit uns forschen, mit uns denken; niemals seine Ansicht ohne Gründe, auf Authorität aufdringen, als Lehrer, seine Meinung geltend machen. Wie sehr bedürfen wir zu unsrer Zeit solcher Muster! ${ }^{47}$

Mit Friedländers Mendelssohn-Fragmenten konnte „der innere Werth, die wohlthätigen Folgen einer guten Denkungsart und eines edlen Betragens anschaulich gezeigt" werden. Das entsprach eben jenen Bestrebungen, die Heinemann mit seiner „Sittenlehre“ verband: „Erzählungen guter Handlungen sollen die Ausbildung des Herzens und die Richtung des Gemüths auf Gott bezwecken“48, wie er es formulierte. Die Unterweisung in „Religion und Moral“ gehörte zu Heinemanns Konzept der Allgemeinen Menschenbildung. Nach diesem Konzept unterteilte er den zweiten Hauptteil von Jedidja in sieben Kategorien (,Sphären“) der allgemeinen Bildung des Menschen: „I. durch Religion und Moral“, „II. durch Pädagogik“, „III. durch Aesthetik“, „IV. durch Poetik und Rhetorik“, „V. durch Literatur und Geschichte“, „VI. durch Kritik wissenschaftlicher Werke“ und „VII. durch Berichte interessanter Ereignisse, Entdeckungen und Nachrichten von allen Ländern und insbesondere vom Preußischen Staate". 49

Dass für „Religion und Moral“ die prominente erste Stelle eingeräumt wurde, belegt die vorrangige Bedeutung, die Heinemann wie Friedländer dem Bildungswert von Religion, Moral und Sittlichkeit einräumten. „Vorzüglich“ bezwecke Jedidja ,die religiöse, moralische und ästhetische Bildung der Menschheit, und richtet dabei ganz besonders sein Augenmerk auf die gegenwärtige Bildungsstuffe seiner Glaubens-Brüder und Schwestern in der Welt“"50, so Heinemann. Unter der hervorgehobenen Kategorie „Religion und Moral“ erschienen 1817 Mendelssohns Andachtsübung eines Weltweisen, die zuerst in Friedländers Lesebuch für jüdische Kinder (1779) erschienen war, Friedländers Rede, gehalten vor einer Gesellschaft gebildeter Israeliten sowie dessen Rede über Psalm 19 und 1818/19 die Mendelssohn-Fragmente. Mit all diesen Beiträ-

47 Friedländer, David: An den Herausgeber der Zeitschrift Jedidja, in: Jedidja II/1 (1818/19), S. 13-14.

48 Heinemann: Grundriß Erziehungs- und Lehr-Anstalt, S. 144-146.

49 Heinemann: Einleitung, S. 3f. Die inhaltliche Nähe zur ersten jüdischen Zeitschrift der Maskilim „Ha-Measef“ ist augenfällig; vgl. Kennecke, Andreas: „Hame’assef” - die erste hebräische Zeitschrift, in: Menora 12 (2001), S. 171-188 und ders.: HaMe'assef. Die erste moderne Zeitschrift der Juden in Deutschland, in: Schulte, Christoph (Hrsg.): Haskala. Die jüdische Aufklärung in Deutschland 1769-1812. Wolfenbüttel 1999, S. 176-199.

50 Heinemann: Einleitung, S. 4. 
gen bekannten sich Friedländer und Heinemann zur Sokratisch-Mendelssohnschen Tradition. Wie Platon und Mendelssohn in ihrem Werk Sokrates als Lehrer und Vorbild charakterisierten, um bei ihren „Lesern das Andenken des Weltweisen aufzufrischen“" ${ }^{51}$ so schreibt Friedländer in Jedidja über Mendelssohn als das große „Muster und Vorbild“ für seine Generation und deren „Nachkommen“: „Ein Bild von ihm [...] wird immer belehrend und erquickend bleiben“. 52

Jahre später sah Jeremias Heinemann das offenbar noch genauso. 1831 veröffentlichte er erneut Lowes Kupferstich mit den „edlen Zwillings-Weisen“ Sokrates und Mendelssohn im Frontispiz der „Sammlung theils noch ungedruckter, theils in andern Schriften zerstreuter Aufsätze und Briefe von ihm, an und über ihn“, die er unter dem schlichten Titel Moses Mendelssohn (Leipzig 1831) herausgab. Diese Sammlung widmete Heinemann „Allen Freunden und Verehrern des verewigten Weisen, die wie Er der Wahrheit huldigen“.

Unter der Überschrift Das Titelkupfer stellte Heinemann ein Zitat aus Johann Caspar Lavaters (1741-1801) vierbändiger Theorie der Physiognomik, Physiognomische Fragmente, zur Beförderung der Menschenkenntniß und Menschenliebe (Leipzig u.a. 1775-1778), seiner Sammlung voran:

Ich weide mich an diesem Umrisse! Mein Blick wälzt sich von diesem herrlichen Bogen der Stirne auf den scharfen Knochen des Auges herab... In dieser Tiefe des Auges sitzt eine sokratische Seele! Die Bestimmtheit der Nase - der herrliche Uebergang von der Nase zur Oberlippe - die Höhe beider Lippen, ohne daß eine über die andere hervorragt, o wie alles dieß zusammenstimmt, mir die göttliche Wahrheit der Physiognomie fühlbar und anschaulich zu machen. ${ }^{53}$

Mit diesem Zitat, das Heinemann zur Beschreibung der Zwillings-Allegorie in Lowes Titelkupfer diente, wird Mendelssohn ganz in den Vordergrund gerückt. Es scheint, dass die Seele seines Zwillings Sokrates ganz in seinem Wesen aufgegangen ist, in Mendelssohn weiterlebt.

51 Mendelssohn: Vorrede, in: Phädon. JubA. Bd. 3.1, S. 9; vgl. Mendelssohns „Leben und Charakter des Sokrates“, in: ebd., S. 10-37.

52 Friedländer: Über Mendelssohn, S. 22.

53 Lavater, Johann Caspar: Physiognomische Fragmente, zur Beförderung der Menschenkenntniß und Menschenliebe. Bd. 1. Leipzig, Winterthur 1775, S. 243f. Zit. nach Heinemann, Jeremias (Hrsg.): Moses Mendelssohn. Leipzig 1831, S. V. Heinemann lässt den Schluss des Lavaterschen Zitats natürlich weg: „Ja, ich seh ihn, den Sohn Abrahams, der einst noch mit Plato und Moses - erkennen und anbeten wird, den gekreuzigten Herrn der Herrlichkeit!“. 


\section{Das Zwillingspaar Sokrates und Mendelssohn}

David Friedländer und Jeremias Heinemann transportierten mit dem allegorisch (Kupferstich) und metaphorisch (Sinnspruch) entworfenen Zwillingspaar Sokrates und Mendelssohn Inhalte und Werte, die auf der SokratischMendelssohnschen Tradition und Lehre basieren. Mit der Aktualisierung dieser Philosophie konstituierten sie ein modernes jüdisches Bildungskonzept, das darum bemüht war, das Allgemeine der Menschheit mit dem Besonderen des Judentums zu verknüpfen. So stützte sich die maskilische Lehre, die an der Freischule und innerhalb der Gesellschaft zur Beförderung des Edlen und Schönen sowie später auch an der Heinemannschen Schule zum Tragen kommen sollte, einerseits auf die von Mendelssohn im Phädon entwickelten universalen Religionswahrheiten und zum anderen auf eine partikulare, auf den Lehren des Tanach basierende Sittenlehre.

Noch vor seinem Tod und insbesondere in den Jahren danach, wurde Mendelssohn von denjenigen, die sich in der Sokratisch-Mendelssohnschen Tradition als seine „Schüler" betrachteten, zu einem Ideal stilisiert, dem antike Züge verliehen wurden. ${ }^{54}$ Friedländer spricht sogar davon, dass „Mendelssohns Seele so griechisch schön“ gebildet gewesen sei, und dass er „durch Attische Sitten ${ }^{\text {“55 }} \mathrm{zu}$ überzeugen wusste. Aus Friedländers Sicht gewann mit Mendelssohn nicht nur das Judentum, sondern die gesamte Menschheit ein Beispiel für ethische Vollkommenheit, das die Antike vorzuweisen nicht im Stande war. Mendelssohn wurde so zum ,musterhaften Bild menschlicher Vollkommenheit" schlechthin ${ }^{56}$ sein Konterfei eine Allegorie der Sittlichkeit. Dergestalt gewann er Züge eines klassischen Bildungsideals, dessen umfassende Tugenden zur Voraussetzung für wissenschaftliche Erkenntnisse gemacht wurden. In dieser Sokratisch-Mendelssohnschen Tradition merkte denn auch Heinemann zu seiner Schulprogrammatik an:

54 Vgl. z.B. die Titelkupfer in „Ha-Measef I“ (1783/84) und in der „,Berlinischen Monatsschrift 9“ (1787). Diese Kupfer von Moses Samuel Lowe und Daniel Berger hatten offensichtlich ein Grisaille-Gemälde von Johann Christoph Frisch zur Vorlage, das 1778 entstand; vgl. JubA. Bd. 24, S. 37 u. 82-85. Später entstand auch Lowes Kupferstich „Mendelssohn und Sokrates im Medaillon“ nach dieser Vorlage. Vgl. auch Krochmalnik, Daniel: Moses Mendelssohn und die Sokrates-Bilder des 18. Jahrhunderts, in: Keßler, Herbert (Hrsg.): Das Lächeln des Sokrates. Sokrates-Studien 4. Heitersheim 1999, S. 155-216.

55 Friedländer: Vorlesung bey der erneuerten Todesfeyer Mendelssohns; zit. nach JubA 23, S. 301f.

56 Ebd., S. 298. 
Ohne sittliche Bildung hat alles Wissen kaum halben Werth. Das moralische Gefühl der Kinder [...] zu wecken, ihr Gewissen zu verfeinern, sie für alles Gute und Schöne empfänglich zu machen - ist die erste und heiligste Pflicht der Aeltern und derer, die ihre Stelle vertreten: der Lehrer! ${ }^{57}$

Aus Friedländers Vorlesung, gehalten in der Gesellschaft zur Beförderung des Edlen und Schönen von 1791 zitierend, schrieb Heinemann später in seiner Mendelssohn-Sammlung, man könne

mit Zuversicht sein öffentliches und sein Privatleben, seinen Karakter als Mensch und als Bürger, als Hausvater und als Ehemann, als Lehrer und als Freund, der strengsten Untersuchung unterwerfen: überall werden wir ihn musterhaft, überall gleich groß, gleich liebenswürdig finden. ${ }^{58}$

Neben den Zwillingen Mendelssohn und Sokrates lassen sich in Friedländers unmittelbarem Umfeld zwei weitere Zwillings-Metaphern ausfindig machen. Zum einen bezeichnete er selbst Wahrheit und Schönheit als „Zwillingsschwestern“. ${ }^{59}$ Zum anderen betitelte der Berliner Maskil Isaak Satanow (1732-1804) eine von ihm herausgegebene Neuauflage seines hebräischen Gebetbuchs von 1786 mit Friedländers deutscher Übersetzung nach Hld 7,4 Teomej zevija (1798), in Anlehnung an Mendelssohns Übersetzung „Zwillingspaar der Rehmutter" - eine metaphorische Anspielung auf die Übereinstimmung und Gleichwertigkeit des Originals mit der Übersetzung. ${ }^{60}$ Doch während diese beiden Metaphern die zwei Kinder einer Mutter bezeichnen und als zweieiige Zwillinge das Verschiedene repräsentieren, das sich im Anderssein ergänzt, erscheinen Sokrates und Mendelssohn als eineiiges Zwillingspaar. Sie sind wesensgleich, übereinstimmend in Charakter, philosophischen Grundsätzen, Tu-

57 Heinemann: Grundriß Erziehungs- und Lehr-Anstalt für Knaben, S. 144.

58 Heinemann, Jeremias: Vorrede von August 1830, in: ders.: Moses Mendelssohn, S. VIII.

59 Vgl. Friedländer, David: An mein Bildniß, als ich es, der Verlobten meines Sohnes, an meinem Geburtstage überschickte, in: Berlinisches Archiv der Zeit und ihres Geschmacks II/1 (Februar 1796), S. 187f.: „Die zarte Wahrheit gleicht der Zwillingsschwester, / Der Schönheit“. In diesem Gedicht reagiert Friedländer vermutlich auf Friedrich Schiller, der angekündigt hatte, mit seiner Literaturzeitschrift „Die Horen“, „,die Idee der Bildung durch Wahrheit und Schönheit einem breiteren Publikum“ nahebringen zu wollen. Zit. nach Gall, Lothar: Wilhelm von Humboldt. Ein Preuße von Welt. Berlin 2011, S. 78 .

60 Hohelied 7,4 lautet in der Übersetzung Moses Mendelssohns: „Deiner Brüste Par / Ein junges Rehepar, / Zwillinge einer Mutter“; vgl. JubA. Bd. 10,1, S. 249. Zu den Gebetbuchübersetzungen vgl. Lohmann, Uta: David Friedländer, Isaak Abraham Euchel und die Gebeteübersetzungen in ihrem bildungshistorischen Kontext, in: Aptroot, Marion u.a. (Hrsg.): Isaac Euchel. Der Kulturrevolutionär der jüdischen Aufklärung. Hannover 2010,

S. 105-133.

Ulrike Schneider, Helga Völkening and Daniel Vorpahl - 978-3-653-98812-3 
gendliebe, in ihrem Kampf gegen Vorurteile und Unsittlichkeit, ihrem Streben nach allgemeiner Glückseligkeit - was sie so geschwisterlich verbindet, ist ihre unübersehbare Seelenverwandtschaft. Und dennoch: In der Aktualisierung durch Mendelssohn wird die sokratische Lehre modernisiert und vervollkommnet, die Antike als Bildungsideal überwunden. In seiner Vorrede zum Phädon sagt Mendelssohn selbst, er habe Platons Werk zwar als Vorlage benutzt, jedoch zum Teil starke Veränderungen vorgenommen:

In dem dritten Gespräche mußte ich völlig zu den Neuern meine Zuflucht nehmen, und meinen Sokrates fast wie einen Weltweisen aus dem achtzehnten Jahrhunderte sprechen lassen. Ich wollte lieber einen Anachronismus begehen, als Gründe auslassen, die zur Ueberzeugung etwas beytragen können. ${ }^{61}$

Konnte Sokrates seine Schüler auf den richtigen Weg bringen, so war es erst Mendelssohn, der in den Augen seiner Schüler zum Ziel der Vervollkommnung führte. Und so ist Mendelssohn in Lowes Kupferstich denn auch ein wenig hervorgehoben vor seinem Zwilling Sokrates.

Während Mendelssohns Phädon die Identifikation mit sokratischer Philosophie und humanistischer Ideologie offenbart, bezeichnet die maskilische Sittenlehre aber auch einen Abgrenzungsprozess vom traditionellen Judentum. Bildungsideal war nun nicht mehr der im rabbinischen Schrifttum versierte Talmudstudent (Talmid Chacham), sondern der tugendhafte, sittlich gebildete Mensch, der aus Eigenerkenntnis moralisch handelt und nicht, weil es ihm zur Vorschrift gemacht ist. Der Mensch sollte freiwillig und undogmatisch, allein durch eigenes Nachdenken zur Erkenntnis des Guten gelangen. Wo diese Selbsterkenntnis nicht stattfand, sollte besser alles beim Alten bleiben. Mendelssohn zitierend stellte Friedländer auch in diesem Sinne Mendelssohn mit Sokrates gleich:

Seinem Sokrates gleich, ließ er alle Lehren unangefochten, die bloß theoretisch falsch, aber den Sitten so großen Schaden nicht bringen konnten, als von einer Neuerung zu befürchten war. Er bekannte sich, wie Sokrates, vielmehr öffentlich zu der herrschenden Meynung, beobachtete die darauf gegründeten Cerimonien und Religionsgebräuche, vermied hingegen alle Gelegenheit zu einer entscheidenden Erklärung. ${ }^{62}$

61 Mendelssohn: Vorrede, in: Phädon. JubA. Bd. 3.1, S. 9.

62 Friedländer, David: An die Verehrer, Freunde und Schüler Jerusalem's, Spalding's, Teller's, Herder's und Löffler's. Leipzig 1823, S. 106. In Mendelssohns „Leben und Charakter des Sokrates“ heißt es: „Eine Lehre aber, die bloß theoretisch falsch, und den Sitten so großen Schaden nicht bringen konnte, als von einer Neuerung zu befürchten war, ließ er unangefochten, bekannte sich vielmehr öffentlich zu der herrschenden Meynung, beobachtete die darauf gegründeten Ceremonien und Religionsgebräuche, vermied 
Mit dieser geschwisterlichen Gleichstellung von Sokrates und Mendelssohn konnte letztendlich der eigene Verzicht auf traditionelle Zeremonien und Gebräuche legitimiert werden. Das Zwillingspaar ist somit Ausdruck eines modernen jüdischen Selbstverständnisses, das sich im Konzept allgemeiner Menschenbildung manifestierte.

\section{Quellen und Literatur}

Altmann, Alexander: Die trostvolle Aufklärung. Studien zur Metaphysik und politischen Philosophie Moses Mendelssohns. Stuttgart-Bad Cannstatt 1969, S. 84-108.

Behm, Britta L.: Mendelssohn und die Transformation der jüdischen Erziehung in Berlin. Münster u.a. 2002.

Czok, Claudia: Schadow, Sokrates und das Judentum. Köln 2002.

Fehrs, Jörg H.: Von der Heidereutergasse zum Roseneck. Jüdische Schulen in Berlin 1712 1942. Berlin 1993.

Feiner, Shmuel: Haskala - Jüdische Aufklärung. Geschichte einer kulturellen Revolution. Hildesheim u.a. 2007.

Friedländer, David: An die Verehrer, Freunde und Schüler Jerusalem's, Spalding's, Teller's, Herder's und Löffler's. Leipzig 1823.

Friedländer, David: An mein Bildniß, als ich es, der Verlobten meines Sohnes, an meinem Geburtstage überschickte, in: Berlinisches Archiv der Zeit und ihres Geschmacks II/1 (1796), S. 186-188.

Friedländer, David: Briefe über die Moral des Handelns, geschrieben im Jahr 1785, in: Lesebuch für alle Stände 9 (1790), S. 31-83.

Friedländer, David: Rede, gehalten vor einer Gesellschaft gebildeter Israeliten, in: Jedidja I/1 (1817), S. 38-56.

Friedländer, David: Sendschreiben an Seine Hochwürden, Herrn Oberconsistorialrath und Probst Teller zu Berlin, von einigen Hausvätern jüdischer Religion. Berlin 1799. Neu ediert in: David Friedländer. Ausgewählte Werke. Hrsg. u. eingeleitet v. Uta Lohmann. Köln u.a. 2013, S. 185-212.

Friedländer, David: Sokrates und Mendelssohn. Inschrift zum Titelkupfer des zweiten Jahrgangs dieser Zeitschrift, in: Jedidja III/2 (1820/21), S. 108.

Friedländer, David: Über den besten Gebrauch der h[eiligen] Schrift in pädagogischer Rücksicht, in: Der Prediger. Aus dem Hebräischen von David Friedländer. Berlin 1788, S. 190. Neu ediert in: Lohmann, Uta; Lohmann, Ingrid (Hrsg.): „Lerne Vernunft!“ Jüdische Erziehungsprogramme zwischen Tradition und Modernisierung. Quellentexte aus der Zeit der Haskala, 1760-1811. Münster u.a. 2005, S. 61-81.

Friedländer, David: Über Mendelssohn, seinen Charakter, seinen Wirkungskreis und seine Verdienste um die Israeliten, in: Jedidja II/1 (1818/19), S. 22-31.

hingegen alle Gelegenheit zu einer entschiedenen Erklärung.“, in: Mendelssohn: Phädon, JubA. Bd. 3.1, S. 20. 
Friedländer, David: Vorlesung bey der erneuerten Todesfeyer Mendelssohns, gehalten in der jüdischen Gesellschaft zur Beförderung des Edlen und Schönen, in: Deutsche Monatsschrift. Berlin 1791, S. 217-229. Neu ediert in: JubA. Bd. 23 (1998). S. 296-305.

Friedländer, Michael: Moses Mendelssohn's Leben, in: Jedidja III/1 (1821), S. 226-249.

Hagen, A.: Der Maler und Kupferstecher Lowe, in: Der neuen Preußischen Provinzial-Blätter andere Folge III (1853), S. 317-329.

Heinemann, Jeremias (Hrsg.): Moses Mendelssohn. Sammlung theils noch ungedruckter, theils in andern Schriften zerstreuter Aufsätze und Briefe von ihm, an und über ihn. Leipzig 1831.

Heinemann, Jeremias: Grundriß der Heinemannschen Erziehungs- und Lehr-Anstalt für Knaben, in: Jedidja I/2 (1817), S. 140-163.

Hinske, Norbert; Specht, Rainer: Die Philosophie der deutschen Aufklärung. Stuttgart 1990.

Kennecke, Andreas: HaMe'assef. Die erste moderne Zeitschrift der Juden in Deutschland, in: Schulte, Christoph (Hrsg.): Haskala. Die jüdische Aufklärung in Deutschland 17691812. Wolfenbüttel 1999, S. 176-199.

Krochmalnik, Daniel: Die Lehre von der Unsterblichkeit der Seele in der Religionsphilosophie der Aufklärung, in: Goodman-Thau, Eveline (Hrsg.): Vom Jenseits. Jüdisches Denken in der europäischen Geistesgeschichte. Berlin 1997, S. 79-107.

Krochmalnik, Daniel: Moses Mendelssohn und die Sokrates-Bilder des 18. Jahrhunderts, in: Keßler, Herbert (Hrsg.): Das Lächeln des Sokrates. Heitersheim 1999, S. 155-216.

Leonard, Miriam: Socrates and the Jews. Hellenism and Hebraism from Moses Mendelssohn to Sigmund Freud. Chicago, London 2012.

Lohmann, Ingrid (Hrsg.): Chevrat Chinuch Nearim. Die jüdische Freischule in Berlin (17781825) im Umfeld preußischer Bildungspolitik und jüdischer Kultusreform. Münster u.a. 2001.

Lohmann, Uta: Chevrat Schocharej haTov wehaTuschija (Gesellschaft der Beförderer des Edlen und Guten), in: Motschmann, Uta (Hrsg.): Handbuch der Berliner Vereine und Gesellschaften, 1786-1815. Berlin, München, Boston 2015, S. 827-837.

Lohmann, Uta: David Friedländer, Isaak Abraham Euchel und die Gebeteübersetzungen in ihrem bildungshistorischen Kontext, in: Aptroot, Marion; Kennecke, Andreas; Schulte, Christoph (Hrsg.): Isaac Euchel. Der Kulturrevolutionär der jüdischen Aufklärung. Hannover 2010, S. 105-133.

Lohmann, Uta: David Friedländer. Reformpolitik im Zeichen von Aufklärung und Emanzipation - Kontexte des preußischen Judenedikts vom 11. März 1812. Hannover 2013.

Lohmann, Uta: „Dem Wahrheitsforscher zur Belehrung“. .Die Herausgaben von Moses Mendelssohns Ha-nefesh (1787) und Phädon (1814-1821) durch David Friedländer: Kontexte, Adressaten, Intentionen, in: Mendelssohn-Studien 19 (2015) (in Vorbereitung).

Lohmann, Uta: „Dieser alte Rheinwein mundet nur noch, wie die Philosophie, unseren Veteranen, die von den Realitäten einen anschaulichen Begriff haben“ - David Friedländer und die Berliner Aufklärung, in: Lehnardt, Andreas (Hrsg.): Wein und Judentum. Berlin 2014, S. 207-228.

Lohmann, Uta: „Ein ganz neues Feld der Erkenntniß“ - David Friedländer zur Bedeutung der Ästhetik für die Bibelexegese der Haskala, in: Trumah 16 (2007), S. 49-71.

Lohmann, Uta: In Geselligkeit und Öffentlichkeit zum Nachdenken anregen und über das Judentum aufklären. Biographische Streiflichter auf David Friedländer. Einführung in: 
David Friedländer. Ausgewählte Werke. Hrsg. u. eingeleitet v. Uta Lohmann. Köln u.a. 2013.

Lohmann, Uta: ,Interkulturalität' in der Bildungskonzeption David Friedländers, in: Behm, Britta L.; Lohmann, Uta; Lohmann, Ingrid (Hrsg.): Jüdische Erziehung und aufklärerische Schulreform. Münster u.a. 2002, S. 291-306.

Lohmann, Uta: „Kenntnisse, welche der künftige Staatsbürger bedarf“. David Friedländers Gutachten zur Etablierung moderner jüdischer Schulen in Südpreußen, in: Brocke, Michael; Pomerance, Aubrey; Schatz, Andrea (Hrsg.): Neuer Anbruch. Zur deutschjüdischen Geschichte und Kultur. Berlin 2001, S. 97-112.

Lohmann, Uta: Lessings Einfluss auf David Friedländer - Ideengeschichtliche Hintergründe des Sendschreibens an Propst Teller (1799), in: Kaufmann, Sylke; Siwcyk, Birka (Hrsg.): Lessing und das Judentum im Zeitalter der Aufklärung. Hildesheim u.a. 2015 (in Vorbereitung).

Lohmann, Uta: "Sustenance for the Learned Soul": The History of the Oriental Printing Press at the Publishing House of the Jewish Free School in Berlin, in: Leo Baeck Institute Year Book LI (2006), S. 11-40.

Lowenstein, Steven M.: The Berlin Jewish Community. Enlightenment, Family, and Crisis, 1770-1830. New York, Oxford 1994.

Mendelssohn, Moses: Ha-nefesch. Hrsg. u. mit einer hebräischen Einleitung versehen v. David Friedländer. Berlin 1787.

Mendelssohn, Moses: Phädon oder über die Unsterblichkeit der Seele in drey Gesprächen. Berlin und Stettin 1767. Neu ediert in JubA. Bd. 3.1 (1932/1972). S. 1-159.

Mendelssohn, Moses: Phädon oder über die Unsterblichkeit der Seele. Fünfte Auflage. Hrsg. v. David Friedländer. Berlin 1814.

Moritz, Karl Philipp: Über Moses Mendelssohn. In: Sämtliche Werke. Bd. 11. Hrsg. v. Claudia Stockinger. Berlin, Boston 2013, S. 39.

Pollok, Anne: Facetten des Menschen. Zur Anthropologie Moses Mendelssohns. Hamburg 2010.

Schulte, Christoph: Die jüdische Aufklärung. Philosophie, Religion, Geschichte. München 2002.

Stern, Moritz: Gutachten und Briefe David Friedländers, in: Zeitschrift für die Geschichte der Juden in Deutschland VI (1935), S. 121-125.

Strauss, Leo: Einleitung in: Moses Mendelssohn: Schriften zur Philosophie und Ästhetik III,1. JubA. Bd. 3.1 (1932/1972). S. XIII-XXXIII. 
Ulrike Schneider, Helga Völkening and Daniel Vorpahl - 978-3-653-98812-3

Downloaded from PubFactory at 01/11/2019 10:54:37AM

via free access 


\title{
„Unsere Demokratie soll Ausdruck unserer Brüderlichkeit sein" - Eine theologische Rekonstruktion von Geschwisterlichkeitskonzeptionen in katholischen Ordensgemeinschaften am Beispiel des Ordo Praedicatorum
}

\author{
Ulrich Engel
}

\begin{abstract}
Domingo de Guzman (ca. 1170-1221), founder of the Order of Preachers or Dominican Order (Ordo Praedicatorum), and the first generation of his friars have left to their community a structure of leadership. This special form of leadership is fixed in the Rule of St. Augustin and the Book of Constitutions. The democratic structure of leadership is the main expression of Dominican brotherhood.
\end{abstract}

\section{Einleitung}

Seht doch, wie gut und schön ist es, wenn Brüder miteinander in Eintracht wohnen. (Ps 133,1)

Idealiter praktiziert die Kirche ihre Wahrheitsdiskurse als „Kommunikationsgemeinschaft ${ }^{\text {"1. }}$. Das gilt auch für die katholische Kirche. Organisiert ist dieses kommunikative Kollektiv als Gemeinschaft verschiedener Subjekte. ${ }^{2}$ In biblischer Diktion werden sie als geschwisterliche Gemeinschaften bezeichnet (vgl. Röm 12,10). Zu diesen kommunitären Subjekten der globalen Catholica zählen seit ihren Anfängen im 4. Jahrhundert die Klostergemeinschaften. Ein Teilsubjekt dieser Klostergemeinschaften wiederum ist der Orden der Predigerbrüder. ${ }^{3}$ Was den 1216 gegründeten Dominikaner- oder Predigerorden (Ordo Praedicatorum) von allen anderen katholischen Klostergemeinschaften grundlegend unterscheidet, ist seine demokratische Leitung. ${ }^{4}$

1 Arens, Edmund: Christopraxis. Grundzüge theologischer Handlungstheorie. Freiburg i.Br. 1992, S. 157.

2 Vgl. ebd.

3 Grundlegend vgl. Eggensperger, Thomas; Engel, Ulrich: Dominikanerinnen und Dominikaner. Geschichte und Spiritualität. Kevelaer 2010; Eggensperger, Thomas; Engel, Ulrich: Gemeinschaft im Dialog. Der Dominikanerorden weltweit, in: HerderKorrespondenz 56 (2002), S. 520-524.

4 Vgl. dazu auch Engel, Ulrich: Konsens und Wahrheit. Der Dominikanerorden als praktisch verfasste Kommunikationsgemeinschaft, in: Engel, Ulrich: Gott der Menschen. Wegmarken dominikanischer Theologie. Ostfildern 2010, S. 14-40. 
Meine These, die ich im Folgenden vorstellen werde, lautet: Die demokratisch verfasste Leitungsstruktur des Predigerordens ist Basis und Ausdruck dominikanischer Brüderlichkeit. Ich habe deshalb nicht eine theologische Rekonstruktion von Geschwisterlichkeitskonzeptionen in katholischen Ordensgemeinschaften im Allgemeinen im Sinn, sondern beschränke mich auf eine Männergemeinschaft: die der Dominikaner. Diese Auswahl und Einschränkung begründet sich subjektiv in meiner persönlichen Mitgliedschaft im Dominikanerorden.

Neben einer biblisch-theologischen Fundierung, der historischen Genese und der konkreten Gestalt der demokratischen Verfasstheit gilt es, machtspezifische Problematiken, die in allen - selbst demokratisch verfassten - Institutionen auftreten, aufzuzeigen.

\section{Biblischer Befund}

Insofern alle klösterlichen Lebensformen Modalformen der sequela Christi (Nachfolge Christi) sind, beziehen sich ihre Geschwisterlichkeitskonzeptionen primär auf die biblischen Zeugnisse über das Leben Jesu. Dementsprechend haben meine Überlegungen zur Geschwisterlichkeitsthematik in katholischen Ordensgemeinschaften mit einer knappen Darstellung des biblischen Befundes zu beginnen. $\mathrm{Zu}$ untersuchen ist in diesem Zusammenhang das Vorkommen des Wortfeldes ,Bruder' bzw. ,Brüderlichkeit' im Neuen Testament und seine theologische Interpretation.

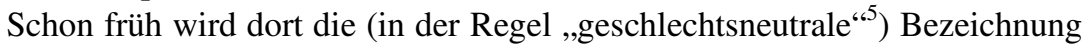
,Bruder' aus dem biologischen Familienzusammenhang gelöst. Speziell in der Perspektive des Markusevangeliums und des Römerbriefes (vgl. bes. Röm 1,3f.) wird damit deutlich, dass nunmehr nicht mehr ,die Ordnung des Fleisches, son-

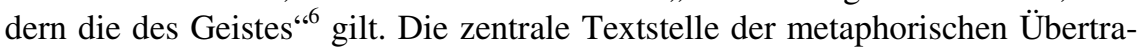
gung des Bruderbegriffs vom Sippenverband auf den Kreis der Jesusanhänger findet sich im Markusevangelium:

Da kamen seine [Jesu] Mutter und seine Brüder; sie blieben vor dem Haus stehen und ließen ihn herausrufen. Es saßen viele Leute um ihn herum und man sagte zu ihm: Deine Mutter und deine Brüder stehen draußen und fragen nach dir. Er erwiderte: Wer ist meine Mutter und wer sind meine Brüder? Und er blickte auf die Menschen, die im Kreis um ihn herumsaßen, und sagte: Das hier sind meine Mutter

5 Söding, Thomas: Art. Bruder. I. Biblisch, in: Lexikon für Theologie und Kirche. Hrsg. v. Walter Kasper. Bd. 2. Freiburg i.Br. u.a. 1994, Sp. 710-711, hier Sp. 710.

6 Ernst, Josef: Das Evangelium nach Markus. Regensburg 1981, S. 124. 
und meine Brüder. Wer den Willen Gottes erfüllt, der ist für mich Bruder und Schwester und Mutter. (Mk 3,31-35 parr $^{7}$ )

Ihren theologischen Kontext hat die Begriffsverschiebung in der neutestament-

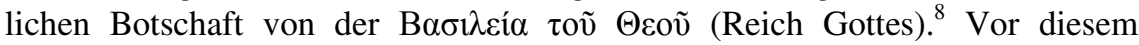
Hintergrund kann mit einiger Wahrscheinlichkeit davon ausgegangen werden, dass die im Markusevangelium tradierte Neubestimmung eines nichtbiologischen Brüderlichkeitsbegriffs ,im Keim auf Jesus selbst zurückgehen“9 dürfte. Die urchristliche Verwendung des Bruderbegriffs zielt also auf die Mitglieder

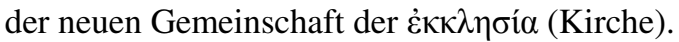

Dem aus dem familiären Verwandschaftskontext geerbten theologischen Begriff ,Bruder' kommt im neuen Ekklesia-Zusammenhang ,repräsentative Bedeutung ${ }^{\text {“10 }} \mathrm{zu}$, insofern er ein Dreifaches markiert: 1. den engen Zusammenhalt der Gemeindemitglieder untereinander, auch in schwierigen Situationen (vor allem der Christenverfolgung) (vgl. Mk 10,30), 2. die Würde der einzelnen Jesusjünger_innen, die nicht mehr im Status des abhängigen „Sklaven“, sondern im freien „Bruder"-Status leben (vgl. Phlm 1,16), sowie 3. ihre grundsätzliche Egalität vor Gott (vgl. Mt 23,8-12). Zur Konsequenz hat dieser theologisch dreifach aufgeladene Bruder-Begriff die Aufforderung zur Praxis der Bruderliebe innerhalb der Gemeinde (vgl. z.B. 1 Thess 4,9f.). Dem korrespondiert die in Mk 3,35 angeführte praktische Bedingung, unter der die neue Geschwisterlichkeitskonzeption Wirklichkeit wird: „Wer den Willen Gottes erfüllt [...]“.

Neben dieser im Markusevangelium als ältestem Evangelium ansetzenden Bestimmung eines postbiologischen Bruderbegriffs sei zumindest noch kurz die - etwas anders argumentierende - paulinische Geschwisterlichkeitskonzeption erwähnt. ${ }^{11}$ Im Römerbrief begründet Paulus den Status der Glaubenden als Brüder im eschatologischen Heilswillen Gottes:

[...] alle, die er [Gott] im voraus erkannt hat, hat er auch im voraus dazu bestimmt, an Wesen und Gestalt seines Sohnes teilzuhaben, damit dieser der Erstgeborene von vielen Brüdern sei. (Röm 8,29 ${ }^{12}$ ).

Die Brüderschaft ist also nicht nur eine der Glaubenden untereinander, sondern schließt auch Jesus als den Christus ein. Die Argumentation erfolgt dabei über

7 Hier und im Folgenden zitiert nach: Die Bibel. Altes und Neues Testament. Einheitsübersetzung. Stuttgart, Klosterneuburg 1980.

8 Vgl. Merklein, Helmut: Jesu Botschaft von der Gottesherrschaft. Stuttgart 1989.

9 Söding: Bruder, Sp. 710.

10 Ernst: Evangelium nach Markus, S. 124.

11 Vgl. dazu Schäfer, Klaus: Gemeinde als Bruderschaft. Ein Beitrag zum Kirchenverständnis des Paulus. Frankfurt/Main 1989.

12 Einfügung in eckiger Klammer: U.E.

Ulrike Schneider, Helga Völkening and Daniel Vorpahl - 978-3-653-98812-3 
die allen gemeinsame Sohn- bzw. Kindschaft Gottes (vgl. Röm 8,3.1416.19.21.23.29.32), wobei Jesus Christus als Gottes eigener Sohn und die Gläubigen ,als seine [Jesu Christi] der ,Adoption“ [...] gewürdigten ,Brüder $(8,29)^{\text {“13 }}$ vorgestellt werden.

Die hier knapp skizzierte neutestamentliche Brüderlichkeitskonzeption gilt zunächst einmal für alle Christen. In besonderer Weise jedoch wurde das Motiv der nicht-biologischen Geschwisterlichkeit im Mönchtum bzw. im kirchlichen Ordenswesen ausgefaltet. ${ }^{14}$ Diese Entwicklung rekurriert wiederum auf den markinischen Makrozusammenhang. In Mk 10,29f. findet sich der Aufruf, zugunsten der Nachfolge die eigenen Familienmitglieder zu verlassen:

Jesus antwortete: Amen, ich sage euch: Jeder, der um meinetwillen und um des Evangeliums willen Haus oder Brüder, Schwestern, Mutter, Vater, Kinder oder Äcker verlassen hat, wird das Hundertfache dafür empfangen $[\ldots] .{ }^{15}$

In der im Professversprechen vollzogenen Lebensübergabe an Gott ${ }^{16}$ und in den Evangelischen Räten der Armut, des Gehorsams und der ehelosen Keuschheit ${ }^{17}$ hat die Tradition des Ordenslebens dieser biblischen Aufforderung Gestalt gegeben - eine Gestalt, die bis zum heutigen Tag das sogenannte gottgeweihte Leben prägt. Die dominikanische Weise der sequela Christi, um die es im Folgenden gehen soll, stellt ein Nachfolgemodell unter vielen historisch gewordenen und theologisch denkbaren dar. Es soll im folgen Abschnitt in seiner Genese kurz vorgestellt werden.

\section{Rückblick in die Anfänge des Dominikanerordens}

$\mathrm{Zu}$ Beginn des 13. Jahrhunderts wurde die von Dominikus gegründete Gemeinschaft von kirchenamtlicher Seite mit der praedicatio, der Glaubensverkündigung, beauftragt. Der Anerkennung durch den Ortsbischof von Toulouse im

13 Theobald, Michael: Der Römerbrief. Darmstadt 2000, S. 245. Einfügung in eckiger Klammer: U.E.

14 Überraschenderweise weist eine ansonsten sehr grundständige Publikation keinen Eintrag zum Thema Brüderlichkeit bzw. Geschwisterlichkeit auf: Frank, Isnard W.: Lexikon des Mönchtums und der Orden. Stuttgart 2005.

15 Vgl. Gnilka, Joachim: Das Evangelium nach Markus (Mk 1-8,26). Zürich u.a. 1998, S. 153.

16 Vgl. dazu Kiechle, Stefan: Consecratio - Communio - Missio. Die drei Grundelemente des Ordenslebens, in: Gruber, Margareta; Kiechle, Stefan (Hrsg.). Gottesfreundschaft. Ordensleben heute denken. Würzburg 2007, S. 51-71.

17 Vgl. dazu Metz, Johann Baptist: Zeit der Orden? Zur Mystik und Politik der Nachfolge. Freiburg i.Br. 1982; Herzig, Anneliese: In der Spur Jesu. Leben nach den Evangelischen Räten. Innsbruck 2012.

Ulrike Schneider, Helga Völkening and Daniel Vorpahl - 978-3-653-98812-3 
Jahre 1215 folgte schon 1216 die päpstliche Bestätigung durch Papst Honorius III. als Orden (durch die Bulle Religiosam vitam vom 22.12.1216) sowie nur wenige Wochen später - ebenfalls durch Honorius III. - als „Orden von Predigern“ (durch die Bulle Gratiarum omnium largitori vom 21.01.1217). ${ }^{18}$ Mit diesen Entscheidungen war dem bis dato existenten Ordo praedicatorum, den das Kollegium der Bischöfe bildete, von den entscheidenden kirchlichen Instanzen offiziell akzeptiert, ein zweiter, nun ganz neuer Ordo Praedicatorum zur Seite gestellt. $^{19}$

Wenn im Folgenden von der demokratischen Verfassung des Dominikanerordens die Rede ist, dann macht der skizzierte historische Hintergrund deutlich, dass es sich keineswegs um oppositionelle Entwicklungen jenseits der Grenzen der umfassenden Catholica handelt, sondern um ein Partizipationsmodell innerhalb der katholischen Kirche. ${ }^{20}$

Der Ordensgründer Domingo de Guzman (ca. 1170-1221) - der hl. Dominikus - hat keinerlei spirituelle Anweisungen in schriftlicher Form hinterlassen: keine Predigten und keine theologischen Traktate, Briefe oder andere Texte. Stattdessen haben Dominikus und die erste Brüdergeneration dem Orden eine Leitungsform vererbt. Sie ist niedergelegt in der schon älteren Augustinusregel sowie im Liber Constitutionum et Ordinationum Fratrum Ordinis Praedicatorum (LCO), dem Buch der Konstitutionen und Ordinationen, auf das (neben der Augustinusregel) alle Dominikaner ihr Professversprechen ablegen.

Von Anfang an waren die Predigerbrüder daran interessiert, nicht die feudalen Strukturen der altehrwürdigen Abteien zu übernehmen. Stattdessen orientierten sie sich am demokratisch-genossenschaftlichen Gefüge der aufstrebenden mittelalterlichen Städte, in deren Mauern zu jener Zeit Universitäten und Zünfte mit der ihnen charakteristischen Selbstverwaltung entstanden. ${ }^{21}$

Entscheidend für die strukturelle Ausgestaltung des Predigerordens war Jordan von Sachsen (ca. 1185-1237), der Nachfolger des Dominikus an der

18 Zur Entstehungsgeschichte des Ordens vgl. Eggensperger; Engel: Dominikanerinnen und Dominikaner, S. 13-28.

19 Vgl. Merten, Manuel: „Wenn alle Macht vom Volk ausgeht ...“. Die demokratische Verfassung des Dominikanerordens als Alternative in einer hierarchisch verfaßten Kirche. Köln [Manuskriptdruck] o.J. [1995], S. 12f.

20 Vgl. dazu grundlegend Eggensperger, Thomas: Orden - Gemeinschaften kritischer Solidarität in der Kirche? Betrachtungen unter ekklesiologischer Perspektive, in: Ordenskorrespondenz 37 (1996), S. 166-176.

21 Vgl. Bauer, Christian: Stadtluft macht frei? Mittelalterliche Stadtpastoral der Bettelorden, in: Wort und Antwort 53 (2012), S. 149-154. 
Spitze der dominikanischen Brüdergemeinschaft. ${ }^{22}$ Die Jahre seiner Amtszeit sollten zu entscheidenden Jahren für den Orden werden; die Gemeinschaft wuchs erheblich an, die Struktur weitete sich immer mehr aus. Es ist das große Verdienst Jordans, den Weg der - um mit Max Weber zu sprechen - ,institutionellen Wendung des Charismas“ ${ }^{\text {“23 }}$ einer kleinen Gruppe „religiöse[r] Virtuo$\mathrm{se}[\mathrm{n}]^{\text {“24 }}$ in Angriff genommen zu haben. Vor allen Dingen das Generalkapitel von 1228 war für den Orden, was seine rechtliche Verfassung anbetrifft, von zentraler Bedeutung.

Wie sieht nun diese Leitungsstruktur im Ordo Praedicatorum aus und wie funktioniert sie (bis heute)?

\section{Zur Gestalt dominikanischer Leitung}

Mit der Profess verspricht der Dominikaner Gehorsam gegenüber der Augustinusregel und dem Buch der Konstitutionen und Ordinationen. ${ }^{25}$ Im zweiten Abschnitt von LCO werden die Leitung und das ausgefeilte Wahlsystem behandelt. Hier offenbart sich die genuine Verfassungsordnung der Dominikaner, welche der Demokratie den Vorrang vor einsamen Entscheidungen übergeordneter Instanzen zuerkennt. Alle Brüder mit feierlicher Profess haben grundsätzlich aktives Wahlrecht. Das heißt, sie dürfen bei allen berechtigten Wahlvorgängen ihre Stimme abgeben. Um als Oberer gewählt werden zu können, braucht es zusätzlich das passive Wahlrecht.

Die Brüder des Predigerordens leben in der Regel gemeinsam in Häusern, die ab einer bestimmten zahlenmäßigen Besetzung als ,Konvente' (Versammlungen der Brüdergemeinschaft; lat. von convenire = zusammenkommen) bezeichnet werden. Der Hausobere wird ,Prior' (Erster) genannt und von den Mitgliedern der Kommunität mit Mehrheit auf drei Jahre gewählt. Alle Leitungsämter im Predigerorden sind auf Zeit verliehen. Auf diese Weise soll das Entstehen einer „Oberenkaste“ ${ }^{\text {26 }}$ ausgeschlossen werden, denn Leitung ist

22 Vgl. dazu Jordan von Sachsen: Von den Anfängen des Predigerordens. Hrsg. v. Wolfram Hoyer. Leipzig 2003.

23 Weber, Max: Wirtschaft und Gesellschaft. Grundriss der verstehenden Soziologie. Neu Isenburg 2005, S. 857f.

24 Weber, Max: Die protestantische Ethik und der Geist des Kapitalismus. Vollständige Ausgabe. Hrsg. u. eingel. v. Dirk Kaesler. München 2010, S. 152.

25 Der folgende Abschnitt orientiert sich an Eggensperger; Engel: Dominikanerinnen und Dominikaner, S. 163-169. Vgl. auch Engel, Ulrich: Zur demokratischen Verfassung des Dominikanerordens, in: Schweizerische Kirchenzeitung 166 (1998), S. 474-477 (Nr. 3334).

26 Radcliffe, Timothy: Gemeinschaft im Dialog. Ermutigung zum Ordensleben. Hrsg. v. Thomas Eggensperger u. Ulrich Engel. Leipzig 2001, S. 160. 
„geteilte Verantwortung aller Brüder“27. Der Hausobere kann für eine zweite Amtszeit wiedergewählt werden, eine dritte Periode ist nicht vorgesehen. Erst wenn sich ein Konvent nicht mehrheitlich auf einen Kandidaten einigen kann, ist die nächsthöhere Ebene verpflichtet, einen Oberen einzusetzen.

Die Konventsmitglieder mit aktivem Wahlrecht bilden das Hauskapitel. Dort trifft man sich, „um Fragen zu besprechen bzw. zu entscheiden, die sich auf das gemeinsame Leben, die apostolische Tätigkeit und schließlich die gute Verwaltung des Konventes beziehen. “28

Alle Konvente und Häuser sind in größeren Entitäten, ,Provinzen' genannt, organisiert. Alle vier Jahre findet in jeder Provinz ein Provinzkapitel statt. Alle Prioren und eine bestimmte Anzahl von gewählten Delegierten (Socii) aus den Konventen versammeln sich dabei für einige Tage. Dem Provinzkapitel kommt eine doppelte Aufgabe zu: Zum einen hat es über Fragen des gemeinsamen Lebens und Arbeitens zu beraten. Dazu etablieren sich in den Monaten vor dem Kapitel mehrere (ihrerseits wiederum demokratisch gewählte) Kommissionen und Arbeitsgruppen, die für das Kapitel Diskussionsvorlagen erarbeiten. Zum zweiten wählt das Provinzkapitel einen neuen Provinzial (Prior provincialis), eine Gruppe von ,Diffinitores ‘ und die Mitglieder eines Beratungsgremiums des Provinzials (,Provinzkonsil'). Die Ergebnisse des Provinzkapitels werden in den Kapitelsakten veröffentlicht. Die Akten spiegeln das rechtlich bindende Ergebnis des Provinzkapitels wider. Ersichtlich sind in den Akten aber auch bestimmte Personalentscheidungen. Außerdem setzen sich die Texte mit grundsätzlichen Fragen auseinander und versuchen dabei, strukturelle und inhaltliche Leitlinien für die vier kommenden Jahre zu entwerfen.

Die allen Provinzen übergeordnete Einrichtung ist das Generalkapitel, welches alle drei Jahre zusammentritt. Ihm kommen - auf den Gesamtorden bezogen - in etwa die gleichen Aufgaben zu wie dem Provinzkapitel. Das Generalkapitel hat sowohl legislative als auch exekutive Funktionen. Abgesehen von der Teilnahme des Ordensmeisters und seiner noch lebenden Vorgänger ändert sich die personelle Besetzung der Kapitel von Mal zu Mal. So gibt es ein Kapitel, auf dem ausschließlich die Provinziale anwesend sind. Ein weiteres Kapitel besteht nur aus gewählten Vertretern aller Provinzen. Das dritte schließlich ist das sogenannte Wahlkapitel, an dem sowohl die Provinziale als auch gewählte Vertreter der Provinzen teilnehmen. Das Wahlkapitel wählt den neuen Magister Ordinis (Ordensmeister), der sein Amt neun Jahre innehat. Ein interessantes Detail: Der Magister Ordinis der Dominikaner ist der einzige Generalobere eines

27 Ebd.

28 LCO 307.

Ulrike Schneider, Helga Völkening and Daniel Vorpahl - 978-3-653-98812-3 
katholischen Männerordens, dessen Wahl nicht durch den Vatikan bestätigt werden muss.

\section{„Unsere Demokratie soll Ausdruck unserer Brüderlichkeit sein“}

Die demokratisch verfasste Leitungsstruktur ist Basis und Ausdruck dominikanischer Brüderlichkeit. Sie ermöglicht der Gemeinschaft, die Verantwortung für ihr Leben gemeinsam zu tragen. In dieser Linie weisen die Konstitutionen darauf hin, dass die Brüder zuallererst eine Gemeinschaft bilden, um zusammen und auf Gott bezogen zu leben. ${ }^{29}$ Darüber hinaus zielt die Rechtsordnung des Ordens darauf, den dominikanischen Sendungsauftrag „für das Heil der Menschen“ - das „,salus animarum“, wie es in LCO 1 § II heißt, - zu realisieren. Der demokratische Entscheidungsprozess im Dominikanerorden dient der apostolischen bzw. pastoralen Sendung des Ordens. Entsprechend heißt es in der Fundamentalkonstitution der Dominikaner ausdrücklich:

Diese gemeinschaftliche Leitung ist gut geeignet zur Förderung der Entwicklung des Ordens und zu seiner ständigen Selbstprüfung [...]. Diese ständige Selbstprüfung ist nicht nur notwendig wegen der dauernden Bekehrungshaltung des Christen, sondern auch wegen der dem Orden eigenen Berufung, die ihn dazu bewegt, seine Präsenz in der Welt in jeder Generation anzupassen. ${ }^{30}$

Die Brüderlichkeitskonzeption in der Tradition des Predigerordens ist also zweifach ausgerichtet: ad intra in Bezug auf das gemeinschaftliche Leben der Ordensmitglieder untereinander, und ad extra in Bezug auf die gemeinsame pastorale und wissenschaftliche Sendung. In diesem bipolaren Sinne ist dann auch das Titel gebende Zitat von Timothy Radcliffe, von 1992 bis 2001 Magister Ordinis der Dominikaner, zu lesen: „Unsere Demokratie soll Ausdruck unserer Brüderlichkeit sein ${ }^{\star 31}$.

Mitglied der brüderlichen Gemeinschaft zu sein, bedeutet im Dominikanerorden vor allem, Sitz und Stimme im Kapitel zu haben. Gleichwohl meint Demokratie im Predigerorden - theologisch gesehen ${ }^{32}$ - mehr als nur das Organisieren von Mehrheiten. Das Ziel der Gespräche und Diskussionen im Kapitel ist, in der Gemeinschaft Einstimmigkeit zu erreichen. Das ist allerdings faktisch nicht immer möglich. Daher kommt man am Ende durch Abstimmung zu einer Entscheidung. In diesem Sinne gehören Abstimmungen und Debatten gleicher-

29 Vgl. LCO 2,1

30 Vgl. LCO 1,7

31 Radcliffe: Gemeinschaft im Dialog, S. 154.

32 Vgl. Engel: Konsens und Wahrheit, S. 14-40.

Ulrike Schneider, Helga Völkening and Daniel Vorpahl - 978-3-653-98812-3 
maßen zu einem Prozess, durch den die Brüder ein bonum commune anstreben. Radcliffe schreibt dazu:

Daraus folgt, dass das Ergebnis einer Abstimmung die Entscheidung der ganzen Gemeinschaft darstellt, und nicht nur der derjenigen, die dafür gestimmt haben. Es ist die Gemeinschaft, die sich zu einer Entscheidung durchgerungen hat. Ich kann so frei sein, diesem Ergebnis nicht zuzustimmen, und mich sogar für seine Aufhebung einsetzen, aber ich gebe meiner Identität als Mitglied der Gemeinschaft dadurch Ausdruck, indem ich die Entscheidung befolge. Dem einfachen Mehrheitsvotum zu vertrauen, war eine der tiefsten Neuerungen in der dominikanischen Tradition. ${ }^{33}$

Das gilt auch für die Wahl der Oberen der Gemeinschaft. Radcliffe formuliert SO:

Ein Oberer wird zum Dienst an allen Brüdern gewählt, d.h. für das Gemeingut des Ordens. Seine Wahl ist das Ergebnis einer Abstimmung, die „wir“ vorgenommen haben, unabhängig davon, für wen wir abgestimmt haben. Und in dem Augenblick, in dem er gewählt ist, braucht er die Unterstützung der ganzen Gemeinschaft, denn wir haben ihn gewählt, unabhängig, wie ich persönlich abgestimmt habe. ${ }^{34}$

Demokratie im Predigerorden impliziert - theologisch gesprochen - immer auch das Entdecken des Willens Gottes im Diskussionsbeitrag des Bruders: „Unsere Demokratie ist nur so lange dominikanisch, solange unsere Debatten und Abstimmungen Versuche sind, das Wort Gottes zu hören, das uns in die Nachfolge ruft. ${ }^{\text {(35 }}$

Das Buch der Konstitutionen und Ordinationen des Ordo Praedicatorum identifiziert den Grund der brüderlichen Gemeinschaft so: ,in Einigkeit zusammenzuleben und ein Herz und eine Seele auf Gott hin zu haben“36. Die hier verwendete Formulierung zitiert das Verhalten der urchristlichen Gemeinde gemäß dem lukanischen Doppelwerk, hier konkret nach Apg 4,32 ${ }^{37}$ : „Die Gemeinde der Gläubigen war ein Herz und eine Seele. Keiner nannte etwas von dem, was er hatte, sein Eigentum, sondern sie hatten alles gemeinsam. ${ }^{\text {‘38 }}$ In der Charakterisierung der brüderlichen Dominikanergemeinschaft als ein Herz und

33 Radcliffe: Gemeinschaft im Dialog, S. 156; vgl. dazu auch Tugwell, Simon: Dominican Risks, in: Dominican Ashram December 1983, S. 182.

34 Radcliffe: Gemeinschaft im Dialog, S. 157.

35 Ebd., S. 141.

36 LCO 2,1:,,[...] ut unanimes habitemus in domo et sit nobis anima una et cor unum in Deo“.

37 Zum ersttestamentlichen Hintergrund vgl. Dtn 6,5; 10,12; 11,13.18; 13,4 u.ö.

38 Zum exegetischen Befund vgl. den Kommentar von Pesch, Rudolf: Die Apostelgeschichte (Apg 1-12). Zürich u.a. 1986, S. 179-182. 
eine Seele spiegelt sich deutlich die urkirchliche ausgerichtete Reformintention der mittelalterlichen Ordensgründung durch Domingo de Guzman wider. ${ }^{39}$

Der Beginn jeder guten Leitung im Dominikanerorden markiert im Sinne einer „Mystik der offenen Augen“40 eine doppelte Aufmerksamkeit: zum einen im gemeinsamen Wahrnehmen des biblisch überlieferten Wort Gottes, zum anderen in der gemeinsamen Aufmerksamkeit den Nöten der Menschen gegenüber. In einem Segensgebet aus dem 13. Jahrhundert baten die Predigerbrüder den Heiligen Geist,

uns zu erleuchten und uns Augen zu geben, mit denen wir sehen können, Ohren zum Hören und Hände, um das Werk Gottes zu vollbringen, einen Mund für die Predigt der rettenden Botschaft und den Engel des Friedens, der über uns wachen und uns führen soll, damit wir durch alle diese Gaben in Gottes Königreich einziehen wer$\operatorname{den}^{41}$.

Deutlich wird nach diesem Durchgang, dass die oben im Blick auf das biblischmarkinische Zeugnis nachgezeichnete spirituelle Beerbung des biologischen Familienbegriffs gerade hinsichtlich der drei dort genannten Aspekte der theologischen Brüderlichkeitskonzeption bei den Dominikanern wiederkehrt: 1. der Zusammenhalt der Mitglieder der klösterlichen Gemeinschaft nach innen, 2. der Status des einzelnen Bruders als freies, verantwortlich agierendes Individuum mit Wahlrecht und 3. ihre grundlegende Gleichheit vor Gott, die sich nicht zuletzt darin ausdrückt, dass in jedem Wort eines Bruders potenziell das Wort Gottes vernommen werden kann. Und ähnlich wie im biblischen Befund taucht auch im Rahmen der demokratisch organisieren Ordenskommunität die postbiologische Bruderliebe wieder auf, und das gleich zweifach: ad intra in Gestalt einer Gemeinschaft, die - zumindest idealiter - ein Herz und eine Seele ist, und ad extra in der Predigt für das ,salus animarum“, das Heil aller Menschen. Letzteres beinhaltet, dass die dominikanische Brüderlichkeit resp. Geschwisterlichkeit ,auch eine Modalität der Evangelisierung ““42 ausdrückt.

39 Vgl. Grundmann, Herbert: Religiöse Bewegungen im Mittelalter. Untersuchungen über die geschichtlichen Zusammenhänge zwischen der Ketzerei, den Bettelorden und der religiösen Frauenbewegung im 12. und 13. Jahrhundert und über die geschichtlichen Grundlagen der Deutschen Mystik. Darmstadt 1977.

40 Metz, Johann Baptist: Mystik der offenen Augen. Wenn Spiritualität aufbricht. Freiburg i.Br. 2011.

41 A Dominican Blessing, in: Tugwell, Simon (Hrsg.): Early Dominicans. Selected Writings. New York 1982, S. 153.

42 Cadoré, Bruno: Die dominikanischen Laien und die Verkündigung, in: Eggensperger, Thomas; Engel, Ulrich (Hrsg.): Dominikanische Predigt. Leipzig 2014, S. 100-118, hier S. 103. 


\section{Brïderlichkeit/Geschwisterlichkeit in Machtbeziehungen}

Damit die Ausführungen nicht spirituell ,abheben', möchte ich meine These noch ein wenig ,erden'. Dazu ist die Machtfrage zu thematisieren. Die weitgehende Egalität der Brüder durch Stimmrecht des Einzelnen im Provinzkapitel sowie das Prinzip der stets nur auf Zeit verliehenen faktischen Macht kann auftretende Machtasymmetrien zwar abfedern und bietet somit einen gewissen systemimmanenten Schutz vor Machtmissbrauch, allerding können damit aber keineswegs einzelne Übergriffe ausgeschlossen werden.

Ich thematisiere die Machtfrage im Zusammenhang mit der dominikanischen Geschwisterlichkeitskonzeption in zweierlei Hinsicht: im Blick auf die Genderthematik im Gesamtorden (1.) und im Blick auf den Umgang mit dem Phänomen der Homosexualität in der Brüdergemeinschaft (2.).

1. Neben den Brüdern, von denen bisher die Rede war (ca. 5.500 weltweit), umfasst die dominikanische Gemeinschaft im Ganzen noch weitere Gruppen. Zu nennen sind die ca. 2.500 klausurierten Dominikanerinnen (Moniales), die über 25.000 Schwestern in weit mehr als einhundert dominikanischen Kongregationen und Gemeinschaften sowie die ca. 144.000 Männer und Frauen, die sich in den sogenannten „Dominikanischen Gemeinschaften“ der Laien organisiert haben. ${ }^{43}$ Die dominikanische Nomenklatur kennt eine Fülle von Bildern bzw. Bezeichnungen, die dem Miteinander der verschiedenen Zweige Ausdruck verleihen und somit den Orden ad intra ekklesiologisch definieren. In unserem Zusammenhang sind zwei Metaphern zentral: die der Geschwisterlichkeit als Zuordnungsbeschreibung der diversen Gruppen im Gesamtorden und - daraus abgeleitet - die Rede von der Familia Dominicana. ${ }^{44}$ Hier ist der Familienbegriff natürlich ein nicht-biologischer und metaphorisch intendiert.

Trotz dieser (relativ jungen) Inklusion anzielenden Begrifflichkeit ist ein gleichberechtigtes Miteinander von Frauen und Männern innerhalb des Ordens längst (noch) nicht überall selbstverständlich. Das ist zum einen der grundlegenden Genderproblematik im Gesamt der katholischen Kirche geschuldet. Die Nichtzulassung von Frauen zum Priesteramt und damit ihr faktischer Ausschluss aus einflussreichen Leitungspositionen in Rom und vor Ort hat auch Ungleichheiten im Gesamt der Familia Dominicana zur Folge. Keine noch so ernst gemeinte Geschwisterlichkeitsrhetorik kann die im wichtigen Bereich der katho-

43 Die Zahlen sind grob gerundet. Genauere - allerdings ältere (Stand 2008) - Angaben finden sich bei Eggensperger; Engel: Dominikanerinnen und Dominikaner, S. $215 f$.

44 Vgl. hierzu Engel, Ulrich: Charismatisch und katholisch. Zur ekklesiologischen Ortsbestimmung des Dominikanerordens, in: Eggensperger, Thomas; Engel, Ulrich; Oosterveen, Leo (Hrsg.). Kirche in Bewegung. Deutsch-niederländische Reflexionen zur Ekklesiologie aus dominikanischer Sicht. Münster 2007, S. 77-82. 
lischen Ämtertheologie gründende Machtasymmetrie zwischen Männern und Frauen ganz allgemein und damit auch zwischen Brüdern und Schwestern im Ordo Praedicatorum verdecken. Dies gilt vor allem im Bezug auf die kirchenamtliche Zulassung zur Predigt im engeren Sinne, die bis heute Frauen versagt wird. ${ }^{45}$ Konkrete Konsequenzen eines gleichberechtigten Miteinanders von Frauen und Männern innerhalb der Familia Dominicana ,sind noch kaum gezogen, das Modell einer geschwisterlichen Kirche, eines geschwisterlichpartnerschaftlichen Ordens, einer geschwisterlichen Verkündigung noch kaum realisiert" ${ }^{* 46}$. Vor diesem Hintergrund steht die theologische Geschwisterlichkeitsrhetorik immer im Verdacht, real existierende Machtasymmetrien ideologisch zu überhöhen. Dieser Verdacht muss eine Ordensgemeinschaft, die sich seit nunmehr fast 800 Jahren der Predigt der veritas (Wahrheit) verschrieben hat, ins Mark treffen. ${ }^{47}$ Mehr noch: In Anbetracht meiner Grundthese, nach der das demokratisch verfasste Miteinander die Geschwisterlichkeit im Ordo Praedicatorum erst konstituiert und qualifiziert, braucht es unbedingt so etwas wie ein dominikanisches ,Gender Mainstreaming'. Umgekehrt gilt aber auch, dass eine konsequent praktizierte demokratische Leitungsstruktur vor Abhängigkeitsbeziehungen und Machtmissbrauch im Orden schützen kann.

2. In den Machtzusammenhang gehört selbstredend auch der Umgang mit Sexualität, speziell mit dem Phänomen der Homosexualität in männlichen Ordensgemeinschaften. Vorsichtige Schätzungen besagen, dass etwa 20 Prozent aller Geistlichen der katholischen Kirche homosexuell sind und etwa die Hälfte von diesen auch sexuell aktiv ist. Genaue Zahlen gibt es nicht. ${ }^{48}$ Problematisch ist dieser Befund nur, insofern die oft nicht offen thematisierte Frage der Homosexualität zu Abhängigkeitsbeziehungen führen kann.

Denn Macht ist immer zwiespältig. Macht als potestas beruht auf einer prinzipiellen Asymmetrie, insofern sie ,innerhalb einer sozialen Beziehung den

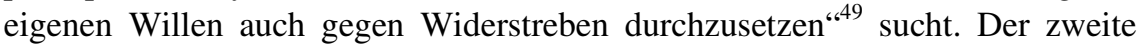
Machttypus, die auctoritas, funktioniert anders: Autorität beruht auf einem Ver-

45 Vgl. kritisch dazu Hilkert, Mary Catherine u.a.: Das dominikanische Predigtcharisma. Eine Untersuchung, in: Eggensperger, Thomas; Engel, Ulrich (Hrsg.): Dominikanische Predigt. Leipzig 2014, S. 135-154.

46 Hintersberger, Benedikta: Maria von Magdala. Patronin des Dominikanerordens, in: Eggensperger; Engel (Hrsg.): Dominikanische Predigt, S. 250-255.

47 Vgl. dazu Vergauwen, Guido: Predigt der Wahrheit, in: ebd., S. 47-52; Eggensperger, Thomas; Engel, Ulrich (Hrsg.): Wahrheit. Recherchen zwischen Hochscholastik und Postmoderne. Mainz 1995.

48 Vgl. dazu immer noch lesenswert Heinz, Hanspeter: Homosexualität und geistliche Berufe, in: Stimmen der Zeit 214 (1996), S. 681-692.

49 Weber: Wirtschaft und Gesellschaft, S. 38. 
hältnis freier und gegenseitiger Anerkennung. Good governance im Dominikanerorden bedeutet, dass Machtfragen nicht tabuisiert, sondern - im Gegenteil thematisiert werden. Die Beziehungs- und Pastoralmacht, die Ordensbrüder mit auctoritas ausüben, zielt auf die De-Potenzierung asymmetrischer Machtbeziehungen: ad intra und ad extra. Das ist das absolute Gegenteil zu Abhängigkeitsverhältnissen und missbräuchlichen Übergriffen.

Machtmissbrauch hat seinen Ort dort, wo Beziehungen nicht geklärt und daraus resultierende Konflikte nicht thematisiert werden. Nun werden aber gerade in der katholischen Kirche das Thema (Homo-)Sexualität und zugespitzter noch homosexuelle Beziehungen bzw. Praktiken immer noch weitgehend tabuisiert. Dagegen gilt es - gerade für Dominikaner - das offene Wort, das ehrliche Gespräch, den demokratischen Diskurs zu stärken, soll nicht die Tabuisierung weiterhin neue Opfer produzieren. Die Opfer (lateinisch: victimae) des kollektiven Verschweigens erinnern uns an - um Georges Bataille zu zitieren - den „verschämten Teil“ (,part maudite“) unserer selbst. ${ }^{50}$ Nur wo Ordensmänner in dieser Weise selbstkritisch ihre Praktiken der Tabuisierung erkennen und ihr (sexuelles) Begehren gemeinsam anzusprechen lernen, kann das real existierende Machtgefüge auch innerhalb der klösterlichen Gemeinschaften für ein wirkliches Empowerment der Brüder genutzt werden. Dazu bedarf es eines Engagements der gesamten Gemeinschaft, welches die demokratische Verfasstheit nicht als Mittel für ein möglichst reibungsloses Funktionieren, sondern als diskursive Chance zur ehrlichen Realisierung des biblischen Ideals der Geschwisterlichkeit als Ausdruck der eigenen sequela Christi begreift. Andernfalls scheitert die brüderliche Gemeinschaft an der Machtfrage. Die Inquisition, für die Dominikaner wesentlich Verantwortung tragen, ${ }^{51}$ steht für ein solches individuelles und kollektives Versagen der Brüderlichkeit im Predigerorden! $!^{52}$

50 Vgl. dazu Bataille, Georges: La Part maudite. Essai d'économie générale, in: ders.: Euvres Complètes. Band 7. Paris 1992, S. 17-179, insb. S. 20.

51 Vgl. dazu das Themenheft „Inquisition“ der Zeitschrift Wort und Antwort 44 (2003), S. 1-48, besonders die selbstkritische Erinnerung des Provinzkapitels der Dominikanerprovinz Teutonia im Jahr 2000 an die Inquisition, ebd., S. 1: „Dominikaner und Inquisition“.

52 Um ein solches Scheitern vor der theologisch hoch aufgeladenen Konzeption christlicher Brüderlichkeit zu verhindern, bedarf es einer Ethik der Verletzbarkeit, die davon ausgeht, dass Menschen grundsätzlich voneinander abhängig sind und somit immer in der Gefahr stehen, einander zu verwunden. Christliche und human begründete Konzeptionen von Geschwisterlichkeit haben gleichermaßen dafür zu arbeiten, dass Menschen vor Gewalt geschützt werden - im Bewusstsein, dass diese niemals ganz beseitigt werden kann. Vgl. Butler, Judith: Gefährdetes Leben. Politische Essays. Aus dem Englischen von Karin Wördemann. Frankfurt/Main 2012. Siehe dazu weiterführend Kohl, Bernhard: Die Anerkennung des Verletzbaren. Eine heuristische Annäherung an die Menschenwürde, in: Theologie der Gegenwart 56 (2013), S. 162-172. 
Glücklicherweise hat die dominikanische Tradition nicht bloß Inquisitoren hervorgebracht, sondern auch Prediger der Menschenrechte wie Antón Montesino (ca. 1485-1540) ${ }^{53}$, eine unerschrockene Kritikerin kirchlichen Machtmissbrauchs wie Katharina von Siena $(1347-1380)^{54}$ oder den Friedensnobelpreisträger Dominique Pire (1910-1969) ${ }^{55}$. Ihrem Engagement verdankt sich meine Hoffnung, dass die demokratisch verfasste Geschwisterlichkeitskonzeption im Ordo Praedicatorum mehr ist als spirituell verbrämte Ideologie. ${ }^{56}$

\section{Quellen und Literatur}

Arens, Edmund: Christopraxis. Grundzüge theologischer Handlungstheorie. Quaestiones disputatae 139. Freiburg i.Br. 1992.

Bauer, Christian: Stadtluft macht frei? Mittelalterliche Stadtpastoral der Bettelorden, in: Wort und Antwort 53 (2012), S. 149-154.

Butler, Judith: Gefährdetes Leben. Politische Essays. Aus dem Englischen von Karin Wördemann. 3. Aufl., Frankfurt/Main 2012.

Cadoré, Bruno: Die dominikanischen Laien und die Verkündigung, in: Eggensperger, Thomas; Engel, Ulrich (Hrsg.): Dominikanische Predigt. Dominikanische Quellen und Zeugnisse 18. Leipzig 2014, S. 100-118.

Die Bibel. Altes und Neues Testament. Einheitsübersetzung. Hrsg. i.A. der Bischöfe Deutschlands, Österreichs, der Schweiz, des Bischofs von Luxemburg, des Bischofs von Lüttich, des Bischofs von Bozen-Brixen. Für die Psalmen und das Neue Testament auch im Auftrag des Rates der Evangelischen Kirche in Deutschland und des Evangelischen Bibelwerks in der Bundesrepublik Deutschland und der Deutschen Bibelgesellschaft (Evangelisches Bibelwerk). Stuttgart, Klosterneuburg 1980.

Eggensperger, Thomas: Orden - Gemeinschaften kritischer Solidarität in der Kirche? Betrachtungen unter ekklesiologischer Perspektive, in: Ordenskorrespondenz 37 (1996), S. 166-176.

Eggensperger, Thomas; Engel, Ulrich: Dominikanerinnen und Dominikaner. Geschichte und Spiritualität. Topos Taschenbücher 709. Kevelaer 2010.

53 Vgl. dazu Engel, Ulrich: Gerechtigkeitstheoretische Ansprüche dominikanischen Predigens. Eine systematisch-theologische Reflexion im Anschluss an die Predigt des Antón Montesino OP und seiner Brüder 1511 in Santo Domingo, in: Delgado, Mariano (Hrsg.): „Ces gens ne sont-ils pas des hommes?“ - Évangile et prophétie. Colloquede la Faculté de théologie de Fribourg / „Sind sie etwa keine Menschen?“ - Evangelium und Prophetie. Kolloquium der Theologischen Fakultät Freiburg. Fribourg 2013, S. 261-285.

54 Vgl. dazu Noffke, Suzanne: Klarer Blick in dunklen Zeiten. Caterina von Siena. Aus dem Amerikanischen von Magdalena Dörtelmann, Angelica Kliem, Franziska Madl, MariaMarkus Przyrembel und Aurelia Spendel. Leipzig 2012.

55 Vgl. Van Damme, Guido: Dominique Pire. Friedensnobelpreisträger. Mit einem Nachwort von Bernhard Kohl OP. Aus dem Französischen von Marcel Oswald OP. Leipzig 2010.

56 Ich danke Lukas Weber (Münster) für die kritisch-wohlwollende Durchsicht des Textes. 
Eggensperger, Thomas; Engel, Ulrich (Hrsg.): Dominikanische Predigt. Dominikanische Quellen und Zeugnisse 18. Leipzig 2014.

Eggensperger, Thomas; Engel, Ulrich: Gemeinschaft im Dialog. Der Dominikanerorden weltweit, in: Herder-Korrespondenz 56 (2002), S. 520-524.

Engel, Ulrich: Charismatisch und katholisch. Zur ekklesiologischen Ortsbestimmung des Dominikanerordens, in: Eggensperger, Thomas; Engel, Ulrich; Oosterveen, Leo (Hrsg.): Kirche in Bewegung. Deutsch-niederländische Reflexionen zur Ekklesiologie aus dominikanischer Sicht / Kerk in beweging. Duits-Nederlandse reflecties over ecclesiologie vanuit dominicaans perspectif. Kultur und Religion in Europa 6. Münster 2007, S. 77-82.

Engel, Ulrich: Gerechtigkeitstheoretische Ansprüche dominikanischen Predigens. Eine systematisch-theologische Reflexion im Anschluss an die Predigt des Antón Montesino OP und seiner Brüder 1511 in Santo Domingo, in: Delgado, Mariano (Hrsg.): „Ces gens ne sont-ils pas des hommes?" - Évangile et prophétie. Colloquede la Faculté de théologie de Fribourg / „Sind sie etwa keine Menschen?“ - Evangelium und Prophetie. Kolloquium der Theologischen Fakultät Freiburg. Studia Friburgensia vol. 116 / Series historica vol. 10. Fribourg 2013, S. 261-285.

Engel, Ulrich: Konsens und Wahrheit. Der Dominikanerorden als praktisch verfasste Kommunikationsgemeinschaft, in: Engel, Ulrich: Gott der Menschen. Wegmarken dominikanischer Theologie. Ostfildern 2010, S. 14-40.

Engel, Ulrich: Zur demokratischen Verfassung des Dominikanerordens, in: Schweizerische Kirchenzeitung 166 (1998), S. 474-477 (Nr. 33-34).

Ernst, Josef: Das Evangelium nach Markus. Regensburger Neues Testament. Regensburg 1981.

Frank, Isnard W.: Lexikon des Mönchtums und der Orden. Stuttgart 2005.

Gnilka, Joachim: Das Evangelium nach Markus (Mk 1-8,26). Evangelisch-Katholischer Kommentar zum Neuen Testament II/1. 5. Aufl., Zürich u.a. 1998.

Grundmann, Herbert: Religiöse Bewegungen im Mittelalter. Untersuchungen über die geschichtlichen Zusammenhänge zwischen der Ketzerei, den Bettelorden und der religiösen Frauenbewegung im 12. und 13. Jahrhundert und über die geschichtlichen Grundlagen der Deutschen Mystik. [Habil.-Schrift 1933]. Darmstadt 1977.

Heinz, Peter: Homosexualität und geistliche Berufe, in: Stimmen der Zeit 214 (1996), S. 681692.

Herzig, Anneliese: In der Spur Jesu. Leben nach den Evangelischen Räten. Spiritualität und Seelsorge 5. Innsbruck 2012.

Hilkert, Mary Catherine u.a.: Das dominikanische Predigtcharisma. Eine Untersuchung, in: Eggensperger, Thomas; Engel, Ulrich (Hrsg.): Dominikanische Predigt. Dominikanische Quellen und Zeugnisse 18. Leipzig 2014, S. 135-154.

Hintersberger, Benedikta: Maria von Magdala. Patronin des Dominikanerordens, in: Eggensperger, Thomas; Engel, Ulrich (Hrsg.): Dominikanische Predigt. Dominikanische Quellen und Zeugnisse 18. Leipzig 2014, S. 250-255.

Jordan von Sachsen: Von den Anfängen des Predigerordens. Hrsg. v. Wolfram Hoyer. Dominikanische Quellen und Zeugnisse 3. 2. Aufl., Leipzig 2003.

Kiechle, Stefan: Consecratio - Communio - Missio. Die drei Grundelemente des Ordenslebens, in: Gruber, Margareta; Kiechle, Stefan (Hrsg.). Gottesfreundschaft. Ordensleben heute denken. Würzburg 2007, S. 51-71. 
Kohl, Bernhard: Die Anerkennung des Verletzbaren. Eine heuristische Annäherung an die Menschenwürde, in: Theologie der Gegenwart 56 (2013), S. 162-172.

Merklein, Helmut: Jesu Botschaft von der Gottesherrschaft. 2. Aufl., Stuttgart 1989.

Merten, Manuel: „Wenn alle Macht vom Volk ausgeht ...“. Die demokratische Verfassung des

Dominikanerordens als Alternative in einer hierarchisch verfaßten Kirche. Ausgewählte Vorträge der Karl-Rahner-Akademie Köln. Köln [Manuskriptdruck] o.J. [1995].

Metz, Johann Baptist: Mystik der offenen Augen. Wenn Spiritualität aufbricht. Freiburg i.Br. 2011.

Metz, Johann Baptist: Zeit der Orden? Zur Mystik und Politik der Nachfolge. 5. Aufl., Freiburg i.Br. 1982.

Noffke, Suzanne: Klarer Blick in dunklen Zeiten. Caterina von Siena. Aus dem Amerikanischen von Magdalena Dörtelmann, Angelica Kliem, Franziska Madl, Maria-Markus Przyrembel und Aurelia Spendel. Dominikanische Quellen und Zeugnisse 16. Leipzig 2012.

Pesch, Rudolf: Die Apostelgeschichte (Apg 1-12). Evangelisch-Katholischer Kommentar zum Neuen Testament V/1. Zürich u.a. 1986, S. 179-182.

Radcliffe Timothy: Gemeinschaft im Dialog. Ermutigung zum Ordensleben. Hrsg. v. Thomas Eggensperger u. Ulrich Engel. Dominikanische Quellen und Zeugnisse 2. Leipzig 2001.

Schäfer, Klaus: Gemeinde als Bruderschaft. Ein Beitrag zum Kirchenverständnis des Paulus. Europäische Hochschulschriften Reihe 23, Theologie 333. Frankfurt/Main 1989.

Söding, Thomas: Art. Bruder. I. Biblisch, in: Lexikon für Theologie und Kirche. Walter Kasper (Hrsg.). Bd. 2. 3. Aufl., Freiburg i.Br. u.a. 1994, Sp. 710-711.

Theobald, Michael: Der Römerbrief. Erträge der Forschung 294. Darmstadt 2000.

Tugwell, Simon: Early Dominicans. Selected Writings. New York 1982.

Van Damme, Guido: Dominique Pire. Friedensnobelpreisträger. Mit einem Nachw. v. Bernhard Kohl. Aus dem Französischen von Marcel Oswald. Dominikanische Quellen und Zeugnisse 14. Leipzig 2010.

Vergauwen, Guido: Predigt der Wahrheit, in: Eggensperger, Thomas; Engel, Ulrich (Hrsg.): Dominikanische Predigt. Dominikanische Quellen und Zeugnisse 18. Leipzig 2014, S. 47-52.

Weber, Max: Die protestantische Ethik und der Geist des Kapitalismus. Vollständige Ausgabe. Hrsg. und eingeleitet von Dirk Kaesler. 3. Aufl., München 2010.

Weber, Max: Wirtschaft und Gesellschaft. Grundriss der verstehenden Soziologie, Lizenzausgabe. Neu Isenburg 2005. 


\title{
Wie Schwestern? Freundschaft in Ann Brashares' Sisterhood-Reihe
}

\author{
Katharina Gerund
}

\begin{abstract}
This article examines the depiction of friendship as sisterhood in Ann Brashares' Sisterhood series of young adult novels. It analyzes the intertwined representations of siblings and friends as well as the appropriation of feminist ideals in contemporary girl culture, and it offers a critique of the individualist, consumerist, and patriarchal underpinnings of friendship in the novels.
\end{abstract}

\section{Einleitung}

Die US-amerikanische Jugendbuchautorin Ann Brashares hat in den vergangenen Jahren mit ihrer Sisterhood-Reihe große Erfolge gefeiert - alle Bände waren New-York-Times-Bestseller, wurden in mehrere Sprachen übersetzt und verfilmt. ${ }^{1}$ Die Popularität der Reihe zeigt sich u.a. auch daran, dass Hillary Clinton in ihrer Kampagne als Präsidentschaftskandidatin 2008 ihr Wahlkampfteam als „sisterhood of the traveling pantsuits“ bezeichnet hat oder Brashares inzwischen mit 3 Willows ein Spin-Off des erfolgreichen Sisterhood-Quartetts vorgelegt hat. Im Zentrum der Sisterhood-Romane stehen vier Freundinnen - Lena Kaligaris, Carmen Lowell, Tibby Rollins, Bridget ,Bee‘ Vreeland -, die zu Beginn des ersten Romans eine ,magische' Jeans finden, die ihnen allen gleichermaßen gut passt und sie über den ersten Sommer, den sie getrennt verbringen, verbinden soll. Die Mädchen begründen daher eine ,Schwesternschaft ${ }^{*}$ - die ,sisterhood of the traveling pants“. Die ersten vier Bände der Reihe - The Sisterhood of the Traveling Pants (2001), The Second Summer of the Sisterhood (2003), Girls in Pants: The Third Summer of the Sisterhood (2005), Forever in Blue: The Fourth Summer of the Sisterhood (2007) - schildern Freud und Leid des Erwachsenwerdens der Freundinnen und ein fünfter Roman, Sisterhood Everlasting (2011), erzählt schließlich, was einige Jahre später aus den Mädchen geworden ist.

Die ersten vier Bände berichten konsekutiv jeweils von einem Sommer im Leben der Mädchen, die seit ihrer Geburt befreundet sind, da ihre schwangeren Mütter im selben Aerobic-Kurs gewesen sind und sich dort angefreundet haben. Die Freundschaft der Mädchen wird bereits in dieser Prämisse einer Geschwisterbeziehung (sisterhood) angenähert, da die Gruppe sich nicht willkürlich und

1 The Sisterhood of the Traveling Pants. USA 2005 und The Sisterhood of the Traveling Pants 2. USA 2008. 
freiwillig zusammenfindet, ${ }^{2}$ sondern zunächst durch die Beziehungen der Mütter fundiert ist: „We started being ,we“ before we were born“"3, berichtet Carmen. Die Bände werden jeweils durch eine Ich-Erzählung aus der Perspektive eines der vier Mädchen gerahmt, wobei jedes der Mädchen einmal an der Reihe ist, ${ }^{4}$ und verweben die unterschiedlichen Erlebnisse der Protagonistinnen in einer auktorialen Erzählsituation mit wechselnden Fokalisierungen. ${ }^{5}$ Briefe und Nachrichten (hauptsächlich) der Freundinnen sind - auch typographisch als persönliche Botschaften markiert - in die Erzählung integriert. Auf der narrativen Ebene, so könnte man argumentieren, wird das Ideal einer gleichberechtigten, lateralen und solidarischen Beziehung im Sinne von sisterhood - wie sie besonders im Rahmen der feministischen Bewegungen propagiert und kritisiert wurde $^{6}$ - im Ansatz eingelöst. Bereits im Titel wird einerseits die Freundschaft der Mädchen mit geschwisterlichen Beziehungen in Analogie gesetzt und andererseits mit sisterhood ein prominentes und kontroverses Schlagwort aufgerufen, das im feministischen Diskurs Frauen affizieren, solidarisieren und politisch ak-

2 In (post-)modernen westlichen Diskursen wird Freundschaft in aller Regel als ,,spontaneous and voluntary“ markiert und definiert als ,,a continuous creation of personal will and choice, [...] ungoverned by the structural definitions that bear on family and kinship“. Pahl, Ray: On Friendship. Cambridge 2000, S. 14 u. 38. Vertrauen stellt dabei den zentralsten Aspekt des modernen Freundschaftsideals dar. Vgl. ebd., S. 61. Freundschaft ruft darüber hinaus häufig Konnotationen von (Wahl-)Freiheit, Individualität und Subversion auf. Vgl. ebd., S. 166.

3 Brashares: Sisterhood, S. 5.

4 Prolog und Epilog können im ersten Band Carmen, im zweiten Lena, im dritten Tibby und im vierten Band Bridget zugeschrieben werden.

5 Diese unterschiedlichen Erzählstränge, die sich um die Erlebnisse der einzelnen Mädchen ranken, sind hier auch bereits im Produktionsprozess angelegt. Ann Brashares schildert, dass sie die Geschichte der Protagonistinnen zunächst in Form von Novellen geschrieben hatte, aus denen dann der Roman entstand. Vgl. Blasingame, James: Interview with Ann Brashares, in: Journal of Adolescent \& Adult Literacy 47.4 (2003/04), S. 350 .

6 Besonders deutlich zeigt sich dies z.B. an Robin Morgans Anthologien „Sisterhood Is Powerful“ (New York 1970), „Sisterhood Is Global“ (New York 1984) u. „Sisterhood Is Forever" (New York 2003), die ,sisterhood" als zentrale Metapher nationaler wie auch internationaler und intergenerationaler Solidarisierung propagieren, aber teils auch kritische Stimmen bezüglich dieser „masks of family roles“ inkludieren. Johnson, Barbara: The Politics of Ageing, in: Morgan, Robin (Hrsg.): Sisterhood Is Forever: The Women's Anthology for a New Millenium. New York 2003, S. 152-161, hier S. 156. Publikationen wie etwa die von Ellen Carol DuBois und Vicki L. Ruiz herausgegebene Sammlung „Unequal Sisters“ (New York 1990) oder Deborah Siegels „Sisterhood Interrupted“ (New York 2001) verweisen bereits im Titel kritisch auf die Zentralität wie auch Problematik von , sisterhood'. 
tivieren soll, wenngleich es u.a. für seine essentialistischen und exklusorischen Aspekte stark kritisiert wird. ${ }^{7}$ Damit stellt sich die Frage, inwiefern hier biographische Geschwisterbeziehungen wie auch feministische Ideale als Matrix für die Freundschaft der Mädchen herangezogen werden und wie v.a. letztere in einem populärkulturellen und postfeministischen Kontext appropriiert werden. Zudem beinhaltet jeder Band das ,Manifest" der sisterhood bzw. die Regeln des Umgangs mit der ,magischen' Jeans welche die Freundinnen zu Beginn festlegen. Carmen fühlt sich beim Erstellen des Manifests wie ein „founding father“ ${ }^{\star 8}$ und deutet damit die Bedeutung patriarchaler Autorität für die ,Schwesternschaft " ebenso an wie deren kulturspezifische Dimension. Das durch die Referenz auf die amerikanischen Gründerväter ebenfalls evozierte Moment der Revolution und Unabhängigkeit erweist sich im Laufe der Erzählung als Vorgriff auf die Entwicklung und das Erwachsenwerden der Mädchen, welche jedoch als Prozess der Anpassung mehr denn als Prozesse der Revolution, Rebellion oder Subversion dargestellt werden. Die einzelnen Kapitel sind durch Seiten getrennt, auf denen im Hintergrund die Jeans und im Vordergrund jeweils ein Zitat bzw. Spruch abgebildet ist, welcher als Motto oder Kommentar gelesen werden kann. Die Jeans, welche die Protagonistinnen auf ihren (buchstäblichen und metaphorischen) Reisen begleitet und augenscheinlich als materielles Zeichen ihrer Freundschaft dient, symbolisiert nicht nur amerikanische Konsum- und Populärkultur, sondern auch die weiß-dominierte, heteronormative und patriarchale Ordnung, in welche sich die Mädchen im Laufe ihrer Entwicklung einpassen, einschreiben und einfügen. ${ }^{9}$

7 Die Jugendbücher richten sich primär an eine weibliche Leserschaft und Brashares ist sich dessen bewusst: „I am realistic enough to know that a book with the word sisterhood in its title and a part of pants on the cover won't be widely embraced by boys. [...] I am very happy to have a special writing relationship with girls“. Blasingame: Interview, S. 350. Man könnte argumentieren, dass sich eine essentialistische Komponente des Konzepts ,sisterhood' mit dem exklusiven Fokus auf Frauen im Prozess der Produktion und Rezeption widerspiegelt. Gleichzeitig ist diese Spezialisierung im Kontext eines wachsenden und zunehmend ausdifferenzierten Marktes für Jugendliteratur zu sehen. Melanie Koss und William Teale konstatieren 2009 eine extensiven Zunahme von Büchern für jugendliche Leser_innen in den vergangenen Jahren und weisen u.a. auf die Etablierung neuer Verlagsmarken hin, die gezielt ein älteres jugendliches Publikum ansprechen. Vgl. Koss, Melanie D.; Teale, William H.: What's Happening in YA Literature? Trends in Books for Adolescents, in: Journal of Adolescent \& Adult Literacy 52.7 (2009), S. 563572, hier S. 563.

8 Brashares: Sisterhood, S. 21.

9 Vgl. McInally, Kate: Who Wears the Pants? The (Multi)Cultural Politics of The Sisterhood of the Traveling Pants, in: Children's Literature in Education 39 (2008), S. 187200, hier S. 193-198. 
Meine Analyse der Tetralogie hinsichtlich der Repräsentation von Freundschaft als sisterhood und vor allem der ideologischen Implikationen dieser Allegorie entwickelt sich im Folgenden in zwei Schritten: Ich analysiere zunächst, wie intradiegetisch die familialen Beziehungen der Mädchen vor allem zu ihren biographischen Geschwistern im Verhältnis zu ihrer freundschaftlichen Verbindung als sisterhood dargestellt und verhandelt werden. In einem zweiten Schritt fokussiere ich die feministischen Ideale und problematischen Aspekte von sisterhood und untersuche, wie diese in der Erzählung figurieren und dabei - so meine These - einen ,Kampfbegriff‘ der feministischen Bewegung in einem postfeministischen Diskurs neutralisieren. Indem der Begriff und das Ideal der sisterhood in populärkulturell-postfeministischen Texten wie der SisterhoodReihe als zentrale Metapher der Solidarität unter Mädchen bzw. Frauen figuriert und in deren Logiken von Patriarchat, weißer Dominanz und Konsumkultur appropriiert wird, verliert er fast jegliches emanzipatorisches Potenzial. Im konkreten Fall mag die Freundschaft der vier Mädchen auf den ersten Blick (be)stärkend, emanzipierend und ermächtigend wirken, letztlich begünstigt sie jedoch vielmehr die Akzeptanz und Affirmation bestehender Herrschaftsverhältnisse durch die Protagonistinnen. In meiner Analyse kontextualisiere ich die Entwicklung der Mädchen und ihrer individuellen Identität(en) als Frau(en) sowie ihrer kollektiven Identität als sisters an der Schnittstelle von Konsumkultur, Individualisierung und Anpassung.

\section{Geschwister und Freunde}

Die Erzählungen um die sisterhood der vier Freundinnen korrespondieren mit einem aktuellen Trend der anglophonen Jugendliteratur, indem sie nicht nur das Erwachsenwerden, sondern in erster Linie Themen wie ,fitting in, finding oneself, and dealing with major life changes ${ }^{\text {(10 }}$ verhandeln. Familien und Geschwister der Mädchen spielen dabei eine wichtige Rolle. Tibby hat zwei deutlich jüngere Geschwister, für die sie oft als ,Ersatzelternteil ‘ fungiert, Bridget einen Zwillingsbruder und Lena eine jüngere Schwester namens Effie, die in ihrem Leben und somit auch in der Erzählung immer wieder recht prominent in Erscheinung tritt. Carmen ist zunächst Einzelkind; durch die Heirat ihres Vaters bekommt sie zwei Stiefgeschwister und später wird ihre Mutter noch einmal schwanger und Carmen bekommt einen Halbbruder. Obgleich oder auch gerade weil die Freundinnen sich als ,Schwestern“ verstehen, werden Familie und (Bluts-)Verwandtschaft als primäre und prioritäre Form der Vergemeinschaftung affirmiert. Besonders deutlich wird dies u.a. in Carmens Neid auf die ,echten' Geschwister ihrer Freundinnen:

10 Koss; Teale: What's Happening, S. 569.

Ulrike Schneider, Helga Völkening and Daniel Vorpahl - 978-3-653-98812-3 
Carmen had her friends, and she counted on them, but she never forgot that they had real sisters and brothers. A deeply insecure part of Carmen reminded herself that if there were a fire, they'd have to save their brothers and sisters first ${ }^{11}$.

Obwohl diese Aussage aus Carmens jugendlich-emotionaler Sicht getroffen wird, ist sie repräsentativ für die Logik zwischenmenschlicher Beziehungen in den Romanen, welche die Bedeutung von Familie (im weitgehend traditionellen Sinne) affirmiert und die klassische Kernfamilie zur Matrix zwischenmenschlicher Beziehungen erhebt. Noch bei ihrem Schulabschluss ist die Differenzierung zwischen ,offiziellen' und ,inoffiziellen' Geschwistern entscheidend für Carmen; ${ }^{12}$ und auch aus Tibbys Perspektive wird eine Unterscheidung zwischen Schwestern als biographischen Geschwistern und Schwestern als Freundinnen markiert, wenn sie sich nach dem Tod von Bridgets Mutter wünscht, ihre Freundin würde von ihrer Familie adoptiert und damit ganz ,offiziell' ihre Schwester (,she had known she was a sister to Lena and Carmen and Bee, but she'd longed to be a sister officially, too ${ }^{\text {“13 }}$ ). Dies reflektiert einerseits die Tatsache, dass im Gegensatz zu familiären und verwandtschaftlichen Beziehungen Freundschaften im soziokulturellen Kontext der Erzählung keine formalen institutionellen Rahmungen erfahren; ${ }^{14}$ andererseits deutet es multiple Überlagerungen von Familie(n) und Freund_innen an - nicht zuletzt, da die Freundschaft in der Semantik der Familie beschrieben wird - ohne jedoch die Differenzierung dauerhaft zu unterlaufen. Man kann diesen Aushandlungsprozess in Ray Pahls Worten treffend beschreiben: „Rather than friendship being an alternative to family and kin links, there is a more fluid interchange of friend-like and family-like relationships ${ }^{\text {115. }}$.

Obwohl den biologischen und biographischen Geschwistern eine besondere Rolle zukommt, werden die Beziehungen der Protagonistinnen zu diesen ambivalent dargestellt. Die Beziehungen zwischen Schwestern stehen dabei im Vordergrund. Bridgets Zwillingsbruder tritt kaum in Erscheinung, ${ }^{16}$ Carmen freundet sich zwar mit ihrem Stiefbruder Paul an, ${ }^{17}$ aber es ist ihre Stiefschwester

11 Brashares: Second Summer, S. 167.

12 Vgl. Brashares: Girls in Pants, S. 8.

13 Brashares: Second Summer, S. 213.

14 Vgl. Pahl: Friendship, S. 14.

15 Ebd., S. 129.

16 Obwohl Bridget sich später aktiv um ihre Beziehung zu ihrem Bruder Perry bemüht, spielt er lange Zeit kaum eine Rolle in ihrem Leben: „Bridget sometimes forgot she lived in the same house with him, let alone that they were twins". Brashares: Second Summer, S. 187.

17 Vgl. ebd., S. 253.

Ulrike Schneider, Helga Völkening and Daniel Vorpahl - 978-3-653-98812-3 
Krista, die ihr in hohem Maße nacheifert, ${ }^{18}$ und auch in Tibbys Beziehung zu ihren jüngeren Geschwistern ist es Katherine, die für sie besonders wichtig wird. Nach dem Tod von Bailey, ${ }^{19}$ mit der sie sich im ersten Band anfreundet, ,entdeckt ' Tibby ihre fürsorglich-feminine Seite. ${ }^{20}$ Dies zeigt sich u.a. in ihrem veränderten Verhältnis zu ihrer Schwester: „She was actually happy to hear Katherine yelping at three fifteen. [...] She snuggled around her sister and cried $^{\text {“21 }}$. Auch als Katherine sich bei einem Sturz aus Tibbys Fenster verletzt, wird noch einmal die Beziehung zwischen den Schwestern in ihrer Relevanz bestärkt. ${ }^{22}$ Lenas Schwester Effie kommt unter den Geschwistern der vier Mädchen die wichtigste Rolle zu. In dem Verhältnis der Kaligaris-Schwestern figurieren Abgrenzungsdiskurse ebenso prominent wie die Betonung ihres ,besonderen" Verhältnisses. Dabei werden sowohl Gemeinsamkeiten als auch Unterschiede hervorgehoben und neben den positiven Aspekten des Geschwisterverhältnisses werden Konkurrenz- und Konfliktmomente sichtbar. Zwar freut sich Lena, wenn z.B. Kostos die äußeren Ähnlichkeiten der Schwestern feststellt und nicht wie viele andere primär auf ihre Unterschiede abhebt; ${ }^{23}$ gleichzeitig sind genau diese Differenzen für sie selbst oft von Bedeutung (,Lena [...] could not believe she and Effie came from the same parents“24). In der Darstellung dieser Geschwisterbeziehung steht Effie ihrer älteren Schwester einerseits sehr nahe, gibt (un)gefragt Ratschläge und spiegelt Lenas Befindlichkeiten („Lena had her private soul read like a poster by her little sister ${ }^{625}$ ), andererseits erscheint sie manchmal aus Lenas Perspektive auch schlicht als „mean“26. Als Effie im letzten Band mit Tibbys Ex-Freund Brian eine Beziehung beginnt, wird auch das Konkurrenzverhältnis zwischen Lenas Schwester und ihren Freundinnen deutlich: „I am your only sister, but you always choose them over me“27, wirft Effie ihrer Schwester vor. Nach diesem Streit mit Lena nimmt Effie die Jeans mit nach Griechenland und verliert sie, aber ihre Schwester verzeiht ihr; nicht zuletzt, da sie und ihre Freundinnen in Santorini zusammenkommen, um

18 Vgl. ebd., S. 216.

19 Die Unterscheidung zwischen Familie als ,natürlich“ gegebener und Freundschaft als gewählter Beziehung wird hier evident: Tibby hofft, dass ihr Schwarm Bailey für ihre kleine Schwester hält und nicht denkt, dass sie mit dem jüngeren Mädchen befreundet ist. Vgl. Brashares: Sisterhood, S. 117.

20 Vgl. McInally: Who Wears, S. 196-197.

21 Brashares: Sisterhood, S. 287.

22 Vgl. Brashares: Girls in Pants, S. 82-83.

23 Vgl. Brashares: Sisterhood, S. 66.

24 Ebd., S. 213.

25 Brashares: Second Summer, S. 329.

26 Vgl. ebd., S. 65.

27 Brashares: Forever, S. 334.

Ulrike Schneider, Helga Völkening and Daniel Vorpahl - 978-3-653-98812-3 
die Hose zu suchen und dort bemerken, dass sie die Jeans nicht (mehr) benötigen, um ihre Freundschaft zu besiegeln. Da der Fokus der Erzählung auf den vier Freundinnen liegt, ist Lenas Perspektive auf die Beziehung zwischen den Schwestern dominant, während Effies Blickwinkel kaum bzw. nur mittelbar eine Rolle spielt. Mit Blick auf die narrative Autorität besteht also eine deutliche Hierarchie, in der die als schüchterner und introvertierter charakterisierte ältere Schwester dominiert. Das Beispiel der beiden Schwestern deutet an, dass Beziehungen zwischen Schwestern mit idealisierten Vorstellungen von sisterhood wenig zu tun haben, sondern vielmehr ambivalent und potenziell konfliktuös sind sowie ständigen Aushandlungsprozessen unterliegen.

Die Freundschaft der Mädchen wird nicht nur in ein Ähnlichkeitsverhältnis zu Geschwisterbeziehungen gesetzt, sondern unterscheidet sich in der Darstellung vor allem mit Blick auf ihre Kontinuität und Intensität von anderen Freundschaften, welche die Mädchen etwa während ihrer Sommeraktivitäten oder später während ihrer College-Zeit knüpfen: „The word friends doesn't seem to stretch big enough to describe how we feel about each other. We forget where one of us starts and the other one stops ${ }^{628}$. Die Einheit und emotionale Verbundenheit der sisterhood wird hier besonders betont und u.a. durch das Gelübde, das sie zu Beginn (fast) jedes Sommers sprechen, formal bestätigt und an die ,magische' Jeans geknüpft. ${ }^{29}$ Die Rituale vor und nach den Sommerferien deuten darauf hin, dass die Freundschaft gerade in Phasen des Umbruchs wiederholter Affirmation bedarf. Tibby kommt es dennoch manchmal so vor, als wäre Freundschaft beständiger und verbindlicher als familiär-verwandtschaftliche Beziehungen (,blood was thicker than water. But friendship [...] was thicker than both $\left.{ }^{‘ 30}\right)$. Dennoch bleibt die Vorstellung von Freundschaft geprägt durch die Bildlichkeit der Kernfamilie sowie die ,heterosexuelle Matrix ${ }^{‘ 31}$. Bridget stellt im vierten Band der Reihe fest, dass die Freundinnen ihre Familie - obgleich eine ,unconventional family“ - sind: „She did have a family. They were all under twenty and none of them related to her by blood, but they made her who she was ${ }^{\text {“32. }}$.

Männerfiguren sind für die vier Protagonistinnen verbunden mit Autorität, Anerkennung oder (sexuellem) Begehren und selten (jenseits von Familie und

28 Brashares: Second Summer, S. 4.

29 Das Gelübde lautet wie folgt: „To honor the Pants and the Sisterhood / And this moment and this summer and the rest of our lives / Together and apart“. Brashares: Second Summer, S. 16.

30 Ebd., S. 26.

31 Vgl. Butler, Judith: Gender Trouble. Feminism and the Subversion of Identity. New York 2006.

32 Brashares: Forever, S. 167.

Ulrike Schneider, Helga Völkening and Daniel Vorpahl - 978-3-653-98812-3 
Paarbeziehung) dauerhaft als Freunde imaginiert. Brian und Tibby zum Beispiel sind anfangs befreundet und werden dann ein Paar, mit dem Effekt, dass ,the

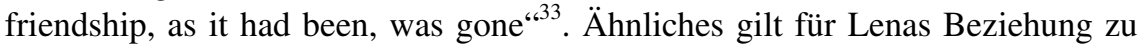
Kostos, Bridgets Verhältnis zu Eric oder Carmens kurzlebige Freundschaft mit Win Sawyer. Freundschaft mag in der Logik der Bücher ein Element einer erfüllenden heterosexuellen Paarbeziehung sein, aber ansonsten sind dauerhafte, ,echte" und nicht von sexuellen Interessen überlagerte Freundschaften fast ausschließlich unter Frauen (bzw. Männern) denkbar. Die Geschlechterbinarität bleibt unhinterfragt und auch Homosexualität ist in der Welt der sisterhood quasi non-existent. Darüber hinaus werden im Rahmen der Identitätsfindung der Protagonistinnen, die dem Genre entsprechend im Zentrum des Interesses stehen, etablierte Geschlechterrollen affirmiert und keinesfalls radikal unterlaufen oder grundlegend modifiziert. Für ihre Identität und ihr Selbstwertgefühl als Frauen sind männliche Autorität und Anerkennung konstituierend. Besonders für Lena und Carmen sind die Vaterfiguren in ihren Familien von großer Bedeutung; man denke hier z.B. an Lenas Anerkennung durch Bapi ${ }^{34}$ und Carmens Ringen um die Aufmerksamkeit ihres Vaters, als sie auf dessen ,neue Familie trifft. Die Romane suggerieren, wie Kate McInally korrekt feststellt, dass die Mädchen ihre , wahre ' Identität nur durch Männer erkennen. ${ }^{35}$ Obwohl also die positiv dargestellte Mädchenfreundschaft einen alternativen Identifikationsraum darstellen könnte, bleibt die Zentralität der Männer weitgehend unangetastet. Dies wird auch über die Mutterfiguren bestärkt, etwa wenn Carmens Mutter Christina sich selbst wie ein Teenager benimmt, als sie ihren neuen Freund David kennenlernt, oder wenn Lena das Gefühl hat, dass ,the mothers were a little eager on the boyfriend issues, as if life would really start once the

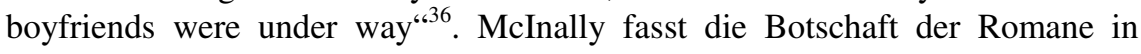
dieser Hinsicht treffend zusammen: ,all girls [...] should discover and accept their ,essential ' femininity, which allows them to recognise the centrality of men, and , outgrow' their connections with each other“37.

Die Freundschaft der Mädchen erscheint in einer solchen Lesart temporär und der als relevanter markierten heterosexuellen Paarbeziehung untergeordnet. Gleichzeitig wird nicht zuletzt durch die Ähnlichkeitsrelation zu familialen Beziehungen die sisterhood als ungewöhnlich und besonders dargestellt. ${ }^{38}$ Obwohl die Freundinnen gerade jugendlichen Leserinnen ein (scheinbar) multikulturell

33 Brashares: Girls in Pants, S. 30.

34 Vgl. Brashares: Sisterhood, S. 253 u. 283.

35 Vgl. McInally: Who Wears, S. 195.

36 Brashares: Second Summer, S. 120.

37 McInally: Who Wears, S. 192.

38 Vgl. ebd., S. 188.

Ulrike Schneider, Helga Völkening and Daniel Vorpahl - 978-3-653-98812-3 
und divers aufgestelltes Identifikationsangebot machen, sind sie als Besonderheit und damit als Ausnahme beschrieben, die keinesfalls repräsentativ für Mädchenfreundschaften ist. ${ }^{39}$ Innerhalb der Erzählung wird dies in den anderen Freundschaften der Protagonistinnen evident; ein eindrückliches Beispiel hierfür ist Carmens destruktive ,Freundschaft" mit Julia im letzten Band, von der sie sich schlussendlich löst und deren Lektion sie wie folgt bewertet:

she felt sorry that she'd been taken in by a snake like Julia. But in some strange way she felt appreciative that it had happened. In friendship terms, she'd lived her life in the Garden of Eden. Her bond with her friends was too powerful, so supportive, so uncompetitive, she'd thought that was how friendship worked ${ }^{40}$.

Die sisterhood wird also auch intradiegetisch nicht als Norm, sondern als Ausnahme und Ideal bewertet. Die Bücher behandeln augenscheinlich Themen und Probleme, die zum Alltag vieler Teenager gehören, aber sie sind dennoch ideologisch fundiert durch die Werte und Normen einer dominanten weißen Mittelstandsgesellschaft. ${ }^{41}$ Dies zeigt sich nicht nur an den weitgehend traditionellen Vorstellungen von Familienstrukturen, Geschlechterrollen sowie Geschwister- und Freundschaftsbeziehungen, die in den Texten transportiert und propagiert werden, sondern auch in dem (post)feministischen Ermächtigungsnarrativ, das in der Coming-of-Age Erzählung verhandelt wird.

\section{Sisterhood und Freundschaft im postfeministischen Kontext}

Kate McInally schreibt den Erfolg der Sisterhood-Reihe auch der Tatsache zu, dass die Romane jenseits des „,mean girl“ syndrom in Young Adult novels“ positive Aspekte von Mädchenfreundschaften betonen und sich durch den affirmierenden Fokus auf „feminine empowerment and solidarity“ von wenig ernsthafter ,chick lit“42 unterscheiden. Mit dem Begriff der sisterhood rufen die Romane zwar einen feministischen Kontext auf, allerdings auch mit all seinen problematischen Aspekten. Als zentrale Solidaritätsmetapher vor allem der sogenannten Zweiten Welle der US-amerikanischen Frauenbewegung war sisterhood zu keinem Zeitpunkt ein unumstrittener Begriff. Kritik richtet sich besonders gegen die biologistische und essentialistische Unterfütterung, den exklusiven und exklusorischen Anspruch sowie die Homogenisierungstendenzen, die dieser Vorstellung von Solidarität zu Grunde liegen. Diese Kritik lässt sich

39 Vgl. ebd.

40 Brashares: Forever, S. 346.

41 Vgl. Litton, Joyce: The Nature of Female Friendship in the Sisterhood of the Traveling Pants Quartet, in: Eiss, Harry Edwin (Hrsg.): Young Adult Literature and Culture. Newcastle upon Tyne 2009, S. 21-37, hier S. 21.

42 McInally: Who Wears, S. 187-188.

Ulrike Schneider, Helga Völkening and Daniel Vorpahl - 978-3-653-98812-3 
u.a. aus einer Perspektive der Critical Whiteness Studies (vgl. Ruth Frankenberg) oder eines „critical race feminism“ (Elizabeth Spelman) nachvollziehen und wurde besonders prononciert von afroamerikanischen Feministinnen oder „womanists“ (Alice Walker) artikuliert. Hazel V. Carby zum Beispiel hat auf die politischen Konsequenzen der feministischen Beschwörung von sisterhood als einheitsstiftender Kategorie der Frauenbewegung hingewiesen: Zum einen die fast vollständige Ausblendung materieller Unterschiede zwischen Frauen der Arbeiter- und Mittelschicht oder weißen und schwarzen Frauen und zum anderen die Negierung hierarchischer Strukturen besonders zwischen weißen und schwarzen Frauen und die Setzung der weißen gebildeten Frau aus der Mittelschicht als Norm. ${ }^{43}$ Und Audre Lorde hat wiederholt auf die ,trappings of sisterhood“ hingewiesen und behauptet: „I think that some of the people who shout sisterhood most strongly have no concept of what real connectedness between women is all about “44. Dabei zeugt ihre Selbstbezeichnung als „sister outsider“ und ihre Adressierung anderer schwarzer Frauen mit den Worten „I am your sister" auch von der Wirkmächtigkeit und möglichen Resignifikation der Schwesternmetapher. Entgegen aller Kritik hat die Metapher nach wie vor nicht ausgedient und findet sich in feministischen, populärkulturellen und politischen Diskursen. ${ }^{45}$

In der Sisterhood-Reihe wird das Konzept weiblicher Solidarität als ,Schwesternschaft' in einen populärkulturellen und postfeministischen Kontext gestellt. Ich beziehe mich hier auf eine postfeministische Medienkultur wie Mary Douglas Vavrus sie beschreibt: ,a revision of feminism that encourages women's private, consumer lifestyles rather than cultivating a desire for public life and political activism “46. Die Sisterhood-Romane lassen sich hinsichtlich ihrer ideologischen Fundierung in diesem Zusammenhang verorten. Zwar kann man die Freundschaft und individuellen wie kollektiven Entwicklungen der

43 Vgl. Carby, Hazel V.: Reconstructing Womanhood. The Emergence of the AfroAmerican Woman Novelist. New York 1987, S. 17.

44 Zit. nach Hall, Joan Wylie (Hrsg.): Conversations with Audre Lorde. Jackson 2004, S. 13.

45 Sisterhood wird hier als ein kulturspezifisches und historisch wandelbares Konzept verstanden, welches unterschiedliche Bedeutungsdimensionen hat und nicht universell definiert werden kann. Die Verwendung des Begriffs kann daher mit Umdeutungen oder Bedeutungsverschiebungen einhergehen. Freundschaft wird hier ebenfalls nicht nur als prozessual, sondern als historisch und kulturell spezifisch verstanden. Wie Ray Pahl korrekt festgestellt hat, „friends and friendship have to be seen in context“. Pahl: Friendship, S. 169.

46 Vavrus, Mary Douglas: Postfeminist News. Political Women in Media Culture. New York 2002, S. 2. 
Mädchen auch als Teil eines Ermächtigungsnarratives im Sinne von girl power ${ }^{47}$ oder sisterhood lesen, vor allem letzteres Konzept wird jedoch primär in seinen problematischen Aspekten reproduziert, ohne dass damit eine politische und/oder emanzipatorische Agenda verfolgt wird. Letztere wird durch eine neoliberale, spätkapitalistische Individualisierungslogik und postfeministische Narrative ,neutralisiert'. Rebecca Hains stellt heraus, dass ,[o]wing to commercial politics, girl power arguably has become our culture's dominant, mainstream form of feminism“48. Macht wird hier verengt auf die Macht zu konsumieren und Konsumentscheidungen zu treffen; girl power wird kommerziell kooptiert und zur hohlen Verkaufsrhetorik bzw. zum leeren Signifikanten. ${ }^{49}$ Damit ist girl power auch in hohem Maße exklusorisch und einer weißen Mittelklassenorm verhaftet. Hains kategorisiert girl power als postfeministisches Phänomen $;^{50}$ ihr zufolge suggeriert girl power zum einen, dass ,playing with femininity can be positive and empowering“, und zum anderen, dass „empowered women and girls can, in fact, play with femininity, wearing makeup and seek glamour, and still be feminist ${ }^{\text {“51 }}$. Diese Logiken sind als Teil der ideologischen Fundierung der Sisterhood-Reihe auszumachen.

Die Bücher perpetuieren auch zentrale Problematiken des feministischen Konzepts der sisterhood: Die Gruppe der Freundinnen ist per se exklusiv und alle Mädchen kommen aus einem Umfeld der Mittelklasse und teilen somit einen relativ privilegierten sozialen Status ${ }^{52}$ - sie gehen alle aufs College und können auf finanzielle Mittel zurückgreifen, die es ihnen erlauben, z.B. im letzten Band spontan nach Santorini zu fliegen, um die verlorene Hose zu suchen.

47 Rebecca Hains skizziert das verbreitete Verständnis von ,girl power": „, [it] is now broadly understood as a form of pro-girl rhetoric that offers support for girls and girl culture by reclaiming the feminine and marking it as culturally valued“. Hains, Rebecca: Power Feminism, Mediated: Girl Power and the Commercial Politics of Change, in: Women's Studies in Communication 32.1 (2009), S. 89-113, hier S. 98.

48 Ebd., S. 92.

49 Vgl. ebd., S. 107.

50 Vgl. ebd., S. 99.

51 Ebd., S. 98.

52 Pat O'Connor behauptet, dass Freundschaften geschlechtsspezifisch sind; sie argumentiert auch, dass Frauenfreundschaften zumeist entstehen, wenn die Beteiligten u.a. der gleichen sozialen Schicht angehören, den gleichen Familienstand haben oder gleichermaßen am Arbeitsleben partizipieren. Sie führt den in dieser Beobachtung markierten Exklusionsmechanismus noch weiter aus, indem sie aufzeigt, dass somit die Bildung und Aufrechterhaltung von Freundschaften nicht allen Frauen gleichermaßen offen steht. Vgl. O'Connor, Pat: Women's Friendship in a Post-Modern World, in: Adams, Rebecca G.; Allan, Graham (Hrsg.): Placing Friendship in Context. Cambridge 1998, S. 117-135, hier S. 127. 
Auch die Jeans markiert die Exklusivität; sie wird zwar in der Gruppe der Freundinnen geteilt, darf aber nicht von anderen getragen werden (die wenigen Ausnahmen beinhalten die todkranke Bailey und Carmens Mutter, welche die Hose versehentlich zu einem Date trägt). Die Jeans symbolisiert allerdings auch die homogenisierenden Tendenzen der ,Schwesternschaft'. Es ist bezeichnend, dass zu Beginn der Reihe die Einheit der Mädchen und deren (Stereo-)Typisierung betont wird:

Sometimes it seems like we're so close we form one single complete person rather than four separate ones. We settle into types - Bridget the athlete, Lena the beauty, Tibby the rebel and me, Carmen, the $\ldots$ what? The one with the bad temper ${ }^{53}$.

Die ,magische“ Transformation, die jede von ihnen durch die Jeans erfährt, kann nicht nur als ein Prozess der Vereinheitlichung gelesen werden, sondern im Laufe der Erzählung auch als eine Form der Anpassung an weiße patriarchale Mittelklassenormen. Wie McInally überzeugend argumentiert, wird hier eine Art von „boutique multiculturalism“ (Stanley Fish) vorgeführt (Carmens Mutter stammt aus Puerto Rico, Lenas Familie aus Griechenland etc.), doch die (kulturellen) Unterschiede der Mädchen spielen in der sisterhood keine nennenswerte Rolle und die Erzählung propagiert eine ,homogeneous culture“ an Stelle von

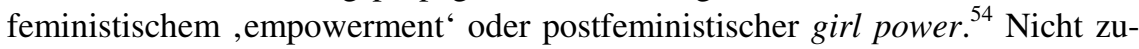
letzt wird die Vorstellung von sisterhood durch eine essentialistische Komponente geprägt: Geschlecht ist die zentrale Identitätskategorie, über die sich die ,Schwesternschaft' konstituiert und unter deren Primat ethnische, kulturelle oder soziale Unterschiede nivelliert werden. Die vier Protagonistinnen ,finden ' im Laufe der Erzählung ihre Geschlechteridentitäten und -rollen, welche aber nicht grundlegend hinterfragt oder gar verändert werden. Was Pat O'Connor für Frauenfreundschaften herausstellt, gilt trotzdem auch ein Stück weit in der Logik der Sisterhood-Reihe:

friendships between women, as far as they affirm women's identity as women, are still in some ways at odds with a patriarchal culture. At the very least they undermine the idea that women's only source of identity and pleasure lies in a relationship with a $\operatorname{man}^{55}$.

Die Freundschaft der Protagonistinnen beruht auch auf der Tatsache, dass bereits ihre Mütter befreundet waren bzw. sind. Die sisterhood wird jedoch ganz deutlich von der Freundschaft der Mütter abgegrenzt, wie sich z.B. an dieser Beschreibung eines Bildes der vier Mütter zeigt: „It was a picture of friendship, but

53 Brashares: Sisterhood, S. 7.

54 Vgl. McInally: Who Wears, S. 188f.

55 O'Connor: Women's Friendship, S. 132.

Ulrike Schneider, Helga Völkening and Daniel Vorpahl - 978-3-653-98812-3 
it wasn't the Sisterhood. It was their mothers, long ago. Tibby noted with joy that all four of them were wearing jeans ${ }^{656}$. Die Jeans werden auch intergenerational als verbindendes Element markiert und der Status der sisterhood als einer ganz besonderen Form der Freundschaft und Verbundenheit wird affirmiert. Das Schlagwort der Frauenbewegung wird allerdings nicht mit der Generation der Mütter assoziiert, sondern den Mädchen zugeordnet. Die ,alternative' und möglicherweise auch feministische Vergangenheit von Tibbys Mutter, die sie jedoch für ein traditionellen Vorstellungen entsprechendes Familienleben im suburbanen Mittelklasseumfeld bereitwillig aufgegeben hat, wird lediglich angedeutet ${ }^{57}$ und insgesamt spielt die Frauenbewegung keine Rolle in der Erzählung. Die Thematik des Generationenkonflikts, wie er hier verhandelt wird, prägt aber auch Diskussionen um die verschiedenen Phasen der Frauenbewegung. Dabei fungiert nicht zuletzt der Begriff sisterhood als Nexus. ${ }^{58} \mathrm{Im}$ Verhältnis der Töchter zu ihren Müttern wird zudem die Bedeutung einer matrilinealen Genealogie für die Identität(en) der Mädchen skizziert. Während Vaterfiguren Instanzen von Autorität und Anerkennung für die Protagonistinnen sind, um die sie sich (teilweise) verdient machen müssen, wird die emotionale Unterstützung, Aufmerksamkeit und Fürsorge durch die Mütter weitgehend als ,natürlich ' gegeben angesehen. Carmens exklusiver Fokus auf ihren Vater und die gleichzeitige relative Ablehnung ihrer Mutter im ersten Band der Reihe kann hierfür als

56 Brashares: Second Summer, S. 373.

57 So heißt es z.B. im zweiten Band der Reihe: „When [Tibby's] parents had been hippies and communists and feminists and everything, her mother had derided women who changed their names when they got married“. Brashares: Second Summer, S. 48f. Alice Rollins hat inzwischen selbst den Namen ihres Mannes angenommen und ihre Tochter Tibby wird als ,product of pure suburbia“, sprich als Produkt des sozialen und kulturellen Umfelds einer weißen Mittelschicht bezeichnet. Ebd., S. 88.

58 In US-amerikanischen feministischen Diskursen findet sich in den letzten Jahren zum einen der Versuch, die anhaltende Relevanz von ,sisterhood“ (und damit die Belange der Zweiten Welle der Frauenbewegung) zu propagieren, zum anderen wird der Umbruch von ,sisterhood“ zu ,girl culture“ thematisiert. Dies lässt sich beispielhaft bereits an den Titeln einschlägiger Publikationen festmachen. Robin Morgan - die bereits 1970 mit „Sisterhood Is Powerful: An Anthology of Writings from the Women's Liberation Movement" eine klassische Sammlung feministischer Texte herausgegeben hatte - brachte mit „Sisterhood Is Forever: The Women's Anthology for a New Millenium“ 2003 eine Handreichung für den Feminismus im 21. Jahrhundert hinaus und schon der Titel macht klar, dass ,sisterhood' weiterhin als zentrales Konzept angesehen wird. Deborah Siegel auf der anderen Seite markiert den Übergang zwischen verschiedenen (post-)feministischen Projekten, von der ,radikalen' Frauenbewegung zur ,girl culture ' ebenfalls bereits im Titel ihres Buches „Sisterhood, Interrupted: From Radical Women to Grrls Gone Wild“ (New York 2001). 
Beispiel dienen und validiert die Bedeutung der „white paternity“ in ihrem Leben. $^{59}$

Bridget wächst seit ihrem elften Lebensjahr ohne Mutter auf, was nicht zuletzt auch als Erklärungshorizont für ihr - in der Logik der Narration ,problematisches ${ }^{6}$ - Verhalten dienen mag. Ihre Entwicklung ist mit Blick auf das Frauenbild der Romane ebenso relevant wie für die Rolle der Mütter. Im ersten Band agiert Bridget als ,aktive“ Verführerin, die strategisch, aggressiv und extrovertiert ihren Schwarm Eric umgarnt, der als Trainer in ihrem Fußballcamp eigentlich ,off limits“ ist. Nachdem sie ihre Jungfräulichkeit verloren hat, wird sie jedoch stark depressiv und ,lernt' auf diese Art - so könnte man argumentieren - ein ,adäquates' weibliches sexuelles Verhalten und ein entsprechendes $\mathrm{Ma} ß$ an Passivität. ${ }^{60}$ Bezeichnenderweise ist es im nächsten Sommer die Reise in ihre Vergangenheit und ihre (Wieder-)Entdeckung ihrer Großmutter und Mutter, welche eine erneute Kehrtwende in Bridgets Leben verursacht. Unter zunächst falscher Identität hilft sie ihrer Großmutter Greta im Haushalt und recherchiert dabei nicht nur das Leben und den Tod bzw. Selbstmord ihrer Mutter, sondern stellt auch das Verhältnis zu Greta wieder her, die sie seit Jahren nicht gesehen hatte. Diese nimmt Bridget ohne zu zögern in ihr Haus auf und bietet ihr einen Zufluchtsort, der nicht zuletzt durch ihre klaren Routinen Verlässlichkeit bietet. Im letzten Band der Reihe übernimmt Bridget dann ein Stück weit die Mutterrolle in ihrer dysfunktionalen Familie; sie kümmert sich um das Haus, organisiert ein gemeinsames Abendessen mit ihrem Vater und Perry, und bringt schließlich auch ihren Freund Eric in ihre Familie. Sie kümmert sich besonders um Perry, indem sie ihn u.a. dazu animiert, sein Zimmer zu verlassen und ihm ein Haustier kauft.

Für die anderen Mädchen ist die Beziehung zur Mutter zentral und in unterschiedlicher Hinsicht von Bedeutung: Carmen sieht die Fürsorge, Verlässlichkeit und bedingungslose Liebe ihrer Mutter als gegeben an und - wie der Konflikt um ihren späteren Stiefvater David zeigt - möchte diese exklusive Beziehung nicht teilen. Als ihre Mutter schwanger wird und sich größere Veränderungen in der Familie abzeichnen, überlegt Carmen - entgegen ihrer bisherigen Pläne - ein College in der Nähe zu besuchen, da sie Angst hat, ihren Platz in der Familie zu verlieren. Sie arrangiert sich allerdings letztlich mit der neuen Situation, baut eine liebevolle Beziehung zu ihrem Halbbruder Ryan auf und beginnt ihr Studium wie geplant am Williams College, wo sie bezeichnenderweise in die Fußstapfen ihres Vaters tritt. Tibby akzeptiert in ihrer Familie recht bald die spezielle Rolle als ältere Schwester, die teilweise einer ,auxiliary

59 Vgl. McInally: Who Wears, S. 194.

60 Vgl. ebd., S. 197.

Ulrike Schneider, Helga Völkening and Daniel Vorpahl - 978-3-653-98812-3 
motherhood “61 nahe kommt, wobei sie dennoch gegen ihre Mutter rebelliert z.B. mit dem Film, den sie im zweiten Band über Alice dreht - und sich von ihr abgrenzen will. Lena schließlich scheint in ihrer Beziehung zu Kostos die tragische Liebesgeschichte ihrer Mutter zu wiederholen, wobei ihre Versuche, die Ereignisse aus dem Leben ihrer Mutter zu rekonstruieren, die Mutter-TochterBeziehung sowie die Freundschaften der Mütter temporär stark belasten, aber letztlich Lenas Verhältnis zu Ari eher intensivieren. Lenas Entwicklung ist darüber hinaus in zweierlei Hinsicht interessant: Sie setzt sich erfolgreich gegen ihren Vater durch, um auf eine Kunstakademie zu gehen und stellt damit das patriarchale Regime in der Familie in Frage. Gleichzeitig lernt sie an der Kunstakademie, sich dem Regime eines ,male gaze (Laura Mulvey) auszusetzen und daran Gefallen zu finden. Im ersten Band, als Kostos sie nackt beim Baden auf Santorini sieht, reagiert sie noch quasi-hysterisch. ${ }^{62}$ Als sie ihre Fähigkeiten als Zeichnerin entdeckt, eignet sie sich auch ein Stück weit die Macht des Blickes an, als sie z.B. ihre Familie und Kostos porträtiert. Im letzten Band der Reihe steht sie ihrem Studienkollegen Leo nackt Modell und findet Gefallen daran, sich dem männlichen Blickregime auszusetzen. Alle Freundinnen durchlaufen eine Entwicklung hinsichtlich ihrer Akzeptanz dominanter und normativer Geschlechteridentitäten und -rollen und diese Transformation wie auch ihre Freundschaft ist an die ,magische' Jeans geknüpft.

Die ,Magie“ der Jeanshose liegt nicht nur darin, dass sie allen vier Mädchen passt, sondern beruht auch darauf, dass sie die jeweilige Trägerin buchstäblich transformiert: Tibby wirkt auf einmal sehr mädchenhaft (Carmen behauptet: „Those pants are in love with you. They want you for your body and your mind"), Lena erscheint noch schöner als zuvor, die amazonenhafte Bridget wirkt plötzlich fast zierlich und Carmen wird durch die Jeans gar zum „,supermodel“ “63 Die Jeans erlaubt den Mädchen eine Art „makeover“ und die Erzählung setzt damit zentral auf ein Phänomen, das Diane Negra als „key ritual of female coming into being “64 in der postfeministischen Konsumkultur bezeichnet hat. Rosalind Gill argumentiert sogar, dass das „makeover paradigm“ konstituierend für die postfeministische Medienkultur und darauf angewiesen sei, dass vor allem Frauen Folgendes glauben:

61 Vgl. Hemphill, C. Dallett: Siblings. Brothers and Sisters in American History. Oxford 2011, S. 166 u. 215.

62 Vgl. McInally: Who Wears, S. $195 f$.

63 Vgl. Brashares: Sisterhood, S. 14-18.

64 Negra, Diane: What a Girl Wants? Fantasizing the Reclamation of Self in Postfeminism. London 2009, S. 123. 
[...] first that they or their lives are lacking or flawed in some way, and secondly that it is amenable to reinvention or transformation by following the advice of relationship, design or lifestyle experts, and practising appropriately modified consumption habits ${ }^{65}$.

Auch wenn die Hose aus einem Second-Hand-Laden stammt und Carmen diese mehr oder weniger zufällig für einen geringen Betrag erworben hat, symbolisiert die Jeans doch US-amerikanische Konsumkultur und deren Ideologie der Individualisierung und Kommerzialisierung von Identitäten. Entsprechend stellen die Freundinnen fest, dass die Hose nicht nur für ihre Freundschaft wichtig ist, sondern sie auch ganz im Sinne neoliberaler Selbstoptimierung zu ,besseren " Menschen macht: „They make us better people and better friends“66.

Aus der Sicht der Mädchen steht die Jeans ,for the promise we made to one another, that no matter what happens, we stick together ${ }^{\text {“67 }}$. Es ist zunächst die dezidierte Funktion der Hose, sie durch Zeiten der Trennung hinweg zu verbinden. Entsprechend zentral erscheint sie den Freundinnen nach dem ersten Sommer: ,The Pants were the only witness to all of our lives. They were the witness and the document too"68. Die Mädchen dokumentieren in einem Ritual jeweils am Ende des Sommers ihre wichtigsten Erlebnisse auf der Jeans, die u.a. durch die Tatsache, dass sie dem Manifest zufolge nicht gewaschen werden darf, in mehrerer Hinsicht die Spuren ihrer Trägerinnen und deren Erfahrungen mit sich trägt. Am Ende des vierten Bandes glauben die Mädchen zu erkennen, dass die Jeans sie über die Jahre weniger verbunden, denn getrennt hat - sie hat sie zwar bei ihren individuellen alltäglichen und außergewöhnlichen Erlebnissen begleitet, aber sie hat es ihnen auch ermöglicht, über längere Zeiträume voneinander getrennt zu sein. Tibby konstatiert schließlich: „I think we were using them [the pants] to help us stay apart ${ }^{\text {} 69}$. Nach dem Verlust der Hose, der das Ende der Adoleszenz und den Start in das Erwachsenenleben symbolisiert, erscheint die Freundschaft der Mädchen entsprechend ungebrochen. Die Hose ist somit ein ambivalentes Symbol der Freundschaft, da sie einerseits den Zusammenhalt zwischen den Mädchen signalisiert, andererseits deren individuelle Entwicklung befördert und damit potenziell die Gemeinschaft der Freundinnen schwächt. Obgleich sie schließlich obsolet wird, werden der Jeans durchweg ,magische“ Qualität und Agenz zugeschrieben. Sie ist zudem ein Zeichen männlicher Dominanz, u.a. da sie als maskulin charakterisiert wird, wie McInally anhand

65 Gill, Rosalind: Gender and the Media. Cambridge 2007, S. $262 \mathrm{f}$.

66 Brashares: Girls in Pants, S. 2.

67 Brashares: Sisterhood, S. 8.

68 Ebd., S. 293.

69 Brashares: Forever, S. 379. 
des ersten Bandes detailliert herausgearbeitet hat. ${ }^{70}$ Joyce Litton liest die Hose als ein Symbol des ,quest for greater maturity“ und des ,gradual achievement of self-esteem ${ }^{\text {"711 }}$, wobei sie zu Recht herausstellt, dass der Jeans innerhalb der Erzählung wechselnde Bedeutungen für die jeweiligen Trägerinnen und das Kollektiv der ,Schwesternschaft" zugeschrieben werden. Dennoch bleibt die Jeanshose durchweg nicht nur Sinnbild einer patriarchalen Struktur und weißer Mittelklassenormen, sondern auch für die Konsumgesellschaft, da sie ein Identitäts- und Selbstoptimierungsversprechen beinhaltet, obgleich sie als SecondHand-Ware und geteilt genutztes Gut auf den ersten Blick nicht ganz in diese Konsumlogik zu passen scheint. Mit dem Verlust der Jeans am Ende des vierten Bandes ist dann auch nicht die Überwindung der in ihr eingeschriebenen Normen verbunden, sondern vielmehr deren Inkorporierung durch die vier jungen Frauen. Sie haben diese so weit habitualisiert, dass sie die Hose als Medium der Anpassung und Subjektivierung nicht mehr benötigen.

\section{Schluss}

Die Sisterhood-Reihe zeichnet ein positives Bild der Mädchenfreundschaft und erweckt zunächst den Eindruck, feministische Ideen und Forderungen im Sinne von sisterhood oder girl power zu aktualisieren und deren (bleibende) Potenziale auszuloten. Dennoch bleibt die Erzählung patriarchalen Logiken und tradierten und konventionellen - wenn nicht sogar klischeehaften - Frauenbildern verhaftet. Die Freundschaft der Mädchen wird in eine Matrix weiblicher Solidarität gepasst, die zwar u.a. zentrale feministische Bestrebungen des 20. und 21. Jahrhunderts aufruft, dabei aber weder die problematischen Aspekte des Konzepts von ,Schwesternschaft" reflektiert, noch eine tragfähige feministisch-emanzipatorische Agenda entwickelt. Die Freundschaft der Protagonistinnen mag als eine Art „hidden solidarity“72 ${ }^{6}$ gelesen werden, welche der oft diagnostizierten Individualisierung und Distanzierung in (post-)modernen Gesellschaften und auch patriarchalen Strukturen entgegensteht. Dennoch verbleibt sie in der Logik familialer Beziehungen und kommt damit weder einem Plädoyer für weibliche Solidarität jenseits von Familienrollen nach ${ }^{73}$ noch der soziologischen Erkenntnis, „that the notion that kinship must, inevitably, be at the core of people's personal

70 Vgl. McInally: Who Wears, S. 193.

71 Litton: The Nature, S. 23.

72 Vgl. Spencer, Liz; Pahl, Ray: Rethinking Friendship. Hidden Solidarities Today. Princeton 2006.

73 Barbara Johnson etwa hat diese Forderung so auf den Punkt gebracht: „We will never build a true Women's Movement until we can organize as equals, woman to woman, without the masks of family roles“. Johnson: Politics, S. 156. 
communities should be questioned“74. Im Gegenteil: Die Sisterhood-Reihe affirmiert sowohl familiale Strukturen als primäre Vergemeinschaftungsform als auch einen kommerzialisierten Postfeminismus. Die Reihe evoziert zwar feministische Solidaritätsdiskurse, positioniert sich allerdings im Kontext eines „postfeminist mystique“, das Rebecca Munford und Melanie Waters im Rückgriff auf Betty Friedans „,feminine mystique“ in kontemporärer Populärkultur identifizieren und wie folgt definieren:

[It] works by mobilizing anachronism [...] [and] reactivates modes of feminine identity that were ,proper to a former age', but which seem , out of harmony' with the present that has - so we are told - reaped all the benefits of second wave feminism $^{75}$.

Es ist Teil eines postfeministischen Diskurses, der sich durch seine „reinvigoration of particular models of white, middle-class femininity that belong to the image repertoire of ,pre-feminist" cultural production" ${ }^{\text {“76 }}$ auszeichnet. Diese Dynamik ist auch den Sisterhood-Romanen eingeschrieben. Oberflächlich erscheint die positive Darstellung der Freundinnen als Individuen und Kollektiv zunächst als eine Form des ,empowerments', dessen potenzielle politische Agenda und Relevanz allerdings durch eine kommerzialisierte Form von girl power und die problematische Konzeption von Solidarität als sisterhood ,neutralisiert" wird. Wie meine Analyse gezeigt hat, wird die Mädchenfreundschaft hier einerseits im direkten Verhältnis zu den biologischen und biographischen Geschwistern der Mädchen verhandelt, andererseits wird sie u.a. durch die sisterhood als Metapher für Solidarität auch in den Kontext (post-)feministischer Diskurse gestellt. Die ideologische Fundierung dieser Imagination von Solidarität und Freundschaft als ,Schwesternschaft' zeigt sich entsprechend u.a. in der Affirmation der heterosexuellen Matrix, weißer Mittelklassenormen und tradierter Geschlechterrollen, sowie der Bedeutung von Postfeminismus, Konsumkultur und girl power.

\section{Quellen und Literatur}

Blasingame, James: Interview with Ann Brashares, in: Journal of Adolescent \& Adult Literacy 47.4 (2003/04), S. 350.

Brashares, Ann: The Sisterhood of the Traveling Pants. New York 2001 (2011).

Brashares, Ann: The Second Summer of the Sisterhood. New York 2003 (2011).

74 Pahl: Friendship, S. 74.

75 Munford, Rebecca; Waters, Melanie: Feminism and Popular Culture. Investigating the Postfeminist Mystique. London 2013, S. 10.

76 Munford; Waters: Feminism, S. 11. 
Brashares, Ann: Girls in Pants. The Third Summer of the Sisterhood. New York 2005 (2011).

Brashares, Ann: Forever in Blue. The Fourth Summer of the Sisterhood. New York 2007 (2011).

Butler, Judith: Gender Trouble. Feminism and the Subversion of Identity. New York (1990) 2006.

Carby, Hazel V.: Reconstructing Womanhood. The Emergence of the Afro-American Woman Novelist. New York 1987.

DuBois, Ellen Carol; Ruiz, Vicki L. (Hrsg.): Unequal Sisters. A Multicultural Reader in U.S. Women's History. New York 1990.

Frankenberg, Ruth: White Women, Race Matters. The Social Construction of Whiteness. Minneapolis 1993.

Gill, Rosalind: Gender and the Media. Cambridge 2007.

Hains, Rebecca: Power Feminism, Mediated: Girl Power and the Commercial Politics of Change, in: Women's Studies in Communication 32.1 (2009), S. 89-113.

Hall, Joan Wylie (Hrsg.): Conversations with Audre Lorde. Jackson 2004.

Hemphill, C. Dallett: Siblings. Brothers and Sisters in American History. Oxford 2011.

Johnson, Barbara: The Politics of Ageing, in: Morgan, Robin (Hrsg.): Sisterhood Is Forever: The Women's Anthology for a New Millenium. New York 2003, S. 152-161.

Koss, Melanie D.; Teale, William H.: What's Happening in YA Literature? Trends in Books for Adolescents, in: Journal of Adolescent \& Adult Literacy 52.7 (2009), S. 563-572.

Litton, Joyce: The Nature of Female Friendship in the Sisterhood of the Traveling Pants Quartet, in: Eiss, Harry Edwin (Hrsg.): Young Adult Literature and Culture. Newcastle upon Tyne 2009, S. 21-37.

McInally, Kate: Who Wears the Pants? The (Multi)Cultural Politics of The Sisterhood of the Traveling Pants, in: Children's Literature in Education 39 (2008), S. 187-200.

Morgan, Robin (Hrsg.): Sisterhood Is Powerful. An Anthology of Writings from the Women's Liberation Movement. New York 1970.

Morgan, Robin (Hrsg.): Sisterhood Is Global. The International Women's Movement Anthology. New York (1984) 1996.

Morgan, Robin (Hrsg.): Sisterhood Is Forever. The Women's Anthology for a New Millenium. New York 2003.

Munford, Rebecca; Waters, Melanie: Feminism and Popular Culture. Investigating the Postfeminist Mystique. London 2013.

Negra, Diane: What a Girl Wants? Fantasizing the Reclamation of Self in Postfeminism. London 2009.

O'Connor, Pat: Women's Friendship in a Post-Modern World, in: Adams, Rebecca G.; Allan, Graham (Hrsg.): Placing Friendship in Context. Cambridge 1998, S. 117-135.

Pahl, Ray: On Friendship. Cambridge 2000.

Spelman, Elizabeth V.: Inessential Woman. Problems of Exclusion in Feminist Thought. Boston 1988.

Spencer, Liz; Pahl, Ray: Rethinking Friendship. Hidden Solidarities Today. Princeton 2006.

Siegel, Deborah: Sisterhood, Interrupted. From Radical Women to Grrls Gone Wild. New York 2001.

Vavrus, Mary Douglas: Postfeminist News. Political Women in Media Culture. New York 2002. 
Ulrike Schneider, Helga Völkening and Daniel Vorpahl - 978-3-653-98812-3

Downloaded from PubFactory at 01/11/2019 10:54:37AM

via free access 


\section{Verzeichnis der Autor_innen}

Dagmar Bruss: Studium der Italianistik, Philosophie und Wirtschaftswissenschaften in Hamburg, Stuttgart-Hohenheim und Leuven. 2015 Promotion im Fach Romanistik (Zwischen Geschwistern und Geschwisterlichkeit. Vom Umschlag des Genealogischen in die Horizontale bei Giovanni Verga und Robert Walser). 2007 bis 2011 wissenschaftliche Mitarbeiterin am Institut für Romanistik an der Universität Hamburg. Arbeitsschwerpunkte: Historische Anthropologie, Verwandtschaftsforschung, Jahrhundertwende (19./20. Jh.) und Psychoanalyse.

Ulrich Engel: Studium der Katholischen Theologie in Münster und Bonn. 1998 Promotion im Fach Katholische Theologie in Fribourg (Umgrenzte Leere: Zur Praxis einer politischtheologischen Ästhetik im Anschluss an Peter Weiss' Romantrilogie „Die Ästhetik des Widerstands“). 2006 Habilitation in Benediktbeuern (Zwischen Inkarnation und Negation). Seit 2001 Direktor des Institut M.-Dominique Chenu, Berlin. Seit 2013 Professor für Philosophisch-theologische Grenzfragen an der Philosophisch-Theologischen Hochschule Münster und seit 2014 Prorektor ebendort. Arbeitsschwerpunkte: Politische Theologie, theologische Rezeption postmoderner Philosophien (G. Vattimo, J. Derrida, J.-L. Nancy, M. de Certeau, G. Agamben, R. Esposito) sowie Theologie des Ordenslebens.

Katharina Gerund: Studium der Amerikanistik (Kulturwissenschaft) in Erlangen und Madison. 2012 Promotion im Fach Amerikanistik in Bremen (Transatlantic Cultural Exchange: African American Women's Art and Activism in West Germany). Seit 2012 Koordinatorin des DFG-Graduiertenkollegs 1718 „Präsenz und implizites Wissen“ an der Friedrich-Alexander-Universität Erlangen-Nürnberg. Arbeitsschwerpunkte: Amerikanisierung/Reeducation, US-amerikanische Populärkultur, Gender Studies und feministische Theorie sowie afroamerikanische Literatur und Kultur.

Anna Głowacka: Studium der Klassischen Philologie und der Germanistik in Toruń und Halle/Saale. Seit 2009 Promotion im Fach Germanistik in Wien (Die Schwesternbeziehung in der Literatur des 19. Jahrhunderts). 2009 bis 2012 wissenschaftliche Mitarbeiterin an der Polnischen Akademie der Wissenschaften in Wien. Derzeit Stipendiatin der Alfred Toepfer Stiftung Hamburg. Arbeitsschwerpunkte: Geschwisterforschung (v.a. Schwesternbeziehung), Familienformen und Familienbeziehungen, Frauenforschung sowie Autorinnen des ausgehenden 18. Jahrhunderts und des 19. Jahrhunderts.

Hans-Michael Haußig: Studium der Religionswissenschaft, Judaistik und Semitistik in Berlin und Jerusalem. 1997 Promotion in Berlin (Der Religionsbegriff in den Religionen. Studien zum Selbst- und Religionsverständnis in Hinduismus, Buddhismus, Judentum und Islam). Seit 1999 wissenschaftlicher Mitarbeiter am Institut für Jüdische Studien und Religionswissenschaft/Lebensgestaltung-Ethik-Religionskunde (LER) an der Universität Potsdam. Arbeitsschwerpunkte: Religionsvergleichende Fragestellungen, Religionstheorie, Methodologie der Religionswissenschaft, Jüdische Mystik, Religionsgeschichte des neuzeitlichen Judentums und Islam. 
Sandra Kaden: Studium der Geschichte und Germanistik in Potsdam und Verona. Seit 2011 Promotion im Fach Geschichte in Potsdam (Die Kaiserfrauen der iulisch-claudischen Dynastie im Spiegel der deutschen Geschichtsschreibung des 19. Jahrhunderts). Seit 2011 wissenschaftliche Mitarbeiterin für Geschichte des Altertums am Historischen Institut der Universität Potsdam. Arbeitsschwerpunkte: iulisch-claudische Dynastie sowie römische Geschlechter- und Rezeptionsgeschichte.

Rainer Kessler: Studium der Evangelischen Theologie in Mainz, Hamburg und Heidelberg. 1972 Promotion im Fach Evangelische Theologie in Heidelberg (Die Querverweise im Pentateuch). Anschließend Pfarrtätigkeit in Worms. 1991 Habilitation (Staat und Gesellschaft im vorexilischen Juda). 1993 bis 2010 (Emeritierung) Professor für Altes Testament im Fachbereich Evangelische Theologie an der Philipps-Universität Marburg. Seit 2014 Research Fellow der University of the Free State in Bloemfontein, Südafrika. Arbeitsschwerpunkte: alttestamentliche Prophetie, Sozialgeschichte des alten Israel und Ethik des Alten Testaments.

Yael Kupferberg: Studium der Neueren deutschen Literatur in Berlin sowie der Jüdischen Studien in Potsdam, Tel Aviv und Philadelphia. 2010 Promotion in Berlin (Dimensionen des Witzes um Heinrich Heine). Seit 2013 wissenschaftliche Mitarbeiterin für Jüdische Religionsphilosophie an der School of Jewish Theology an der Universität Potsdam. Arbeitsschwerpunkte: deutsch-jüdische Geistes- und Philosophiegeschichte des 18.-20. Jahrhunderts, Kritische Theorie sowie das Spätwerk Max Horkheimers (Habilitationsarbeit).

Uta Lohmann: Studium der Judaistik und Germanistik in Freiburg, Berlin und Jerusalem. 2012 Promotion in Duisburg-Essen (David Friedländers Reformpolitik im Zeichen von Aufklärung und Emanzipation der Juden in Preußen). Seit 2012 wissenschaftliche Mitarbeiterin am Institut für Erziehungswissenschaft an der Universität Hamburg (Leitung des DFGProjekts „David Friedländer und Wilhelm von Humboldt im Gespräch. Zur Wechselwirkung zwischen Haskala und neuhumanistischer Bildungstheorie"). Arbeitsschwerpunkte: Jüdische Bildungsgeschichte, Berliner Haskala und Kulturtransfer.

Constanze Musterer: Studium der Kunstgeschichte, Religionswissenschaft und Psychologie in Berlin. 2000 Magistra Artium (Die Kunstprojekte auf dem U-Bahnhof Alexanderplatz von 1958-1990). Seit 2007 freiberuflich als Projektleiterin, Kunstkritikerin, Kuratorin und Kunstvermittlerin in dem Bereich der modernen bis zeitgenössischen Kunst und Kultur. 2010 bis 2012 Kuratorin des Museo Murillo La Greca in Recife. Arbeitsschwerpunkte: Kunst und Gesellschaft, Kunst im urbanen Umfeld, Genderthematik sowie Kunst außereuropäischer Länder, speziell Lateinamerika und Afrika.

Ulrike Schneider: Studium der Jüdischen Studien und Germanistik in Potsdam. 2010 Promotion im Fach Germanistik in Potsdam (Jean Améry und Fred Wander. Erinnerung und Poetologie in der deutsch-deutschen Nachkriegszeit). Seit 2010 wissenschaftliche Mitarbeiterin am Institut für Germanistik/Jüdische Studien und Religionswissenschaft sowie Koordinatorin des Studienganges Jüdische Studien an der Universität Potsdam. Arbeitsschwerpunkte: deutschjüdische Literatur, Holocaustliteratur, Erinnerungstheorie.

Helga Völkening: Lehramtsstudium für Sonderpädagogik, Katholische Theologie und Deutsch in Dortmund. Magisterstudium der Jüdischen Studien, Religionswissenschaft, der Alten Geschichte, Theologie und Judaistik in Potsdam, Berlin und Köln. Seit 2008 Promotion 
in Potsdam (Die Imago-Dei-Vorstellung in der Sapientia Salomonis). 2001 bis 2004 sowie seit 2011 wissenschaftliche Mitarbeiterin am Institut für Jüdische Studien und Religionswissenschaft (Schwerpunkt Christentum) an der Universität Potsdam. Arbeitsschwerpunkte: Exegese biblischer und deuterokanonischer Schriften, Biblische Motiv- und Rezeptionsgeschichte in religiösen und literarischen Traditionen, Mariologie und Mystik.

Daniel Vorpahl: Studium der Jüdischen Studien, Religionswissenschaft und Allgemeinen und Vergleichenden Literaturwissenschaft in Potsdam. Seit 2010 Promotion im Fach Judaistik in Bamberg (Die Rezeptionsgeschichte des Buches Jona in der frühjüdischen und rabbinischen Schriftauslegung von der Antike bis ins 10. Jh.). Seit 2013 wissenschaftlicher Mitarbeiter für Hebräische Bibel und Exegese an der School of Jewish Theology am Abraham Geiger Kolleg an der Universität Potsdam. Arbeitsschwerpunkte: Bibelexegese, Motivgeschichte und Rezeptionsforschung.

Jenny Vorpahl: Studium der Geschichte und Religionswissenschaft in Potsdam. Seit 2012 Promotion im Fach Religionswissenschaft in Potsdam (Die Rolle der Trauansprachen bei der Ritualisierung und Sakralisierung standesamtlicher Eheschließungen in Deutschland). Seit 2010 wissenschaftliche Mitarbeiterin am Institut für Jüdische Studien und Religionswissenschaft/Lebensgestaltung-Ethik-Religionskunde (LER) an der Universität Potsdam. Arbeitsschwerpunkte: Ritualforschung und das Verhältnis von Säkularem und Religiösem im postmodernen Europa.

Denise von Weymarn-Goldschmidt: Studium der Geschichte und Deutschen Philologie in Basel. Seit 2012 Promotion im Fach Geschichte an der Basel Graduate School of History (Von Konkurrenten und Lieblingen - Geschwisterbeziehungen im deutschbaltischen Adel des 18. und 19. Jahrhunderts). Arbeitsschwerpunkte: Geschlechtergeschichte, historische Anthropologie und deutschbaltische Geschichte. 